Frogs of the

Genus Eleutherodactylus

in Western Ecuador

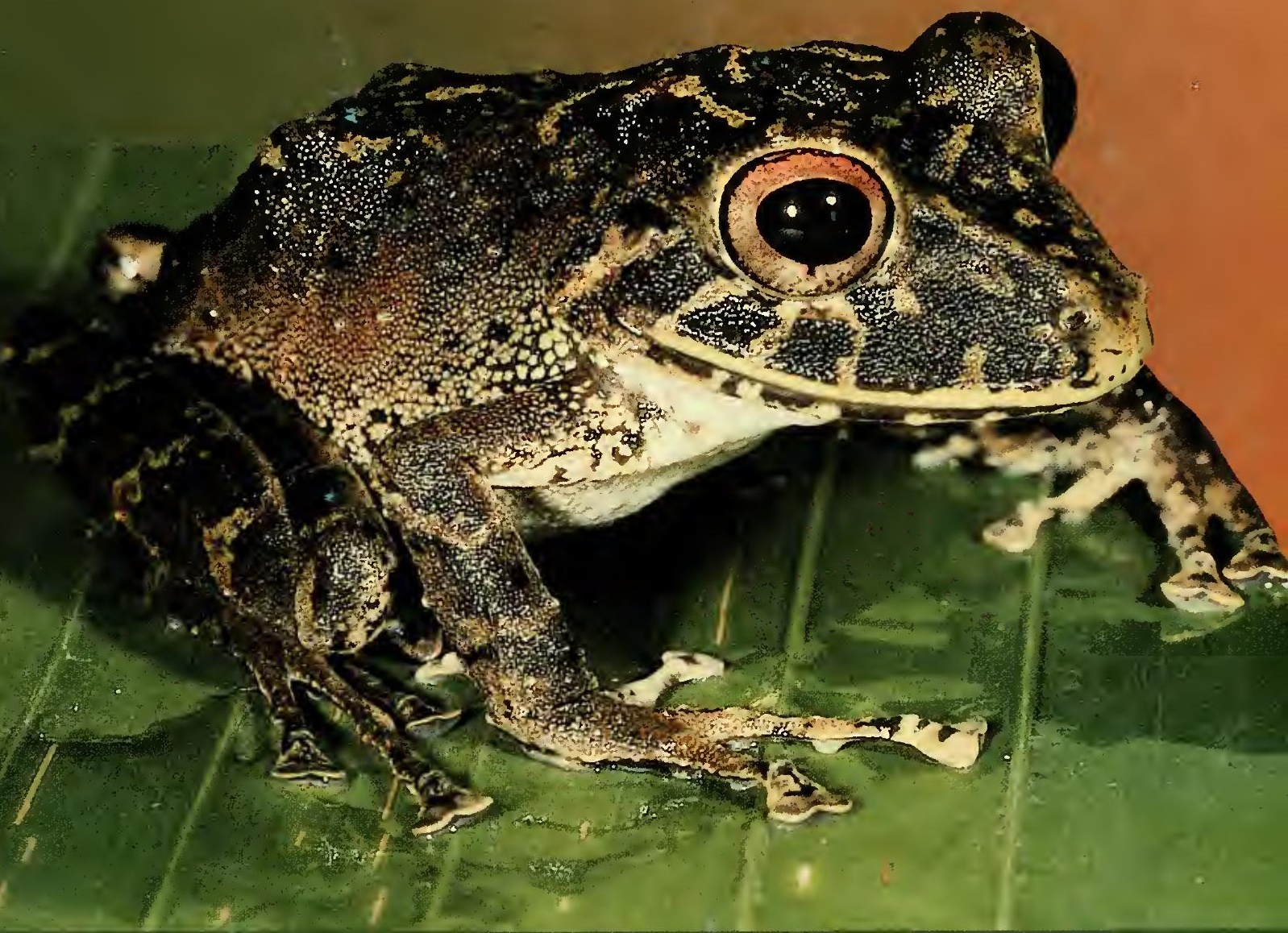

s

Systematics, Ecology, and

Biogeography

John D. Lynch and William E. Dyetriman 

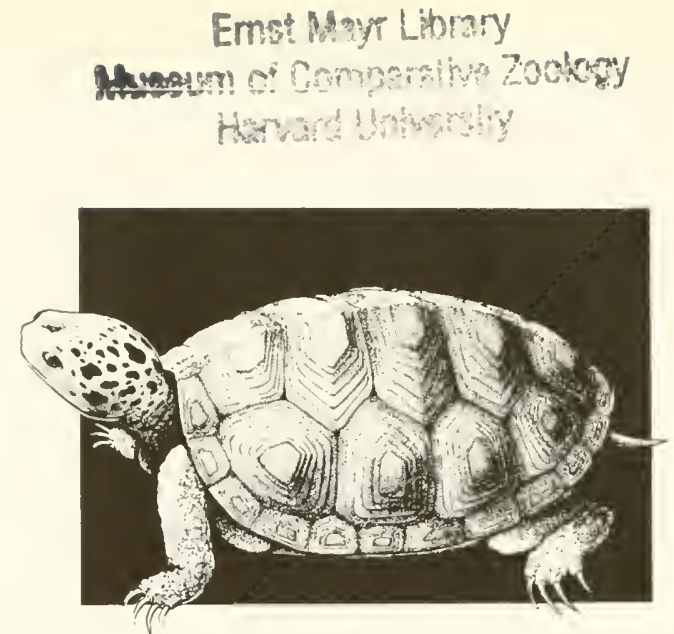

THE U]

The Universi

1946, was disco above series we
Museum of Comparative Zoology HERPETOLOGY LIBRARY

Papers until Number 180 in December 1996. The University of Kansas Natural History Museum Miscellaneous Publications began with Number 1 in 1946 and ended with Number 88 in February 1996. Monographs of the The University of Kansas Natural History Museum were initiated in 1970 and discontinued with Number 8 in December 1992. The foregoing publication series now are combined in a new series entitled The University of Kansas Natural History Museum Scientific Papers, begun in January 1997. Special Publications began in 1976 and continue as an outlet for longer contributions that are available for purchase only. All manuscripts are subject to critical review by intra- and extramural specialists; final acceptance is at the discretion of the Editor.

This publication is printed on acid-free paper. Publications are typeset using Microsoft ${ }^{\circledR}$ Word and Adobe PageMaker ${ }^{\circledR}$ on a Macintosh computer.

Institutional libraries interested in exchanging publications may obtain the Scientific Papers of the Natural History Museum. The University of Kansas, by addressing the Exchange Librarian, The University of Kansas Library, Lawrence, Kansas 66045-2800, USA. Separate numbers and Special Publications can be purchased from the Office of Publications, Natural History Museum. The University of Kansas, Lawrence, Kansas 66045-2454, USA. Purchasing information may be obtained by calling (913) 864-4450, fax (913) 864-5335, or e-mail (huerter@ falcon.cc.ukans.edu). VISA and MasterCard accepted. Include expiration date.

Cover design by Linda Trueb.

Photograph of Eleutherodactylus labiosus by the late Kenneth Miyata. 
The University of Kansas

Natural History Museum

Special Publication No. 23

21 February 1997

Frogs of the Genus Eleutherodactylus (Leptodactylidae) in Western Ecuador: Systematics, Ecology, and Biogeography

\author{
JOHN D. LYNCH \\ Professor, School of Life Sciences \\ The University of Nebraska, Lincoln, Nebraska 68588 USA, \\ Associate, Division of Herpetology \\ Natural History Museum, The University of Kansas \\ Lawrence, Kansas 66045, USA \\ William E. Duellman \\ Curator, Division of Herpetology \\ Natural History Museum \\ Professor, Department of Systematics and Ecology \\ The University of Kansas \\ Lawrence, Kansas 66045, USA
}




\section{SPECIAL PUBLICATIONS}

Editor: Linda Trueb

Managing Editor: Joseph T. Collins

Special Publication No. 23

pp. i-iv, 1-236

Plates 1-8

Published 21 February 1997

ISBN 0-89338-054-7

(C) 1997 by Natural History Museum

DyChe HaLl

The University of Kansas

LaWrence, Kansas 66045-2454 USA 


\section{CONTENTS}

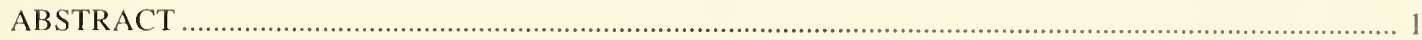

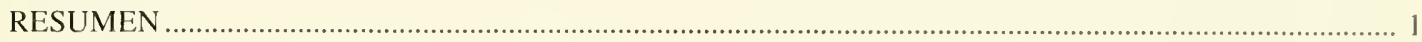

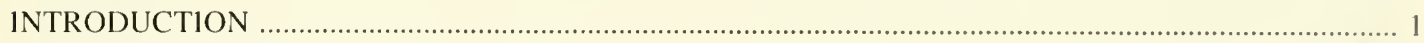

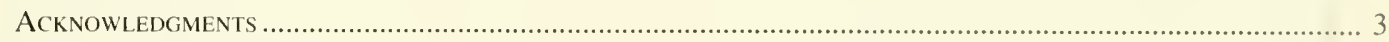

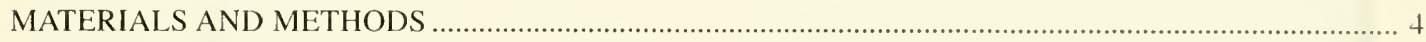

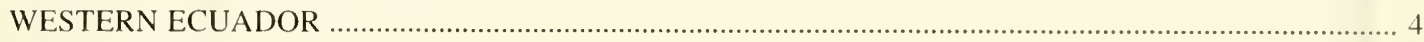

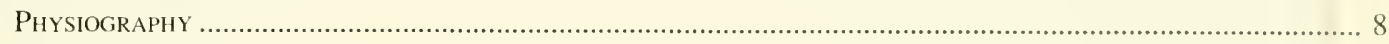

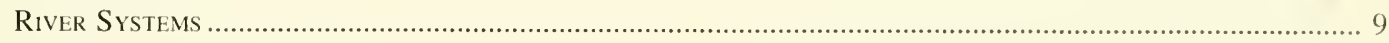

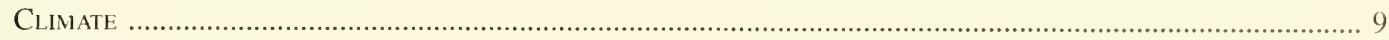

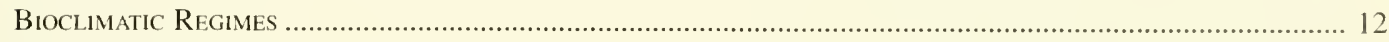

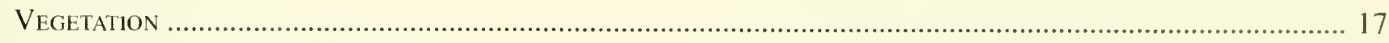

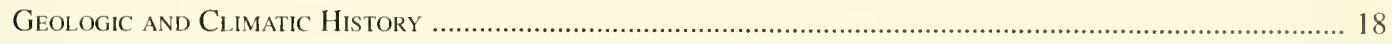

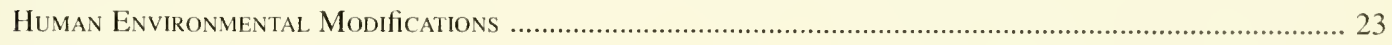

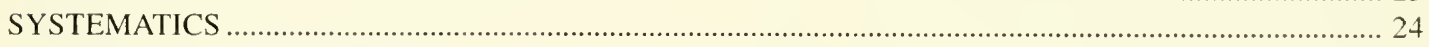

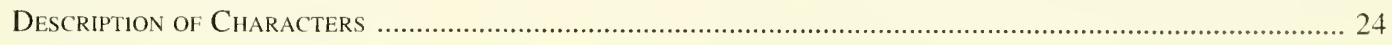

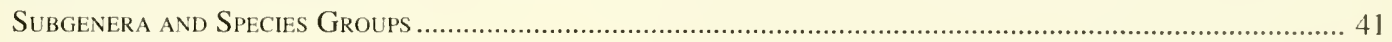

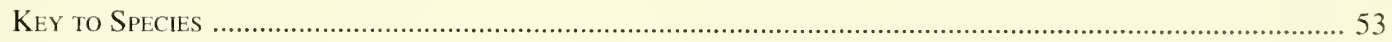

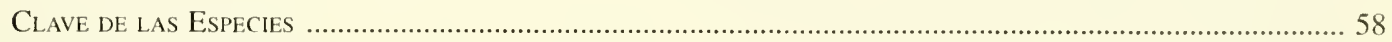

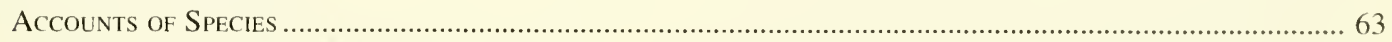

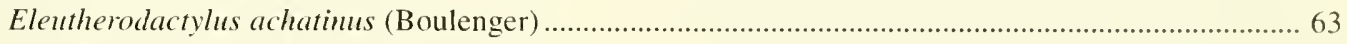

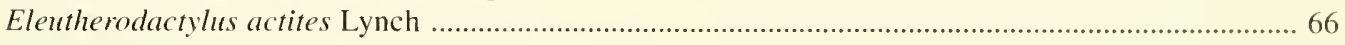

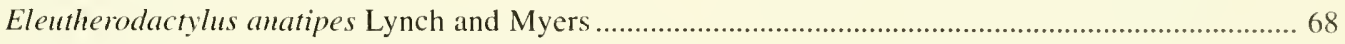

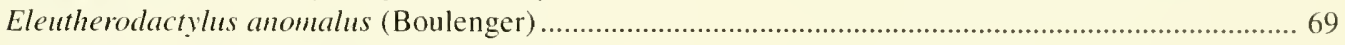

Eleutherodactylus apiculatus Lynch and Burrowes .............................................................. 70

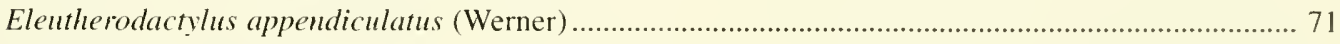

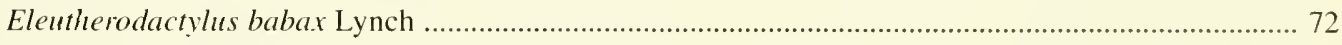

Eleutherodactylus cajamarcensis Barbour and Noble .......................................................... 73

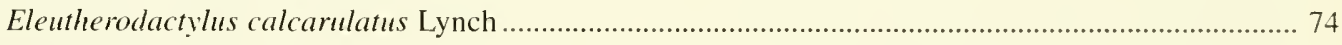

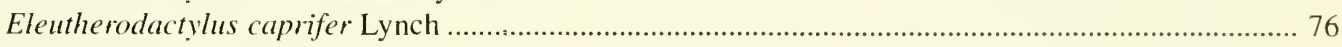

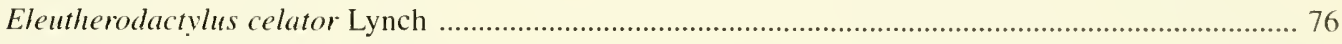

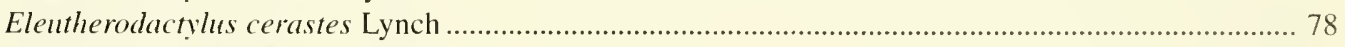

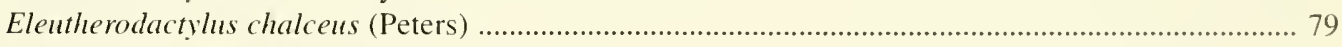

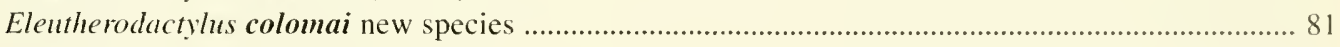

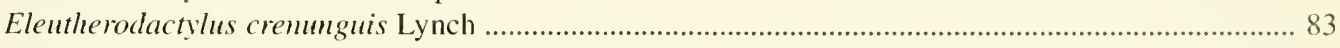

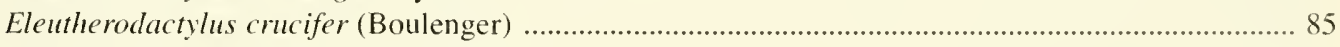

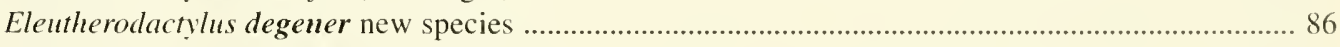

Eleutherodactylus dissimulatus new species ........................................................................... 88

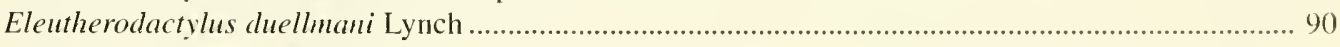

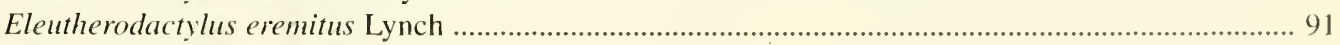

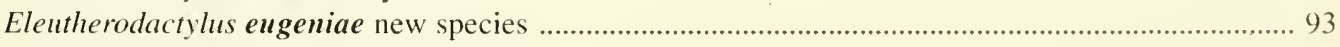

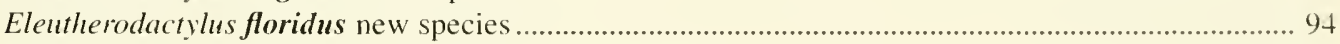

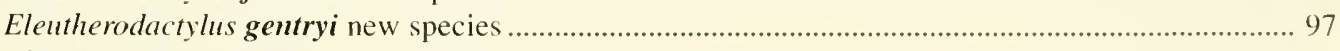

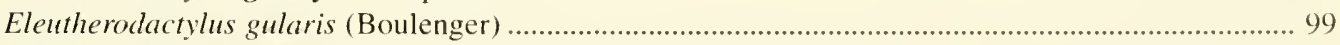

Eleutherodactylus hamiotae Flores ................................................................................ 102

Eleutherodactylus hectus Lynch and Burrowes ...................................................................... 103

Eleutherodactylus helonotus (Lynch) ............................................................................. 104

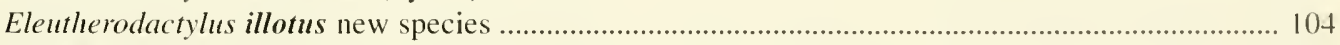

Eleutherodactylus labiosus Lynch, Ruíz, and Ardila ......................................................... 106

Eleutherodactylus laticlavius Lynch and Burrowes ................................................................. 107

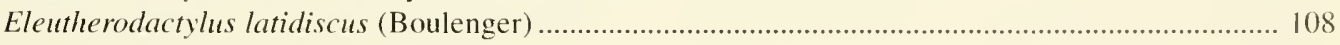

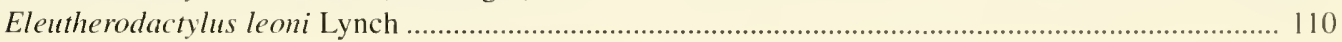




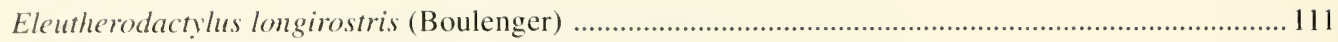

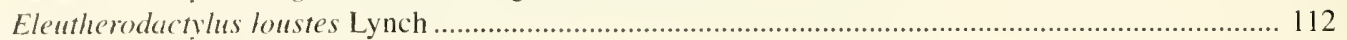

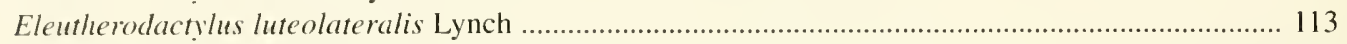

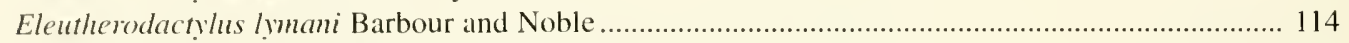

Eleutherodactylus imuricatus Lynch and Miyata ....................................................................... 115

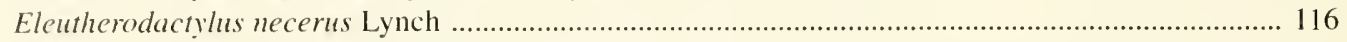

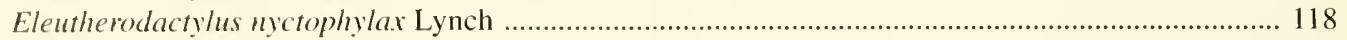

Eleutherodactylus ocellatus Lynch and Burrowes ..................................................................... 119

Eleutherodactylus omatissimus (Despax) ................................................................................. 120

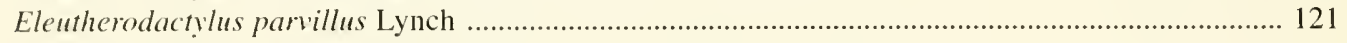

Eleutherodactylus phoxocephalus Lynch .................................................................................. 122

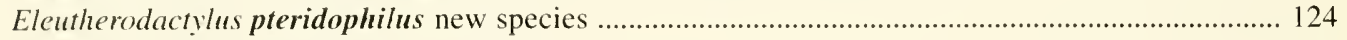

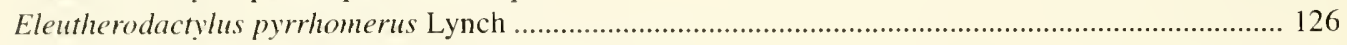

Eleutherodactylus quinquage simus Lynch and Trueb .................................................................. 127

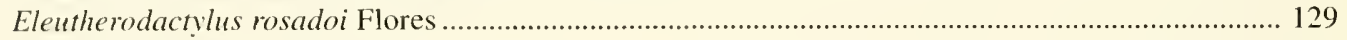

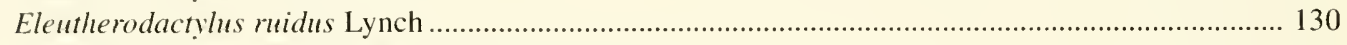

Eleutherodactylus scolodiscus Lynch and Burrowes ................................................................... 131

Eleutherodactylus simonbolivari Wiens and Coloma .............................................................. 132

Eleutherodactylus siopelus Lynch and Burrowes .......................................................................... 133

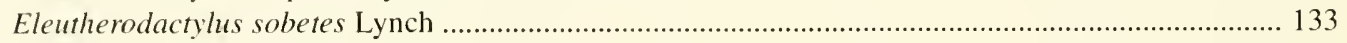

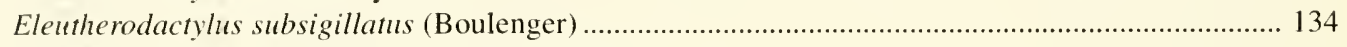

Eleutherodactylus sulculus Lynch and Burrowes ....................................................................... 135

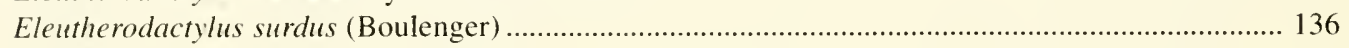

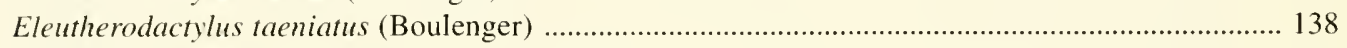

Eleutherodactylus tenebrionis Lynch and Miyata ....................................................................... 138

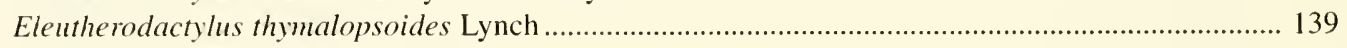

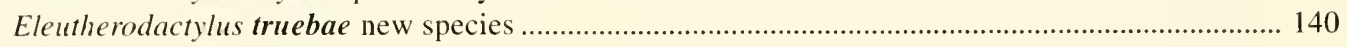

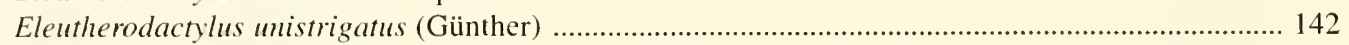

Eleutherodactylus verecundus Lynch and Burrowes .................................................................. 143

Eleutherodactylus vertebralis (Boulenger) ................................................................................ 144

Eleutherodactylus w-nigrum (Boettger) ………........................................................................... 145

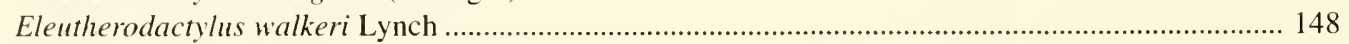

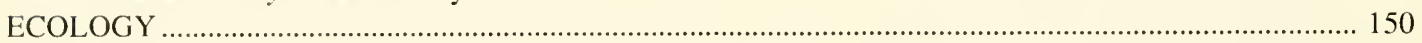

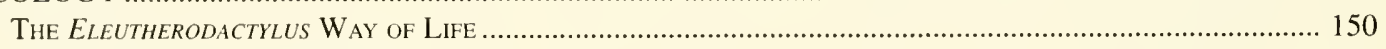

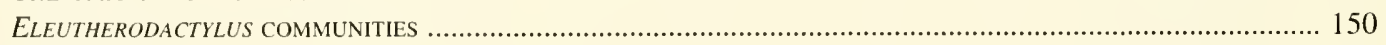

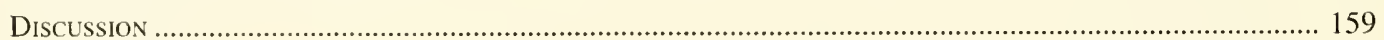

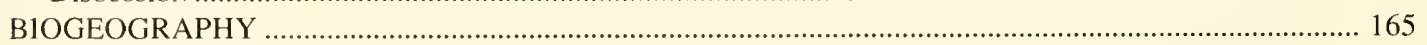

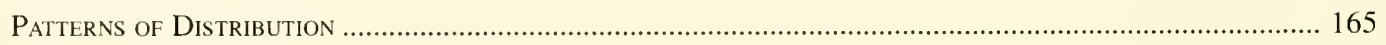

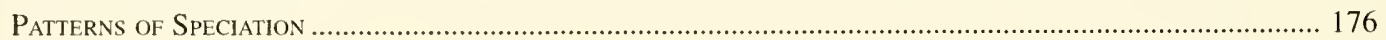

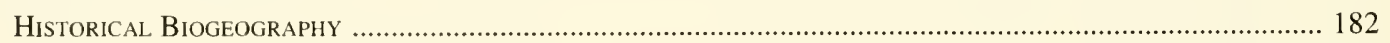

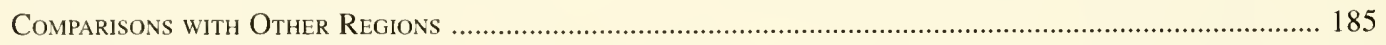

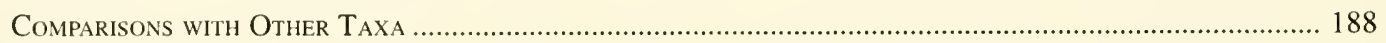

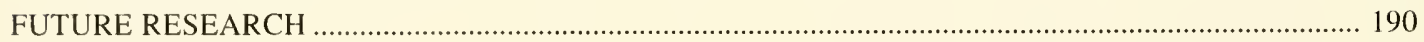

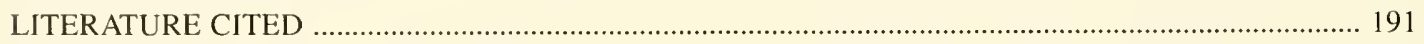

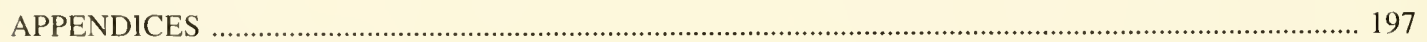

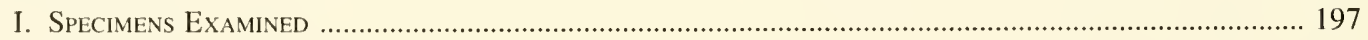

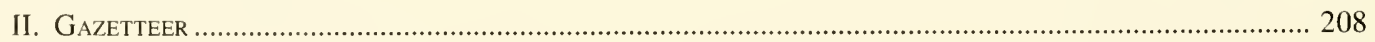

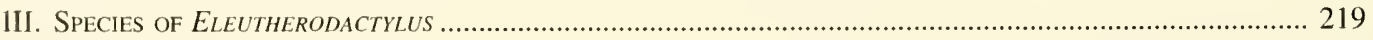

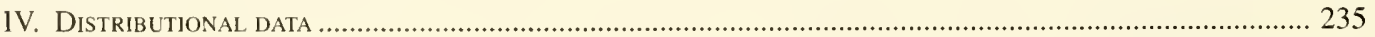

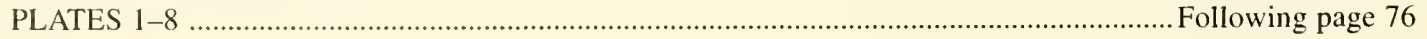


ABSTRACT Western Ecuador encompasses the Pacific lowlands, a series of low coastal mountains, and the Andes, which rise to heights of more than $6000 \mathrm{~m}$. Within this region, bioclimatic regimes range from humid tropical rainforest to desert on the lowlands, from subtropical dry and subtropical humid environments on the lower slopes of the Andes to humid temperate and subtemperate forests, subparamo, and paramo at high elevations in the Andes. This region is inhabited by 61 species of Eleutherodactylus, each of which is treated in an account that includes a diagnosis, description or reference to a description, coloration in life, natural history, and distribution. Nine new species are described, and E. albercli is placed in the synonymy of E. surdus. Records for E. taeniatus in Ecuador are based on misidentifications. All morphological characters used in the identification and systematics of Eleutherodactylus are defined and illustrated, and a key to the identification of the species in western Ecuador is provided.

Nine communities containing six to fifteen species of Eleutherodactylus were analyzed with respect to species diversity, rank and relative abundance of species, body size, and microhabitat untilization. Fidelity of species to bioclimatic regimes is rather low; the highest degree of endemism is $26 \%$ in the humid subtropical regime. Among the Eleutherodactylus in western Ecuador, 32 species are endemic to the region, and 24 other species reach the southern limits of their distributions there. Altitudinally, the greatest number of species is between 1200 $\mathrm{m}$ and $2200 \mathrm{~m}$. Sizes of distributions are large at low elevations compared to smaller ranges of species in the Andes. Patterns of speciation include upland vicariants of lowland relatives, latitudinal replacement of sister taxa in the Andes, and trans-Andean relatives.

Key words: Ecuador; Pacific versant; Leptodactylidae; Eleutherodactylus; Taxonomy; New species; Community ecology; Biogeography.

RESUMEN La parte oeste de Ecuador abarca las tierras bajas del Pacífico, una serie de montañas bajas costeñas. y los Andes que suben a elevaciones mayores de los $6000 \mathrm{~m}$. Dentro de esta región los regímenes bioclimáticos varían desde selva húmeda tropical hasta desierto en las tierras bajas, desde ambientes secos subtropicales hasta húmedos subtropicales en las pendientes bajas de los Andes, y hasta bosques templados y subtemplados, subpáramo, y páramo en las elevaciones altas de los Andes. Esta región es habitada por 61 especies de Eleutherodactylus, cada una de estas se cubre en un sumario que incluye diagnosis, descripción o referencia a una descripción, coloración en vida, historia natural, y distribución geográfica. Se describe nueve especies nuevas y se coloca E. alberchi en la sinonimia de E. surdus. Los registros de E. taeniatus en Ecuador han sido basados en identificaciones erróneas. Todos los caracteres morfológicos utilizados en la identificación y sistemática son definidos e ilustrados, y se provee una clave para la identificación de las especies en el oeste del Ecuador.

Nueve comunidades que contienen de seis a quince especies de Eleutherodactylus fueron analizadas con respecto a diversidad, grado de abundancia y abundancia relativa de especies, tamaño del cuerpo, y utilización de microhabitat. La fidelidad de especies a régimenes bioclimáticos es algo bajo; el grado más alto de endemismo es $26 \%$ y se encuentra en el régimen húmedo subtropical. De las especies de Eleutherodactylus en el oeste del Ecuador, 32 son endémicas a la región, y las otras 24 especies llegan a su límite sur en esta región. Altitudinalmente el mayor número de especies se encuentran entre $1100 \mathrm{~m}$ y $2200 \mathrm{~m}$. El tamaño de las distribuciones es grande en las tierras bajas en comparación con las extensiones más pequeñas de las especies en los Andes. Los patrones de especiación incluyen vicariantes en las tierras altas que tiene párientes en las tierras bajas, reemplazo latitudinal de especies hermanas en los Andes, y parientes transandinos.

Palabras claves: Ecuador; región Andina-Pacífica; Leptodactylidae; Eleutherodactylus; Taxonomía: Especies nuevas; Ecología de comunidades; Biogeografía.

\section{INTRODUCTION}

Anyone who has ventured into the humid lowland rainforests of northwestern Ecuador on into the cloud forests on the Pacific slopes of the Andes in Ecuador at night has been greeted by a variety of "chirps" and "peeps." Inspection of the low vegeta- tion and rocks along streams with a headlight immediately reveals to the visitor a variety of frogs of the genus Eleutherodacty/us, the most speciose group of vertebrates in the neotropics, with more than 500 species recognized (Duellman, 1993). In 
many places in the neotropics, especially in Andean cloud forests and adjacent lowland rainforests, these are the most diverse and abundant anurans. As such, they should be ideal subjects for ecological studies and monitoring of populations. However, such has not been the case, principally because these frogs have been a notoriously difficult group taxonomically. We anticipate that this dilemma can be remedied by thorough and precise taxonomic treatments of members of the genus in various geographic regions.

We began our investigations of the Ecuadorian herpetofauna in the mid-1960s. Duellman worked sporadically in western Ecuador from 1967-1984. Lynch's field work there in 1967-1979 focused almost exclusively on Eleutherodactylus, and although his interests shifted to the rich Colombian fauna about 15 years ago, he retained an obligation to summarize the Eleutherodactylus fauna of Ecuador. Four summaries of the Eleutherodactylus of geographical regions of the country have appeared-the Andes of southern Ecuador (Lynch, 1979a), the Amazon Basin (Lynch, 1980a), the Andes of northern Ecuador (Lynch, 1981a), and the Amazonian slopes of the Andes of Ecuador (Lynch and Duellman, 1980). Most recently, we (Lynch and Duellman, 1995) described E. philipi from páramos in southern Ecuador.

The present work is a summary of the Eleutherodactylus of the Pacific lowlands and the western slopes of the Andes of Ecuador. Herein, the upper altitudinal limit is arbitrary; it is defined not by elevation but, rather, by assemblages of Eleutherodactylus. Some species (e.g., E. curtipes) from the paramos do encroach into the upper cloud forests, but we do not include these species; they were treated by Lynch ( 1981 a). Our intent here is to treat the species confined to forested regions of western Ecuador. This small fragment of the total range of the genus contains more than $12 \%$ of the species of Eleutherodactylus. In addition to a thorough taxonomic treatment, we examine patterns of distribution with respect to climate, vegetation. topography, and historical biogeography. We also focus on several eleuthero-dactyline communities in western Ecuador and compare these with communities elsewhere. In so doing, we hope to provide the ground work for future studies on the ecology of eleutherodactyline frogs in northwestern South America.

A seminal paper on Eleutherodactylus in western Ecuador was that in which Boulenger (1898) described six new species (as Hylodes and Syrrhophus) collected by W. F. H. Rosenberg for the British Museum. Of the 61 species now known from western Ecuador, only 16 of these were described prior to our work in the region. Lynch (and coworkers) described 32 species, and nine are named herein; three other species (E. hamiotae Flores, E. rosadoi Flores, and E. simonbolivari Wiens and Coloma) have been named in recent years. Eight of the 11 species of Eleutherodactylus now known from cloud forest at Tandapi, Ecuador, were treated by Lynch (1976a). Lynch and Burrowes (1990) reported on the Eleuthero-dactylus in the cloud forest at La Planada in southwestern Colombia; of the eight species described as new (and then known only from Colombia), we have found six in collections from Ecuador. Some of the most common species on the Pacific lowlands of Ecuador are members of the paraphyletic Eleutherodactylus "fitzingeri" group of Lynch (1976) and Lynch and Myers (1983), the Chocoan members of which were treated monographically by Lynch and Myers (1983).

Most of the species known from western Ecuador have been described, and we do not repeat descriptions in the accounts of those species; rather, we provide references to adequate descriptions. Complete descriptions are given for the nine species named herein. We provide a redescription of Eleutherodactylus gularis (Boulenger) because existing descriptions (Boulenger, 1898; Cochran and Goin, 1970) are inadequate and because more than one species has been confounded under that name. For all species, we provide lengthy, numbered diagnoses, including comparisons and comments, even when doing so results in duplication of material published elsewhere; we have done this to facilitate comparisons and identifications. Accounts of two species, E. siopelus and E. sulculus that are known from extreme southwestern Colombia but yet to be recorded from Ecuador, are included because we are confident that they will be found in Ecuador. Our other departure is the inclusion of the only other eleutherodactylines (Barycholos pulcher 
and Phyllonastes sp.) known from western Ecuador in the key and in comparisons in appropriate diagnoses.

This is the last in a series of papers on Ecuadorian eleutherodactylines, and we take this opportunity to review, and expand on, the characters we find to be most useful in the identification of species. This concern for well-defined characters reflects Lynch's interest in the phylogenetic relationships within the genus and the desire to have groups of species defined by shared derived characters rather than by phenetic similarity. The initial understanding of relationships within Eleutherodactylus came with the recognition that the subgenus Crangastor could be diagnosed by a derived condition of the m. adductormandibulae (Lynch, 1986). That discovery caused JDL to question (and ultimately to reject) many of his earlier groupings of Eleutherodactylus and to continue to search for synapomorphies for various units within the genus.

\section{Acknowledgments}

More than a quarter of a century has passed since we initiated our work in Ecuador. During that time we have built up a debt of gratitude to many persons who contributed directly or indirectly to the completion of this work. We are especially grateful to our field companions whose efforts greatly enhanced the collection of specimens and field data. At various times, JDL was accompanied by Thomas J. Berger, David C. Cannatella, Thomas H. Fritts, Robert W. Hen-derson, Marsha C. Lynch, and Gerald R. Smith. Duellman variously was accompanied by Patricia A. Burrowes, Dana T. Duellman, David M. Hillis, Bruce MacBryde, Alan H. Savitzky, John E. Simmons, and Linda Trueb. Duellman's field work was accomplished as part of research supported by the National Science Foundation (Grants DEB 74-02998, 76-09986, and 8219388) and the National Geographic Society (Grant 1304); the biogeographic analysis herein is part of a project on patterns of anuran speciation and biogeography supported by the National Science Foundation (Grant BSR 8805920). Lynch's field work was made possible by grants from the Society of the Sigma Xi, Watkins Fund of the Natural History Museum, and the University of Nebraska
Research Council. Funding for the color plates was provided by the School of Biological Sciences, University of Nebraska, Lincoln.

For the loan of specimens and/or providing working space in their respective institutions, we are grateful to Darrel R. Frost, Charles W. Myers, and Richard G. Zweifel, American Museum of Natural History; Alice G. C. Grandison, British Museum (Natural History); Alan E. Leviton, California Academy of Sciences; Robert F. Inger, Field Museum of Natural History; José P. Rosado and Ernest E. Williams, Museum of Comparative Zoology, Harvard University; Josef Eiselt, Naturhistorisches Museum, Wien; Dorothy Smith, University of Illinois Museum of Natural History: Arnold G. Kluge, Ronald A. Nussbaum, and the late Charles F. Walker. University of Michigan Museum of Zoology; the late Doris M. Cochran, W. Ronald Heyer, Roy W. McDiarmid, the late James A. Peters, and George R. Zug, National Museum of Natural History. We acknowledge the cooperation of AnaAlmendáriz (Escuela Politécnica Nacional), Luis A. Coloma (Pontificia Universidad Católica del Ecuador), and Alexandra Quiguango (Ecociencia) for loaning specimens from Ecuadorian collections and providing data on localities in Ecuador. Coloma and Martha L. Crump, who acted as liaison with Ecociencia, provided color slides, as did Patricia A. Burrowes and Roy W. McDiarmid. Credits for photographs in Plates $1-8$ are noted in the legends as: JDL $=$ John D. Lynch, $\mathrm{KM}=$ Kenneth Miyata, LAC $=$ Luis A. Coloma, $\mathrm{MLC}=$ Martha L. Crump, PAB = Patricia A. Burrowes, $\mathrm{RWM}=$ Roy $\mathrm{W}$. McDiarmid, $\mathrm{WED}=$ William E. Duellman. We thank Patricia A. Burrowes and Erik R. Wild for helpful suggestions on the analysis of the ecological data, Joseph R. Mendelson III for checking specimens against our list of specimens examined, Santiago F. Burneo and Ignacio de la Riva for providing the Spanish version of the key. and Rafael Joglar for assistance with the Spanish Resumen. We also thank Eugenia del Pino and Fernando Ortiz C., who generously provided facilities for our use at the Universidad Católica in Quito, and to Sergio Figueroa and Abel Tovar V., Ministerio de Agricultura y Ganadería. for issuing permits for collection and exportation of specimens. 
An earlier version of this manuscript benefitted from thoughful comments by Martha L. Crump, throrough review by Luis A. Coloma, and critical evaluation by Jay M. Savage, who encouraged us to eschew certain hectoring terms in our discussion of anatomy. To these three persons in particular we extend our profound thanks. We especially thank Linda Trueb, whose careful editing and assistance with the electronic transfer of illustrations resulted in the improvement of our otherwise benign efforts. Lastly, we dedicate this paper to the memories of two deceased friends and colleaguesKenneth Miyata and James A. Peters; they loved Ecuador and collected many of the specimens on which this work is based.

\section{MATERIALS AND METHODS}

Specimens are identified by standardized museum codes designated by Leviton et al. (1985), except for the addition of four collections housed in Quito, Ecuador: $\mathrm{ECO}=$ Ecociencia (specimens to be deposited in a museum), EPN = Escuela Politécnica Nacional, MECN = Museo Ecuatoriano de Ciencias Naturales, and QCAZ = Museo de Zoología, Pontificia Universidad Católica del Ecuador. Some specimens collected recently by Ana Almendáriz are identified by field numbers (e.g., EPN-AA). References are made to some specimens in Colombian collections: ICNMHN = Instituto de Ciencias Naturales, Museo de Historia Natural, Universidad Nacional de Colombia, Bogotá; 1ND-AN = amphibian collection. Instituto Nacional de los Recursos Naturales Renovables y del Ambiente, Bogotá; UVC = Universidad Valle de Cauca, Cali.

All specimens from western Ecuador that have been studied are listed in Appendix I. Localities from which specimens have been examined are listed with their geographic coordinates and elevations (when known) in Appendix II. Localities that have been located are plotted on distribution maps in the Accounts of Species; because of crowding of symbols, some closely approximated localities are not shown.

Methods for taking measurements and ascer- taining structural features are defined in a following section, Description of Characters. Measurements were taken with dial calipers to the nearest $0.1 \mathrm{~mm}$; measurements, and proportions are given for each sex when their means differ significantly $(\mathrm{P} \leq 0.05)$; otherwise these data are combined. The following abbreviations are used: $\mathrm{E}-\mathrm{N}=$ eye-nostril distance; $\mathrm{HL}=$ head length, $\mathrm{HW}=$ head width, $1 O D=$ interorbital distance, $\mathrm{SVL}=$ snout-vent length. Areas of distribution were measured from maps using a Micro-Plan Il image analysis system (Laboratory Computer Systems, Inc., Cambridge, MA).

Throughout the text, we have avoided using the terms senior and junior author, because in this case the junior is senior chronologically; therefore, the authors are noted simply as JDL and WED. Although we both assume responsibility for the material presented herein, JDL is the primary author for the sections on systematics, and WED is the primary author for the sections on western Ecuador, ecology, and biogeography. All morphological illustrations were drawn by JDL using a dissecting microscope equipped with a camera lucida. All graphs and maps were generated by WED using Aldus Freehand ${ }^{\circledR}$ on a Macintosh computer. The color photographs were reproduced electronically from color transparencies.

\section{WESTERN ECUADOR}

Western Ecuador encompasses the area from Colombia to Peru and from the Pacific Ocean to the western crest of the Andes; this region includes all of the provinces of Bolívar, El Oro, Esmeraldas, Guayas, Los Ríos, and Manabí, and the western parts of the provinces of Azuay, Carchi, Cañar, Chimborazo, Cotopaxi, Imbabura, Loja, and Pichincha (Fig. 1). In order to provide a working basis for the ecological and biogeographic analyses of the Eleutherodactylus of the region, we provide 


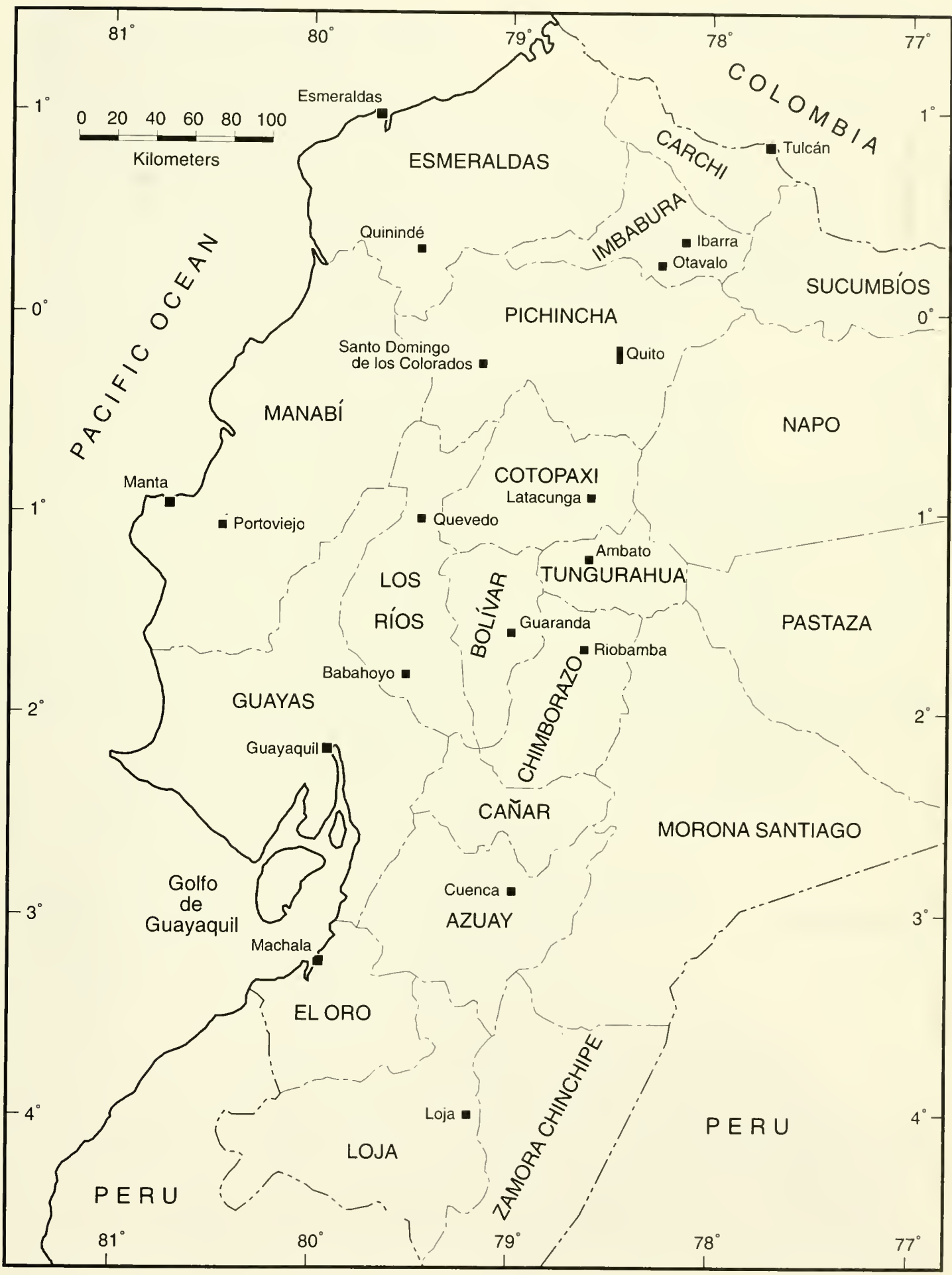

Fig. 1. Western and central Ecuador showing provinces and major cities. 


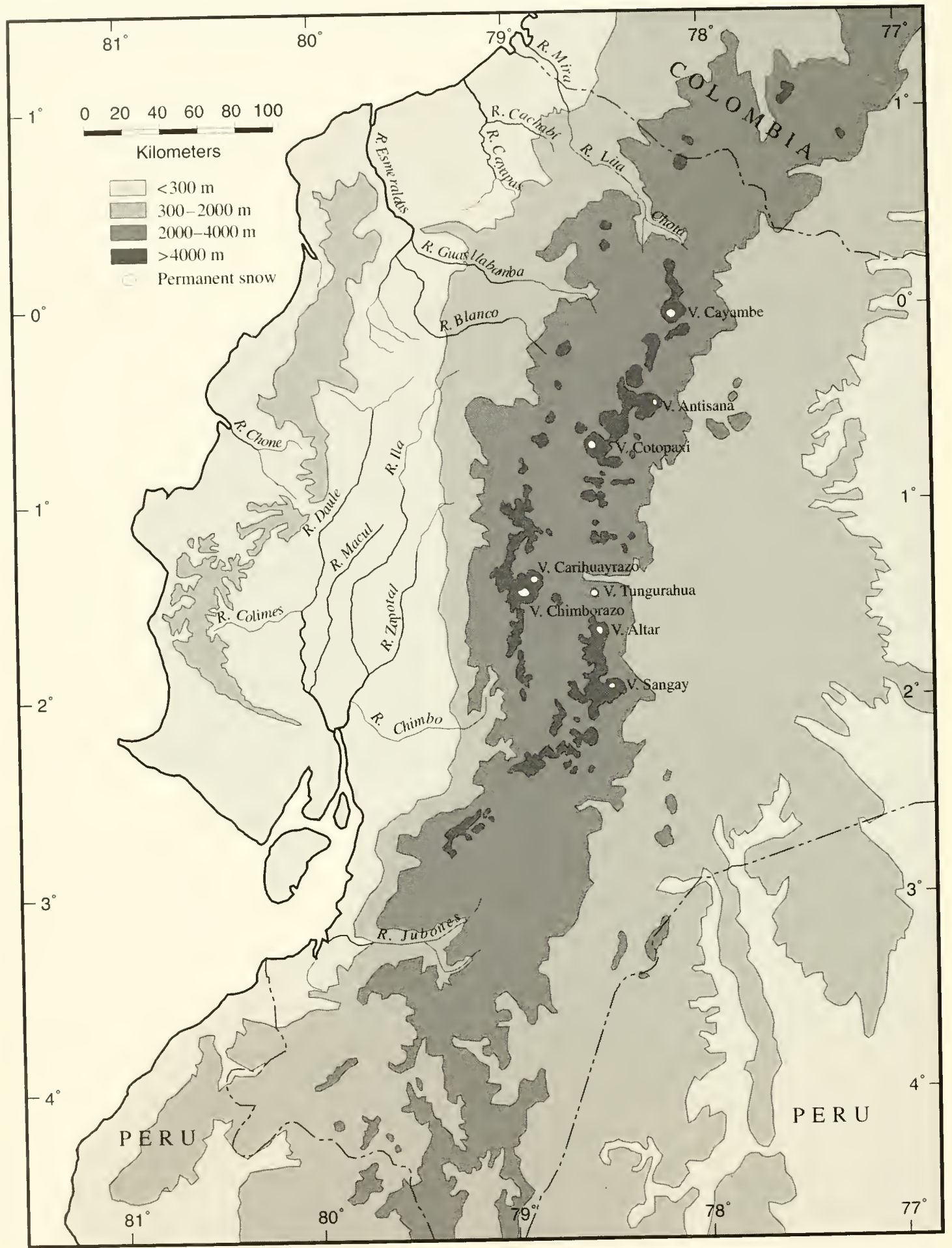

Fig. 2. Western Ecuador showing physical features. 


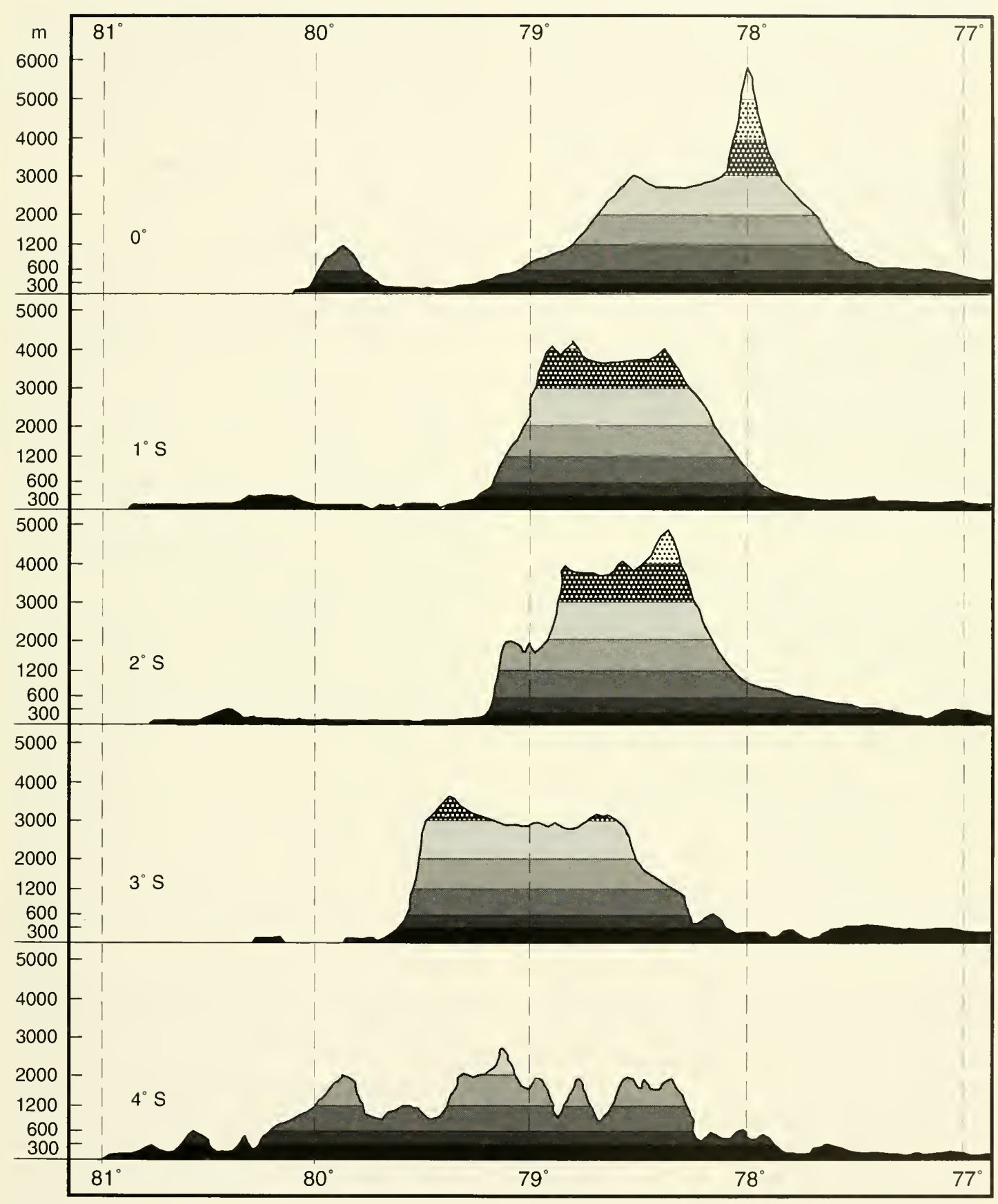

Fig. 3. Profiles of western Ecuador at $0^{\circ} \mathrm{S}$ to $4^{\circ} \mathrm{S}$ Latitude. Note the varying widths of the Pacific lowlands, the precipitous slopes of the Andes, and the complex lower topography at $4^{\circ} \mathrm{S}$ Latitude, which is the northern part of the Huancabamba Depression. Based on Mapa Físco 1:2,000,000, 1971, Instituto Geográfico Militar, Quito. Ecuador. Vertical exaggeration $=20 \times$. 
synopses of geography, climates, and bioclimatic regimes of the region, as well as a brief synopsis of its geological and climatic history and comments on changes during historic times. The complexities of physiography and climate cannot be appreciated readily by someone who has not descended the precipitous slopes from the lofty Andes, where many peaks within one degree of the Equator have permanent snow, to the Pacific lowlands. In fact, the snow-covered summit of one of the highest peaks in South America, Volcán Chimborazo at a height of $6310 \mathrm{~m}$, is only $50 \mathrm{~km}$ airline from the $300-\mathrm{m}$ contour at the base of the Andes. In such a transect, mean annual temperatures increase from below $0^{\circ} \mathrm{C}$ to more than $25^{\circ} \mathrm{C}$. Likewise, on the Pacific Coastal Plain, majestic rainforests receiving more than $3500 \mathrm{~mm}$ of rain annually gradually give way southward to deserts receiving less than $200 \mathrm{~mm}$ of rainfall annually.

\section{Physiography}

Western Ecuador can be divided into three physiographic regions, each of which is described below (Fig. 2).

Pacific Lowlands. - The lowlands between the Pacific Ocean and the base of the Andes at an elevation of approximately $600 \mathrm{~m}$ vary in breadth from about $200 \mathrm{~km}$ at Punta Santa Elena (02 $11^{\prime} \mathrm{S}$ ) to about $40 \mathrm{~km}$ in northern Provincia Esmeraldas; however, the lowlands are even narrower - in places no more than $20 \mathrm{~km}$ wide-south of the Golfo de Guayaquil. The terrain is nearly flat, especially in the south and northwest, whereas low, rolling terrain is encountered in southern Provincia Esmeraldas and northwestern Provincia Pichincha. The coastal region is swampy along the borders of the Golfo de Guayaquil southward nearly to the Peruvian border.

Cordillera de la Costa.--Nearly paralleling the coast and inland for distances of 5-60 km from just south of Esmeraldas to just west of Guayaquil is a range of low mountains that is interrupted at about $01{ }^{\circ} \mathrm{S}$ Lat. Local names are applied to various higher parts of this system of eroded ridges. Most of these highlands are less than $600 \mathrm{~m}$ in elevation (Fig. 2). Although there are some higher regions to the north and south, the largest continuous high- land area $(>600 \mathrm{~m})$ extends from $00^{\circ} 12^{\prime} \mathrm{N}$ Lat. to $00^{\circ} 25^{\prime} \mathrm{S}$ Lat. in northern Provincia Manabí; in this range, Cerro de Pata de Pájaro rises to $800 \mathrm{~m}$, and Cerro San Sebastián to $780 \mathrm{~m}$. To the north in the Montañas de Muisne south of Esmeraldas, the highest ridges are at elevations of $600-800 \mathrm{~m}$, whereas in the extreme south in the Cerros de Chongón, few ridges are above $400 \mathrm{~m}$.

Andes.-The Andes are the dominant physiographic feature in Ecuador; this high volcanic range extends the length of the country and is divided into eastern (Cordillera Oriental) and western (Cordillera Occidental) ranges separated by inter-Andean basins and connected, or nearly so, by transverse ridges. For a detailed description, see Duellman (1979). The Andes along the western versant of Ecuador consist of three distinct regions:

1. To the north of the Río Chota, the Andes in extreme northwestern Ecuador are part of a mass, the Nudo de Pasto centered in southern Colombia; the highest peak is Volcán Chiles (4723 m) on the Ecuadorian-Colombian border.

2. South of the Río Chota Valley, the major range of the Cordillera Occidental extends southward to the Río Jubones Valley. The entire range exceeds elevations of $3000 \mathrm{~m}$, and there is one continuous area more than $100 \mathrm{~km}$ long that exceeds $4000 \mathrm{~m}$. The highest volcanoes in this range (from north to south) are Yanahurco de Piñán (4535 m), Cotacachi (4944 m), Rucu-Pichincha (4324 m), Guagua-Pichincha (4675 m), Atacazo (4463 m), Corazón (4788 m), Illiniza Norte (5126 m), Illiniza Sur (5248 m), Quilotoa (3914 m), Sagoatoa (4153 m), Carihuayrazo (5020 m), Chimborazo $(6310 \mathrm{~m})$, Chanlor (4300 m), Patul (4l63 m), and Minas $(4096 \mathrm{~m})$. Except in the northern part of this range, the western slopes are extremely precipitous (Fig. 3).

3. To the south of the Río Jubones southward into northern Peru, the mountains are lower and fragmented into complex series of north-south or northeast-southwest ranges that are separated by valleys, many of which are at elevations below $1500 \mathrm{~m}$ (Fig. 3). This complex system of low ranges and basins collectively is referred to as the Huancabamba Depression, wherein exists the lowest breach in the Andes (Abra de Porculla at 2145 $m$ in northern Peru) between Colombia and south- 
ern Chile. Along the western versant of the Huancabamba Depression in Ecuador, the highest mountains are in the Cordillera de Chilla (Cerro Chillacocha, $3580 \mathrm{~m}$ ) and in the Cordillera de Celica with one long ridge above $3000 \mathrm{~m}$.

\section{River Systems}

As might be expected from the topography, drainage systems in western Ecuador are complex (Fig. 2). In the lowlands in northwestern Ecuador, the major rivers flow north or northwest. One of the major drainages is the Río Mira system, the mouth of which is in Colombia. In the headwaters of this system is the Río Chota originating in the Ibarra Basin and forming a depression between the Nudo de Pasto and the Cordillera Occidental. Other major affluents of the Río Mira are the Río San Juan on the Colombian-Ecuadorian border and the Río Lita, tributaries of which drain the northernmost part of the Cordillera Occidental. The broad, meandering Río Esmeraldas has many affluents draining the northwestern Pacific lowlands. Two of these, the Río Guayllabamba and the Río Blanco, drain the Pacific slopes of the Andes from about $0^{\circ} 30^{\prime} \mathrm{N}$ Lat. to $1^{\circ} \mathrm{S}$ Lat. Major rivers flowing into the Río Guayllabamba include the Río Nanegal, Río Pachijal, and Río Pitsará. The headwaters of these streams are narrowly separated from the Río Blanco, which has many tributaries (e.g., Río Mindo, Río Saloya, Río Toachi, and Río Pilatón) draining the slopes of the Andes.

Between the Cordillera de la Costa and the Andes southward from about $0^{\circ} 15^{\prime} \mathrm{S}$ Lat., the major rivers flow southward to the Golfo de Guayaquil. The major rivers are the Río Daule and the Río Babahoyo, which converge just north of Guayaquil to form the broad Río Guayas. Most of the rivers draining the adjacent precipitous slopes of the Andes are rather short; major exceptions are south of $2^{\circ} \mathrm{S}$ Lat. and include the Río Chimbo-Río Coco and the Río Chanchán. Southward and draining directly into the Pacific Ocean are numerous small rivers and two major rivers, the Río Jubones and the Río Puyango, both of which extend far inland in deep valleys in the Andes. The western slopes of the Cordillera de la Costa are drained by many small rivers flowing into the Pacific Ocean.
The largest of these, Río Calceta and Río Portoviejo, separate the northern and southern parts of the Cordillera de la Costa.

\section{Climate}

Irrespective of the effects of altitude, the climate in western Ecuador is influenced by two drastically different ocean currents. The cold Humboldt Current originating in the Antarctic Ocean sweeps northward along the west coast of South America to about $2^{\circ} \mathrm{S}$ Lat. where it swings westward away from the land. Most of the moisture in onshore winds condenses as fog offshore, so that rainfall is slight on the Pacific lowlands and only moderate at higher elevations. Contrariwise, the warm equatorial current, El Niño, flows southward along the coast of Colombia and northern Ecuador before turning westward. The onshore winds are heavily laden with moisture, which condenses over the lowlands and continues to do so as the air masses rise along the face the Andes. This results in heavy rainfall throughout the year in northwestern Ecuador and moderately heavy rainfall throughout the year on the Andean slopes north of $1^{\circ} \mathrm{S}$ Lat.

In January-March, the equatorial current shifts farther south; consequently, during these months, rain falls more frequently and heavily throughout the region, and it is at this time that most, if not all, of the rain falls in the lowlands south of $2^{\circ} \mathrm{S}$. Lat. (Fig. 4). However, even on the Andean slopes, there is a marked decrease in rainfall in June-August; for example, at Lita $\left(00^{\circ} 50^{\prime} \mathrm{N}, 78^{\circ} 27^{\prime} \mathrm{W} ; 570 \mathrm{~m}\right)$, rainfall exceeds $300 \mathrm{~mm}$ per month in OctoberApril, but it drops to less than $200 \mathrm{~mm}$ per month in June-August. Likewise, farther south and also at higher elevations the same annual pattern prevails, but the rainy period is shorter; for example, at Pilaló $\left(00^{\circ} 56^{\prime} \mathrm{S}, 79^{\circ} 00^{\prime} \mathrm{W} ; 2400 \mathrm{~m}\right)$, rainfall exceeds $125 \mathrm{~mm}$ per month in December-April, but it declines to less than $40 \mathrm{~mm}$ per month in July and August.

The western slopes of the Andes are characterized by a humid adiabatic lapse rate that, because of lower evaporation rates at higher elevations, results in high humidity even though rainfall is less than at lower elevations (Table 1). Dense cloud banks are almost of daily occurrence at various 


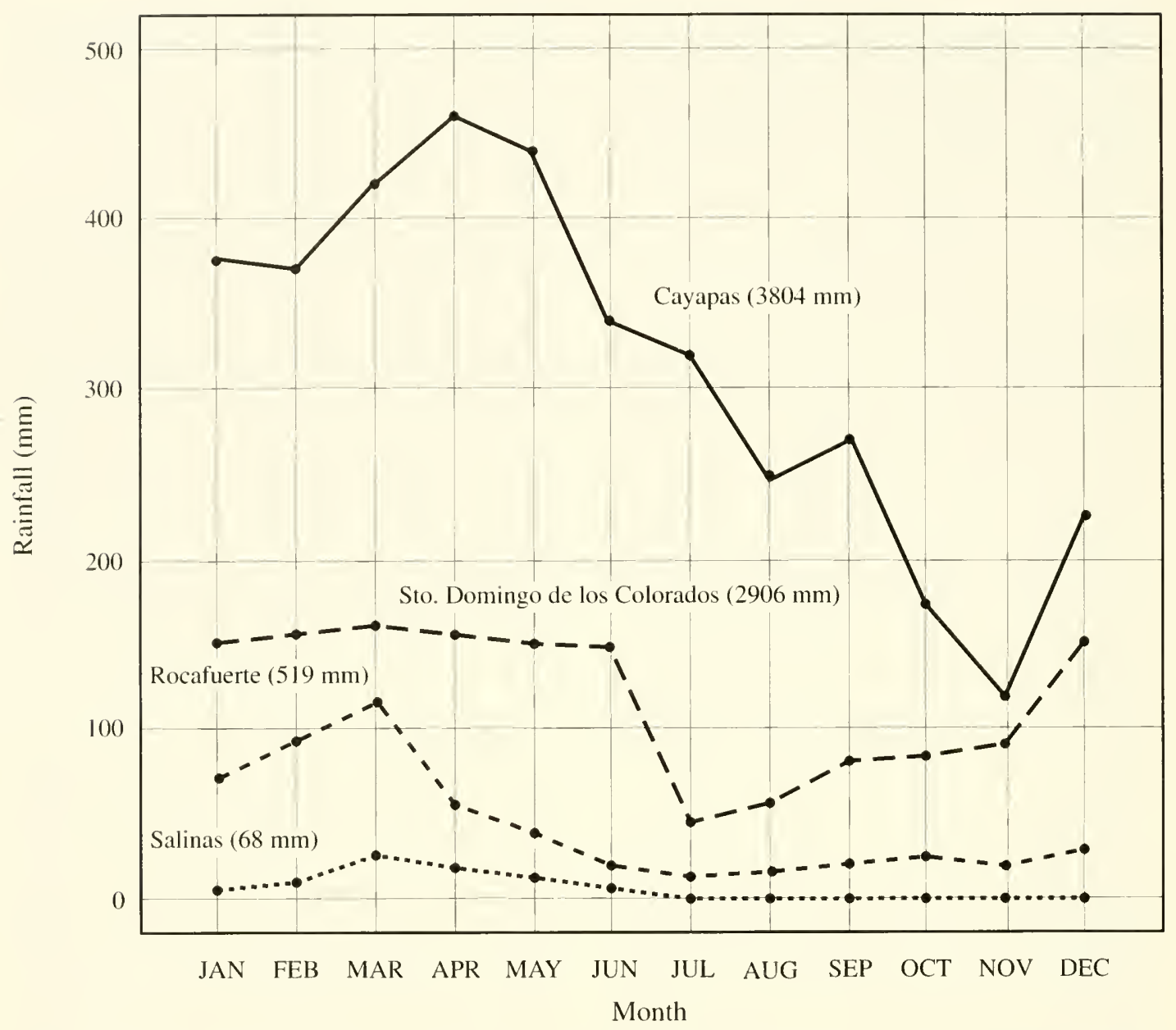

Fig. 4. Annual patterns of rainfall on the Pacific lowlands of Ecuador. Note the decrease in rainfall from north to south. Cayapas is at $00^{\circ} 50^{\prime} \mathrm{N}, 79^{\circ} 01^{\prime} \mathrm{W}, 65 \mathrm{~m}$; Santo Domingo de los Colorados is at $00^{\circ} 15^{\prime} \mathrm{S}, 79^{\circ} 10^{\prime} \mathrm{W}, 600 \mathrm{~m}$; Rocafuerte is at $00^{\circ} 55^{\prime} \mathrm{S}, 80^{\circ} 27^{\prime} \mathrm{W}, 10 \mathrm{~m}$; Salinas is at $02^{\circ} 11^{\prime} \mathrm{S}, 80^{\circ} 59^{\prime} \mathrm{W}, 6 \mathrm{~m}$. Data from Cañadas (1983).

elevations along the western slopes of the Andes. Climatic data are not available for sites in the Cordillera de la Costa. However, at elevations of 700-800 $\mathrm{m}$ on Cerro Sebastián, just inland from Machalilla, Provincia Manabí, Foster (1992a:36) commented on the moisture in the fog forest in January: "With every passing cloud that comes up against the ridge, the forest starts dripping heavily, very much as if it were raining. Stepping out into the clearing, however, one immediately finds that there is no rain at all."

Throughout all but the southern part of western Ecuador the great physiographic relief results in rapidly declining temperatures from average annual temperatures of more than $25^{\circ} \mathrm{C}$ in the lowlands to below $0^{\circ} \mathrm{C}$ on the highest snow-covered volcanoes (Fig. 5). Annual variation in monthly mean temperatures is less than $3^{\circ} \mathrm{C}$ in the humid tropical lowlands (e.g., $25-27^{\circ} \mathrm{C}$ at Cayapas) but somewhat greater in arid tropical lowlands (e.g., 21$26^{\circ} \mathrm{C}$ at Salinas). Likewise, the annual variation in monthly means is minuscule at sites on the western slopes of the Andes-for example, $21-23^{\circ} \mathrm{C}$ at Lita $(570 \mathrm{~m}), 16-18^{\circ} \mathrm{C}$ at Chiriboga $(1910 \mathrm{~m})$, and $13-$ $14^{\circ} \mathrm{C}$ at Pilaló $(2400 \mathrm{~m})$. In contrast, daily fluctuations are greater than the variation in monthly means. Temperatures obtained from a maximum-minimum thermometer at actual collecting sites in 1975 are given in Table 2. 
Table 1. Climatic data for selected sites in western Ecuador (exerpted from Cañadas, 1983).

\begin{tabular}{|c|c|c|c|c|c|c|}
\hline Site & Lat. \& Long. & Elev. (m) & $\begin{array}{l}\text { Mean } \\
\text { annual } \\
\text { temp. } \\
\left(0^{\circ} \mathrm{C}\right)\end{array}$ & $\begin{array}{l}\text { Mean } \\
\text { annual } \\
\text { precip. } \\
(\mathrm{mm})\end{array}$ & $\begin{array}{c}\text { Days } \\
\text { without } \\
\text { rain }\end{array}$ & $\begin{array}{c}\text { Ecological } \\
\text { regime }\end{array}$ \\
\hline Salinas, Guayas & $02^{\circ} 11^{\prime} \mathrm{S}, 80^{\circ} 59^{\prime} \mathrm{W}$ & 6 & 23.0 & 68 & 233 & Desert \\
\hline Guayaquil, Guayas & $02^{\circ} 12^{\prime} \mathrm{S} .79^{\circ} 53^{\prime} \mathrm{W}$ & 6 & 25.0 & 820 & 172 & Dry tropical \\
\hline Salinas, Imbabura & $00^{\circ} 30^{\prime} \mathrm{N}, 78^{\circ} 06^{\prime} \mathrm{W}$ & 1730 & 19.4 & 307 & 205 & Dry subtropical \\
\hline Ibarra. Imbabura & $00^{\circ} 21^{\prime} \mathrm{N}, 78^{\circ} 06^{\prime} \mathrm{W}$ & 2228 & 15.4 & 589 & 60 & Dry temperate \\
\hline Muisne. Esmeraldas & $00^{\circ} 37^{\prime} \mathrm{N}, 80^{\circ} 01^{\prime} \mathrm{W}$ & 6 & 24.7 & 1574 & 43 & Suhumid tropical \\
\hline Cayapas. Esmeraldas & $00^{\circ} 50^{\prime} \mathrm{N}, 79^{\circ} 01^{\prime} \mathrm{W}$ & 65 & 25.6 & 3804 & - & Humid tropical \\
\hline Lita. Imbabura & $00^{\circ} 50^{\prime}$ N. $78^{\circ} 27^{\prime} \mathrm{W}$ & 570 & 22.4 & 3678 & - & Humid subtropical \\
\hline Pilaló, Cotopaxi & $00^{\circ} 56^{\prime} \mathrm{S}, 79^{\circ} 00^{\prime} \mathrm{W}$ & 2400 & 18.0 & 1408 & 18 & Humid subtemperate \\
\hline Otavalo. Imbabura & $00^{\circ} 14^{\prime} \mathrm{N}, 78^{\circ} 16^{\prime} \mathrm{W}$ & 2556 & 14.4 & 735 & 41 & Humid temperate \\
\hline
\end{tabular}

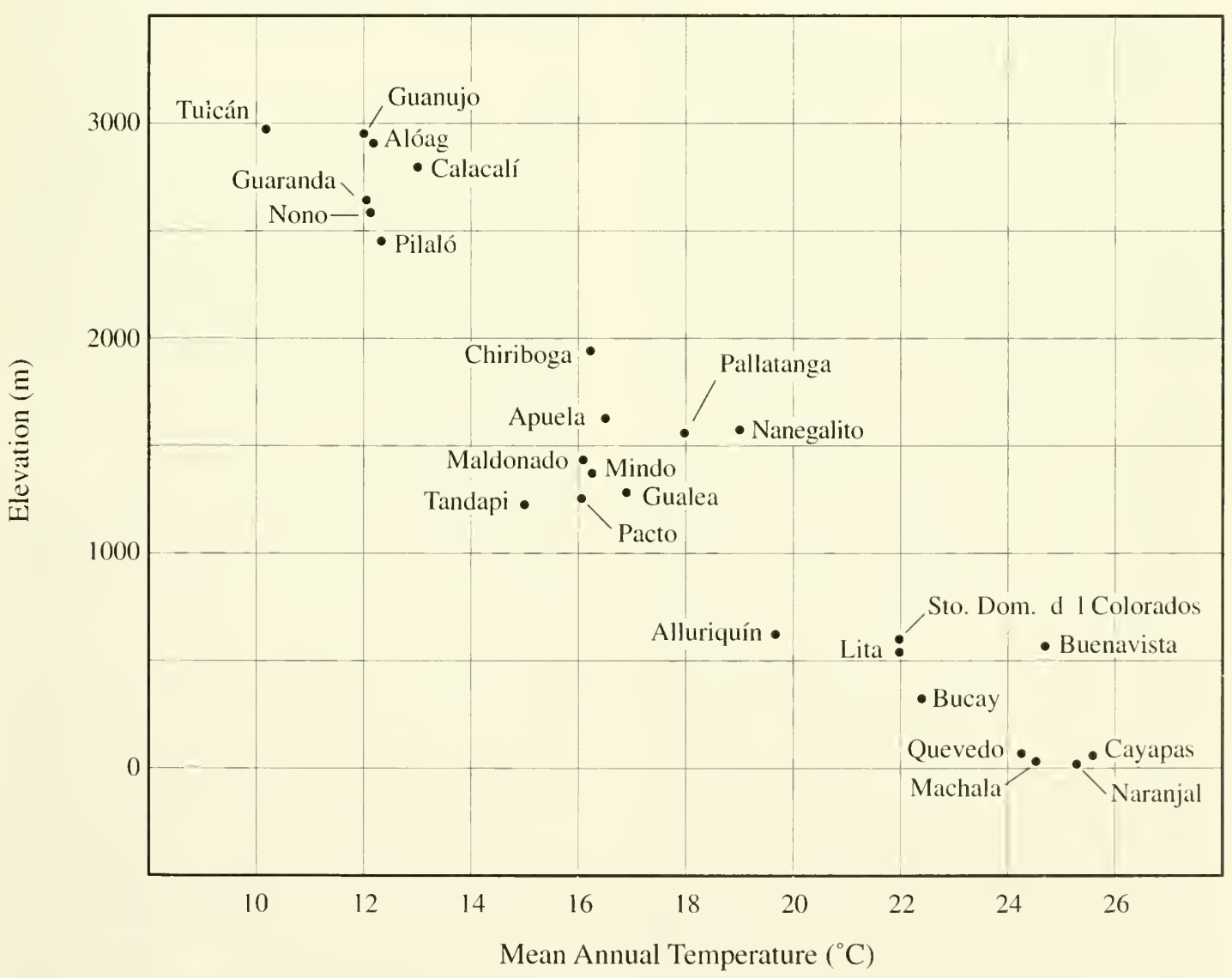

Fig. 5. Mean annual temperatures at selected sites over an elevational range in western Ecuador. See Appendix Il for locations. Data from Cañadas (1983) and Indice Toponímico de la República del Ecuador (1972). 
Table 2. Daily fluctuations in air temperatures $\left({ }^{\circ} \mathrm{C}\right)$ at collecting sites in western Ecuador in 1975.

\begin{tabular}{lcccc}
\hline \hline \multicolumn{1}{c}{ Site } & Elevation & Dates & $\begin{array}{c}\text { Min. } \\
\text { temp. }\end{array}$ & $\begin{array}{c}\text { Max. } \\
\text { temp. }\end{array}$ \\
\hline C. C Río Palenque, Los Ríos & $220 \mathrm{~m}$ & 27-31 Mar. & 20.0 & 29.5 \\
$8 \mathrm{~km}$ ESE Pto. Quito, Pichincha & $530 \mathrm{~m}$ & 06-07 Apr. & 20.5 & 27.5 \\
$18 \mathrm{~km}$ W Piñas, El Oro & $780 \mathrm{~m}$ & 06-07 Mar. & 19.0 & 25.0 \\
$4 \mathrm{~km}$ E Dos Ríos, Pichincha & $1140 \mathrm{~m}$ & $01-02 \mathrm{Apr}$. & 14.5 & 20.5 \\
$3.5 \mathrm{~km}$ NE Mindo, Pichincha & $1540 \mathrm{~m}$ & $07-08 \mathrm{Apr}$. & 15.0 & 25.0 \\
$14 \mathrm{~km}$ W Chiriboga, Pichincha & $1960 \mathrm{~m}$ & 08-09 May & 8.5 & 23.0 \\
Quebrada Zapadores, Pichincha & $2010 \mathrm{~m}$ & $03-04$ Apr. & 10.5 & 22.0 \\
$9 \mathrm{~km}$ SE Tandayapa, Pichincha & $2150 \mathrm{~m}$ & 09-10 Apr. & 10.0 & 23.0 \\
$9.5 \mathrm{~km}$ NW Nono, Pichincha & $2530 \mathrm{~m}$ & $11-12 \mathrm{Apr}$. & 10.5 & 19.5 \\
$14 \mathrm{~km}$ SW Tulcán, Carchi & $3340 \mathrm{~m}$ & 18-19 May & 0.0 & 18.0 \\
\hline \hline
\end{tabular}

\section{Bioclinatic Regines}

The concept of life zones based on temperature, precipitation, and evapotranspiration rates proposed by Holdridge (1947) for recognizing plant formations and elaborated upon by Holdridge (1967) was applied to Ecuador by Cañadas (1983). Although in theory the life zones are defined by abiotic factors, in practice, they are recognized by characteristic flora. A weakness of the system is that edaphic differences are not taken into consideration; consequently, areas having similar climates but drastically different soils (e.g., sandy karst vs. deep alluvial) will be placed in the same bioclimatic category.

For Ecuador, the Holdridge system was modified and refined by Cañadas (1983), who included data on soils and topography. We agree with Savage (1975) that the Holdridge system seems to be too sophisticated for determining broad vegetational correlates to animal distributions. Thus, although we follow Cañadas's classification (Fig. 6), we simplify it by combining many of his categories (Table 3). We use Cañada's terms "temperate" and "subtemperate" in his sense of temperature; these terms do not refer to temperate zone climates.

The 10 bioclimatic regimes that we recognize are defined below; they are arranged from tropical to temperate or cooler within dry to wet regimes (Fig. 7). The type of vegetation and characteristic plant taxa are given for each regime. For ease of comparison, we include the synonymous terms of the Holdrige system. Unless noted otherwise, data are summarized from Cañadas (1983).
Desert.-Extremely arid conditions exist in two coastal regions in southwestern Ecuador. These isolated deserts lie at elevations below $300 \mathrm{~m}$ and receive less than $200 \mathrm{~mm}$ of rainfall annually, mostly in February-May. The soils are mostly sandy, but some areas have clay, which characteristically has deep cracks throughout the long dry season. The sandy soils support the characteristic candelabra cactus (Lemairocereus cartwrightianus) and sparse grasses of the genera Panicium, Chloris, and Eragrostis. On the low hills, small trees, such as Bursera graveolens and Capparis angulata, occur.

In the Holdridge system, this regime includes lowland desert and lowland desert scrub.

Dry tropical.-Most of the Pacific lowlands south of $1^{\circ} \mathrm{S}$ Lat. are in this category, which also extends northward along the western lowlands to $0^{\circ} 15^{\prime} \mathrm{N}$ Lat.; discontinuous areas of this regime also occur along the northwestern coast. Rainfall is lowest $(<500 \mathrm{~mm}$ annually, mostly in JanuaryApril) along the coastal regions and becomes progressively higher inland, where annual rainfall may approach $1500 \mathrm{~mm}$, most of which falls in December-mid-May. The soils are sandy; in some places along the coast the sand is heavy, dark, and deep, and in other places along the coast the soils are alkaline. Clays predominate inland and along river valleys toward the coast.

There is a gradual change in vegetation from low $(<3 \mathrm{~m})$, scrub along much of the coast to dense scrub forest (5-10 $\mathrm{m}$ high) inland; in both areas the trees and bushes are primarily deciduous. In the 


\begin{tabular}{|c|c|c|c|c|c|c|c|}
\hline $\begin{array}{c}\text { Páramo } \\
0-6^{\circ}\end{array}$ & & Humid & Very Humid & Rainy & Very Rainy & & \\
\hline $\begin{array}{l}\text { Subtemperate } \\
\quad 6-12^{\circ}\end{array}$ & & Subhumid & Humid & Very Humid & Rainy & Very Rainy & Pluvial \\
\hline $\begin{array}{c}\text { Temperate } \\
12-18^{\circ}\end{array}$ & & Dry & Subhumid & Humid & Very Humid & Rainy & Very Rainy \\
\hline $\begin{array}{c}\text { Subtropical } \\
18-22^{\circ}\end{array}$ & & Very Dry & Dry & Subhumid & Humid & Very Humid & Rainy \\
\hline $\begin{array}{l}\text { Tropical } \\
22-26^{\circ}\end{array}$ & Desert & Subdesert & Very Dry & Dry & Subhumid & Humid & Very Humid \\
\hline $\begin{array}{l}\uparrow \stackrel{\text { Regime; }}{\uparrow} \\
\text { Temperature } \\
\text { Precipitation } \\
\rightarrow\end{array}$ & $<200$ & $200-500$ & $500-1000$ & $1000-1500$ & $1500-2000$ & $2000-3000$ & $>3000$ \\
\hline
\end{tabular}

Fig. 6. Classification of bioclimatic regimes (ecological zones) of Ecuador (Cañadas, 1983).

former, characteristic trees are Bursera graveolens and Jacquinia pubescens, whereas in the latter, trees (e.g., Cordia lutea, Prosopis juliffora, and Capparis crotonoides) are common. Extensive areas of mangroves occur along the coast in the northwest and around the Golfo de Guayaquil; the alkaline soils along the coast support a distinctive flora dominated by bushes-Mollugo, Mesentbryantheum, and Portulaca oleracea. The areas of highest rainfall (>1000 mm annually) support semideciduous forest with some trees attaining heights of 20-25 m; characteristic trees are Ceiba trichistandra (endemic, but absent in the north- west), Bombax ruizii, Tabebuia chrysantha, and palms of the genera Astrocaryum, Attalea, and Phytelephas. In places where the water table is high, there are many false bananas (Heliconia).

In the Holdridge system, this regime includes lowland thorn woodland, semidry forest, and dry forest.

Dry subtropical.-The major regions occupied by this regime are at elevations above $300 \mathrm{~m}$ in the Cordillera de la Costa, the slopes of the Andes to elevations of about $2000 \mathrm{~m}$ south of $2^{\circ} \mathrm{S}$ Lat., and the Catamayo and Loja basins in southern Ecuador. The dry subtropical regime also exists in the Río

Table 3. Comparison of bioclimatic regimes recognized herein and by Cañadas (1983).

\section{Herein}

Desert

Dry tropical

Dry subtropical

Dry temperate

Subhumid tropical

Humid tropical

Humid subtropical

Humid temperate

Humid subtemperate

Paramo
Cañadas (1983)

Desert

Subdesertic, dry and very dry tropical

Dry, very dry, and subhumid subtropical

Dry and subhumid temperate

Subhumid tropical

Humid and very humid tropical

Humid, very humid, and rainy subtropical

Humid, very humid, rainy, and very rainy temperate

Humid, very humid, rainy, and very rainy temperate

Humid, very humid, rainy, and very rainy paramo 


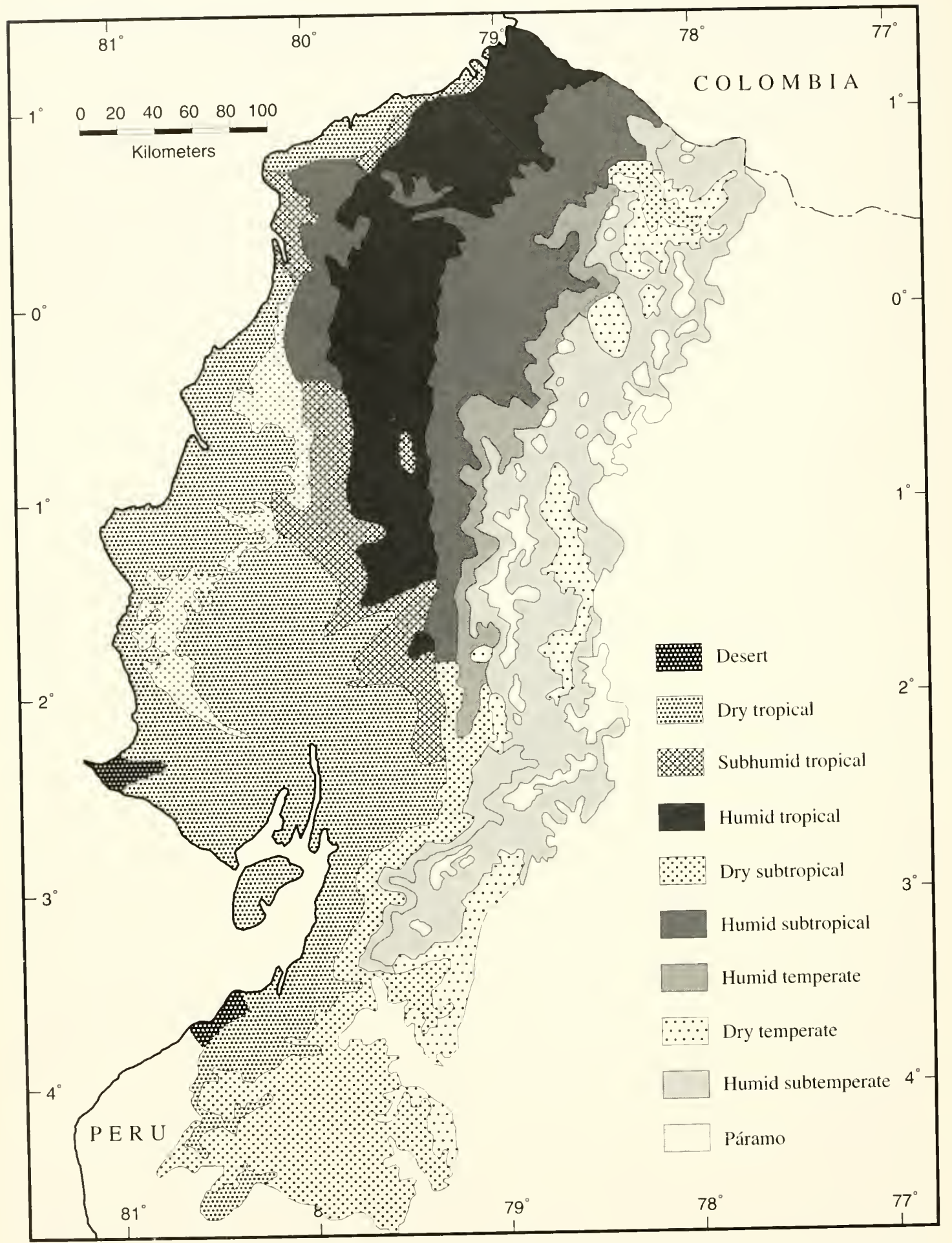

Fig. 7. Bioclimatic regimes on the Pacific lowlands and western slopes of the Andes in Ecuador. Adapted from Cañadas (1983). 
Chota Valley in the Ibarra Basin in northern Ecuador. Mean annual temperatures are $18-22^{\circ} \mathrm{C}$. Rainfall is lowest $(<500 \mathrm{~m})$ in the Cordillera de la Costa between $1^{\circ} 15^{\prime}$ and $1^{\circ} 50^{\prime} \mathrm{S}$. Lat., where rain occurs primarily in January-April; however, relatively high humidity is maintained by fog (Foster, 1992a). Areas receiving $500-1000 \mathrm{~mm}$ of precipitation annually include the rest of the high elevations in the Cordillera de la Costa, some parts of the Catamayo Basin, the valleys of the Río Chota and Río Jubones. In the Cordillera de la Costa, rainfall is concentrated in December-April, but in the other areas, there are two rainy periods - one in February-March or April and another in September or October-November or December. Soils range from sandy clays to reddish clays in the Sierra de la Costa to clays and soils derived from volcanic ash in the Andes.

The vegetation in this tropical dry forest consists of semideciduous trees with the largest trees attaining heights of $15-20 \mathrm{~m}$. In the drier areas, characteristic trees are Cedrela sp., Jacquinia pubescens, and Tabebuia crysantha. In the Machalilla region of the Cordillera de la Costa, important trees are Erythrina megistophylla, Phytolacca sp., Palicourea sp., Poulsenia armata, Quararibaea grandifolia, and the palms Chamaedorea polychada and Phytelephas aequatorialis (Gentry, 1992). On the Andean slopes and in the Catamayo and Loja basins, characteristic trees include Acacia macracantha, Brosimum latifo-lium, Centrolobium patinensis, Coultheria tinctoria, $\mathrm{Fi}$ cus sp., Juglans neotropica, and Sapindus saponaria, plus palms of the genera Bactris and Phytelephas. Ground vegetation consists of grasses, Agave americana, and cacti-Cereus and Opuntia . Agave and Opuntia are especially prevalent in the Río Chota Valley, and a peculiar cactuslike euphorb is common in the Río Jubones Valley. Climbers of the families Bignoniaceae and Malpighiaceae are common, and the most abundant epiphytes are bromeliads of the genus Tillandsia.

In some areas on the lower slopes of the Andes, dense cloud banks provide considerable moisture and low evapotranspiration rates, so that humidity and temperatures are more like that of the humid subtropical regime. Such is the case at elevations of 600-1240 m on the western slopes of Cerro San
José Chico east of Manta Real ( $\left.2^{\circ} 34^{\prime} \mathrm{S}, 79^{\circ} 21^{\prime} \mathrm{W}\right)$, Provincia Cañar. The largest trees in this forest are Huertera glandulosa, Landen-bergia pavonii, Otoba sp., Sapium sp., and Tetragastrispanamensis; epiphytes are common and woody vines are uncommon (Foster, 1992b).

In the Holdridge system, this regime includes premontane desert scrub, thorn woodland, dry forest, and moist forest.

Dry temperate.-This bioclimatic regime is typical of many inter-Andean basins at elevations of 2000-3050 m, where mean annual temperatures are $12-18^{\circ} \mathrm{C}$. Annual rainfall is $200-1000 \mathrm{~mm}$; the heaviest rains are in March-April and OctoberNovember, and the driest months are June-September. Soils are sandy, volcanic ash, or a mixture thereof.

The vegetation consists mostly of xerophytic, deciduous shrubs and low $(<10 \mathrm{~m})$ trees. Characteristic plants are Croton sp., Datura stramonium, Inga sp., Juglans neotropica, Mimosa quitensis, Nicotania rustica, and Puya sp. In drier areas, Agave americana and Opuntia tuna are common, and the reed Scirpus totora occurs at the margins of lakes and rivers.

In the Holdridge system, this regime includes lower montane thorn scrub and dry forest.

Subhumid tropical.- This regime is intermediate climatically, geographically, and floristically between dry and humid tropical regimes. It occurs continuously up to elevations of $460 \mathrm{~m}$ between $0^{\circ} 20^{\prime}$ and $2^{\circ} 15^{\prime} \mathrm{S}$ Lat. and has isolated patches in the northwestern lowlands. Mean annual temperatures are $23-26^{\circ} \mathrm{C}$. Annual rainfall is 1500 $2000 \mathrm{~mm}$, with the rainy season being in December-June. The soils mostly are sandy gray or red clays, but in some inland areas volcanic sands also are present.

This quasi-rainforest is composed of evergreen, broadleaf trees usually reaching heights of more than $20 \mathrm{~m}$, with some emergents attaining heights of $30 \mathrm{~m}$ or more. Characteristic trees are Bombax sp., Centrolobium patinensis, Ficus sp., Myroxylon balsamum, Octotea sp., Poulsenia armata, Pouteria sp., Tabebuia ecuadorensis, and palms-Astrocaryum sp., Phytelephas aequatori-alis, and Attalea colenda. Dominant climbers are members of the Bignoniaceae and Malpighiacea. False bananas 
(Heliconia), elephant-ear plants (Xanthosoma), and the large terrestrial, spiny bromeliad (Aechmea magdalenae) occur in wet areas.

In the Holdridge system, this regime includes lowland moist forest.

Humid tropical.-This regime supporting the Chocoan lowland rainforest extends southward from Colombia to about $1^{\circ} 40^{\prime} \mathrm{S}$ Lat.; in Ecuador, this regime reaches the Pacific coast only in the extreme northwest. A small area supporting this regime is at the base of the Andes at about $1^{\circ} 50^{\prime} \mathrm{S}$ Lat. The maximum elevation attained is $600 \mathrm{~m}$. Mean annual temperatures are $23-26^{\circ} \mathrm{C}$. Throughout much of the region the mean annual rainfall is 2000-3000 mm, with the driest months (all of which receive more than $35 \mathrm{~mm}$ of rain) being August-November. Inland and north of the Equator, rainfall is higher, with as much as $3804 \mathrm{~mm}$ recorded at Cayapas, where in the driest months (October-November) rainfall exceeds $120 \mathrm{~mm}$ per month. Soils are derived primarily from volcanic ash.

The vegetation is classical lowland tropical rainforest having three principal strata with many woody vines, epiphyes, mosses, and lichens. The canopy is discontinuous at about $30-35 \mathrm{~m}$ above the ground; some emergents may exceed $40 \mathrm{~m}$ in height. This upper stratum is made up of many species of trees, including Brosimum utile, Dacroydes occidentalis, Huberodendron pationoi, Humiriastrum procerum, Virola dixonii, and various Lauraceae. The middle stratum of the forest contains trees such as Callophyllum longifolium, Eschweilera pittieri, Platymiscium pinnatum, Terminalia amazonica, various species of Brownea, Nectandra, and Ocotea, and two dominant palmsGuilielma gasipaes and Iriartea cometo. The lowermost layer of trees is discontinuous and composed of many species, among the most conspicuous of which are Herrania balaensis, Piper sp. Rollinia mucosa, Tetra-thylacium macrophyllum, Vismia obtusa, and Urea sp.

In the Holdridge system, this regime includes lowland wet forest and rainforest.

Humid subtropical. - This regime exists in the northern part of the Cordillera de la Costa and on the slopes of the Andes at elevations of 300-1800 $\mathrm{m}$ from the Colombian border southward to $1^{\circ} 55^{\prime} \mathrm{S}$
Lat. Mean annual temperatures are $18-24^{\circ} \mathrm{C}$. Annual rainfall generally is $2000-3000 \mathrm{~mm}$, but an area on the lower slopes of the Andes between the Equator and $1^{\circ} \mathrm{N}$ Lat. receives more than $3000 \mathrm{~mm}$. Lita, at an elevation of $570 \mathrm{~mm}$, has an annual mean rainfall of $3678 \mathrm{~mm}$. Seasonality of rainfall increases from north to south. At Lita $\left(0^{\circ} 50^{\prime} \mathrm{N}\right.$ Lat. $)$ and Santo Domingo de los Colorados $\left(0^{\circ} 15^{\prime} \mathrm{S}\right.$ Lat.), only July is relatively dry- $120 \mathrm{~mm}$ of rain at Lita and $43 \mathrm{~mm}$ at Santo Domingo de los Colorados-but at Caluma ( $1^{\circ} 37^{\prime}$ S Lat.) only 10 $22 \mathrm{~mm}$ of rain falls monthly during July-November. Mostly, the soils are derived from volcanic ash and have the capacity to retain water.

The forest in this regime commonly is referred to as cloud forest or lower montane rainforest. The forest is characterized by many ferns, vines, epiphytes, mosses, and lichens. In many areas, three strata of vegetation are recognizable, but on steep slopes stratification is difficult to recognize. There is no continuous canopy; in many places palms (Attalea colenda and Iriartea cometo) are the highest trees with fronds reaching $20 \mathrm{~m}$ above the ground. Somewhat lower are treeferns and a variety of trees, including Brosimum utile, Clarisia racemosa, Clavija eggersi, Dactroydes sp., and Virola sp. Among the lowermost trees are Apeiba membranacea, Matista coloradorum, Poulteria sp., and Pouruma chocoana, among others.

In the Holdridge system, this regime includes premontane moist forest. wet forest, and rainforest.

Humid temperate.-With the exception of intrusions by the dry valleys of the Río Chota in the north and the Río Jubones in the south, this regime is a continuous narrow zone along the west face of the Andes at elevations of 1800-3000 m from the Colombian border to $3^{\circ} 30^{\prime} \mathrm{S}$ Lat. Annual rainfall is 2000-3000 $\mathrm{mm}$ on the lower slopes but declines to $1000-1500$ on the upper slopes. July-August are the driest months, but at Chiriboga $(1910 \mathrm{~m})$ more than $40 \mathrm{~mm}$ of rain falls in the driest month (July), and at Uyumbicho $(2725 \mathrm{~m})$ more than $30 \mathrm{~mm}$ of rain falls during the driest month (July). However, to the south the dry season is more intense and extends from June to November; for example, at Celica ( $4^{\circ} 7^{\prime} \mathrm{S}$ Lat., $2700 \mathrm{~m}$ ), only about $10 \mathrm{~mm}$ of rain falls in June and August. However, at least on the western slopes of the Andes, high humidity is 
maintained by dense fogs that are almost of daily occurrence. The soils are primarily derived from volcanic sands and ash, but some clays are present: the soils characteristically contain a high amount of organic matter.

This regime usually is referred to as high cloud forest or upper montane rainforest. Evergreen broadleaf trees attain heights of about $20 \mathrm{~m}$, but at higher elevations trees may be dwarfed; trees commonly are festooned with bromeliads, mosses, lichens, and other epiphytes. Among the characteristic trees are Cedrela rosei, Cinchona sp., Croton sp., Didymopanaxmorototoni, Eugenia sp., Guarea sp., Podocarpus sp., Polylepis sp., and Weinmannia descendens. Understory bushes include Baccharis sp., Bocconia frutescens, and in the south Embothrium grandifolimm. Ferns of the genera Blechnum and Dicksonia commonly are the most abundant ground cover. In some places, especially along streams, the vinelike bamboo, Chusquea scandens, forms almost impenetrable thickets. At the edges of the forest, a large-leafed herb, Gunnera, is conspicuous.

In the Holdridge system, this regime includes lower montane moist forest, wet forest, and rainforest.

Humid subtemperate.-This regime includes the uppermost forests and subparamos at elevations of $3000-4000 \mathrm{~m}$ throughout the Andes to about $3^{\circ} 30^{\prime} \mathrm{S}$ Lat. Mean annual temperatures are 6 $12^{\circ} \mathrm{C}$. Throughout most of the region, annual rainfall is $500-1000 \mathrm{~mm}$, but at places on the upper western slopes of the Cordillera Occidental annual rainfall is $1550-2000 \mathrm{~mm}$; on these slopes at $0^{\circ} 20^{\prime}-$ $0^{\circ} 30^{\prime} \mathrm{N}$ Lat., annual rainfall is $2000-3000 \mathrm{~m}$. Throughout the regime rainfall is lowest in July and August. Most soils are volcanic sands and ash.

At lower elevations, sometimes referred to as elfin forest, dwarf trees of the genera Clusia, Podocarpus, and Weinmannia, together with the bush Loricaria thuyoides, are present; commonly they are festooned with mosses. At higher elevations, commonly called subparamo, grasses (Festuca and Stipa) and low herbaceous plants (Hypericum laricifolitu and Vaccinium mortinia) are common, as are ferns of the genus Blechnum and low bushes of the genus Baccharis. In the area south of Tulcán, Senecio abietinus, Espeletia hartwegiana, and the spiny terrestrial bromeliad Puya are present.

In the Holdridge system, this regime includes montane moist forest and rainforest.

Paramo.-At the high elevations (4000-5000 $\mathrm{m})$ on the volcanoes along the Cordillera Occidental exists the highest life zone in the Andes. This regime is highly fragmented into zones on the slopes of the higher volcanoes and on some of the connecting ridges; the largest continuous area of paramo in the Cordillera Occidental extends from about $1^{\circ}$ to $2^{\circ} \mathrm{S}$ Lat. Mean annual temperatures are $3-6^{\circ} \mathrm{C}$, and annual rainfall is $500-1500 \mathrm{~mm}$. The soil is mostly volcanic ash.

The low vegetation in paramo consists mostly of low grasses, Bromus and Poa, and taller grasses, Festuca. Scattered among the grasses are Senecio and in some places extensive areas of cushion plants, a life form consisting of closely packed individuals of several unrelated species. Cushion plants in the central part of the Cordillera Oriental usually consist of five species-Arenaria dicranoides, Azorella sp., Draba bethomaniana, Plantago rigida, and Werneria humilis (AcostaSolís, 1984). In wet areas mosses, Lycopodium and Sphagnum, also may be parts of cushion plants.

In the Holdridge system, this regime includes wet paramo and Pluvial paramo.

\section{Vegetation}

Characteristic species of plants have been listed in the definition of the bioclimatic regimes. Herein, we attempt to provide comparisons of the life forms of vegetation in different parts of Ecuador with respect to elevation and rainfall (and its seasonality). The flora of western Ecuador is best known, but albeit incompletely, on the lowlands. Dodson and Gentry (1991) estimated that as many as 6300 species of vascular plants ( $20 \%$ endemic) occur in this region; many of the endemics are known from small areas of only a few square kilometers (Gentry, 1986). The flora of three areas has been studied intensively - humid tropical forest at Río Palenque (Dodson and Gentry, 1978), subhumid tropical forest at Jauneche (Dodson et al., 1985), and tropical dry forest in the Cordillera Chongón-Colonche in Guayas (Valverde, 1991). 
Table 4. Diversity of woody plants having diameters of $\geq 2.5 \mathrm{~cm}$ in 0.1 -ha plots in forests in western Colombia (C) and Ecuador (E) (from Gentry, 1988).

\begin{tabular}{lcrrrr}
\hline \hline \multicolumn{1}{c}{ Site } & Lat. \& long. & Elevation & Rainfall & Species & Regime \\
\hline Tutunendo, C. & $05^{\circ} 46^{\prime} \mathrm{N}, 76^{\circ} 35^{\prime} \mathrm{W}$ & $90 \mathrm{~m}$ & $9000 \mathrm{~mm}$ & 258 & Humid tropical \\
Bajo Calima, C. & $03^{\circ} 55^{\prime} \mathrm{N}, 77^{\circ} 02^{\prime} \mathrm{W}$ & $100 \mathrm{~m}$ & $7470 \mathrm{~mm}$ & 265 & Humid tropical \\
Centinela, E. & $00^{\circ} 34^{\prime} \mathrm{S}, 79^{\circ} 18^{\prime} \mathrm{W}$ & $550 \mathrm{~m}$ & $3000 \mathrm{~mm}$ & 140 & Humid tropical \\
Río Palenque, E. & $00^{\circ} 34^{\prime} \mathrm{S}, 79^{\circ} 20^{\prime} \mathrm{W}$ & $200 \mathrm{~m}$ & $2980 \mathrm{~mm}$ & 121 & Humid tropical \\
Juaneche, E. & $01^{\circ} 16^{\prime} \mathrm{S}, 79^{\circ} 42^{\prime} \mathrm{W}$ & $60 \mathrm{~m}$ & $1855 \mathrm{~mm}$ & 96 & Dry tropical \\
Capeira, E. & $02^{\circ} 00^{\prime} \mathrm{S}, 79^{\circ} 58^{\prime} \mathrm{W}$ & $50 \mathrm{~m}$ & $804 \mathrm{~mm}$ & 60 & Dry tropical \\
\hline \hline
\end{tabular}

There is a conspicuous change from deciduous to evergreen forests at the lower end of the precipitation gradient from coastal southwestern Ecuador inland and northeastward (Fig. 7). However, equally important biologically but less conspicuous to the casual observer is the dramatic increase in species diversity of woody plants along the north-south rainfall gradient. This phenomenon was demonstrated effectively by Gentry (1988), who compared diversity among equal-sized plots in western Ecuador and Colombia. Diversity decreases by more than $50 \%$ in humid tropical forests from the north with $9000 \mathrm{~mm}$ of rainfall annually to the southern limits of these forests where rainfall is only about $3000 \mathrm{~mm}$ (Table 4). Diversity decreases by another $50 \%$ in the dry tropical forest.

Unfortunately, comparable data are not available from the Andean slopes. However, Valencia and Jørgensen (1992) reported 32 species of trees in a 1-ha plot at an elevation of 3260-3300 $\mathrm{m}$ on Volcán Pasochoa.

In addition to the deciduous-evergreen nature of the woody vegetation along the lower part of the rainfall gradient, which is at least in part influenced by the length of the dry season, there is a noticeable change in the presence of a canopy. A continuous canopy is important in providing shade and reducing evaporation in the lower strata; thus, the soil and leaf litter retain high moisture contents. Although the canopy is discontinuous and rainfall generally declines with altitude in the humid subtropical and temperate regimes on the slopes of the Andes, these environments are characterized by high humidity. In addition to rainfall, moisture is achieved by fog, low dew points, and low evaporation rates. The vegetation in these regimes is characterized by many ferns and moisture dependent herbs in the lowermost strata. Trees commonly are heavily laden with epiphytes, including bromeliads, orchids, ferns, and mosses. At the highest elevations with low temperatures, species of trees characteristic of lower elevations are either absent or dwarfed and commonly festooned with epiphytic mosses.

One of the most striking vegetation formations in the Andes is the paramo. These supra-treeline regions generally lack woody plants and are predominately grasslands with some areas having characteristic Espeletia or cushion plants. Thus, in western Ecuador, vegetation ranges from hot deserts with candelabra cacti through dry to wet tropical, subtropical, and temperate forests to the tundralike paramos. These highly diverse vegetation types provide highly different kinds of habitats for animals.

\section{Geologic and Climatic History}

The dominant physiographic feature in western South America, the long Andean chain, was not always so prominent. Orogenic events associated with plate tectonics along the west coast of South America in the Late Cretaceous first uplifted the Andes to elevations probably not greatly exceeding $1000 \mathrm{~m}$ (Simpson, 1979; Zeil, 1979). According to Galvis (1982) and Galvis and Mojica (1994), in the early Tertiary, an island arc existed to the west of the present Cordillera Occidental in Colombia and remnants persist today as the Serranía de Baudó in northern Departamento de Chocó and possibly also the Serranía de Gallinazo in Departamento de Nariño. Following the reasoning of Galvis and Mojica, we suggest that the Cordillera de la Costa in Ecuador represents remnants of the southern part of this island arc. 
Volcanism and uplift of this island arc resulted from tectonic activities, particularly the subduction of the Pacific plate, so that sections of the island arc were uplifted to elevations much greater than exist today- $1810 \mathrm{~m}$ at Alto del Buey in the Serranía de Baudó to $800 \mathrm{~m}$ at Cerro de Pata de Pájaro in Ecuador. The erosion of these elevated islands provided sediments to fill in the basins of what are now the Río San Juan and Río Atrato in Colombia and presumably the lowlands between the Cordillera de la Costa and the Cordillera Occidental of the Ecuadorian Andes.

According to Sauer (1971), the uplifted terrain resulting from the Cretaceous orogeny subsequently was eroded into low hills before the major uplift of the Andes north of the Huancabamba Depression was initiated in the Pliocene; this uplift continued into the Quaternary, as is evidenced by many active volcanoes in Colombia and Ecuador. These stupendous orogenies and subsequent erosion resulted in the deposition of deep volcanic-ash soils on the slopes of the Andes and ash and alluvium on the lowlands.

However, geological evidence points to some volcanic activity and associated uplift, erosion, and deposits in the Cordillera Occidental of Colombia in the Oligocene (Galvis and Mojica (1994). If sediments originating from erosion of the early Tertiary island arc covered the region now occupied by the Cordillera Occidental and the volcanism reported for Colombia during the Oligocene extended into Ecuador, elevations of the Ecuadorian Cordillera Occidental may have been much higher in the mid-Tertiary than formerly presumed.

In the Quaternary, three periods of glaciation occurred in the Andes north of the Huancabamba Depression (Sauer, 1971). The first of these probably was insignificant because few peaks had been raised to elevations that were suitable for glaciation; in fact, the absence of evidence of glaciation on some high peaks strongly indicates that they were uplifted to their present heights after the last glaciation. However, glacial striae and moraines provide evidence that during the last glaciation snow line was depressed 1500-2000 m.

We can only speculate about the climate in what is now western Ecuador during the Cenozoic, but several models and supporting evidence provide an insight into Quaternary climates. The first of these is the climatic model proposed by Fairbridge (1972) that predicts a southern shift in the equatorial current during glacial maxima; this would result in higher rainfall farther south along the Pacific coast (Fig. 8). The second model (Vuilleumier, 1971;

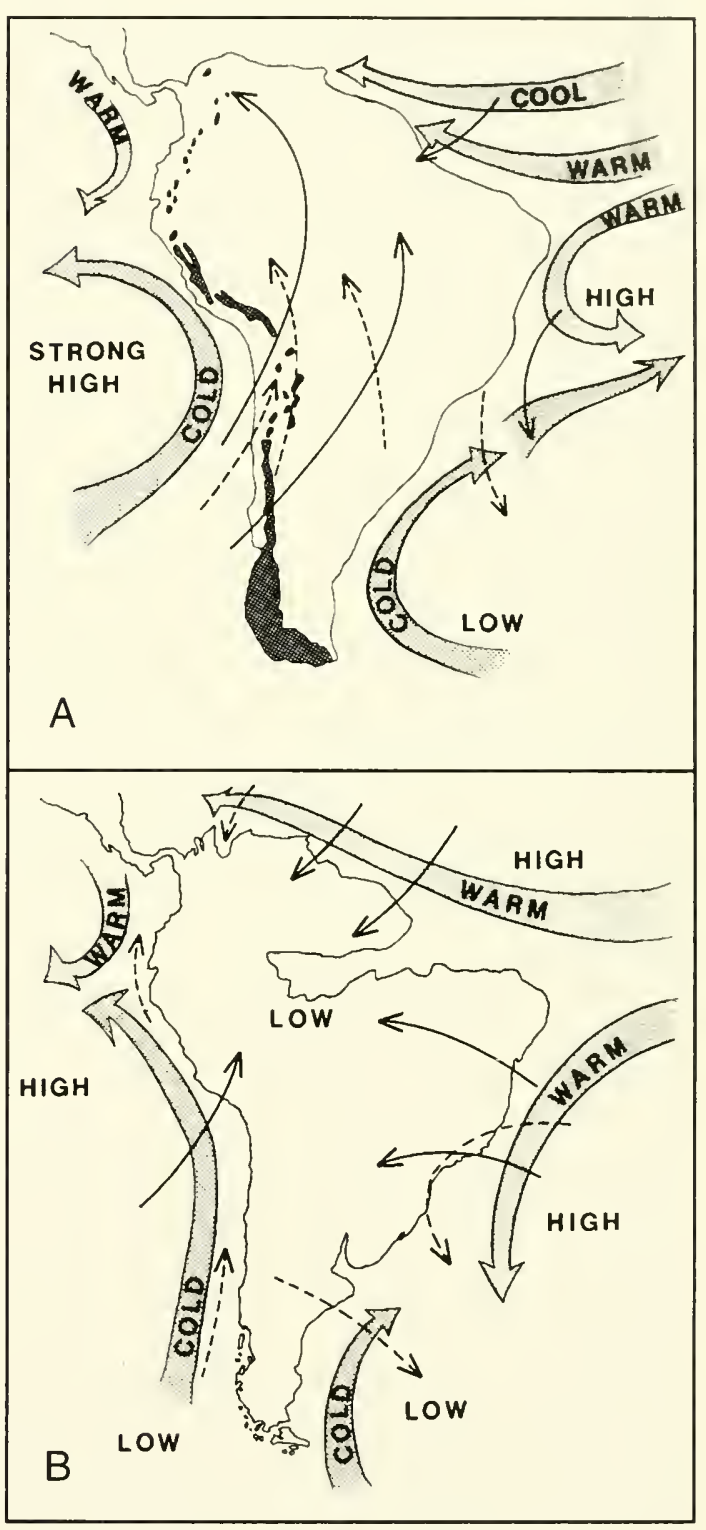

Fig. 8. Climatic models of a maximum glacial (A) and interglacial (B) cycle proposed by Fairbridge (1972) showing ocean currents. pressure systems, and wind directions. (Solid arrows are July; dashed arrows are January.) Continental outlines and extent of glacial ice (shaded areas in A) are based on Simpson (1971). Adapted from Simpson (1979). 
Simpson, 1975) predicts altitudinal oscillations in climate and vegetation in the Andes; this model is strongly supported by palynological data from the Andes of Colombia, which show that the Recent vegetation of the high Andes did not come into existence there until the Late Pliocene (consistent with orogenic evidence) and that changes in vegetation correspond to cool glacial and warm interglacial phases during the Quaternary (van der Hammen, 1974); during glacial maxima, temperatures in the high Andes were depressed $6-7^{\circ} \mathrm{C}$, but in the lowlands temperatures were depressed only about $3{ }^{\circ} \mathrm{C}$ (Haffer, 1979). According to Simpson (1979), major glaciations occurred about 250,000 and 130,000 years ago, and the last minor glacial advance took place only 14,000 years ago. The once-popular conception of the stability and antiquity of lowland tropical forests was dispelled by Haffer (1969; 1974), who proposed the refuge theory that forest and nonforest biomes changed continuously in distribution, fragmenting and coalescing during the varying humid and arid climatic conditions in the Quaternary.

How do the events proposed in these models apply to the western Andean slopes and Pacific lowlands of Ecuador? Four aspects of Pleistocene glaciation and associated climatic oscillations contribute to biological distributions:

1. Temperatures were lower during glacial phases and higher during interglacials.

2. Sea level was lower during glacial phases and higher during interglacials.

3. Rainfall decreased during the height of glaciation and increased during interglacials.

4. The water table in the lowlands was lower during glacial phases and higher during interglacials.

With the exception of temperature fluctuations, each of these phenomena is associated with an increased amount of the earth's water being frozen during glacial periods; thus, rainfall diminished and sea level and water tables dropped. Therefore, during glacial maxima, the lowlands of western Ecuador were only slightly broader than they are now, probably had a lower water table, and most likely received less rainfall than at present. These phenomena are not inconsistent with proposed forest refuges in Chocoan Colombia, where rain- fall today is significantly higher than in the lowlands of Ecuador; refuges were proposed for birds (Haffer, 1974), Heliconius butterflies (Brown, 1982), and woody plants (Gentry, 1982; Prance, 1982).

The models for depressed temperatures and decreased rainfall during glacial phases predict climatic depression to such a degree that lower bioclimatic regimes would either be eliminated or compressed. Climatic compression was addressed by Duellman (1983a), who applied adiabatic lapse rates to climatic data from four elevations on the Amazonian slopes of the Andes and the upper Amazon Basin in Ecuador to predict climates and zones of vegetation on those slopes during glacial maxima. Because moist air cools more slowly than dry air, there is a range of adiabatic lapse rates from a loss of $6^{\circ} \mathrm{C}$ per $1000 \mathrm{~m}$ of elevation for saturated air to a loss of $10^{\circ} \mathrm{C}$ per $1000 \mathrm{~m}$ of elevation for dry air (Trewartha, 1943).

This concept was applied to data on temperatures at 17 stations between 6 and $3560 \mathrm{~m}$ and within one degree of the Equator in western Ecuador When these data are plotted against the theoretical humid adiabatic lapse rate, it is evident that at elevations below $1500 \mathrm{~m}$, the rate of temperature reduction with respect to elevation is less than $6^{\circ} \mathrm{C}$, whereas the opposite is true at elevations of more than $1500 \mathrm{~m}$ (Fig. 9). Using van der Hammen's (1974) and Haffer's (1979) predicted depression of temperatures by $6^{\circ} \mathrm{C}$ in the highlands and $3^{\circ} \mathrm{C}$ in the lowlands, temperature was lower for each of the sites proportional to a $6^{\circ} \mathrm{C}$ depression at $4000 \mathrm{~m}$ and a $3{ }^{\circ} \mathrm{C}$ depression at sea level, and the humid adiabatic lapse rate was depressed accordingly. Again, at elevations below $1500 \mathrm{~m}$, the rate of temperature reduction is less than that predicted by the humid adiabatic lapse rate, and at higher elevations the opposite is true. This discrepancy can be explained by change in moisture content of the air masses as they rise along the front of the Andes. Although some moisture is lost at lower elevations. the air masses retain great quantities of moisture at higher elevations, as is evidenced by heavy fog banks above $1500 \mathrm{~m}$.

The oscillations in temperature and changes in adiabatic lapse rates during the Quaternary resulted in altitudinal shifts in vegetation zones in the Andes. 


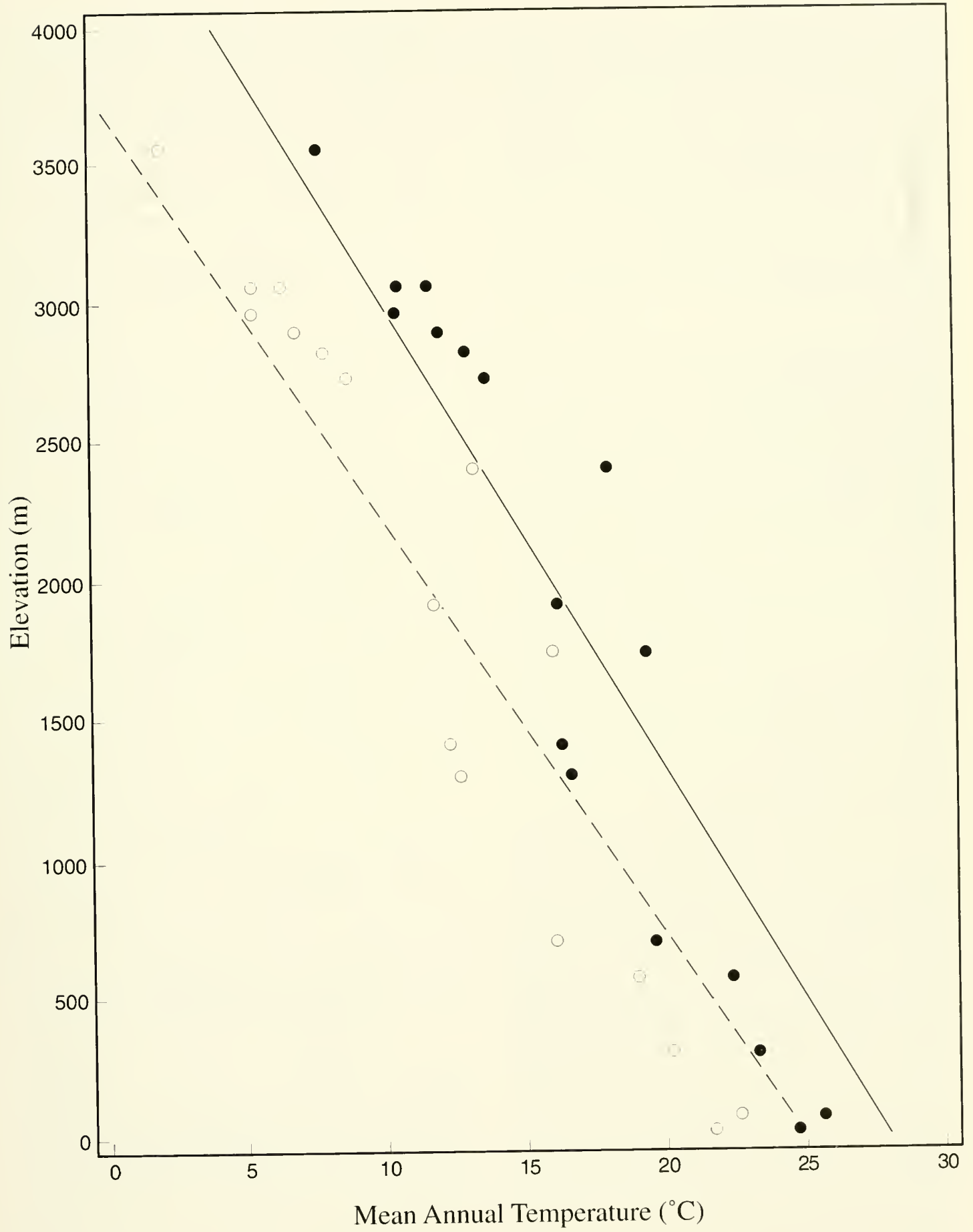

Fig. 9. Mean annual temperatures at sites at different elevations in western Ecuador $(\bullet)$ and hypothesized mean annual temperatures at those same sites during glacial maxima (o). The humid adiabatic lapse rate is shown as a solid line; the hypothesized humid adiabatic lapse rate during glacial maxima is shown as a dashed line. 
These were calculated for the eastern slopes of the equatorial Andes by Duellman (1983a). Using a depression of $6^{\circ} \mathrm{C}$ and a corresponding lowering of vegetation zones in the high Andes and a depression of $3{ }^{\circ} \mathrm{C}$ at low elevations, it is possible to postulate the elevational ranges of vegetation zones during a glacial maximum. Likewise, the same can be postulated for a maximum interglacial, when, according to van der Hammen (1974), temperatures in the high Andes were elevated about $3^{\circ} \mathrm{C}$; an increase of $1.5^{\circ} \mathrm{C}$ was used at low elevations (Fig. $10)$.

Interglacial times are predicted to be much the same as at present, except all vegetation zones were shifted upward slightly at lower elevations and more so at higher elevations; the snow line was at approximately $5500 \mathrm{~m}$ and the upper limits of forest and therefore the frost line was at about 4000 $\mathrm{m}$. in contrast to elevations of $4900 \mathrm{~m}$ and $3400 \mathrm{~m}$ today, respectively. This upward climatic shift resulted in paramos being more restricted and isolated than at present and much of the area covered by paramo today being dominated by subparamo. Elfin forest and high cloud forest would have breached many Andean passes, and in places, high cloud forest may have been continuous between the Pacific and Amazonian slopes of the Andes. Otherwise, vegetation zones were nearly as continuous as they are today.

In contrast, glacial times were characterized not only by depression of temperatures, more so at higher than lower elevations, but lower rainfall, which probably was most reduced at lower elevations. These climatic modifications resulted in a lowering and compression of montane vegetation zones and drier conditions that eliminated or greatly restricted lowland tropical rainforest in western Ecuador. Cool-air drainage in river valleys deepened by rushing waters from melting glaciers would have resulted in cooler temperatures and lower evaporation rates and allowed the existence of cloud forest at moderately low elevations. The intervening ridges would have been more susceptible to insolation and dry winds off of the lowlands and probably supported tropical dry forest. Pockets of lowland tropical rainforest probably persisted in areas of high rainfall, such as in the region between Cayapas and Lita at the base of the Andes.

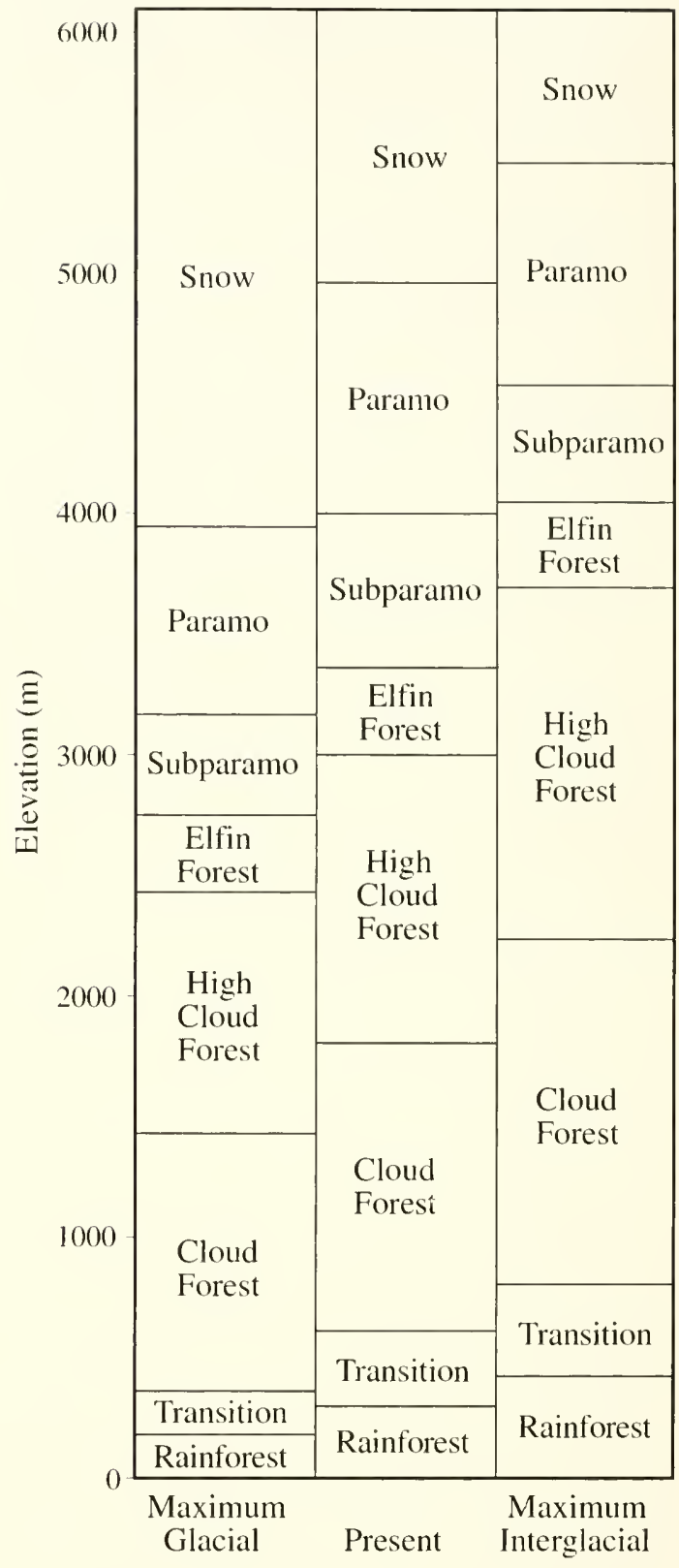

Fig. 10. Present and postulated vegetation zones during maximal glacial and interglacial times with respect to elevation in equatorial western Ecuador

Admittedly, this scenario assumes that during glacial periods the Andes were not significantly higher than at present and also is based on a restricted amount of evidence, some of which has been interpreted in support of a contrary position 
(e.g., Collinvaux, 1993). Most of this evidence is extrapolated from the paleoecological work of van der Hammen (1974) and van der Hammen and Cleef (1986), and the hypotheses of Haffer (1969) and Vuilleumier (1971). However, it provides a basis for refinement as new paleoclimatic and paleoecological data become available and a model for interpretation of ecological and geographic effects on patterns of speciation and distribution of organisms inhabiting western Ecuador.

\section{Human Environiental Modifications}

Prior to the early 1960s, the human population on the Pacific lowlands and on the Pacific slopes of the Andes in Ecuador was relatively low. Indigenous peoples, such as the Cayapas and Colorados, were primarily hunter-gatherers, and the few colonists who inhabited the region were mostly subsistence farmers. For decades, the only town of any size on the coastal lowlands was Guayaquil, estimated to have about 28,000 inhabitants in 1879 (Whymper, 1892). In the vicinity of Guayaquil and less so in smaller towns and villages, adjacent forests were cut for firewood and construction materials, and palm trees were cut for their fronds for thatched roofs. Most rural inhabitants were located along the rivers that provided transit to towns. As Guayaquil became a port more frequently visited by freighters, timber cruisers began removing economically important trees, such as caoba (Persea theo-bromifolia), balsa (Ochroma lagopus) and colorado (Pouteria sp.) that were near rivers and easily accessible; during the period of World War II, rubber collectors worked the native rubber trees (Castilla elastica) (Dodson and Gentry, 1978).

Narrow "avenues" of colonization emerged along the two railroads that crossed the Andes and penetrated the lowlands to the coast; the northern railroad extended from Ibarra to San Lorenzo, and the southern from Alausí to Guayaquil. Although these railroads provided important trade routes, they had only limited impact on the natural resources of the region. The first commercial crops of any significance were banana and cacao plantations at lower elevations and coffee plantations in the shade of native trees at higher elevations; most of these plantations were within a short traveling distance to the railroad. Prior to the mid-1900s, few roads penetrated the region: the most important of these was the "old road" from Quito via Chiriboga to Santo Domingo de los Colorados. Aside from subsistence farming and some dairy cattle, coffee was the major agricultural product.

Two coincident events in the early 1960s dramatically affected the Pacific lowlands. The first was the initiation of a large road-building program-a new paved road from Quito to Santo Domingo de los Colorados, paved roads from there to Esmeraldas and to Guayaquil, and later, paved roads from Cuenca to Guayaquil. These roads provided the routes for commerce and colonization, which were bolstered by opportunities for the second event, commercial agriculture involving cacao, sugar cane, oil palms, and especially bananas (the "oro verde" or green gold), and forest extraction for commercial purposes. Within a decade hundreds of thousands of hectares of forest were cut, burned, and planted. Chemical pesticides (DDT and Bordeaux) were used with abandon; the latter sprayed from planes gave banana plants a bluish hue. During our various trips to the lowlands between Esmeraldas and Babahoyo between 1967 and 1984, we witnessed this wanton destruction and pollution of the lowland tropical forest.

The natural resources have been pressured further by the great increase in population by burgeoning colonization and birth rates. Guayaquil now has more than 2.5 million inhabitants, and Provincia Manabí more than 1 million (Mejía et al., 1995). Small towns or villages of two decades ago now are major metropolises, some with more than 100,000 people.

According to Dodson and Gentry (1991), the forests of western Ecuador are among the most severely threatened of the world's ecosystems; more than $90 \%$ of the forests on the lowlands in the foothills have been converted to agriculture. This rapid destruction in the lowlands and on the higher slopes of the Andes was documented further by Mejía et al. (1995). Although there is notably less destruction of natural forests on the steep slopes, an 
increasing number of roads (and the accompanying colonists) results in ribbons of destruction, even in protected areas, such as the Bosque Protector de Molleturo. Two large natural reserves on the western versant in Ecuador, the Reserva Ecológica Cotacachi-Cayapas and the Reserva Etnica y Forestal Awa totaling about 280,000 ha. face destruction as squatters establish themselves within the boundaries of the reserves and economically valuable trees are removed. At higher elevations, monocultures of Eucalyptus and Pinus form a barren, inhospitable habitat for native animals.

Over a short period of time, the changes wrought by humans equal or exceed those by natural causes during the Pleistocene. Certainly, within the past few decades, many species have become extinct, as noted for plants by Dodson and Gentry (1991). We regret that this publication is a requiem for extirpated and surely threatened species of Eleutherodactylus.
My antecedents were Eleutherodactylus Long ago when there were just a few of us But as the Andes arose

Some of us nearly froze

So we dispersed in response to this stimulus

We differentiated without much of a fuss Preferring climates that others would cuss Where it rained, it would pour

So we'd speciate more

For us, others' nonplus was a plus

But all did not remain thus

For the diversity of Eleutherodactylus

The forests were cleared

Our habitats disappeared

So now there are fewer species left of us

\section{SYSTEMATICS}

\section{Description of Characters}

In many museums, frogs of the genus Eleutherodactylus often are among the last specimens to be identified in incoming collections. This is owing not only to the plethora of species, but also the confusion about many taxonomic characters. In an attempt to rectify this situation and hopefully to standardize terminology, we clearly define and illustrate the morphological characters that we have found to be useful in eleutherodactyline systematics: examples are provided from species from western Ecuador. However, "definition" of some characters (e.g., skin texture) is difficult, because although the character states are not discrete, their characterization in descriptions may suggest that they are discrete. We realize that this may confuse nonspecialists; for this we apologize. The characters are presented in approximately the same order in which they appear in the numerical diagnoses.

Texture of skin.-In several species (e.g., $E$. achatinus, anomalus, and w'-nigrum) in western Ecuador, the skin on the ventral surfaces is smooth, except for being granular on the proximal surfaces of the thighs. In most species in the region, the skin on the belly is granular ("areolate"); the throat and chest may be less strongly granular or smooth. In a few of these species (e.g., E. crenunguis, labiosus, and ocellatus), the granules are poorly defined; the belly in individual specimens might appear to be smooth or weakly granular in separate observation events. The texture of the skin on the venter (if granular) is affected by preservation fluids and techniques; thus, a dead specimen that is later preserved may appear to have smooth skin on the belly, even under high magnification.

The skin on the dorsum, flanks, and upper surfaces of the limbs tends to have the same texture in any given species, but some departure from that generality occurs. In many species (e.g., $E$. hamiotae, laticlavius, quinquagesimus, and vertebralis), the texture of the skin on the posterior part of the dorsum is coarser than that on the anterior part. Among those species with tubercles on the dorsal surfaces, the tubercles usually are smaller on the limbs than on the dorsum of the body, except in those taxa (e.g., E. appendiculatus) in which the tubercles are closely associated with the color pattern on the limbs. Transitional zones between the texture of the dorsum and that of the venter occur on the flanks, but the texture of the flanks is not always intermediate between the dor- 
sal and ventral textures; in some species in the $E$. fitzingeri and E. conspicillatus groups, the dorsum is finely granular and the venter is smooth, but the flanks bear larger granules.

The extreme conditions of texture on the dorsum are: (1) smooth (e.g., E. apiculatus, caprifer; gularis, and loustes), and (2) coarsely tuberculate. and usually bedecked with folds (e.g., E. anomalus, cerastes, and necerus). Most species (e.g., E. actites, crenunguis, leoni, nyctophylax, ornatissimus, and siopelus) have dorsal skin that is described as uniformly finely granular (shagreen). If some granulations are notably higher than others, the skin is described as tuberculate if the granules are conical or subconical (e.g., E. hectus and E. latidiscus) or warty if the granules are flattened (e.g., E. babax, duellmani, and ruidus). The descriptors of dorsal skin texture are intended to define the average condition into a few categories (e.g., smooth, shagreen, weakly tuberculate, or coarsely tuberculate) qualified with reference to folds and/or regular (i.e., named) tubercles. The dorsal skin texture is strongly affected by numerous factors-inadequate preservatives, death by desiccation and/or heat stress, early decomposition, and desiccation of a preserved specimen followed by some effort at rehydration. Commonly, juveniles are more tuberculate than conspecific adults.

The specific terms describing elevations on the skin are defined as follow. Tubercles are relatively large elevations that may be elongate, conical, or subconical (in order of decreasing elevation). Warts also are relatively large, but flattened or rounded in contrast to tubercles; the base of a wart is broader than its elevation. The terms pustules and spicules are applied to smaller structures; pustules are small warts, and spicules are minute tubercles. Pustules and spicules are difficult to distinguish from some descriptors of skin texture (e.g., shagreen). Therefore, a comparsion is made between the general texture of the skin and the relative sizes and shapes of protuberances on a given individual.

Tubercles.-A part from being used to describe texture, certain tubercles regularly appear in different individuals and species of eleutherodactyline frogs. These tubercles have specific names because they occur in particular places on the frog. Savage (1987) used the term "accessory" for what we call supernumerary tubercles. He used the term "supernumerary" to describe tubercles other than subarticular tubercles on the undersides of digits.

Body: Aside from scapular tubercles associated with postocular folds, few body tubercles have specific names, at least among species in western Ecuador. (See Folds.) However, the pattern of tubercles on the dorsum of several species (e.g., $E$. anomalus and E. necerus) is nonrandom, but the details of tubercular arrangements have not been investigated as a source of taxonomic characters. (See Skin Texture.)

Eyelid: If the posterolateral quadrant of the upper eyelid bears an enlarged tubercle, the structure is termed the evelid tubercle. In some frogs. this tubercle is elongate (i.e., much longer than wide; e.g., E. cerastes) or conical (i.e., longer than wide; e.g., E. appendiculatus). The upper eyelid usually bears a single enlarged tubercle (e.g., $E$. labiosus), but some species (e.g., E. leoni and E. verecundus) have three or four enlarged tubercles. If the upper eyelid is simply warty or tuberculate with none of the tubercles being larger than others. the frog is described as lacking an eyelid tubercle.

Foot: The plantar surface of the foot bears several tubercles having particular names. Toes 1 and II each have a single subarticular tubercle; Toes III and V each have two subarticular tubercles, and Toe IV has three subarticular tubercles. The inner (preaxial) metatarsal tubercle is longer than wide; it is usually oval, but it is elongate in some species (e.g., E. anomalus and E. longirostris) and laterally compressed in a few species (e.g.. $E$. necerus). The outer (postaxial) metatarsal tubercle usually is much smaller than the inner metatarsal tubercle and round or slightly longer than wide; in a few species (e.g., E. eremitus, hectus, and quinquagesimus) it is conical or subconical. Supernumerary plantar tubercles are absent in some species (e.g., E. anatipes, cerastes, and hamiotae); they are present as low, diffuse structures in a few species (e.g., E. chalceus and E. loustes), but more commonly (e.g., E. achatinus, labiosus, ocellatus, and parvillus) only three or four tubercles are present at the bases of Toes I-IV or II-IV. In a few species (e.g., E. celator; eremitus, and hectus), supernumerary tubercles are more numerous. thereby rendering the plantar surface areolate. 
Forearm: The postaxial surface of the forearm bears enlarged tubercles in many species. The most constant of these is the antebrachial tubercle that lies just proximal to the wrist, but several species (e.g., E. appendiculatus, cerastes, and verecundus) have a row of equally large tubercles between the wrist and elbow. These may be low or conical and are termed ulnar tubercles, unless they are compressed and juxtaposed, in which case they are termed an ulnar fold. (See Folds: Ulnar.)

Hand: The tubercles on the palmar surface of the hand closely parallel those on the foot. Subarticular tubercles occur beneath the joints between phalanges; thus, there is one subarticular tubercle on the thumb and second finger and two on the third and fourth fingers. Subarticular tubercles vary in elevation (low and rounded vs. conical and projecting) and shape (base rounded vs. base elongate). In a few eleutherodactylines (e.g., $E$. chalceus), the subarticular tubercles are broad and some (usually distal ones on outer digits) are bifid. Other prominent tubercles are on the proximal edge of the palm. The thenar tubercle at the base of the thumb is oval, whereas the palmar tubercle on the outer part of the palm usually is bifid (partially divided distally). In older literature, the palmar and thenar tubercles were called the metacarpal and carpal tubercles. On the fleshy part of the palm, supermumerary (palmar) tubercles (also called accessory tubercles) may be present. These usually are low and difficult to see clearly, but in some species (e.g., Barycholos pulcher), the supernumerary tubercles are prominent and conical.

Head: Apart from the eyelid, postrictal, and snout tubercles discussed separately, there are a few tubercles that occur sporadically on the head. Some species (e.g., E. labiosus) possess an interocular tubercle between the eyes; others (e.g., E. latidiscus and E. muricatus) have tubercles on the upper surface (usually on the midline) of the snout. A few species (e.g., E. ocellatus) have small conical tubercles along the margin of the lower jaw.

Hind limb: Many species (e.g., E. anomalus, cerastes, latidiscus, and necerus) have obvious, enlarged tubercles associated with features of the color pattern on the shank. but these tubercles are not named. The upper edge of the heel commonly bears one or more tubercles variously called tu- bercles or calcars. We term those that are enlarged, but not longer than wide, heel tubercles. If the tubercle is elongate and pointed, it is identified as a conical heel tubercle. A conical heel tubercle may be only twice as long as wide (e.g., E. calcarulatus, crucifer, muricatus, and verecundus) or much more than twice as long as wide, as in the extralimital $E$. calcaratus or E. inusitatus. Some authors (e.g., Savage, 1987) employ the term calcar for a variety of ornamentations on the heel, but we restrict the term calcar to describe an elongate tubercle having a broad, flat base (e.g., E. quinquagesimus and $E$. siopelus).

In many eleutherodactyline frogs (e.g., $E$. appendiculatus, crenunguis, crucifer, quinquagesimus, and siopelus), the postaxial surface of the tarsus bears a series of distinguishable tubercles called outer tarsal tubercles; these display the same range of variation as ulnar tubercles. (See Tubercles: Forearm.) The inner edge of the tarsus may bear one or more tubercles, but these are homologous with the tarsal fold. (See Folds: Tarsus.)

Postrictal: Posteroventral to the tympanum and just anterior to the posterior edge of the jaw musculature is a pair of postrictal tubercles. These may be low and rounded, as in E. luteolateralis and $E$. nyctophylax, or conical, as in E. pyrrhomerns. In a few species (e.g., E. babax), the tubercles are compressed and fused so as to form a short ridge that extends ventrolaterally from the tympanum.

Snout: Several species (e.g., E. eremitus, phoxocephalus, and subsigillatus) have a conical tubercle (papilla) at the tip of the snout (visible in either dorsal or lateral view) that breaks the smooth curve of the margin of the snout. This tubercle has a broad base and seldom is longer than broad, but E. appendiculatus has an exaggerated tubercle, more appropriately termed a proboscis.

Dermal folds.-Among the species in western Ecuador, eight kinds of dermal folds can be found.

Discoidal: This fold defines the ventral disc on the belly and is most obvious laterally and posteriorly, but the fold is absent in a few species (e.g., $E$. helonotus). In most Ecuadorian, as well as other South American Eleutherodactylus, the margin of the discoidal fold is well anteriad to the groin; this is in contrast to some Mexican taxa in which the 
margin of the fold nearly reaches the bases of the hind limbs.

Dorsolateral: These paired folds extend posteriorly from the posterolateral corner of the orbit and lie lateral to the sacrum and blades of the ilia. Of the 6 I species of Elentherodacty/us known from western Ecuador, 43 have no traces of dorsolateral folds. In those species having folds, the folds usually are most prominent anteriorly and become pustular (fragmented into a series of pustules) posteriorly before terminating above the groin. Distinct dorsolateral folds that are not fragmented into pustules posteriorly are present in only a few taxa (E. appendiculatus, hectus, and vertebralis). In 10 other species (E. achatimus, actites, gentryi. illotus, laticlavius, lymani, sobetes, thymalopsoides, and truebae), the folds are thinner or fragmented into pustules throughout their entire lengths. Four species (E. babax, duellmani, quinquagesimus, and siopelus) have short dorsolateral folds that are not evident posterior to the level of the sacrum. Eleutherodactylus anatipes has a longitudinal series of elevations in the topographic position of dorsolateral folds. Although there is no evidence that these elevations are parts of a whole, we refer to them collectively as a fragmented dorsolateral fold. In $E$. anatipes, additional shorter, longitudinal elevations are present ventrolateral to the dorsolateral folds, and, with the same reservations, we also refer to these as dorsolateral folds. In three species (E. sulculus, surdus, and verecundus), the dorsolateral folds are evident only along the midlength of the body; the folds are difficult to see in E. surdus, in some specimens of which the folds are absent.

Interocular: This transverse fold lies between the eyes on the top of the head. In western Ecuador, it is present in only one species (E. quinquagesimus).

Paravertebral: These folds lie above the transverse processes of the vertebrae and are median to the dorsolateral folds (if present). Paravertebral folds commonly are associated with a specific pattern-polymorph, in which a broad, pale, middorsal (vertebral) raphe is present (e.g., $E$. laticlavius, vertebralis, and walkeri); the folds are at the lateral margins of the raphe. In other species (e.g., E. cerastes and E. necerus), the paravertebral folds contribute to a pattern of dorsal ridges, especially those in which there is an $\mathrm{H}$-shaped fold in the scapular region. The $H$-shaped fold usually is associated with a pair of short paravertebral ridges above the coccyx.

Postocular: These foldsextend posteromedially from the eyes onto the occiput. The anterior extremity of a postocular fold commonly is an enlarged tubercle on the upper eyelid, and the posterior extremity commonly is an enlarged scapular tubercle. as seen in E. crenunguis. In several species (e.g., E. labiosus, latidiscus, and tenebrionis), folds extend anteromedially from the scapular tubercles; these, together with the postocular folds, define a W-shaped occipital fold. Flores (1993) included the postocular fold as a kind of dorsolateral fold.

Supratymanic: This fold begins at the posterior corner of the orbit, extends posteriorly along the upper edge of the temporal region, and usually angles posteroventrally toward the insertion of the arm. However, in E. colomai, the fold continues straight from the temporal region to a point above the insertion of the arm. In a few species (e.g., $E$. longirostris and $E$. lonstes), the supratympanic fold is distinct, but in most species, its limits are difficult to define; the ambiguities obtain from color pattern (edges of supratympanic stripe) and the superposition of tubercles on the fold.

Tarsal: In many species in western Ecuador (e.g.. E. actites, anomalus, longirostris, loustes, lymani, and midus), a longitudinal fold is present on the inner edge of the tarsus. This fold usually is a more or less clearly defined ridge extending a variable distance proximal to the inner metatarsal tubercle, but the fold is flaplike in E. lonstes. Short inner tarsal folds sometimes have been called inner tarsal tubercles, but we term them folds when they are within one length of the inner metatarsal tubercle and if they appear to be connected to the inner metatarsal tubercle, as in E. hectus, laticlavius, latidiscus, leoni, muricatus, ocellatus, pirrhomerus, siopelus, sulculus, and verecundus. In a few species (E. hamiotae, sobetes, truebae, vertebralis, and $w$-nigrum), we are unsure as to whether or not a short foldlike tubercle lies immediately proximal to the inner metatarsal tubercle; in some specimens, a structure appears to be present. In 13 species (E. achatinus, calcamlatus, cajamarcensis, crucifer, duellmani, engeniae, gentryi, illotus, quin- 
quagesimus, rosadoi, subsigillatus, thymalopsoides, and walkeri), a distinct, small tubercle is present on the distal one third of the inner surface of the tarsus and is clearly separated from the inner metatarsal tubercle. We think that this structure is a homologue of the inner tarsal fold because of the common position of the two structures and because gradation between a fold and a tubercle has been observed in the Mexican E. rhodopis.

Ulnar: In none of the Eleutherodactylus in western Ecuador do the ulnar tubercles fuse into an ulnar fold, such as is seen in E. latens and E. ruizi in Colombia.

Tympanum. - The terms "tympanum" and "external ear" have been used to identify a combination of characters rather than a single character. The "tympanum" is a combination of (1) a differentiated tympanic membrane and (2) a tympanic annulus. Wever (1985:43) defined the tympanic membrane as " ... an area of modified skin, much thinner than ordinary skin and largely lacking subcutaneous layers ... and its edges are attached to the flaring rim of a funnel-shaped cartilage, the tympanic annulus... ." We concur that the skin comprising the tympanic membrane is thinner than the skin elsewhere on the side of the head; also, the tympanic membrane usually has a smoother texture. commonly has a distinctive coloration, and in many cases is slightly to obviously translucent because of the underlying tympanic cavity. Whenever a differentiated membrane is apparent, the annulus also is present, but the absence of a differentiated membrane does not necessarily signify the absence of the annulus. Long ago, Noble (1931:334) recognized that " ... a few [frogs] have the integument unmodified and separable from the underlying drum, ... ." This equals the absence of a tympanic membrane but the presence of a tympanic annulus. Such a combination frequently has been designated as "tympanum concealed," an unfortunate descriptor that confuses more than it informs.

Externally, conditions vary from a prominent tympanic membrane lying within the flaring rim of the tympanic annulus to the absence of a tympanic membrane and no external evidence of a tympanic annulus (Fig. 11). Between these extremes is a gradation of conditions that may be difficult to discern owing to variations in thickness of the skin and degree to which desiccation might have drawn the skin tight against the underlying structures. Reduction of auditory structures in anurans seems to follow an obligate sequence involving loss of structures in a distal-medial sequence (Trueb, 1993). Thus, the tympanic membrane may be absent, but the tympanic annulus and the remainder of the plectral apparatus present; subsequent loss of the tympanic annulus leaves the stapes (= columella), which also may diminish in size or disappear.

Some of the problems inherent to the description of the tympanum are artifacts of preservation: others result from investigators being unaware of the internal anatomy of the otic region. Specimens preserved in alcohol that is too strong or specimens desiccated and subsequently rehydrated might seem to have an "external tympanum," whereas living or well-preserved specimens appear to lack an "external tympanum." Some authors have reported the tympanum to be "hidden" (e.g., Flores, 1988a, for E. alberchi, a synonym of E. surdus), because they could not discern an external tympanum but, curiously, assumed that one was present beneath the skin. Ever since his early investigation of eleutherodactyline frogs. JDL consistently has dissected the otic region in order to evaluate the condition of the tympanic annulus if it is not visible externally. With the reconciliation that the "tympanum" is a combination of characters, we are forced to abandon descriptors such as "tympanum hidden" and "tympanum concealed" and urge our colleagues to do likewise.

A prominent tympanic membrane and tympanic annulus are present in most Eleutherodactylus in western Ecuador (e.g., E. calcarulatus, hectus, longirostris, tenebrionis, and w-nigrum). Usually the skin circumscribed by the annulus is thin and in some species, it may be translucent; typically, the tympanic annulus is elevated with respect to the temporal musculature and its entire circumference is visible, although commonly, the annulus is obscured dorsally by a supratympanic fold. In a few species (e.g., E. gularis and E. scolodiscus), a tympanic annulus is evident through thin skin that is not connected to the annulus. In other species (e.g., E. loustes and E. truebae), only the lower part of the tympanic annulus is evident under undiffer- 

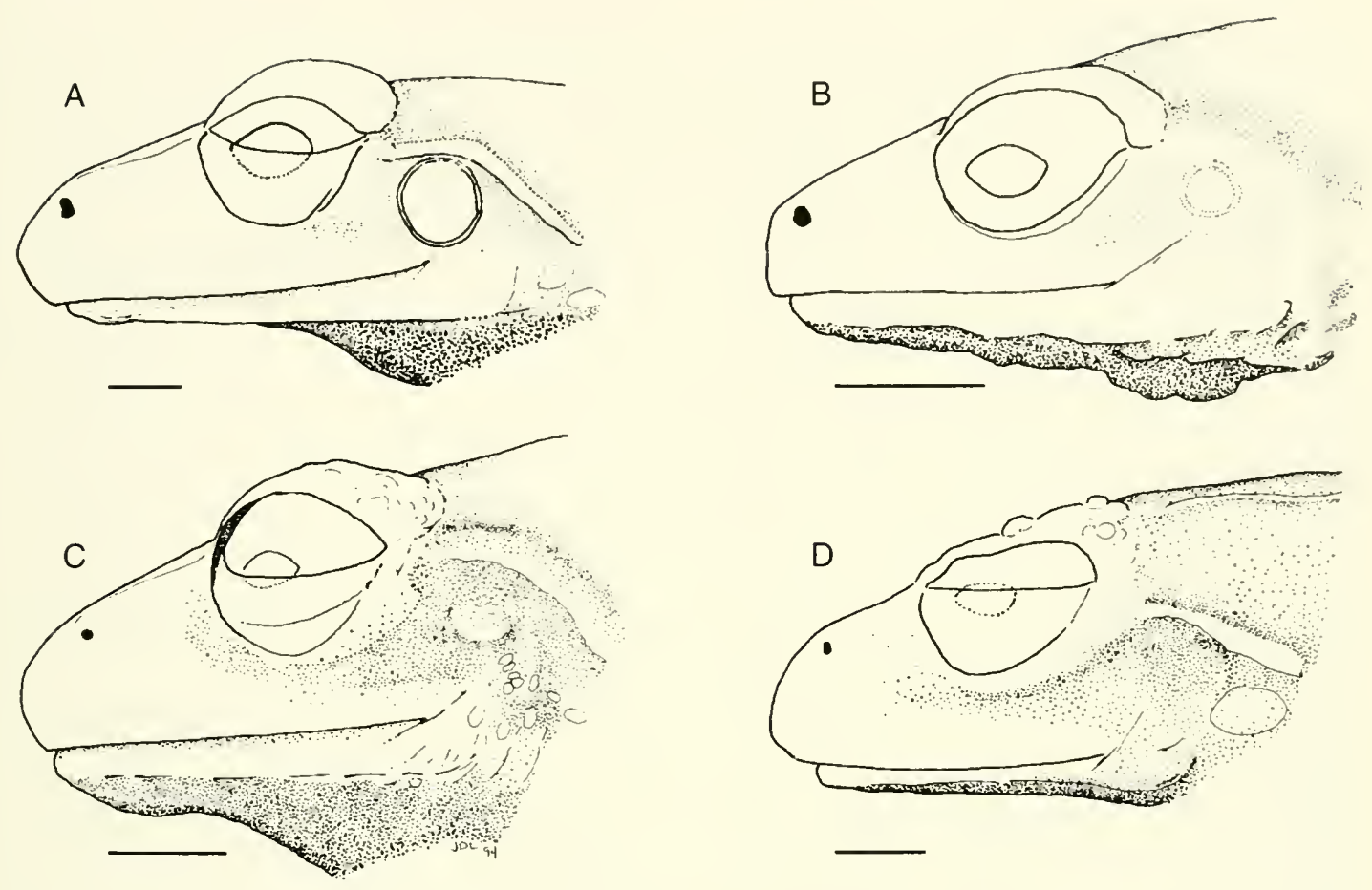

Fig. 11. Sides of heads showing comparative distinctness of tympanic annuli and membranes in Eleutherodactylus. A. E. longirostris, LACM 47170, with distinct annuli and membrane. B. E. gularis, QCAZ 4316, with annulus distinctly visible beneath skin. C. E. truebae, QCAZ 2475, with annulus partially visible beneath skin. D. E. lıamiotae, USNM 239843, with no ear structures evident externally. Scale bars $=2 \mathrm{~mm}$.

entiated skin; otherwise, there is no external evidence of a tympanic annulus. Among the Eleutherodacty/us in western Ecuador, a tympanic annulus is absent in six species-E. duellmani, hamiotae, ruidus, siopelus, sobetes, and surdusand reduced or absent in one other (E. gentryi).

Thus, we recognize four character combinations of the ear among eleutherodactyline frogs in western Ecuador, as follow: (1) tympanic membrane and tympanic annulus prominent; (2) tympanic membrane absent, but most of the circumference of the tympanic annulus evident through the skin; (3) tympanic membrane absent but tympanic annulus evident only ventrally; and (4) tympanic membrane and tympanic annulus reduced in size or absent.

Among eleutherodactylines in western Ecuador, sexual dimorphism in the diameter of the tympanic annulus is appreciable only in $E$. longirostris, in which the tympanic membrane and tympanic annulus are prominent and the horizontal length (i.e., "diameter") of the annulus in females is about half the length of the eye. However, in males, the annulus occupies most of the temporal region, and the ventral rim of the annulus nearly extends to the lip. The length of the annulus in males is about three-fourths the length of the eye. Such dramatic sexual dimorphism is common, but not universal, among frogs of the subgenus Craugastor. In the other three species in the subgenus in western Ecuador (E. anatipes, anomalus, and necerus), there is no sexual dimorphism in the diameter of the tympanic annulus, or the annuli of males are only slightly larger than those of females.

Snout shape.-In most species of Eleutherodactylus in western Ecuador, the margin of the snout is rounded or subacuminate in dorsal view (Fig. 12). There seems to be a clear association between snout length measured from the anterior corner of the orbit to the nostril $(\mathrm{E}-\mathrm{N})$ and snout 

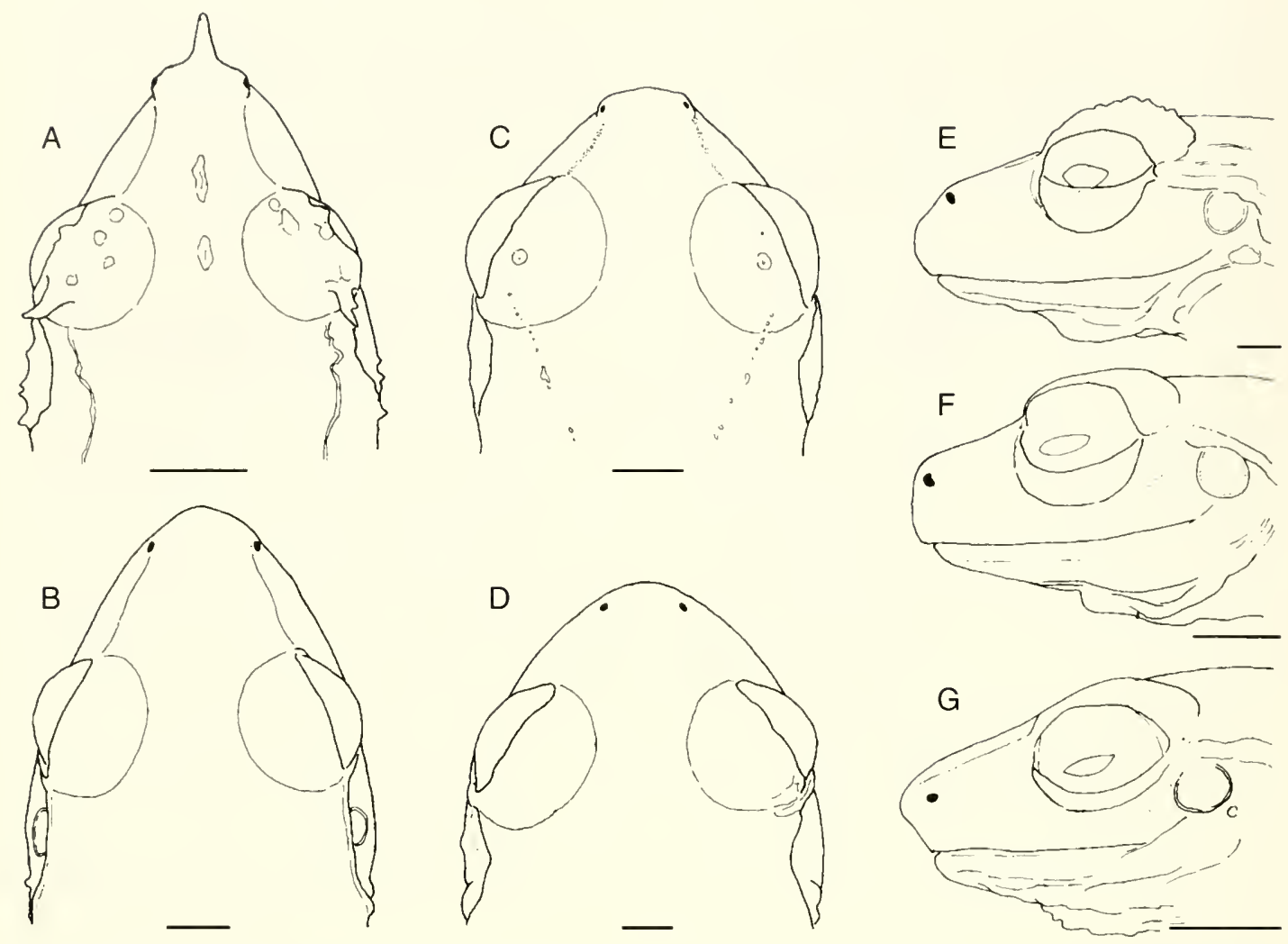

Fig. 12. Snouts of Eleutherodactylus showing different shapes. Dorsal views: A. E. appendiculatus, USNM 204713, acuminate. B. E. longirostris, LACM 47170, subacuminate. C. E. tenebrionis, MCZ 92081, rounded. D. E. loustes, KU 179243, rounded. Profiles: E. E. anomalus, LACM 46881, rounded. F. E. degener; QCAZ 1297, truncate. G. E. colomai, QCAZ 1289, protruding. Scale bars $=2 \mathrm{~mm}$.

shape. Thus, those species (e.g., E. achatimus and E. ornatissimus) having longer snouts (E-N/eye length $\geq 0.8$ ) have subacuminate snouts, whereas those species (e.g., E. anonalus and E. duellmani) having short snouts $(\mathrm{E}-\mathrm{N}<0.8)$ have rounded snouts. The most acuminate snout among species of Eleutherodactylus in western Ecuador is that of the long-snouted E. appendiculatus.

In lateral view (profile), the snout usually is rounded, but the profile is nearly truncate in a few species (e.g., E. subsigillatus) or protrudes well anteriad of the margin of the jaw in E. colonai (Fig. 12). The profile of snout shape reflects the orientation of the alary processes of the premaxillae and the degree to which the nasal cartilages extend anteriorly.

The outline curvature of the jaws in dorsal view is disrupted by the protruding nostrils if the frog has a truncate snout in profile. The only other disruption is caused by the presence of a tubercle or vertical keel on the tip of the snout.

In dorsal view, the canthus rostralis usually is concave in Eleutherodactylus, but in several species (e.g., E. achatinus and E. illotus), the underlying nasal bone bulges laterally, thereby causing the canthus to be an uneven curve. In these species, the curvature is concave just anterior to the orbit and just posterior to the nostrils but convex throughout most of its length. We term such canthi as sinuous in contrast to the concave or straight canthi seen in most Eleutherodactylus. In transverse cross section, the canthus rostralis may be angular (e.g., $E$. calcarulatus, colomai, and nyctoplylax) or obsolete (e.g., E. hamiotae, latidiscus, and loustes). Variation exists in the breadth of the top of the snout, defined as the dorsal plane in front of the 
orbits and bordered laterally by the canthi rostrali. One extreme is exhibited by E. colomai, in which the top of the snout is broad, the canthi rostrali are angular, and the loreal regions are nearly vertical. Adult females of E. latidiscus exhibit the other extreme, in which the top of the snout is narrow, the canthi rostrali are curved concavely in dorsal view, and the loreal regions slope gradually toward the flared lips.

Cranial crests.-In several species of Eleutherodactylus in western Ecuador (e.g., E. cerastes, necerus, ruidus, and vertebralis), bony crests develop on the frontoparietal bones. These crests lie just medial to the origin of the $m$. pterygoideus but may extend both anterior to and posterior to that origin. As is true for many features of Eleutherodactylus, crests are better developed in larger than in smaller individuals; therefore, they are most prominent in adult females, less so in adult males, and the least so in juveniles. When present, crests usually are lowest anteriorly and highest posteriorly, but they may be uniform in height. Crests may be thick or thin, be lateral or parasaggital on the frontoparietals, and be smooth or bear bony projections. Because there is ontogenetic and sexual variation in this character, we have characterized species based on the condition in adult females, even when that misrepresents what might be observed in adult males or juveniles. This places an added burden on investigators to ascertain the sex and maturity of specimens when reading this account or other papers that we have authored individually and jointly.

Vomerine odontophores.-There is considerable variation in vomerine odontophores (= dentigerous processes of the vomers) in Eleutherodactylus. Species of the subgenus Syrrhophus lack odontophores, as do several species in other subgenera. All species in western Ecuador have odontophores, although they may be concealed beneath the tissue of the palate and be difficult to see in some species (e.g., E. chalceus and E. scolodiscus). Likewise, all species have odontophores that are posteromedial to the choanae. Frogs of the E. discoidalis group (Lynch, 1989) are distinctive in having odontophores that are located more anterior than are these structures in most Eleutherodactylus.
Odontophores increase in size as the frog grows. Therefore, odontophores in females normally are larger and more easily observed than those in males; larger odontophores usually are more narrowly separated from one another in the midline than are smaller odontophores. These structures commonly are difficult to detect in juveniles.

Historically, much of the attention to odontophores concerned the "widths" of the structures; this has been "measured" in terms of how far laterally the odontophores extend relative to the middle or lateral margins of the choanae. Many species of the subgenus Euhyas have extremely broad odontophores that extend laterally to the lateral margins of the choanae. In Barycholos pulcher; the odontophores are comparable to those in Euhyas. However, in species of Eleutherodactylus in western Ecuador, the odontophores are much narrower and do not extend laterally even to the middle of the choanae. A few species in western Ecuador (e.g., E. helonotus and E. necerus) have odontophores that might be described as arched or broad, but these are relative terms and should not be confused with similar wording used by other authors for frogs such as members of the subgenus Euhyas.

In addition to width, the shapes of odontophores vary, as observed in ventral view (Fig. 13). For example, in adults of E. achatinus, the odontophore is approximately triangular in outline with the teeth in a transverse row along the base of the triangle. In adult $E$. calcarulatus, the odontophores are described as oblique or slanted, because there is no development of the tooth row posterolaterally, and the teeth are either in a clump or in an oblique row. In some species with massive odontophores (e.g., E. hamiotae and E. pteridophilus), the outline of the structure is oval, and the tooth row is not so well defined as in taxa having triangular odontophores.

Secondary sex characters.-Males of many species of Eleutherodactylus have vocal apparati (sac and slits) and/or nuptial pads. Eleven species (E. celator, cerastes, floridus, gentryi, hamiotae, illotus, laticlavius, pteridophilus, quinquagesimus, siopelus, and surdus) lack vocal slits and nuptial pads. Their absence makes the determination of adulthood difficult in these species, in which maturity in males must be determined by examination of 
the testes in conjunction with field observations on amplectant pairs.

Vocal slits: These slits are known to occur in 34 species of Eleutherodactylus in western EcuadorE. achatinus, actites, anatipes, appendiculatus, babax, calcarulatus, caprifer, chalceus, colomai, crenunguis, crucifer, eremitus, degener, engeniae, gularis, hectus, labiosus, leoni, longirostris, loustes, luteolateralis, muricatus, necerus, nyctoplylax, ornatissimus, panillus, phoxocephalus, pyrrhomerus, scolodiscus, subsigillatus, tenebrionis, verecundus, walkeri, and w-nigrum. Slits are thought to be absent in 20 species-E. anomalus, duellmani. latidiscus, lymani, rosadoi, ruidus, thymalopsoides, truebae, and vertebralis, in addition to the 11 species listed above. Adult males are not known for E. dissimulatus, helonotus, ocellatus, and sobetes.

Nuptial pads: White, nonspinous nuptial pads are present on the dorsomedial and medial surfaces of the base of the thumb in breeding males of 23 species of Eleutherodactylus in western EcuadorE. achatinus, actites, anatipes, anomalus, crucifer; degener, duellmani, eremitus, eugeniae, latidiscus, longirostris, lymani, necerus, nyctophylax, ornatissimus, phoxocephalus, rosadoi, ruidus, subsigillatus, thymalopsoides, truebae, vertebralis, and w-nigrum. Obviously, for four species known only from adult females (E. dissimulatus, helonotus, ocellatus, and sobetes), the condition of nuptial pads is unknown.

Fingers.-The groups of characters associated with the hands are the relative lengths of the fingers, especially (and usually) Fingers I and II, the development of lateral fringes or keels on the fingers, and the anatomical details (discs and pads) on the tips of the fingers.

Relative lengths of digits: In most Eleutherodactylus in western Ecuador, the thumb (Finger I) is noticeably shorter than Finger II (when each is adpressed equally). Finger I is only slightly shorter than Finger II in E. labiosus and E. ocellatus. Finger 1 is longer than Finger II in species of the subgenus Craugastor (E. anatipes, anomalus, longirostris, and necerus), most of the species in the E. conspicillatus group (E. achatinus, actites, illotus, lymani, and w-nigrum), the E. sulcatus group (E. cerastes and E. helonotus), and in $E$. babax, crenunguis, and loustes, as well as in
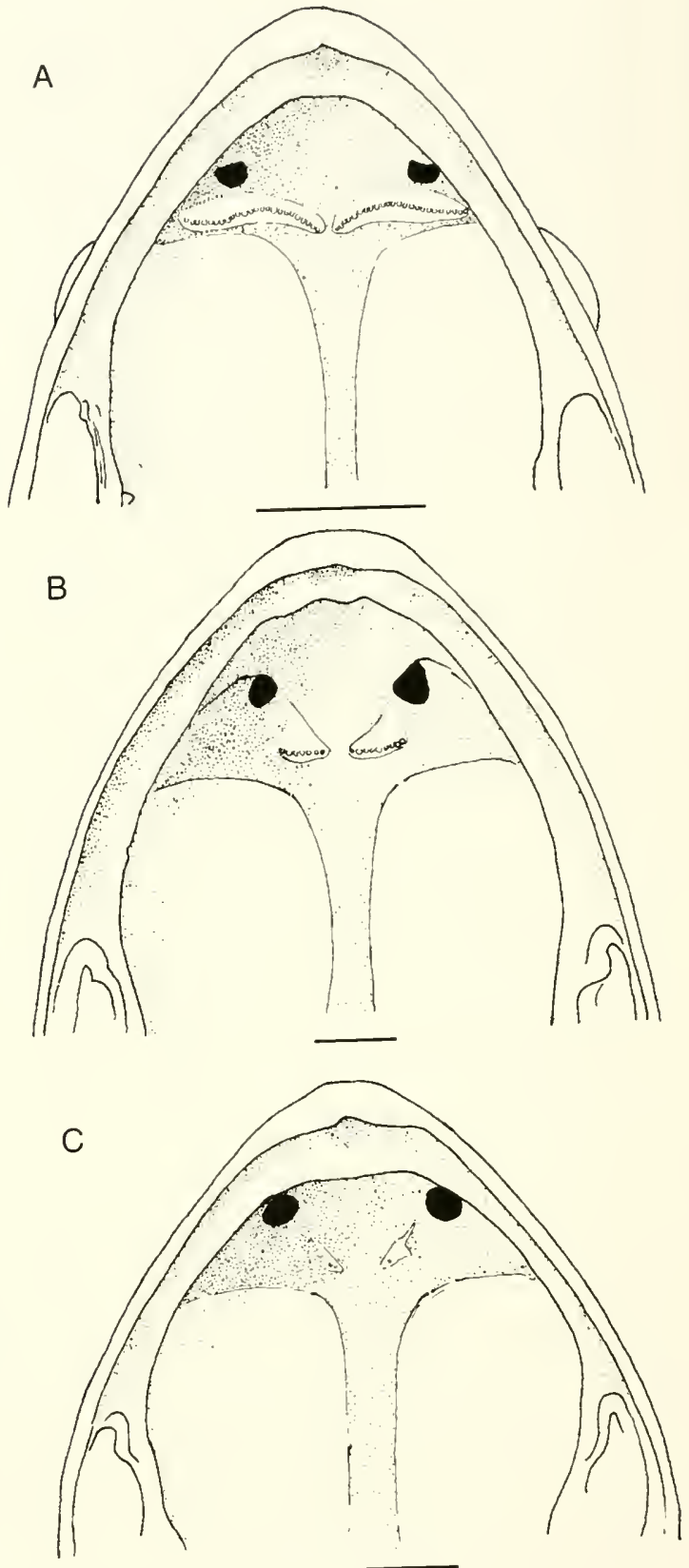

Fig. 13. Ventral views of palates showing shapes and separation of vomerine odontophores in eleutherodactyline frogs. A. Barycholos pulcher; KU 218152 , arched and barely separated. B. E. crenunguis, QCAZ 1310, triangular and narrowly separated. C. E. leoni, KU I30870, oblique and widely separated. Scale bars $=2$ $\mathrm{mm}$. 
Barycholos pulcher (Figs. 14, 15). The fingers of several of these species (E. babax, crenunguis, labiosus, and ocellatus) seem to be exceptionally long, because they are higher than wide and lack any trace of lateral folds. The narrowness and lengths of the fingers are accentuated in those species (e.g.. E. crenunguis) that bear prominent terminal discs. Other species have short ("stubby") digits either because the fingers are short (e.g., E. helonotus) or because they are wider than high (e.g., E. gularis).

Lateral fringes and webbing: In many species, fleshy keels (e.g.. E. gentryi and E. lymani) or fringes (e.g., E. duellmani, siopelus, and thymalopsoides) are present on the lateral margins of the fingers; there is a continuum from keels to fringes, and in some cases the distinction is arbitrary. Generally, the digits are narrower when bearing a lateral keel than when bearing a fringe. In a few species (e.g., E. loustes), the fringes partially obscure the subarticular tubercles in preserved specimens. Lateral folds and especially fringes are sensitive to desiccation. In a subset of species having lateral fringes on the fingers (e.g., $E$. siopelus), there is a comparable fringe on the outer edge of Finger IV; in species such as E. eugeniae and E. pteridophilus, the fringe continues proximally onto the edge of the palm. No such fold occurs on the median edge of Finger I. Webbing between the fingers is absent in all species.

Discs and pads: When the tips of the digits are expanded, the digit is described as having a disc. Within individuals, discs are larger and wider on the outer fingers than on the inner ones. In most species bearing discs, the disc on the thumb is only slightly wider than the digit proximal to the disc, and the disc on Finger II is intermediate in size between that on the thumb and those on Fingers III and IV. In most species of Eleutherodactylus, the skin on the underside of the digital tip is modified to form a pad defined by a circumferential groove. Usually the pad is wider than long, and its distal border is a smooth curve. The disc cover or ungual flap is visible distal to the pad and usually is curved (= "round"), but in some species (e.g., E. crenunguis), it is emarginate (notched) and in others (e.g., E. tenebrionis), it is truncate. In some frogs of the E. diastema group, the pad is lanceolate (i.e., having a pointed tip) and bears a papilla on the underside of the disc cover or extending as a free papilla beyond the margin of the disc cover.

Even when no disc is developed, the ventral pad may be present (= "narrow discs" or "discs absent" (unctorum), but the disc may be incompletely defined, (i.e., circumferential disc evident only distally). The heavy-bodied, toadlike E. anomalus, cerastes, helonotus, and necerus lack digital discs on the fingers and either lack digital pads or have poorly developed, incomplete circumferential grooves. In these frogs, the digital discs and pads are better developed on the toes.

Toes. - The groups of characters associated with the feet mostly are the same ones on the hands.

Relative lengths of digits: The relative lengths of Toes III-V differ (Fig. 16). In some species (e.g., E. anomalus, cerastes, and necerus), Toe $\mathrm{V}$ is shorter than Toe III (Fig. I6A). In several species (e.g., species of the E. conspicillatus group), Toe V is only slightly longer than Toe IIl, and the disc of Toe $V$ does not reach the distal subarticular tubercle on Toe IV (Fig. 16B). In other species (e.g., members of the E. cerasinus group), Toe $\mathrm{V}$ is obviously longer than Toe III, but the tip of the disc does not reach the distal subarticular tubercle on Toe IV (Fig. 16C). In many species (e.g., E. apiculatus, chalceus, laticlavius, and rosadoi), Toe $\mathrm{V}$ is much longer than Toe III; the tip of the disc of Toe V reaches to the distal border of the distal subarticular tubercle on Toe IV (Fig. 16D).

Lateral fringes and webbing: Conditions of lateral fringes on the toes are the same as those on the fingers, but in a few species (e.g., E. loustes), a fringe extends from the disc to the inner metatarsal tubercle on the median surface of Toe I. The lateral fringes coalesce to form "webbing" in a few species. We avoid using the term "webbing" to describe conditions in which the lateral folds coalesce but do not encompass the basal subarticular tubercles; this condition has been termed "basal webbing."

Webbing is measured to subarticular tubercles in the manner proposed by Savage and Heyer (1967) as modified by Myers and Duellman (1982). If webbing does not encompass the basal subarticular tubercles, the webbing is termed basal. Among the species of Eleutherodactylus in west- 


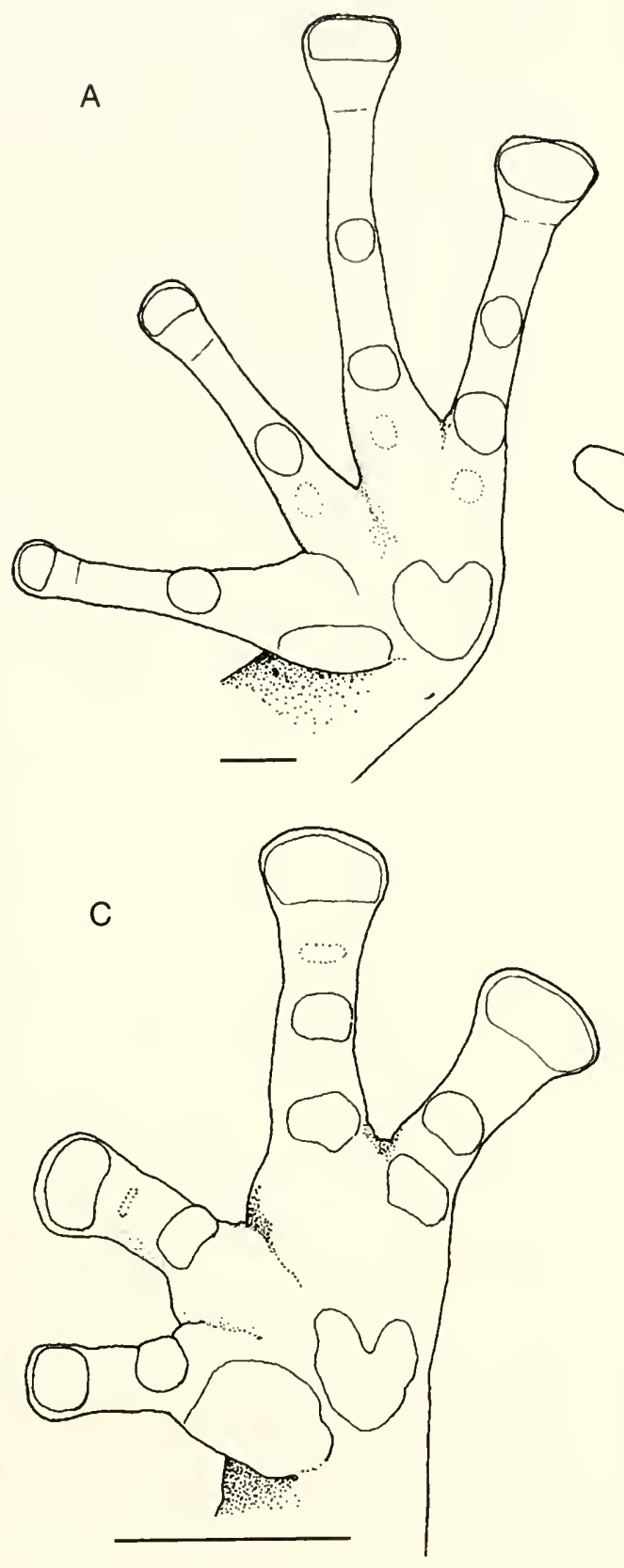

B
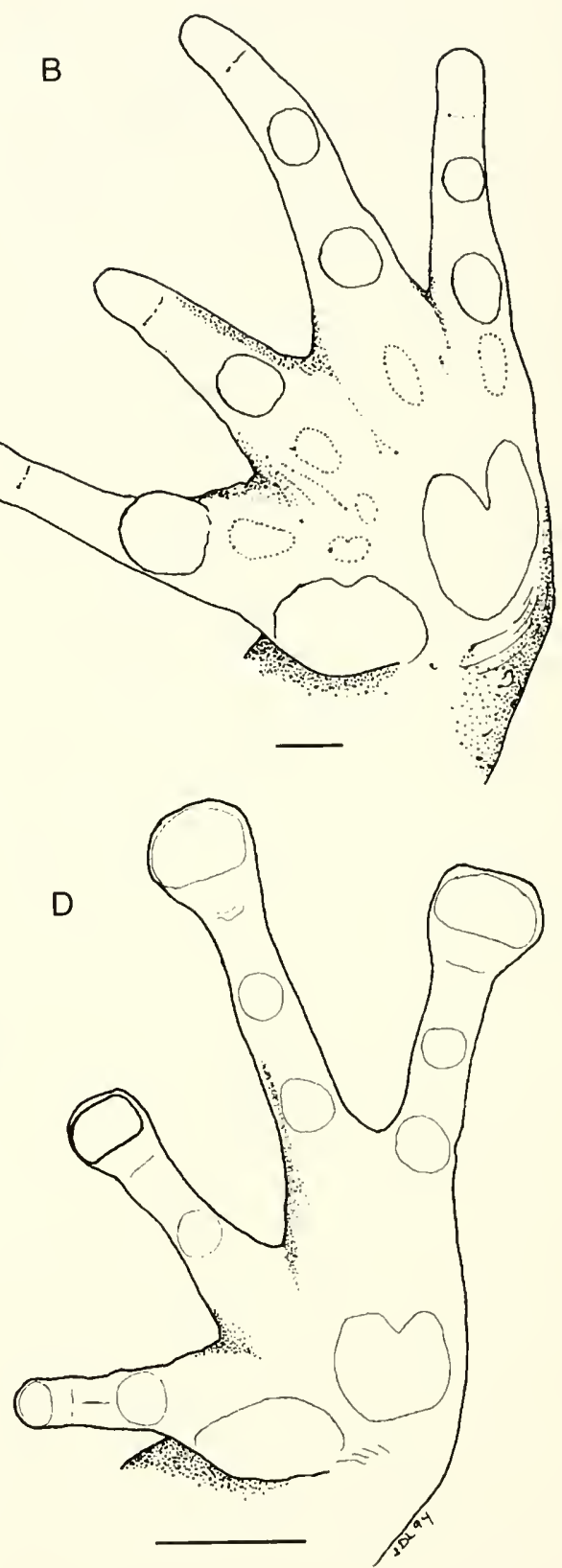

Fig. 14. Palmar views of hands showing lengths and thickneses of digits in Eleutherodactylus. A. E. w-nigrum, ICN (JDL 1 1265), Finger $1>$ II, digits slender and long (discs present). B. E. helonotus, BM 1970.178, Finger I > II, digits slender and short (discs absent). C. E. celator, KU 131574, Finger I < II, digits short and broad (discs present). D. E. duellmani, USNM 286044, Finger I < II, digits long and broad (discs present). Scale bars $=2 \mathrm{~mm}$. 

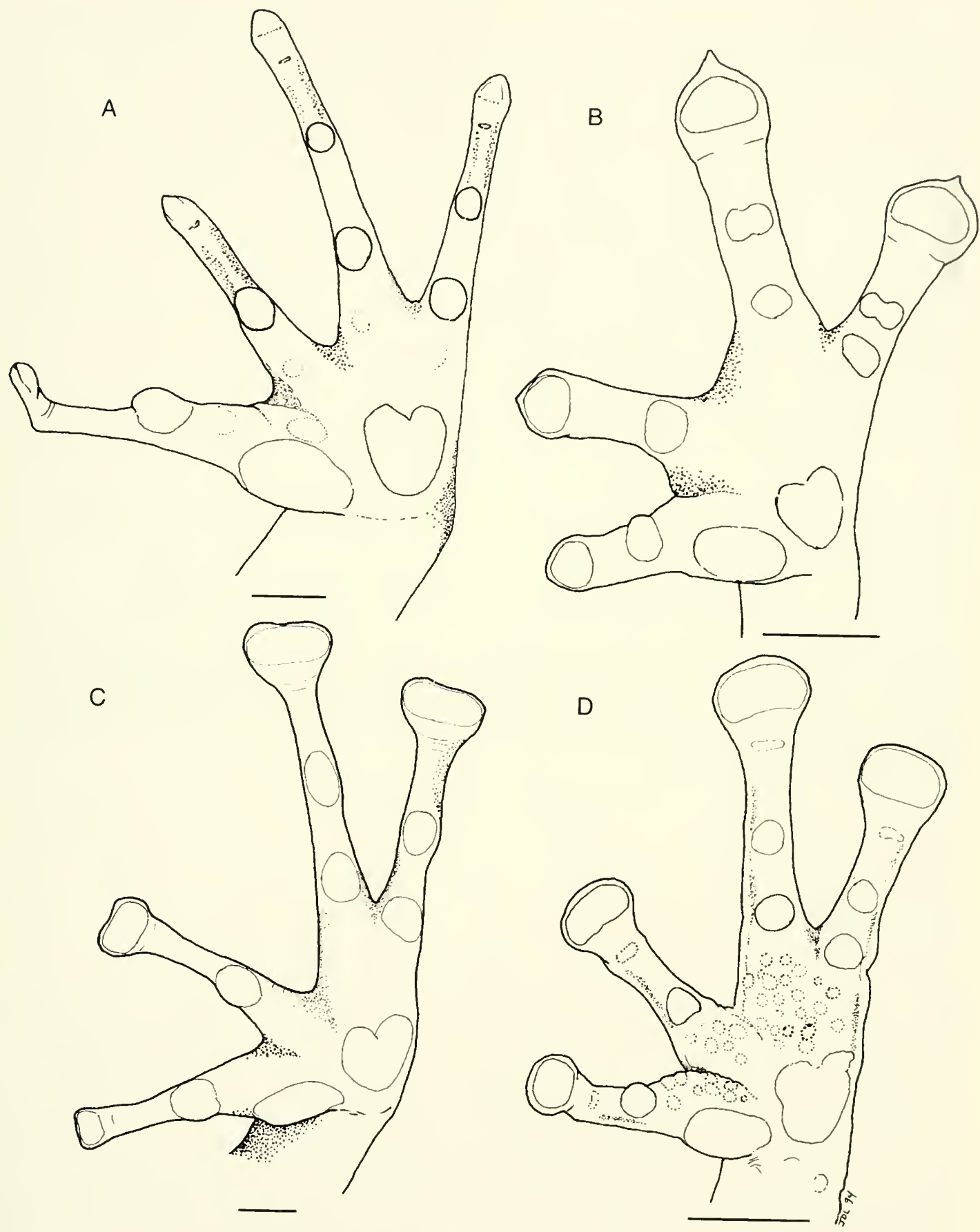

Fig. 15. Palmar views of hands showing variation in size and shapes of discs in Eleutherodactylus. A. E. babax, USNM 285970, narrow. B. E. chalceus, KU 119484, cuspidate bearing terminal papilla. C. E. crenunguis, KU 120126, expanded and emarginate. D. E. subsigillatus, KU 131567, expanded and rounded. Scale bars $=2 \mathrm{~mm}$. 


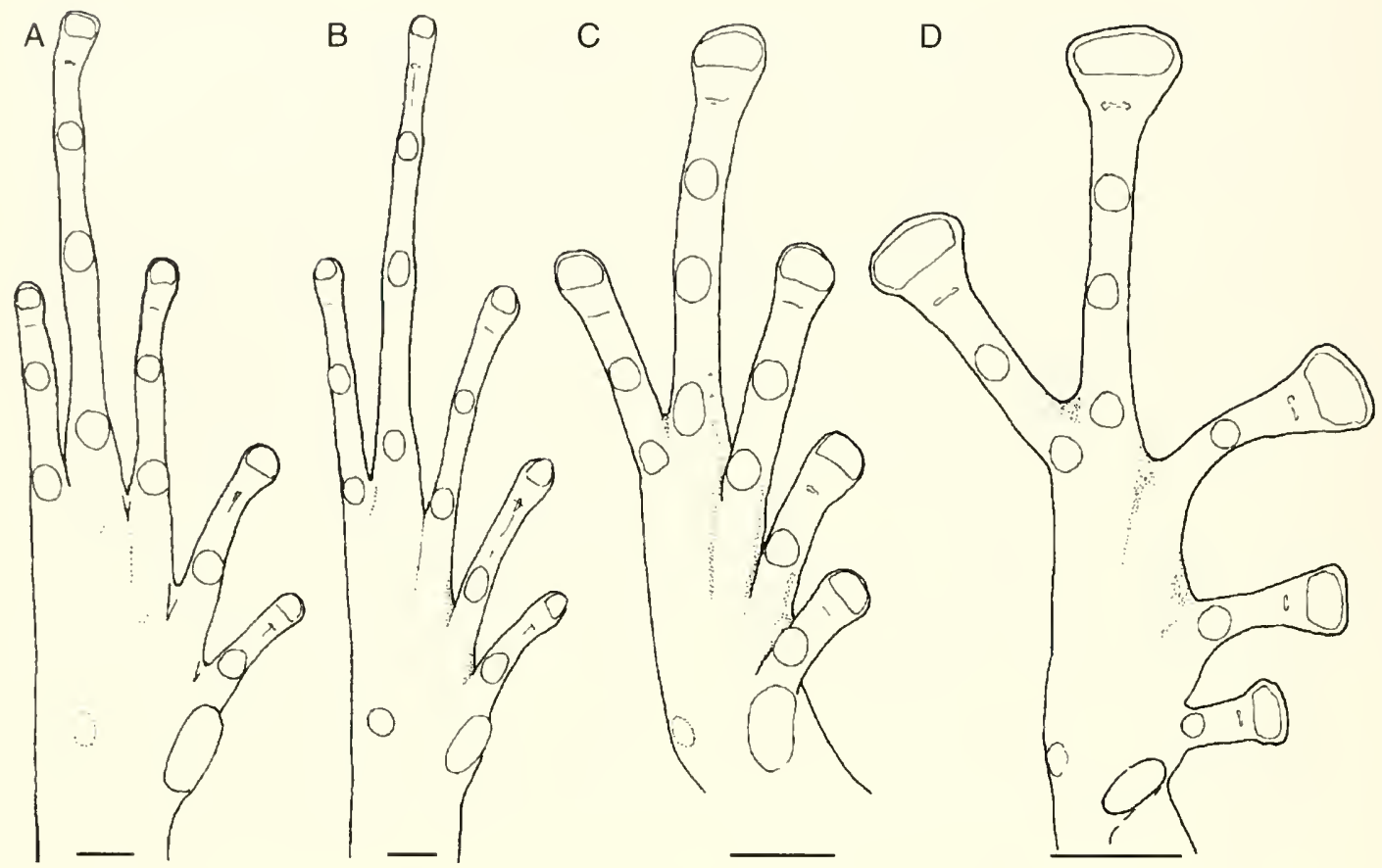

Fig. 16. Plantar views of feet showing variation in lengths of Toes III and V in Eleutherodactylus. A. E. cerastes, UVC 8429, Toe V shorter than Toe III (Condition A in Appendix I1I). B. E. babax, USNM 285970, Toe V sightly longer than Toe III (Condition B in Appendix III). C. E. duellmani, USNM 286044, Toe V longer than Toe III (also Condition B in Appendix III). D. E. ornatissimus, KU I I9745, Toe V much longer than Toe III (Condition C in Appendix III). Scale bars $=2 \mathrm{~mm}$.
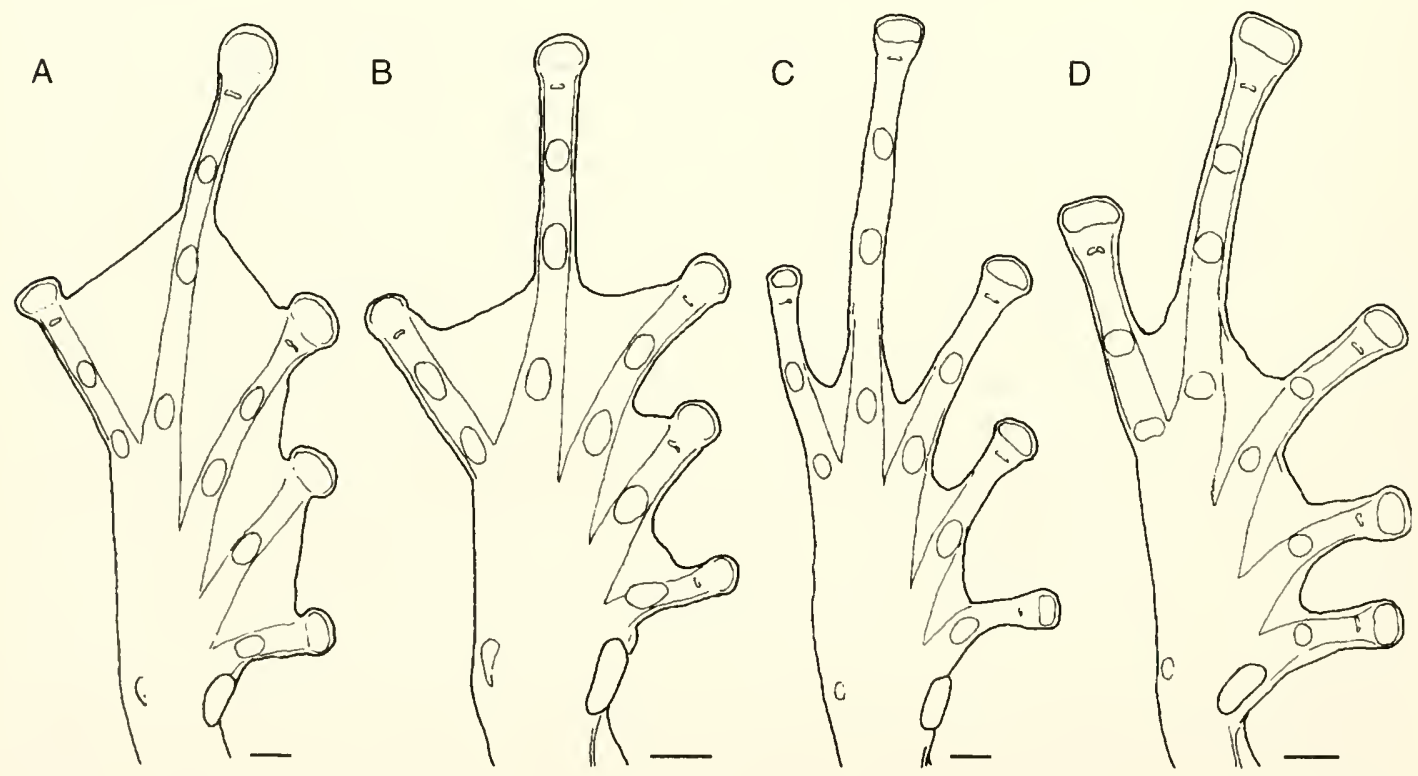

Fig. 17. Plantar views of feet showing variation in webbing in Eleutherodactylus. A. E. anatipes, ICN 12113. B. E. anomalus, CAS-SU I0467. C. E. longirostris, USNM I5048I. D. E. lonstes, KU 179243. Scale bars $=2 \mathrm{~mm}$. 
ern Ecuador, measurable toe webbing occurs only in four species-E. anatipes, anomalus, longirostris, and loustes (Fig. 17). Webbing extends to the discs on Toes I-III and V in E. anatipes and nearly so in E. anomalus, but extends only to a point between the distal and penultimate subarticular tubercles on Toe IV. Webbing also is obvious in $E$. longirostris, but it does not extend appreciably beyond the basal subarticular tubercles except between Toes IV and V. The webbing in E. loustes is less extensive than in E. longirostris.

Discs and pads: The structure of the dises and pads on the toes closely parallels that of the fingers, but in many species having little or no evidence of discs and pads on the fingers, those on the toes are obvious; this point was made by Boulenger (1898) in his choice of the trivial name for E. anomalus. However, a common condition in Eleutherodactylus is that the discs on the fingers are larger than those on the toes. Commonly, the discs on the inner toes are smaller than those on the outer toes, but in species having a short Toe $\mathrm{V}$, the disc on Toe $\mathrm{V}$ is noticeably smaller than that on Toe IV.

Coloration.-Although many other kinds of frogs can be identified easily from their dorsal coloration, such is not the case with most Eleutherodactylus, most of which are various shades of brown or gray dorsally, with or without distinct or diffuse darker markings. These markings may consist of spots of varying sizes, blotches, longitudinal stripes, transverse bars, chevrons ( $V$-shaped marks with the apex anteriad), or W-shaped mark in the occipital-scapular region. The exceptions in western Ecuador are $E$. chalceus, which is creamy tan with red spots or reticulations, and E. ornatissinus, which is green with black lines and spots. This problem of identification is confounded by distinct dorsal-pattern polymorphism in some species (e.g., E. calcarulatus, laticlavins, vertebralis, and walkeri), whereas some other species (e.g., E. achatimus, phoxocephalus, and w-nigrum) simply are highly variable in coloration. A common pattern polymorphism in many species is the presence of a pale middorsal stripe that may be yellow, orange, red, or green in life. In most species, dark transverse bars are present on the dorsal surfaces of the forearms and shanks (also on thighs and tarsi in some species), but dark bars are absent in $E$. chalceus.
Ventral coloration also is highly variable and usually consists of various shades of brown or gray with or without pale or dark flecks or mottling. However, a few have uniform pale venters - white in E. chalceus and E. cremitus, creamy-yellow in $E$. achatinus and E. anatipes, and greenish-yellow in E. ornatissimuls. Two species have distinctive patterns on the throat and/or chest; in E. caprifer, a pair of dark longitudinal lines is present on the throat. and in E. longirostris, pairs of dark spots are present on the throat and chest. Use of ventral coloration in identification of species is further confounded by sexual dimorphism in some species. Females of $E$. degener and E. subsigillatus have dark reticulations on the belly, whereas the belly in males is uniform.

Most Eleutherodactylus in western Ecuador have two or three dark labial bars, a dark canthal stripe, and a dark supratympanic stripe. In a few species (e.g., E. colomai), the entire side of the head is dark, so that canthal and supratympanic stripes are not distinguishable; facial markings are absent in $E$. degener: A pale labial stripe appears as a polymorphism in E. achatinus, illotus, longirostris, and walkeri.

The color pattern on the flanks (exclusive of the axilla and groin) is distinctive in several species of Eleutherodactylus in western Ecuador. The flanks are pale with large black spots in E. w-nigrum, black with white spots in E. cajamarcensis, and brown with thin diagonal black lines in E. caprifer. Eleutherodactylus luteolateralis has pale dorsolateral stripes, and E. parvillus has a pale yellow patch on the posterior half of the flanks. A dark reticulum encloses large, pale spots on the flanks in $E$. phoxocephalus, subsigillatus, and females of $E$. degener. However, striking polymorphism in flank pattern occurs in E. quinquagesimus; in some individuals, the flanks are dark with diffuse pale spots, whereas bold black and white diagonal bars are present on the flanks of other individuals.

The color pattern on the posterior surfaces of the thighs is highly variable among species of Eleutherodactylus in western Ecuador. The most common pattern of a dark brown or black ground color with yellow, cream, or white spots or flecks occurs in 27 species (e.g., E. achatinus, crenunguis, duellmani, labiosus, and surdus); in five species ( $E$. 
degener, hamiotae, hectus, subsigillatus, and walkeri), the pale spots or flecks may be present or absent. In 13 species (e.g., E. appendiculatus, longirostris, ocellatus, and sobetes), the posterior surfaces of the thighs are uniform brown, whereas in eight species (e.g.. E. anatipes, anomalus, and phowocephalus) the thighs are cream or dull yellow with brown or black mottling or reticulation, and the thighs are brown, with black reticulations in $E$. helonotus and cream mottling in E. pteridophilus. The thighs also are cream or yellow, but with dark flecks, in E. actites and E. celator: The thighs are unpigmented in E. chalceus and uniform cream in E. dissimulatus. In E. w-nigrum, the thighs (and flanks) may be yellow or white with large black spots or black with large yellow or white spots. Living individuals of a few species have distinctive coloration on the posterior surfaces of the thighs; also, the same color usually is on the underside of the shank and in the groin and axilla. These examples are: deep blue in E. crucifer, green with pale spots in E. ornatissimus, yellow in E. eremitus and E. parvillus, orange in E. dissimulatus and E. scolodiscus, and red in E. leoni and E. pyrrhomerus.

In living individuals of most species of Eleutherodactylus in western Ecuador, the iris varies from bronze to reddish-copper with varying amounts of black flecking and a variably distinct red or reddish-brown median, horizontal streak. We are convinced that the intensity of the color in the iris depends on the brightness of ambient light when observations are made. In some of the large, streamside species (E. anatipes, anomalus, and necerus), the iris is pale bronze with brown or gray triangles (apex medial) anteriorly and posteriorly. However, distinctive iris colors are present in living individuals of several species-green in $E$. cerastes, blue in E. calcarulatus and E. scolodiscus, bluish-gray in E. hectus and E. leoni, orange in $E$. degener and E. sobetes, red in E. vertebralis, chocolate-brown in E. duellmani, and black in E. chalceus.

Adult sizes.-Body size is useful to distinguish species of Eleutherodactylus, but it must be used with care (Table 5). Because frogs of the genus Eleutherodacty/us have direct development and because adults and juveniles occur in the same habitat, for at least some parts of the year there seems to be a continuum in sizes from a few to as much as 80-100 mm SVL. At other times, if reproduction is seasonal, two clear modes of sizes are evident in a single sample of a species.

Adulthood in males can be determined externally if secondary sex characters (vocal slits and/or vocal sac, nuptial pads) are present, but adulthood is best verified by inspection of the testes. Reproductive males have larger, swollen testes than do nonreproductive males and immature individuals. In a few species, mesorchial pigmentation seems to be age-dependent (e.g., E. curtipes; Lynch, 1981a), but this is of limited value in western Ecuador where most species have white mesorchia.

Unless ovarian eggs are visible through the body wall, adulthood in females can be determined only by inspecting the reproductive system. For nearly all eleutherodactyline frogs, convolution of the oviducts precedes development of large ovarian eggs, and once the oviducts are convoluted, they do not regress during the nonreproductive season; however, this may not be true in E. labiosus (Lynch et al., 1994). Thus, females can be sorted into three age/size classes: (1) juveniles having thin, straight oviducts containing no enlarged ovarian eggs; (2) subadults having thin oviducts with some convolutions containing only small or moderate-sized eggs; and (3) adults having strongly convoluted oviducts with large lumina, and ovarian eggs enlarged or not. If there is regularity to sexual maturity (i.e., no regression after reproduction), these three size classes seem to be largely sequential with only modest overlap between classes.

Frogs of the genus Eleutherodactylus are markedly sexually dimorphic in size. This is most obvious in amplectant pairs, because males typically are only about two-thirds the size of the females. Some caution must be used when referring to amplectant pairs taken from collecting bags (and possibly field observations as well), because amplexus only assures the observer of the male's maturity. We have found males in amplexus with other males, juvenile females, and adult females. Males of one species have been observed to amplex individuals of another species in the collecting bag, and taxonomic decisions should not be made on the assumption that the male "knew" what he was doing. Because of the sexual dimorphism in the 
Table 5. Body sizes (SVL in $\mathrm{mm}$ ) of Eleutherodactylus in western Ecuador. Values include range (mean \pm I SE, sample size). SD = sexual dimorphism.

\begin{tabular}{|c|c|c|c|}
\hline Species & Males & Females & SD \\
\hline E. achatinus ${ }^{1}$ & $23.0-35.1(28.7 \pm 0.4,46)$ & $33.6-45.4(39.9 \pm 0.6,22)$ & 1.39 \\
\hline E. achatinus $^{2}$ & $24.4-34.2(28.8 \pm 0.3 .42)$ & $37.0-46.1(42.1 \pm 0.4,33)$ & 1.46 \\
\hline E. actites & $30.0-40.0(35.0 \pm 0.4 .32)$ & $48.2-64.2(54.9 \pm 1.0,21)$ & 1.57 \\
\hline E. anatipes & $42.9-64.3(53.9 .4)$ & $98.6(1)$ & 1.83 \\
\hline E. anomalus & $31.5-61.0(47.0 \pm 1.4 .46)$ & $76.5-92.4(85.4 \pm 1.5,10)$ & 1.82 \\
\hline E. apiculatus & $17.8-21.8(20.3 \pm 0.2,24)$ & $21.6-26.3(23.3 \pm 0.3,17)$ & 1.15 \\
\hline E. appendiculatus & $18.8-21.0(19.7 .3)$ & $30.0-35.0(32.2,5)$ & 1.63 \\
\hline E. $b a b a x^{3}$ & $42.4(1)$ & $45.6-48.7(47.0,6)$ & 1.11 \\
\hline E. cajamarcensis & $19.2-24.1(22.4 \pm 0.3 .21)$ & $27.1-33.8(29.8 \pm 0.5,17)$ & 1.33 \\
\hline E. calcarulatus & $17.8-24.6(22.2 \pm 0.3 .21)$ & $25.3-28.9(26.8 \pm 0.2,20)$ & 1.12 \\
\hline E. caprifer ${ }^{4}$ & $21.0-30.4(25.8 \pm 1.1 .9)$ & $40.5-43.8(42.7,3)$ & 1.66 \\
\hline E. celator & $19.6-21.4(20.5 \pm 0.2 .6)$ & $22.0-24.5(23.5 \pm 0.3,7)$ & 1.15 \\
\hline E. cerastes & $28.3-33.4(30.8,2)$ & $44.4-55.8(47.0 \pm 1.2 .9)$ & 1.52 \\
\hline E. chalceus & $17.5-26.9(23.5 \pm 0.4,26)$ & $27.7-31.2(29.7 \pm 0.3,13)$ & 1.26 \\
\hline E. colomai & $16.5-17.8(17.2 .2)$ & - & - \\
\hline E. crenunguis & $32.4-49.2(40.3 \pm 1.9 .9)$ & $59.1-64.5(61.9,3)$ & 1.54 \\
\hline E. crucifer & $18.3-20.6(19.4 \pm 0.2,9)$ & $22.8-34.5(26.8 \pm 1.3,8)$ & 1.38 \\
\hline E. degener & $22.2(1)$ & $31.0-31.9(31.4,2)$ & 1.41 \\
\hline E. dissimulatus & - & $27.4-32.7(29.9,5)$ & - \\
\hline E. duellmani & $24.9-36.0(31.2 \pm 1.2,32)$ & $36.6-45.8(41.8 \pm 1.3,17)$ & 1.34 \\
\hline E. eremitus & $17.2-21.8(19.3 \pm 0.6,7)$ & $27.1-27.6(27.4,2)$ & 1.42 \\
\hline E. eugeniae & $26.0(1)$ & $30.5-37.6(33.6 \pm 0.9 .7)$ & 1.29 \\
\hline E. floridus & $17.4-18.3(17.8,2)$ & $23.3-26.7(25.5 \pm 0.2,17)$ & 1.43 \\
\hline E. gentryi & $23.0-28.5(25.9 \pm 0.5,13)$ & $29.5-35.8(33.4 \pm 0.8 .7)$ & 1.29 \\
\hline E. gularis & $20.2-21.6(21.0 \pm 0.2,9)$ & $21.7-24.8(23.5 .5)$ & 1.12 \\
\hline E. hamiotae & $28.2-30.9(29.6,2)$ & $35.7-36.2(36.0 .2)$ & 1.22 \\
\hline E. llectus & $13.6-16.8(15.2 \pm 0.2,13)$ & $19.4-22.5(20.7 \pm 0.2,20)$ & 1.36 \\
\hline E. helonotus & - & $69.6(1)$ & - \\
\hline E. illotus & $25.9-29.3(27.6,2)$ & $38.3-44.6(41.0 \pm 0.8 .7)$ & 1.48 \\
\hline E. labiosus & $35.4-50.8(44.3 \pm 1.6,12)$ & $48.5-52.3(50.4,4)$ & 1.14 \\
\hline E. laticlavius & $22.5-26.3(25.1,5)$ & $37.2-42.9(39.9 .5)$ & 1.59 \\
\hline E. latidiscus & $21.9-25.9(23.8 \pm 0.3,16)$ & $35.2-53.4(42.3 \pm 1.3 .14)$ & 1.78 \\
\hline E. leoni & $14.8-18.3(16.7 \pm 0.5,7)$ & $19.7-25.0(21.9 \pm 0.3 .22)$ & 1.31 \\
\hline E. longirostris & $28.8-34.4(31.9 \pm 0.5,14)$ & $43.1-59.6(48.2 \pm 1.1 .15)$ & 1.51 \\
\hline E. loustes & $31.2-37.1(34.8,6)$ & $46.7(1)$ & 1.34 \\
\hline E. luteolateralis & $16.6-23.6(22.0 \pm 0.4,10)$ & $25.6-29.5(27.9 .5)$ & 1.27 \\
\hline E. lymani & $25.7-43.6(33.2 \pm 1.2,23)$ & $52.9-69.3(60.2 \pm 1.8,10)$ & 1.81 \\
\hline E. muricatus ${ }^{5}$ & $18.7(1)$ & $33.8-36.0(34.9,2)$ & 1.89 \\
\hline E. muricatus ${ }^{6}$ & $31.8-40.7(36.0,4)$ & - & - \\
\hline E. necerus & $44.9-68.4(54.2,4)$ & $83.8-93.3(88.3,4)$ & 1.63 \\
\hline E. nyctophylax & $21.9-31.4(26.8 \pm 0.5,21)$ & $32.1-37.8(33.8 \pm 0.4,22)$ & 1.26 \\
\hline E. ocellatus & - & $45.7(1)$ & - \\
\hline E. ormatissimus & $21.6-27.0(24.1 \pm 0.6,9)$ & $37.8-38.1(38.0,2)$ & 1.58 \\
\hline E. parvillus & $15.5-19.6(18.0 \pm 0.2,27)$ & $18.4-25.9(23.4 \pm 0.6,11)$ & 1.30 \\
\hline E. phoxocephalus & $22.3-29.9(27.2 \pm 0.4 .29)$ & $29.6-38.4(35.1 \pm 0.6,22)$ & 1.29 \\
\hline E. pteridophilus & $17.6-25.1(22.4 \pm 0.3,32)$ & $31.9-33.9(33.1,3)$ & 1.48 \\
\hline E. pyrhomerus & $16.2-18.9(17.5 .3)$ & $19.8-24.0(21.6 \pm 0.3,6)$ & 1.23 \\
\hline E. quinquagesimus & $27.8-30.8(29.0 \pm 0.2,12)$ & $33.6-40.1(36.5 \pm 0.5,14)$ & 1.26 \\
\hline
\end{tabular}


Table 5. Continued.

\begin{tabular}{|c|c|c|c|}
\hline Species & Males & Females & $\mathrm{SD}$ \\
\hline E. rosadoi & $16.5-16.7(16.6 .2)$ & $23.4-25.7(24.4 .3)$ & 1.47 \\
\hline E. ruidus & $25.8-31.1(28.9 \pm 0.7 .7)$ & $37.1-39.8(37.9 \pm 0.4 .7)$ & 1.31 \\
\hline E. scolodiscus & $17.6-20.4(19.2 \pm 0.3,10)$ & $18.4-22.3(20.7,6)$ & 1.08 \\
\hline E. simonbolivari & $16.0-19.2(17.2 .4)$ & $18.5-22.0(20.6 \pm 1.2,22)$ & 1.20 \\
\hline E. siopleus & $18.6-27.3(23.7 \pm 0.7,14)$ & $34.3-40.0(37.4,4)$ & 1.58 \\
\hline E. sobetes & - & $41.3(1)$ & - \\
\hline E. subsigillatus & $19.3-28.5(24.4 \pm 0.7,17)$ & $30.0-33.4(31.6 \pm 0.4,8)$ & 1.30 \\
\hline E. sulculus & $26.3(1)$ & $43.0(1)$ & 1.63 \\
\hline E. surdus & $24.5-36.9(31.1 \pm 0.6,34)$ & $40.4-54.6(45.8 \pm 0.7,14)$ & 1.47 \\
\hline E. tenebrionis & $20.8-26.8(23.8 \pm 0.4,16)$ & $30.6-36.9(33.8 \pm 0.8,7)$ & 1.42 \\
\hline E. thymalopsoides & $28.0-34.4(31.1,5)$ & $46.9-55.4(52.2 \pm 09.9)$ & 1.68 \\
\hline E. truebae & $25.5-39.0(32.2 \pm 1.2,12)$ & $39.8-45.8(42.6 .5)$ & 1.32 \\
\hline E. unistrigatus ${ }^{7}$ & $14.5-24.0(19.1 \pm 0.4,46)$ & $23.0-31.0(26.8 \pm 0.4 .22)$ & 1.40 \\
\hline E. verecundus & $18.0-21.9(19.5 \pm 0.6 .7)$ & $20.7-22.5(21.8 .5)$ & 1.12 \\
\hline E. vertebralis & $21.1-28.0(24.8 \pm 0.6,15)$ & $35.0-43.9(37.7 \pm 0.6,20)$ & 1.52 \\
\hline E. w-nigrum ${ }^{8}$ & $25.0-46.1(33.0 \pm 0.6 .58)$ & $50.2-71.5(59.8 \pm 1.2 .21)$ & 1.81 \\
\hline E. walkeri & $13.8-18.5(16.2 \pm 0.2,24)$ & $19.4-25.3(21.6 \pm 0.3,23)$ & 1.33 \\
\hline
\end{tabular}

${ }^{1}$ Specimens from lowlands below $700 \mathrm{~m}$.

¿Specimens from Pacific slopes (Balsapamba, Mindo, Tandapi).

${ }^{3}$ Specimens from southern Colombia and Ecuador.

${ }^{+}$Specimens from Ecuador only.

${ }^{5}$ Specimens from Río Palenque and Santo Domingo de los Colorados $(220-600 \mathrm{~m})$.

${ }^{6}$ Specimens from Río Faisanes (1380 m).

${ }^{7}$ Specimens from Pilaló, Provincia Cotopaxi.

${ }^{8}$ Specimens from Provincia Pichincha.

sizes of adults, it is necessary to determine the sex and stage of maturity to avoid the apparent continuous variation in size. Juvenile and young females are about the same size, or only slightly larger than, adult males and bridge the size gap that typically occurs between adult males and adult females.

The last exacerbating factor relative to size is the tendency for frogs from higher elevations to be larger that conspecifics of the same age from lower elevations. In some species, the spotty nature of sampling demonstrates sharp differences in sizes between frogs that otherwise are alike (Heyer, 1970, for Leptodactylus; Lynch, 1980a, for $E$. nigrovittatus). Given these caveats, size data are extremely useful in sorting and distinguishing preserved specimens of most, if not all, species of Eleutherodactylus.

Proportions.-We provide proportional data (ranges, means \pm one standard error of the mean) in our descriptions, because proportions give preci- sion to such ambiguous modifiers as "wide," "long," or "short." While we agree that proportions are of little or no value in the identification of most species, we report the data at our disposal in order to permit more accurate comparisons than otherwise would be possible.

Some proportional data are of limited use. For example, some species of the subgenus Craugastor and those of the E. sulcatus group are designated as "broad-headed," and the adjective can be expressed as a proportion, HW/SVL $>46 \%$. Species of the $E$. diastema group have short hind limbs; this can be expressed most accurately as Tibia/SVL, but species not included in that group have equally short hind limbs. Many species in the E. conspicillatus and E. fitzingeri groups have long legs, and an accurate determination of relative leg length can be obtained from the ratio, Tibia/S VL. The concern of those investigators who eschew using proportions is that some users will make too much of a depar- 
ture of a tympanum/eye ratio relative to reported ranges when most of the difference possibly is owing to differences in technique of measurement and/or shrinkage. All of the measurements reported herein were taken by JDL, who, from time to time because of memory lapses or misplaced files, has measured some individuals repeatedly over a span of 20 years and finds only modest variation in values.

Out of habit and tradition (which may be rooted in some forgotten reasoning), JDL measures snoutvent length (SVL), tibia length, greatest head width (HW), an estimate of head length (straight line distance parallel to body axis from angle of jaw to point equal to tip of snout) (HL), chord of head length (tip of snout to posterior angle of jaws), upper eyelid width (perpendicular to outer edge of eyelid), interorbital distance (IOD), horizontal diameter (length) of tympanum, length of orbit (= visible eye), and distance between eye and nostril. Five proportions are calculated from these 10 measurements-Tibia/SVL, HW/SVL, eyelid/IOD, tympanum/eye, and E-N/eye.

\section{Subgenera and Species Groups}

For the past quarter century, the genus Eleutherodactylus has grown in size to the point that most of our colleagues think that the genus should be divided into several smaller genera. As the number of known species has grown, so too has developed the necessity for some book-keeping devices (species groups) to sort the many species into at least phenetic groups. Lynch (1976b) proposed a series of species groups for the many species then known from South America and attempted to review the species group arrangement for the entire genus. Among the least useful consequences of that review was the recognition of an Eleutherodactylus unistrigatus group for more than 100 species distributed primarily within South America; most colleagues thought this group too large to be useful. Subsequently, Lynch and Duellman (1980) proposed using assemblies as a category within species groups, especially for the E. unistrigatus group. They assigned all species from the Amazonian slopes of the Ecuadorian Andes to assemblies and allocated many other extralimital species to those assemblies. Those proposals of species groups and assemblies were admittedly phenetic but based on the hope that the monophyly of at least some of the units could be established. The use of such units was driven primarily by pragmatism.

During the past decade Eleutherodactylus systematics has undergone something of a revolution as the operational taxonomic work (including the recognition of species groups defined only by content) was joined with explicit searches for synapomorphies and the adoption of a convention that only monophyletic units be recognized. Lynch (1986a) suggested that the subgenus Craugastor might be used for the Middle American clade of Eleutherodactylus. In Craugastor; the mandibular ramus of the trigeminal nerve lies medial to the $m$. levator posterior mandibulae subexternus (= "econdition" of adductor muscle), whereas in all other Eleutherodactylus (and all other leptodactylids), the mandibular ramus of the trigeminal nerve is lateral to the $m$. levator posterior mandibulae subextermus (= "s-condition" of the adductor muscle). Obviously, only the "e-condition" is phylogenetically informative.

Hedges (1989) proposed the recognition of a total of five subgenera, one of which (Elcutherodactylus) was viewed by him as paraphyletic because no synapomorphies were known. Hedges (1989) and Savage (1987) also employed series, a category between subgenus (or genus) and species group. Savage (1987) suggested that Lynch and Duellman's (1980) assemblies should be treated simply as species groups on the grounds that the assemblies appeared to be coordinate categories to his species groups. We agree with Savage`s suggestion concerning assemblies because we think they have outlived their usefulness.

The 63 species we recognize or anticipate to occur in western Ecuador are placed by us in 15 species groups in two subgenera. The species groups are defined using the format employed by Savage (1987) with only minor modifications. We also employ "series," a category between subgenera and species groups, to reflect our perception of systematic arrangement and as a "temporary device" until subgenera can be diagnosed effectively. We restrict usage of Series to the subgenus 


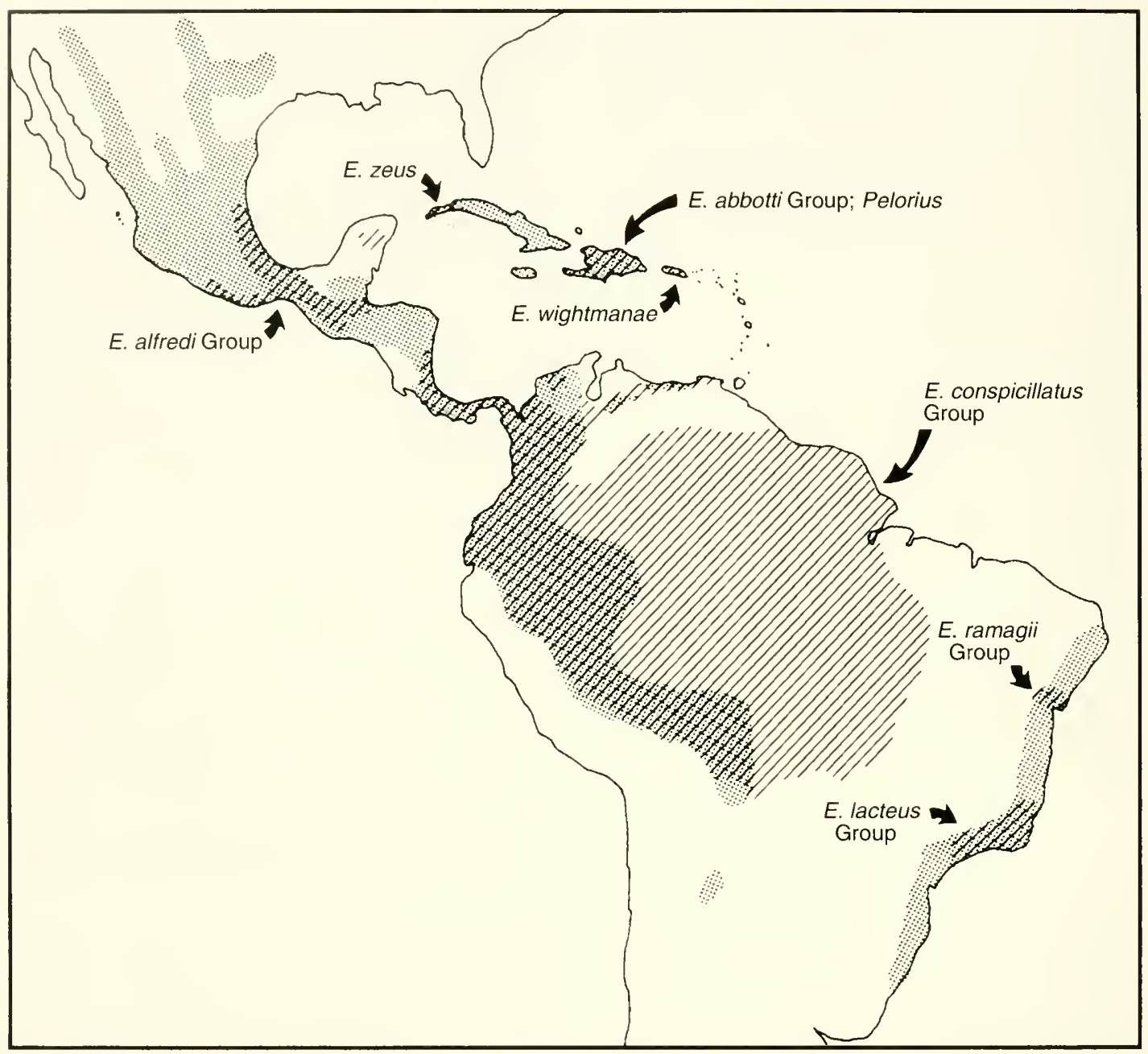

Fig. 18. Distribution of the genus Eleutherodactylus (stippled and hatched areas plus Lesser Antilles). Stippled area is inhabited by species having plesiomorphic state of relative lengths of toes (Toe V shorter than Toe III). Hatched areas are inhabited by species having Toe V longer than Toe III but not extending to distal subarticular tubercle of Toe IV. (See Appendix III.)

Eleutherodactylus sensu Hedges (1989). When diagnostic synapomorphies are known to us, they are identified as such by asterisks (*). All named species of Eleutherodactylus are listed with respect to subgenus, series, and species group in Appendix III.

Variation in toe lengths as a character of systematic importance.-The I5 species groups can be assembled into three clusters based on variations in the lengths of the third and fifth toes (Fig. 16). In the E. anomalus, bufoniformis, fitzingeri, and sulcatus groups, Toe V is shorter than Toe III, whereas in the
E. diastema and E. unistrigatus groups, Toe $\mathrm{V}$ is much longer than Toe III. (The disc on Toe V extends to level of distal subarticular tubercle on Toe IV.) In the other nine species groups, Toe $\mathrm{V}$ is longer than Toe III. Each toe reaches about to the level of the penuitimate subarticular tubercle on Toe IV in the frogs of the E. conspicillatus and E. myersi groups. In the other seven groups, the Toe $\mathrm{V}$ reaches about half way between the distal and penultimate subarticular tubercles on Toe IV.

This variation seems to be significant. If all 


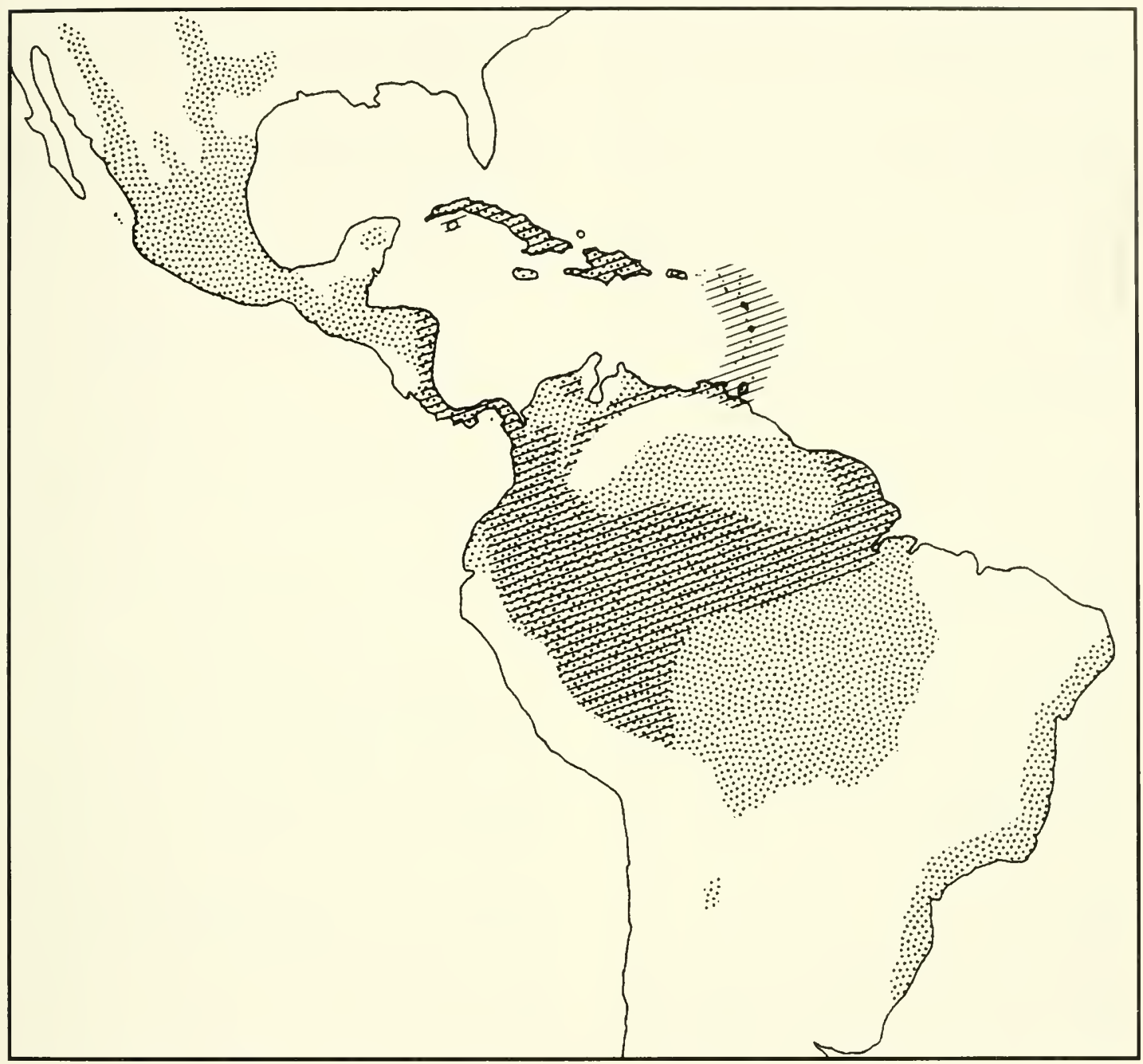

Fig. 19. Hatching defines the distribution of species of Eleutherodactylus having Toe V much Ionger than Toe III. (See Appendix III.) The distribution of the genus is stippled.

leptodactylids except Eleutherodactylus are used as an outgroup, a short fifth toe (Condition A in Appendix 11I) is plesiomorphic (found in all other leptodactylids) and is seen in some species of all subgenera of Eleutherodactylus recognized by Hedges (1989) except Pelorius, whereas the other conditions are not seen in leptodactylids other than in the genus Eleutherodactylus. The fifth toe being longer than the third but not extending to the distal subarticular tubercle on the fourth toe (Condition B in Appendix III) is sporadic in distribution (the E. alfredi group of Craugastor, one Cuban species of Euhyas, all Pelorius, and many South American species of the subgenus
Eleutherodactylus) (Fig. I8). The spotty distribution of this condition and its incompatibility with the "econdition" of the adductor mandibulae (Lynch. 1986a) suggest that the third condition has evolved repeatedly. The fifth toe being much longer than the third (Condition C in Appendix III) is confined to a subset (186 named taxa) of the species assigned to the subgenus Eleutherodactylus by Hedges (1989) and Duellman ( 1993), primarily those assigned to the $E$. auriculatus and E. unistrigatus species groups. In contrast, the condition of the fifth toe being much longer than the third seems to be a uniquely derived feature (Fig. 19). The classificatory consequence of 
such a conclusion is that the 186 named species, including E. martinicensis, the type species of Eleutherodactylus, having the fifth toe much longer than the third would constitute a subgenus Eleutherodactylus (sensu stricto) and some 150 other species placed in that subgenus by Hedges (1989) and Duellman (1993) would need to be assigned to some other subgenus or subgenera.

Subgeneric names are available for some of these clusters. In addition to a subgenus Eleutherodactylus (cluster for the E. diastema and E. unistrigatus groups), Limnophys could be applied as a subgenus for the E. sulcatus group. The third cluster ( 9 groups) is diagnosed by a toe-length character that we suspect to be convergent and, thus, are reluctant to apply any of the available subgeneric names (e.g., Pristimantis, Trachyphrynus). Therefore, we continue Hedges' (1989) practice of recognizing a subgenus Eleutherodactylus as a catchall for species and groups not included in the subgenera Craugastor: Euhyas, Pelorius, and Syrrhophlus. However, to identify the apparent systematic structure, we employ the informal category series for apparent subdivisions within this subgenus.

\section{Subgenera}

Of the five subgenera of Eleutherodactylus recognized by Hedges (1989), only two (Craugastor and Eleutherodactylus) occur in Ecuador. The other three subgenera include one (Syrhophus) that is essentially Mexican and two (Euhyas and Pelorius) that are restricted to the Greater Antilles. Our use of Hedges' (1989) classification is not an unqualified endorsement of his analysis of his dataset. Rather, we find his proposed classification to be a useful point of departure for discussion of relationships within this large genus. We are skeptical of the monophyly of the subgenera Euhyas (as defined by Hedges, 1989) and of Pelorius (Lynch, 1996), and we view the subgenus Eleutherodactylus as a nonmonophyletic assemblage of species, as evidenced by the disparity between Hedges's and our treatments of series and species groups included therein. The basis of an alternate informal classification proposed by Savage (1987) overemphasized the importance of variation in the $m$. depressor mandibulae. For reasons given by Lynch (1993), we doubt the validity of the six lineages identified by Savage (1987).

In order to provide some measure of comparability with the groups found in western Ecuador, we provide brief definitions of the three extralimital subgenera before addressing the subgenera and species groups that occur in western Ecuador.

\section{Subgenus Syrrhophus Cope, 1878}

Definition.-Mostly small frogs (SVL in females 21-40 mm) having the "s-condition" of adductor musculature; head narrow; cranial crests absent; frontoparietals fused with prootics; vomerine odontophores absent; skin on venter areolate or smooth; Finger I about equal in length to Finger II; vocal slits present (except in E. longipes); nuptial pads absent; tympanic membrane and annulus prominent, not sexually dimorphic in size; supernumerary tubercles prominent, numerous: Toe V shorter than Toe III; toe webbing absent.

Content and distribution.- Twenty-four species (Duellman, 1993) distributed from Texas to Guatemala.

Remarks.-Hedges (1989) suggested that Syrrhophus and Euhyas are sister groups. This was based in part on their common possession of frontoparietal-prootic fusion. However, they are unique in having this fusion (Lynch I971 b; Savage, 1987).

\section{Subgenus Euhyas Fitzinger, 1843}

Definition.-Minute to large, mostly small to medium-sized frogs (SVL in females $12-83 \mathrm{~mm}$ ) having the "s-condition" of adductor musculature; head narrow; cranial crests absent; frontoparietals fused with prootics; vomerine odontophores present, broad and arched in about half the known species; skin on venter smooth; Finger I shorter than Finger II; vocal slits usually absent (present in about $25 \%$ of species): nuptial pads absent; tympanic membrane and annulus prominent. not sexually dimorphic in size; supernumerary tubercles prominent. numerous; Toe V shorter than Toe III; toe webbing absent, except in $E$. orcutti.

Content and distribution.-Approximately 80 
recognized species (Duellman, 1993) primarily distributed in Cuba, Hispaniola, and Jamaica, with two species on Puerto Rico (E. lentus and E. richmondi) and one on Mona Island (E. monensis).

Remarks.-Hedges (1989) inexplicably assigned E. lentus and E. richmondi to the subgenus Eleutherodactylus, but Joglar (1989) included both of these species in his E. ricordii group, which we recognize as belonging to the subgenus Euhyas. Each species shares the distinctive arched vomerine odontophores of many other Euhyas.

\section{Subgenus Pelorius Hedges, 1989}

Definition.--Medium-sized to large frogs (SVL in males 41-73 mm) having the "s-condition" of adductor musculature; head narrow; cranial crests present in E. inoptatus group, absent in E. ruthae group; frontoparietals not fused with prootics; vomerine odontophores present, prominent, short to moderately broad and arched; skin on venter smooth; Finger I usually longer than Finger II: vocal slits present; nuptial pads absent; tympanic membrane and annulus prominent, not sexually dimorphic in size; supernumerary tubercles prominent, numerous; Toe V longer than Toe III; toe webbing absent.

Content and distribution.- -Six species in two groups on Hispaniola (Duellman, 1993).

Remarks.-Unlike other Eleutherodactylus, males of the subgenus Pelorius are not markedly smaller than conspecific females (Hedges and Thomas, 1987). Despite this putative synapomorphy, the monophyly of Pelorius is questionable (Lynch, 1996).

\section{Subgenus Craugastor Cope, 1862}

Definition.-Minute to huge frogs (SVL in females 14-120 mm) having the "e-condition" of adductor musculature*; head narrow, except in $E$. anomalus, biporcatus, and bufoniformis groups; cranial crests absent, except in E. biporcatus and $E$. bufoniformis groups; frontoparietals not fused with prootics; vomerine odontophores large, triangular in outline, and narrowly separated in most taxa (absent in E. hobartsmithi and E.pygmaeus; slanted and widely separated in $E$. sartori); skin on venter snooth, except areolate in E. omiltemamus group and some members of E. rhodopis group; Finger I longer than Finger II in most taxa (shorter in some members of E. omiltemanus and E. rhodopis groups): vocal slits usually present; nuptial pads usually present; tympanic membrane and annulus prominent in most species, sexually dimorphic in size, except E. alfredi, anomalus, and bufoniformis groups, and parts of E. argusti and E. fitzingeri groups: supernumerary tubercles usually absent (present in E. clugusti and E. rhodopis groups): Toe $\mathrm{V}$ shorter than Toe III (longer in E. alfredi group): toe webbing obvious in E. anomalus, fitzingeri, gollmeri, matudai, and rugulosis groups.

Content and distribution.-At present, the subgenus is divided into 11 species groups (the $E$. alfredi, anomalus, augusti, biporcatus, bufoniformis, fitzingeri, gollmeri, matudai, omiltemams, rhodopis, and rugulosus groups) to accommodate 74 species. In addition, E. uno is not assigned to a species group. Two groups, the E. anomalus group and E. bufoniformis group, are proposed here. Frogs of subgenus Craugastor are distributed primarily in Middle America, from Arizona and Texas through Panama, into western Colombia and Ecuador. In addition, there is a single species, E. maussi, in Venezuela. Cramgastor is the most diverse subgenus of eleutherodactyline frogs in Middle America, which also is inhabited by 24 species of the subgenus Syrrhophus (Texas to Guatemala) and 10 species of the subgenus Eleutherodactylus (Honduras to Panama).

Remarks. - The subgenus Craugastor; as recognized by Lynch (1986a) and Hedges (1989). includes the nominal genus Hylactophryne. However, Savage (1987) sometimes recognized Hylactoplurne in his arrangement of "Section I" of the genus Eleutherodactylus, and at other times, treated the three species of Hylactophryme as one of seven species groups within the "Elentherodactylus fitzingeri series." For example, in Savage"s (1987:47) cladogram. Hylactophryne and two "lineages" are grouped in Section I, whereas elsewhere (Savage, 1987:44) one lineage (presumably Lineage 1) is stated to contain "E. alfredi, E. biporcatus, E. fitzingeri series, and E. omiltimamus [sic] group." Reanalysis of Savage's data suggests that some plesiomorphic similarities were used to group pre- 
sumed entities (e.g., Hylactophryne + Lineage 1). Each of Savage's arrangements has merit, but here we opt for a third arrangement in which there are no series recognized within Crangastor: Thus, tentatively we accept Salvage's (1987:48) arrangement but with two modilications: (1) recognition of the $E$. biporeatus and $E$. bufoniformis groups within what Savage appears to have viewed as the $E$. biporcatus series (following Lynch, 1976b, 1986a), although we do not view these groups to be closely related to one another; and (2) fragmentation of Savage's E. rugulosus group into two groups - the E. anomalus group and the E. rugulosus group. A full critique of Savage's arrangement will be presented elsewhere (JDL. in prep.).

\section{Eleutherodactylus (Craugastor) anomalus Group}

Definition.-- Large frogs (SVL in females 76$106 \mathrm{~mm}$ ) with narrow to moderately wide heads (HW 37-48\% SVL) and short snouts: cranial crests absent; upper eyelids much broader than IOD; body stout: limbs moderately long; skin on venter smooth; vomerine odontophores large, triangular in outline, narrowly separated medially; vocal slits present (except in E. anomalns), nuptial pads present; tympanic membrane and annulus relatively small, obscure, lacking sexual dimorphism in size. Discs on fingers and toes narrow (except in E. anomalus); Finger I longer than Finger II; subarticular tubercles not projecting; supernumerary tubercles absent; tarsus bearing fold on inner edge in E. anomalus and E. zygodacty/hs (absent in other species); Toe V shorter than Toe III; toes moderately webbed to well webbed.

Content and distribution.--Four species ( $E$. anatipes, anomalus, cheiroplethus, and zygodactylus) distributed in western Colombia and Ecuador; two species (E. anatipes and E. anomalus) in western Ecuador.

Remarks.-The E. anomalus group has not been recognized previously; formerly its members were assigned to the E. rugulosus group (Savage et al.. 1988; Lynch, 1990). The species in the $E$. nugulosus group (sensu stricto) have pronounced sexual dimorphism in tympanum size.

\section{Eleutherodactylus (Craugastor) bufoniformis Group}

Definition.-Large frogs (SVL in females 52$94 \mathrm{~mm}$ ) with broad heads (HW 43-58\% SVL) and short snouts; cranial crests relatively low, parasagittal; upper eyelids much broader than IOD; body stout; limbs moderately long; skin on venter smooth; vomerine odontophores large, triangular in outline, narrowly separated medially; vocal slits present (E. necerms) or absent (E. bufoniformis); nuptial pads present; tympanic membrane and annulus relatively small, obscure, lacking sexual dimorphism in size. Discs on fingers and toes narrow; Finger I longer than Finger II; subarticular tubercles not projecting; supernumerary tubercles absent; tarsus lacking fold; Toe V shorter than Toe III; inner metatarsal tubercle laterally compressed; toes webbed basally ( $E$. bnfoniformis) or unwebbed (E. necerus).

Content and distribution.-Two species-E. bufoniformis in western Colombia, Panama, and eastern Costa Rica, and E. necerus in western Ecuador.

Remarks.-Previously, the E. bufoniformis has not been recognized formally; formerly its members were assigned to the E. biporcatus group or series (Lynch, 1975a, 1986a; Savage, 1987). These two species do not have the strong sexual dimorphism in tympanum size typical of species in the $E$. biporcatus group (E. aphanus, biporcatus, and manssi) and most other species in the subgenus Crangastor:

\section{Eleutherodactylus (Craugastor) fitzingeri Group}

Definition.-Medium-sized frogs (SVL in females 34-74 mm) with narrow heads (HW 33$41 \%$ SVL) and long snouts; cranial crests absent; upper eyelids not broader than IOD; body slender; limbs long; skin on venter smooth; vomerine odontophores large, triangular in outline, narrowly separated medially; vocal slits and nuptial pads present; tympanic membrane and annulus prominent, strongly sexually dimorphic in size in $E$. crassidigitatus, fitzingeri, longirostris, melanostictus, monnichorum, raniformis, rayo, and 
talamancae (no dimorphism in E. andi, cauquero, or emcelae). Discs on all fingers and toes, those on outer fingers emarginate in many species; Finger I longer than Finger 1I; subarticular tubercles not projecting; supernumerary tubercles absent; tarsus bearing fold on inner surface; Toe $\mathrm{V}$ shorter than Toe III: toes webbed basally except in E. talamancae (no webbing).

Content and distribution.-Eight species in Central America (Honduras southward) and northwestern South America. Although three species ( $E$. fit-ingeri, longirostris, and raniformis) are common and widespread in western Colombia, only $E$. longirostris extends into western Ecuador.

Remarks.-Savage (1987) defined the $E$. fitzingeri group and included 12 species, but we include only the eight species exhibiting sexual dimorphism in the size of the tympanic annulus; JDL thinks that E. bocourti should not be included in the group, and we have doubts about the inclusion of three Talamancan species (E. andi, canquero, and emcelae).

\section{Subgenus Eleutherodactylus Duméril and} Bibron, 1841

Definition.-Small to large frogs (maximum SVL in females 15-75 mm) having the "s-condition" of adductor musculature; head narrow, except in E. sulcatus group; cranial crests absent, except in E. curtipes, devillei, sulcatus, and surdus groups, and a few members of other groups; frontoparietals not fused with prootics; vomerine odontophores usually present, slanted and widely separated to large, triangular in outline, and narrowly separated; skin on venter areolate; Finger I shorter than Finger II (longer in E. binotatus, conspicillatus, discoidalis, dolops, guentheri, nigrovittatus, and sulcatus groups); vocal slits usually present; nuptial pads present in most species in northwestern South America, absent in all species in southeastern Brazil and the West Indies; outer and middle ear structures absent in about two dozen taxa (e.g., $E$. anotis, baryecuus, ruidus, and surdus); otherwise, tympanic membrane present or absent and annulus present, not sexually dimorphic in size; supernumerary tubercles absent to prominent and numerous; Toe V shorter than Toe III in some groups (e.g.,
E. discoidalis and E. sulcattus groups), longer than Toe III in several groups (e.g., E. conspicillatus, devillei, and myersi groups), and much longer than Toe III in the E. martinicensis series*; toe webbing absent, except in E. diaphonus and E. pugnax.

Content and distribution.-Approximately 336 named species (number updated from Duellman, 1993) occurring primarily in South America, with 10 species in Central America and 35 species in the West Indies (absent in Jamaica).

Remarks.-At present, we are not willing to disrupt the subgeneric classification proposed by Hedges (1989), although we think that we have detected a large (186 species) monophyletic unit within the subgenus; herein, we refer to that unit as the E. martinicensis series. Little is to be gained by recognizing additional subgenera when most taxa within the subgenus Eleutherodactylus remain to be studied in detail. To restrict the subgenus Eleutherodactylus to some 186 species might be tempting to many of our colleagues (as it is to us) and irresistible to some, but such action would leave some 150 other species in oblivion in the taxonomic hierarchy. Thus, we employ the expedient, but nomenclaturally informal, category of series to express our emerging notions of relationships among species within the subgenus Eleutherodactylus (sensu Hedges, 1989) and recognize four series to accommodate the species in western Ecuador. We are aware of no less than five such series; one series including the entire complement of Eleutherodactylus in southeastern Brazil is not discussed here (see Lynch, 1976b).

\section{The Eleutherodactylus myersi Series}

\section{Eleutherodactylus (Eleutherodactylus) myersi Group}

Definition.--Small frogs (SVL in females 17$27 \mathrm{~mm})$ having narrow heads (32-42\% SVL) and short snouts; cranial crests absent; upper eyelid narrower than IOD (except in some males); body robust; limbs short to moderately long; skin on venter areolate; vomerine odontophores small, oval or oblique, usually well separated medially; vocal slits present (except E. floridus), nuptial pads absent (erroneously reported as present in E. myersi 
by Lynch, 1980it): tympanic membrane present (except in E. leoni and E. ocreatus); tympanic annulus relatively large, not sexually dimorphic in size. Discs en fingers and toes narrow (widest in $E$. floridus): pads absent on inner fingers in E. ocreatus; Finger I shorter than Finger II; subarticular tubercles not projecting: supernumerary tubercles small, numerous; tarsus bearing low tubercle on inner edge (absent in E. ocreatus); Toe V slightly longer than Toe III.

Content and distribution.-Nine species in the Andes of southern Colombia and Ecuador, of which four species (E. floridus, hectus, leoni, and pyrhomerus) occur in cloud forests in western Ecuador.

Remarks.- The only available generic name for this group is Trachyphrymus Cochran and Goin. 1963 (type species T. myersi). At present, there is no evidence that the E. nyersi group is monophyletic; nor is there evidence to the contrary.

\section{The Eleutherodactylus sulcatus Series}

\section{Eleutherodactylus (Eleutherodactylus) sulcatus Group}

Definition.-Medium-sized to large frogs (SVL in females $29-70 \mathrm{~mm}$ ) with broad heads (49-63\% SVL) and short siouts; cranial crests present, most prominent in females; upper eyelid not wider than IOD; body robust; limbs relatively short; skin on venter areolate (E. helonotus, ingeri, ruizi, and sulcatus) or smooth (E. cadenai, cerastes, cormutus, and sernai); vomerine odontophores large, triangular in outline (nearly arched in some species). narrowly separated medially: vocal slits and nuptial pads present in E. ruizi, absent in E. cerastes, cornutus, and sulcatus (condition unknown in other species); tympanic membrane and annulus prominent, some sexual dimorphism in size. Fingers lacking dises and pads: Finger I longer than Finger II; subarticular tubercles not projecting; supernulinerary tubercles numerous; tarsus bearing fold on inner edge in E. cornutus, ingeri, ruizi, and sulcatus (absent in other species); Toe V shorter than Toe III.

Content and distribution.--Seven species in the Andes of Colombia and Ecuador and one species (E. sulcatus) in the upper Amazon Basin of
Colombia, Ecuador, Peru, and western Brazil. Two species (E. cerastes and E. helonotus) are found in cloud forests in western Ecuador.

Remarks.-Herpetologists long have been puzzled by a series of eleutherodactyline frogs having large, broad heads and massive cranial crests. Although Peters (1864) and Cope (1874) used the generic name Strabomantis, Boulenger (1882) set precedence by including the species known at that time within Hylodes (=Eleutherodactylus). Lynch (1975a) attempted an early survey, which has undergone several revisions (Lynch, 1981a; 1986a, b), as additional species were discovered and as cladistic methodology was applied more rigorously. Our usage of the E. sulcatus group follows Lynch (1986a, b) wherein E. biporcatus and $E$. matssi are assigned to the subgenus Craugastor: At present, no synapomorphy is known for frogs of the E. sulcatus group, but it seems inappropriate to treat these eight species merely as part of an amorphous subgenus Eleutherodactylus. Pending publication of a revision in progress by JDL, we defer usage of the earliest available subgeneric name, Limnophys Jiménez de la Espada. 1870.

\section{The Eleutherodactylus conspicillatus Series}

\section{Eleutherodactylus (Elentherodactylus) cerasinus Group}

Definition.-Small to medium-sized frogs (SVL in females $25-64 \mathrm{~mm})$ with narrow heads $(37-42 \%$ SVL) and short snouts; upper lips flared in large females producing a less slender head shape; cranial crests absent: upper eyelid usually wider than IOD; body slender; limbs relatively long; skin on venter areolate (often appears smooth in large females); vomerine odontophores large, triangular in outline, narrowly separated medially: vocal slits usually present (absent in E. orpacobates and $E$. rubicundus); nuptial pads usually absent (present in E. cerasinus and E. orpacobates); tympanic membrane and annulus present, relatively large, not sexually dimorphic in size. Dises on fingers and toes expanded; Finger I shorter than, or subequal to, Finger II; subarticular tubercles not projecting. except for basal subarticular tubercles; supernu- 
merary tubercles few or absent; tarsus lacking fold on inner edge: Toe V longer than Toe III.

Content and distribution.-Six species occur in lower Central America and western Colombia and Ecuador; a seventh (E. rubicumdus) inhabits cloud forests on the Amazonian slopes of the Andes in Ecuador. Four species (E. crenunguis, labiosus, ocellatus, and tenebrionis) occur in western Ecuador.

Remarks.-Frogs of the E. cerasimus group have long, slender digits with large digital discs. The slenderness of the digits is accentuated because the digits lack lateral fringes or keels that in other frogs make the digits appear to be thicker. Lynch et al. (1994) proposed this species group, for which no synapomorphy is known.

\section{Eleutherodactylus (Eleutherodactylus) conspicillatus Group}

Definition.-Small to large frogs (SVL in females $25-75 \mathrm{~mm}$ ) with narrow heads $(30-45 \%$ SVL) and long snouts; cranial crests absent: upper eyelid usually narrower than IOD, rarely as wide as, or wider than, IOD; body slender; limbs relatively long (short in E. vilarsi): skin on venter smooth (areolate in E. caprifer); vomerine odontophores large, triangular in outline, narrowly separated medially; vocal slits usually present ( $a b-$ sent in E. carmelitae, gaigei, illotus, insignitus, johannesdei, lymani, thectopternus, and viridicans); nuptial pads usually present (absent in E. caprifer, gaigei, illotus, insignitus, and viridicans); tympanic membrane and annulus present, relatively large, not sexually dimorphic in size. Discs on fingers and toes expanded, those on inner fingers narrow; Finger I usually longer than Finger I1; subarticular tubercles not projecting; supernumerary tubercles few or absent; tarsus bearing short fold on inner edge in many species; Toe V slightly longer than Toe III; toes unwebbed (basal webbing in E. malkini).

Content and distribution.--Twenty-nine species in the lowlands and cloud forests from Costa Rica to Suriname and Bolivia. Several species inhabit the Andean slopes in Colombia and Ecuador, and six species (E. achatinus, actites, caprifer; illotus, lymani, and w-nigrum) occur in western
Ecuador.

Remarks. - The E. conspicillatus group was recognized by Lynch (1986a) to accommodate those species once assigned to the E. fitsingeri group (Lynch, 1976a. Lynch and Myers. 1983) that are not members of the subgenus Craugastor: Externally, frogs of the E. conspicillatus group closely resemble many of those in the subgenus Craugastor, but even juveniles can be separated by the relative lengths of Toes III and IV (Lynch, 1994).

Most species occur in the lowlands from Costa Rica to southeastern Brazil and Bolivia, but members of this group also inhabit the highlands of the Sierra Nevada de Santa Marta (E. carmelitce and E. insignitus) and the Andes in Colombia. Ecuador, and northern Peru. The most widely distributed species (E.fenestratus, malkini, permvianus, vilarsi, and zeuctotylus) occur east of the Andes.

At present, there is no evidence that the $E$. conspicillatus group is monophyletic. Eleutherodactylus caprifer is assigned here (following Lynch and Myers, 1983) although it has areolate skin on the venter anci Finger I is shorter than Finger II. Eleutherodactylus gaigei (Dunn) is assigned here despite its bearing little resemblance to any other species in the group (Lynch, 1980b). No generic name is available for frogs of the E. conspicillatus group.

\section{Eleutherodactylus (Eleutherodactylus) curtipes Group}

Definition.--Small to medium-sized frogs (SVL in females $26-50 \mathrm{~mm}$ ) with narrow heads (29-42\% SVL) and short snouts; cranial crests present; upper eyelid narrower than IOD; body robust: limbs short; skin on venter areolate; vomerine odontophores small, slanted, widely separated medially; vocal slits absent: nuptial pads absent (present in $E$. buckleyi); tympanic membrane and annulus absent (present in E. buckleyi). Discs on fingers and toes narrow; Finger I shorter than Finger II; subarticular tubercles not projecting, except for basal subarticular tubercles: supernumerary tubercles numerous; tarsus lacking fold on inner edge but indistinct tubercle present in some; Toe V longer than Toe III but not extending to distal subarticular tubercle on Toe IV. 
Content and distribution.--Six species occur at high elevations (usually above $3000 \mathrm{~m}$ ) in the western Andes of Colombia and Ecuador south to the Nudo de Azuay; only E. gentry $i$ is treated as part of the fauna of western Ecuador.

Remarks.-Lynch (1995) proposed that the cranial crests of these frogs represent a synapomorphy for the group. Many other highland Eleutherodactylus are known from the Cordillera Central of Ecuador and from Ecuador, but these lack cranial crests and have Toe $\mathrm{V}$ much longer than Toe III, as is characteristic of the subgenus Eleutherodactylus (sensu stricto).

\section{Eleutherodactylus (Eleutherodactylus) dolops Group}

Definition.-Medium-sized frogs (SVL in females $42-58 \mathrm{~mm}$ ) with narrow heads $(38-42 \%$ SVL) and long snouts; cranial crests absent; upper eyelid broader than IOD; body slender; limbs relatively long; skin on venter smooth; vomerine odontophores large, triangular in outline, narrowly separated medially; vocal slits present: nuptial pads absent; tympanic membrane and annulus present, relatively large, not sexually dimorphic in size. Discs on fingers and toes narrow, larger on toes than on fingers; Finger I much longer than Finger II; subarticular tubercles not projecting; supernumerary tubercles absent; tarsus lacking folds and tubercles: Toe V slightly longer than Toe III.

Content and distribution.-Two species $(E$. babax and $E$. dolops) have been described; the former is distributed in cloud forests in western Colombia and Ecuador, the latter in cloud forests on the Amazonian slopes of the Aindes in Colombia and Ecuador. There is an undescribed species on the western flanks of the Cordillera Central in Departamento de Caldas, Colombia.

Remarks.-Lynch (1989) proposed this species group when he dismantled what he had earlier (Lynch, 1976b) termed the E. discoidalis group. The "synapomorphy" cited by Lynch (1989) remains to be studied in a larger suite of eleutherodactylines; at present, it seems unlikely that the cited character (large nasal bones in median contact) is uniquely derived.

\section{Eleutherodactylus (Eleutherodactylus) devillei Group}

Definition.-Medium-sized frogs (SVL in females $28-52 \mathrm{~mm}$ ) having narrow heads $(35-43 \%$ SVL) and short snouts; cranial crests present (absent in E. acatallelus and E. appendiculatus); upper eyelid not wider than IOD; body slender to robust; limbs moderately short to relatively long; skin on venter areolate; vomerine odontophores prominent, triangular in outline, narrowly separated medially; vocal slits absent (present in $E$. acatallelus and E. appendiculatus); nuptial pads absent (present in E. vertebralis); tympanic membrane and annulus present (absent in E. siopelus), not sexually dimorphic in size. Discs on fingers and toes expanded; Finger I shorter than Finger II; subarticular tubercles not projecting; supernumerary tubercles present; tarsus lacking or having illdefined fold along inner edge; Toe $\mathrm{V}$ longer than Toe III, but not extending to distal subarticular tubercle on Toe IV.

Content and distribution.-Eight species occur in cloud forests in western Colombia and Ecuador, and one species (E. devillei) inhabits the Amazonian slopes of the Andes in northern Ecuador. Of these, E. appendiculatus, quinquagesimus, truebae, and vertebralis) are in western Ecuador.

Remarks.-We are not confident in associating these species but are convinced that within the group, E. devillei, truebae, and vertebralis form a subgroup, and that E. cacao and E. sulculus are sister species. In South America, there is a broad array of species having the intermediate fifth toe length and the general pattern of structure indicated in the definition. At present, too little is known of most species to be confident in delimiting this species group.

\section{Eleutherodactylus (Eleutherodactylus) loustes Group}

Definition.--Medium-sized frogs (SVL in females $37-56 \mathrm{~mm})$ with narrow heads $(38-43 \%$ SVL) and long snouts; cranial crests present in females of E. jaimei and E. loustes; upper eyelid broader than IOD; body slender; limbs relatively long; skin on venter areolate; vomerine odonto- 
phores large, oval to triangular in outline, narrowly separated medially; vocal slits present; nuptial pads absent: tympanic membrane and annulus present, small in E. hybotragus and E. jaimei (membrane absent in E. (oustes), not sexually dimorphic in size. Discs on fingers and toes expanded; Finger I usually slightly shorter than Finger II (except in $E$. loustes); subarticular tubercles not projecting; supernumerary tubercles few or absent; tarsus bearing fold along inner edge; Toe V longer than Toe III, but not extending to distal subarticular tubercle on Toe IV; toes unwebbed (E. hybotragus) to about I/ 3 webbed (E. loustes). Ventral edge of zygomatic ramus of squamosal expanded, evident externally as a knob immediately anterior to tympanic annulus*.

Content and distribution.--Three species are known from the lowlands and cloud forests of western Colombia and northwestern Ecuador; only E. loustes is found in Ecuador.

Remarks.--Lynch (1992a) proposed the E. loustes group based on the synapomorphy of the expanded zygomatic ramus of the squamosal. Prior to the association of these three species, E. loustes was suspected to be related to certain species in the E. cerasinus group; this was based on an overemphasis by JDL of head shape; the upper lips of females of several species in the two groups are flared. Curiously, the toe length associates the two groups as well, but the condition of the moderately long fifth toe seems to have evolved repeatedly within Eleutherodactylus.

\section{Eleutherodactylus (Eleutherodactylus) orestes Group}

Definition.--Small frogs (SVL in females 18$27 \mathrm{~mm}$ ) with narrow heads (34-40\% SVL) and short snouts; cranial crests absent; upper eyelid narrower than IOD; body robust; limbs relatively short; skin on venter areolate; vomerine odontophores oval, well separated medially; vocal slits present; nuptial pads absent; tympanic membrane ill-defined, annulus present; discs on fingers and toes narrow (only slightly wider than digit); Finger I shorter than Finger II; subarticular tubercles not projecting; supernumerary plantar tubercles numerous, low; ill-defined tubercle along inner edge of tarsus; Toe V longer than Toe III, extending to proximal border of distal subarticular tubercle of Toe IV; toes unwebbed.

Content and distribution.-Three species ( $E$. orestes, simonbolivari, and vidua) inhabit paramos in southern Ecuador and high-altitude cloud forests in Provincia Bolívar. Ecuador.

Remarks.-Because the fifth toe is considerably longer than the third, we initially considered these frogs to be associated with the E. martinicensis series. However, because there are several terrestrial paramo inhabitants (e.g., E. obmutescens, orcesi, philipi, racemus, simoterus, and thymelensis) in that series having a long fifth toe (extending to distal border of distal subarticular tubercle of Toe IV), we decided that these three small species are best disassociated systematically. The three species are structurally similar and have been confused (Wiens and Coloma, 1992) with frogs of the E. myersi group (frogs having much shorter fifth toes). The available osteological data are inadequate for us to argue against several possible hypotheses of relationships, but we are inclined to continue in the spirit of Savage's (1987) approach in recognizing species groups so long as the database remains narrow. All three of these species have the frontoparietals fused with the prootics, in contrast to the plesiomorphic condition of unfused elements in most species of the E.unistrigatus group.

\section{Eleutherodactylus (Eleutherodactylus) surdus Group}

Definition.-Medium-sized frogs (SVL in females $36-55 \mathrm{~mm})$ with narrow heads $(35-41 \%$ SVL) and short snouts; cranial crests prominent in E. surdus, less prominent in other species; upper eyelid about as wide as IOD; body robust; limbs relatively long: skin on venter areolate; vomerine odontophores prominent, triangular in outline. narrowly separated medially; vocal slits absent: nuptial pads present (E. duellmani and E. hamiotae) or absent; tympanic membrane and annulus absent. Discs on fingers and toes expanded; Finger 1 shorter than Finger 11; subarticular tubercles not projecting; supernumerary tubercles few; tarsus lacking fold along inner edge; Toe $\mathrm{V}$ longer than Toe I11, but 
not extending to distal subarticular tubercle on Toe $1 \mathrm{~V}$; toes unwebbed (basal webbing in E. ducllmani).

Content and distribution.-Four species $(E$. duellmani, hamiotae, sobetes, and surdus) inhabit cloud forests in western Ecuador.

Remarks.--Since having been proposed by Lynch (1980c), the E. surdus group has contimued to undergo revision. Initially, the group was diagnosed in part by the absence of tympana and tympanic annuli, but a variety of other species lack these structures and are not thought to be related to this cluster of species in western Ecuador. Several of the species included by Lynch (1980c) in the group (E. baryecuus, pugnax, and ruidus) have the fifth toe much longer than the third and are now assigned to the Elentherodactylus martinicensis series. Osteological material is available for only two species in the E. surdus group, and, as yet, no osteological features are apparent that might be restricted to this group of frogs.

\section{The Eleutherodactylus martinicensis Series}

In frogs of this series, Toe $\mathrm{V}$ is much longer than Toe III; the tip of the fifth toe extends to the distal subarticular tubercle of Toe $\mathrm{IV}^{*}$. This feature is derived and provides evidence for a monophyletic grouping of some 186 species distributed throughout the West Indies (except Jamaica) and northwestern South America. The type species of Elentherodactylus is included in this series, which equals the subgenus Eleutherodactylus (sensu stricto). Eight Central American species (E. altae, caryophyllacens, crmentus, diastema, hylaeformis, pardalis, ridens, and vocator) join with more than 140 species found primarily in Colombia, Ecuador, and northern Peru in composing the mainland component of the series. In South America, the series is absent from the Brazilian and Guianan highlands and from coastal Brazil (Fig. 19). Species are present along the Amazon and in the Guianas ( $E$. inguinalis and E. marmoratus) and extend as far south as southern Peru (E. ockendeni and E. platydactylus). The only purported Mexican species (E. batrachylus) is thought by JDL to be a member of the West Indian fauna that became mislabeled as originating from Tamaulipas.

\section{Elentherodactylus (Eleutherodacty/us) diastema Group}

Definition.-Mimute to small frogs (SVL in females $13-31 \mathrm{~mm}$ ) with narrow heads (34-41\% SVL) and short snouts; cranial crests absent; upper eyelid narrower than IOD; body robust; limbs short; skin on venter areolate; vomerine odontophores slanted and widely separated medially in $E$. chalceus and E. scolodiscus, large, oval, and narrowly separated in other species; vocal slits present; nuptial pads absent; tympanic membrane present or absent, annulus present, not sexually dimorphic in size. Discs on fingers and toes large, usually cuspidate or bearing terminal papillae; Finger I shorter than Finger II; subarticular tubercles not projecting, bifid in some species; supernumerary tubercles numerous, ill defined; tarsus lacking fold along inner edge; toes unwebbed (basal webbing in E. gularis).

Content and distribution.-Six species recognized at present are distributed from Honduras to Ecuador; three of these (E. chalceus, gularis, and scolodiscus) occur in western Ecuador.

Remarks.-At present, the E. diastema group is undiagnosed and may be an illusion, but these six species are placed in it pending further resolution. Eleutherodactylus chalceus and E. scolodiscus are distinctive among members of the group (and species of the genus in western Ecuador) in lacking vomerine teeth or having greatly reduced vomerine dentition.

Cochran and Goin (1970) attempted to define the group based on the possession of longitudinal folds (of the vocal sacs) on the throat. This trait is of uncertain polarity or importance and was mentioned first by Dunn (1926) when discussing relationships among Cuban Eleutherodactylus. Dunn noted that several Cuban Elentherodactylus were like E. diastema in having the longitudinal folds on the vocal sacs. Such folds may reflect some particular character, but until throat musculature is investigated in several groups of Eleutherodacty/us (including members of the E. diastema group as well as the peculiar taxa in Cuba and Hispaniola), we defer to use this trait as diagnostic. Our reluctance is heightened because we do not see such distinctive folds in either E. chalceus or E. scolodiscus. 


\section{Eleutherodactylus (Eleutherodactylus) unistrigatus Group}

Definition.-Small to medium-sized frogs (SVL in females $18-55 \mathrm{~mm})$ with narrow heads $(31-43 \%$ SVL) and short snouts; cranial crests usually absent (present in a few taxa, e.g., E. ruidus and $E$. thymalopsoides); upper eyelid usually as wide as, or wider than, IOD: body slender to robust: limbs moderately long (shorter in many highland species); skin on venter areolate; vomerine odontophores slanted and widely separated medially to large, triangular in outline, and narrowly separated; vocal slits usually present; nuptial pads usually present: tympanic membrane usually prominent, not sexually dimorphic in size. Discs on fingers and toes broad; Finger I shorter than Finger II; subarticular tubercles not projecting; supernumerary tubercles few in number to numerous and ill defined; tarsus usually lacking fold along inner edge (tubercle or foldlike tubercle in some species): toes usually unwebbed (basal webbing in $E$. diaphonus and E. pugnax).

Content and distribution.-Approximately 150 species can be assigned to this group, but we are uncertain about the limits of the group. We confidently place five Central American species $(E$. altae, caryophyllaceus, cruentus, pardalis, and ridens) in this group, as well as one species ( $E$. tayrona) from the Sierra Nevada de Santa Marta. This group is well represented in the Andes of Colombia and Ecuador and the upper Amazon Basin, but remains unknown from Venezuela. The species in western Ecuador are E. apiculatus, cajamarcensis, calcarulatus, celator, colomai, crucifer, degener, dissimulatus, eremitus, eugeniae, laticlavius, latidiscus, luteolateralis, muricatus, nyctophylax, ornatissimus, parvillus, phoxocephalus, pteridophilus, rosadoi, ruidus, subsigillatus, thymalopsoides, unistrigatus, verecundus, and walkeri.

Remarks.-One of us (JDL) was once confident that the superficially similar Antillean group (E. martinicensis) would prove to be separable from the South American frogs placed by Lynch (1976b) in the E. unistrigatus group based on fusion of the frontoparietals and prootics in the former. The studies of Joglar (1986, 1989) sug- gested that more variation obtains among the Antillean representatives than once thought, but few South American taxa exhibit the fusion.

Using the relative lengths of the toes to sort mainland Eleutherodactylus results in the discovery that the long fifth toe is curiously distributed. Most species with a long fifth toe occur in Colombia and Ecuador; only a few are distributed along the Amazon into northeastern South America (the Guianas). Especially curious is the near absence of such species from Venezuela and their absence from the Guiana Highlands. A number of species are known from Peru (Amazonian slopes as well as Amazonian lowlands) but only one (E. platydactylus) extends into Bolivia. No species having this toe condition occurs in association with the Brasilian Shield or along the once-forested Atlantic coast of Brasil. These observations do not assure that the E. unistrigatus group is monophyletic but suggest that it may be so.

The long fifth toe condition is not an ecological association because although most species having the condition are arboreal, several are not. The terrestrial representatives are found in the high Andean grasslands of Colombia. Ecuador. and northern Peru.

\section{Key to the SPecies}

This key emphasizes external features mostly independent of maturity and sex. However, in attempting to identify Eleutherodactylus, there is no substitute for knowing the sex of the individual frog or for having an estimate as to whether or not it is mature. Juveniles are always difficult to identify because the distinctness of the tympanic membrane and annulus increases with age, and many features of color patterns on the venter and concealed surfaces of the limbs develop with age. Furthermore, juveniles commonly are more warty dorsally than are adults. So long as the specimen is an adult, we think the key will enable quick and correct identifications. If the specimen is poorly preserved, we doubt that most users can identify the frog correctly using this key. Given these caveats. we agree with Stuart's (1955:10) qualification regarding the use of keys: " . . the worker who knows what species he has before him should experience few difficulties in its use." 
This key does not take into account the bright colors that disappear after extended storage in alcohol. If a living individual is at hand or colors in life are known, several species can be identified readily because the dorsum is green or because flash colors are evident in the axilla, groin, or concealed surfaces of the thighs. Refer to the plates and the descriptions of colors in life in the Accounts of Species.

1. Toe III longer than Toe V (Fig. 16B-D) ..... 2 Toe 1II shorter than Toe V (Fig. 16A) 9

2. Toes webbed, webbing enclosing at least basal subarticular tubercles on all toes 3

Toes lacking webbing 5

3. Toe webbing extending to dises on some toes; skin of dorsum spiculate, tuberculate, or bearing numerous folds 4

Toe webbing not reaching disc on any toe; skin of dorsum smooth ..... E. longirostris

4. Inner tarsal fold present; fingers lacking discs E. anomalus

Inner tarsal fold lacking; fingers bearing narrow discs E. anatipes

5 Skin on venter areolate (granular)

E. helonotus

Skin on venter smooth 6

6. Inner edge of tarsus bearing tubercle: HW/ SVL $<0.35$ 7

Inner edge of tarsus lacking tubercles; HW/ $\mathrm{SVL}>0.45$ 8

7. Tympanic membrane prominent; digit tips rounded; Finger I longer than Finger 11

Barycholos pulcher

Tympanic membrane absent; digit tips swollen; Finger I shorter than Finger II Phyllonastes sp.

8. One elongate tubercle evident on upper eyelid E. cerastes
Upper eyclid tuberculate, none elongate ...... E. necerils

9. Skin on venter smooth ............................. 10

Skin on venter areolate 18

10. Tip of Toe $V$ extending about half way between penultimate and distal subarticular tubercles of Toe IV (Fig. 16C); skin of dorsum shagreen or tuberculate 11

Tip of Toe $\mathrm{V}$ reaching no more than one fourth of the way between penultimate and distal subarticular tubercles of Toe IV (Fig. 16B); skin of dorsum smooth to shagreen, never tuberculate

11. Enlarged conical tubercles present on upper eyelids E. labiosus

Enlarged tubercles absent on upper eyelids .

12. Brown chevrons across throat; posterior surfaces of thighs brown

E. ocellatus

Throat unicolor or reticulated; posterior surfaces of thighs black with cream flecks

E. crenunguis

13. Discs narrow, less than twice width of digit (Fig. 15A) E. babax

Some discs broad (twice or more width of digit), especially on outer fingers

14. Inner surface of tarsus bearing fold extending at least one half length of tarsus 15

Inner edge of tarsus bearing tubercle or not, never a fold 16

15. Posterior surfaces of thighs and flanks densely stippled with black E. actites Posterior surfaces of thighs and flanks marbled black and cream E. lymani

16. Body lacking dorsolateral folds; usually black spots in groin E. w-nigrum Body with dorsolateral folds; groin lacking black spots 17 
17. Small tubercle on heel; throat and chest spotted with black E. illotus

Heel lacking tubercles; throat and chest immaculate to reticulate E. achatinus

18. Tip of Toe $\mathrm{V}$ not reaching distal subarticular tubercle of Toe IV....

Tip of Toe $\mathrm{V}$ reaching distal border of distal subarticular tubercle of Toe IV 40

19. Tympanic annulus and membrane absent (no external evidence of ear)

Tympanic annulus and membrane visible externally.....

20. Tip of Toe V extending slightly (or not at all) beyond distal border of penultimate subarticular tubercle of Toe IV (Fig. 16B)

Tip of Toe $\mathrm{V}$ extending beyond (by length of disc) distal border of penultimate subarticular tubercle of Toe IV (Fig. 16C)

21. At least some subarticular tubercles of foot enclosed by basal webbing; posterior surfaces of thighs brown with cream flecks

No basal webbing on foot; posterior surfaces of thighs brown with white spots; groin marbled brown and white E. surdus

22. Snout truncate in profile; tubercles on heel and outer edge of tarsus E. duellmani

Snout sloping in profile; heel and outer edge of tarsus lacking tubercles E. hamiotae

23. Toes webbed basally (webbing enclosing basal subarticular tubercles) E. loustes

Toes lacking webbing

24. Elongate tubercle (calcar) on heel; dorsolateral folds on anterior half of body E. siopelus

Noelongate tubercle on heel; dorsolateral folds extending length of body (if evident) ....... 25

25. Axilla and groin bearing small white spots; adults less than $23 \mathrm{~mm} \mathrm{SVL}$
Axilla and groin brown or pigmentless; adults more than $23 \mathrm{~mm}$ SVL 26

26. Posterior surfaces of thighs brown with cream spots E. truebae

Posterior surfaces of thighs uniformly brown

27. Upper eyelid narrower than IOD; finger dises narrow; skin on dorsum bearing low warts ..

E. gentryi

Upper eyelid as wide as IOD; finger discs broad; skin of dorsum smooth with scattered pustules.....

E. sobetes

28. Tip of Toe $\mathrm{V}$ extending slightly (or not at all) beyond distal border of penultimate subarticular tubercle of Toe IV

Tip of Toe $\mathrm{V}$ extending beyond (by length of disc) distal border of penultimate subarticular tubercle of Toe IV 32

29. Discs on fingers twice as wide as digits; no inner tarsal tubercle E. floridus

Discs on fingers only slightly wider than fingers; tubercle or ridge on inner edge of tarsus

30. Dorsolateral folds present; small tubercle on heel E. hectus

Dorsolateral folds absent; heel lacking tubercles...

31. One conical tubercle on upper eyelid E. pyrhomerus

Several conical tubercles on upper eyelid .... E. leoni

32. Fleshy proboscis at tip of snout; elongate tubercle on upper eyelid ..... E. appendiculatus Fleshy proboscis and conical eyelid tubercles absent . 33

33. Elongate tubercle (calcar) on heel; interocular fold present . E. quinquagesimus 
Heel lacking tubercles (or only a conical tubercle present); interocular fold absent .... 34

34. Finger discs scarcely wider than digits; white spots in axilla and groin .....E. simonbolivari

Some finger dises 1.5-2.5 times digit width: lacking white spots in axilla and groin ..... 35

35. Dorsolateral folds extending from supratympanic fold to above groin . 36

Dorsolateral folds absent

36. Tympanic membrane and annulus distinct; tops of digits black E. vertebralis Tympanic membrane and annulus often indistinct; tops of digits not black E. truebae

37. Small conical tubercles on upper eyelid and heel 38

Upper eyelid and heel lacking conical tubercles

38. Skin on dorsum finely granular ... E. labiosus Skin on dorsum smooth but bearing scattered tubercles E. tenebrionis

39. Skin on dorsum smooth; brown streaks on throat E. caprifer Skin on dorsum bearing many small tubercles; throat mottled with brown E. sulculus

40. Groin dark enclosing pale spots (yellow or orange in life); no conical tubercles on upper eyelid or heel

Groin lacking dark field enclosing pale spots (or, if present, conical tubercle on upper eyelid or heel)

41. Inner edge of tarsus bearing tubercle ....... 42 Inner edge of tarsus lacking tubercles 43

42. Thin dorsolateral folds present; cranial crests in adults; adults $>28 \mathrm{~mm} \mathrm{SVL}$

E. thymalopsoides

Dorsolateral folds and cranial crests absent; adults $<25 \mathrm{~mm}$ SVL E. walkeri
43. Conical tubercle on heel; pale spots in groin and on anterior surface of thigh irregular in shape E. luteolateralis

Heel lacking tubercles; pale spots in groin and on anterior surfaces of thigh ovoid

E. parvillus

44. Inner edge of tarsus bearing tubercle or distinct fold 45

Inner edge of tarsus lacking tubercle; fold, if present, short, indistinct, and connected to inner metatarsal tubercle 46

45. Tympanic membrane and annulus absent; no conical tubercles on upper eyelid or heel .....

E. ruidus

Tympanic membrane and annulus present; conical tubercles on upper eyelid or heel .....

46. Upper eyelid bearing three or more conical tubercles

Upper eyelid bearing one conical tubercle or tubercles flattened 54

47. Conical tubercles along outer edge of forearm and tarsus E. crucifer

Only small tubercles along outer edge of forearm and tarsus 48

48. Partial dorsolateral folds (region of sacrum) present; posterior surfaces of thighs brown with cream flecks E. verecundus Dorsolateral folds absent; posterior surfaces of thighs brown E. muricatus

49. Posterior surfaces of thighs uniformly brown 50

Posterior surfaces of thighs bearing cream spots (or posterior thigh mostly cream).... 51

50. Three conical tubercles on upper eyelid E. muricatus

One conical tubercle on upper eyelid E. calcarilatus 
51. Conical tubercle on upper eyelid larger than heel tubercle E. rosadoi Conical tubercle on upper eyelid not larger than heel tubercle 52

52. Papilla on tip of snout; males with vocal slits; flanks and concealed thighs cream with dark markings E. subsigillatus

Tip of snout lacking papilla; males lacking vocal slits; flanks and concealed thighs predominantly brown

53. Skin on dorsum smooth with tubercles only on lower back and along stripes; males lacking nuptial pads E. laticlavius Skin on dorsum tuberculate or having tubercles on both anterior and lower back; males bearing nuptial pads E. latidiscus

54. Snout rounded or truncate in profile; heel lacking enlarged tubercle 54 Snout protruding in profile (Fig. 12F); heel bearing calcar E. colomai

55. Tips of at least some toes bearing papillae; digital pads usually cuspidate. 57 Tips of toes rounded, lacking papillae; digital pads rounded or truncate 58

56. Skin on dorsum areolate; outer fingers bearing papillae (Fig. 15B) E. clatceus Skin on dorsum shagreen; fingers lacking papillae E. scolodiscus

57. Small conical tubercle on upper eyelid .... 58 Tubercles on upper eyelid flattened (if present), none conical 60

58. Posterior surfaces of thighs uniformly brown E. apiculatus

Posterior surface of thighs not uniformly brown

59. Posterior surfaces of thighs colorless E. eremitus
Posterior surfaces of thighs (and flanks) cream with black lines E. dissimulatus

60. Tympanic annulus concealed beneath skin; toes short and broad with basal webbing .....

E. gularis

Tympanic annulus visible externally; toes usually long and slender, never basally webbed

61. Skin on dorsum finely areolate; posterior surfaces of thighs cream with brown flecks; digits short E. celator

Skin on dorsum smooth or shagreen; posterior surfaces of thighs variable; digits long and slender

62. Digital pads less than twice width of digit proximal to pad 63

Digital pads large, more than twice width of digit proximal to pad 65

63. Small conical tubercles along outer edges of forearm and tarsus E. pteridophilus

Forearm and tarsus lacking tubercles on outer edges

65. White (red in life) spots on concealed surfaces of thighs; venter with brown or gray spots...

E. cajamarcensis

Concealed surfaces of thighs lacking white spots (not red in life); venter lacking distinct spots

E. unistrigatus

65. Skin on dorsum smooth E. degener

Skin on dorsum shagreen 66

66. Dorsum bearing black spots and lines, including a curved stripe along flank; snout long (E$\mathrm{N}$ greater than eye length) ... E. omatissimus Dorsum lacking distinct pattern. never a pattern of black lines; snout short (E-N less than eye length)

67. Posterior surfaces of thighs reticulate, bearing large cream spots; vertical keel at tip of snout E. phoxocephalus 
Posterior surfaces of thighs not bearing large cream spots; snout lacking vertical keel at tip 68

68. Posterior surfaces of thighs brown with cream llecks E. nyctophylax

Posterior surfaces of thighs cream with brown reticulation

E. engenicie

\section{Clave de las Especies}

Esta clave pone énfasis en los rasgos externos independientemente de la madurez y sexo de los especímenes. Sin embargo, para intentar identificar Eleutherodactylus no hay nada como conocer el sexo del individuo o tener una estima de si es maduro o no. Los juveniles son siempre difíciles de identificar debido a que la membrana y el anillo timpánicos se hacen más visibles con la edad, y muchos rasgos del patrón de coloración del vientre y superficies ocultas de los miembros se desarrollan también con la edad. Además los juveniles suelen tener la piel dorsal más verrugosa que los adultos. Siempre que el espécimen sea un adulto, creemos que la clave posibilitará una rápida y correcta identificación. Si se trata de un ejemplar pobremente preservado, dudamos que la mayoría de los usuarios puedan identificarlo correctamente usando esta clave. Dadas estas advertencias, estamos de acuerdo con la opinión de Stuart (1955:10) en relación al uso de claves: “ ... el investigador que sabe qué especie tiene delante debería tener pocas dificultades en su uso."

La clave no tiene en cuenta los colores vistosos que desaparecen después de una prolongada preservación en alcohol. Si se tiene el individuo vivo en la mano o se conocen los colores en vida, algunas especies pueden ser identificadas en seguida porque el dorso es verde o porque hay colores vistosos en la axila, ingle o superficies ocultas de los muslos. Recomendamos fijarse en las láminas y las descripciones de coloración en vida de la sección "Account of Species."

1. Dedo Pedial 111 más largo que el Dedo V (Fig. 16B-D)

Dedo Pedial IIl más corto que el Dedo V (Fig. 16A)
2. Dedos posteriores con palmeadura, las pálmeaduras incluyen por lo menos los tubérculos subarticulares basales en todos los dedos 3

Dedos posteriores sin palmeaduras 5

3. La palmeadura pedial se extiende hasta los discos en algunos dedos; piel del dorso con espínulas, tubérculos o numerosos pliegues 4

Palmeadura pedial no llega a los discos en ningún dedo; piel del dorso lisa.

E. longirostris

4. Pliegue tarsal interno presente; dedos sin dis$\cos$

E. anomalus

Pliegue tarsal interno ausente; dedos con discos no expandidos

E. conatipes

5. Piel del vientre areolada (granular)

E. helonotus

Piel del vientre lisa 6

6. Borde interno del tarso con tubérculo; $\mathrm{AC} /$ LRC $(\mathrm{HW} / \mathrm{SVL})<0.35$

Borde interno del tarso sin tubérculos; $\mathrm{AC} /$ LRC $(\mathrm{HW} / \mathrm{SVL})>0.45$ 8

7. Membrana timpánica prominente; extremos digitales redondeados; Dedo Manual I más largo que el Dedo 11 ....... Barycholos pulcher

Membrana timpánica ausente; extremos digitales hinchados; Dedo Manual I más corto que el Dedo $1 \mathrm{I}$ Phyllonastes sp.

8. Un tubérculo grande evidente en el párpado superior

E. cerastes

Párpado superior con tubérculos, ninguno de ellos grande E. necerus

9. Piel del vientre lisa 10

Piel del vientre areolada 18

10. Extremo del Dedo Pedial V se extiende hasta la mitad de la distancia entre el ćltimo (distal) 
y penúltimo tubérculos subarticulares del Dedo Pedial IV (Fig. 16C); piel del dorso con tubérculos o áspera 11

Extremo del Dedo Pedial V no se extiende más allá de la cuarta parte de la distancia entre el último (distal) y penúltimo tubérculos subarticulares del Dedo Pedial IV (Fig. 16B); piel del dorso desde lisa hasta áspera, nunca con tubérculos 13

11. Tubérculos cónicos grandes en párpados superiores E. labiosus

Sin ubérculos grandes en párpados superiores

12. Marcas en foma de $\mathrm{V}$ invertida cafés a través de la garganta, superficie posterior de los muslos café E. ocellatits

Garganta de un solo color o reticulada; superficie posterior de los muslos negra con pintas crema E. crenunguis

13. Discos no expandidos, menos del doble del ancho del dígito (Fig. 15A) E.babax

Algunos discos expandidos (el doble o más del ancho del dígito), especialmente en dedos externos 14

14. Superficie tarsal interna con pliegue que se extiende por lo menos hasta la mitad de la longitud del tarso 15

Borde interno del tarso puede o no tener un tubérculo, nunca un pliegue 16

15. Superficie posterior de muslos y flancos densamente punteada de negro ...... E. actites Superficie posterior de muslos y flancos marmórea con negro y crema ........ E. lymani

16. Cuerpo sin pliegues dorsolaterales; usualmente manchas negras en la ingle ...... E. w-nigrum Cuerpo con pliegues dorsolaterales; ingle sin manchas negras 17

17. Tubérculo pequeño en el talón; garganta y pecho moteado de negro..... E. illotus
Talón sin tubérculos; garganta y pecho de inmaculados a reticulados E. achatinus

I8. Extremo del Dedo Pedial $V$ no alcanza el tubérculo subarticular distal del Dedo IV ....

Extremo del Dedo Pedial V alcanza el tubérculo subarticular distal del Dedo IV

19. Anillo y membrana timpánica ausente (no hay evidencia externa del oído) 20

Anillo y membrana timpánica visible externamente

20. Extremo del Dedo Pedial V se extiende apenas (o nada) sobre el borde distal del penúltimo tubérculo subarticular del Dedo IV (Fig. 16B)

Extremo del Dedo Pedial V se extiende más allá (toda la longitud del disco) del borde distal del penúltimo tubérculo subarticular del Dedo IV (Fig. 16C) 23

21. Por lo menos algunos tubérculos sub-articulares del pie incluidos por la palmea-dura basal: superficie posterior de los muslos café con puntos crema

Sin palmeadura basal pedial; superficie posterior de los muslos café con manchas blancas: ingle marmórea con café y blanco E. surdus

22. Perfil del rostro truncado; tubérculos en el talón y borde externo del tarso

E. duellmani

Perfil del rostro inclinado; talón y borde externo del tarso sin tubérculos E. hamiotae

23. Dedos pediales con palmeaduras basales (la palmeadura incluye los tubérculos subarticulares basales) E. loustes

Dedos pediales sin palmeaduras 24

24. Tubérculo grande (calcar) sobre el talón: pliegues dorsolaterales en la mitad anterior del cuerpo E. siopelus 
Sin tubérculo elongado en el talón: pliegues dorsolaterales se extienden a lo largo del cuerpo (si son evidentes)

25. Axila e ingle con pequeñas manchas blancas; en adultos $\mathrm{LRC}(\mathrm{SVL})<23 \mathrm{~mm}$

E. simonbolivari

Axila e ingle cafés o sin pigmento; en adultos LRC $($ SVL $)>23 \mathrm{~mm}$

26. Superijcie posterior de los muslos café con manchas crema E. truebae

Superficie posterior de los muslos uniformemente café

27. Párpado superior más corto que la distancia interorbital; discos digitales no expandidos; piel del dorso con verrugas poco elevadas ...

E. gentryi

Párpado superior tan ancho como la distancia interorbital; discos digitales expandidos; piel del dorso lisa, con espínulas dispersas

E. sobetes

28. Extremo del Dedo Pedial V se extiende apenas (o nada) sobre el borde distal del penúltimo tubérculo subarticular del Dedo IV

Extremo del Dedo Pedial V se extiende más allá (toda la longitud del disco) del borde distal del penúltimo tubérculo subarticular del Dedo IV

29. Discos digitales el doble de ancho que los dígitos; sin tubérculo tarsal interno E. floridus

Discos digitales sólo un poco más anchos que los dígitos; tubérculo o reborde en el borde interno del tarso 30

30. Pliegue dorsolateral presente; pequeño tubérculo sobre el talón E. hectus Pliegue dorsolateral ausente; sin tubérculos sobre el talón 31

31. Un tubérculo cónico en el párpado superior E. pyrthomerus
Varios tubérculos cónicos en el párpado superior E. leoni

32. Proboscis carnosa en la punta del rostro; tubérculo grande en el párpado superior

E. appendiculatus

Sin proboscis carnosa ni tubérculos cónicos en el párpado (ni cercanamente tan bien formados) 33

33. Tubérculo grande (calcar) sobre el talón; pliegue interocular presente

E. quinquagesimus

Sin tubérculos sobre el talón (o solo un tubérculo cónico presente); pliegue interocular ausente

34. Discos digitales escasamente más anchos que los dígitos; manchas blancas en la axila e ingle E. simonbolivari

Algunos discos digitales de 1.5 a 2.5 veces el ancho del dígito; $\sin$ manchas blancas en la axila e ingle

35. Pliegues dorsolaterales se extienden desde el pliegue supratimpánico hasta sobre la ingle 36

Sin pliegues dorsolaterales 37

36. Membrana y anillo timpánicos diferenciados; superficies dorsales de los dígitos negras....

E. vertebralis

Membrana y anillo timpánicos frecuentemente indiferenciados; superficies dorsales de los dígitos no negras E. truebae

37. Pequeños tubérculos cónicos en el párpado superior y talón 38

Párpado superior y talón sin tubérculos cónicos 39

38. Piel del dorso finamente granular E. labiosus

Piel del dorso lisa pero con tubérculos dispersos E. tenebrionis 
39. Piel del dorso lisa; línears cafés en la garganta E. colprifer

Piel del dorso con muchos tubérculos pequeños: garganta moteada con café .......... E. sulculus

40. Ingle oscura encerrando manchas pálidas (amarillas o naranjas cuando vivos); sin tubérculos cónicos en el párpado superior o talón

Ingle sin fondo oscuro encerrando manchas pálidas (o, si presente, tubérculos cónicos en el párpado superior o talón) 44

41. Borde interno del tarso con tubérculo 42 Borde interno del tarso sin tubérculos 43

42. Pliegues dorsolaterales delgados presentes; crestas craneales en adultos; en adultos LRC $(\mathrm{SVL})>28 \mathrm{~mm}$ E. thymalopsoides

Pliegues dorsolaterales y crestas craneales ausentes; en adultos LRC (SVL) $<25 \mathrm{~mm}$ E. walkeri

43. Tubérculo cónico sobre el talón; manchas pálidas en la ingle y en la superficie anterior del muslo de forma irregular de dos

\section{E. luteolateralis}

Talón sin tubérculos: manchas pálidas en la ingle y en la superficie anterior de los muslos ovoide E. parvillus

44. Borde interno del tarso con tubérculo o pliegue fuerte 45

Borde interno del tarso sin tubérculo; carece pliegue tarsal o, si presente, corto, indistinto, y tocando tubérculo metatarsal interno 46

45. Membrana y anillo timpánicos ausentes; sin tubérculos cónicos en el párpado superior o talón E. ruidus

Membrana y anillo timpánicos presentes; con tubérculos cónicos en el párpado superior o talón

46. Párpado superior con tres o más tubérculos cónicos 47
Párpado superior con un tubérculo cónico u tubérculos aplanados 54

47. Tubérculos cónicos a lo largo de los bordes externos del antebrazo y tarso ..... E. crucifer

Sólo pequeños tubérculos a lo largo de los bordes externos del antebrazo y tarso ...... 48

48. Pliegues dorsolaterales parciales (en la región del sacro); superficie posterior de los muslos cafés con puntos color crema

E. verecundus

Sin pliegues dorsolaterales; superficie posterior de los muslos café E. muricatus

49. Superficie posterior de los muslos uniformemente café 50

Superficie posterior de los muslos con manchas crema (o muslo posterior mayormente crema)

50. Párpado superior con tres tubérculos cónicos E. muricatus

Párpado superior con un túberculo cónico ... E. calcarulatus

51. Tubérculo cónico en el párpado superior más grande que el tubérculo del talón

E. rosadoi

Tubérculo cónico en el párpado superior no más grande que el tubérculo del talón ...... 52

52. Papila en la punta del rostro; machos con hendiduras vocales; flancos y partes ocultas de los muslos crema con marcas oscuras

E. subsigillatus

Punta del rostro sin papila; machos sin hendiduras vocales; flancos y partes ocultas de los muslos predominantemente cafés ....... 53

53. Piel del dorso lisa con tubérculos sólo en la parte baja y a lo largo de las bandas; machos sin cojinetes nupciales E. laticlavius

Piel del dorso tuberculada o con tubérculos en la espalda alta y baja; machos con cojinetes mupciales

E. latidiscus 
54. Perfil del rostro redondeado o truncado; talón sin tubérculo agrandado .55

Perfil del rostro hacia afuera (Fig. 12F); talón sin calcar E. colomai

55. Puntas de por lo menos algunos dedos posteriores con papilas; cojinetes digitales usualmente en cúspid 56

Puntas de los dedos posteriores redondeadas, sin papilas; cojinetes digitales redondeados o truncados 57

56. Piel del dorso areolada; dedos anteriores externos con papilas (Fig. 15B)

E. chalceus

Piel del dorso áspera; dedos anteriores sin papilas E. scolodiscus

57. Tubérculos en el párpado superior aplanados (si presentes), ninguno cónico 58

Pequeños tubérculos cónicos en el párpado superior

58. Superficie posterior de los muslos uniformemente café E. apiculatus Superficie posterior de los muslos no uniformemente café 59

59. Superficie posterior de los muslos sin color E. eremitus Superficie posterior de los muslos (y flancos) crema con líneas negras... E. dissimulatus

60. Anillo timpánico oculto bajo la piel; dedos pediales cortos y anchos con palmeaduras basales E. gularis Anillo timpánico visible externamente; dedos pediales usualmente largos y delgados, nunca con palmeaduras basales 61

61. Piel del dorso finamente areolada; superficie posterior de los muslos crema con puntos cafés: dígitos cortos E. celator Piel del dorso desde lisa hasta áspera; superficie posterior de los muslos variable; dígitos largos y delgados.

62. Cojinetes digitales con menos del doble de ancho del dígito próximo al cojinete ........ 63

Cojinetes digitales grandes, más del doble de anchos que el dígito próximo al cojinete ......

63. Pequeños tubérculos cónicos a lo largo de los bordes externos del antebrazo y tarso

E. pteridophilus

Antebrazo y tarso sin tubérculos en los bordes externos 64

64. Manchas blancas (rojas cuando vivos) en las superficies ocultas de los muslos; vientre con manchas cafés o grises ...... E. cajamarcensis Superficies ocultas de los muslos sin manchas blancas (no rojas cuando vivos); vientre $\sin$ manchas que lo diferencien ... E. unistrigatus

65. Piel del dorso lisa E. degener

Piel del dorso áspera 66

66. Dorso con líneas y manchas negras, incluída una banda curva a lo largo del flanco; rostro largo (distancia ojo-narina mayor a la longitud del ojo)

E. ornatissimus

Dorso sin patrón que lo diferencie, nunca líneas negras; rostro corto (distancia ojo-narina menor a la longitud del ojo)

67. Superficie posterior de los muslos reticulada, con grandes manchas crema; quilla vertical en el extremo del rostro E. phoxocephalus

Superficie posterior de los muslos sin grandes manchas crema; rostro sin quilla vertical en el extremo 68

68. Superficie posterior de los muslos cafés con manchas crema E. nyctophylax

Superficie posterior de los muslos crema con reticulación café E. engeniae 


\section{Accounts of Species}

Each of the following accounts (except that of Eleutherodactylus taeniatus, a name misapplied to specimens from western Ecuador) begins with a synonymy in which the following are given (1) original name(s) with reference to citation, type specimen(s), and type locality; (2) first usage of present name combination (if different from original combination); and (3) junior synonym(s), if any, with citation to work in which the name was placed in synonymy. In all accounts, except that of E. unistrigatus, a species that has been discussed at length elsewhere (Lynch, 1981a), the following sections are included.

Diagnosis. - A statement of association with a species group is followed by a series of 14 numbered statements (or sets of statements) that are modified slightly in content, but not numerical sequence, from those used by Lynch and Duellman (1980) and followed in most subsequent descriptions of Eleutherodactylus. These statements summarize the taxonomically informative characters of the species; characters are defined and discussed in a foregoing section (Description of Characters). The same format is used in all accounts to facilitate comparison. A final paragraph is devoted to comparisons with similar species.

Description.-A complete description is given for all new species. In cases of previously described taxa, references to, and where appropriate comments on, published descriptions are provided.

Coloration in life.- - In addition to general statements, detailed descriptions have been taken from collectors' field notes. The notes on particular specimens (noted herein by present museum code and number) are referenced to the field notes by their author. Those referenced most frequently are designated by initials only; thus, JAP = James A. Peters, JDL $=$ John D. Lynch, LAC $=$ Luis A. Coloma, RWM = Roy M. McDiarmid, THF = Thomas H. Fritts, and WED = William E. Duellman. For those species for which a color photograph is provided, reference to the color plate is given immediately beneath the name at the beginning of the account.

Natural history.-Information on habitat, habits, life history, and behavior are summarized from field notes and the literature. In some cases, detailed notes have been taken from collectors' field notes; such cases are noted in the same manner as those on coloration in life.

Distribution. - The geographic and altitudinal distribution is stated with respect to physiography and bioclimatic regimes in western Ecuador. For those species occurring beyond western Ecuador, the entire geographic range is given.

Etymology.-The origin, meaning, and application of the specific name is given in accounts of new species.

Remarks.-Herein we provide comments on particular specimens, synonymies, relationships with other species, and any other topics not appropriate for other sections.

\section{Eleutherodactvlus achatinus (Boulenger) Plate 2}

Hylodes achatimus Boulenger, 1898:120.-Holotype: BM 1947.2.15.69, an adult female, from Cachabé. Provincia Esmeraldas, Ecuador.

Hylodes pagmae Fowler, 1913:162.-Holotype: ANSP 18244, juvenile female, from Pagma forest in the Chanchán River Basin, Provincia Chimborazo, Ecuador. Synonymy fide Lynch and Myers (1983:509).

Eleutherodactylus brederi Dunn, 1934:1.-Holotype: AMNH 40523, adult female, from Chalichiman's Creek, Provincia Darién, Panama. Synonymy fide Lynch and Myers, 1983:509.

Eleutherodactylus achatimus-Peters, 1955:339; Lynch and Myers, 1983:509.

Eleutherodactylus pagmae-Peters, 1955:350.

Diagnosis.-A member of the Eleutherodactylus (Eleutherodactylus) conspicillatus group having (1) skin on dorsum shagreen, that on venter smooth; discoidal fold prominent; dorsolateral folds low, granular; (2) tympanic membrane and tympanic annulus prominent, its length $2 / 5-2 / 3$ length of eye; (3) snout subacuminate in dorsal view, rounded in profile; (4) upper eyelid lacking tubercles, about as wide as IOD; cranial crests absent; (5) vomerine odontophores triangular in outline; (6) males with vocal slits and nuptial pads; (7) first finger longer than second; dises on outer fingers broad; (8) fingers bearing lateral fringes; (9) ulnar tubercles absent; (10) heel tubercles absent; outer tarsal tubercles absent; inner tarsal tubercle small, usually present; 
(11) inner metatarsal tubercle elongate, 4-6×round outer metatarsal tubercle: supernumerary tubereles at base of Toes II-IV; (12) toes bearing lateral fringes but no webbing; fifth toe slightly longer than third: (13) dorsum tan or pale brown with brown markings; venter cream with brown flecks on throat and chest: posterior surfaces of thighs brown with cream flecks or spots; (14) SVL in males $23.0-35.1 \mathrm{~mm}$, in females $33.6-46.1 \mathrm{~mm}$.

The absence of heel tubercles and webbing, combined with the fifth toe being slightly longer than the third, distinguishes E. achatinus from all other species in western Ecuador except E. actites and $E$. w-nigrum. Of these three species, only $E$. achatimus has dorsolateral folds. In E. achatinus, the posterior surfaces of the thighs are brown with cream flecks, whereas they are brown with black flecks in E. actites and cream with black spots or black with cream spots in E. w-nigrum. Furthermore, adults of E. achatinus are smaller than adults of the other species.

Description.-A detailed description and information on geographic variation were provided by Lynch and Myers (1983).

Coloration in life.-The dorsal ground color is tan to grayish, greenish, yellowish, reddish brown with darker brown chevrons (narrowly bordered with cream or greenish-gray in some individuals) and transverse bars on the shanks. Distinct dark brown or black canthal and postorbital stripes are present, as is usually a pale (white to creamybronze) labial stripe. Some individuals have a pale tan to yellow middorsal stripe, usually narrowly bordered by dark brown or black. The venter is cream to white, mottled with gray on the chest and throat in some individuals, tending to become pale yellow posteriorly in some individuals; the vocal sac is pale yellow. The posterior surfaces of the thighs are various shades of brown with cream. yellow, orange, or red flecks or small spots. The iris is grayish green to usually golden bronze with black flecks and a median, horizontal red streak. Variation in series from diverse localities is evident from the following descriptions made from living or freshly killed individuals.

KU 111278-85 from Tandapi, Provincia Pichincha: Dorsum pale reddish brown to dark greenish gray with black and brown markings; usually black dashes along dorsolateral fold; flanks colored like dorsum but with some yellow-cream invasion; side of head darker than dorsum; black canthal stripe; lip white in some; belly yellowcream; throat heavily mottled with brown or black; concealed surface of thigh reddish brown with red spots reticulated with black; red spots in groin in some individuals; iris gray with green tint, reticulated with black; reddish bronze anterior and posterior to pupil (JDL, 15 July 1967).

$K U$ 111287-96 from Tandapi, Provincia Pichincha: Posterior surfaces of thighs pale reddish brown or fuscus-brown, usually with red spots; iris yellowish bronze to reddish bronze with bright reddish-bronze areas in front of, and behind, pupil (JDL, 17 July 1967).

$K U 119465$ from Santo Domingo de los Colorados, Provincia Pichincha: Dorsum pale brown with only slightly darker markings edged with pale green-gray; flanks invaded with cream (hence, more yellowish); limbs like dorsum; canthal and supratympanic stripes black, former grading through brown on side of head; yellow-bronze area below eye; iris gold above, gray below, reddishbrown horizontal streak, all finely reticulated with black; posterior surface of thigh brown with creamyyellow spots; venter white; vocal sac pale offyellow; chin edged with white (JDL, 2 August 1968).

KU 119469-72 from Santo Domingo de los Colorados, Provincia Pichincha: Dorsum rust brown, medium brown, or yellow brown; markings, if present, brown; canthal and postocular stripes black. former grading to lip; lip yellow or pale cream-bronze; one individual has two pale yellow spots on dorsum; venter white; vocal sac dirty pale yellow; iris bright gold-bronze above, reddish-brown horizontal streak grading into grayish lower quarter, all reticulated with black; posterior surfaces of thighs greenish brown with dull yellow spots (JDL, 4 August 1968).

KU 130365-67 from $4 \mathrm{~km}$ NQuevedo, Provincia Los Rios: Dorsum pale reddish brown, pale brown to dark brown with brown to black markings edged with cream; canthal stripe dark brown to black; throat very pale cream; venter becoming yellowish posteriorly; posterior surfaces of thigh dull brown with cream flecks to dark brown with pale orange 
flecks; labial stripe cream with bronze wash; iris bright gold, finely reticulated with black and having dull red horizontal streak (JDL, 8 July 1970).

KU 135326-38from $4 \mathrm{~km}$ NQuevedo, Provincia Los Ríos: Dorsum brown with a green cast or brown marked with darkergreenish-brown to brown to black; dorsal stripe pale yellow to cream edged with black; throat and chest white weakly mottled with gray; posterior venter and undersides of thighs washed with a pale yellowish-green; posterior surfaces of thighs dull greenish-brown to brown flecked with cream to dull orange (THF, 8 July 1970).

KU 165088-89 from $18 \mathrm{~km}$ W Piñas, Provincia El Oro: Dorsum olive-brown with pale red tubercles and dorsolateral folds; posterior thighs brown with tan flecks; venter cream-in larger individual mottled with black and orange suffusion in groin; iris bronze with horizontal red streak (WED, 6 March 1975).

Natural history.-This species is unusual among Eleutherodactylus in northwestern South America because it is the only species commonly found in clearings. In forested areas, E. achatimus is absent or uncommon; if present, it is confined to roadcuts. Although the species apparently does not occur in deep forest, it is common in areas of "tree" crops-e.g., banana, cacao, and coffee groves. In Ecuador, the species has been found to elevations of $1800 \mathrm{~m}$, but it may have dispersed along roads to these elevations; in areas of cloud forest where roads do not exist, E. achatimus seldom is found at elevations exceeding $800 \mathrm{~m}$.

At night, the frogs have been found on low $(<0.5$ $\mathrm{m})$ bushes and herbs, grass, earth banks, rocks along streams and near waterfalls, and the ground. By day, adults have been found under rocks, logs, and banana leaves, in the axils of elephant ears. One individual (KU 111336), when uncovered from beneath a rock at the edge of a stream, leaped into the stream, swam back toward the shore and took refuge under a rock in about $7 \mathrm{~cm}$ of water (JDL, 23 July 1967). Juveniles commonly are seen in leaf litter during the day, but their activity may be the result of disturbance. Apparently recently hatched young collected on 6 July 1976 at Río Palenque, Provincia Los Ríos, have SVLs of $6.6-6.8 \mathrm{~mm}$.

Throughout the range of the species in Ecuador, males have been noted calling in March. May, July. and November. The call has been described as single note or series of notes. (See Remarks.)

Distribution.-Eleutherodactylus achatinus primarily is an inhabitant of lowlands from eastern Panama to southwestern Ecuador and in the Río Cauca Valley in Colombia (Lynch and Myers, 1983:map 1). The southern limit of the range on the Pacific slopes is in the vicinity of Piñas, Provincia El Oro (03⒋ S) (Fig. 20). Of 109 collecting stations, 11 are in the dry tropical regime on the coastal lowlands south of the Equator and on the lowlands between the Cordillera de la Costa and the Andes south of $1^{\circ} \mathrm{S}$ Lat. Eight stations are in the dry subtropical regime either in the Cordillera de la Costa or on the Andean slopes south of $2^{\circ} \mathrm{S}$ Lat. Twenty-nine stations are in the humid tropical

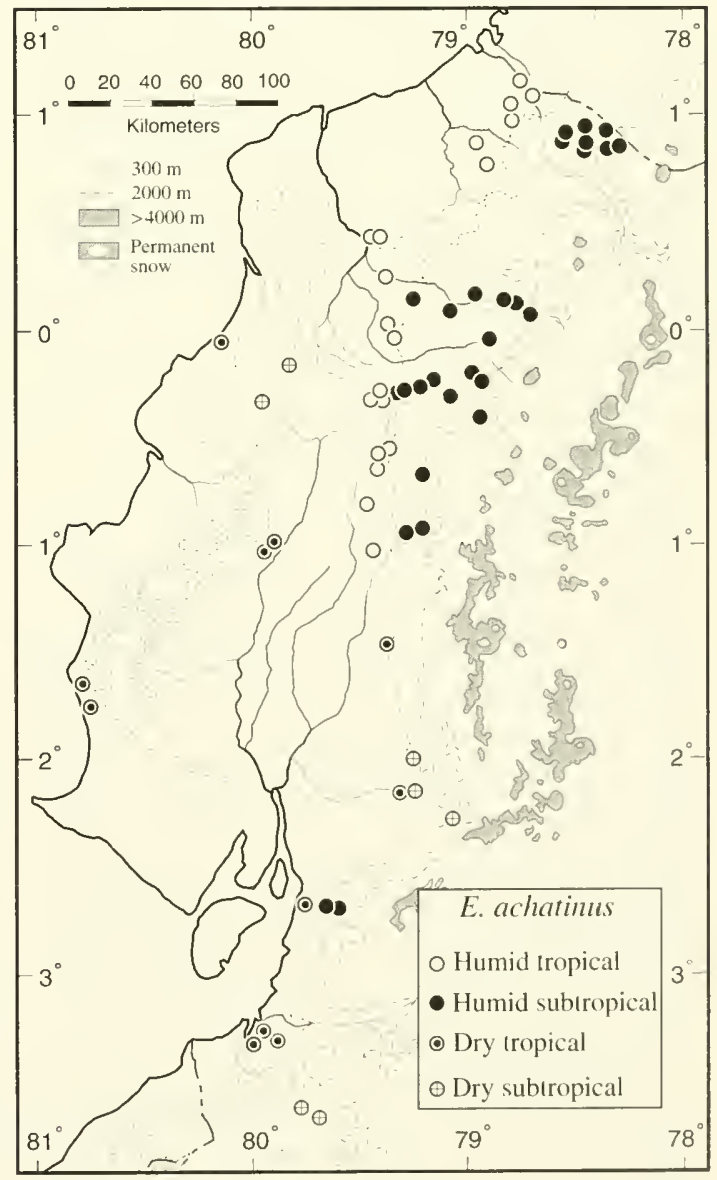

Fig. 20. Distribution of Elentherodactylus achatiuus in western Ecuador with respect to bioclimatic regimes. 
regime, and 61 are in the humid subtropical regime. Records for the species extend from near sea level to elevations of $1800 \mathrm{~m}$, but of 77 localities for which elevation is known, 34 are below $500 \mathrm{~m}$, an additional 23 are below $1000 \mathrm{~m}$, and only three are above $1500 \mathrm{~m}$.

Remarks. - A small amount of geographic variation in body size was reported by Lynch and Myers (1983), who noted that the smallest adult females are from western Colombia and northwestern Ecuador; these differences are more evident in the lower limits of the ranges than in the means. Females from the western slopes of the Andes in Ecuador (samples from Balsapamba, Mindo, and Tandapi) are larger than those from the lowlands by an average of 2-3 $\mathrm{mm}$ (about $5 \%$ larger). Adults from the southern Ecuador (Provincia El Oro) are the smallest; SVL in 47 males is $26.5-31.5 \mathrm{~mm}(\bar{x}$ $=28.1 \pm 0.6)$ and in 8 females, $36.5-41.7 \mathrm{~mm}(\bar{x}=$ $38.5 \pm 0.7$ ). In every sample that we have studied. young females with weakly convoluted oviducts are only slightly smaller than adult females; for example, in the sample from Provincia El Oro, young females have SVLs of 35.9-36.0 mm, and the upper limit of juvenile females is $32.2 \mathrm{~mm}$ SVL.

Lynch and Myers (1983) defined two color pattern morphs in this species. The "brederi" morph is distinctive in having pale borders to the dark markings on the dorsum, whereas the dark markings lack pale borders in the "achatinus" morph. They reported the "brederi" morph to be the most common in Panama, relatively abundant in the drainages of the Río Atrato and Río San Juan in western Colombia, and unknown south of the Río Cajambre in Departamento Valle de Cauca, Colombia. They overlooked the fact that in his field notes, JDL described the dorsal markings as edged with pale green-gray in KU 119465 from Santo Domingo de los Colorados, Provincia Pichincha, and as edged with cream in KU 130365-67 from 4 km N of Quevedo, Provincia Los Ríos, Ecuador. (See Coloration in life.)

Lynch and Myers (1983) were concerned that they might have combined distinct species that differed, at least in part, by frequencies of two pattern polymorphs. Their concern was heightened because tape recordings of frogs from Panama ("ribit" calls) are notably different from a recording of E. achatimus from Maldonado, Provincia Carchi, Ecuador ("kree" call). However, the calls of three males (USNM 204640-42) from $2 \mathrm{~km}$ NE of Río Blanco (town), Provincia Carchi, were described as "waah-waah, [a] single note repeated 5-7 times" (JAP, 26 November 1958). Other descriptions of calls of males from Ecuador are equally variable. The call of KU 117778 from Tandapi, Provincia Pichincha, was described as a series of high "quinks" (JDL, 4 March, 1968); that of KU 141749 from Santo Domingo de los Colorados, Provincia Pichincha, was described as a long, nasal "baaa" followed by "rap-ap-ap-ap" (WED, 4 July 1971). Until tape recordings of calls from throughout the range of the species are analyzed, these apparent differences in calls remain an unsolved mystery. Perhaps E. achatinus is a complex of cryptic species that have different calls, but that are structurally so similar that we have been unable to distinguish more than one species.

This species was included in the Eleutherodactylus conspicillatus group by Lynch (1986a). Other than its placement in the E. conspicillatus group, no explicit claims about the relationships of E. achatinus have been made.

\section{Eleutherodactylus actites Lynch Plate 2}

Eleuthe rodactyllis actites Lynch, 1979b:230.-Holotype: KU 120111. adult female, from Pilaló, $2486 \mathrm{~m}$, Provincia Cotopaxi, Ecuador.

Diagnosis.-A member of the Eleutherodactylus (Eleutherodactylus) conspicillatus group having (1) skin on dorsum shagreen, that on venter smooth; discoidal fold present; dorsolateral folds thin; (2) tympanic membrane and tympanic annulus prominent, its length $1 / 3-1 / 2$ length of eye; (3) snout acuminate in dorsal view, rounded in profile; (4) upper eyelid lacking tubercles, about as wide as IOD; cranial crests absent; (5) vomerine odontophores triangular in outline; (6) males with vocal slits and nuptial pads; (7) first finger longer than second; discs on fingers broad; (8) fingers bearing lateral keels; (9) ulnar tubercles absent; 
(10) heel tubercles small; outer tarsal tubercles absent; inner tarsal fold thin, present on distal $2 / 5$ of tarsus; (11) inner metatarsal tubercle elongate, 46x subconical outer metatarsal tubercle; supernumerary tubercles only at bases of toes; (12) toes bearing lateral keels but no webbing; fifth toe slightly longer than third; (13) dorsum gray with darker markings; venter cream with gray spots; posterior surfaces of thighs with black flecks; (14) SVL in males $30.0-40.0 \mathrm{~mm}$, in females $48.2-64.2$ $\mathrm{mm}$.

Eleutherodactylus actites is most similar to $E$. w-nigrum (and E. achatimus; see previous account). Unlike E. w-nigrum, E. actites has an inner tarsal fold, but the two species are most easily distinguished by color pattern. In E. actites, the groin and posterior surfaces of the thighs have black flecks rather than having large black spots on a white or yellow background or large cream or yellow spots on a black background, as in E. w-rigrum.

Description.-The original description by Lynch (1979b) is complete.

Coloration in life.- The dorsum is gray, greenish brown, pale reddish brown, or dark brown, usually with darker markings. Dark canthal and postorbital stripes and a pale labial stripe are present. The venter is white or yellow with brown flecks (smaller individuals) to a heavier suffusion of brown in larger individuals. The posterior surfaces of the thighs are yellow to bluish gray with black flecks. The iris is pale yellow with black flecks and a median, horizontal red streak.

Coloration of the type series ( $K U$ 120111-24): Dorsum gray, pale reddish brown to dark brown; markings darker brown edged with black; canthal and supratympanic stripes black, edged with creamy yellow-bronze; flanks paler than dorsum, usually with faint rose wash; lower flanks pale blue-gray with black spots; limbs colored as dorsum; concealed surfaces of thighs pale bluish gray speckled with silver and spotted with black; anal patch gray; venter white to yellow speckled with brown; undersides of thighs deep flesh; palms, feet, and tarsi black; labial region rose-bronze with black markings; iris pale yellow reticulated with black and with a red horizontal streak (JDL, 25 June 1968). A topotype (KU 131213) was described as having the posterior surface of the thigh yellow, becoming orange distally, heavily marbled with black (JDL, 2 July 1970), and another series of topotypes (KU 131214-58) were described as having a pale copper labial stripe and the dorsum dull greenish brown medially, washed with reddish brown laterally (JDL, 4 July 1970).

Natural history.-Eleutherodactylus actites inhabits a region of cool cloud forest, but it is rarely observed within the forest. It seems to have a proclivity for exceedingly moist microhabitats. Most individuals found by day were under rocks along streams or in a moist pasture; two were in a mossy bank at the edge of a stream. All individuals active in grass by day were juveniles. Of 132 specimens with ecological data, only three were collected at night - two on broad-leafed plants $(<1$ $m$ above ground) at the edge of the forest and one from low $(<1 \mathrm{~m})$ vegetation along a stream.

Breeding occurs at least in January; many adults in breeding condition but no juveniles are in a series of 96 specimens obtained by James A. Peters in the vicinity of the type locality on 18-19 January 1959. Samples $(n=116)$ obtained at the type locality in June 1968, July 1970, and July 1971 contain many juveniles. We interpret this seasonal distribution of juveniles as evidence that the breeding season is short and that sexual maturity is achieved in a single year, even by this relatively large species of Eleutherodactylus.

Juvenile males lack vocal slits and nuptial pads. In the type series, juvenile males are $23.0-29.0 \mathrm{~mm}$ SVL. Females from the type series having only straight, thin oviducts are as large as $41.1 \mathrm{~mm} \mathrm{SVL}$; females with SVLs of $43.3-46.8 \mathrm{~mm}$ have only slight convolutions of the oviducts.

Distribution.-Except for two specimens from La Esperanza (below Pilaló) at an elevation of 1500 $\mathrm{m}$ in the humid subtropical regime, this species is known only from elevations of 1760-2486 $\mathrm{m}$ in the vicinity of Pilaló on the Pacific slope of the Cordillera Occidental in central Ecuador (Fig. 2l). This is an area of cool, moist cloud forest in the humid temperate regime; Pilaló has a mean annual temperature of $12.6^{\circ} \mathrm{C}$ and an average annual rainfall of $2400 \mathrm{~mm}$. We believe that a record for the species from "Latacunga" in a much drier inter- 


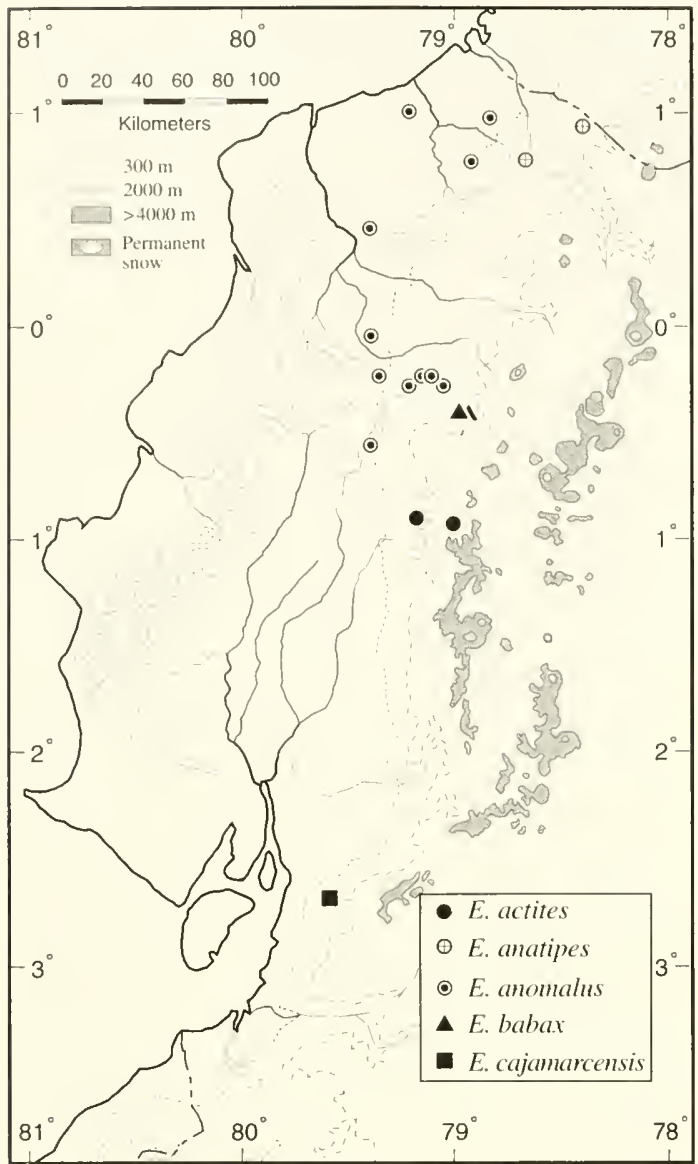

Fig. 21. Distribution of five species of Elentherodacty/us in western Ecuador.

Andean basin to the east represents an error in transcribing field notes.

Remarks.-Eleutherodactylus actites is a member of the Eleutherodactylus conspicillatus group (Lynch, 1986a). Lynch (1979b) suggested that $E$. actites is most closely related to E. w-nigrum, but there is no evidence to support his hypothesis. We consider E. actites to be a geographic replacement of E. w-nigrum, which occurs at both higher and lower elevations to the north and to the south of Pilaló and, thus, has a range encompassing that of $E$. actites. Our characterization of E. actites as replacing E. w-nigrum in the region of Pilaló is based on their occupancy of the same (or nearly the same) microhabitat, their phenetic similarity, and our failure to find the two species in sympatry.

\section{Elentherodactylus anatipes Lynch and Myers \\ Plate 1}

Eleutherodactylus analipes Lynch and Myers, 1983:516. Holotype: KU 177626, subadult female, from Maldonado, $1410 \mathrm{~m}$, Provincia Carchi, Ecuador.

Diagnosis.-A member of the Eleutherodactylus (Craugastor) anomalus group having (1) skin on dorsum finely spiculate in males, bearing low warts in females, that on venter smooth; discoidal fold prominent; dorsolateral folds interrupted; (2) tympanic membrane evident, tympanic annulus obscured by spicules, small, its length $1 / 4$ length of eye; (3) snout rounded in dorsal view, truncate in profile; (4) upper eyelid lacking tubercles, much wider than IOD; cranial crests absent; (5) vomerine odontophores triangular in outline; (6) males with vocal slits and nuptial pads; (7) first finger longer than second; discs on fingers relatively small; (8) fingers lacking lateral fringes; (9) ulnar tubercles absent; (10) tubercles and folds on heel and tarsus absent; (11) inner metatarsal tubercle elongate, $6 \times$ indistinct outer metatarsal tubercle; supernumerary tubercles absent: (12) toes webbed; webbing extending to dises except only to distal subarticular tubercle on Toe IV; fifth toe shorter than third; (13) dorsum brown with darker brown blotches; venter cream; posterior surfaces of thighs yellow with brown mottling; (14) SVL in males 42.9-64.3 mm, in one female $98.6 \mathrm{~mm}$.

Eleutherodactylus anatipes has more toe webbing than any other mainland member of the genus except the Colombian E. zygodactylus. Both species have the toes fully webbed except for the last one or two phalanges of Toe IV. Eleutherodactylus anomalus with slightly less webbing is easily confused with $E$. anatipes, but $E$. anomalus has a broader head, lacks discs on the fingers (small discs present in E. anatipes), and has an inner tarsal fold (absent in $E$. anatipes).

Description.--Lynch and Myers (1983) described juveniles and subadults; Lynch and ArdilaRobayo (1993a) provided descriptive notes and illustrated an adult female.

Coloration in life.-The colors of the holotype and paratype (KU 177625-26) were described as 
follows: Dorsum dull greenish brown with orangish warts and ridges; concealed thigh and groin dull yellow reticulated with black: throat white with brown vermiculations; venter and undersides of legs yellow; iris bright copper with black flecks and brown horizontal streak (JDL, 30 May 1977).

Natural history.-This is one of the largest species of Eleutherodactylus and is one of the streamside species; others in western Colombia and Ecuador are E. anomalus, bufoniformis, cheiroplethus, necerns, and zygodactylus. As this common name implies, these frogs never or seldom stray from the immediate vicinity of streams. Adults and juveniles sit on the ground or on rocks within $1 \mathrm{~m}$ of streams or in protected places beneath undercut banks of streams. In exceptionally wet areas, mule trails become streams in rainy seasons, and $E$. anatipes can be found sitting beside, or in, mule trails. All records for the species are for small streams and not any of the rivers that course through its range; the limited data suggest that $E$. anatipes avoids rivers.

Distribution.-Eleutherodactylus anatipes is known from 11 localities between 100 and $1600 \mathrm{~m}$ in the foothills and lower cloud forests on the western slopes of the Andes in western Colombia (Departamento Valle de Cauca) and extreme northern Ecuador (provincias Carchi and Esmeraldas). Both Ecuadorian localities are in the humid subtropical regime (Fig. 21).

Remarks. - A single adult female is known. The holotype (KU 177626) is a juvenile female having a SVL of $73.1 \mathrm{~mm}$.

In having extensive webbing between the toes, Eleutherodactylus anatipes is like E. zygodactylus, a species distributed in the lowlands of the northern part of Chocoan Colombia (Lynch and Myers, 1983:map 2). The extensive webbing is considered to be a shared, derived character uniting these two species. Eleutherodactylus anatipes, but not E. zygodactylus, has spiculate dorsal skin-a character shared with E. anomalus and E. cheiroplethus. These four species also are unusual among members of the subgenus Craugastor in lacking obvious sexual dimorphism in the size of the tympanic annulus (a plesiomorphic character) and in having exceptionally large eyes resulting in a narrow IOD. These characters (either unpolarized or plesio- morphic) make the species seem similar, but they do not represent evidence that the species are closely related, although we think (perhaps irrationally) that the four species are close relatives, and we assign them to the E. anomalus group of the subgenus Craugastor:

\section{Eleutherodactylus anomalus (Boulenger)} Plate 1

Hylodes anomalus Boulenger, 1898:119.-Syntypes: BM 1947.2.16.8-10 from Cachabé, Provincia Esmeraldas. Ecuador.

Eleutherodactylus anomalus-Peters, 1955:339.

Diagnosis. - A member of the Eleutherodactylus (Craugastor) anomalus group having (1) skin on dorsum tuberculate, bearing many short ridges, that on venter smooth; discoidal fold present; dorsolateral folds absent; (2) tympanic annulus evident, tympanic annulus bearing warts. small, its length $1 / 3$ length of eye; (3) snout rounded in dorsal view and in profile; head relatively broad, HW 42 $48 \%$ SVL; (4) upper eyelid lacking tubercles, much wider than IOD; cranial crests absent; (5) vomerine odontophores broad, nearly arched; (6) males lacking vocal slits; nuptial pads present; (7) first finger longer than second; discs absent; (8) fingers lacking lateral fringes; (9) ulnar tubercles absent; (10) tubercles on heel and tarsus absent; inner tarsal fold present; (11) inner metatarsal tubercle elongate, $3 \times$ oval outer metatarsal tubercle; supernumerary tubercles absent: (12) toes webbed; webbing extending to disc on Toe $\mathrm{V}$ and lateral edge of Toe III; penultimate subarticular tubercle on Toe IV absent; discs small; fifth toe shorter than third: (13) dorsum brown with indistinct darker mottling; throat brown with diffuse cream spots; otherwise venter cream; posterior surfaces of thighs cream with brown reticulation; (14) SVL in males 31.5-62.1 mm, in females 76.5-92.4 mm.

Eleutherodactylus anomalus can be confused with the larger $E$. anatipes; both have tuberculate skin on the dorsum and extensive webbing. Unlike E. anatipes, E. anomalus lacks discs on the fingers (small discs on toes), has broader vomerine odontophores, coarser skin on the dorsum (folds and tubercles), and an inner tarsal fold. Eleuthero- 
dactylus anomalus also has a wider head than does E. anatipes, but these differences can be detected only by measurements.

Description.-Lynch and Myers (1983) provided a complete account of the species. Cochran and Goin's (1970) description of a syntype is more nearly complete than Boulenger's (1898) description, but the illustrations are better in Boulenger (1898) than in Cochran and Goin (1970).

Coloration in life.-Color notes on two Ecuadorian specimens are, as follow.

KU 165129 from Estación Biológica Río Palenque, Provincia Los Ríos: Dorsum dull brown; flanks cream with brown reticulations; posterior thighs dark brown with yellow flecks; venter creamy white with brown reticulations on throat; iris orange-brown with radiating brown triangles (WED, 28 March 1975).

KU 177627 from Santo Domingo de los Colorados, Provincia Pichincha: Iris pale copper with brown triangles fore and aft; pale areas on posterior thigh and in groin dull yellow (JDL, 12 June 1977).

Natural history.-As might be guessed from the digital morphology, E. anomalus is strictly terrestrial.Adults and juveniles commonly are found along small, sluggish streams at night. When disturbed, the frogs may jump into pools and hide in the leaf litter or debris on the bottom, or they may run along the bank of the stream. Two individuals were in shaded areas on the banks of streams by day.

Lynch and Myers (1983) reported breeding in February. A pair in axillary amplexus was observed in a small depression; $2 \mathrm{hr}$ later the female was sitting on a clutch of 69 eggs. This is a large frog; juvenile females (ICNMHN 13204, 13206) having thin, unconvoluted oviducts are as large as $66 \mathrm{~mm}$ SVL.

Distribution.-Eleutherodactylus anomalus is distributed in forested lowlands below $1100 \mathrm{~m}$ in western Colombia and northwestern Ecuador (Lynch and Ardila-Robayo, 1993b); of 14 localities of known elevation in Ecuador, all are between 100 and $700 \mathrm{~m}$. In Ecuador, the distribution of this species is broadest near the Colombian border, and it tapers inland to the south, and thus, is absent in the drier coastal region (Fig. 21); six Ecuadorian localities for this species are in the humid tropical regime, and nine are in the humid subtropical regime.

Remarks.-This species is most closely related to E. cheiroplethus, which is distributed at higher elevations (1140-1540 m) than E. conomalus on the western flank of the Cordillera Occidental (Lynch, 1990). In Ecuador, but not in Colombia, E. anomalus is not found in the same streams as $E$. anatipes.

\section{Eleutherodactylus apiculatus Lynch and} Burrowes

Plate 7

Eleutherodactylus apiculatus Lynch and Burrowes, 1990:8. Holotype: IND-AN 1506, adult female, from the Reserva Natural La Planada, $1780 \mathrm{~m}, 7 \mathrm{~km}$ S of Chucunés, Municipio de Ricaurte, Departamento Nariño, Colombia.

Diagnosis.-A member of the Eleutherodactylus (Eleutherodactylus) unistrigatus group having (1) skin on dorsum smooth; that on venter areolate: well anteriad to groin; dorsolateral folds absent; (2) tympanic membrane and tympanic annulus prominent, small, its length $1 / 4-2 / 5$ length of eye: (3) snout subacuminate in dorsal view, subtruncate in profile; (4) upper eyelid bearing one small, nonconical tubercle, narrower than IOD; cranial crests absent; (5) vomerine odontophores oblique; (6) males having vocal slits; nuptial pads absent; (7) first finger shorter than second; discs broad; (8) fingers bearing narrow lateral fringes; (9) ulnar tubercles absent; (10) small tubercles on heel and outer edge of tarsus; inner tarsal fold absent; (11) inner metatarsal tubercle oval, 3x elongate outer metatarsal tubercle; supernumerary tubercles numerous, largest at bases of Toes II-IV; (12) toes bearing lateral fringes; webbing absent; fifth toe much longer than third; (13) dorsum brown with pale interorbital bar and white line above dark cloacal patch; venter pale brown; posterior surfaces of thighs brown; (14) SVL in males 17.8$21.8 \mathrm{~mm}$. in females $21.6-26.3 \mathrm{~mm}$.

Eleutherodactylus apiculatus is most similar to E. calcarulatus, which differs in having a conical tubercle (calcar) on the heel rather than one or more small, nonconical tubercles, small ulnar tubercles, 
and an inner tarsal tubercle. Eleutherodactylus apiculatus is smaller than E. calcarulatus (males 17.8-24.6 mm, females 25.3-28.9 mm SVL). Living individuals are easily distinguished by the color of the iris-blue-gray in E. calcarulatus and bronze in E. apiculatus.

Description.-The original description (Lynch and Burrowes, 1990) is complete.

Coloration in life.-The dorsum is tan or yellowish tan with or without small, irregularly shaped brown blotches; some individuals have a broad, middorsal yellow-tan stripe, and others have many fine yellow stripes on the dorsum. There is a black interorbital bar. The limbs are tan with brown bars, and the venter is white or yellow with brown flecks. A dark brown, triangular cloacal patch is bordered dorsally by a yellowish-tan line. The concealed surfaces of the limbs are brown. The iris is bronze with black reticulations and a median, horizontal red streak (Lynch and Burrowes, 1990).

Natural history.-This forest-dwelling species has been studied extensively only in the cloud forest at the type locality, where PatriciaA. Burrowes found it to be active every night in April-June, when gravid females were found on nearly every night. Males call from leaves and branches 1.0-3.5 $\mathrm{m}$ above the ground; the call consists of two peeps. Juvenile females are $21.2-21.6 \mathrm{~mm}$ in SVL. The two Ecuadorian specimens were in axils of leaves of elephant ear plants by day.

Distribution.-This species is known only from the type locality at an elevation of $1780 \mathrm{~m}$ on the western slope of the Cordillera Occidental in southern Colombia and in cloud forest at 1750 and 2120 $\mathrm{m}$ in Provincia Pichincha, Ecuador (Fig. 22); thus, it occurs in the humid subtropical and humid temperate regimes. We anticipate that E. apiculatus will be found to be more widely distributed in northwestern Ecuador.

Remarks.--Direct evidence is lacking, but we suspect that this species may have a restricted distribution. Both E. apiculatus and E. calcarulatus are peculiar in that each is abundant at some localities and inexplicably scarce elsewhere. Thus, we cannot estimate confidently distributions or be confident in inferences about the ecological interactions of these two species whose distributions may interdigitate. The indirect evidence is that the spe-

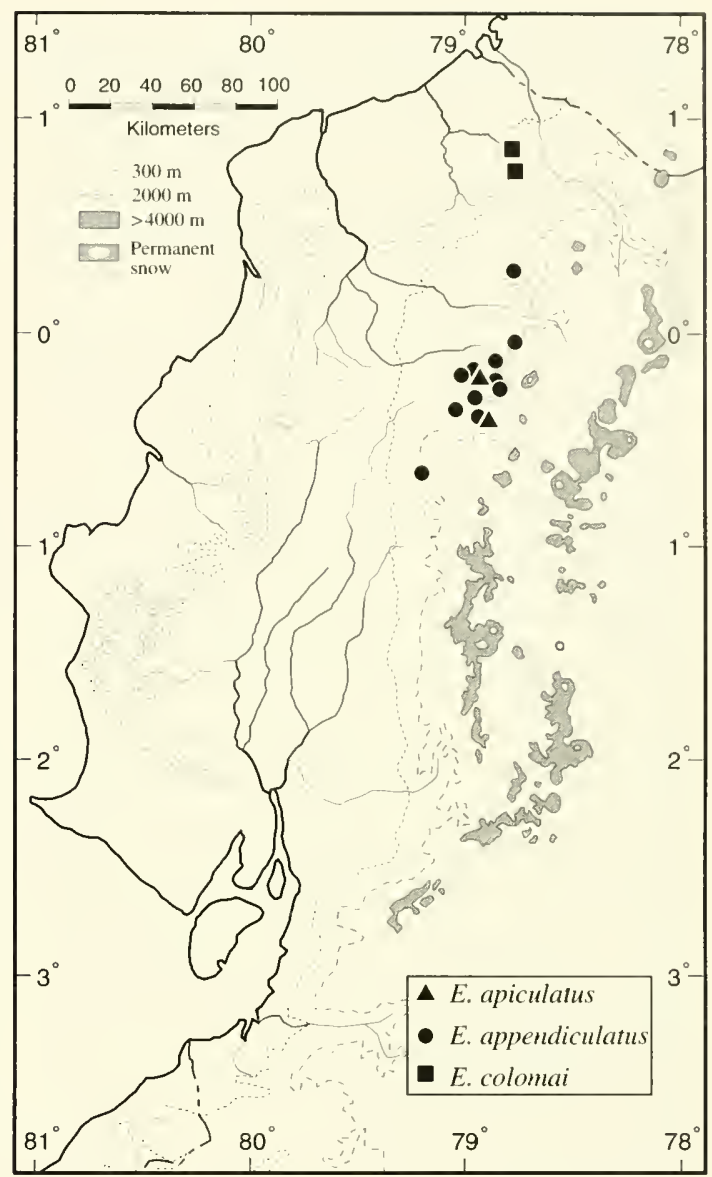

Fig. 22. Distribution of three species of Eleutherodactylus in western Ecuador.

cies thought to be related to E. apiculatus are distributed to the north and to the south of the distribution of E. apiculatus. One assumption underlying this indirect evidence is that allied species are distributed allopatrically. However, sampling has not been exhaustive at appropriate elevations in the Departamento Nariño, Colombia, or in provincias Carchi and lmbabura, Ecuador.

\section{Eleutherodactylus appendiculatus (Werner) Plate 4}

Hylodes appendiculatus Werner, 1894:4 10.-Holotype: NHM 16507, juvenile female, from "Ecuador." Eleutherodactylus appendiculatus-Peters, 1955:350.

Diagnosis.-A member of the Eleutherodactylus (Eleutherodactylus) devillei group having 
(1) skin on dorsum relatively smooth with large tubercles on eyelids, between eyes, and on limbs, that on venter coarsely areolate; discoidal fold absent: dorsolateral folds prominent: (2) tympanic membrane and tympanic annulus prominent, small, slightly more than $1 / 3$ length of eye; (3) snout acuminate in dorsal view, pointed or rounded in profile, with fleshy proboscis at tip; (4) upper eyelid bearing long, conical tubercle, wider than IOD; cranial crests absent; (5) vomerine odontophores oblique, slightly elevated well behind choanae; (6) males having vocal slits; nuptial pads absent; (7) first finger much shorter than second; discs large, weakly emarginate; (8) fingers bearing narrow lateral fringes; (9) ulnar tubercles present; (10) tubercles on heel absent, on outer edge of tarsus prominent; inner tarsal fold absent; (11) inner metatarsal tubercle elongate, $4 \times$ elongate outer metatarsal tubercle; supernumerary tubercles minute; (12) toes bearing lateral fringes; webbing absent; discs large, weakly emarginate; fifth toe longer than third; (13) dorsum brown with brown blotches; narrow bars present on limbs; venter cream with dark brown reticulations; throat, labial bars, and canthal stripe dark brown; posterior surfaces of thighs brown; (14) SVL in males $18.8-21.0 \mathrm{~mm}$, in females $30.0-35.0 \mathrm{~mm}$.

Eleutherodactylus appendiculatus is one of the most distinctive species in western Ecuador. The presence of a fleshy proboscis is unique; this and the presence of elongate tubercles on the upper eyelids serve to distinguish this species from all others in western Ecuador (and elsewhere).

Description.-Lynch (1971a) redescribed the species based on the holotype and USNM 204712 13. Miyata (1980a) provided additional information on adults.

Coloration in life.-Dorsolateral stripes contrast with the dorsum and flanks as noted in the following field notes.

KU 165133-38 from $5 \mathrm{~km}$ ESE of Chiriboga, Provincia Pichincha:-Dorsum and flanks pale green to reddish tan with reddish-brown markings; dorsolateral stripes orange-tan or pale green; fingers and toes creamy tan; discs black and cream; heels and anal region black; venter bluish gray with black mottling; iris pale bronze with median, horizontal. dull brown streak (WED, 3-4 April 1975).
KU 165142 from $14 \mathrm{~km} W$ of Chiriboga, Provincia Pichincha:-Dorsum tan with dark brown markings; venter bluish gray with black markings; iris greenish gray with black flecks and median, horizontal, orange-tan streak (WED, 8 May 1975).

Natural history.-Adults and juveniles have been found on low vegetation $(<\mathrm{l} \mathrm{m})$ in dense forest at night; some were near streams. Miyata (1980a) reported individuals along roadcuts on rainy nights. Juveniles are active on the ground in wet forest by day (Lynch and Burrowes, 1989; WED, pers. obs.).

Distribution.-The species is known from the Reserva La Planada in extreme southern Colombia and 12 localities in Ecuador (Fig. 22). All localities are in cloud forest at elevations of 1460-2800 $\mathrm{m}$ on the western slopes of the Cordillera Occidental; six sites are in the humid subtropical regime, and six are in the humid temperate regime.

Remarks.-Females having no convolutions of the oviducts are as large as $27.3 \mathrm{~mm} \mathrm{SVL} \mathrm{(MCZ}$ 98030); KU 177637 (27.9 mm SVL) has thin oviducts with only slight convolutions. Two males from Provincia Pichincha (MCZ 92885, 94818) have white testes, whereas another male (KU 165140) has dark flecks on the mesorchium. One mature male having a SVL of $16.2 \mathrm{~mm}$ (QCAZ 7968) lacks a fleshy proboscis; there is no apparent trace of injury. In adult males, the vocal slits are short and located posterolateral to the tongue. Although we assign E. appendiculatus to the E. devillei group, we are not confident in doing so. Its nearest relatives are undescribed species from cloud forests in western Colombia.

\section{Eleutherodactylus babax Lynch Plate 3}

Eleutherodactylus babax Lynch, 1989a:10. Holotype: ICNMHN 13592, adult male, from Finca La Planada. $1970 \mathrm{~m} .5 \mathrm{~km}$ by road from Chucunés, Municipio de Ricaurte, Departamento Nariño, Colombia.

Diagnosis.-A member of the Eleutherodactylus (Eleutherodactylus) dolops group having (1) skin on dorsum bearing low warts, that on venter smooth; discoidal fold present; dorsolateral folds incomplete: (2) tympanic membrane and tym- 
panic annulus prominent, small, its length $1 / 4-1 / 3$ length of eye; (3) snout subacuminate in dorsal view. rounded to truncate in profile; (4) upper eyelid lacking tubercles, wider than IOD; cranial crests absent; (5) vomerine odontophores triangular in outline: (6) males having vocal slits: nuptial pads absent; (7) first finger longer than second; discs narrow: (8) fingers lacking lateral fringes; (9) ulnar tubercles absent; (10) heel and tarsus lacking tubercles and folds; (11) inner metatarsal tubercle oval, $3 \times$ round outer metatarsal tubercle; supernumerary tubercles only at bases of toes; (12) toes lacking lateral fringes and webbing; fifth toe slightly longer than third: (13) dorsum brown with darker brown blotches: venter cream: posterior surfaces of thighs brown with cream flecks; (14) SVL in one male $42.4 \mathrm{~mm}$. in females $45.6-48.7 \mathrm{~mm}$.

By virtue of having long, slender digits with narrow digital discs, E. babax is distinguished immediately from all other Eleutherodactylus in western Ecuador. The similar E. dolops from the eastern slopes of the Andes is larger. The smaller Barycholos pulcher superficially resembles $E$. babax but has an inner tarsal tubercle and a short fifth toe.

Description.-Lynch (1989a) described this species on the basis of limited material from three localities in Colombia. Additional material has not amplified the described variation.

Coloration in life.- No color notes are available for the two specimens known from Ecuador; the following descriptions are based on specimens from Colombia.

La Planada, Departamento Nariño: Dorsum yellowish olive to reddish brown with dark brown markings (commonly outlined with cream); flanks and concealed surfaces of hind limbs dull orange to salmon; flanks with brown spots; posterior surfaces of thighs with brown reticulations; throat and chest brown; belly and undersides of thighs salmon; iris bronze above and black below brown horizontal streak (P. A. Burrowes, April-June, 1986).

Boquerón, Vereda Las Amarillas, Municipio El Cairo, Departamento Valle del Canca: Dorsum brown with darker brown markings edged with cream; groin and posterior surfaces of thighs brown with cream flecks; throat brown with cream flecks; belly dull pale yellow with some gray flecks; un- dersides of limbs with orange cast; upper iris heavily flecked with pale olive; lower iris brownish gray (JDL 18556-57, 25 June 1991).

Natural history.-Because it is terrestrial and nocturnal, this species is easily overlooked. Individuals have been found in dense cloud forests as well as in clearings. It is not restricted to the margins of streams, but individuals at La Planada, Departamento Nariño, Colombia, and near Tandapi, Provincia Pichincha, Ecuador, were collected along streams.

Distribution.-Eleutherodactylus babax occurs in cloud forests at elevations of $1500-2200 \mathrm{~m}$ on the Pacific slopes of the Cordillera Occidental from Departamento Antioquia, Colombia, to Provincia Pichincha, Ecuador. The two Ecuadorian localities are at elevations of 1550 and $1750 \mathrm{~m}$ in the humid temperate regime (Fig. 21).

Remarks.-Eleutherodactylus babax was placed in the Eleutherodactylus dolops group by Lynch (1989a), who recognized two species in the group-E. babax on the Pacific slopes of the Andes and $E$. dolops on the Amazonian slopes.

\section{Eleutherodactylus cajamarcensis Barbour and Noble \\ Plate 5}

Eleutherodactylus cajamarcensis Barbour and Noble. 1920:404. Holotype: MCZ 5407, adult male, from Ruins near Huambos, Departamento Cajamarca, Peru.

Diagnosis.-A member of the Eleutherodactylus (Eleutherodactylus) unistrigatus group having (1) skin on dorsum shagreen, bearing illdefined rows of pustules, that on venter areolate: discoidal fold prominent; dorsolateral folds absent; (2) tympanic membrane and tympanic annulus prominent, round, its length $1 / 3-1 / 2$ length of eye; (3) snout rounded in dorsal view and in profile. canthus rostralis angular; (4) upper eyelid bearing small tubercles, slightly narrower than IOD; cranial crests absent; (5) vomerine odontophores oblique, not prominent: (6) males having vocal slits and nuptial pads; (7) first finger shorter than second; discs small; (8) fingers lacking lateral fringes: (9) ulnar tubercles indistinct or absent; ( 10 ) heel and outer edge of tarsus lacking tubercles; inner edge of 
tarsus usually bearing one tubercle; (11) inner metatarsal tubercle oval, 4-6x oval outer metatarsal tubercle; supernumerary tubercles numerous: (12) toes bearing lateral fringes; webbing absent; fifth toe much longer than third; discs as large as those on fingers: (13) dorsum gray to pale brown with darker brown markings; venter cream with brown or gray spots; posterior surfaces of thighs. groin, and lower flanks black with white spots; (14) SVL in males $19.2-24.1 \mathrm{~mm}$, in females 27.1-33.8 mm.

Eleutherodactylus cajamarcensis clearly is a member of the E. unistrigatus group, but does not seem to be closely allied to any of the other species in western Ecuador. Lynch ( 1969) compared it with E. unistrigatus and a species that later was named E. modipeplins (Lynch, 1979a). In habitus and morphology of the digits, it is most like E. petrobardus, versicolor, and wiensi, but it differs from these by having white spots in fields of red flash colors on the flanks and posterior surfaces of the thighs. The digit discs are slightly narrower than those in $E$. petrobardus, versicolor, and wiensi.

Description.-The redescription by Lynch (1969) is adequate.

Coloration in life.-Detailed notes on coloration are not available for specimens from western Ecuador; the following descriptions are based on specimens from southern Ecuador.

$K U$ 141896-909 from $5 \mathrm{~km}$ NE Cariamanga, Provincia Loja: Dorsum gray, tan, dark brown, or reddish brown; venter pale gray; spots in groin and on posterior surfaces of thighs tomato-red; iris bronze with reddish-brown median, horizontal streak (WED, 18 July 1971).

KU 165190-92 from $12.5 \mathrm{~km}$ S Loja, Provincia Loja: Dorsum tan to reddish brown with dark brown markings; groin and anterior surfaces of thighs rose; posterior surfaces of thighs black with white flecks or mottling; iris pale bronze with reddish-brown, median, horizontal streak (WED, 9 March 1975).

Natural history.-Although E. cajamarcensis sometimes is found on low vegetation at night, most individuals have been found by day; many were under rocks in subparamo, others were in either terrestrial or arboreal bromeliads in forests; as many as 11 individuals have been obtained from a single bromeliad.

Distribution. - This species is widely distributed on the Pacific slopes in the region of the Huancabamba Depression in northern Peru and the Loja Basin in southern Ecuador. It occurs in tropical dry forest, cloud forest, and subparamo at elevations of $1800-3100 \mathrm{~m}$. The specimens reported here are from Luz María $\left(02^{\circ} 4 l^{\prime} S\right)$, Provincia Azuay, the northernmost known locality for the species (Fig. 21). This site is at an elevation of 1880 $\mathrm{m}$ in the humid temperate regime.

Remarks. - The presence of E. cajamarcensis in western Ecuador is somewhat surprising. Luz María, Provincia Azuay, is the northernmost known locality for the species, which, together with its apparent allies ( $E$. petrobardus, versicolor, and wiensi), are distributed to the south. These four species (and E. lymani) seem to be elements of a Huancabamba Depression fauna (Duellman and Wild, 1993), some of whose members encroach into the area here termed western Ecuador.

\section{Eleutherodactylus calcarulatus Lynch \\ Plate 6}

Eleutherodactylus calcarulatus Lynch, 1976a:6.-Holotype: KU 111218, adult female, from Tandapi, 1460 $\mathrm{m}$, Provincia Pichincha, Ecuador.

Diagnosis.-A member of the Eleutherodactylus (Eleutherodactylus) unistrigatus group having (1) skin on dorsum smooth, that on venter areolate; discoidal fold prominent; dorsolateral folds absent; (2) tympanic membrane and tympanic annulus prominent, round, small, its length $1 / 4-2 / 5$ length of eye; (3) snout subacuminate in dorsal view, rounded in profile, with papilla at tip; (4) upper eyelid bearing one or two tubercles, slightly wider than IOD; cranial crests absent; (5) vomerine odontophores oblique; (6) males having vocal slits; nuptial pads absent; (7) first finger shorter than second: discs dilated; (8) fingers bearing lateral fringes; (9) ulnar tubercles small, conical; (10) heel bearing elongate, conical tubercle; inner tarsal tubercle present: (11) inner metatarsal tubercle oval, 4-6× oval outer metatarsal tubercle; supernumerary tubercles few; (12) toes bearing narrow lateral fringes; webbing absent; fifth toe much longer than 
third; (13) dorsum pale brown with darker brown markings; venter cream with brown flecks; posterior surfaces of thighs uniform brown; (14) SVL in males $17.8-26.6 \mathrm{~mm}$, in females $25.3-28.9 \mathrm{~mm}$.

Eleutherodactylus calcarulatus is most easily recognized because it is relatively small and has smooth skin on the dorsum and prominent tubercles on the upper eyelid and on the heel. Additionally, if living material is available, the bluegray iris is distinctive. Several other species have prominent tubercles on the upper eyelids and heels, but among those in western Ecuador, E. appendiculatus, crucifer, latidiscus, and muricatus have tuberculate skin on the dorsum, or the tubercles are small, as in E. eremitus, laticlavius, and nyctophylax; moreover, E. appendiculatus, labiosus, and tenebrionis have shorter fifth toes. The smaller $E$. scolodiscus has a bright blue iris, but it has papillae on the tips of some of the digits.

Description.-The original description by Lynch (1976a) is complete.

Coloration in life.--The dorsal coloration is highly variable, ranging from cream with a green tint to dark brown or nearly black; the dorsal markings usually are diffuse and barely distinguishable in some individuals, as noted in the following descriptions.

KU 111216-44 from Tandapi, Provincia Pichincha: Dorsum cream with green tint, yellowish brown, reddish brown, or dark brown to nearly black; dorsal markings and limb bars same color as ground color but darker, diffuse in some individuals. Some have a reddish-brown dorsum with brown stripes. Venter dark creamy yellow to brown or grayish black; groin and concealed surfaces of thighs gray to blackish brown. Cream or yellow spots evident on labial border in some individuals. Iris blue-gray, usually with a reddish-bronze, median, horizontal streak (JDL, 15-23 July 1967).

KU 165189 from $3.5 \mathrm{~km}$ NE Mindo, Provincia, Pichincha: Dorsum dull olive-green with dark brown markings; venter dull greenish yellow with gray suffusion; iris bluish gray with dull red streak (WED, 8 April 1975).

Natural history.-Eleutherodactylus calcarulatus was observed every night during JDL's visits to Tandapi, Provincia Pichincha, in 1967, 1968, 1970, and 1977. The species is arboreal and espe- cially abundant along trails through cloud forest, particularly in the proximity of small streams. In spite of its abundance at Tandapi, no calls were associated with this species. However, at La Delicia, Provincia Imbabura, on 16 January 1978, males were calling at night from high perches $(2.4-3.0 \mathrm{~m}$ above the ground) in deep forest and at the edge of the forest; the call is an explosive, musical "tink." By day, individuals have been found in arboreal bromeliads, in the axils of elephant ear plants, under bark on logs, and in rotting fence posts.

Distribution.-This species occurs in cloud forests at moderate elevations (1140-2700 m) on the western flank of the Cordillera Occidental in Ecuador (Fig. 23); 10 localities are in the humid tropical regime and nine are in the humid temperate regime. The presence of the species on the slopes southeast of Maldonado, Provincia Carchi, almost assures that it will be discovered in adjacent Departamento Nariño, Colombia.

Remarks.-The largest juvenile female (thin. straight oviducts) is $25.0 \mathrm{~mm} \mathrm{SVL}$. One specimen (MCZ 98076) from the Río Corazón, $6.3 \mathrm{~km}$ E of Tandapi, Provincia Pichincha, is an adult female having a SVL of $32.4 \mathrm{~mm}$; this specimen is $3.5 \mathrm{~mm}$ larger (SVL) than any other female examined and is tentatively referred to $E$. calcarulatus.

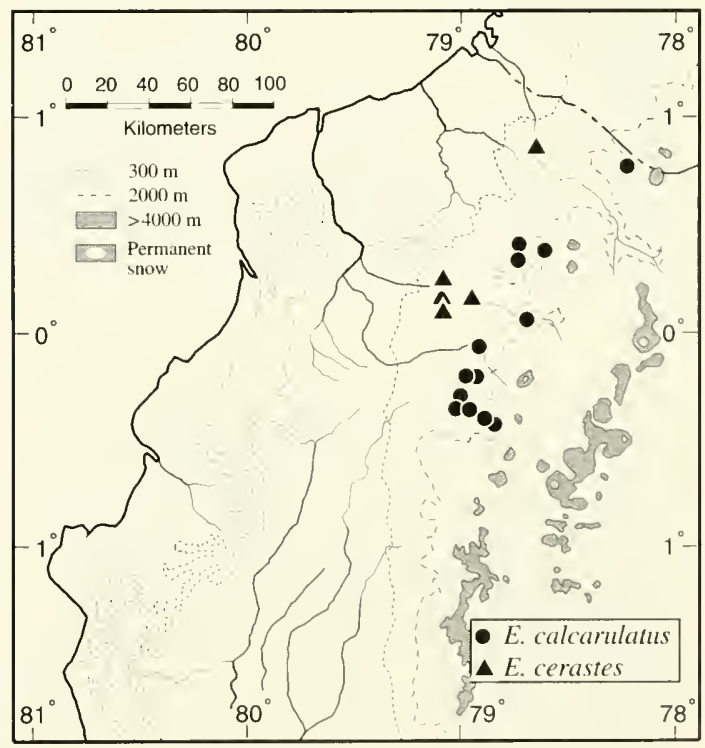

Fig. 23. Distribution of two species of Elentherodactylus in western Ecuador. 


\section{Eleutherodactylus caprifer Lynch}

Plate 2

Eleutherodactylus caprifet Lynch 1977:282.-Holotype: KU 131589, adult male, from Las Palmas (= La Palma), 920 m. Provincia Pichincha, Ecuador.

Diagnosis.-A member of the Eleutherodactylus (Eleutherodactylus) conspicillatus group having (1) skin on dorsum smooth, that on venter areolate; discoidal fold prominent; dorsolateral folds absent: (2) tympanic membrane and tympanic annulus prominent, round, small, its length $1 / 4-1 / 3$ length of eye; (3) snout short, subacuminate in dorsal view, truncate in profile; (4) upper eyelid lacking tubercles, slightly wider than IOD; cranial crests absent: (5) vomerine odontophores triangular in outline; (6) males having vocal slits; nuptial pads absent; (7) first finger longer than second; discs broad: (8) fingers bearing narrow lateral fringes; (9) ulnar tubercles absent; (10) heel and tarsus lacking tubercles; (11) inner metatarsal tubercle elongate, $4 \times$ elongate outer metatarsal tubercle; supernumerary tubercles absent; (12) toes bearing narrow lateral keels; webbing absent; fifth toe slightly longer than third: (13) dorsum tan with numerous thin brown chevrons and broad brown dorsolateral stripe; venter white with brown stripes on throat; posterior surfaces of thighs brown with cream flecks; (14) SVL in males 21.0-30.4 mm, in females $40.5-43.8 \mathrm{~mm}$.

Like other species in the Eleutherodactylus conspicillatus group. E. caprifer has the first finger longer than the second and the fifth toe only slightly longer than the third. The color dorsal pattern of $E$. caprifer resembles some E. achatinus ("brederi" morph) but is readily distinguished by the presence of areolate skin on the venter and short, brown, longitudinal stripes on the throat in females, and by the absence of dorsolateral folds.

Description.-Lynch (1977) and Lynch and Myers (1983) provided thorough descriptions.

Coloration in life.-The following description is of the type series, which illustrates the sexual dimorphism in color.

KU 131589-602 from La Palma, Provincia Pichincha: In males, dorsum yellow (with green tint in some individuals) with brown tint on snout; concealed surfaces of thighs yellow; throat flesh- colored. In females, dorsum reddish brown (pale orange in some individuals), with paler, nearly yellowish-brown flanks; groin and concealed surfaces of thighs dull brown with pale green flecks on latter; throat white with pair of dull gray longitudinal stripes. In both sexes, narrow brown or black chevrons and dorsolateral stripes on dorsum and transverse bars on limbs; face yellow fading to reddish brown; venter (except throat) uniform offwhite; iris bright copper, darkest below, with dark brown, median, horizontal streak (JDL, 8 August 1977).

Natural history.-At the type locality, Eleutherodactylus caprifer is reasonably abundant in the spray zone of a small waterfall, where individuals have been found on low vegetation (up to $20 \mathrm{~cm}$ above the ground). Males have been noted calling in July and August; the call is a series of 8 10 high, piercing chirps.

Distribution.-This species is distributed in lowlands $(50-950 \mathrm{~m})$ in southwestern Colombia (Departamento Valle de Cauca southward) and northwestern Ecuador (Fig. 24). Four of the five Ecuadorian localities are in the humid subtropical regime, whereas one is in the humid tropical regime.

Remarks.-As noted by Lynch and Myers (1983), this species is seldom collected; perhaps this reflects some microhabitat preference not apparent to collectors. On various occasions, JDL has found two or three individuals in an hour or so at one site, but there is nothing obvious about why the species is abundant at the type locality.

\section{Eleutherodactylus celator Lynch Plate 7}

Eleutherodactylus celator Lynch 1976a:22.-Holotype: KU 131573, adult female, from La Delicia, $2700 \mathrm{~m}$. Provincia Imbabura, Ecuador.

Diagnosis.-A member of the Eleutherodactylus (Eleutherodactylus) unistrigatus group having (1) skin on dorsum finely areolate, that on venter coarsely areolate; discoidal fold prominent; dorsolateral folds absent; (2) tympanic membrane and tympanic annulus prominent, round, its length $1 / 3-3 / 5$ length of eye; (3) snout subacuminate in dorsal view, rounded in profile; (4) upper eyelid 
PLATE 1

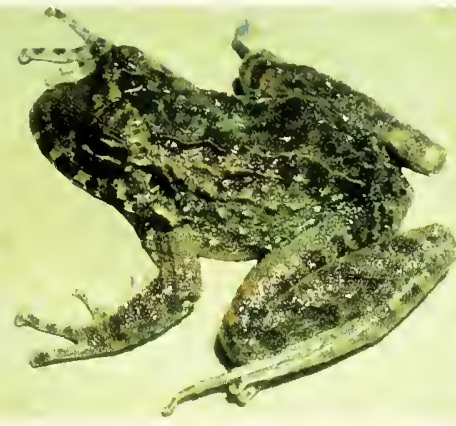

E. anatipes, IND-AN (PAB 568), juvenile. La Planada, Nariño. Colombia. PAB

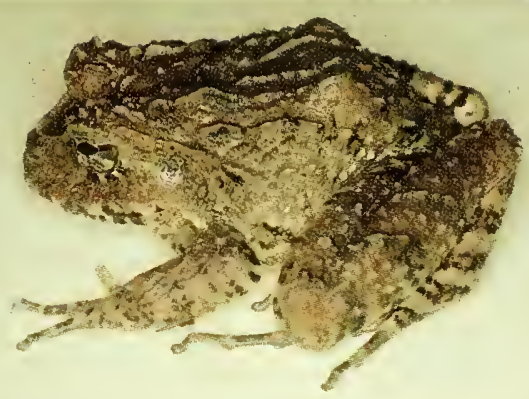

E. necerus, KU 179077, female, $72.3 \mathrm{~mm}$ SVL. Maldonado, Carchi, Ecuador. JDL.

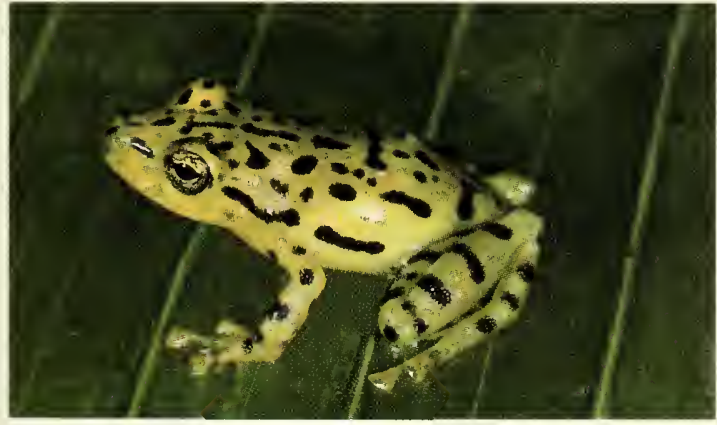

E. omatissimus, USNM 285614. male, $18.8 \mathrm{~mm}$ SVL, Centinela, Pichincha, Ecuador. KM.

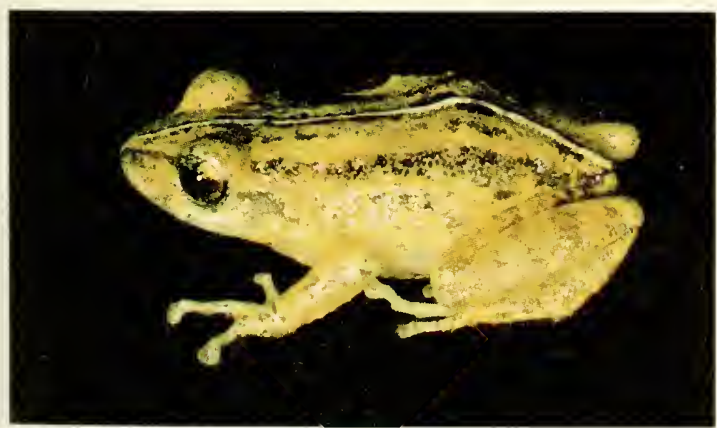

E. umistrigatus, KU 165591, male, $22.1 \mathrm{~mm}$ SVL. $9.5 \mathrm{~km} \mathrm{NW}$ Nono, Pichincha, Ecuador. WED.

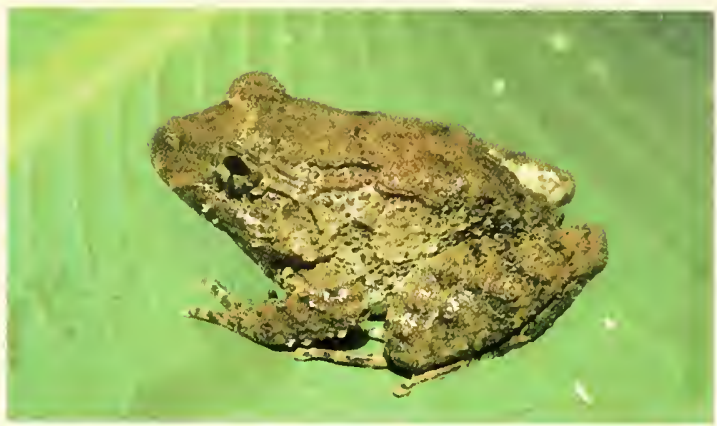

E. anmulus, KU 165130, female, 58.4 mm SVL. Río Palenque. Pichincha. Ecuador. WED.

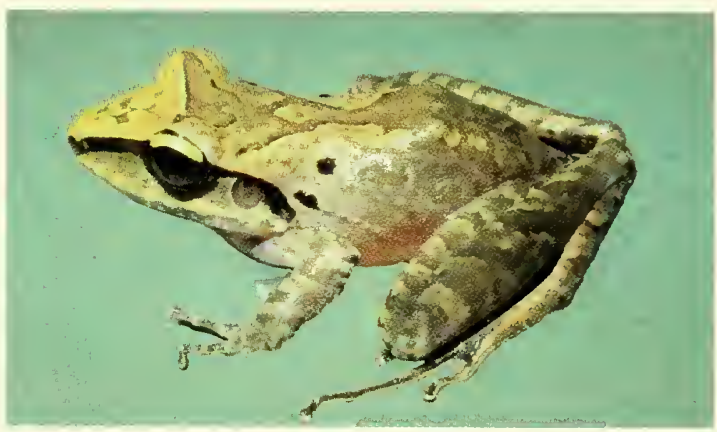

E. longirostris, ICNMHN 13215, female, $49.6 \mathrm{~mm}$ SVL. Río Calima. Valle de Cauca, Colombia. JDL.

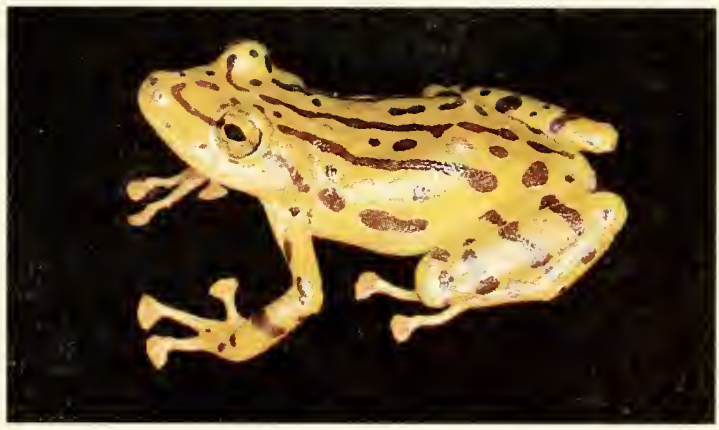

E. ornatissimus, KU 141967, female, 37.2 mm SVL. Río Baba, Pichincha, Ecuador. WED.

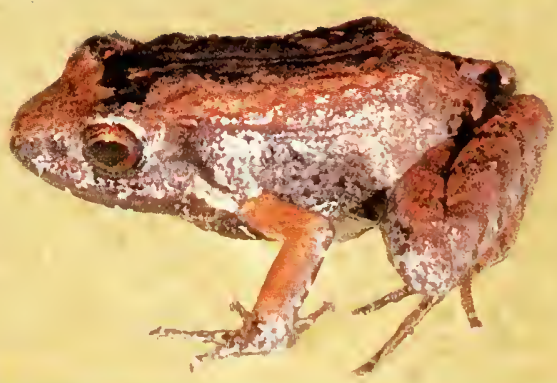

Barycholos mulcher; KU 1460)+6, female, $18.1 \mathrm{~mm}$ SVL. Río Palenque, Pichincha, Ecuador. WED. 


\section{PLATE 2}
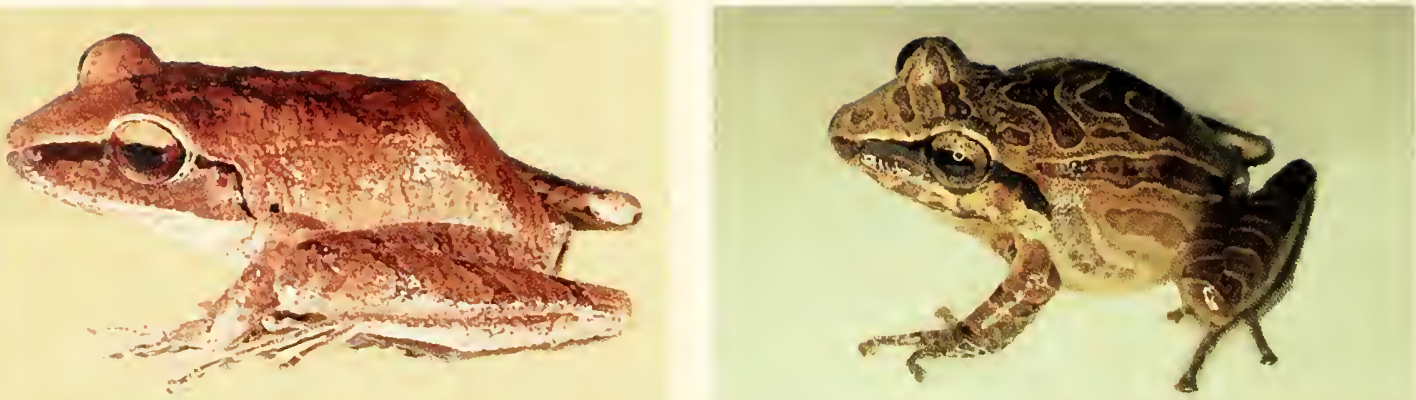

E. achatimus, KU 1 46054 , female, $37.6 \mathrm{~mm}$ SVL. Rio Palenque, Pichincha, Ecuador. WED.

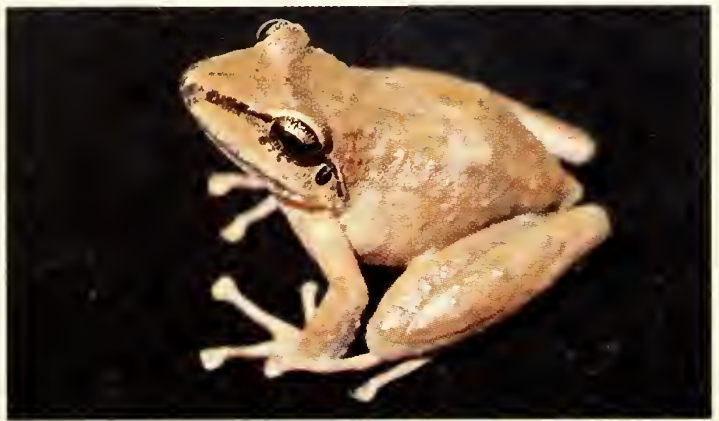

E. achatinus, KU 177600, male, $29.8 \mathrm{~mm}$ SVL. Maldonado, Carchi, Ecuador. JDI

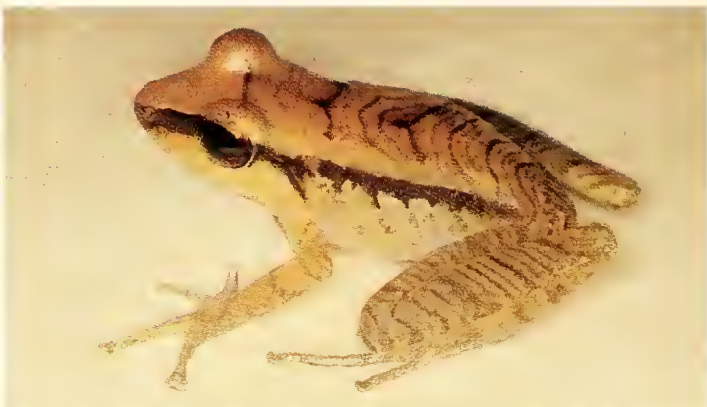

E. actites, KU 1+1776, female, $53.8 \mathrm{~mm}$ SVL. Pilaló, Cotopaxi, Ecuador. WED.

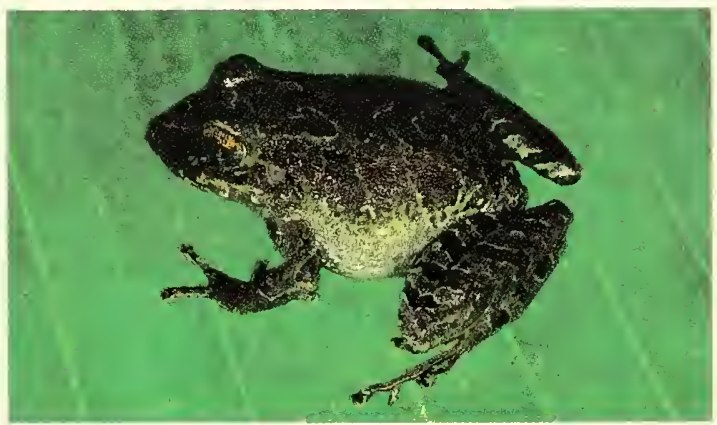

E. caprifer; KU 131591, female, 30.8 mm SVL. La Palma, Pichincha, Ecuador. JDL.

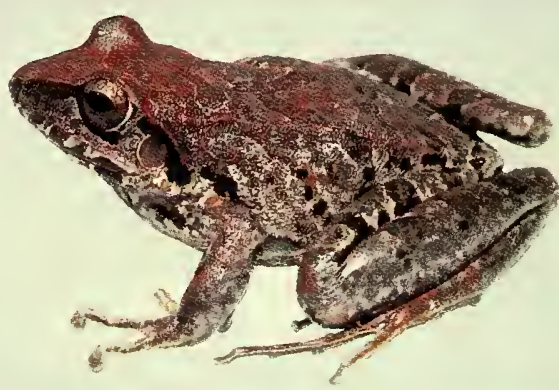

E. illotus, KU 165881, female, $38.3 \mathrm{~mm}$ SVL. $3.5 \mathrm{~km}$ NE Mindo, Pichincha, Ecuador. WED.

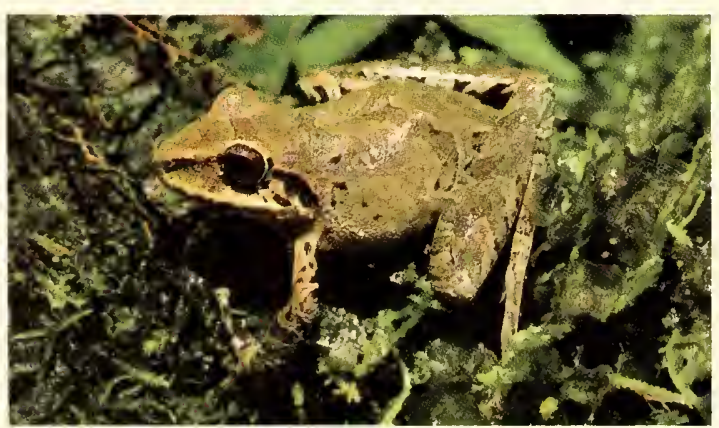

E. INmani, KU 165539, female, $52.5 \mathrm{~mm}$ SVL. $9 \mathrm{~km} \mathrm{~S} \mathrm{Loja.}$ Loja. Ecuador. WED.

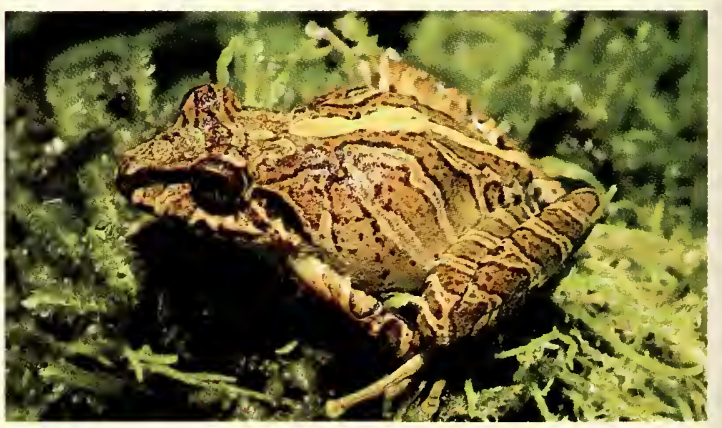

E. w-nigrnm, KU 165741, female, 59.9 mm SVL. Quebrada Zapadores, Pichincha, Ecuador. WED.

E. W-nigrmm, KU 165740, female, 51.4 mm SVL. Quebrada Zapadores, Pichincha, Ecuador. WED. 


\section{PI.ATE 3}

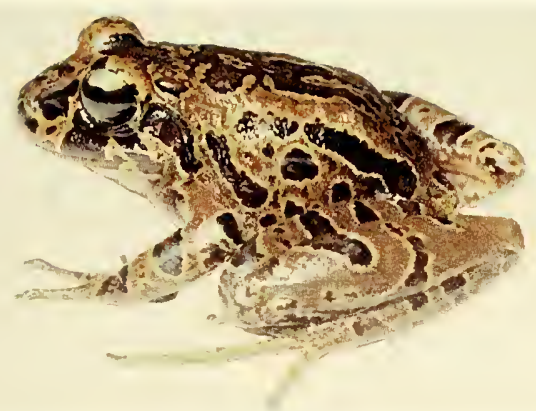

E. babax, ICNMHN 2924t, female, $47.7 \mathrm{~mm}$ SVL. Boquerón. Valle de Cauca, Colombia. JDL.

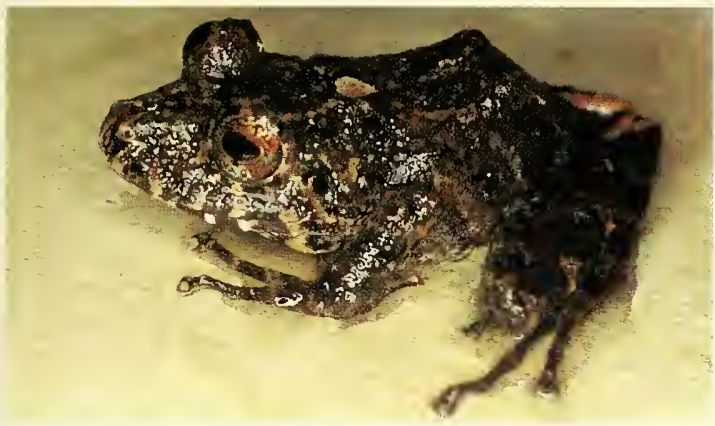

E. crenunguis, KU 131606, female, $36.4 \mathrm{~mm}$ SVL. Tandapi, Pichincha, Ecuador. JDL.

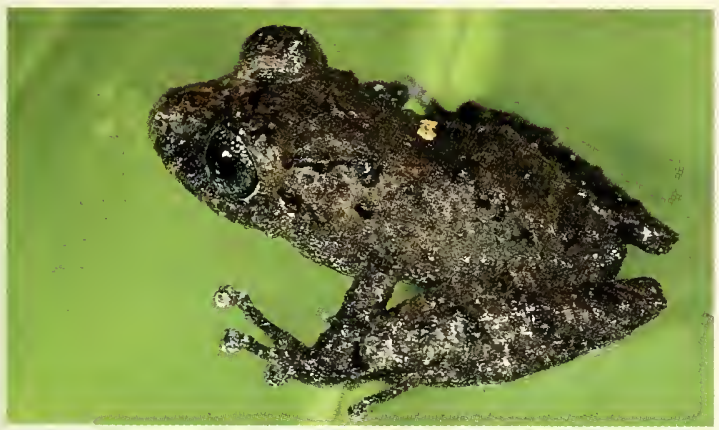

E. tenebrionis, MCZ 98164, male, 25.6 mm SVL. Río Palenque, Pichincha, Ecuador. KM.

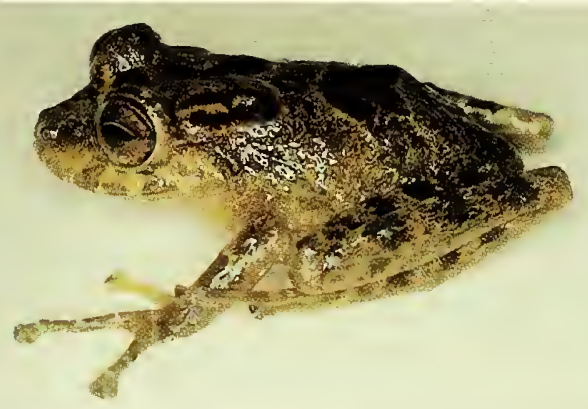

E. loustes, KU 179233, male, $30.2 \mathrm{~mm}$ SVL. Maldonado, Carchi, Ecuador. JDL.

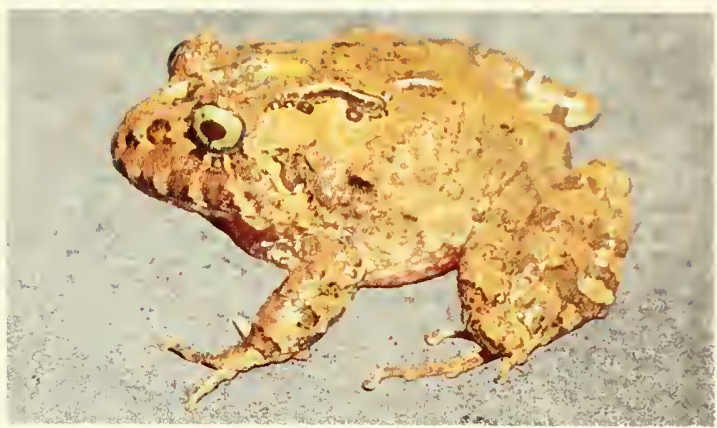

E. cerastes, ICNMHN 29065, female, $36.7 \mathrm{~mm}$ SVL. Serranía de Paraguas, Chocó, Colombia, JDL.

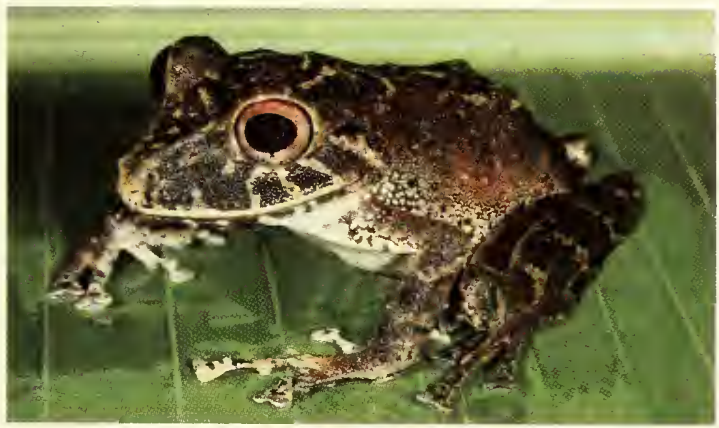

E. labiosus. Centinela, Pichincha. Ecuador. KM.

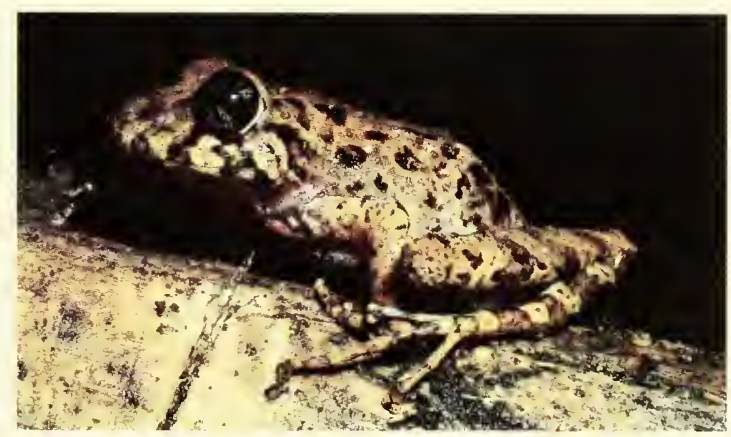

E. ocellatıs, IND-AN 1441, female, 45.7 mm SVL. La Planada, Nariño, Colombia. PAB.

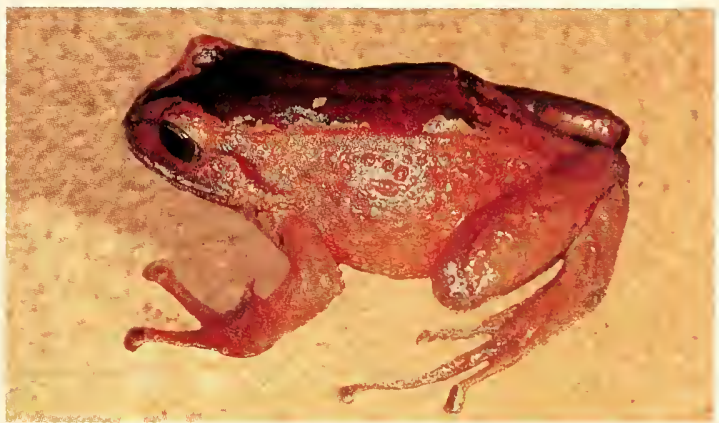

E. gentrii, KU 131540, female, 34.4 mm SVL. 5 km E Pilaló, Cotopaxi, Ecuador. JDL 


\section{PIATE 4}

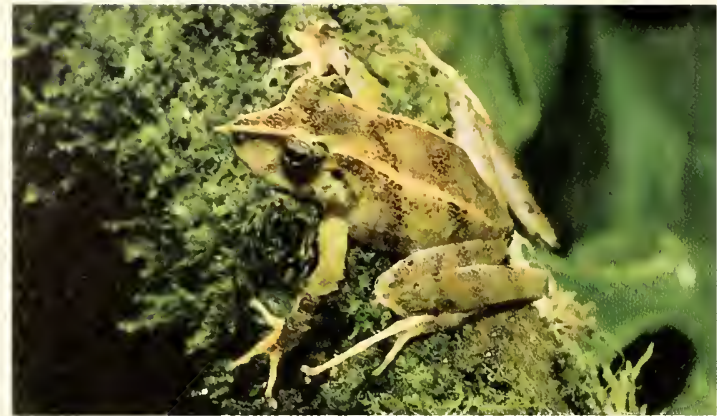

E. appendiculatus, KU 165133, female, $30.9 \mathrm{~mm}$ SVL. Quebrada Zapadores, Pichincha, Ecuador. WED.

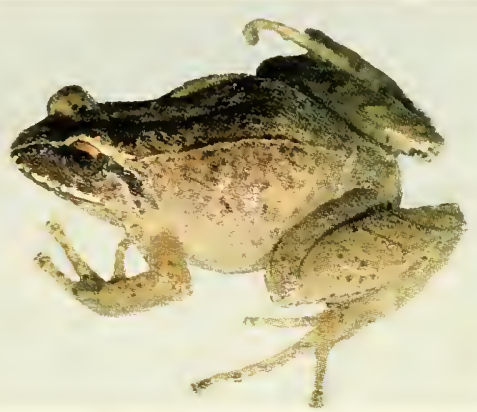

E. truebae. KU I66068, femate, $39.2 \mathrm{~mm}$ SVL. $15 \mathrm{~km} \mathrm{NW} \mathrm{El}$ Tambo, Cañar, Ecuador. WED.

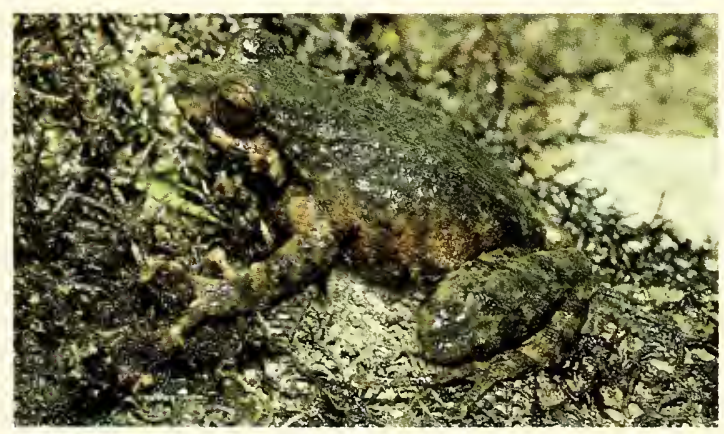

E. duellmani, KU 165908, female, $393 \mathrm{~mm}$ SVL $9 \mathrm{~km}$ SE Tandayapa, Pichincha, Ecuador. WED.

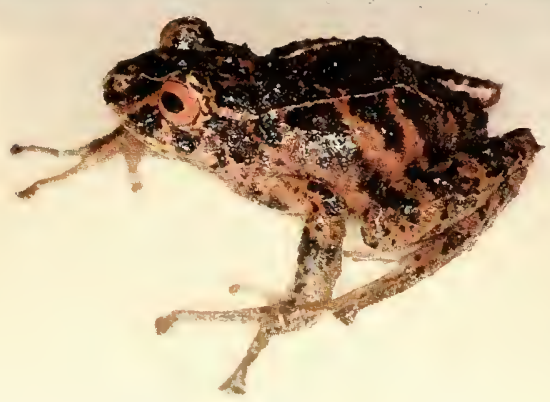

E. sobetes, KU 179389, female, $40.7 \mathrm{~mm}$ SVL. Quebrada Zapadores, Pichincha, Ecuador. JDL.

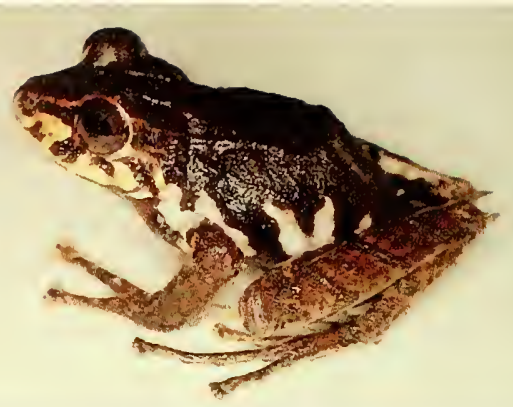

E. quinquagesimus, KU 179379, male, $28.6 \mathrm{~mm}$ SVL. Quebrada Zapadores. Pichincha. Ecuador. JDL.

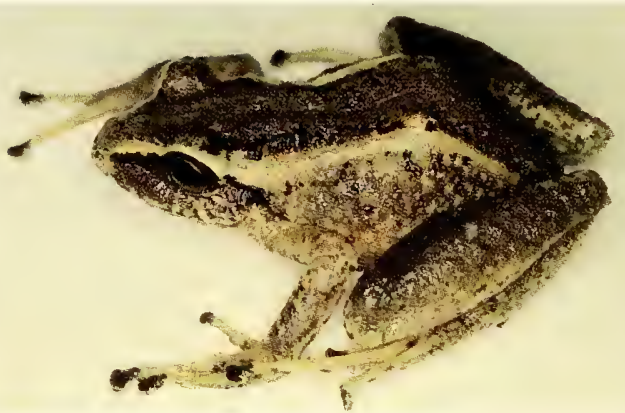

E. vertebralis, KU 177970, female, $40.2 \mathrm{~mm}$ SVL. La Delicia, Imbabura, Ecuador. JDL.

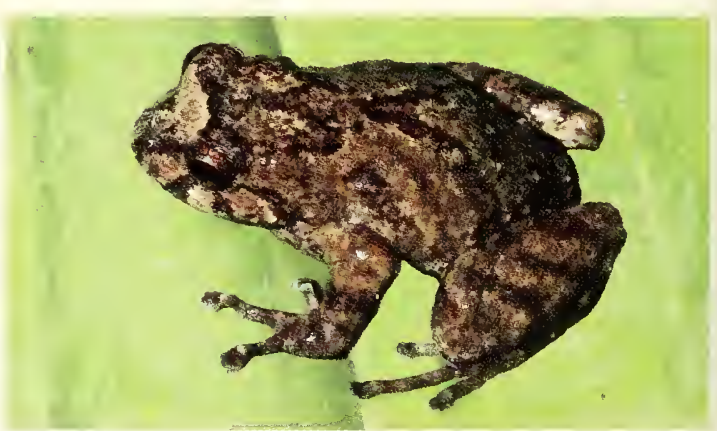

E. Lamiotae, USNM 239843, male, $30.9 \mathrm{~mm}$ SVL. $13.1 \mathrm{~km} \mathrm{NW}$ Nono, Pichincha. Ecuador. RWM.

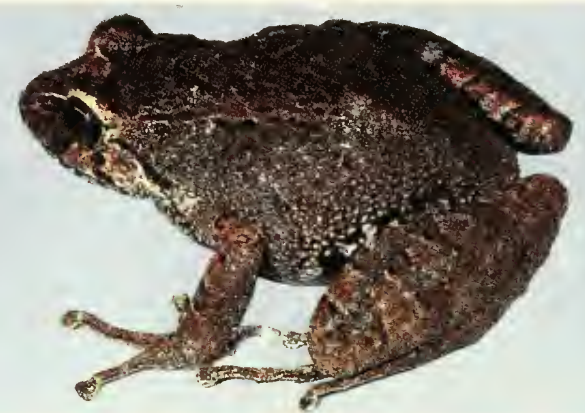

E. surdus, MCZ 97482, female, 45.2 mm SVL. Quebrada Silante Grande, Pichincha, Ecuador. KM. 


\section{PLATE 5}

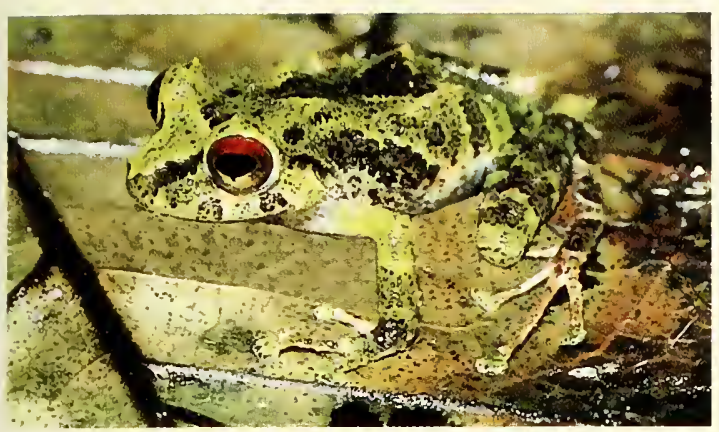

E. crucifer; ECO 87, lemale, $23.0 \mathrm{~mm}$ SVL. Above Lita, 1mbabura. Ecuador. MLC.

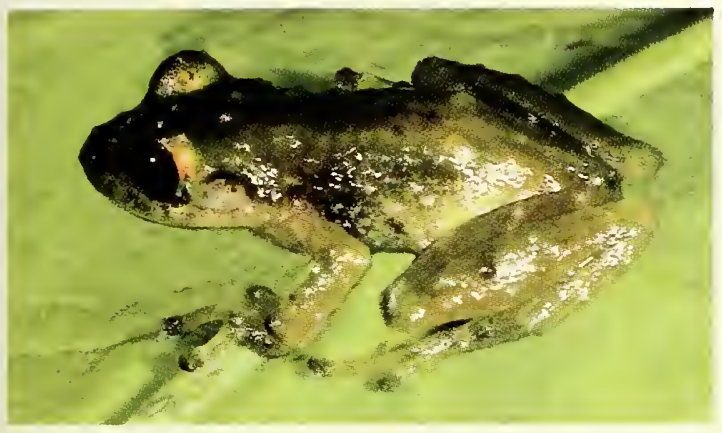

E. eremitus, MCZ 98189, male, $16.2 \mathrm{~mm}$ SVL. $8.6 \mathrm{~km}$ SE Tandayapa, Pichincha, Ecuador. KM.

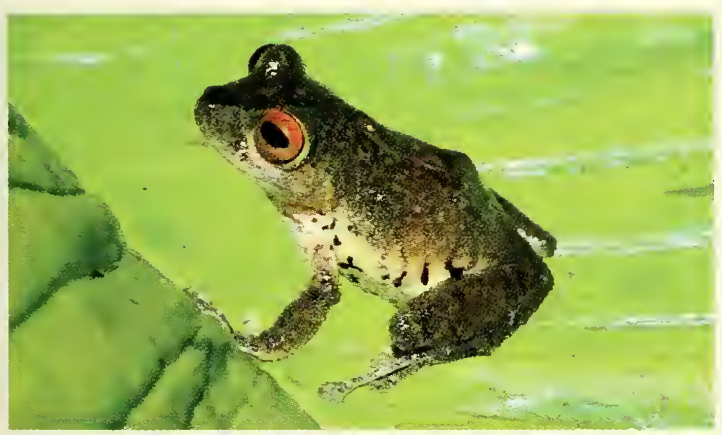

E. degener; ECO 77, female, $31.9 \mathrm{~mm}$ SVL. El Cristal, Esmeraldas. Ecuador. MLC.

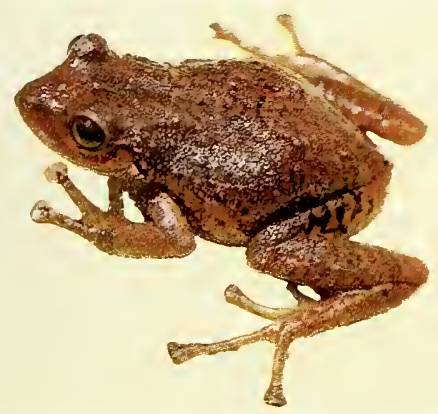

E. phoxoceplalus, KU 142076, female, $36.2 \mathrm{~mm}$ SVL. Pilaló, Cotopax. Ecuador. WED.

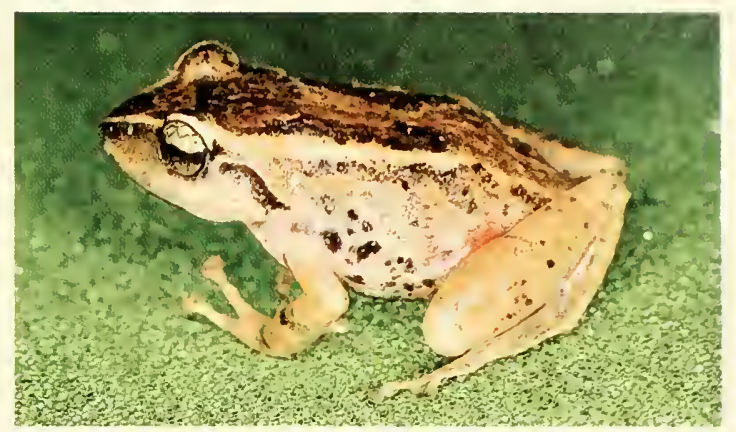

E. cajanarcensis, KU 120008 , female, $30.2 \mathrm{~mm}$ SVL. $6 \mathrm{~km} \mathrm{~N}$ San Lucas, Loja, Ecuador. JDL.

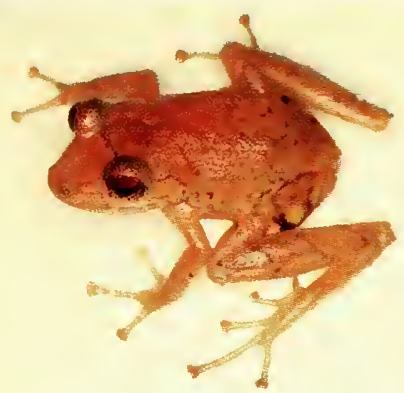

E. dissimulatus, KU 179096, female, $27.4 \mathrm{~mm} \mathrm{SVL}$. I km SW San 1 gnacio, Pichincha. Ecuador. JDL.

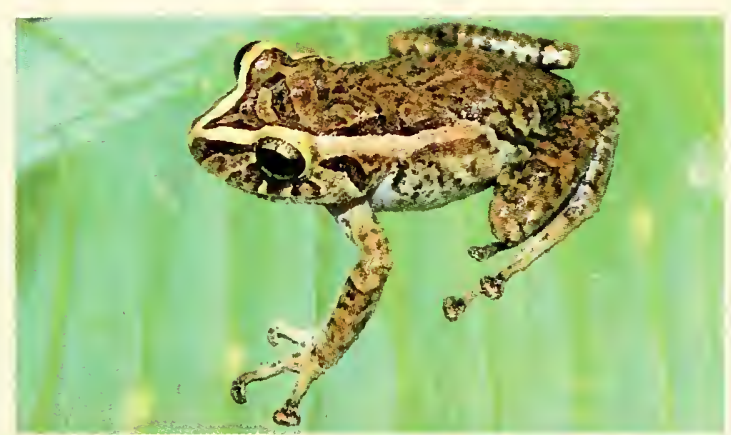

E. laticlarius, ECO 92, male, $14.6 \mathrm{~mm}$ SVL. El Cristal, Esmeraldas, Ecuador. MLC.

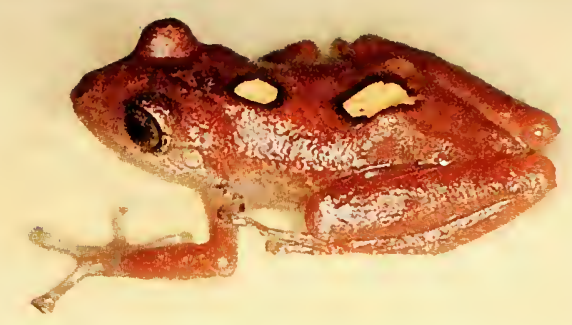

E. phoxocephalus, KU 131403, female, $36.2 \mathrm{~mm}$ SVL. Pilaló. Cotopax, Ecuador. JDL. 
PLATE 6

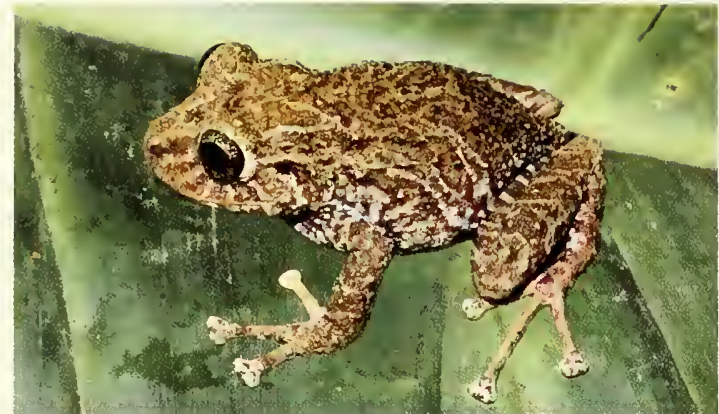

E. latidiscus, USNM 285540, female, $41.5 \mathrm{~mm}$ SVL. Centinela, Pichincha, Ecuador. RWM.

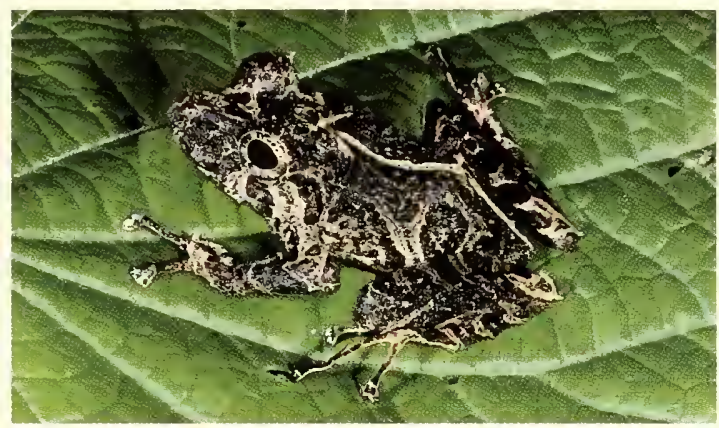

E. muricatus, MCZ 94456, female, 33.8 mm SVL. Río Palenque Pichincha, Ecuador. KM

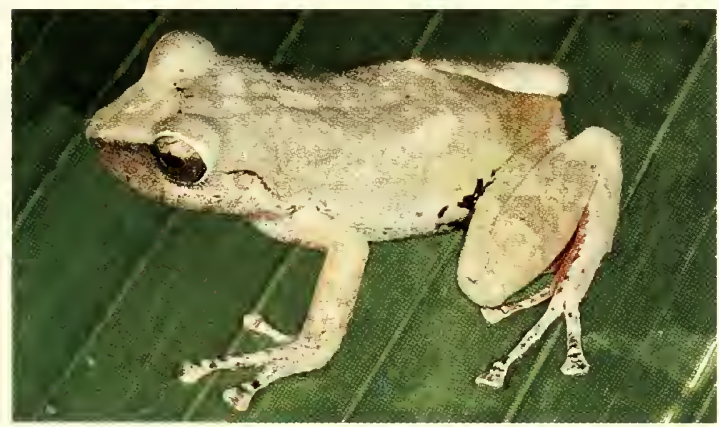

E. subsigillatus, MCZ 97559, male, $29.2 \mathrm{~mm}$ SVL. Centinela, Pichincha, Ecuador. KM.

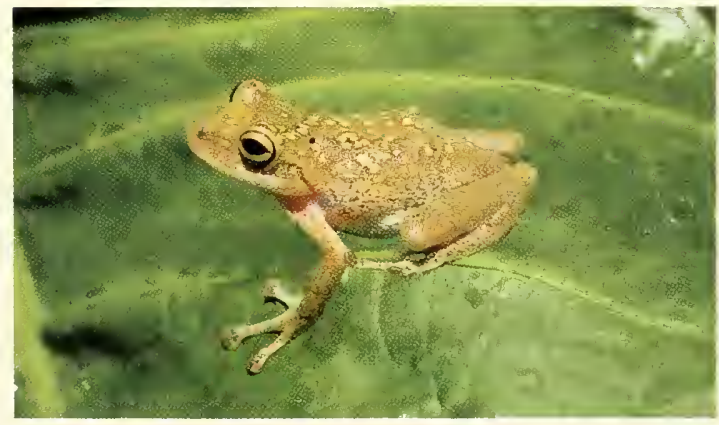

E. eugenite, KU 165899, female, $30.5 \mathrm{~mm}$ SVL. Quebrada Zapadores, Pichincha, Ecuador. IVED.

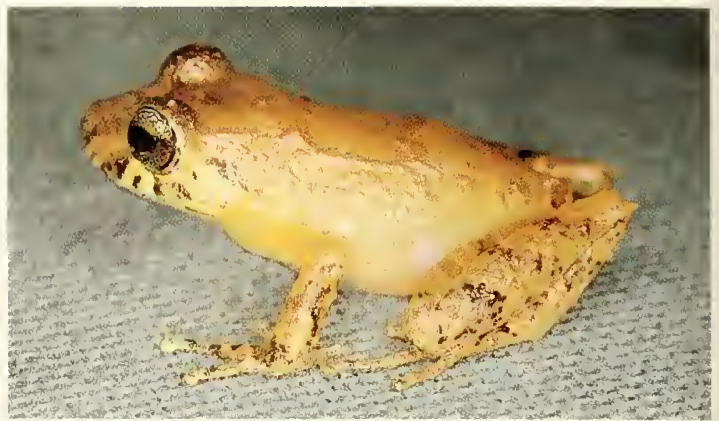

E. caltarulatus, KU 111267, male, $21.9 \mathrm{~mm}$ SVL. Tandapi, Pichincha, Ecuador. JDL.

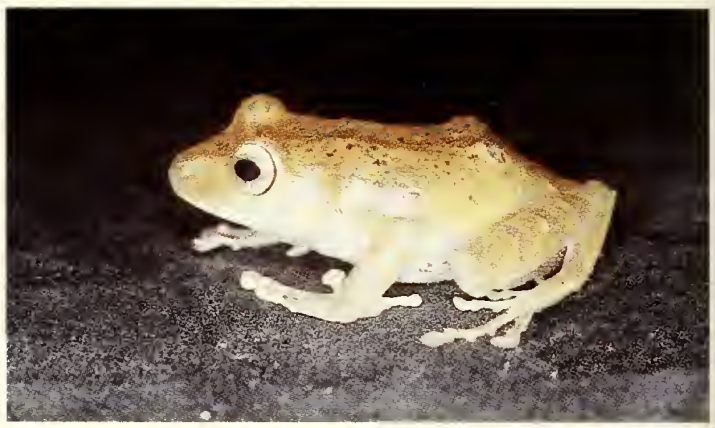

E. nvephylax, KU 110954, male, 24.8 mm SVL. Tandapi. Pichincha, Ecuador. JDL.

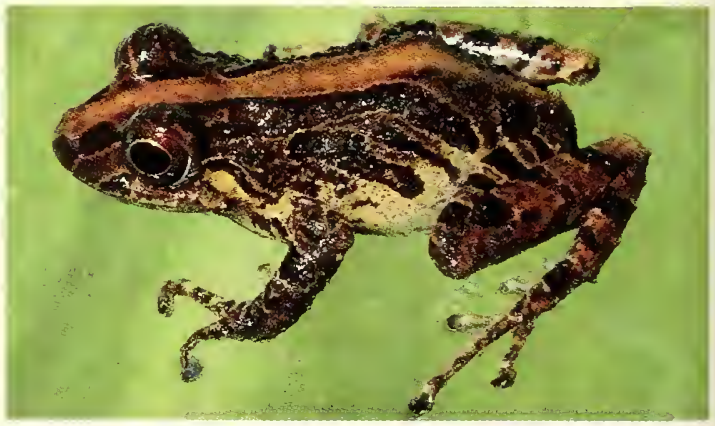

E. pteridophilus, USNM 286043, male, $24.7 \mathrm{~mm}$ SVL. $13.1 \mathrm{~km}$ NW Nono, Pichincha, Ecuador. RWM.

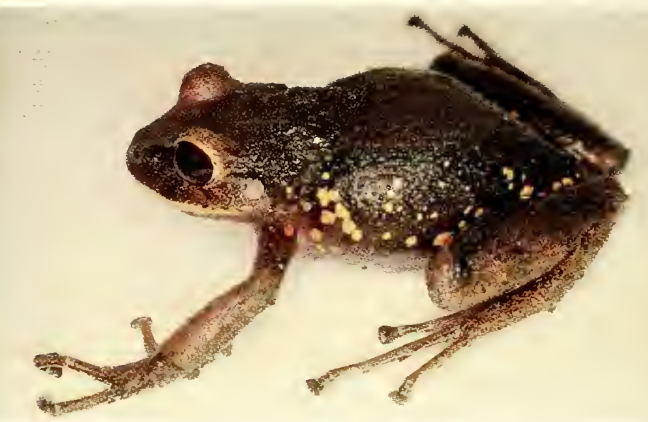

E. thymalopsoides, KU 177863, female, 44.9 mm SVL. Pilaló, Cotopaxi, Ecuador. JDL. 


\section{PLATE 7}

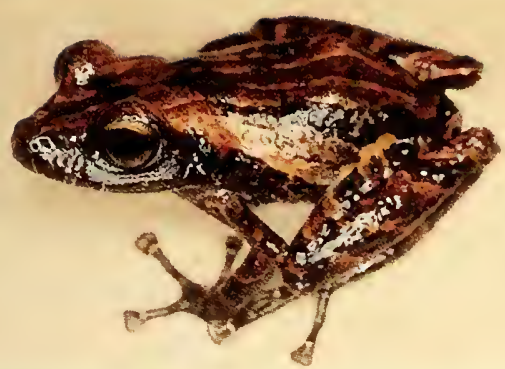

E. luteolateralis, KU 12015 4 , female, 23.5 mm SVL. Tandapi. Pichincha, Ecuador. JDL.

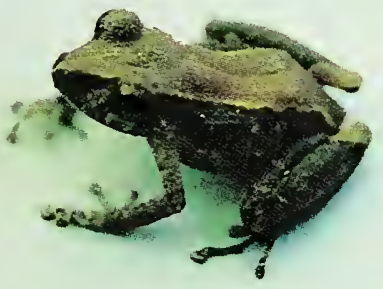

E. walkeri, KU 142017. female, $19.5 \mathrm{~mm}$ SVL. Río Baba, Pichincha. Ecuador. WED.

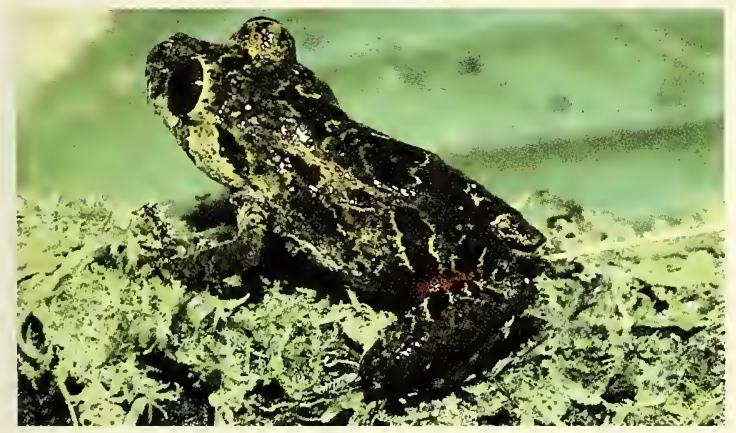

E. verecundus. ECO 94, female. $21.4 \mathrm{~mm}$ SVL. El Cristal, Esmeraldas, Ecuador. MLC.

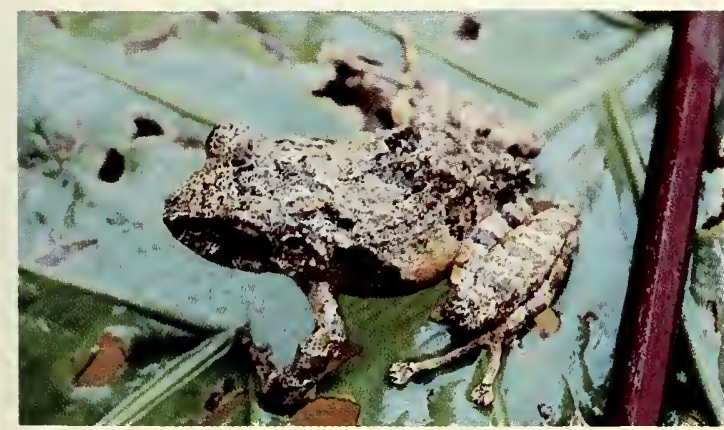

E. rosadoi, KU 2I 805I, female, 25. I mm SVL. Río Canoi, Pichin cha, Ecuador. LAC.

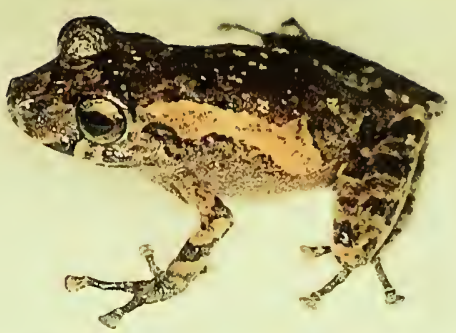

E. walkeri, KU 178010, female, $21.9 \mathrm{~mm}$ SVL. Santo Domingo de los Colorados, Pichincha, Ecuador. JDL.

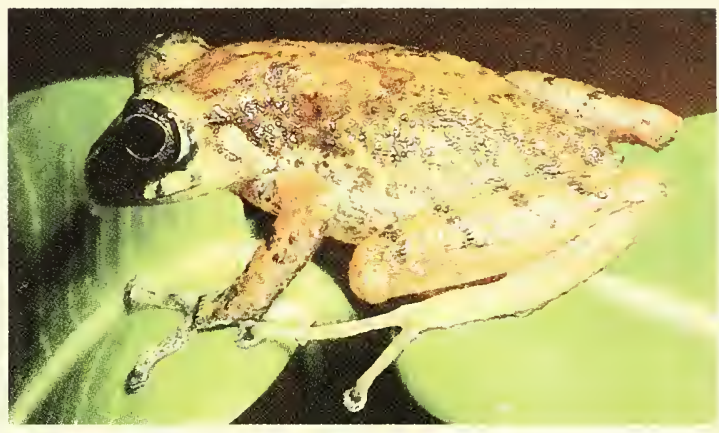

E. apiculatus, IND-AN 1755, female, 21.6 mm SVL. La Planada, Nariño, Ecuador. PAB.

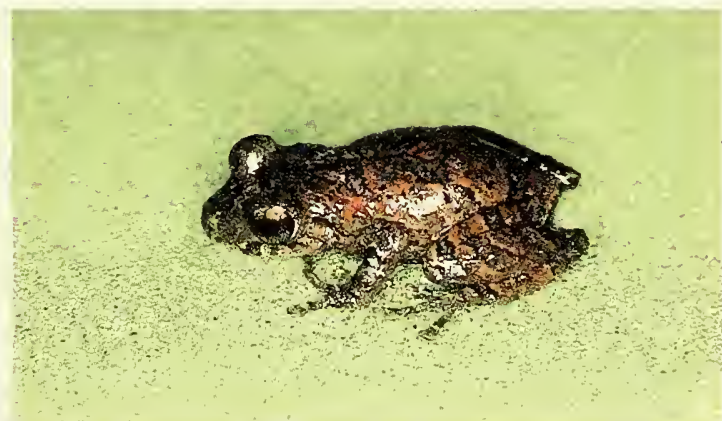

E. parilltis, KU 120244, female, $24.1 \mathrm{~mm}$ SVL. Tandapi. Pichincha. Ecuador. JDL.

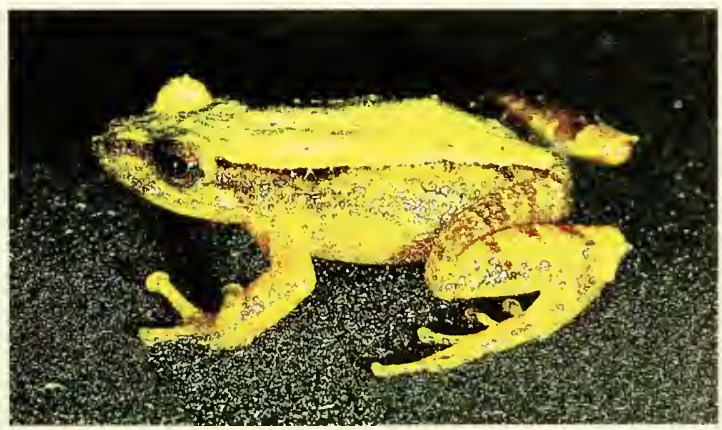

E. celator; KU 165200, male, $20.5 \mathrm{~mm} \mathrm{SVL.} 9.5 \mathrm{~km}$ NW Nono, Pichincha, Ecuador. WED. 
PILATE 8

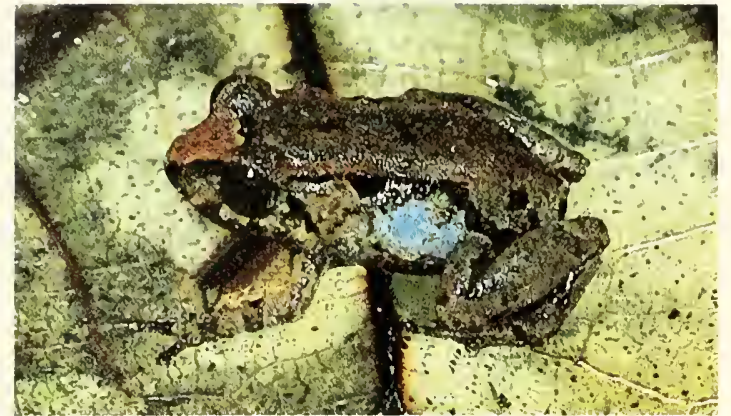

E. hectus, ECO 88, male, $14.1 \mathrm{~mm}$ SVL. El Cristal, Esmeraldas, Ecuador. MLC.

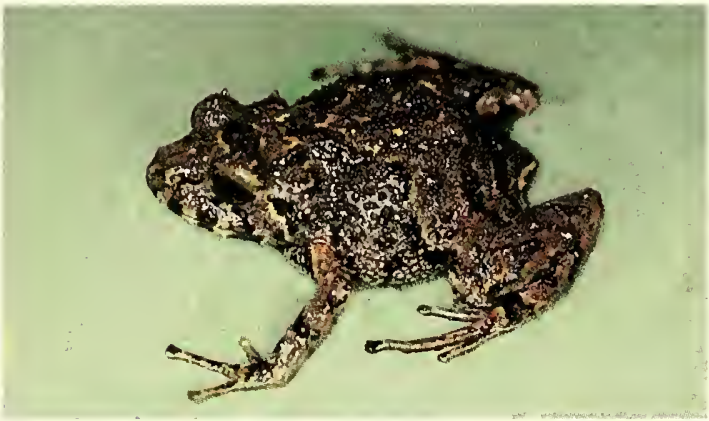

E. prrhomerus, KU 131607, female, $20.8 \mathrm{~mm}$ SVL. Pilaló, Cotopaxi, Ecuador. JDL

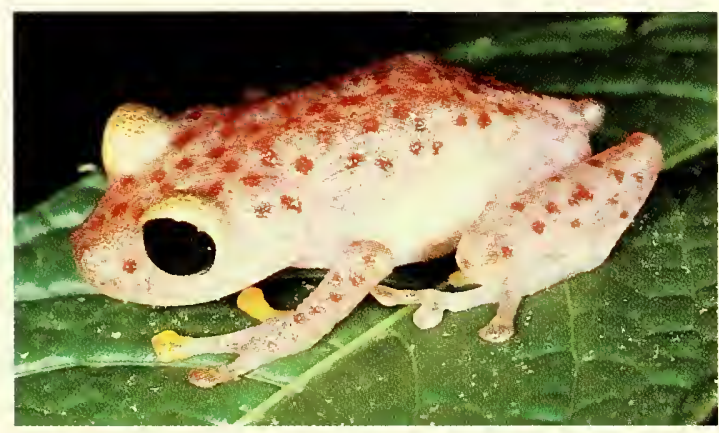

E. chalceus, KU 200152, female, 30.5 mm SVL. La Planada, Nariño, Colombia. WED.

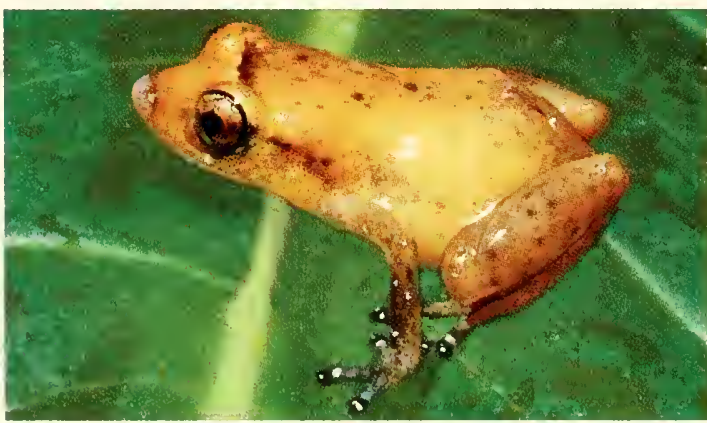

E. gukaris, ICNMHN 13739. female, 22.6 mm SVL. 1sla Gorgona, Cauca, Colombia. JDL.

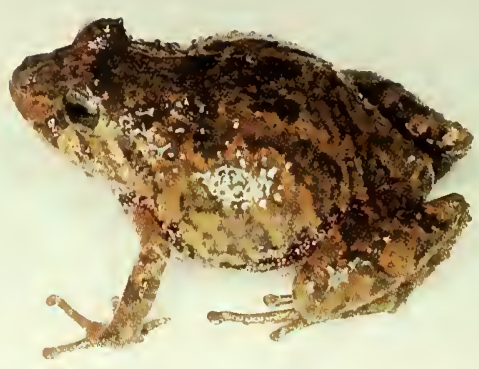

E. lemi, KU 177323, female, $22.3 \mathrm{~mm}$ SVL. $14 \mathrm{~km}$ SE Maldonado, Carchi, Ecuador. JDL

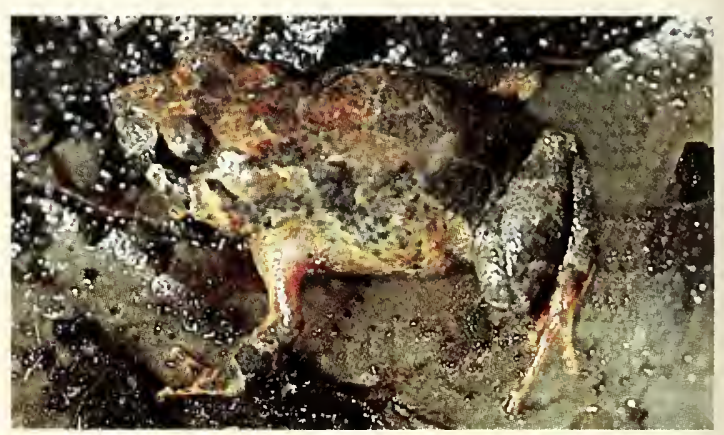

E. simmbolivari, KU 218253, male, $15.7 \mathrm{~mm}$ SVL. Cashea Totoras, Bolívar, Ecuador. LAC.

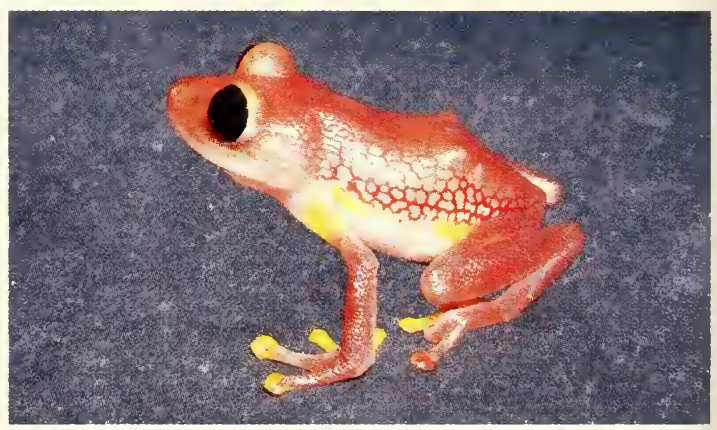

E. chalceus, ICNMHN 19186, female, $33.7 \mathrm{~mm}$ SVL. Parque Nacional Las Orquídeas, Antioquia, Colombia. JDL.

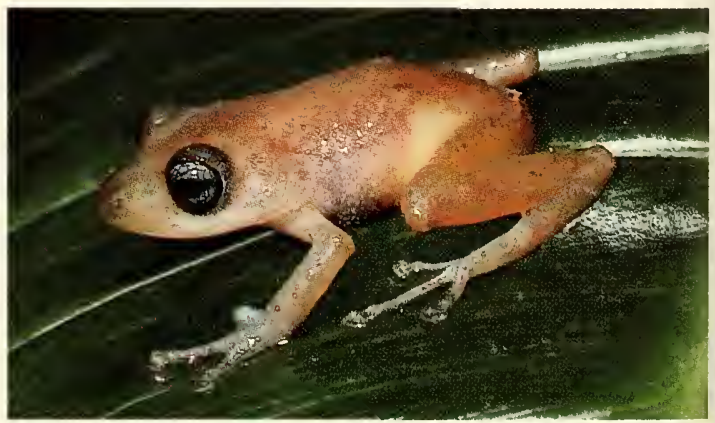

E. scoldiscus, IND-AN 1778, female, $22.3 \mathrm{~mm}$ SVL. La Planada, Nariño, Colombia. PAB. 
lacking tubercles, much narrower than flat IOD; cranial crests absent; (5) vomerine odontophores prominent, triangular in outline: (6) males lacking vocal slits and nuptial pads; (7) first finger shorter than second; fingers short; discs large; (8) fingers bearing narrow lateral fringes; (9) ulnar tubercles absent; (10) heel and tarsus lacking tubercles; (II) inner metatarsal tubercle elongate, 5-6× subconical outer metatarsal tubercle; supernumerary tubercles numerous; (12) toes bearing narrow lateral fringes; webbing absent; discs as large as those on fingers; fifth toe much longer than third; (13) dorsum brown with darker brown markings; venter cream with minute brown flecks; posterior surfaces of thighs cream with minute brown flecks; (14) SVL in males 19.6-21.4 mm, in females 22.0-24.5 mm.

Eleutherodactylus celator resembles $E$. chalceus in having areolate skin on the dorsum and short digits, but E. chalceus has elongate papillae on Fingers II-IV (absent in E. celator), bifid distal subarticular tubercles on fingers and toes (round in $E$. celator), and brown mesorchia (white in $E$. celator).

Description.-Lynch's (1976a) original description is adequate.

Coloration in life.-Coloration in this small species is highly variable, as noted in the following descriptions.

KU 131573-86 from La Delicia, Provincia Imbabura: Dorsum reddish brown, medium brown, or tan with brown, reddish-brown, or black markings (enamel-white flecks in a few individuals; one individual mostly pale grayish cream with soft gray markings; some individuals with pale gray to cream spots bordered by black); dorsolateral stripes black enclosing fawn-yellow to pale rust areas; concealed surfaces of limbs colorless or pale orange; venter yellow, dirty cream, or pale gray when collected (later changed to black); throat of males more lemon-yellow than belly; iris deep brown with median, horizontal, dark brown streak (JDL, 5 August 1970).

KU 165200-01 from 9.5 km NW Nono, Provincia Pichincha: Dorsum yellowish tan to pale orange; flanks tan; venter pale yellow; iris copper with median, horizontal brown streak (WED, 11 April 1975).

KU 177683-725 from $14 \mathrm{~km}$ SE Maldonado, Provincia Carchi: Dorsum yellow, pale orange, reddish brown, or brown with or without brown marbling; limbs tending to be more orange than body; ventercreamy metallic-yellow to nearly black, in which case dark cream flecks obvious; throat dirty dull yellow; limbs gray; iris bright copper with black reticulations and brown, median, horizontal streak (JDL, 31 May 1977).

Natural History.-All Ecuadorian specimens have been found in terrestrial bromeliads in cloud forest by day; usually only one individual was found in a given bromeliad, but one large bromeliad contained eight individuals. Arboreal bromeliads at a site $14 \mathrm{~km}$ SE of Maldonado, Provincia Carchi, were searched, but no individuals were found, whereas terrestrial bromeliads yielded 43 individuals. Lynch and Burrowes (1990) reported specimens from terrestrial bromeliads in Colombia, but they also noted individuals on low vegetation not associated with bromeliads at night.

Distribution.-Eleutherodactylus celator is known from only six localities at elevations of $1750-2800 \mathrm{~m}$ on the western slopes of the Cordillera Occidental in northwestern Ecuador and adjacent Colombia (Fig. 24). The five Ecuadorian localities are in the humid temperate regime.

Remarks. - The distribution of this small frog is poorly documented because of inadequate searches of terrestrial bromeliads in cloud forest.

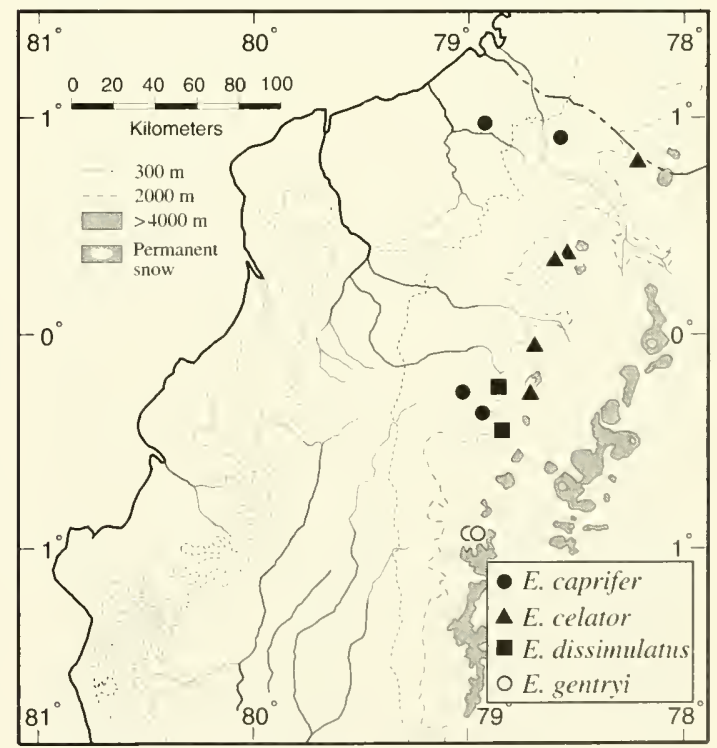

Fig. 24. Distribution of four species of Eleutherodactylus in western Ecuador. 


\section{Eleutherodactylus cerastes Lynch}

Plate 3

Eleutherodactylus cerastes Lynch, 1975a:25.-Holotype: USNM 195785, juvenile female, from Palma Real, Provincia Pichincha, Ecuador.

Diagnosis.-A member of the Eleutherodactylus (Eleutherodactylus) sulcatus group having (1) skin on dorsum bearing heterogeneous tubercles and longitudinal ridges, that on venter smooth; discoidal fold absent; dorsolateral folds absent: (2) tympanic membrane and tympanic annulus prominent, its length $1 / 3-3 / 5$ length of eye; (3) snout rounded in dorsal view, truncate in profile; (4) upper eyelid bearing many conical tubercles (one elongate), broader than IOD; cranial crests present: (5) vomerine odontophores arched, broad: (6) males lacking vocal slits and nuptial pads; (7) first finger longer than second; discs barely developed: (8) fingers lacking lateral fringes; (9) ulnar tubercles in a distinct row; (10) heel bearing one small tubercle; outer surface of tarsus having small tubercles; inner tarsal fold and tubercles absent; (11) inner metatarsal tubercle compressed, $3 \times$ low, round outer metatarsal tubercle; supernumerary tubercles absent; (12) toes lacking lateral fringes; webbing absent; discs small, but larger than those on fingers; fifth toe shorter than third; (13) dorsum brown with darker markings associated with tubercles and ridges; venter cream with brown reticulation; throat brown with cream flecks; posterior surfaces of thighs brown with cream spots: iris green in life; (14) SVL in two males 28.3-33.4 mm, in nine females $44.4-55.8 \mathrm{~mm}$.

West of the Andes, this is the only species of broad-headed Eleutherodacty/us in which there is an elongate tubercle on the upper eyelid. Superficially, it resembles E. ruizi, which has granular skin on the venter and an inner tarsal fold. Eleutherodactylus helonotus also has granular skin on the venter, but it lacks elongate tubercles on the upper eyelids and has low, flat warts on the dorsum (but only large females are known). Like E. cerastes, $E$. cadenai has smooth skin on the venter and an elongate eyelid tubercle, and lacks an inner tarsal fold, but it is easily distinguished by having an ossified cheek region. The absence of webbing on the feet readily distinguishes $E$. cerastes from the coarsely tuberculate E. anomalus. Eleutherodactylus necerns (a large member of the subgenus Crangastor) is similar in skin texture and lacks webbing on the feet, but it lacks conical tubercles on the eyelids. Additionally, E. cerastes is distinguished from other members of the genus in western Ecuador by having a lime-green iris in life.

Description.-Lynch (1975a) based the original description primarily on specimens from western Ecuador.

Coloration in life.-Color notes are not available for Ecuadorian specimens; the following notes are based on specimens from Colombia.

Parque Nacional Natural Las Orquídeas, Vereda Calles, Municipio Urrao, Departamento Antioquia: Dorsum brown to rusty brown with or without black highlights, dark green patch, or orange tint on ridges: posterior surfaces of thigh black with cream flecks; venter cream with brown reticulation; pale yellow line on lips of one individual; iris pale green with brown or black radiations (JDL 16359-62, 23-25 May 1988).

Vicinity of Boquerón, Departamento Chocó: Dorsum brown to dark brown with black markings beside ridges or ridges rust colored; labial bars black and cream or dark brown and reddish brown; throat brown or dull brownish yellow with brown marbling; posterior surfaces of thighs dark brown with cream flecks; iris lime-green with dark gray radiations or black reticulation (JDL 18539 and 18686, 24-25 June 1991).

Natural history.-This species inhabits cloud forests and clearings therein. Occasionally, individuals of this terrestrial, primarily nocturnal frog are found in leaf litter by day, but it is assumed that these were disturbed and fled their diurnal retreats. At night, the frogs have been observed sitting in an alert posture on upper surfaces of leaves, walking across trails, and climbing banks of streams.

Distribution.-Ecuadorian records for the species are at elevations of $500-1200 \mathrm{~m}$ in the humid subtropical regime on the western face of the Andes (Fig. 23), but in Colombia, where the species is better known, it extends to about $2000 \mathrm{~m}$. Present records suggest a continuous distribution from northwestern Departamento Antioquia. Colombia, to the Río Guayllabamba in Provincia Pichincha, Ecuador. 
Remarks. - This species was included in the Eleutherodactylus sulcatus group as redefined by Lynch (1986a). Eleutherodactylus semai Rivero from the extreme northern part of the Cordillera Occidental in Colombia probably is not distinct from E. cerastes, but that issue will be addressed in a monograph of the frogs of the E. sulcatus group by JDL. At present, the relationships of several species in the E. sulcatus group, including $E$. cerastes and E. helonotus (the only members of the group in western Ecuador), are not resolved.

\section{Eleutherodactylus chalceus (Peters) Plate 8}

Phyllobates chalceus Peters, 1874:609.-Syntypes: Lost, from "Pastasasathal" (= Pastassa-Tal, Colombia, fide Nieden, 1923:402).

Syrrhophus chalceus-Boulenger, 1888:206.

Syrrhophus areolatus Boulenger, 1898:122.-Syntypes: BM 1947.2.15.38-39 from Cachabé, Provincia Esmeraldas, and "Chimbo" (= Puente del Chimbo). Provincia Guayas, Ecuador. Synonymy fide Lynch. 1980b: 179.

Eleutherodactylus areolatus-Lynch, 1968:291.

Eleutherodacty/us chalceus-Lynch 1968:291: 1980b: 179.

Diagnosis. - A member of the Eleutherodactylus (Eleutherodactylus) diastema group having (1) skin on dorsum and venter areolate; discoidal fold prominent; dorsolateral folds absent; (2) tympanic membrane absent but tympanic annulus evident beneath skin, its length about $1 / 3$ length of eye; (3) snout short, subacuminate in dorsal view, truncate in profile; (4) upper eyelid lacking tubercles, as wide as IOD; cranial crests absent; (5) vomerine odontophores oblique; (6) males having vocal slits and large, external vocal sac: nuptial pads absent; (7) first finger slightly shorter than second; discs round, with papillae at tips of discs on Fingers II-IV; (8) fingers broad, bearing narrow lateral fringes; distal subarticular tubercles bifid; (9) ulnar tubercles absent; (10) heel and tarsus lacking tubercles and folds; (11) inner metatarsal tubercle oval, $3 \times$ flat, round outer metatarsal tubercle; supernumerary tubercles not obvious; (12) toes lacking lateral fringes; webbing absent; discs round, bearing distal papillae of Toes II-IV; distal subarticular tubercles weakly bifid; fifth toe much longer than third; (13) dorsum cream to brown with or without reddish brown spots or reticulations: venter white: posterior surfaces of thighs unpigmented; (14) SVL in males 17.5-26.9 mm, in females 27.7-31.2 mm.

Eleutherodactylus chalceus is distinctive in the genus by having areolate skin on the dorsum. Also, the presence of elongate papillae on the tips of the digits and bifid distal subarticular tubercles readily distinguish this species from all others. Eleutherodactylus scolodiscus is similar, but it has short (not elongate) papillae only on Finger III and Toes IIIV, round instead of bifid distal subarticular tubercles, less prominent granulations on the dorsum, orange in the groin and on the concealed surfaces of the thighs, and a blue iris in life.

Description.-Lynch's (1971) redescription (as E. areolatus) is complete and accurate, except that he did not distinguish adequately between adults and subadults and juveniles. The size range give here is based only on calling males and ovigerous females.

Coloration in life.-Many Eleutherodactylus chalceus have no color pattern; others have reddish-brown flecks on the dorsum (most common in Departamento Valle de Cauca, Colombia), bold reddish-brown spots, or reddish-brown reticulations. The variation and ability to change color are documented by the following field notes:

$K U$ 117487-91 from Santo Donningo de los Colorados, Provincia Pichincha: At night, dorsum uniform creamy yellow to pale reddish-bronze or pale reddish-brown; by day, some individuals creamy yellow with reddish-brown spots; flanks pale yellow; hands and feet of yellow phase, orange, or of reddish phase, yellow; colors well set off from color of shank and forearm; venter uniform white, but throat may have yellowish tint; posterior surfaces of thighs unpigmented (JDL, 5 March 1968).

KU 119474-85 from Santo Domingo de los Colorados, Provincia Pichincha: Dorsum reddish brown at night; by day creamy yellow with or without reddish-brown spots; venter white; hands and feet yellow or orange (JDL, 2 August 1968).

KU 165143-48 from $3.5 \mathrm{~km}$ NEMindo, Provincia Pichincha: Dorsum pale greenish tan with reddish- 
brown spots; thighs creamy white; venter white: palpebrum bronze; iris black with faint. dull bronze reticulations (WED, 7 April 1975).

One individual (KU 141773) from the Río Baba. Provincia Pichincha, and two (KU 141774-75) from $10.5 \mathrm{~km}$ N Quinindé, Provincia Esmeraldas, were noted to have a metallic green dorsum (WED, 2 and 4 July 1971). Another individual (KU 120252) from Santo Domingo de los Colorados, Provincia Pichincha, was noted to have the groin and concealed surfaces of the thighs red (JDL, 3 August 1968).

Natural history.-During the day, these small frogs take shelter in the axils of leaves of bromeliads and elephant ear plants. At night, they are active on native and cultivated vegetation, usually no more than $1.5 \mathrm{~m}$ above the ground. During 19771978, JDL marked large numbers of E. chalceus in a banana grove at the edge of Santo Domingo de los Colorados, Provincia Pichincha. As many as 30 individuals were encountered in a single evening on herbaceous vegetation in the banana grove, as well as on the leaves of the banana plants. The ease of collecting in the banana grove may contribute to JDL's impression that $E$. chalceus was more abundant in the banana grove than in primary forest 1 or $2 \mathrm{~km}$ away.

Eleutherodactvlus chalceus often is found on vegetation beside streams, but the observation of the species there probably reflects collectors ' preferences for streams rather than that of the frogs, which also are abundant in the forest away from streams.

Males were found calling in May at Maldonado, Provincia Carchi, and in June at Santo Domingo de los Colorados, Provincia Pichincha.

Distribution.-This species occurs at elevations of 50-1970 m from southwestern Departamento Antioquia, Colombia, to Provincia Guayas, Ecuador (Fig. 25). Twenty of the 25 Ecuadorian localities for this species are below $1000 \mathrm{~m}$, where it seems to be far more abundant than it is at higher elevations. The species is absent from the drier regions of southwestern Ecuador, but one of the syntypes supposedly originated from Chimbo, Provincia Guayas, in the dry subtropical regime. Six Ecuadorian localities are in the humid tropical regime, whereas 18 are in the humid subtropical regime.
Remarks.-The two trivial names, areolatus and chalceus, were carried in Syrrhophus for much of this century, but little literature accumulated on either name until Lynch (1971a) provided a redescription of what he called E. areolatus, although Lynch (1968) briefly confused E. chalceus with what is now called $E$. lacrimosus, a species in the Amazon Basin. Lynch (1980b) subsequently decided that the purported type locality of Phyllobates chalceus (Pastassa-Tal, Colombia) must be some unknown locality on the western side of the Andes rather than the Pastaza Valley of eastern Ecuador; thus, he combined the two species because no features were available to distinguish Syrrhophus areolatus from Phyllobates chalceus.

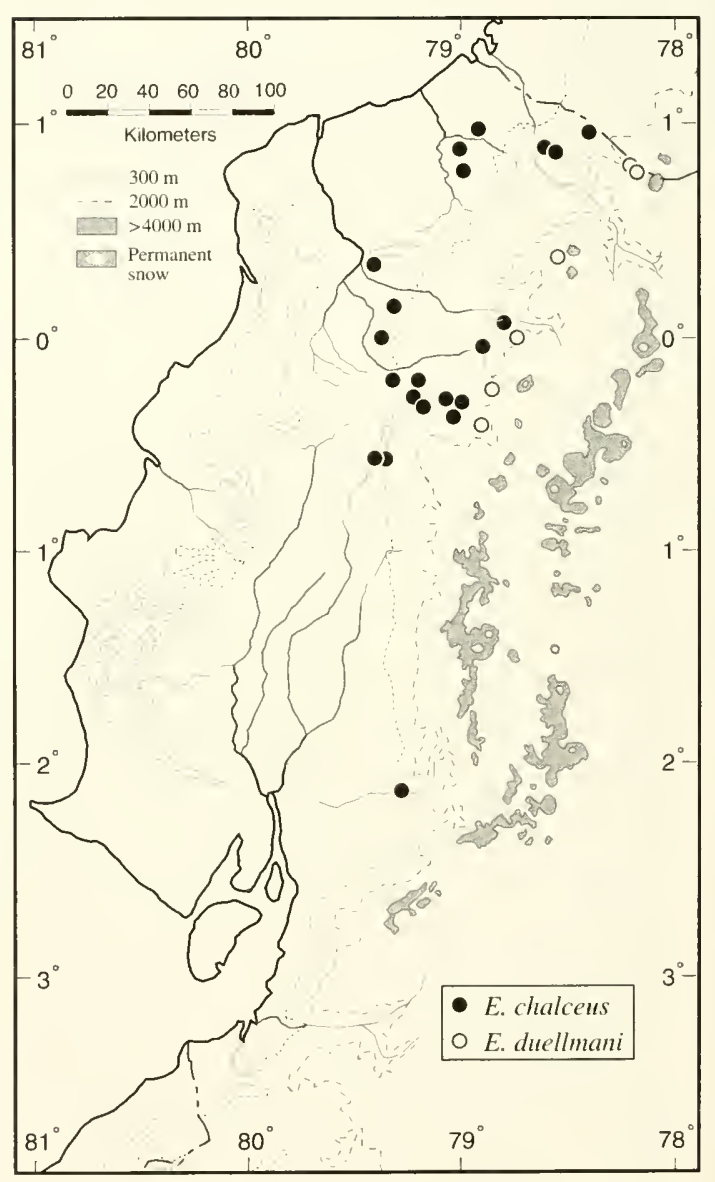

Fig. 25. Distribution of two species of Eleutherodactylus in western Ecuador. 
Lynch and Burrowes (1990:20) included E. chalceus and E. scolodiscus in a "small group of species having papillae at the digital tips $(E$. chalceus, E. gularis [Boulenger], and E. vocator [Taylor])." They added that these four species usually were associated with two species in lower Central America-E. diastema (Cope) and E. hylaeformis (Cope) - in spite of the absence of explicit shared characters. Eleutherodactylus chalceus has papillae on the tips of the digits on Fingers II-IV and Toes II-IV. The digital pads and disc covers of E. vocator are pointed but do not bear papillae. Lynch and Burrowes (1990) were confused about the condition of the digits in E. gularis as well; this resulted from Lynch's (1976b) incorrect report concerning $E$. gularis. In the latter, the fingers bear no papillae on the pads or disc covers, but Toes II-IV have papillae. Eleutherodactylus scolodiscus is like E. gularis, except that it has papillae on the third fingers. Eleutherodactylus diastema and E. hylaeformis lack papillae on either fingers or toes. Lynch thinks that there are no fewer than two or three undescribed species in Colombia and Panama that have been confused (by various authors) with E. diastema, E. gularis, and E. vocator; two of these undescribed species have papillae on the fingers.

Although most students of Costa Rican frogs have mentioned an Eleutherodactylus diastema group, none has been explicit about its characters. Cochran and Goin (1970) attempted to be explicit and cited the shape of the vocal sac (folds) and the short fingers and toes as supporting evidence. However, Savage (1968) argued against the inclusion of E. moro in the group; although his comments were directed against the original description of a synonym of E. moro, his comments represent an effective criticism of the subsequently published account by Cochran and Goin (1970). Savage (1968) noted that frogs of the E. diastema group have short, stubby fingers but pointed out that E. moro does not have short, stubby fingers and therefore is not a member of the E. diastenla group.

The fingers of E. chalceus are short and stubby and resemble, in some ways, those of E. diastema and E. gularis, but it is premature to suggest that we have any idea about the homologies among "short, stubby fingers" and "longer, less stubby fingers," let alone any thing about polarities among the states of the character(s).

\section{Eleutherodactylus colomai sp. nov.}

Holotype.-QCAZ 1289, adult male, from Alto Tambo, 830 m (0051'42" N, 78³0'54" W), Provincia Esmeraldas, Ecuador, one of a series collected on 6 December 1990 by Stella de la Torre, Diego Lombeida, Jean-Marc Touzet, and Felipe Campos.

Paratype.-QCAZ 1296, collected with the holotype.

Diagnosis.-A member of the Eleutherodactylus (Eleutherodactylus) unistrigatus group having (1) skin on dorsum smooth, that on venter finely areolate; discoidal fold prominent; dorsolateral folds absent; (2) tympanic membrane and tympanic annulus prominent, its length about $1 / 3$ length of eye; (3) snout subacuminate in dorsal view, protruding in profile; (4) upper eyelid lacking small tubercles, about as wide as IOD; cranial crests absent: (5) vomerine odontophores elongately oval, prominent; (6) males having vocal slits and white nuptial pads; mesorchium white; (7) first finger shorter than second; discs broad, round: (8) fingers lacking lateral fringes; (9) ulnar tubercles low; (10) heel bearing short calcar; outer edge of tarsus bearing indistinct tubercles; inner edge of tarsus lacking one tubercle and fold; (1I) inner metatarsal tubercle oval, $2 \frac{1}{2}-4 \times$ round outer metatarsal tubercle; plantar surfaces areolate; (12) toes bearing indefinite lateral fringes near bases of digits; webbing absent; fifth toe much longer than third; (13) dorsum tan with dark sacral and suprainguinal spots; side of head and flanks darker brown with white flecks; venter cream with brown flecks; (14) SVL in two males 16.5 and $17.8 \mathrm{~mm}$. females unknown.

Eleutherodactylus colomai is most readily confused with $E$. rosadoi. These small frogs have similar color patterns, at least in preservative. However, E. colomai has a protruding snout (rounded in E. rosadoi) and a calcar on the heel (small tubercles in $E$. rosadoi ), and lacks tubercles on the upper eyelid (present in E. rosadoi). Moreover, the mesorchium is white in E. colomai and black in $E$. rosadoi. 
Description. $-n=2$ males. Head narrower than body, slightly wider than long; HW 34.5 and $35.4 \%$; snout subacuminate in dorsal view, protruding in profile, acuminate at tip (Fig. 26); E-N 84.8 and $95.2 \%$ length of eyes; nostrils slightly protuberant (primarily laterally), directed laterally; canthus rostralis angular, straight or weakly sinuous; loreal region flat, sloping abruptly (nearly vertically) to lips; lips not flared; upper eyelid and rest of head lacking tubercles; upper eyelid width 87.5 and $100.0 \%$ IOD; cranial crests absent; temporal region vertical; supratympanic fold poorly defined, obscuring upper edge of tympanic annulus, extending posteriorly to about level of upper arm but not curving ventrally; tympanic annulus adpressed against skin, clearly visible except uppermost portion; tympanic annulus round, its length 32.0 and
$38.1 \%$ length of eye, separated from eye by distance about half length of tympanic annulus; postrictal tubercles small, separate nonconical. Choanae round, not concealed by palatal shelf of maxillary arch; vomerine odontophores elongately oval, transverse, posteromedian to choanae, relatively prominent, separated medially by distance equal to about half width of odontophore, each bearing four or five teeth in transverse row; tongue wider than long, its posterior border not notched, posterior $1 / 4$ not adherent to floor of mouth; vocal slits posterolateral to tongue; vocal sac single, subgular.

Dorsum smooth, lacking tubercles and folds except for pair of supra-inguinal tubercles just lateral to midline; cloacal sheath and enlarged tubercles in cloacal region absent; skin on throat

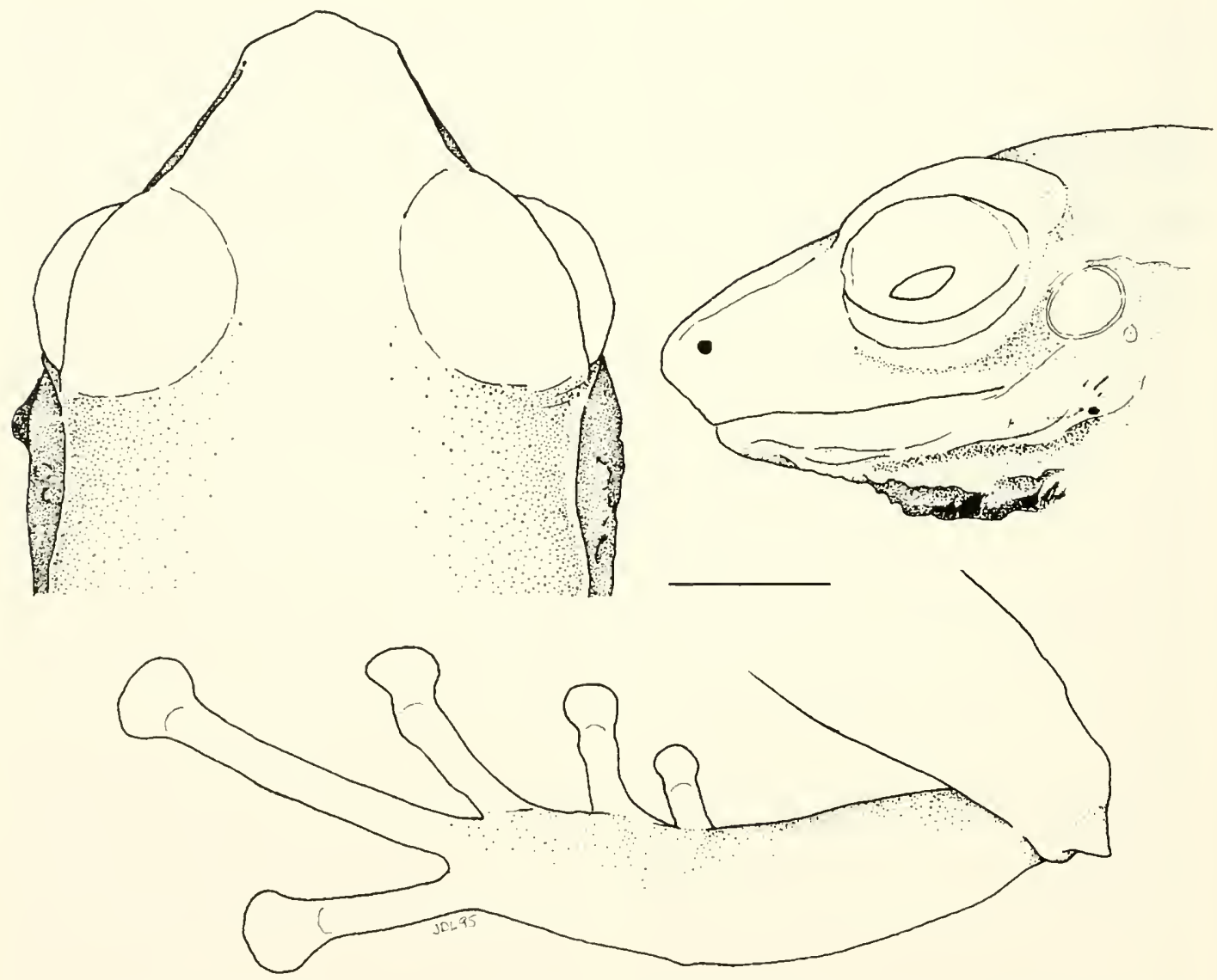

Fig. 26. Eleutherodactylus colomai, $\sigma$, QCAZ 1289, showing top and side of head and dorsal view of left foot, tarsus and heel. Scale bar $=2 \mathrm{~mm}$. 
and belly finely areolate; discoidal fold well anteriad to groin. Upper and lower surfaces of limbs smooth, except skin below and ventrolateral to vent areolate; three ulnar tubercles in row, antebrachial tubercle largest; thenar tubercle oval, smaller than bifid palmar tubercle; supernumerary palmar tubercles numerous; subarticular tubercles low, round; fingers lacking lateral fringes (QCAZ 1296 might be scored as having thickened lateral folds on Fingers II and III); first finger shorter than second; discs on fingers broad, rounded, those on Fingers III and IV about twice width of digit proximal to disc, on Finger II about $1.5 \times$ width of digit (same size as tympanic annulus), on Finger I slightly wider than width of digit; all discs bearing broad ventral pads having complete circumferential grooves; nuptial pad white, on median surface of thumb above joint with metacarpal. Heel bearing short calcar (width at base equals length); outer edge of tarsus bearing row of indistinct tubercles; inner surface of tarsus lacking tubercle and fold; inner metatarsal tubercle twice as long as wide, about of round outer metatarsal tubercle; plantar surfaces areolate; subarticular tubercles round, low; toes bearing indefinite lateral fringes, most obvious at bases of toes; webbing absent; discs on toes slightly smaller than those on outer fingers; tip of Toe $\mathrm{V}$ extending to middle of distal subarticular tubercle on Toe IV; tip of Toe III extending to distal edge of penultimate subarticular tubercle on Toe IV; when hind limbs flexed perpendicular to axis of body, heels overlapping; shank 49.4 and $49.7 \%$ SVL.

Dorsum tan with diffuse darker markings across interocular region, in scapular region, and forming vague $\mathrm{X}$-shaped mark postsacrally; dark brown spot above sacrum and darker suprainguinal spot; side of head dark brown with black spots above, and posterior to, tympanic annulus; brown facial mark extending onto flank to about level of sacrum, bordered above by slightly darker line, with white fleck within brown region; forearms dark brown with some darker brown spots (possibly remnants of cross bars); hind limbs pale brown with darker brown bars-oblique on shank, narrower than interspaces; knees dark brown; posterior surfaces of thighs brown heavily punctated with cream or cream with dense brown flecking. Throat and chest brown with cream flecks; posterior part of belly unpigmented except for brown flecks; undersides of hind limbs cream with brown flecks; region below vent brown but no defined triangular patch.

Measurements of holotype: SVL 17.8, shank 8.8, HW 6.3, head length 6.0, upper eyelid width 1.8 , IOD 1.8, tympanic annulus length 0.8 , eye length 2.5, E-N 2.1.

Coloration in life.-Color notes on three individuals from Km 18 on Altaquér-Tumaco Road, Departamento Nariño, Colombia, were provided by Pedro M. Ruíz-Carranza: Dorsum brown to coppery brown with dark brown transverse bands and yellow dorsolateral line; flanks olive-green with diagonal brown bars; loreal region brown; tympanum ochre; posterior surfaces of thighs dull yellow; throat dark brown; chest, belly, and undersides of limbs red; iris bronze or brown above, red below.

Natural history.-Both specimens were found on leaves of bushes $50-60 \mathrm{~cm}$ above the ground at night; one was in primary forest and one in secondary forest.

Distribution.--This species is known from the humid subtropical regime at elevations of 830$1200 \mathrm{~m}$ in the foothills of the Andes in northwestern Ecuador and southwestern Colombia (Fig. 22).

Etymology.-The specific name is a noun in the genitive case and is a patronym for our Ecuadorian colleague, Luis A. Coloma, who made many collections of specimens available for our use.

Remarks.-In Ecuador, this species is known from only the two males (holotype and paratype having a SVL of $16.5 \mathrm{~mm}$ ) collected in 1990 and a juvenile female (ECO 217) having a SVL of 14.5 mm collected in 1994. Four specimens collected in 1995 in Departamento Nariño, Colombia, include two males having SVLs of 13.1 and $14.5 \mathrm{~mm}$, one subadult female, $17.1 \mathrm{~mm}$, and one juvenile female, $11.3 \mathrm{~mm}$. Based on the somber dorsal color and pattern, we anticipate that this small species inhabits the leaf litter on the forest floor by day.

\section{Eleutherodactylus cremunguis Lynch Plate 3}

Eleutherodactylus crenumguis Lynch, 1976a:2.-Holotype: KU 120126, adult male, from Tandapi, $1460 \mathrm{~m}$. Provincia, Pichincha, Ecuador. 
Diagnosis.-A member of the Eleutherodactylus (Eleutherodactylus) cerasinus group having (1) skin on dorsum finely shagreen with scattered warts and ridges, that on venter smooth; discoidal fold prominent; dorsolateral folds absent: (2) tympanic membrane and tympanic annulus prominent, round, small, its length $1 / 3-2 / 5$ length of eye; (3) snout subacuminate in dorsal view, rounded in profile, lips flared; (4) upper eyelid lacking tubercles, much broader than IOD; cranial crests absent; (5) vomerine odontophores triangular in outline; (6) males having vocal slits; nuptial pads absent; (7) first finger longer than second; discs large, emarginate; (8) fingers lacking lateral fringes; (9) uhnar tubercles absent; (10) heel and tarsus bearing small, conical tubercles; inner tarsal fold absent: (11) inner metatarsal tubercle elongate, 4$6 \times$ round outer metatarsal tubercle; supernumerary tubercles few; (12) toes lacking lateral fringes; webbing absent; fifth toe longer than third; (13) dorsum gray with brown blotches; venter creamy white with brown marbling; posterior surfaces of thighs black with cream flecks; (14) SVL in males 35.2-49.2 mm, in females 59.1-64.5 mm.

Eleutherodactylus crenunguis is most similar to E. ocellatus. The two species can be distinguished by $E$. crenunguis having tubercles on the heels (absent in E. ocellatus) and having the first finger longer than the second (shorter than the second in E. ocellatus). Juveniles of E. labiosus can be confused with E. crenunguis, but E. labiosus has a conical tubercle on the upper eyelid and the first finger shorter than the second. Moreover, E. crenunguis usually has dark marbling on the venter, whereas the venter in E. labiosus usually is white or cream without dark reticulations.

Description.-The original description (Lynch, $1976 a)$ is adequate.

Coloration in life.-Detailed color notes in life are available for specimens from two localities; the differences may indicate geographic variation in color or different perceptions of color by two observers.

KU 111213 from Tandapi, Provincia Pichincha: Dorsum pale brown with black mottling and minute yellow flecks; flanks gray, invaded by brown above and spotted with brown and black; lip barred with cream; groin gray; posterior surfaces of thigh black with white flecks; limbs pale burnt-orange with brown and black bars; throat creamy white with gray mottling; venter same but with pale orange blotches; under surfaces of hind limbs black with white spots; iris heavily reticulated with black, upper edge bright yellow bronze; most of iris brown-bronze, lowermost edge gray-bronze (JDL, 24 July 1967).

KU 120125-29 from Tandapi, Provincia Pichincha: Dorsum medium brown to rust-brown with rust-orange to dark brown markings (one individual with white spots; another individual with yellow flecks and black mottling); flanks with black spots; hind limbs pale brown with darker brown bars; posterior surfaces of thighs dull brown to black with cream to white spots; venter dull yellow to orange (chin and throat black with white flecks in one individual); iris gold above and gray below median, horizontal brown streak (JDL, 2729 July 1968).

KU 165223-29 from $3.5 \mathrm{~km}$ NEMindo, Provincia Pichincha: Dorsum brown, reddish brown, or olive-tan with orange-brown tubercles and ridges; upper lips with black and cream bars; posterior surfaces of thighs black with bluish white flecks; throat dull bluish white with gray mottling; belly dull pink to pale orange; iris bronze with black reticulations (WED, 7 April 1975).

Natural history.-All individuals for which ecological data are available were found on low vegetation along, or on banks of, streams at night. During field work at Tandapi, Provincia Pichincha, in 1967 and 1968, adult males and juveniles of both sexes were found on the ground; subsequently, adult females were found on leaves and branches. A male was calling at $3.5 \mathrm{~km}$ NE of Mindo, Provincia Pichincha, on 8 April 1975.

Distribution. - This species occurs at moderate elevations $(800-1640 \mathrm{~m})$ in the humid subtropical regime on the western slopes of the Andes in Ecuador (Fig. 27).

Remarks.-When first described, Eleutherodactylus crenunguis was associated with the $E$. fit-ingeri group (Lynch, 1976a) because the first finger is much longer than the second, and the skin on the venter is smooth. During the next decade, JDL, encouraged by the criticism of J. M. Savage, began to abandon and then to dismantle that con- 


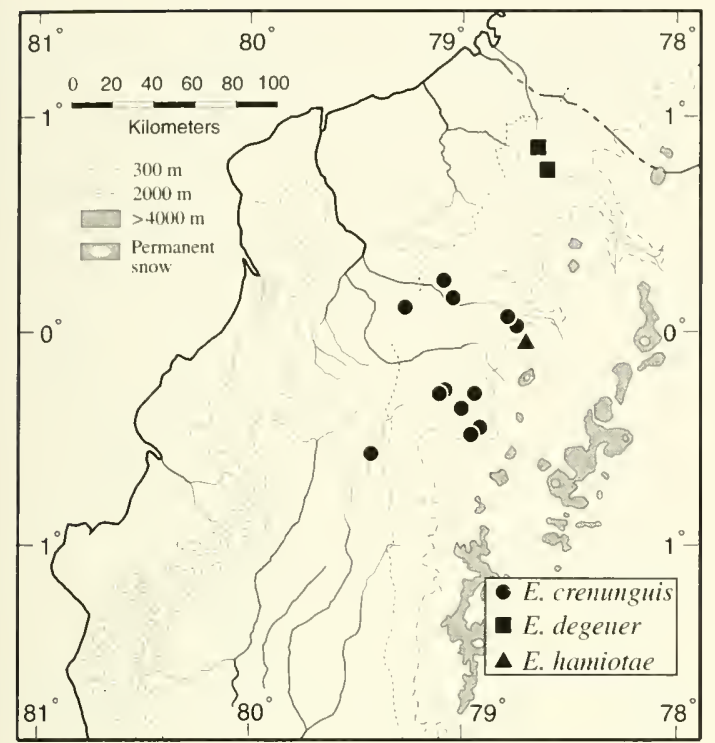

Fig. 27. Distribution of three species of Eleutherodactylus in western Ecuador.

struction (the E. fitzingeri group sensu Lynch), and E. crenunguis was associated with $E$. rubicundus from the Amazonian slopes of the Andes. Finally, Lynch et al. (1994) associated E. crenunguis with other Chocoan taxa-E. cerasinus, labiosus, ocellatus, orpacobates, and tenebrionis. We think that $E$. ocellatus is the closest relative to $E$. crenunguis. The range of E. ocellatus is immediately to the north of that of E. cremunguis in Provincia Carchi, Ecuador, northward to Departamento Cauca, Colombia; hence, we do not expect E. crenunguis to range northward into Colombia.

\section{Eleutherodactylus crucifer (Boulenger) Plate 5}

Hylodes crucifer Boulenger, 1899:456.-Holotype: BM 1947.2.16.91 from Porvenir, $1760 \mathrm{~m}$. Provincia Bolívar, Ecuador.

Diagnosis.-A member of the Eleutherodactylus (Eleutherodactylus) unistrigatus group having (1) skin on dorsum finely tuberculate with scattered conical tubercles on eyelids, back, and shanks, that on venter areolate; discoidal fold prominent; dorsolateral folds absent; (2) tympanic membrane and tympanic annulus prominent, round, small. its length $1 / 4-1 / 3$ length of eye; (3) snout short. rounded in dorsal view, truncate in profile; (4) upper eyelid bearing conical tubercles, broader than IOD: cranial crests absent: (5) vomerine odontophores triangular in outline; (6) males having vocal slits and external vocal sac; nuptial pads present; (7) first finger shorter than second; discs on outer fingers broad; (8) fingers bearing crenulated lateral fringes; (9) ulnar tubercles conical: (10) heel bearing short calcar; inner and outer edges of tarsus bearing conical tubercles; (11) inner metatarsal tubercle oval, 4-6× round outer metatarsal tubercle; supernumerary tubercles absent; plantar surface areolate; (12) toes bearing crenulated lateral fringes; webbing absent; fifth toe much longer than third; (13) dorsum cream with brown markings; venter cream with dark gray flecks; posterior surfaces of thighs cream with brown reticulation (uniform deep blue in life); (14) SVL in males 18.3-20.6 mm, in females 22.8-34.5 mm.

Eleutherodactylus crucifer is distinctive in having conical tubercles on the upper eyelids, forearm (ulnar tubercles), heel, and outer edge of the tarsus. This pattern of conical tubercles also is present in the Colombian E. calcaratus, but that species lacks crenulated lateral fringes on the digits and has a much longer calcar. Living individuals are easily distinguished because the dorsum is green and the groin and concealed surfaces of the thighs are blue in E. crucifer, as contrasted with a brown dorsum and concealed surfaces of the thighs in E. calcaratus.

Description.-Lynch (1976a) redescribed the species based on a series of specimens from Tandapi. Provincia Pichincha, Ecuador.

Coloration in life.--This species has a distinctive coloration-green dorsum with dark blue in the groin and on the concealed surfaces of the thighs; the blue is paler in juveniles and absent in the smallest individuals. Color notes on specimens from two localities are, as follow.

KU 120133-40 from Tandapi, Provincia Pichincha: Dorsal surfaces of body and limbs bright green with dark green to black markings on dorsum, flanks, and limbs; groin, distal part of posterior surface of thigh, and underside of shank dark blue: proximal part of posterior surface of thigh cream with brown reticulations; venter dull cream (whitish cream on throat) with brown spots: 
gray tint along lip; iris red above and white-bronze below median, horizontal brown streak. One individual with almost black venter; one individual pale green with white venter, and another with a cream patch on the middle of the back (JDL, 29 July 1968).

KU 165235 from $3.5 \mathrm{~km} \mathrm{NE} \mathrm{Mindo,} \mathrm{Provincia}$ Pichincha: Dorsum bright green with dark green markings on body and dark brown bars on limbs; flanks pale yellowish-green with dark brown markings; groin and underside of knee dark blue; venter silvery-white; other ventral surfaces greenish yellow, all with brown flecks; iris dark red with pale bronze ventrally (WED, 7 April 1975).

Natural history.-At night, individuals have been found on ferns and leaves up to $2 \mathrm{~m}$ above the ground, in dense forest, and along streams. The occurrence of a green frog with many conical warts on moss-covered leaves suggests that the frog is practicing some sort of crypsis, not unlike that of highland populations of Hyla lancasteri reported by Trueb (1968). By day, the frogs were found in arboreal bromeliads.

Distribution.-Eleutherodactylus crucifer is known only from cloud forest in the humid subtropical regime at elevations of $1200-1800 \mathrm{~m}$ on the Pacific slopes of the Cordillera Occidental in Ecuador (Fig. 28).

Remarks. - Two gravid females (ECO 087 and 123) from El Cristal, Provincia Esmeraldas, are remarkable in their small size (SVLs of 23.0 and $22.8 \mathrm{~mm}$, respectively) in comparison with gravid females from Tandapi, Provincia Pichincha (SVLs of $26.2-28.5 \mathrm{~mm}$ ).

\section{Eleutherodactylus degener sp. nov. Plate 5}

Holotype.-QCAZ 1297, adult male, from Alto Tambo, $830 \mathrm{~m}\left(00^{\circ} 5 \mathrm{l}^{\prime} 42^{\prime \prime} \mathrm{N}, 78^{\circ} 30^{\prime} 54^{\prime \prime} \mathrm{W}\right)$, Provincia Esmeraldas, Ecuador, obtained on 6 December 1990 by Stella de la Torre, Jean-Marc Touzet, Diego Lombeida, and Felipe Campos.

Paratypes.-ECO 77, 122. (See Appendix I for localities.)

Diagnosis.-A member of the Eleutherodactylus (Eleutherodactylus) unistrigatus group having (1) skin on dorsum smooth, that on venter

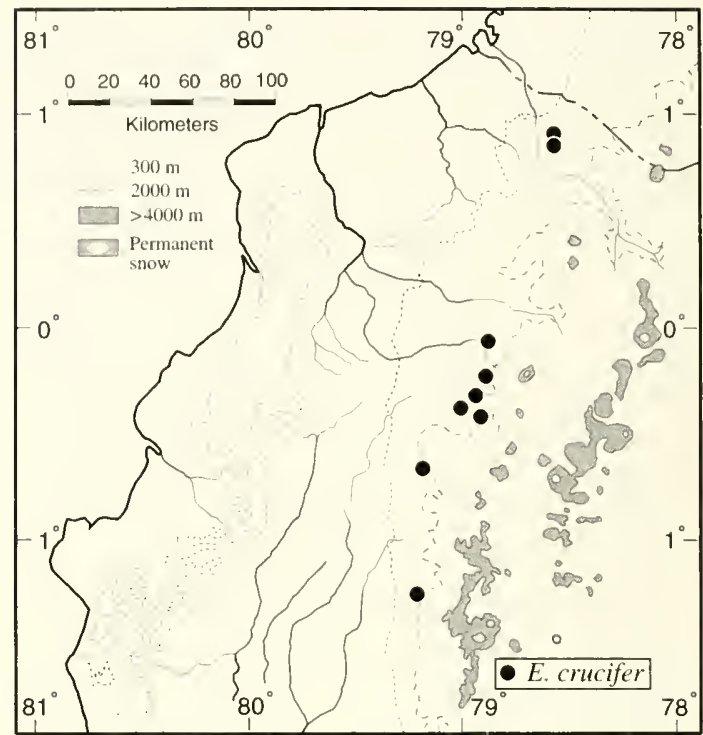

Fig. 28. Distribution of Eleutherodactylys crucifer.

areolate; discoidal fold absent; dorsolateral folds absent; (2) tympanic membrane and tympanic annulus prominent, round, its length $1 / 3-2 / 5$ length of eye; (3) snout rounded in dorsal view, truncate in profile; (4) upper eyelid lacking tubercles, as wide as or slightly wider than IOD; cranial crests absent; (5) vomerine odontophores triangular in outline; (6) males having vocal slits; nuptial pads absent; (7) first finger shorter than second; dises round; (8) fingers bearing lateral fringes; (9) ulnar tubercles small; (10) heel bearing minute tubercles; tarsus lacking tubercles; (11) inner metatarsal tubercle oval, $4 \times$ subconical outer metatarsal tubercle; supernumerary plantar tubercles indistinct; (12) toes bearing lateral fringes; webbing absent; fifth toe much longer than third; (13) dorsum brown or cream with brown flecks; venter white, with brown reticulation in females; posterior surfaces of thighs brown in male, cream with brown reticulations in females; (14) SVL in one male $22.2 \mathrm{~mm}$, in two females $31.0-32.7 \mathrm{~mm}$.

Eleutherodactylus degener is most similar to $E$. subsigillatus and, hence, presumably most closely related to E. eugeniae, nyctophylax, phoxocephalus, and subsigillatus. Unlike the other species, E. degener lacks nuptial pads and has a smooth dorsum (shagreen or finely tuberculate in the others). Moreover, E. subsigillatus differs by having small 
tubercles on the tip of the snout, upper eyelids, and tarsi. In western Ecuador, the only other species having an orange iris is E. sobetes, which differs from $E$. degener by having cranial crests, dorsolateral folds, and a tuberculate dorsum.

Description.- $(n=3 ; 1$ male, 2 females $)$ Head wider than long, narrower than body: HW 39.6$40.8 \%(\bar{x}=40.3)$ SVL; snout rounded in dorsal view (margin interrupted by protruding nostrils), truncate in profile (Fig. 29); E-N 81.2-100\% ( $\bar{x}=$ 92.0) length of eye; snout longer than length of eye; nostrils small, protuberant, directed laterally; canthus rostralis angular, weakly concave: loreal region concave, sloping abruptly to lips; upper eyelid width equal to IOD in females, $112 \%$ in male; interorbital space flat; cranial crests absent; supratympanic fold low, angling posteroventrally behind tympanic annulus; tympanic membrane prominent, directed dorsolaterally; tympanic annulus visible except uppermost edge, round, its

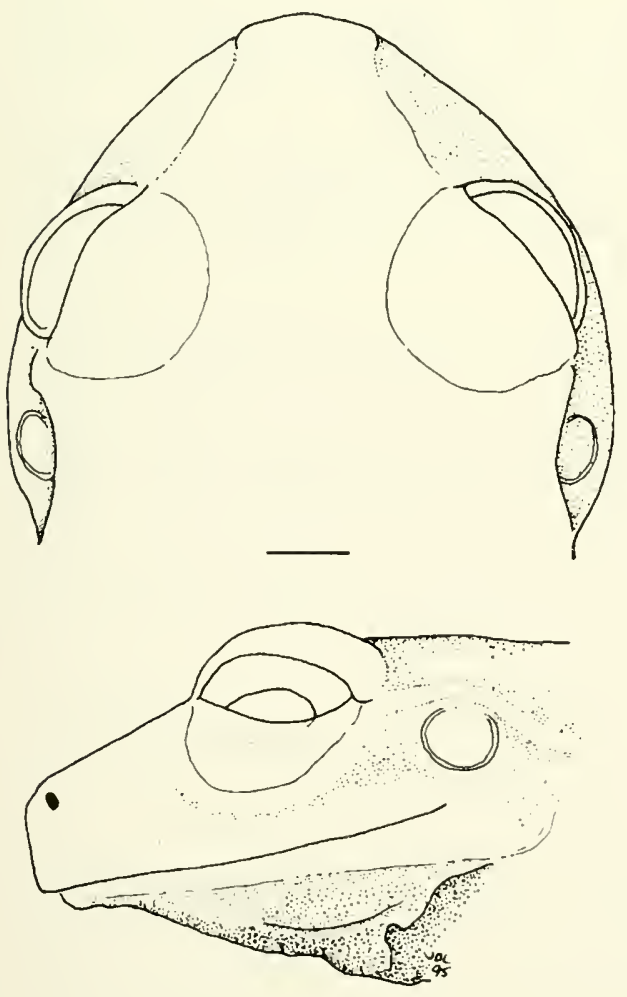

length $35.9-41.7 \%(\bar{x}=38.5)$ length of eye, separated from eye by distance about $1 \frac{1}{2} \times$ tympanic membrane; postrictal tubercles low. Choance round. not concealed by palatal shelf of maxillary arch; vomerine odontophores posteromedian to choanae, separated medially by a distance equal to width of one odontophore, each bearing five or six teeth in diagonal row; tongue round in male, longer than wide and feebly emarginate behind in females. posterior $2 / 5$ not adherent to floor of mouth; vocal slits short, posterolateral to tongue; vocal sac single, subgular.

Skin on dorsum smooth, that on venter areolate; dorsolateral and discoidal folds absent; cloacal sheath and tubercles absent: ulnar tubercles small; palmar tubercle bifid, slightly larger than oval thenar tubercle; supernumerary palmar tubercles numerous; subarticular tubercles broader than long, simple, not elevated; first finger shorter than second; fingers bearing lateral fringes; similar fringe

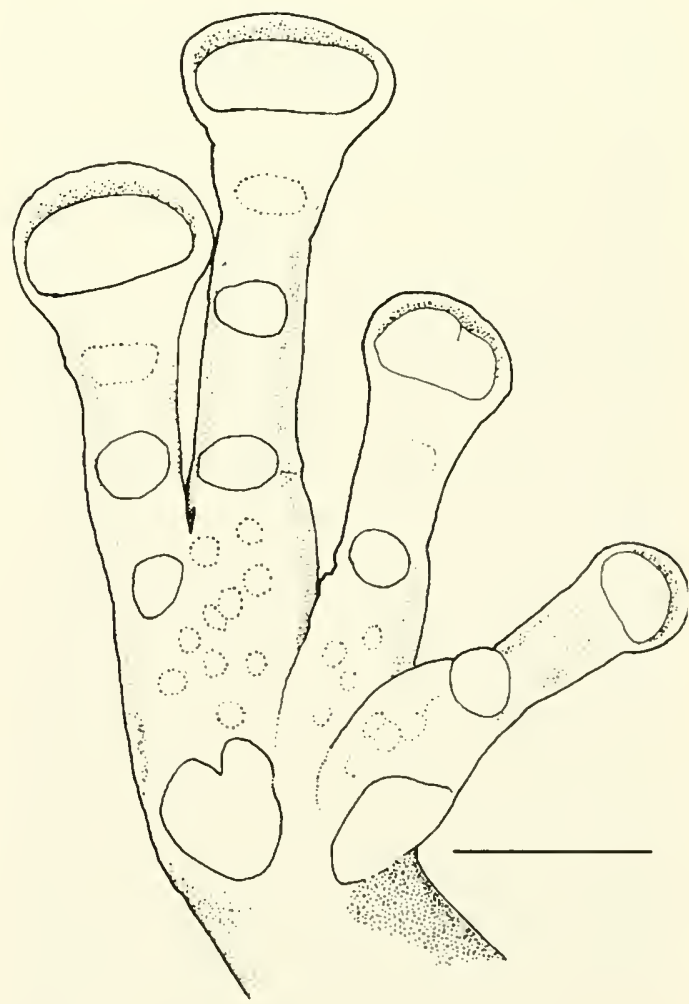

Fig. 29. Eleutherodactylus degener, @, ECO 77. showing top and side of head and palmar view of hand. Scale bars $=2 \mathrm{~mm}$. 
evident along outer edge of palm; dises round, those of male I. $3 \times$ width of digit proximal to disc, of females about $2 \times$ width: ventral surfaces of discs bearing pads defined by circumferential grooves: male lacking nuptial pads. When hind limbs flexed perpendicular to body axis, heels broadly overlapping; shank $47.0-50.3 \%(\bar{x}=49.1)$ SVL; heel bearing minute tubercle on upper edge: tarsus lacking tubercle and folds; inner metatarsal tubercle about $2.5 \times$ as long as wide, about $4 \times$ size of rounded, subconical outer metatarsal tubercle; supernumerary plantar tubercles low: subarticular tubercles low, round, simple; toes bearing lateral fringes; webbing absent; discs on toes as large as those on outer fingers: tip of Toe $\mathrm{V}$ extending to distal edge of distal subarticular tubercle on Toe IV: tip of Toe III not extending to middle of penultimate subarticular tubercle on Toe IV.

In preservative, dorsum of holotype brown with diffuse, slightly paler markings (interorbital bar and $\mathrm{W}$-shaped mark in occipital region) and small dark brown flecks; limb bars and canthal stripe absent; white flecks along upper lip and on most tubercles; posterior surfaces of thighs uniform brown; preaxial surfaces of arms, groin. anterior surfaces of thighs, concealed surfaces of shanks, preaxial surfaces of tarsi, and feet unpigmented; brown encroachment on chin, but otherwise vocal sac and venter unpigmented. Dorsum of adult female paratypes cream with brown flecks forming pattern-interorbital bar and chevrons in scapular and sacral regions; bars on limbs narrow; upper lips lacking flecks; labial bars and canthal and supratympanic stripes absent; throat uniform white: flanks and anterior surfaces of thighs with brown or black marks forming a reticulum; belly and undersides of hind limbs white with brown spots and reticulations on belly and less distinct reticulations on hind limbs; posterior surfaces of thighs with large pale spots separated by brown lines having clusters of dark flecks within them; undersides of shanks patterned like posterior surfaces of thighs but less clearly so.

Measurements of holotype: SVL 22.2, shank II.1, HW 8.8, head length 8.3, upper eyelid width 2.8, IOD 2.5, tympanic annulus length 1.2 , eye length 3.2, E-N 2.6.

Coloration in life.-Based on 35-mm trans- parencies of an adult female provided by Martha $\mathrm{L}$. Crump, the dorsum is brown with vague darker markings; the flanks are white with black reticulations, and the iris is orange. Color notes on a specimen collected in 1995 at Altaquér, Departamento Nariño, Colombia, were provided by Pedro M. Ruíz-Carranza, as follow. Dorsum carmel colored, with a broad occipital triangle outlined with yellow; venter and hidden surfaces of hind limbs creamy yellow with red vermiculations; periphery and anterior part of chin reddish ochre; iris bright reddish-orange with brown flecks.

Natural history.-The holotype was on a leaf of a bush $50 \mathrm{~cm}$ above the ground in primary forest at night.

Distribution.-Eleutherodactylus degener is known from only three localities at 830 and $1200 \mathrm{~m}$ in the humid subtropical regime on the lower slopes of the Andes in northwestern Ecuador and adjacent Colombia (Fig. 27).

Etymology.-The specific epithet is a Latin noun meaning "different." The name is used in allusion to the orange eyes, which are strikingly different from the colors of the irises in most Eleutherodactylus.

Remarks.--There is striking sexual dimorphism in coloration in the small sample of one male and two females. The dorsal pattern is subdued in the male in contrast to that in females. The groin and posterior surfaces of the thighs in females have reticulations, whereas these surfaces are uniform brown in the male; moreover, the belly is reticulated in females and unpigmented in the male. In the better known E. subsigillatus, a ventral pattern of reticulation develops with size in females. and the absence of dark markings on the belly in males is taken to be dependent on their smaller size than that of adult females.

\section{Eleutherodactylus dissimulatus sp. nov.}

\section{Plate 5}

Holotype.-KU 179088, adult female, one of a series collected at Quebrada Zapadores, $5 \mathrm{~km}$ ESE Chiriboga, $2010 \mathrm{~m}\left(00^{\circ} 15^{\prime} \mathrm{S}, 78^{\circ} 43^{\prime} \mathrm{W}\right)$, Provincia Pichincha, Ecuador, on 8 July 1977 by David C. Cannatella, Marsha Lynch, and John D. Lynch.

Paratopotypes.-KU 165923-25, 179087, 179089-94. 
Diagnosis.-A member of the Eleutherodactylus (Elentherodactylus) unistrigatus group having (1) skin on dorsum smooth except for minute ridges, that on venter areolate; discoidal fold well anteriad of groin; dorsolateral folds absent; (2) tympanic membrane and tympanic annulus present, round, its length $1 / 3-2 / 5$ length of eye: (3) snout long, subacuminate in dorsal view, angularly rounded in profile; (4) upper eyelid bearing minute tubercles, narrower than IOD; cranial crests absent; (5) vomerine odontophores oval; (6) adult males unknown; (7) first finger shorter than second; discs on outer fingers large, apically rounded; (8) fingers bearing narrow lateral fringes; (9) ulnar tubercles absent except for low antebrachial tubercle; (10) heel bearing subconical tubercle; outer edge of tarsus bearing poorly defined tubercles; inner edge of tarsus lacking tubercle or fold: (11) inner metatarsal tubercle elongate, 6-8× subconical outer metatarsal tubercle; supernumerary plantar tubercles at bases of toes; (12) toes lacking lateral fringes; webbing absent; fifth toe much longer than third; (13) dorsum cream to brown with brown interorbital bar and scattered spots on flanks and thighs; venter cream with small brown spots; posterior surfaces of thighs, groin, and concealed shanks cream (orange in life) with black spots and irregular lines; (14) SVLin adult males unknown, in females 27.4 $32.5 \mathrm{~mm}$.

Eleutherodactylus dissimulatus is most similar to the slightly smaller E. calcarulatus. In addition to the slight difference in size, E. dissimulatus has a longer snout, straight rather than concave canthus rostralis, oval rather than oblique vomerine odontophores, and a pattern of spots or lines on an orange background in the groin and on the concealed surfaces of the hind limbs (uniform brown in E. calcarulatus).

Description.- $(n=8 ; 1$ male, 7 females $)$ Head wider than long, narrower than body; HW 38.2$42.0 \%(\bar{x}=39.5) \mathrm{SVL}$; snout longer than length of eye (Fig. 30); E-N 83.3-100\% ( $\bar{x}=91.2)$ length of eye; nostrils small. protuberant, directed laterally; canthus rostralis sharply angular, nearly straight: loreal region weakly concave, sloping abruptly to nonflared lips; upper eyelid width 72.7-87.5\% ( $\bar{x}=$ 80.3) IOD; interorbital space flat; most individuals with minute conical tubercle on upper eyelid;

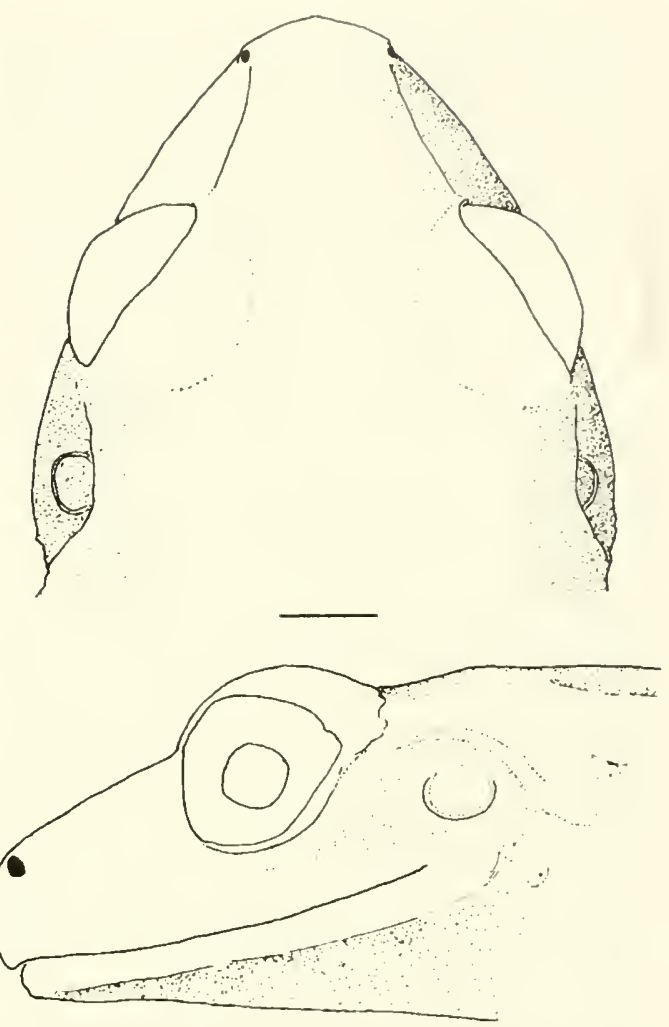

Fig. 30. Eleutherodactylus dissimulatus, @. KU 179088. Scale bar $=2 \mathrm{~mm}$.

supratympanic fold indistinct; tympanic annulus. round, its length $31.4-40.5 \%(\bar{x}=35.8)$ length of eye, separated from eye by distance equal to $1 \frac{1}{2}-2 \times$ tympanic annulus; postrictal tubercles small, conical. Choanae moderate-sized, round, not concealed by palatal shelf of maxillary arch; vomerine odontophores posteromedian to choanae, separated medially by a distance equal to width of one odontophore, each as large as a choana, each bearing three or four teeth in transverse row; tongue longer than wide, its posterior border feebly notched, posterior $2 / 5$ not adherent to floor of mouth.

Skin on dorsum smooth except for minute eyelid tubercle and a system of fine anatomizing ridges; discoidal fold well anteriad to groin; skin on flanks relatively smooth, that on venter areolate: cloacal sheath and tubercles absent. Palmar tubercle bifid, larger than oval thenar tubercle; supernumerary palmar tubercles indistinct: subarticular tubercles round; first finger shorter than second; fingers bear- 
ing narrow lateral fringes; disc on thumb scarcely wider than digit proximal to disc, that on Finger II as wide as tympanic annulus; dises on Fingers III and IV larger than tympanic annulus; fingers long, slender. When hind limbs flexed perpendicular to body axis, heels broadly overlapping; shank 54.8 $60.0 \%(\bar{x}=57.7) \mathrm{SVL}$; inner margin of tarsus lacking tubercle or fold; inner metatarsal tubercle three times as long as wide, not compressed; subarticular tubercles low, round; supernumerary plantar tubercles at bases of toes: fifth toe much longer than third; toes lacking lateral fringes; webbing absent; discs on toes as large as those on fingers.

In preservative, dorsum cream to brown with a dark brown interorbital bar and scattered small brown spots, especially on flanks and thighs; oblique bars on shanks brown, narrower than pale interspaces; canthal and supratympanic stripes and labial bars indistinct or absent. Venter cream with small brown spots; groin, posterior surfaces of thighs, and concealed surfaces of shank nearly colorless with black spots or irregular line; in $\mathrm{KU}$ 179089, posterior surfaces of thighs black with cream spots.

Measurements of holotype: SVL 30.7, shank 16.9, HW 12.1, head length 11.7, upper eyelid width 2.4, IOD 3.2, tympanic annulus length 1.7 , eye length 4.2, E-N 3.8 .

Coloration in life.--The dorsum and venter are pale tan, orange, olive, or brown with an orange tint above and minute black flecks on the venter. The throat is orange with black flecks. The concealed surfaces of the hind limbs are orange or yellow with black spots or marbling. The iris is bright copper with a median, horizontal brown streak.

Natural history.-All individuals were on low vegetation along streams in cloud forest at night.

Distribution.- This species is known from only two localities at 1920 and $2020 \mathrm{~m}$ in cloud forest in the humid temperate regime on the western flanks of the Andes in Provincia Pichincha, Ecuador (Fig. 24).

Etymology.-The specific name is a Latin adjective meaning "disguised" or "hidden." The name is used in reference to the bright color pattern hidden on the concealed surfaces of the hind limbs.

Remarks.--Only 13 specimens are known; the single male (KU 179094) is a juvenile having a SVL of $13.1 \mathrm{~mm}$. Juvenile females having minute, white, ovarian eggs and narrow, straight oviducts are as large as $25.4 \mathrm{~mm}$ in SVL (KU 165923). Eleutherodactylus dissimulatus seems to be most closely related to E. apiculatus and E. calcarulatus. Our association of these three species is not based on any synapomorphies.

\section{Eleutherodactylus duellmani Lynch Plate 4}

Eleutherodactylus duellmani Lynch, 1980c:332.-Holotype: KU 179325, adult male, from Quebrada Zapadores, $5 \mathrm{~km}$ ESE Chiriboga, $2010 \mathrm{~m}$, Provincia Pichincha. Ecuador.

Diagnosis.-A member of the Eleutherodactylus (Eleutherodactylus) surdus group having (1) skin on dorsum bearing numerous small, flat warts, that on venter areolate; discoidal fold illdefined; dorsolateral folds short, extending to level of sacrum; (2) tympanic membrane and tympanic annulus absent; (3) snout short, rounded in dorsal view, rounded to truncate in profile; (4) upper eyelid lacking tubercles, as wide as IOD; interorbital region furrowed; (5) vomerine odontophores large, subtriangular in outline; (6) males lacking vocal slits; nuptial pads small; (7) first finger shorter than second; discs broad; (8) fingers bearing lateral fringes; (9) ulnar tubercles absent; (10) heel and outer edge of tarsus bearing small tubercles; inner edge of tarsus bearing large tubercle; (11) inner metatarsal tubercle oval, at least $8 \times$ indistinct outer metatarsal tubercle; supernumerary tubercles few at base of Toe IV; (12) toes having lateral fringes and basal webbing; fifth toe longer than third; (13) dorsum brown with diffuse darker markings; venter gray to cream with diffuse brown spots or reticulations; posterior surfaces of thighs brown with a few cream flecks; (14) SVL in males 24.9 $36.0 \mathrm{~mm}$, in females $36.6-45.8 \mathrm{~mm}$.

Eleutherodactylus duellmani is most similar to E. hamiotae and E. surdus in that all three species have relatively short fifth toes that are only slighter longer than the third toes, and all three lack tympanic annuli. Eleutherodactylus duellmani differs from the others in having basal webbing on the toes and distinct, short dorsolateral folds, as contrasted 
to dorsolateral folds weak or absent and webbing between toes absent or extremely basal in the other species. Also, the fingers in E. duellmani are longer than those in E. hamiotae.

Description.-The original description by Lynch (1980c) is adequate.

Coloration in life.-Although this species lacks distinctive coloring, subtle differences in coloration exist, as noted in the following descriptions.

KU 165908 from $9 \mathrm{~km}$ SE Tandayapa, Provincia Pichincha: Dorsum dull gray with tan dorsolateral folds; flanks grayish tan anteriorly, yellowish tan posteriorly, with dark olive-brown mottling; dorsal surfaces of limbs olive-tan with dark olive-brown bars; venter grayish tan with dark brown mottling; iris dull reddish-brown (WED, 9 April 1975).

KU 165913-15 from Quebrada Zapadores, Provincia Pichincha: Dorsum olive-brown with dark brown interorbital crest and W-shaped scapular crest, and dark brown and orange tubercles; posterior surfaces of thighs grayish tan with yellow flecks; venter dull yellow with cream flecks and greenish suffusion on belly; iris copper with black reticulations (WED, 3 April 1975).

KU 179299-315 from La Delicia, Provincia Imbabura: Dorsum green, rust, or pale to dark brown with darker brown to black markings; venter gray to black with dirty white spots; throat same with white flecks; posterior surfaces of thighs brown with pale yellow spots; facial markings tinged with yellow; iris chocolate-brown to copper with black reticulations and hint of median, horizontal streak (JDL, 16 January 1978).

KU 179338-46 from $14.8 \mathrm{~km}$ E Chiriboga, Provincia Pichincha: Dorsum green in males, dull brown in females; flanks bearing nearly yellow spots; posterior surfaces of thighs fleshy brown with cream flecks; dark labial bars and postocular stripe, latter bordered anteriorly by cream or yellowish mark; venter dull gray with cream flecks; iris chocolate-brown (JDL, 2 January 1978).

Natural history.-At night, E. duellmani perches on branches and herbs immediately above small streams and sits on rock faces in the spray zones of waterfalls; some have been found in crevices or between rocks in small streams. This species apparently is sensitive to drying and remains where humidity approaches $100 \%$. By day, these frogs were found under rocks, humus, or leaves in seepages, where water was running under the covers over the frogs. Some frogs escaped by hopping into streams.

Distribution.-Eleutherodactylus duellmani occurs in cloud forests at elevations of 1550-2700 $m$ on the west flank of the Andes from Departamento Cauca, Colombia, southward to Provincia Pichincha, Ecuador (Fig. 25). One locality is in the humid subtropical regime, whereas eight are in the humid temperate regime.

Remarks.--Lynch (1980c) included $E$. duellmani in his E. surdus group, then defined on the basis of having lost the middle ear and having a short, blunt snout. That species group (and association) now seems to be an artificial grouping of most of the Ecuadorian Eleutherodactylus lacking a middle ear. Species such as E. baryecuus, pugnax, and ruidus have long fifth toes in contrast to the shorter fifth toes in the four species here restricted to the E. surdus group. Presently we suspect that Lynch's (1980c) original grouping confounded a series of species united only by inhabiting seepages. The character of relative lengths of the third and fifth toes rather sharply cleaves the E. surchus group of Lynch (1980c); many additional earless species, such as E. diaphonus and E. gracilis that are not members of the E. surdus group, have been found in Colombia. Eleutherodactylus duellmani, hamiotae, and surdus closely resemble one another and presumably are closely related; however, all three species occur in seepages and small streams, and their similarities may reflect only morphological adaptations to these microhabitats. Until additional skeletal material becomes available, it is premature to include more than E. duellmani, hamiotae, sobetes, and E. surdus in the E. surdus group.

\section{Eleutherodactylus eremitus Lynch Plate 5}

Eleutherodactylus erenitus Lynch, 1980d:2.-Holotype. MCZ 92103, adult female, from La Palma-Chiriboga road, $25.7 \mathrm{~km}$ above (NE) La Palma, $1820 \mathrm{~m}$, Provincia Pichincha, Ecuador.

Diagnosis.-A member of the Eleutherodactylus (Eleutherodactylus) unistrigatus group 
having (1) skin on dorsum finely areolate, that on venter areolate; discoidal fold well anteriad to groin; dorsolateral folds absent; (2) lower part of tympanic annulus visible, round, its length, $2 / 5-1 / 2$ length of eye: (3) snout subacuminate in dorsal view, rounded or weakly protruding in profile; (4) upper eyelid bearing conical tubercle, narrower than IOD; cranial crests absent; (5) vomerine odontophores oval; (6) males having vocal slits and nuptial pads; (7) first finger shorter than second: discs broad; (8) fingers bearing lateral fringes; (9) ulnar tubercles small, subconical; (10) heel and outer edge of tarsus bearing small tubercles; inner tarsal tubercle or fold absent: (11) inner metatarsal tubercle oval, $4 \times$ subconical outer metatarsal tubercle; supernumerary tubercles numerous; (12) toes bearing lateral fringes; webbing absent; fifth toe much longer than third; (13) dorsum cream with faint brown flecks and dark canthal stripe continuing onto flank; venter white; posterior surfaces of thighs and areas on flanks colorless (pale yellow in life): (14) SVL in males 17.2-21.8 mm, in females 27.1-27.6 mm.

Eleutherodactylus eremitus is a small green frog having either a loose reddish-brown reticulum on the dorsum or broad reddish brown dorsolateral stripes. This coloration sets it apart immediately from all other species in western Ecuador. Because E. eremitus has small tubercles on the heels and tarsi and a relatively large tympanic annulus, it might be confused with the lowland E. subsigillatus, which lacks a tubercle on the upper eyelid and usually has a pattern in the groin and on the concealed surfaces of the thighs.

Description.-The original description by Lynch (1980d) is adequate.

Coloration in life.- The dorsum is green, usually with darker markings, and the venter is pale yellow; descriptions of individuals are, as follow.

KU 165884 from $3.5 \mathrm{~km}$ NE Mindo, Provincia Pichincha: Dorsum pale green with dull red markings; limbs greenish yellow; venter pale yellow; iris copper (WED, 7 April 1975).

KU 179085-86 from Quebrada Zapadores, Provincia Pichincha: Head brown or reddish brown; body green, latter with black spots in one and reddish-brown dorsolateral stripes in one; venter pale yellow or white with minute brown flecks on throat; concealed surfaces of hind limbs pale yellow; iris bright copper with brown flecks (JDL, 8, 9 July 1977).

Natural history.-Eleutherodacty/us eremitus is relatively uncommon in collections. An observation by Lynch and Burrowes (1990) that one was seen $7 \mathrm{~m}$ above the ground on an observation tower suggests that the species may seldom occur near the ground. By day, several individuals have been found in arboreal bromeliads, and one was in a terrestrial bromeliad; others were sitting on leaves of herbs and bushes to heights of $2 \mathrm{~m}$ above the ground.

Distribution.-This small species occurs in cloud forests at elevations of 1540-2100 m on the western flanks of the Andes in extreme southern Colombia (Departamento Nariño) and northwestern Ecuador (provincias Cotopaxi and Pichincha) (Fig. 31). Three localities are in the humid subtropical regime, and five are in the humid temperate regime.

Remarks. - The relatively broad and flat head of this species led Lynch (1980d) to consider Eleutherodactylus eremitus to be a member of the E. lacrimosus group (or assembly). The features cited by Lynch (1980d) and Lynch and Duellman (1980) possibly reflect the bromeliad habitat rather

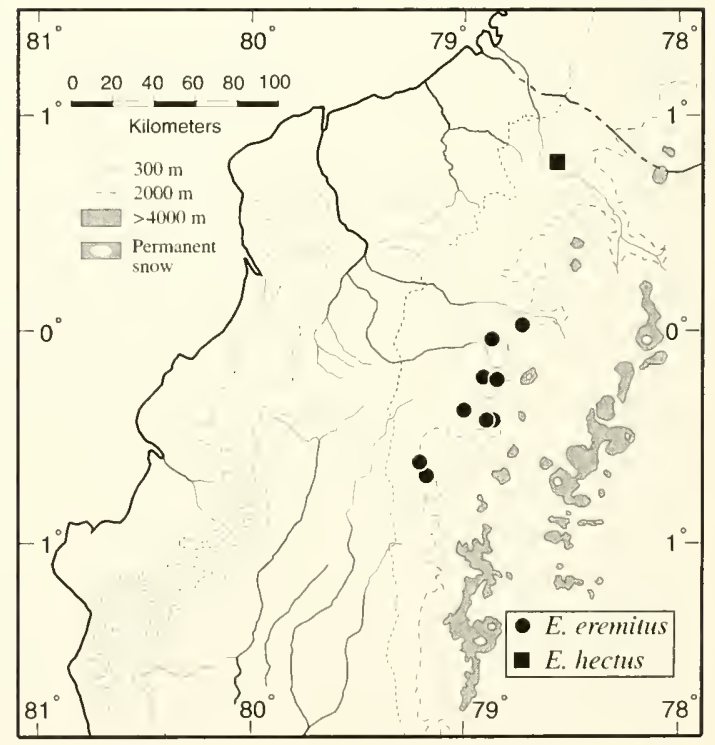

Fig. 31. Distribution of two species of Eleutherodactylus in western Ecuador. 
than relationships. As noted by Lynch (1980d), this species may have been under collected because few collectors sample bromeliads in the cloud forest.

\section{Eleutherodactyhus eugeniae sp. nov. Plate 6}

Holotype.-KU 165899, adult male, one of a series collected at Quebrada Zapadores, $5 \mathrm{~km}$ ESE Chiriboga, $2010 \mathrm{~m}\left(00^{\circ} 15^{\prime} \mathrm{S}, 78^{\circ} 43^{\prime} \mathrm{W}\right)$, Provincia Pichincha, Ecuador, on 3 April 1975 by William E. Duellman.

Paratypes.-KU 165900-904, 179382-83, and QCAZ 2629. (See Appendix I for localities.)

Diagnosis. - A member of the Eleutherodactylus (Eleutherodactylus) unistrigatus group having (1) skin on dorsum finely shagreen, becoming coarse on flanks, that on venter areolate; discoidal fold well anterior to groin; dorsolateral folds absent: (2) tympanic membrane and tympanic annulus prominent, round, its length $1 / 3-1 / 2$ length of eye; (3) snout moderately long, subacuminate in dorsal view, rounded in profile, with papilla at tip; (4) upper eyelid lacking tubercles, narrower than IOD; cranial crests absent; (5) vomerine odontophores triangular in outline; (6) males having vocal slits, subgular vocal sac, and white nuptial pads; (7) first finger shorter than second; Fingers II-IV bearing large, apically rounded discs; (8) fingers bearing lateral fringes; (9) ulnar tubercles absent, except for antebrachial tubercle; (10) heel and outer edge of tarsus lacking tubercles; inner tarsal tubercle indistinct; (11) inner metatarsal tubercle oval, 4-6x oval outer metatarsal tubercle; supernumerary plantar tubercles low, at bases of toes; (12) toes bearing lateral fringes; webbing absent; fifth toe much longer than third; (13) dorsum cream to pale brown with brown spots; bars absent on limbs; venter cream with brown flecks on throat; posterior surfaces of thighs and flanks cream with brown reticulations; (14) SVL in males 25.2-26.0 mm, in six females 30.5-37.6 $\mathrm{mm}$.

Eleutherodactylus eugeniae is most similar to E. nyctophylax, a species of equal size on the Pacific versant of the Ecuadorian Andes. The two differ in that E. nyctophylax has small tubercles on the upper eyelid and heel, a more angular canthus rostralis, areolate plantar surfaces, and the posterior surfaces of thighs brown with cream flecks.

Description. - $(n=7$ for proportions of females [including one immature] or 8 , if sex not specified) Head as wide as body, as wide as long; HW 36.5$40.8 \%(\bar{x}=39.2)$ SVL; papilla at tip of snout (Fig. $32)$ : E-N $90.6 \%$ length of eye in one male, 89.5$113.9 \%(\bar{x}=104.6)$ in females; snout longer than length of eye; nostrils weakly protuberant, directed dorsolaterally; canthus rostralis weakly angular, nearly straight; loreal region flat, sloping abruptly to lips; lips weakly flared; upper eyelid width 65.9$80.6 \%$ ( $\bar{x}=71.8$ ) IOD; interorbital space flat; most individuals with minute conical tubercle on upper eyelid; supratympanic fold indistinct; tympanic annulus round, superficial, indistinct externally in

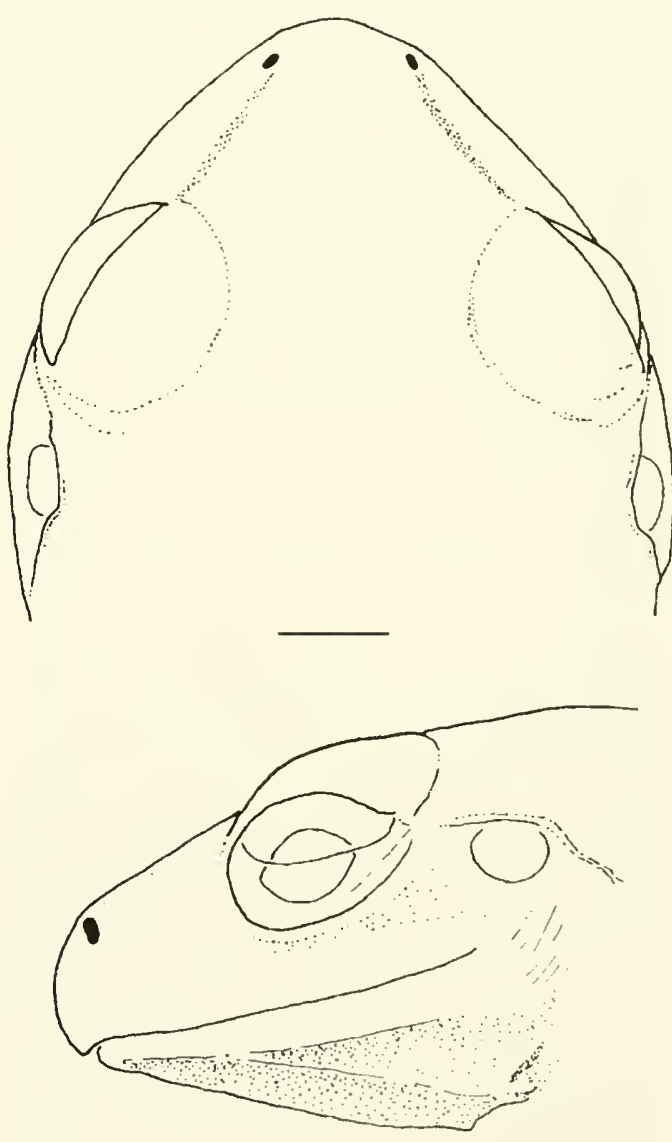

Fig.32. Eleutherodactylus engeniae, o, KU 165899. Scale bar $=2 \mathrm{~mm}$. 
only male, prominent in lemales, its length $31.2 \%$ length of eye in one male, $36.7-42.7 \%(\bar{x}=41.5)$ in females, separated from eye by distance equal to $1 \frac{1}{2} \times$ length of tympanic annulus; postrictal tubercles small, conical; tongue as long as wide, its posterior border feebly notched, posterior $1 / 3$ not adherent to floor of mouth; choanale moderate sized, round, not concealed by palatal shelf of maxillary arch: vomerine odontophores posteromedian to choanae, separated medially by a distance equal to width of one odontophore, each larger than a choana. each bearing five or six teeth in transverse row: male with vocal slits lateral to tongue.

Skin on dorsum of body finely shagreen, coarser on flanks, and finely granular on upper surfaces of limbs; skin on belly areolate, that on throat smooth; discoidal fold well anteriad to groin; cloacal sheath and tubercles absent. Palmar tubercle bifid, slightly larger than oval thenar tubercle; supernumerary palmar tubercles small, indistinct; subarticular tubercles round, pungent; fringe along outer edge of palm and Finger IV; disc on thumb narrow, that on Finger Il as wide as tympanic annulus: dises on Fingers III and IV larger than tympanic annulus. Heel of adpressed hind limb reaching point just anterior to eye; when hind limbs flexed perpendicular to body axis. heels overlapping; shank $51.4-56.6 \%(\bar{x}=53.2)$ SVL; inner margin of tarsus having indistinct tubercle (difficult to detect): inner metatarsal tubercle twice as long as wide, not compressed; subarticular tubercles round, not conical; supernumerary plantar tubercles at bases of toes: discs on toes as large as those on fingers.

In preservative, dorsum cream, gray, or pale brown with scattered brown spots on the limbs and (or not) on digits; flanks with brown reticulations; dorsum with or without creamy-white spots outlined in brown and/or white interorbital bar edged with brown. Faint supratympanic stripe evident; labial bars, canthal stripe, and limb bars absent. Venter cream, with or without faint brown reticulation on belly; brown flecks on throat; ventral surfaces of thighs and shanks unmarked; unpigmented area in groin; anterior surfaces of thighs brown. posterior surfaces cream with brown reticulations, except for brown patch behind knee.

Measurements of holotype: SVL 30.5, shank 16.4, HW 12.1, head length 10.1, upper eyelid width 2.9. IOD 3.9, tympanic annulus length 1.4 , eye length 3.8, E-N 3.4.

Coloration in life.-The dorsum is pale creamy tan to dusky yellow; if pale spots are present, they are pale yellow to pale orange. There is a faint brown reticulum on the flanks; the throat and venter are white, and the concealed surfaces of the hind limbs are a flesh color to brown. The iris is pale greenish-gray to coppery orange with brown llecks or fine black reticulation.

Natural history.-Elentherodactylus eugeniae inhabits cloud forests away from streams. In July 1977, one individual was $2 \mathrm{~m}$ and another $4 \mathrm{~m}$ above the ground; JDL no longer recalls what possessed him to climb the tree to find the latter specimen, but this observation suggests that the apparent rarity of this species may reflect the frog's use of a stratum above the collecting zone of most biologists.

Distribution.-This species is known only from three localities in a limited area of cloud forest at elevations of 1700-2010 $\mathrm{m}$ in the upper valley of the Río Pilatón in Provincia Pichincha, Ecuador (Fig. 33). One locality is in the humid subtropical regime, and two are in the humid temperate regime.

Etymology.-The specific name is a noun in the genitive case and is a patronym for Eugenia del Pino of the Pontificia Universidad Católica del Ecuador. For more than a decade she extended many courtesies to us while we were working in Ecuador, and she accompanied WED to the type locality in 1977.

Remarks.-Only nine specimens are known. The only juvenile (KU I65901) is a female 25.5 $\mathrm{mm}$ in SVL. We think that E. engeniae is most closely related to E. nyctophylax, but we are unaware of any synapomorphy to link the pair of species.

\section{Eleutherodactylus floridus sp. nov.}

Holotype.-USNM 239672, adult male, obtained in "region of Sigchos, [Provincia] Cotopaxi," Ecuador, in June 1957 by Manuel Olalla.

Paratypes.-USNM 239674-92. (See Appendix I for localities.)

Diagnosis.-A member of the Eleutherodactylus (Eleutherodactylus) myersi group having 


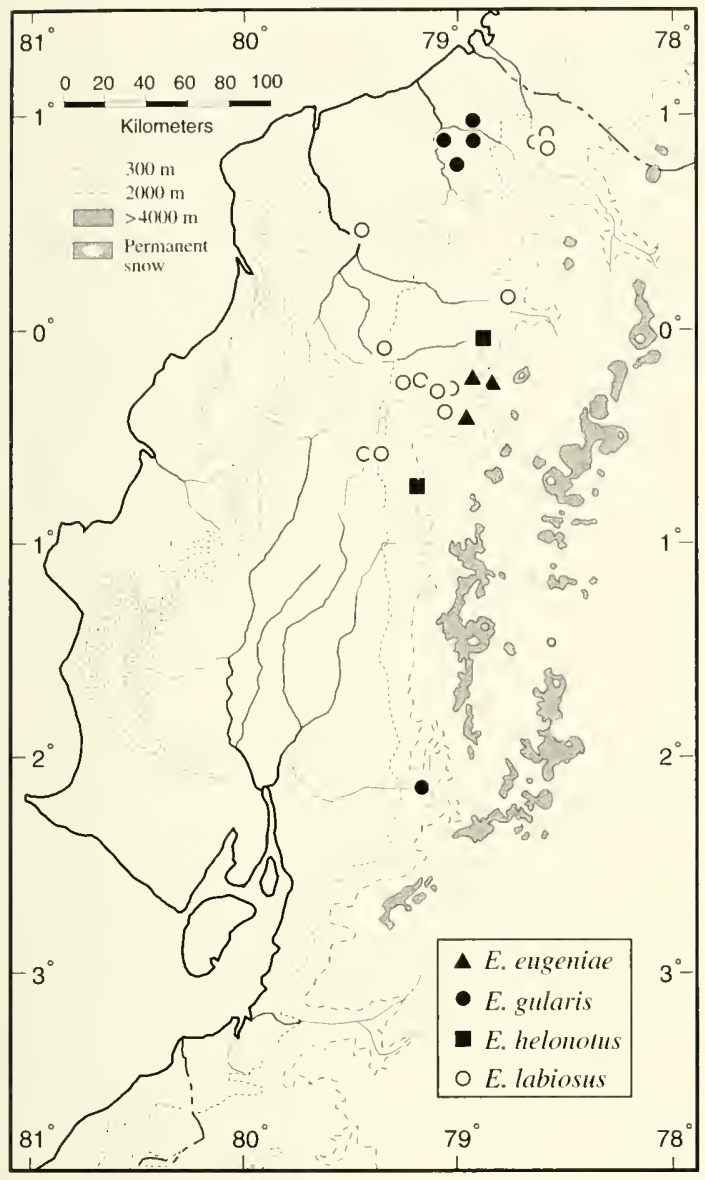

Fig. 33. Distribution of four species of Eleutherodactylus in western Ecuador.

(1) skin on dorsum shagreen with many rounded warts, that on venter areolate; discoidal fold absent; dorsolateral folds absent; (2) tympanic membrane prominent, and tympanic annulus thin and not prominent, higher than long, its length $1 / 3-2 / 5$ length of eye; (3) snout short, subacuminate in dorsal view, rounded in profile; (4) upper eyelid bearing low tubercles, about as wide as IOD; cranial crests absent; (5) vomerine odontophores prominent, oval to triangular in outline: (6) males lacking vocal slits and nuptial pads; (7) first finger shorter than second; discs on outer fingers round, about twice width of digit proximal to pad; (8) fingers bearing narrow lateral keels; (9) ulnar tubercles absent; (10) heel and inner edge of tarsus lacking tubercles; outer edge of tarsus bearing row of small tubercles;
(I1) inner metatarsal tubercle oval, about $4 \times$ round outer metatarsal tubercle; supernumerary plantar tubercles absent: (12) toes bearing narrow lateral keels; webbing absent; fifth toe slightly longer than third; discs smaller than those on outer fingers; (13) dorsum brown with diffuse darker markings; venter cream with brown marbling; throalt brown: groin and posterior surfaces of thighs cream with brown marbling; (14) SVL in two males 17.4 and $18.3 \mathrm{~mm}$, in 17 females $23.3-26.7 \mathrm{~mm}(\bar{x}=25.5)$.

Eleutherodactylus floridus differs from all other species in the E. myersi group by having larger discs. It also differs in color pattern, but probably has red areas on the concealed surfaces of the hind limbs. Eleutherodactylus floridus lacks dorsolateral folds (present in E. hectus) and has white mesorchial lining (black in E. leoni). Because of its large digital discs, E. floridus superficially resembles species in the E. leptoloplus group in Colombia, but in all of those frogs the fifth toe is much longer than the third (only slightly longer in E. floridus).

Description.- $(n=19 ; 2$ males, 17 females $)$ Head wider than body in males and immature females, slightly narrower than body in gravid females, wider than long; HW 40.2 and $40.4 \%$ in males, $38.9-42.5 \%(\bar{x}=40.3)$ in females; snout short, subacuminate in dorsal view, rounded in profile (Fig. 34); E-N 70.8 and $71.4 \%$ length of eye in males, $65.7-80.6 \%(\bar{x}=72.7)$ in females; nostrils protuberant, directed laterally; canthus rostralis angular, concave; loreal region weakly concave, sloping abruptly to lips; lips not flared; upper eyelid bearing small, pustular tubercles (not larger than those on rest of head); upper eyelid width 100.0 and $135.3 \% 10 D$ in males, $88.0-107.7 \%(\bar{x}=98.2)$ in females; cranial crests absent; supratympanic fold indistinct but obscuring upper edge of tympanic annulus; side of head vertical: tympanic annulus thin, only anterior and ventral parts visible when pressed against skin; tympanic membrane not pustular or thickened; tympanic annulus round in males, higher than long in females; length of tympanic annulus 33.3 and $39.3 \%$ length of eye in males, $31.4-39.2 \%(x=34.0)$ in females: postrictal tubercles subconical, posterior to tympanic annulus; skin on head bearing low warts, even on face. but those above tympanic annulus most prominent. Choanae oval, not concealed by palatal shelf of 

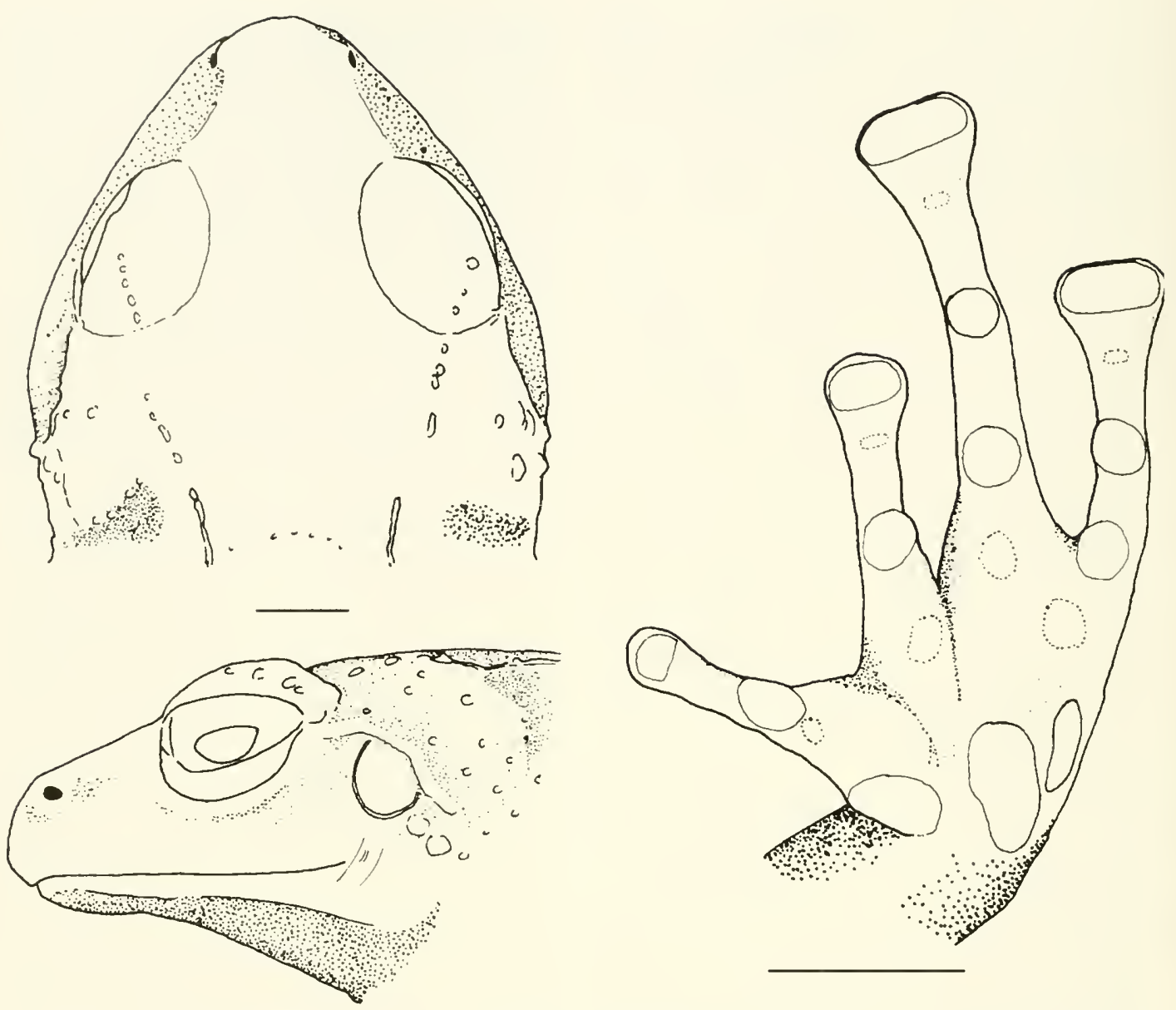

Fig. 34. Eleutherodactylus floridus, USNM 239673, ọ, showing top and side of head, and USNM 239674. op, showing palmar view of hand. Scale bars $=2 \mathrm{~mm}$.

maxillary arch, especially small in adult females, proportionately larger in small individuals; vomerine odontophores posteromedian to choanae, oval to nearly triangular in outline, each $3-5 \times$ size of a choana, separated medially by distance equal to width of odontophore, each bearing three to five teeth in transverse row; tongue longer than wide, its posterior border not notched, posterior $2 / 5-1 / 2$ not adherent to floor of mouth; males lacking vocal slits.

Dorsum shagreen with many, scattered large warts; largest warts in areas of darker pigment; warts forming postocular ridges and in some individuals shorter ridges postsacrally; dorsolateral folds absent; flanks with higher density of large warts than on dorsum; cloacal sheath and enlarged tubercles in cloacal region absent; skin on throat smooth or wrinkled; skin on venter areolate; discoidal fold absent. Upper surfaces of arms tuberculate: ulnar tubercles absent or in low row along postaxial surface of forearm; thenar tubercle oval, much smaller than bifid palmar tubercle; supernumerary palmar tubercles prominent, round, smaller than round, nonconical subarticular tubercles; fingers bearing narrow lateral fringes; first finger shorter than second; disc on thumb not expanded; discs on Fingers III and IV about twice width of digits, that on Finger II smaller; all fingers having ventral pads defined by circumferential grooves; nuptial pads absent in males. Upper surfaces of 
hind limbs warty, largest warts on limb bars; heel tubercles absent; outer edge of tarsus bearing row of small tubercles; inner surface of tarsus lacking tubercles; inner metatarsal tubercle two and onehalf times as long as wide, about four times size of round outer metatarsal tubercle: supernumerary plantar tubercles absent; subarticular tubercles round, nonconical; toes bearing narrow lateral keels; webbing absent; discs on toes expanded but smaller than those on outer fingers; tip of Toe $V$ extending just beyond penultimate subarticular tubercle on Toe IV; tip of Toe III extending to base of that tubercle; when hind limbs flexed perpendicular to axis of body, heels overlapping; shank 53.4 and $56.5 \%$ SVL in males, $50.0-57.1 \%(\bar{x}=53.6)$ in females.

Dorsum brown with subdued, darker brown markings (chevrons, blotches, labial bars, canthalsupratympanic stripe); cloacal triangular dark brown; bars on shanks (when present) transverse, about equal to width of interspaces; throat brown with cream flecks; belly and ventral surfaces of limbs cream with brown marbling; areas at bases of arms, on lower flanks, in groin colorless (cream); anterior and posterior surfaces of thighs cream with dark brown marbling.

Measurements of holotype: SVL 26.0, shank 13.6, HW 10.2, head length 9.6, upper eyelid width 2.2, IOD 2.5, tympanic annulus 1.0 , eye length 3.3 , E-N 2.5.

Coloration in life.-Unknown.

Natural history.-Unknown

Distribution.-This species is known only from provincias Cotopaxi, Imbabura, and Pichincha. Many of the specimens have elevational data and were collected by members of the Olalla family. Paynter and Traylor (1977) discussed many of these localities; thus, it seems that E. floridus occurs at elevations of 700-2000 $\mathrm{m}$ on the western flank of the Andes (Fig. 35). Nine of the 12 localities seem to be in the humid subtropical regime; the other three are in the humid temperate regime.

Etymology.-The specific name is a Latin adjective meaning "abounding with flowers." The name is used in allusion to Glen Flores in recognition of his contributions to the study of Eleutherodactylus and whose surname is Spanish for "flowers."

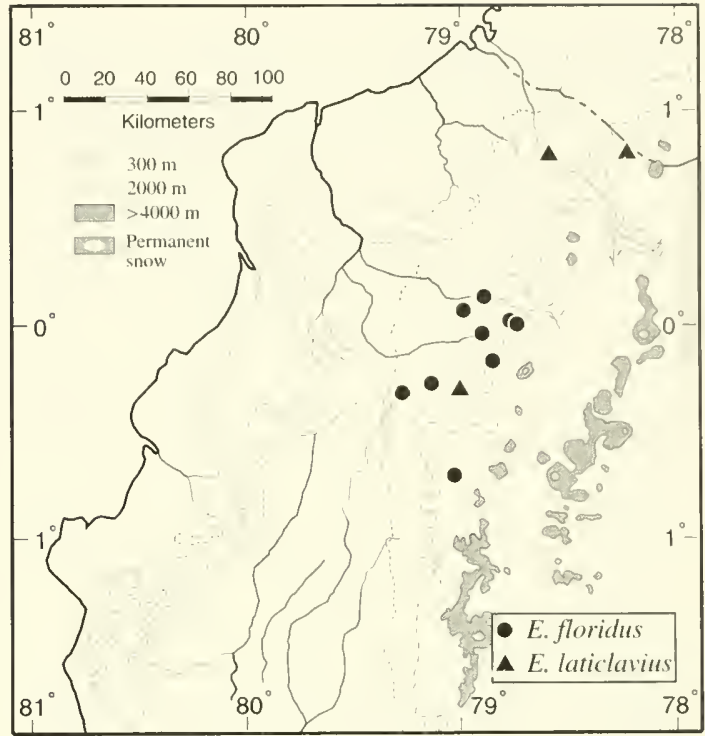

Fig. 35. Distribution of two species of Elentherodactylus in western Ecuador.

Remarks.-One juvenile female (USNM 239791 ) has a SVL of $16.1 \mathrm{~mm}$, and one nearly adult female (MCZ 90320) has a SVL of $22.2 \mathrm{~mm}$. We think that $E$. floridus is the nearest relative of $E$. pyrrhomerus, even though E. floridus has much larger digital discs. However, most of the features held in common by the two species seem to be plesiomorphic.

\section{Eleutherodactylus gentryi sp. nov. Plate 3}

Holotype.-KU 131540, adult female, one of a series collected " $5 \mathrm{~km}$ E (by road) Pilaló" (estimated distance). $3200 \mathrm{~m}\left(\approx 00^{\circ} 56^{\prime} 15^{\prime \prime} \mathrm{S} .78^{\circ} 45^{\circ} 30^{\prime \prime}\right.$ W), Provincia Cotopaxi, Ecuador. on 7 July 1970 by John D. Lynch.

Paratypes.-KU 131541-50, USNM 239763. 239768-71. (See Appendix I for localities.)

Diagnosis.-A member of the Elentherodactylus (Eleutherodactylus) curtipes group having (1) skin on dorsum bearing low warts (most obvious on flanks), that on venter areolate; discoidal fold well anteriad to groin: dorsolateral folds present: (2) tympanic membrane and usually tympanic annulus absent: (3) snout short, subacuminate 
to rounded in dorsal view, rounded in profile; (4) upper eyelid lacking tubercles, narrower than IOD; cranial crests and bony tubercles between eyes; (5) vomerine odontophores oblique; (6) males lacking vocal slits and nuptial pads; (7) first finger shorter than second; discs on outer fingers narrow, about $1.5 \times$ width of digit proximal to pad; (8) fingers bearing narrow lateral keels; (9) ulnar tubercles absent except for low antebrachial tubercle: (10) heel bearing nonconical tubercle; inner and outer edges of tarsus bearing minute tubercles; (11) inner metatarsal tubercle oval, about $3 \times$ subconical outer metatarsal tubercle: supernumerary plantar tubercles numerous; ( 12 ) toes bearing lateral fringes; webbing absent: fifth toe longer than third; (13) dorsum brown with little pattern; pale labial stripe present; venter cream with small brown flecks; posterior surfaces of thighs brown: (14) SVL in males 23.0-28.5 mm, in females 29.6-35.5 mm ( $\bar{x}$ =33.4).

Eleutherodactylus gentryi is similar to E. curtipes but differs from that species in having obvious (albeit small) digital discs, bony tubercles on the frontoparietals between the cranial crests, longer hind limbs, and in lacking a tympanic annulus; in $E$. curtipes, the tympanic annulus is fully formed but lies concealed beneath the skin.

Description.- $(n=12 ; 4$ males, 8 females $)$ Head no broader than body (less so in gravid females), wider than long; HW 39.4-40.0\% ( $\bar{x}=$ 39.7) SVL in males, $36.3-41.7 \%(\bar{x}=39.2)$ in females; snout short, subacuminate to rounded in dorsal view, rounded in profile; E-N 78.6-82.8\% $(\bar{x}=80.9)$ length of eye in males, $70.7-86.5 \%(\bar{x}=$ $81.6)$ in females; nostrils weakly protuberant, directed dorsolaterally; canthus rostralis angular, straight or weakly concave; loreal region concave. sloping abruptly to lips; lips not flared; upper eyelid bearing low tubercles, its width $65.7-86.2 \%(\bar{x}=$ 76.5) IOD in males, $63.0-78.8 \%(\bar{x}=68.3)$ in females; interorbital region broad, its surface reflecting structure of underlying bones (low cranial crests just medial to eyes, bony tubercles between crests, extending onto nasals in some specimens); supratympanic fold indistinct, made less evident by tubercles above and below fold; tympanic annulus never visible externally: when detectable, annulus weak, higher than long; postrictal tubercles round, not prominent. Choanae small, round, not concealed by palatal shelf of maxillary arch; vomerine odontophores posteromedian to choanae, oblique, each about three times size of a choana, separated medially by distance equal to half width of odontophore, each bearing four or five teeth in oblique row: tongue broader than long, its posterior border not notched, posterior $2 / 5$ not adherent to floor of mouth; males lacking vocal slits and sac.

Dorsum smooth to feebly warty; dorsolateral folds usually distinct, fragmented posterior to sacrum; area between dorsolateral folds bearing small warts; skin on flanks bearing larger warts; skin of venter areolate; discoidal fold well anteriad to groin: cloacal sheath and tubercles absent; skin on upper surfaces of limbs smooth or shagreen; ulnar tubercles indistinct except for small antebrachial tubercle. Thenar tubercle oval, about $1 / 2$ size of bifid palmar tubercle; numerous, low supernumerary palmar tubercles; subarticular tubercles round to wider than long, low; first finger shorter than second; fingers bearing fleshy lateral keels; tip of thumb not expanded into disc; Fingers II-IV bearing round discs, those on Fingers III and IV about $1 \frac{1}{2} \times$ width of digit proximal to disc: all digits having broad ventral pads; nuptial pads absent in males. Upper edge of heel bearing low tubercle; less prominent tubercles on inner edge of tarsus and forming row on outer edge of tarsus: inner metatarsal tubercle oval, about $3 \times$ subconical outer metatarsal tubercle; numerous low supernumerary plantar tubercles, indistinct except at bases of toes; subarticular tubercles round, not conical; toes bearing lateral fringes; webbing absent; toe discs round, bearing ventral pads, smaller than those on outer fingers; tip of Toe $\mathrm{V}$ extending to distal base of distal subarticular tubercle on Toe IV; tip of Toe III extending to proximal border of penultimate subarticular tubercle on Toe IV; when hind limbs flexed axis of body, heels not overlapping (touching in a few specimens): shank 46.5$50.0 \%(\bar{x}=47.8)$ SVL in males, 41.6-50.9 $(\bar{x}=$ $46.0)$ in females.

In preservative, dorsum brown with darker brown markings consisting of rectangular blotch extending from eyes to sacrum, scattered small spots on body, limb bars fragmented into spots, indistinct canthal-supratympanic stripe, and hints of labial 
bars; throat paler brown; belly cream with small brown flecks or uniform brown; anterior and posterior surfaces of thighs pale brown in most individuals: pale patch behind knee and in groin, and venter pale in USNM 239763.

Measurements of holotype: SVL 34.4, shank 17.5, head width 13.5, head length 12.0, chord of head length 13.0, upper eyelid width 2.9. IOD 4.6 eye length 4.2, E-N 3.6.

Coloration in life.-The dorsum is variable, and the venter and concealed surfaces of the hind limbs usually are at least tinted with a salmon color, as noted in the following description.

KU 131540-65 from $5 \mathrm{~km}$ E Pilaló, Provincia Pichincha: Dorsum red to brown with darker brown to black markings (usually a dark reddish-brown blotch); flanks paler than dorsum; venter dirtycream to salmon; posterior surfaces of thighs salmon-brown to brown: labial stripe creamy bronze; iris pale copper with reddish-brown, median, horizontal streak (JDL, 7 July 1970).

Natural history.-All individuals were under rocks by day. Males collected in July have swollen testes with dark mesorchia (either brown reticulation or uniform stippling). The smallest gravid female (USNM 239763, $29.5 \mathrm{~mm}$ in SVL) is only slightly larger than a female estimated to be entering reproductive condition (USNM 239738, 28.2 $\mathrm{mm}$ ).

Distribution.- - This species is known only from elevations of 2850-3380 $\mathrm{m}$ in the upper reaches of cloud forest, principally in the humid subtemperate regime, west of the Páramo de Apagua, Provincia Cotopaxi, Ecuador (Fig. 24).

Etymology.-The specific name is a noun in the genitive case and is a patronym for our late friend and colleague, the intrepid botanist Alwyn H. Gentry, who was killed while conducting field work in western Ecuador on 3 August 1993. We think of this species as residing high in the cloud forests of western Ecuador and figuratively looking westward over the remnants of forest on the lowlands of western Ecuador, and dedicate this species to the memory of "Al" Gentry, who loved the tropical forests and who enriched the lives of everyone who knew him.

Remarks.-Numerous specimens referred to this species are either juveniles or, in the case of
USNM 239738-62, partially crushed. Although specific identity is not a problem, we are reluctant to designate juveniles and poorly preserved specimens as paratypes. Eleutherodactylus gentryi is a member of the E. curtipes group, which also includes E. buckleyi, cryophilus, curtipes, and two recently described species (E. satagins and E.xestus) from Colombia (Lynch, 1995) The sharing of broadly expanded frontoparietals that extend over the posteromedial portions of the orbits unites $E$. curtipes and $E$. gentryi as probable sister species.

\section{Eleutherodactylus gularis (Boulenger) Plate 8}

Hylodes gularis Boulenger, 1898:463.-BM 1947.2.15.82, adult male, from Cachabé, Provincia Esmeraldas, Ecuador.

Hyloxalus huigrue Fowler, 1913:165.-Holotype: ANSP 18113, adult male, from Huigra, $4000 \mathrm{ft}$, Provincia Chimborazo, Ecuador. Synonymy fide Lynch, 1976b:14.

Eleutherodactylus diastema-Dunn, 1942:2.

Eleutherodactylus gularis-Cochran and Goin. 1970:441; Lynch, 1976b:14.

Diagnosis.-A member of the Elentherodactylus (Eleutherodactylus) diastema group having (1) skin on dorsum smooth, that on venter areolate; discoidal fold absent; dorsolateral folds absent; (2) tympanic membrane absent: tympanic annulus visible through skin, round, $1 / 32^{2 / 3}$ length of eye; (3) snout subacuminate in dorsal view, truncate in profile; (4) upper eyelid lacking tubercles, narrower than IOD; cranial crests absent; (5) vomerine odontophores oval in outline, narrowly separated; (6) males having vocal slits and large subgular vocal sac; nuptial pads absent: (7) first finger shorter than second; discs slightly wider than digits; disc covers feebly pointed but lacking papillae: (8) fingers broad, bearing weak lateral fringes; (9) ulnar tubercles absent: (10) heel and tarsus lacking tubercles and folds; (11) inner metatarsal tubercle oval, $3 \times$ round outer metatarsal tubercle; supernumerary plantar tubercles absent; (12) toes broad, lacking lateral fringes; webbing basal; fifth toe much longer than third; discs lanceolate with minute papillae at tips of Toes II-IV: (13) dorsum pale brown with vague markings; snout pale; venter 
cream with brown stippling on throat; posterior surfaces of thighs brown; (14) SVL in males 20.2$21.6 \mathrm{~mm}$, in females $23.3-24.8 \mathrm{~mm}$.

Eleutherodactylus gularis is most similar to $E$. diastema but differs in having fleshy, basal webbing on the foot and in having pointed disc covers. which on Toes III-IV bear small papillae.

Description.- $(n=16: 9$ males, 7 females $)$ Head as broad as body (less so in gravid females), longer than broad: HW $34.0-39.1 \%(\bar{x}=36.7 \pm$ $0.4)$ SVL; snout long, subacuminate in dorsal view. truncate in profile (Fig. 36); nostrils not protuberant, directed laterally (with slight dorsal vector), near tip of snout: E-N 64.7-92.6\% ( $\bar{x}=78.4 \pm 1.9)$ length of eye; canthus rostralis rounded, straight; loreal region flat, sloping abruptly to lips; lips not flared: upper eyelid lacking tubercles, its width
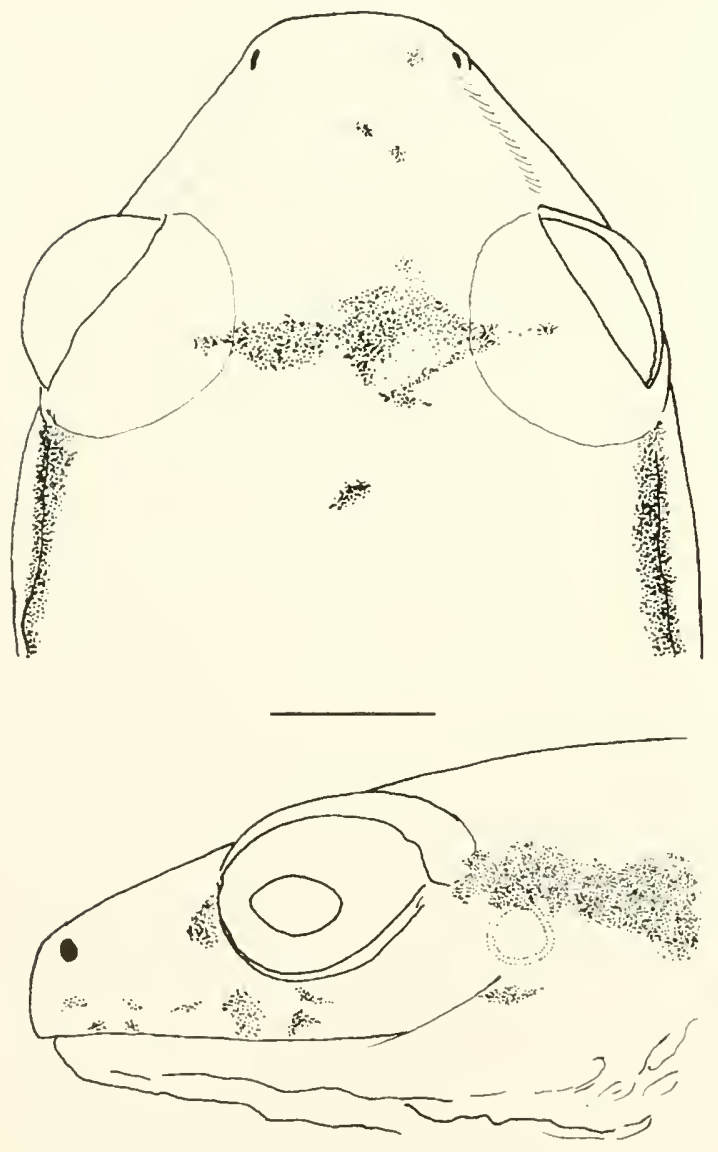

$55.2-80.8 \%(\bar{x}=66.0 \pm 2.8)$ IOD; interorbital region flat; cranial crests absent; temporal region nearly vertical; supratympanic fold low, poorly defined; lower $3 / 4$ of tympanic annulus evident, round, separated from eye by distance equal to $2 / 3$ of its diameter; length of tympanic annulus 28.6$42.4 \%(x=34.5 \pm 1.3)$ length of eye; two postrictal tubercles posteroventral to tympanic annulus. Choanae long, oval, not concealed by palatal shelf of maxillary arch; vomerine odontophores posteromedian to choanae, oblique, each larger than a choana, separated medially by distance equal to half width of odontophore, bearing five or six teeth in oblique row; tongue much longer than broad, its posterior border not notched, posterior half not adherent to floor of mouth; males having short vocal slits lateral to tongue; external vocal sac

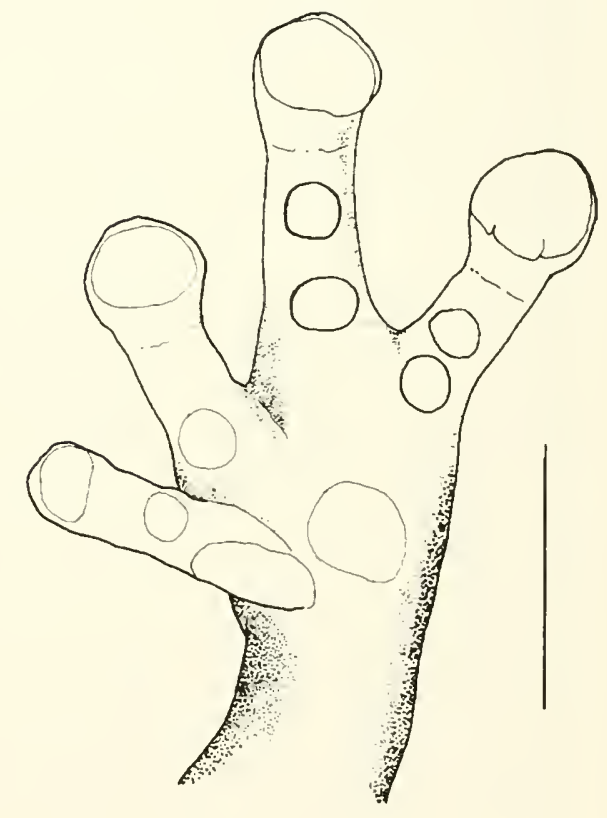

Fig. 36. Eleutherodactylus gularis, o, QCAZ4316, showing top and side of head and palmar view of hand. Scale bars $=2 \mathrm{~mm}$. 
commonly forming longitudinal folds median to mandibles in preserved specimens.

Dorsum smooth except for some low tubercles on back postsacrally in some specimens; dorsolateral folds absent; skin on lower flanks and venter with low areolations (most evident laterally); discoidal fold absent; cloacal sheath and tubercles absent; forearm slender; ulnar tubercles absent. Thenar tubercle oval, smaller than oval palmar tubercle; supernumerary palmar tubercles absent; subarticular tubercles round, flattened: first finger shorter than second; fingers broad, bearing weak lateral keels; digital dises only slightly wider than digits (Fig. 36); disc covers feebly pointed: nuptial pads absent in males. Heel and tarsus lacking tubercles and folds; inner metatarsal tubercle about $2 \frac{1}{2}$ times as long as wide, not compressed, $3 \times$ round, unelevated outer metatarsal tubercle; supernumerary plantar tubercles absent; subarticular tubercles low, round; digits flattened, lacking lateral keels; webbing basal, formula: I $2^{-}-2^{+}$II $2-3^{+}$ III $2^{1 / 2}-4^{+}$IV $4^{+}-2^{-} \mathbf{V}$; toe discs lanceolate with minute papillae at tips of Toes III-V; fifth toe much longer than third; when hind limbs flexed against axis of body, heels touching or barely overlapping; hind limbs short, shank $39.5-44.6 \%(\bar{x}=42.2 \pm$ 0.4) SVL.

Dorsum pale brown with small brown spots and nearly black interorbital bar; snout paler than rest of dorsum; limbs pale brown with dark brown bars and white flecks on forearms; supratympanic stripe and spot at anterior corner of eye dark brown; subocular spot white with brown border: all ventral surfaces white except for brown stippling along jaws; posterior surfaces of thighs pale brown; disc covers and outer digits dark brown; innermost digits cream; white line separating disc cover from brown on top of digit.

Coloration in life.-A color photograph of an individual from Isla Gorgona, Colombia, reveals a yellowish-tan dorsum and yellow flanks: reddishbrown dorsal markings consist of an interorbital bar, narrow canthal stripe, broader postorbital stripe, short, irregular marks in the scapular region, and transverse dots on the shanks. The iris is goldenbronze with a reddish-brown horizontal streak.

Natural history.-Eleutherodactylus gularis inhabits lowland tropical rainforest. Kenneth Miyata obtained two specimens on vegetation along a small stream at San Miguel, Provincia Esmeraldas. on the night of 20 June 1977.

Distribution.-This species occurs at low elevations in the humid tropical regime in northwestern Ecuador and Colombia northward to at least Pizarro (Departamento Chocó) (Fig. 33). The only record above $400 \mathrm{~m}$ is the purported type locality of Hyloxalus huigrae at $1200 \mathrm{~m}$ in the dry subtropical regime.

Remarks.-Dunn(1942) combined Eleutherodactylus gularis with E. diastema (Cope). Cochran and Goin (1970) did not reference Dunn's paper and reported E. gularis and E. diastema from Colombia. They stated (1970:374) that the two species could be distinguished by the "disc of third finger and of fourth toe two or three times the size of tympanum" in E. diastema and "not quite as large as tympanum" in E. gularis. However, the discs in E. diastema never are that large, even in the specimens that they reported and described. Lynch (1976b) suggested that E. gularis differs from $E$. diastema in that the former has papillae on the tips of [some] discs; he used this observation to remove Hylodes huigrae Fowler from the synonymy of $E$. diastema and to allocate it to the synonymy of $E$. gularis.

However, not all specimens from the lowlands of Colombia and none of those from Ecuador have discs with papillae as long as those illustrated by Lynch (1976b). Specimens from Ecuador and southern Colombia have papillae only on Toes II-1V. usually in the form of rounded knobs at the apex of the pad on the underside of the disc cover, but sometimes they are more prominent. Frogs of this group from the Atrato and San Juan drainages in Chocoan Colombia have larger papillae on the toes (some on fingers as well) and many of these frogs are small in contrast to those from Ecuador and lsla Gorgona. There are probably three species involved in western Colombia but only one in Ecuador. In E. gularis, the digital tips are somewhat pointed, and casual observation (not under a dissecting microscope) would lead one to consider the discs to be papillate; the holotypes of E. gularis and Hyloxalus huigrae do not have papillae at the tips of the digits.

On the strength of the presence of short papillae 
on some toes and fleshy basal webbing between the toes, we recognize $E$. gularis as distinct from $E$. diastema. The latter is known as far east as extreme eastern Panama and is expected to be found in Colombia. Along the Pacific coast, but apparently not inland, E. gularis ranges as far north as Pizarro in Departamento Chocó, Colombia. Two unnamed species occur in Colombia and Panama. One of those was illustrated by Lynch (1976b) as E. gularis, but it is a smaller frog with prominent papillae on the finger tips but not the toe tips. Eleutherodactylus gularis is the same size as E. diastema but may be more closely related to E. vocalis Taylor, a small species with pointed disc covers.

\section{Eleutherodactylus hamiotae Flores Plate 4}

Eleutherodactylus hamiotae Flores, 1993:427.- Holotype: MCZ 98027, adult female, from $13.1 \mathrm{~km} \mathrm{NW}$ Nono, 2140 m. Provincia Pichincha, Ecuador.

Diagnosis.-A member of the Eleutherodactylus (Eleutherodactylus) surdus group having (1) skin on dorsum shagreen with flat warts posteriorly and slightly more pungent pustules on flanks, that on venter areolate; discoidal fold poorly defined; dorsolateral folds absent; postocular folds pustular; fold lower on flank extending to level of sacrum, becoming lost posteriorly amidst pustules; (2) tympanic membrane and tympanic annulus absent: (3) snout short, rounded in dorsal view, rounded to slightly sloping in profile; (4) upper eyelid bearing flattened warts, as wide as or slightly broader than IOD; cranial crests absent; (5) vomerine odontophores oval in males, triangular in females; (6) males lacking vocal slits; thumb of males swollen, lacking nuptial pads; testes white; (7) first finger shorter than second; thumb lacking disc; discs on outer fingers nearly twice width of digit, all bearing ventral pads; (8) fingers bearing fleshy lateral keels; (9) ulnar tubercles absent (Flores, 1993:430, reported "indistinct ulnar tubercles"); (10) heel and outer edge of tarsus bearing minute tubercles; inner edge of tarsus bearing thickened area along distal half; (11) inner metatarsal tubercle twice as long as wide; outer metatarsal tubercle not apparent (Flores (1993:430, reported outer metatarsal tubercle as "variably present, minute"): supernumerary plantar tubercles absent; (12) toes having lateral fringes and basal webbing; webbing formula for outer toes IV $4^{+}-2 i \frac{1}{2} \mathbf{V}$; fifth toe longer than third, not reaching distal subarticular tubercle on Toe IV; (13) dorsum brown to tan with scattered dark areas; facial markings poorly defined; venter cream with dense brown stippling; posterior surfaces of thighs brown with cream spots (or uniform brown, USNM 239843); (14) SVL in males $28.2-30.9 \mathrm{~mm}$, in females $35.7-36.2$ $\mathrm{mm}$.

Eleutherodactylus hamiotue is most similar to E. duellmani, but it is smaller with less well developed basal webbing between the toes, a more sloping snout (truncate in E. duellmani), less obvious dorsolateral folds, more robust fingers, and no tubercles on the heel and outer edge of the tarsus. Breeding males of E. duellmani have nuptial pads (absent in E. hamiotae).

Description.-The type description (Flores, 1993 ) is complete. This species is represented by few specimens; we provide measurements for the second known male (USNM 239843): SVL 30.9, shank 13.4, HW 11.3, head length 10.0, chord of head length 10.5, upper eyelid width 2.9, IOD 2.3, eye length 4.0, E-N 2.6.

Coloration in life.-Based on field notes of Kenneth Miyata, Flores (1993:430-31) reported colors in life of the two paratypes, as follow. "MCZ 97486: 'Dorsum dark greenish olive mottled with dark brown. Limbs dark brown barred with black. Venter gray with dark gray reticulations. Iris dark brown.' MCZ98052: 'Dorsum clay colored mottled with cinnamon brown. Venter translucent smoke gray. Iris deep coppery brown'."

Natural history.-The type locality is a wellwatered roadcut; the type series was collected on the dripping rock face (Flores, 1993). James A. Peters collected a single specimen (USNM 239843) at a locality " 12 km W Nono (Nono-Nanegal road)" on 26 October 1958. Peters" field notes suggest that he collected at the same site visited 19 yr later by Kenneth Miyata, who collected the type series.

Distribution.--Eleutherodactylus hamiotae is known only from the vicinity of the type locality in cloud forest at an elevation of $2140 \mathrm{~m}$ in the humid temperate regime on the western slopes of the Andes in Ecuador (Fig. 27). 
Remarks.-The distribution of Eleutherodactylus duellmani, which occurs at elevations of 1550-2500 m, encompasses that of E. hamiotae. The closest record of $E$. duellmani to that of $E$. hamiotae is $9 \mathrm{~km}$ SE Tandayapa $(2150 \mathrm{~m})$, which is only about $6 \mathrm{~km}$ (airline) from the type locality of E. hamiotae. Eleutherodactylus hamiotae seems to be more closely related to E. duellmani than to either of the other species in the E. surdus group ( $E$. sobetes and E. surdus).

\section{Eleutherodactylus hectus Lynch and Burrowes}

Plate 8

Eleutherodactylus hectus Lynch and Burrowes. 1990:11.-Holotype: IND-AN 1947, adult female, from Reserva Natural La Planada, $1780 \mathrm{~m}$. Municipio de Ricaurte, Departamento Nariño, Colombia.

Diagnosis.-A member of the Eleutherodactylus (Eleutherodactylus) myersi group having (1) skin on dorsum tuberculate to granular, that on venter areolate; discoidal fold absent; dorsolateral folds prominent; (2) tympanic membrane and tympanic annulus prominent, $2 / 5-1 / 2$ length of eye; (3) snout subacuminate in dorsal view, rounded in profile; (4) upper eyelid bearing two or three subconical tubercles, narrower than IOD; cranial crests absent; (5) vomerine odontophores oval in outline; (6) males having vocal slits; nuptial pads absent; (7) first finger shorter than second; discs small; (8) fingers bearing lateral fringes; (9) ulnar tubercles present; (10) heel and outer edge of tarsus bearing small tubercles; inner edge of tarsus bearing small, foldlike tubercle; (11) inner metatarsal tubercle oval, $4 \times$ conical outer metatarsal tubercle; supernumerary plantar tubercles numerous, minute; (12) toes bearing narrow lateral fringes and lanceolate discs; webbing absent; fifth toe slightly longer than third; (13) dorsum gray to brown with darker brown markings; venter pale brown with vague blotches; posterior surfaces of thighs brown with or without cream spots; (14) SVL in males 13.6-16.8 mm, in females 19.4-22.5 mm.

Eleutherodactylus hectus is most similar to frogs included in the E. pyrrhomerus group by Lynch (1976c), but it differs from each of them by having dorsolateral folds and larger digital dises, although some specimens of E. leoni may have dorsolateral folds (fide L. A. Coloma, in litt.). In addition, $E$. hectus lacks red or orange on the concealed surfaces of the hind limbs and/or in the groin; instead, $E$. hectus has white spots.

Description.-The type description by Lynch and Burrowes (1990) is complete, but see Remarks.

Coloration in life.-According to Lynch and Burrowes (1990), the dorsum is brown, tan, or reddish brown with creamy white, black, or brown markings. An orange-tan blotch on the head or a black interorbital bar usually are present. The limbs are brown or tan with darker brown or black transverse bars. The groin and hidden surfaces of the hind limbs are brown with white flecks, which may be clumped into spots, and the flanks are brown with varying degrees of creamy white mottling. The venter is yellow-tan with brown flecks or brown with creamy-white flecks. The iris is dull brown to greenish or bluish gray with a median, horizontal red streak.

Natural history. - In contrast to other Eleutherodactylus on the western slopes of the Andes in Ecuador, this species is diurnal in cloud forest. During the day, individuals were observed in recesses formed by buttresses and roots, and hopping in the leaf litter. Because of the cryptic coloration, stationary individuals were difficult to detect. At night, the frogs were observed sleeping on low herbaceous vegetation, a habit reminiscent of many dendrobatids.

Distribution.-Eleutherodactylus hectus is known from two localities at intermediate elevations $(1200-1780 \mathrm{~m})$ in cloud forests in the humid tropical regime on the western slopes of the Andes in extreme southern Colombia (type locality) and northwestern Ecuador (“above” Lita) (Fig. 31).

Remarks.-Specimens from Ecuador and recently collected topotypes (UVC) do not have the inner metatarsal tubercles projecting medially: this condition, cited as diagnostic by Lynch and Burrowes (1990), probably is an artifact of preservation. Eleutherodactylus hectus probably is most closely related to $E$. leoni, from which it differs in coloration and the presence of lanceolate discs on the toes. The limited distributional data for $E$. 
hectus suggest that this species may be restricted to elevations below the altitudinal range (1960-3400) m) of E. leoni.

\section{Eleutherodactylus helonotus Lynch}

Amblyphryus helonotus Lynch, 1975a: 19.-Holotype: BM 1970:178. adult female, from the Río Pitzara (=

Río Pitsará). Provincia Pichincha, Ecuador. Eleutherodactvins helonotus-Lynch. 1981b:318.

Diagnosis.-A member of the Eleutherodactylus (Eleutherodactylus) sulcatus group having (1) skin on dorsum with heterogeneous tubercles, that on venter coarsely areolate; discoidal fold not apparent; dorsolateral folds absent: (2) tympanic membrane and tympanic annulus prominent. higher than long. $2 / 5-1 / 2$ length of eye; (3) snout subacuminate in dorsal view, truncate in profile: head broad (HW $\pm 50 \%$ SVL): (4) upper eyelid bearing flattened warts, much broader than IOD; cranial crests low, parasagittal; (5) vomerine odontophores arched: (6) males unknown: (7) first finger longer than second; discs absent; (8) fingers bearing weak lateral keels; (9) ulnar tubercles present; (10) heel lacking tubercles: outer edge of tarsus bearing row of small tubercles: inner edge of tarsus lacking fold or tubercles: (11) inner metatarsal tubercle weakly compressed, $2-3 \times$ round outer metatarsal tubercle: supernumerary plantar tubercles absent: (12) toes bearing lateral fringes; tips of toes not expanded; webbing absent; fifth toe slightly shorter than third: (13) dorsum brown with indefinite black markings associated with tubercles and folds; venter cream with large brown blotches; posterior surfaces of thighs brown with black reticulation: (14) SVL in males unknown. in one female $69.6 \mathrm{~mm}$.

Eleutherodactylus helonotus is the only broadheaded species of Eleutherodactylus in western Ecuador having areolate skin on the venter. We expect that males and juvenile females. when discovered, will have tuberculate skin on the dorsum comparable to that in E. anomalus, cerastes, and necerus, but the two large females now known have low warts on the dorsum and appear to be smoother skinned. Unlike $E$. anomalus, the digital tips in $E$. helonotus are not expanded, and the toes lack any trace of webbing. The upper eyelid does not bear clongate tubercles as in E. cerastes. Elewtherodactylus necerus differs from E. helonotus by having the posterior surfaces of the thighs black with pale spots, an unpatterned venter, and numerous short ridges on the dorsum.

\section{Coloration in life.-Unknown.}

Natural history.-This species is known from two females. The holotype is gravid, and the paratype is a slightly smaller (60.6 $\mathrm{mm} \mathrm{SVL})$ female having moderate oviductal convolutions and small ovarian eggs. The paratype was on a mule trail in cloud forest. The short limbs, narrow digital tips. and bulk indicate that it is a terrestrial species.

Distribution.-One individual is from the Rio Pitsará. and the other is from the immediate environs of Mindo ( $1410 \mathrm{~m}$ ), both in Provincia Pichincha on the western slopes of the Andes in Ecuador (Fig. 33). Presumably, this species has a limited distribution at intermediate elevations in cloud forest in the humid subtropical regime.

Remarks.-When first described (Lynch. 1975a), E. helonotus was placed in the genus Amblyphrynus because no ventral pads could be seen on the tips of the digits. The two species of Amblyphrynus were considered by Lynch (1975a) as somehow being derived from the broad-headed group of Eleutherodactylus: such a classification is incompatible with a cladistic interpretation. It was not until freshly collected specimens of Amblyphrynus ingeri became available that Lynch (1981b) realized that ventral pads were present in that species and discontinued recognizing the genus Amblyphrynus. No additional material of $E$. helonotus has become available, but it too probably will be found to have traces of ventral pads. What little anatomical data are available place $E$. helonotus securely within the E. sulcatus group. More precise placement is not possible, although $E$. helonotus does have areolate skin on the venter, as do $E$. ingeri, ruizi, and sulcatus, in contrast to smooth skin on the venter in E. cadenai, cerastes, and $E$. cornutuls.

\section{Eleutherodactylus illotus sp. nov. Plate 2}

Holotype.-KU 165881, adult female, one of a series collected $3.5 \mathrm{~km} \mathrm{NE}$ (by road) Mindo, 1540 
m $\left(00^{\circ} 02^{\prime} 53^{\prime \prime} \mathrm{S}, 78^{\circ} 46^{\prime} 20^{\prime \prime} \mathrm{W}\right)$, Provincia Pichincha, Ecuador, on 7 April 1975 by W. E. Duellman.

\section{Paratypes.-KU 165882-83, USNM 239722-} 33. (See Appendix I for localities.)

Diagnosis.-A member of the Elewtherodactylus (Eleutherodactylus) conspicillatus group having (1) skin on dorsum shagreen with scattered tubercles, that on venter smooth; discoidal fold present; dorsolateral folds pustular, complete; (2) tympanic membrane and tympanic annulus prominent, its length $1 / 3-2 / 5$ length of eye; (3) snout subacuminate in dorsal view, rounded in profile; (4) upper eyelid bearing tubercles, about as wide as 1OD; cranial crests absent; (5) vomerine odontophores triangular in outline; (6) males lacking vocal slits and nuptial pads; (7) first finger longer than second; outer fingers bearing small dises about twice width of digit: (8) fingers bearing lateral keels; (9) ulnar tubercles absent; (10) heel bearing small subconical tubercle; outer edge of tarsus bearing minute tubercles; one inner tarsal tubercle: (11) inner metatarsal tubercle elongate, 4-6x conical outer metatarsal tubercle; supernumerary plantar tubercles few; (12) toes bearing narrow lateral fringes; webbing absent; fifth toe slightly longer than third; (13) dorsum brown with darker brown markings; venter cream with brown wash or mottling; groin and posterior surfaces of thighs brown without pale flecks or spots; (14) SVL in males 25.9-29.3 mm, in seven females 38.3$44.6 \mathrm{~mm}(\bar{x}=41.0)$.

Elentherodactylus illotus is similar to $E$. achatinus, but differs by having a small tubercle on the heel and brown coloration on the venter; also the former lacks vocal slits and nuptial pads (both present in E. achatimus). Eleutherodactylus illotus is similar to, but differs from, E. thectoptermus from western Andean Colombia (Lynch, 1975b) by having a small tubercle on the heel (rather than a calcar), larger tympanic annulus, and dorsolateral folds, and by lacking white spots on the posterior surfaces of the thighs.

Description.- $(n=10 ; 2$ males, 8 females $)$ Head broader than body (except in gravid females), broader than long; HW 42.3 and $44.8 \%$ SVL in males, $40.2-43.1 \%(\bar{x}=41.9)$ SVL in females; snout relatively long, subacuminate in dorsal view, rounded in profile; nostrils slightly protuberant. directed dorsolaterally; E-N 92.5 and $95.6 \%$ SV1. in males, $90.3-103.8 \%(\bar{x}=100.0)$ length of eye: canthus rostralis angular, prominent. sinuous: loreal region slightly concave, sloping abruptly to lips; lips not flared; posterior portion of upper eyelid bearing low to subconical tubercles (anterior terminus of postocular fold), width of upper eyelid 88.9 and $113.3 \%$ IOD in males, $83.9-121.9 \%(\bar{x}=$ 104.5) $10 D$ in females; interorbital region flat; cranial crests absent; temporal region nearly vertical; supratympanic fold curving posterior to tympanic annulus; tympanic membrane and tympanic annulus prominent, round in males, slightly higher than long in females, separated from eye by distance equal to length of tympanic annulus; length of tympanic annulus 35.0 and $40.0 \%$ length of eye in males, $32.3-40.5 \%(\bar{x}=36.8)$ length of eye in females; two subconical postrictal tubercles. Choanae approximately triangular (apex posteriad), not concealed by palatal shelf of maxillary arch; vomerine odontophores posteromedian to choanae, elevated and triangular in outline. each slightly smaller than a choana, separated medially by distance equal to one-half to one width of odontophore. bearing 8-10 teeth in transverse row; tongue longer than wide. its posterior border not notched, posterior $2 / 5-1 / 2$ not adherent to floor of mouth; males lacking vocal slits and nuptial pads.

Skin on dorsum of head shagreen except for round tubercles on upper eyelids, on occipital W (postocular folds), immediately adjacent to supratympanic fold, and immediately anterior to tympanic annulus; skin on dorsum of finely shagreen, becoming more coarse posteriorly; dorsolateral folds low, granular, extending to level of groin; skin on venter smooth: discoidal fold well anteriad to groin; cloacal sheath and tubercles absent; ulnar tubercles absent. Thenar tubercle oval, much smaller than oval palmar tubercle: supernumerary palmar tubercles not evident; subarticular tubercles round, not conical; first finger longer than second; fingers bearing faint lateral keels; outer fingers bearing expanded, round to subtruncate discs about twice as wide as digit proximal to disc: inner digits bearing much narrower discs, only slightly wider than digit; all fingers bearing pads on digital tips: pads defined by 
circunferential grooves; nuptial pads absent in males. Skin on dorsal surfaces of hind limbs tinely shagreen; heel bearing subconical tubercle; up to six minute tubercles along outer border of tarsus (at level of color change between black subtarsal color and paler color on dorsal and lateral surfaces); inner edge of tarsus bearing round tubercle on distal third of tarsus (some specimens with smaller tubercle between round one and inner metatarsal tubercle. but no specimen having tarsal fold); inner metatarsal tubercle thrice as long as wide, about $6 ¥$ subconical outer metatarsal tubercle (longer than wide); supernumerary plantar tubercles few, low, at bases of Toes II-IV; subarticular tubercles round to longer than wide, not conical; digits bearing narrow lateral fringes; webbing absent; toe discs expanded (largest dises about twice width of digit proximal to disc); fifth toe slightly longer than third; tip of Toe $\mathrm{V}$ extending to distal edge of penultimate subarticular tubercle on Toe IV, tip of Toe Ill extending to proximal border of penultimate subarticular tubercle on Toe IV; when hind limbs flexed against axis of body, heels broadly overlapping; hind limbs long, shank 57.3 and $60.6 \%$ SVL in males, $54.3-61.3 \%(\bar{x}=57.3) \mathrm{SVL}$ in females.

Dorsum brown with darker brown interorbital bar, dorsal chevrons, and inguinal spots; dark brown border below dorsolateral folds grading into brown spots on flanks; canthal stripe and labial bars brown; supratympanic stripe black; cloacal patch black; limbs pale brown with darker brown bars, those on shanks oblique, narrower than interspaces; undersides of forearms and tarsi black; groin, anterior and posterior surfaces of thighs, and concealed surfaces of shanks brown without pale flecks; throat pale brown with vague cream areas; belly cream with brown reticulation.

Measurements of holotype: SVL 38.3, shank 22.5. HW 16.5, head length 16.0 , eyelid width 3.8 , IOD 4. 1, tympanic annulus length 2.0, eye length 5.3, E-N 5.5.

Coloration in life.- The only color notes for living individuals are for $\mathrm{KU}$ 165881-82 from 3.5 $\mathrm{km}$ NE Mindo, Provincia, Pichincha, as follow. Dorsum brown with dark brown markings; throat and belly bluish white with brown mottling; other ventral surfaces dull gray; iris dark bronze with black reticulations (WED, 7 April 1975).
Natural history.-This species is an inhabitant of cloud forest. Limited data on habitat reveal that the species is found on low vegetation at night.

Distribution.-For this species, explicit elevational data are available for only five collections (1380, 1540, 1770, 1780, and $2560 \mathrm{~m}$ ). The latter is the only record from the humid temperate regime; other localities lie at elevations in the humid tropical regime on the Pacific slopes of the Andes from Provincia Carchi southward to Provincia Pichincha, Ecuador (Fig. 37).

Etymology.-The specific name is a Latin adjective meaning "unwashed" or "dirty"; the name is applied in allusion to the dark marbling on the belly.

Remarks.-We are unaware of any synapomorphy to link E. illotus and E. thectoptermus, but suspect that the two are sister species. Eleutherodactylus thectopternus occurs on the Pacific slopes of the Andes in Colombia as far south as Departamento Cauca.

\section{Eleutherodactylus labiosus Lynch, Ruíz, and Ardila Plate 3}

Eleutherodactylus labiosus Lynch, Ruíz, and Ardila. 1994:29.-Holotype: KU 131612, juvenile female. from La Palma. $920 \mathrm{~m}$. Provincia Pichincha, Ecuador. on 8 August 1970 by John D. Lynch.

Diagnosis.-A member of the Eleutherodactylus (Eleutherodactylus) cerasirus group having (1) skin on dorsum shagreen with low occipital folds, that on venter areolate; discoidal fold well anteriad to groin; dorsolateral folds absent; (2) tympanic membrane and tympanic annulus prominent, higher than long, its length $1 / 4-1 / 3$ length of eye; (3) snout subovoid in dorsal view, rounded in profile, lips flared in adult females; (4) upper eyelid bearing one conical tubercle, broader than IOD; cranial crests low in females, absent in males; (5) vomerine odontophores triangular in outline; (6) males having vocal slits; nuptial pads absent; (7) first finger slightly shorter than second; dises broad on outer fingers, usually emarginate; (8) fingers lacking lateral fringes; (9) ulnar tubercles absent; (10) heel bearing small, conical tubercle; outer 


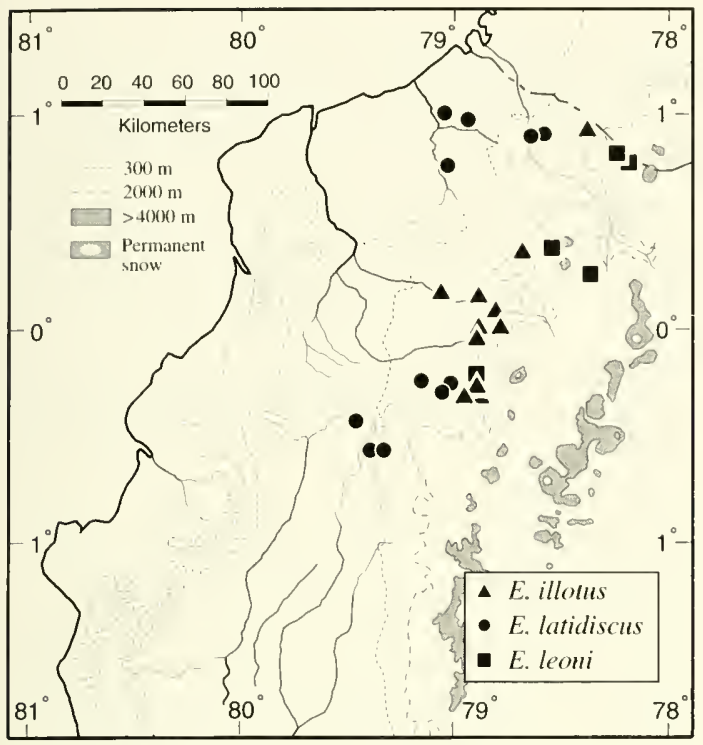

Fig. 37. Distribution of three species of Eleutherodactylus in western Ecuador.

edge of tarsus bearing row of small tubercles; inner tarsal fold absent; (11) inner metatarsal tubercle oval, $4 \times$ round outer metatarsal tubercle; supernumerary tubercles only at bases of toes; (12) toes lacking lateral fringes; webbing absent; fifth toe longer than third; (13) dorsum brown with darker markings; venter cream with brown flecks; posterior surfaces of thighs brown with cream flecks; (14) SVL in males $35.4-50.8 \mathrm{~mm}$, in females 48.5$52.3 \mathrm{~mm}$.

Eleutherodactylus labiosus is most similar to $E$. crenunguis and E. ocellatus, but differs from both by having a conical tubercle on the upper eyelid. Furthermore, the first finger is longer than the second in E. crenunguis, and E. ocellatus lacks a tubercle on the heel. Superficially, E. labiosus is like the smaller E. tenebrionis, which differs by having smooth skin on the dorsum and lacks flared lips in adult females.

Description.-The original description (Lynch et al., 1994) is complete.

Coloration in life.-The dorsum is various shades of brown from olive-brown to reddish brown with indistinct slightly darker markings. The detailed description of holotype is, as follows. KU 131612 from La Palma, Provincia Pichincha: Dorsal surfaces of body and limbs brown with a rusty cast, and greenish tint on shanks; body with illdefined darker brown markings; labial stripe dull yellow; posterior surfaces of thighs dull brown: groin, anterior surfaces of thighs, and lower flanks soft yellow with brown marbling; iris bright reddish-rust in upper quarter, nearly gray elsewhere (JDL, 8 August 1970).

Natural history.-Eleutherodactylus labiosus is primarily an inhabitant of lowland rainforest. where individuals perch on broad leaves or branches along streams at night. This seems to be an uncommon species. Our field work has yielded few specimens, usually no more than one or two individuals at a given locality, but the late Kenneth Miyata collected 14 specimens, mostly juveniles, at Tinalandia, Provincia Pichincha.

Distribution.-This species occurs at elevations of $150-1500 \mathrm{~m}$ on the Pacific versant of Colombia (south of Buenaventura) and Ecuador. Only one individual is known from an elevation of more than $1000 \mathrm{~m}$ (Fig. 33). Three of the Ecuadorian localities are in the humid tropical regime, and 14 are in the the humid subtropical regime.

Remarks.-For several years JDL confused this species with Eleutherodacty/us latidiscus, a smaller species with lateral fringes on the digits and a much longer fifth toe. The large digital discs are consistent with an arboreal existence. The arboreal habit of this species is important in establishing the fact that variation in the length of the fifth toe does not reflect degree of arboreality. Lynch et al. (1994) suggested that E. labiosus is replaced at higher elevations by . crenunguis; that seems to be a fair description of the distributions of the two species, but there is no evidence of interspecific competition. Some large females have thin, unconvoluted oviducts: Lynch et al. (1994) suggested that females may undergo regression of the oviducts following reproduction.

\section{Eleutherodactylus laticlaviuts Lynch and} Burrowes

Plate 5

Eleutherodactylus laticlavizs Lynch and Burrowes, I990:14.- Holotype: IND-AN 1564, adult female, from Reserva Natural La Planada, $1780 \mathrm{~m}$, Municipio de Ricaurte, Departamento Nariño, Colombia. 
Diagnosis.--A member of the Eleutherodactylus (Elentherodactylus) mistrigatus group having ( 1) skin on dorsum smooth with nonconical tubercles on dorsum posterior to sacrum and along dorsolateral stripes, that on venter areolate; discoidal fold just anteriad to groin: dorsolateral folds low; (2) tympanic membrane and tympanic annulus prominent, its length $1 / 4-1 / 3$ length of eye: (3) snout rounded in dorsal view and in profile: (4) upper eyelid bearing small tubercle, narrower than IOD; cranial crests absent: (5) vomerine odontophores triangular in outline; (6) males lacking vocal slits; nuptial pads absent; (7) first finger shorter than second; discs broad; (8) fingers bearing lateral keels; (9) ulnar tubercles absent; (10) heel bearing small, conical tubercle; outer edge of tarsus bearing row of small tubercles; inner edge of tarsus bearing short tuberclelike fold; (1I) inner metatarsal tubercle oval, $6 \times$ elongate outer metatarsal tubercle; supermumerary tubercles numerous, low; (12) toes bearing lateral fringes; webbing absent: fifth toe much longer than third; (13) dorsum either brown with broad pale dorsolateral stripes or brown with darker dorsolateral stripes and brown flanks; venter cream with brown mottling; posterior surfaces of thighs brown with cream spots; ( 14) SVL in males 22.5-26.3 mm, in females $35.0-42.9 \mathrm{~mm}$.

Eleutherodactylus laticlavins is most similar to the lowland E. latidiscus. The two species can be distinguished by $E$. laticlavius having smoother skin on the dorsum and narrower digital dises, and by lacking nuptial pads in males.

Description.-The original description by Lynch and Burrowes (1990) is complete.

Coloration in life.-According to Lynch and Burrowes (1990), living individuals of the striped morph have a chocolate-brown dorsum with wide, yellow canthal-dorsolateral stripes. The other morph has a tan dorsum with thin, reddish-brown canthaldorsolateral lines and a narrower, creamy-yellow middorsal line. In both morphs, the dorsal surfaces of the limbs are tan with brown bars edged with creamy white; the flanks and posterior surfaces of the thighs are yellow with brown marbling, or brown to reddish brown with whitish blotches. The venter is white to tan with pink, orange, or greenish yellow tint and brown flecks. The iris is golden- copper with fine black reticulations and a median, horizontal red streak.

Natural history.-This species has been found only on low vegetation near streams at night in cloud forest.

Distribution.-Elentherodactylus laticlavius is known from five localities at elevations of 1200$2565 \mathrm{~m}$ on the western flanks of the Andes in extreme southwestern Colombia and in provincias Carchi and Pichincha in northern Ecuador, where it occurs in the humid subtropical and humid temperate regimes (Fig. 35).

Remarks.-Lynch and Burrowes (1990) reported 10 specimens from the type locality. Subsequently, E. laticlavius was found at three localities in Ecuador. but essentially no information is available on the biology of the species. At the time of the original description, E. laticlavius was not compared with E. latidiscus, which may be its closest relative. This suggestion is based solely on phenetic similarity, which includes sharing pattern polymorphs.

\section{Eleutherodactylus latidiscus (Boulenger) Plate 6}

Hylodes latidiscus Boulenger, 1898:121.—Syntypes: BM 1947.2.15.66-67, adult females. from Cachabé, Provincia Esmeraldas, Ecuador. Eleutherodactylus latidiscus-Dunn, 1933:68.

Diagnosis.-A member of the Eleutherodactylus (Eleutherodacty/us) unistrigatus group having (1) skin on dorsum tuberculate in males, shagreen with scattered tubercles in females, that on venter areolate; discoidal fold prominent, well anteriad to groin; dorsolateral folds absent; (2) tympanic membrane and tympanic annulus prominent, round, its length $1 / 4-2 / 5$ length of eye; (3) snout subacuminate to rounded in dorsal view, rounded in profile; lips flared in adult females; (4) upper eyelid bearing subconical tubercle, broader than IOD: cranial crests absent; (5) vomerine odontophores triangular in outline; (6) males lacking vocal slits; nuptial pads present; (7) first finger slightly shorter than second; discs broad on Fingers II-IV; (8) fingers bearing lateral fringes; (9) ulnar tubercles absent; (10) heel bearing small tubercle; 
outer edge of tarsus bearing row of small tubercles; inner edge of tarsus bearing thick tuberclelike fold; (11) inner metatarsal tubercle oval. $4 \times$ round outer metatarsal tubercle: supernumerary plantar tubercles indistinct; (12) toes bearing lateral fringes; webbing absent: fifth toe much longer than third: (13) dorsum pattern polymorphic, usually with pale lines along outer edges of $W$-shaped occipital mark: venter white with some brown stippling; posterior surfaces of thighs brown with small cream spots: (14) SVL in males 21.9-25.9 $\mathrm{mm}$, in females $35.2-53.4 \mathrm{~mm}$.

Among species in western Ecuador, E. latidiscus is most similar to E. laticlavius, which has smaller digital discs and less coarse skin on the dorsum and lacks nuptial pads in males.

Description.-The species was redescribed thoroughly by Lynch et al. (1994).

Coloration in life.-The coloration in life is highly variable as attested to by the following descriptions.

KU 109059 from Santo Domingo de los Colorados, Provincia. Pichincha: Dorsum olivegreen with brown markings; throat bright orange; rest of venter brown, darkest on limbs; flanks and anterior and posterior surfaces of thighs with bluish gray flecks; iris pale bronze with black reticulations and median, horizontal, reddish-brown streak (WED, 29 March 1967).

KU 120222-26 from Santo Domingo de los Colorados, Provincia, Pichincha: By night, dorsum largely gray. By day, dorsum dark brown with black spots; paler brown on flanks with green wash and brown markings; limbs dark brown with black markings: one individual with reddish-brown head cap; venter and posterior surfaces of thighs dusky black; iris pale golden-bronze with red horizontal stripe and black reticulation (JDL, 3 August 1968).

KU 120232-33 from Santo Domingo de los Colorados, Provincia. Pichincha: Dorsum pale rust-brown with dark brown markings; flanks with slight green wash and pale brown markings; limbs pale brown with dark brown bands; venter dirty yellow mottled with greenish brown in one individual, dark gray in the other; iris bright bronze above, reddish brown below with reddish horizontal streak (JDL. 4 August 1968).

KU 141957-61 from Río Baba, Provincia
Pichincha: At night, dorsum pale greenish-tan; by day, dorsum olive-brown to reddish brown with darker brown markings; venter dull yellow to creamy white with brown to black markings; iris bronze with median, horizontal red streak (WED, 5 July 1971).

KU 165468-70 from Estación Biológica Rio Palenque, Provincia Los Ríos: Dorsum tan with olive-brown markings; groin reddish brown; throat and inner two fingers yellow; rest of venter gray; iris dull bronze with black reticulations and horizontal red-brown streak (WED, 30 March, 1975).

KU 165470 from Estación Biológica Río Palenque, Provincia Los Ríos: At night, tan with creamy-yellow dorsolateral stripes; venter pale gray: by day, dorsum brown and venter dark gray (WED. 31 March 1975).

Natural history.-Most individuals have been observed at night perched on low vegetation or on tree trunks in forest. By day, this species has been found in leaf litter on the forest floor and in bromeliads; one individual was in the axil of a palm frond $5 \mathrm{~m}$ above the ground. An amplectant pair collected $5 \mathrm{~km}$ W La Florida. Provincia Pichincha. deposited eggs in a plastic bag on the night of 28 December 1989. The female (KU 218017) has a SVL of 42.4 mm: the loosely adherent clutch contained 40 eggs with capsules about $4.5 \mathrm{~mm}$ in diameter and ova about $2.4 \mathrm{~mm}$ in diameter.

Distribution.- This species occurs in lowland tropical rainforest and humid lower montane forest at elevations of 20-1230 $\mathrm{m}$ in northwestern Ecuador and western Colombia as far north as the Río San Juan (Fig. 37). The highest reported elevation for the species in Ecuador is $830 \mathrm{~m}$ in the humid subtropical regime, where seven other localities are recorded; four localities are in the humid tropical regime, and one is in the dry tropical regime.

Remarks.-Eleutherodactylus latidiscus most likely is related to E. laticlavius and E. cruentus. The three species are approximately the same size and have much the same shape, but they differ in disc size, skin texture, relative sizes of the tubercles on the heel and outer edge of the tarsus, distinctness of the tympanic annulus, and color pattern on the concealed surfaces of the hind limbs. In Ecuador and southern Colombia, E. laticlavius occurs at higher elevations than E. latidiscus; at present. 
collections are inadequate to assess the nature of the contact between E. latidiscus and E. cruentus in northwestern Colombia (Lynch et al., 1994).

\section{Eleutherodactylus leoni Lynch Plate 8}

Eleutherodacty/us leoni Lynch, 1976c:313.--Holotype: $\mathrm{KU} 130870$, adult female, from the noth slope of Nudo de Mojanda, 3400 m. Provincia Imbabura, Ecuador.

Diagnosis.-A member of the Eleutherodactyhus (Elcutherodactylus) myersi group having (1) skin on dorsum shagreen with numerous short ridges, that on venter areolate; discoidal fold absent; dorsolateral folds absent; (2) tympanic membrane absent but tympanic annulus visible through skin, higher than long, its length $1 / 3-2 / 5$ length of eye; (3) snout subacuminate in dorsal view, semitruncate in profile: (4) upper eyelid bearing many subconical tubercles, narrower than IOD; cranial crests absent; (5) vomerine odontophores low, oblique; (6) males having vocal slits: nuptial pads absent; (7) first finger shorter than second; dises narrow; (8) fingers lacking lateral fringes; (9) ulnar tubercles indistinct: (10) heel lacking small tubercle; outer edge of tarsus bearing small tubercles; inner edge of tarsus bearing ridgelike tubercle; (11) inner metatarsal tubercle elongate, $2 \times$ round outer metatarsal tubercle; supernumerary plantar tubercles small: (12) toes bearing narrow lateral fringes; webbing absent; fifth toe slightly longer than third; (13) dorsum brown with darker brown markings: venter gray to brown with cream spots; white spots and/or colorless areas (salmon or bright red in life) in axilla, groin, and on thighs; (14) SVL in males $14.8-18.3 \mathrm{~mm}$, in females $19.7-25.0 \mathrm{~mm}$.

Eleutherodactylus leoni is most similar to $E$. floridus, hectus, and pyrhomerus, but differs by having black testes (white in others) and red spots in the axilla and groin and on the concealed surfaces of the hind limbs; these areas are white in $E$. hectus. Elentherodactylus hectus, leoni, and pyrrhomerus have narrower digital discs that $E$. floridus.

Description.-The original description (Lynch, 1976b) is adequate.
Coloration in life.-The known variation is covered adequately in the following descriptions.

$K U$ 130871-72 from the north slope Nudo de Mojanda, Provincia Imbabura: Dorsum of body and limbs brown or reddish brown with gray markings; lips barred cream and brown; vocal sac yellow; rest of venter gray with a few yellow spots or washed with salmon; groin and lower flank with yellow spots; posterior surface of thigh gray with yellow spots in one individual, salmon-red in the other; iris powder-blue with black punctations and black streak (JDL, 2 August 1970).

$K U$ 165897-98 from $14 \mathrm{~km} W$ Chiriboga, Provincia Pichincha: Dorsum grayish brown with black and orange markings or brown with dark brown markings; venter dull gray with bluish- or silver-white flecks; groin and hidden surfaces of hand limbs orange-red with black markings; iris pale green with median, horizontal, red stripe.

KU 117320-40 from $14 \mathrm{~km}$ SE Maldonado, Provincia Carchi: Dorsum brown or rust-brown or washed with green; groin and concealed limbs red in females, brown or cream in males; venter of females dull cream heavily flecked with brown, of males bluish with brown flecks or reticulations; throat dusted with brown; iris blue-gray with red horizontal streak (JDL, 31 May 1977).

Natural history.-Most specimens of Eleutherodactylus leoni have been collected by day. Adults are relatively common under rocks and logs in paramo and upper cloud forest, but individuals have been found on low vegetation $(<30 \mathrm{~cm})$ in cloud forest and in paramo at night. Males were calling from the ground by day on the north slope of Nudo de Mojanda, Provincia Imbabura, on 2 August 1970 and $5 \mathrm{~km} \mathrm{~W} \mathrm{La} \mathrm{Gruel,} \mathrm{Provincia}$ Carchi, on 26 February 1984. The call is a distinct "tink."

Distribution.-Although this species is restricted geographically to a relatively small area of the Andes in northern Ecuador and southern Colombia, it occurs at elevations of 1960-3400 m. It seems to have two disjunct populations-one on the eastern slopes of the Andes in Provincia Carchi. Ecuador, and Departamento Putumayo, Colombia, and the second on the western slopes of the Andes in provincias Carchi and Imbabura, Ecuador (Fig. 37). Of the nine known localities in western Ecua- 
dor, six are in the humid temperate regime and three in the humid subtemperate regime.

Remarks.-Specimens from cloud forests are indistinguishable from those from paramo. The only efforts to determine relationships among the species of the E. myersi group are rather unsatisfactory. Phenetically, E. leoni is most similar to $E$. hectus and E. repens.

\section{Eleutherodactylus longirostris (Boulenger) Plate 1}

Hylodes longirostris Boulenger, 1898:120.--Syntypes: BM 1947.2.15.56-60 from Cachabé, Provincia Esmeraldas, Ecuador.

Eleutherodactylus Iongirostzis-Dunn. 1931:411.

Diagnosis.-A member of the Eleutherodactylus (Craugastor) fitzingeri group having (1) skin on dorsum smooth or finely shagreen with low ridges outlining scapular markings, that on venter smooth; discoidal fold well anterior to groin; dorsolateral folds absent; (2) tympanic membrane and tympanic annulus prominent, round, its length $1 / 2-$ $3 / 4$ length of eye; (3) snout subacuminate in dorsal view, rounded in profile: (4) upper eyelid lacking tubercles, as wide as IOD; cranial crests absent; (5) vomerine odontophores triangular in outline; (6) males with vocal slits and nuptial pads; (7) first finger longer than second; discs on outer fingers broad; (8) fingers lacking lateral fringes; (9) ulnar tubercles absent; ( 10 ) heel tubercles absent; outer tarsal tubercles absent; fold on distal $2 / 3$ of inner edge of tarsus; (11) inner metatarsal tubercle elongate, 4- $5 \times$ round outer metatarsal tubercle; supernumerary tubercles absent; (12) toes bearing lateral fringes; webbing encompassing all basal subarticular tubercles; fifth toe shorter than third: (13) dorsum reddish tan to dark brown. usually with darker brown hourglass-shaped mark; throat cream with dark spots/stripes extending onto chest; rest of venter cream or white: posterior surfaces of thighs uniformly brown; (14) SVL in males 28.8-34.4 $\mathrm{mm}$, in females $43.1-59.6 \mathrm{~mm}$.

Eleutherodacty/us longirostris is the only member of the genus in the lowlands of western Ecuador with moderate webbing (enclosing all basal subarticular tubercles but not reaching the distal subarticular tubercles except on Toe V). A different species in the cloud forests (E. loustes) has nearly as much webbing but has a small tympanic annulus under the skin and a rounded snout in dorsal view. A smaller frog, E. achatinus, superficially resembles E. longirostris but has a longer fifth toe (longer than the third), lacks webbing between the toes, and usually has pale flecks on the posterior surfaces of the thighs.

Description.-The species was redescribed by Lynch and Myers (1983).

Coloration in life.-The dorsum is various shades of gray to brown with darker markings; the ventral surfaces of the hind limbs are pinkish-red to orange. Some ontogenetic change is evident in the following description.

KU 165475-79 from Estación Biológica Río Palenque, Provincia Los Ríos: Dorsum tan to brown with dark brown markings; upper lip creamy white. barred with brown in larger individuals; throat white with dark brown to black markings; belly white in juveniles, yellow in adults; groin and ventral surfaces of hind limbs pale rose; iris pale gold above and red below median, horizontal, brown streak (WED, 28 March 1975).

Natural history.-In Colombia and northern Ecuador, this species occurs throughout the lowland rainforest, but in the southern part of its range in Ecuador, it usually is found near streams. At night, individuals sit on the ground or perch on low $(<0.5 \mathrm{~m})$ vegetation; by day, individuals take shelter under debris on the forest floor. Apparent recent hatchlings (SVL 8.5-8.8 mm) were found on 6 July 1976 at Río Palenque, Provincia Pichincha.

Distribution.-Eleutherodactylus longirostris has an extensive distribution in the lowlands $(<1200$ m) from eastern Panama to southern Provincia Guayas, Ecuador; a disjunct population occurs in the middle Magdalena Valley in Colombia. Localities where this species has been found in Ecuador are at elevations of $20-600 \mathrm{~m}$. Most records for the species in Ecuador (20) are from the humid tropical regime, and 14 are from the humid subtropical regime. However, two are from the dry tropical regime, and one of these (Naranjito, Provincia Guayas) is about $150 \mathrm{~km}$ south of the next most southern locality (Fig. 38). 


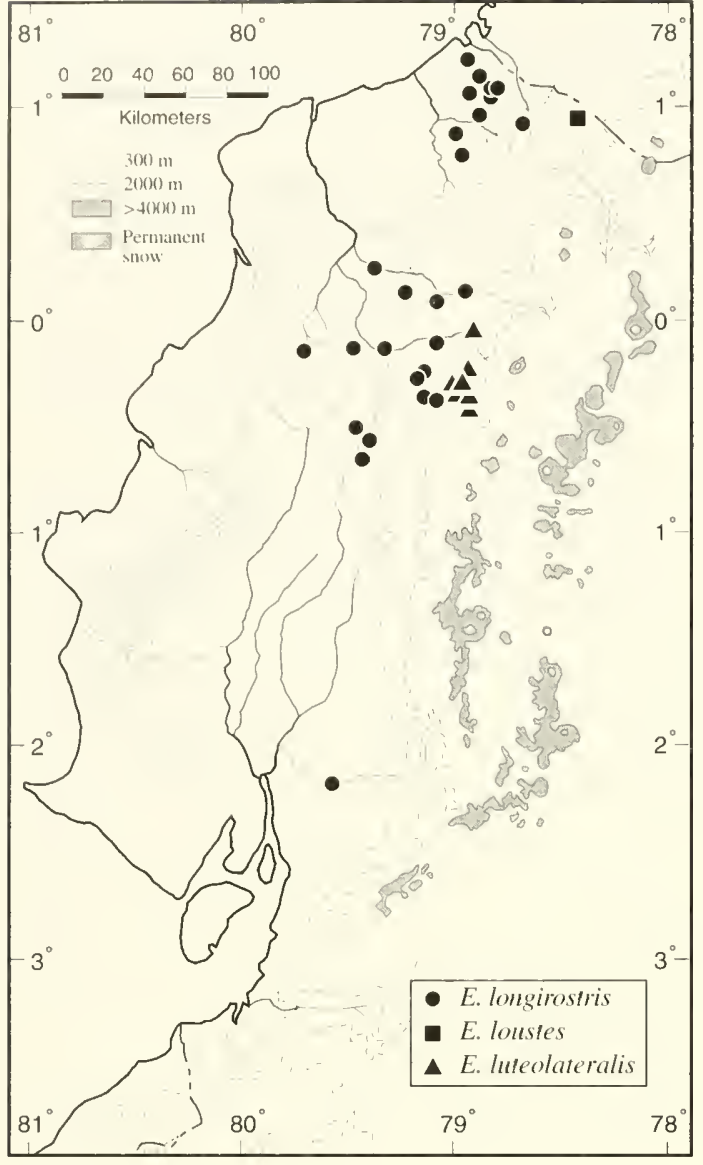

Fig. 38. Distribution of three species of Eleutherodactylus in western Ecuador.

Remarks.-Lynch and Myers ( 1983) suggested that $E$. longirostris is the sister species of $E$. talamancae. Among the many specimens reported by Lynch and Myers ( 1983), three (UIMNH 53393 and 53424 purportedly from the Río Caoni, Provincia Esmeraldas, and UIMNH 55721 purportedly from San Javier, Provincia Esmeraldas) are misidentified; these specimens are E. malkini, a species known only from the upper Amazon Basin. The misidentification was noted by JDL upon reexamining these specimens in 1984. Eleutherodacty/us malkini has appreciable toe webbing, but the posterior surfaces of the thighs are mottled cream and black.
Eleutherodactylus loustes Lynch Plate 3

Eleutherodactylus loustes Lynch, 1979c:498.- Holotype: KU 179234, adult female, from Maldonado, $1410 \mathrm{~m}$, Provincia Carchi, Ecuador.

Diagnosis.-A member of the Eleutherodactylus (Eleutherodacty/us) loustes group having (1) skin on dorsum smooth, that on venter areolate; discoidal fold anterior to groin; dorsolateral folds absent; (2) tympanic membrane absent: tympanic annulus small; (3) snout short, rounded in dorsal view, angularly rounded in profile; (4) upper eyelid bearing small tubercles, broader than IOD; low cranial crests present in adult females: (5) vomerine odontophores oval; (6) males with vocal slits; nuptial pads absent: (7) first finger slightly longer than second; discs broad; (8) fingers bearing lateral fringes; (9) ulnar tubercles absent; (10) heel and outer edge of tarsus lacking tubercles: inner edge of tarsus bearing flaplike fold; (11) inner metatarsal tubercle oval, $8 \times$ conical outer metatarsal tubercle; supernumerary plantar tubercles indistinct; (12) toes bearing prominent flaplike lateral fringes, basally webbed; webbing encompassing all basal subarticular tubercles; fifth toe longer than third; (13) dorsum brown with darker brown markings; throat gray: rest of venter cream with diffuse brown reticulations; posterior surfaces of thighs brown; (14) SVL in males $31.2-27.1 \mathrm{~mm}$, in one female $46.7 \mathrm{~mm}$.

Eleutherodactylus loustes most closely resembles $E$. jaimei from southwestern Colombia; the latter differs by having a visible tympanic membrane and less webbing between the toes.

Description.- The original description by Lynch (1979c) is complete.

Coloration in life.-Description of the types series (KU 17923 I-49) from Maldonado, Provincia Carchi. indicated that in an adult female, the dorsum was reddish brown with black spots; green wash on spaces between bars on limbs and on lower flank: concealed surfaces of thighs black with greenish flecks; throat brown with cream flecks; rest of venter cream with brown spots; webbing pale yellowish-green; iris deep brown. In males, the dorsum was greenish brown to green with gold or 
copper wash, especially anteriorly, and brown spots; venter dirty cream with brown flecks; tips of digits cream: iris dark brown with black flecks. In juveniles, the heels and rump were reddish orange (JDL, 30-31 May, 1977).

Natural history.-At Maldonado, Provincia Carchi. E. loustes was encountered only in the vicinity of small waterfalls. Adults and juveniles were clinging to wet rocks and perched on vegetation in the spray zone of the falls. Likewise, at La Planada, Departamento Nariño, Colombia, frogs of this species were found on rocks in streams and on mud banks beneath waterfalls (Lynch and Burrowes, 1990).

Distribution.-Eleutherodactylus loustes is known from two geographically close localities in cloud forest on the western slopes of the Cordillera Occidental-La Planada, 1200 m, Departamento Nariño, Colombia, and Maldonado, $1410 \mathrm{~m}$. Provincia Carchi, Ecuador; both localities are in the humid subtropical regime (Fig. 38). Because of its specialized habitats (spray zone of waterfalls), the species may enjoy a wider distribution that is not obvious from present collections.

Remarks.-Lynch (1992a) placed this species and two Colombian species (E. hybotragus and $E$. jaimei) is the E. loustes species group. These three species share a synapomorphy of an abnormally large zygomatic ramus of the squamosal, which is evident externally as a swelling just in front of the tympanic region. Eleutherodactylus jaimei occurs at elevations comparable to those of E. loustes in Departamento Cauca. Colombia, but E. Lybotragus inhabits the lowlands of Departamento Valle del Cauca. Colombia.

\section{Eleutherodactylus luteolateralis Lynch}

\section{Plate 7}

Eleutherodactylus luteolateralis Lynch, 1976a: 13.-Holotype: KU 131674, adult female, from Tandapi. $1460 \mathrm{~m}$. Provincia Pichincha, Ecuador.

Diagnosis. - A member of the Eleutherodactylus (Eleutherodactylus) unistrigatus group having ( 1 ) skin on dorsum shagreen, that on venter areolate; discoidal fold prominent; dorsolateral folds absent: (2) tympanic membrane and tympanic annu- lus prominent, round, its length $3 / 4-1 / 3$ length of eye: (3) snout subacuminate in dorsal view, rounded in profile; (4) upper eyelid lacking tubercles, slightly broader than IOD; cranial crests absent: (5) vomerine odontophores oblique; (6) males having vocal slits; nuptial pads absent; (7) first finger shorter than second; discs broad; (8) fingers bearing narrow lateral fringes; (9) ulnar tubercles absent; (10) heel bearing one large, nonconical tubercle; tarsus lacking tubercles: (II) inner metatarsal tubercle oval, 2-3× oval outer metatarsal tubercle: supernumerary tubercles numerous; (12) toes bearing lateral fringes; webbing absent; discs smaller than those on fingers; fifth toe much longer than third: (13) dorsum gray with pale and dark brown stripes; pale dorsolateral bands from eye to groin: venter cream with brown flecks; posterior surfaces of thighs brown; lower flanks, groin, and anterior surfaces of thighs with cream spots (lemon-yellow to orange-yellow in life) edged in black: (14) SVL in males 16.6-23.6 mm, in females $25.6-29.5 \mathrm{~mm}$.

Eleutherodactylus luteolateralis closely resembles the smaller $E$. walkeri (males $15-18 \mathrm{~mm}$. females 2 l-25 mm SVL) occurring at lower elevations. Structurally, the two species seem to be identical. However, dorsal stripes are present in all E. liteolateralis, whereas this pattern occurs in few $E$. walkeri. All individuals of E. litteolateralis have a pale band extending from the eye to the groin; no such band occurs in E. walkeri, even those individuals having a striped pattern. The smaller E.parvillus also has yellow spots on the flanks, groin, and anterior surfaces of the thighs, but these spots are not outlined in black.

Description.-The original description by Lynch (1976a) is complete.

Coloration in life. - The variation in coloration is documented as follows.

KU 111380-84 from Tandapi, Provincia Pichincha: Dorsum pale and dark brown; flanks and anterior and posterior surfaces of thighs with bright yellow spots; side of head black; venter cream and brown; iris pale bronze-brown with brown, median, horizontal streak (JDL, 27 July 1967).

KU $12025+$ from Tandapi, Provincia, Pichincha: Dorsum striped with medium brown and pale brown or reddish brown; pale creamy-brown stripes above 
llanks; limbs reddish brown with dark brown bars; groin, anterior surfaces of thighs, and concealed surfaces of shanks with lemon-yellow spots; posterior surfaces of thighs dark gray; some narrow white bars on lips; iris gold above and gray below reddish-brown median, horizontal streak, linely stippled with black (JDL, 29 July 1968).

KU 165505-l4 from $4 \mathrm{~km}$ NE Dos Ríos, Provincia Pichincha: Dorsum reddish tan to yellowish tan: groin and anterior and posterior surfaces of thighs with orange-yellow spots; iris dull bronze (WED, I April 1975).

Natural history.-All individuals have been found on low vegetation $(<2 \mathrm{~m})$ at night in cloud forest: many individuals were on herbs and ferns near streams. This species is collected infrequently. The observation that the species became more abundant as trails became more overgrown at Tandapi, Provincia Pichincha, between 1967 and 1970 (Lynch, 1976a) hints that E. luteolateralis inhabits deep forest rather than forest edge.

Distribution.--This species is restricted tocloud forests at elevations of 1140-1960 m in the Río Blanco drainage in Provincia Pichincha. Ecuador (Fig. 38). One locality is in the humid tropical regime, and 10 are in the humid temperate regime.

Remarks.- This species has worried JDL for nearly 20 years because of the absence of structural differences from $E$. walkeri. The larger size of $E$. luteolateralis may reflect only the higher elevations of collections, and the monomorphy (striped pattern only) could be a consequence of fixation by drift; E. walkeri has a low frequency of striped morphs (Lynch, 1974). The pale dorsolateral bands of E. luteolateralis are not associated with any pattern polymorphs and represent the only unequivocal (albeit weak) evidence that $E$. luteolateralis is a species apart from the lowland $E$. walkeri.

\section{Eleutherodactylus lymani Barbour and Noble}

\section{Plate 2}

Eleutherodactylus lymani Barbour and Noble, 1920:403.-Holotype: MCZ 5422, young female, from Perico, Departamento Cajamarca, Peru.

Eleutherodactylus carrioni Parker, 1932:23.-Holotype: BM 1947.2.15.99, adult female, from Loja, Provincia Loja, Ecuador. Synonymy fide Lynch, 1969:263.

Eleutherodactylus lymani-Lynch, 1969:236.
Diagnosis.-A member of the Eleutherodactylus (Eleutherodactylus) conspicillatus group having (1) skin on dorsum shagreen with scattered tubercles, that on venter smooth; discoidal fold prominent; dorsolateral folds present; (2) tympanic membrane and tympanic annulus prominent, its length $1 / 2-2 / 4$ length of eye; (3) snout subacuminate in dorsal view, rounded in profile; (4) upper eyelid lacking tubercles, usually narrower than IOD; cranial crests absent; (5) vomerine odontophores subtriangular in outline; (6) males lacking vocal slits; nuptial pads present; (7) first finger longer than second; discs small; (8) fingers bearing lateral keels; (9) ulnar tubercles absent; (10) heel and outer edge of tarsus lacking tubercles; inner surfaces of tarsal bearing fold; (11) inner metatarsal tubercle elongate, $4 \times$ round outer metatarsal tubercle; supernumerary plantar tubercles absent; (12) toes bearing lateral fringes; webbing absent; fifth toe slightly longer than third; (13) dorsum brown with dark brown or black markings; venter cream to white; groin and posterior surfaces of thighs black with white spots or reticulations; (14) SVL in males $25.7-43.6 \mathrm{~mm}$, in females 52.9-69.3 $\mathrm{mm}$.

By having the first finger shorter than the second and the fifth toe only slightly longer than the third, E. lymani in western Ecuador requires comparison only with E. achatinus, actites, and w-nigrum. From all of these, E. lymani differs by having an inner tarsal fold. In E. lymani, the posterior surfaces of the thighs are black with white spots or reticulations; this pattern enables quick distinction from $E$. achatinus (brown with small cream flecks), $E$. actites (black flecks), and E. w-nigrum (yellow with black spots or reticulation). Eleutherodactylus lymani resembles the smaller E. achatinus in having dorsolateral folds; these are absent in $E$. actites and $E$. w-nigrum, both of which are comparable in size to E. lymani. Eleutherodactylus lymani closely resembles two other species in the E. conspicillatus group $-E$. citriogaster and $E$. condor: The three species are distinguishable on the basis of color pattern on the posterior surfaces of the thighsbold black and white spots or reticulations in $E$. lymani, brown with pale flecks in E. condor, and dark brown and tan mottling in E. citriogaster: 
Description.- The redescription of the species by Lynch (1969) is adequate.

Coloration in life.--The dorsum is olive-green to reddish brown. Descriptions of living specimens from western Ecuador are not available; the following description is based on specimens from southern Ecuador.

KU 165539-40 from $9 \mathrm{~km} S$ Loja, Provincia Loja: Dorsum reddish brown with darker reddishbrown chevrons on back and dark gray bars on limbs narrowly outline with creamy gray; dorsolateral fold dull red; flanks and posterior surfaces of thighs mottled cream and black; palmar and plantar surfaces black; other ventral surfaces creamy white; iris bronze with black flecks (WED, 9 March 1975).

Natural history.-Most individuals have been found by day beneath rocks and logs in pastures. Most records are from disturbed areas in relatively dry forest. A female (KU 165540) was found with what is presumed to be her egg mass ( $\mathrm{KU}$ 166231) beneath a rock on 9 March 1975 .

Distribution.- This species is known from elevations of $610-3000 \mathrm{~m}$ on the western slopes of the Andes in southern Ecuador and up into subparamo in Provincia Loja, Ecuador, and northern Peru (mapped by Duellman, 1992). In western Ecuador, the species has been taken at elevations of 610-1600 $\mathrm{m}$ in the dry subtropical regime (Fig. 39). The specimen reported here from Cataviña, Provincia Azuay ( $3^{\circ} 15^{\prime} \mathrm{S}$ Lat.) is the northernmost record for the species.

Remarks.-No cladistic analysis has been performed of the species in the mostly lowland Eleutherodactylus conspicillatus group, but we follow Duellman (1992) in suggesting that E. lymani is most closely related to $E$. citriogaster and $E$. condor, species found in the Amazonian, rather than the Pacific, drainage.

\section{Eleutherodactylus muricatus Lynch and Miyata Plate 6}

Eleutherodactylus muricatus Lynch and Miyata, 1980:2.-Holotype: MCZ 94469, adult male, from the Río Faisanes, $14.4 \mathrm{~km}$ (by road) E La Palma, 1380 $\mathrm{m}$. Provincia, Pichincha, Ecuador.

Diagnosis. - A member of the Eleutherodactylus (Eleutherodactylus) unistrigatus group

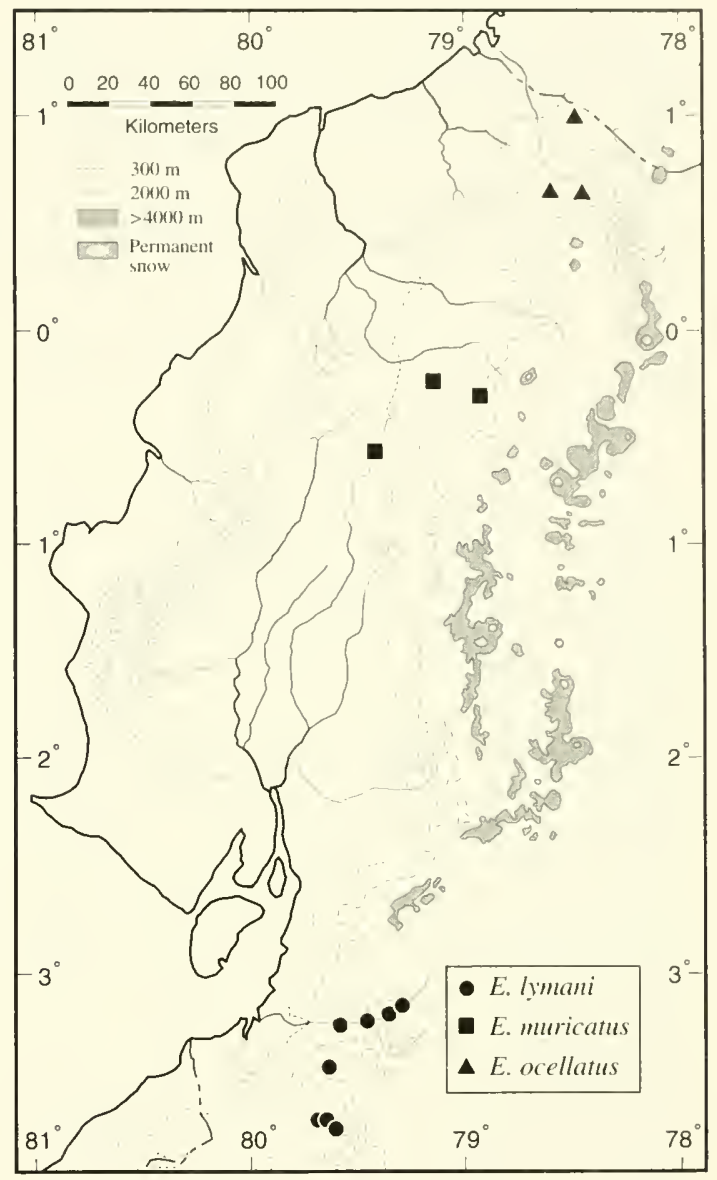

Fig. 39. Distribution of three species of Eleutherodactylus in western Ecuador.

having (1) skin on dorsum smooth with many conical tubercles, that on venter feebly areolate: discoidal fold well anteriad to groin; dorsolateral folds absent; (2) tympanic membrane and tympanic annulus moderately distinct, its length $1 / 4$ length of eye; (3) snout subacuminate in dorsal view, rounded in profile; (4) upper eyelid bearing many conical tubercles, much broader than IOD: cranial crests absent: (5) vomerine odontophores triangular in outline; (6) males usually having vocal slits; nuptial pads absent; (7) first finger shorter than second; discs broad; (8) fingers bearing lateral keels: (9) one or two small ulnar tubercles present; (10) heel bearing one conical tubercle: outer edge of tarsus bearing low tubercles: inner tarsal fold present, short: (11) inner metatar- 
sal tubercle elongate. $10 \times$ subconical outer metatarsal tubercle; supernumerary tubercles at bases of toes: (12) toes bearing lateral fringes; webbing absent; fifth toe much longer than third; (13) dorsum brown with black spots; venter brown with cream flecks on belly and darker brown chevrons on throat; posterior surfaces of thighs brown; lower flanks, groin, and anterior surfaces of thighs with cream spots (lemon-yellow to orange-yellow in life) edged in black; (14) SVL in males 31.8-40.7 $\mathrm{mm}$, in females $36.8-46.3 \mathrm{~mm}$.

Eleutherodactylus muricatus perhaps is most closely related to E. laticlavius and E. latidiscus. but differs from both by having vocal slits. Lynch and Miyata (1980) compared E. muricatus with frogs of the $E$. cerasinus group (especially $E$. crenunguis and frogs now known as E. labiosus). but the similarities among these three species are superficial. Skin texture, tubercle development. and color patterns of E. laticlavius, latidiscus, and muricatus are alike in most cases, so much so as to cause skepticism as to how many species are involved. This problem is exacerbated by size differences between lowland and cloud forest samples and the apparent rarity of E. muricatus.

Description.-The original description by Lynch and Miyata (1980) is adequate.

Coloration in life.-According to Lynch and Miyata (1980), the dorsum in topotypes is pale to dark brown with black rings around large tubercles, and the flanks are paler brown with a yellowish wash; the venter is dark purplish brown with yellowish-brown mottling, and the iris is gold with black flecks. Specimens from the lowlands lack the black rings around the tubercles on the dorsum, and the venter is muddy yellow with dark brown mottling; the groin and ventral surfaces of the hind limbs are purplish brown, and the iris is copper.

Natural history.--One individual was about $60 \mathrm{~cm}$ above the ground at the edge of a banana grove at night, and some were on vegetation in primary lowland rainforest at night; others were on streamside vegetation within $1.5 \mathrm{~m}$ of the surface of the water at night.

Distribution.-This species is known from only three localities at elevations of $200-1380 \mathrm{~m}$ in Provincia Pichincha, Ecuador (Fig. 39). One locality is in the humid tropical regime and two are in the humid subtropical regime.
Remarks. - An obvious difference in size exists between specimens from the lowlands ( 2 adult females $33.8-36.0 \mathrm{~mm} \mathrm{SVL}$ ) and the type locality at $1380 \mathrm{~m}$ (I female $46.3 \mathrm{~mm}$ SVL). However, structurally these individuals are alike. One adult male (MCZ 94710) lacks vocal slits.

\section{Eleutherodactylus necerus Lynch Plate 1}

Eleutherodactyhus necerus Lynch, 1975a:32.-Holotype: USNM 195798, adult female, from Mindo, Provincia Pichincha, Ecuador.

Diagnosis.-A member of the subgenus Eleutherodactylus (Craugastor) bufoniformis group having (1) skin on dorsum tuberculate, bearing many short ridges, that on venter smooth: discoidal fold prominent; dorsolateral folds absent; (2) tympanic membrane and tympanic annulus prominent, higher than long, its length $1 / 3-2 / 5$ length of eye: (3) snout short, rounded in dorsal view, truncate in profile; (4) upper eyelid tuberculate (none elongate), much broader than IOD: low parasagittal crests on frontoparietals; (5) vomerine odontophores arched; (6) males having vocal slits and white nuptial pads; (7) first finger longer than second; discs narrow; (8) fingers lacking lateral fringes; (9) ulnar tubercles absent; (10) heel and tarsus lacking tubercles and folds; (11) inner metatarsal tubercle compressed, 6-7× obscure outer metatarsal tubercle; supernumerary tubercles absent; (12) toes bearing thin lateral keels: webbing absent; discs small, but larger than those on fingers; fifth toe shorter than third; (13) dorsum brown with indefinite darker brown mottling; venter cream or white with brown spots along margin of jaw and bases of arms; posterior surfaces of thighs black with large cream spots: (14) SVL in males 44.9-68.4 mm, in females 82.2-93.3 mm.

Eleutherodactylus necerus is difficult to confuse with other species, especially if an adult female is at hand, because of the large size. It is a species with a broad head and thus likely to be confounded only with other broad-headed species-E. cerastes and E. helonotus. Eleutherodactylus necerus lacks an elongate tubercle on the upper eyelid (present in E. cerastes) and has smooth 
skin on the venter (areolate in E. helonotus). In $E$. necerus, the inner metatarsal tubercle is compressed. whereas in E. cerastes and E. helonotus (and in most South American Eleutherodacty/us) the inner metatarsal tubercle is not compressed.

Description.-The original description (Lynch, 1975a) is largely complete, even though it was based on a single adult female and several juveniles. Proportions for four males and eight females are: tibia length/SVL $58.5-63.2(\bar{x}=61.0) .55 .3-$ $65.8(\bar{x}=59.6 \pm 1.2) ; \mathrm{HW} / \mathrm{SVL} 45.9-50.8(\bar{x}=$ 47.3), 43.0-46.9 ( $\bar{x}=45.0 \pm 0.4)$; upper eyelid/IOD $137.1-216.2(\bar{x}=168.6), 141.7-197.5(\bar{x}=162.0$ $\pm 7.7)$; tympanic annulus/eye 35.4-50.0 $(\bar{x}=44.7)$, $30.8-43.4(\bar{x}=37.2 \pm 1.5)$; E-N/eye 71.0-85.5 $(\bar{x}$ $=77.7), 74.7-92.7(\bar{x}=83.7 \pm 1.9)$. Aside from size and nuptial pads in males, there is little external sexual dimorphism. Males have vocal slits posterolaterally in the floor of the mouth. The tympanic annulus is slightly larger in males than in females, but E. necerns is like E. anatipes, anomalus, cheiroplethus, and zygodactylus in not exhibiting pronounced sexual dimorphism in tympanic annulus size.

Coloration in life.-The variation is noted in the following descriptions.

KU 166067 from $4 \mathrm{~km}$ E Dos Ríos, Provincia, Pichincha: Dorsum dull brown; throat cream with brown reticulations; belly creamy yellow; anterior surfaces of thighs and ventral surfaces of hind limbs pale orange with dark brown flecks; posterior surfaces of thighs orange with dark brown reticulations; iris dark brown with radiating cream bars (WED, 2 April 1975).

KU 179076-77 from Maldonado, Provincia Carchi.: Dorsum brown with some black markings in one individual and faint green wash on flanks in another; throat brown with white flecks or spots; belly dull yellow or pale yellow-orange with cream spots: ventral surfaces of hind limbs orange: posterior surfaces of thighs orange with brown reticulations; iris bronze with black flecks and anterior and posterior brown triangles (JDL, 27, 29 May 1977).

KU 179080 from Tandapi, Provincia Pichincha: Dorsum greenish and brown; belly off-white: throat brownish with cream flecks; concealed surfaces of limbs pale orange; upper edge of iris copper with brown reticulation, gray below with brown tri- angles anterior and posterior to pupil (JDL, 2 I June 1977).

Natural history.-Most individuals have been observed in the immediate vicinity of streams. where they sit on the bank or on rocks in the stream: they have been observed to leap into the water to evade capture. One was under a log at the base of a waterfall by day.

Distribution.-Elentherodactylus necerus inhabits humid lower montane forest at elevations of $600-1540 \mathrm{~m}$ on the lower Pacific slopes of the Andes in Ecuador from Provincia Cotopaxi northward to Provincia Carchi (Fig. 40): all localities are in the humid subtropical zone. We anticipate that it will be found in southern Colombia, because it has been found at Maldonado, $1 \mathrm{~km}$ from the Colombian border.

Remarks.-Eleutherodactylus necerus is the nearest relative of $E$. bufoniformis, an inhabitant of lowlands in Colombia and Panama. Its apparent rarity probably is a consequence of being overlooked by collectors. It was not found at Tandapi in 1967-1970 when we thought the locality had been sampled thoroughly, but it was found there in 1977. Lynch is guilty of spending too much time gazing at vegetation in quest of dainty centrolenids and

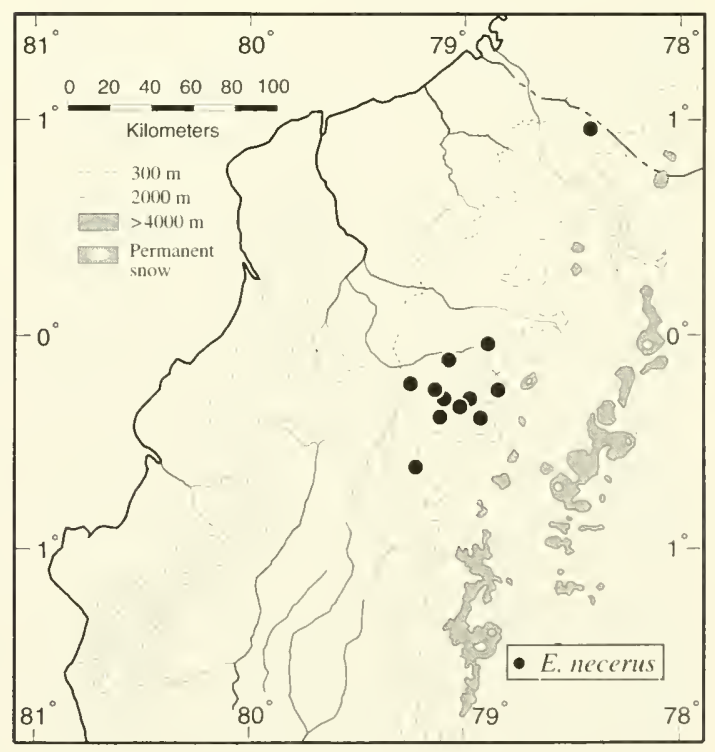

Fig. 40. Distribution of Eleutherodacty/us necerus in Ecuador. 
small Eleutherodactylus and will always be thankful to Thomas J. Berger for showing him large toadlike frogs on the ground along the stream where he had just passed; search images sometimes are so powerful that a frog weighing a half kilogram somehow is not seen.

\section{Eleutherodactylus nyctoplyy.x Lynch Plate 6}

Eleutherodactylus palmeri-Lynch 1971b:146-47, fig. 29. 226.

Eleutherodactylus nyctoplylax Lynch, 1976a:16.-Holotype: KU 110909, adult male, from Tandapi, 1460 m. Provincia Pichincha, Ecuador.

Diagnosis.-A member of the Elentherodactylus (Eleutherodactylus) mistrigatus group having (1) skin on dorsum finely shagreen, that on venter areolate; discoidal fold prominent: dorsolateral folds absent: (2) tympanic membrane and tympanic annulus prominent, higher than long, its length, $1 / 5-1 / 2$ length of eye; (3) snout long, subacuminate in dorsal view, pointed in profile; (4) upper eyelid bearing one small tubercle, slightly narrower than IOD; cranial crests absent; (5) vomerine odontophores triangular in outline; (6) males having vocal slits, subgular vocal sac, and nuptial pads: (7) first finger shorter than second: discs broad: (8) fingers bearing lateral fringes; (9) ulnar tubercles small; (10) heel bearing small conical tubercle; tarsus lacking tubercles and folds; (11) inner metatarsal tubercle elongate. 5-6x round outer metatarsal tubercle; plantar surface areolate; (12) toes bearing prominent lateral fringes: webbing basal (not encompassing basal subarticular tubercles); discs large; fifth toe much longer than third; (13) dorsum brown with darker brown mottling; venter dirty cream with brown flecks: posterior surfaces of thighs dark brown with cream flecks; (14) SVL in males 21.9-31.4 mm, in females 32.1-37.8 $\mathrm{mm}$.

Eleutherodactylus nyctophylax is most similar to E. eugenicue and E. subsigillatus. It differs from E. engenicie by having a small conical tubercle on the heel and a small tubercle on the upper eyelid; moreover, in E. engeniac, the posterior surfaces of the thighs are cream with brown reticulations. Structurally, the smaller E. subsigillatus (males
19.3-28.5 mm, females $30.0-33.4 \mathrm{~mm}$ SVL) is like E. nyctophylax, but in many specimens the dorsum has more small tubercles; furthermore, $E$. subsigillatus has white spots on the llanks and concealed surfaces of the limbs and may have black marbling associated with those spots (more common in females than in males).

Description.-The original description by Lynch (1976a) is complete.

Coloration in life.- The dorsum is greenishtan to brown, with or without a middorsal cream stripe; the venter is white to yellow. The eye is distinctive in having orange or red sclera. The variation is evident from the following descriptions.

KU 110899-905 from Tandapi, Provincia Pichincha: Dorsum creamy tan, brown, or pale greenish-tan with a diffuse pattern of brown and black; some individuals with yellow spots on dorsum; venter creamy-white to gray; lower flanks, groin, and anterior surfaces of thighs white or yellow with gray reticulations; iris greenish gray, with fine black reticulations; concealed surface of eye orange (JDL, 17 July 1967).

KU 110942-53 from Tandapi, Provincia Pichincha: Dorsum creamy tan, brown, greenish brown, or reddish brown with brown or black markings: vertebral stripe cream: venter cream with pink or orange cast, with or without brown flecks; groin cream with brown reticulations; posterior surfaces of thighs dark with cream flecks; iris creamy gray with pale green cast and brown reticulation (JDL, 23 July 1967).

KU 165548-89 from 3.5 km NEMindo, Provincia Pichincha: At night, dorsum dull tan; by day, dull brown with darker brown bars on limbs; venter dull creamy-tan with grayish-brown suffusion; groin mottled black and creamy white: iris pale bronze with fine black reticulation; sclera of eye red (WED, 7 April 1975).

Natural history.-At night, this inhabitant of cloud forests perches on vegetation up to $3 \mathrm{~m}$ above the ground; individuals were found in deep forest, along forest edge, and near streams. By day, frogs were found in leaf litter, in bromeliads, and in the axils of leaves of elephant ear plants. Although hundreds of individuals were observed at Tandapi in 1967-1978, no vocalizations were traced to this 
species, and no egg masses were found. A pair in amplexus was found on 3 July 1968, and small juveniles were abundant in June-August.

Distribution.-Eleutherodactylus nyctophylax occurs at elevations of 1 I $40-2100 \mathrm{~m}$ on the western flank of the Andes in provincias Cotopaxi and Pichincha, Ecuador (Fig. 41). Nine records of occurrence are in the humid subtropical regime and two are in the humid temperate regime.

Remarks.-To date, Eleutherodactylus nyctoplylax and E. subsigillatus have allopatric distributions, whereas E. nyctoplylax and E. eugeniae are sympatric at $6.3 \mathrm{~km}$ E of Tandapi, Provincia Pichincha, and their distributions overlap in the Mindo-Tandapi area.

\section{Eleutherodactylus ocellatus Lynch and Burrowes}

\section{Plate 3}

Eleutherodactylus ocellatus Lynch and Burrowes, 1990:18.- Holotype: IND-AN 1441, adult female, from Reserva Natural La Planada, 1780 m, Municipio Ricaurte, Departamento Nariño, Colombia.

Diagnosis.-A member of the Eleutherodactylus (Eleutherodactylus) cerasinus group having (I) skin on dorsum shagreen, that on venter smooth; discoidal fold well anteriad of groin; dorsolateral folds absent; (2) tympanic membrane and tympanic annulus prominent, small, its length $1 / 3$ length of eye; (3) snout subacuminate in dorsal view, rounded in profile; (4) upper eyelid lacking prominent tubercles, about as wide as IOD; cranial crests absent; (5) vomerine odontophores triangular in outline; (6) adult males unknown; (7) first finger slightly shorter than second; discs large, emarginate or truncate; (8) fingers bearing lateral fringes; (9) ulnar tubercles small; (10) heel and tarsus bearing small tubercles; inner tarsal fold short: (II) inner metatarsal tubercle elongate, $4 \times$ round outer metatarsal tubercle; supernumerary tubercles at bases of Toes II-V; (12) toes lacking lateral fringes; webbing absent; fifth toe longer than third: (13) dorsum brown with black spots having pale centers; venter cream with brown mottling; posterior surfaces of thighs dark brown; (14) SVL in one female $45.7 \mathrm{~mm}$.

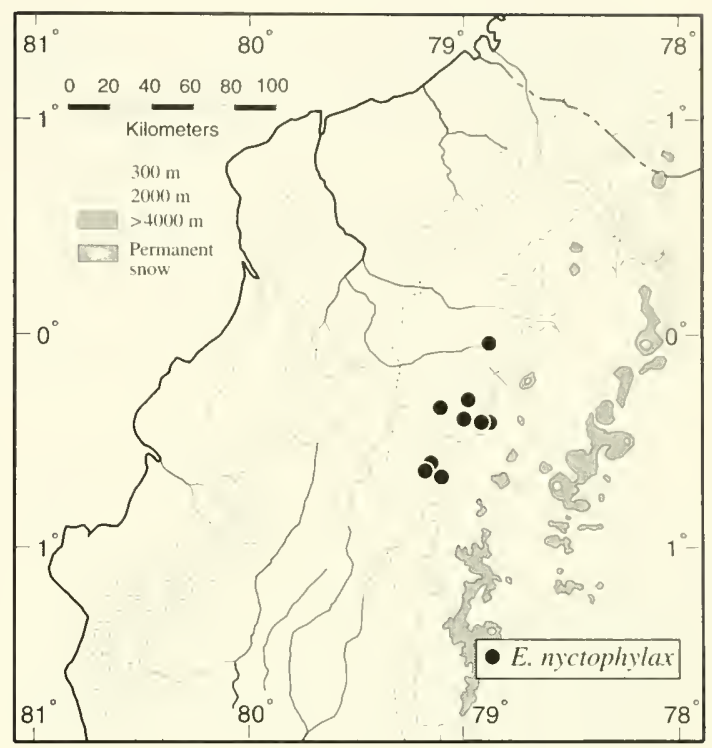

Fig. 41. Distribution of Eleutherodacty/us nyctophylax.

Eleutherodactylus ocellatus is most similar to E. crenunguis but differs from that species in lacking a tubercle on the heel, having the first finger shorter than the second (first longer than second in E. crenunguis), and in color pattern. Species in the E. cerasimus group differ in the combination of male secondary sex characters (Lynch et al., 1994), but adult males of $E$. ocellatus are not known.

Description.- The original description by Lynch and Burrowes (1990) was based on only two specimens.

Coloration in life.-Lynch and Burrowes (1990:19) described the coloration of specimens from the type locality as: "In life, E. ocellatus was grayish-tan with brown ocelli surrounding tan tubercles: limbs grayish-tan with brown transverse bars: venter creamy tan with brown marbling: brown chevrons were visible on the throats of larger individuals; iris brown with gray blotches."

Natural history.-According to Lynch and Burrowes (1990), at La Planada, Departamento Nariño, Colombia, individuals were on low vegetation $(0.5-2.0 \mathrm{~m})$ above stream banks or on branches high in the canopy at night. One Ecuadorian specimen (USNM 286293) was obtained from the canopy of a felled tree by day. 
Distribution.-Limited distributional data indicate that Eleutherodacrylus ocellatus inhabits cloud forests at elevations of $1255-1780 \mathrm{~m}$ on the Pacilic versint of the Andes in the departmentos Cauca and Nariño, Colombia, and extreme northem Provincia Carchi, Ecuador. Three of the Ecuadorian localities are at elevations of 1200-1500 in the humid subtropical regime; an additional locality is at $2560 \mathrm{~m}$ in the humid temperate regime in Provincia Imbabura (Fig. 39).

Remarks. - The scarcity of specimens and observations of this species in the canopy suggest that this species inhabits a stratum of forest not adequately sampled by collectors. A juvenile female (USNM 286293) with a SVL of $21.7 \mathrm{~mm}$ from Provincia Carchi, Ecuador, agrees in all details with the type specimen. Two specimens (ECO 168-69) from Cuellaje, Provincia Imbabura, are juvenile females (SVL 26.6 and $22.1 \mathrm{~mm}$, respectively) but appear to have tubercles on the upper eyelids and have relatively large tubercles on the heels. Furthermore, these two frogs have bold black-and-white bars on the undersides of the shanks, anterior surfaces of the thighs, posterior surfaces of the flanks, and in the groin. As in typical E. ocellatus (and those from Departamento Cauca, Colombia), the throat has a pattern of dark, reverse chevrons. The differences in tuberculation might be a reflection of immaturity, but the color pattern on the throat suggests that these specimens are $E$. ocellatus. Until the species is collected in larger numbers (including adult males), there will remain some doubt as to its characters with respect to $E$. crenunguis.

\section{Eleutherodactylus ornatissimus (Despax)} Plate I

\footnotetext{
Hylodes omatissimus Despax, 1911:91.-Holotype: MNHN 6264, from "Ecuador." Eleutherodactylus ormatissimus-Peters, 1955:350.
}

Diagnosis.-A member of the Eleutherodactylus (Elentherodactylus) unistrigatus group having (1) skin on dorsum shagreen, that on venter smooth; discoidal fold poorly defined posteriorly; dorsolateral folds absent: (2) tympanic membrane and tympanic annulus evident, round, its length $1 / 3$ length of eye; (3) snout long, acuminate in dorsal view, rounded in profile: (4) upper eyelid lacking tubercles, slightly narrower than IOD; cranial crests absent; (5) vomerine odontophores low; (6) males having vocal slits and nuptial pads; (7) first finger shorter than second; discs large, round; (8) fingers lacking lateral fringes; (9) ulnar tubercles absent; (10) heel and tarsus lacking tubercles and folds; (11) inner metatarsal tubercle oval, 4-5x round outer metatarsal tubercle; supernumerary plantar tubercles numerous. indistinct; (12) toes bearing lateral fringes; webbing absent; discs large; fifth toe much longer than third; (13) dorsum and venter pale cream (green in life) with black markings dorsally tending to form lines on body and limbs; posterior surfaces of thighs with a few pale spots; (14) SVL in males $21.6-27.0 \mathrm{~mm}$, in two females 37.8 and $38.1 \mathrm{~mm}$.

In life, this pale green frog with black lines and spots on the dorsum is so distinctive as to be impossible to confuse it with any other species of neotropical frog. It is sufficiently "pretty" that some persons have doubted that it is an Eleutherodactylus. Among frogs of the subgenus Eleutherodactylus, it is relatively distinctive in having a long snout and in lacking tubercles on the dorsum.

Description.-Lynch's (1971a) description is adequate, but he did not distinguish between adult and juvenile females and failed to notice the nuptial pads of adult males.

Coloration in life. - The ornate coloration of this frog consists of a green dorsum and paler green venter and posterior surfaces of the thighs; the stripes and spots on the dorsum are black. The vocal sac is yellow, and the hands and feet are tinted with orange. The iris is green with a bronze tint and fine black reticulations. However, one individual was described as having a yellow venter, greenishyellow limbs, orange toes, and greenish-gold iris (RWM, 7 January 1979).

Natural history.-In 1968. JDLcollected many juveniles in a small woods (probably mostly secondary forest) on the outskirts of Santo Domingo de los Colorados, Provincia Pichincha, but otherwise usually only one to three individuals have been collected at a given locality. However, Luis A. Coloma (pers. comm.) noted the existence of many 
specimens in the QCAZ collection from San Francisco de Las Pampas, Provincia Cotopaxi. Those collected in 1968 were found mostly on the nearly vertical leaves of large elephant ear plants at night. During a longer stay at Santo Domingo de los Colorados in 1977, three biologists failed to find a single specimen of E. ornatissimus, although they sampled a variety of forested (primary and secondary) habitats. At other sites, individuals have been found in the axils of leaves of large elephant ear plants by day. Thus, it seems that there is a close association between this distinctive frog and these large plants.

Distribution.-Eleutherodactylus ornatissimus has been collected at 15 localities at elevations of $400-1800 \mathrm{~m}$ on the western flank of the Andes in Ecuador (Fig. 42); only four of the localities are above $1000 \mathrm{~m}$. Two localities are in the lower part of the humid temperate regime, whereas 13 are in the humid subtropical regime.

Remarks.-Lynch (1971a) reported that males are "19.5 to $25.0 \mathrm{~mm}$ SVL" and did not mention females. The smallest adult male available (KU 141968) has a SVL of $21.6 \mathrm{~mm}$ and has vocal slits and nuptial pads, but a male (KU 119748) with a SVL of $19.5 \mathrm{~mm}$ lacks both. Only two adult females are known; a juvenile female (KU 141969) has a SVL of $34.0 \mathrm{~mm}$.

Eleutherodactylus ornatissimus does not seem to be closely related to any other species known to us. Its peculiarity stems mostly from its being structurally undistinguished and having a stunning coloration. At present, it can be assigned to the $E$. unistrigatus group.

\section{Eleutherodactylus parvillus Lynch Plate 7}

Eleutherodactylus parvillus Lynch, 1976a: 19.-Holotype: KU 11 I345, adult female, from Tandapi, 1460 m. Provincia Pichincha, Ecuador.

Diagnosis.-A member of the Eleutherodactylus (Eleutherodactylus) unistrigatus group having (1) skin on dorsum finely shagreen, that on venter areolate; discoidal fold prominent; dorsolateral folds absent; (2) tympanic membrane and tympanic annulus evident, round, its length $1 / 4-2 / 5$

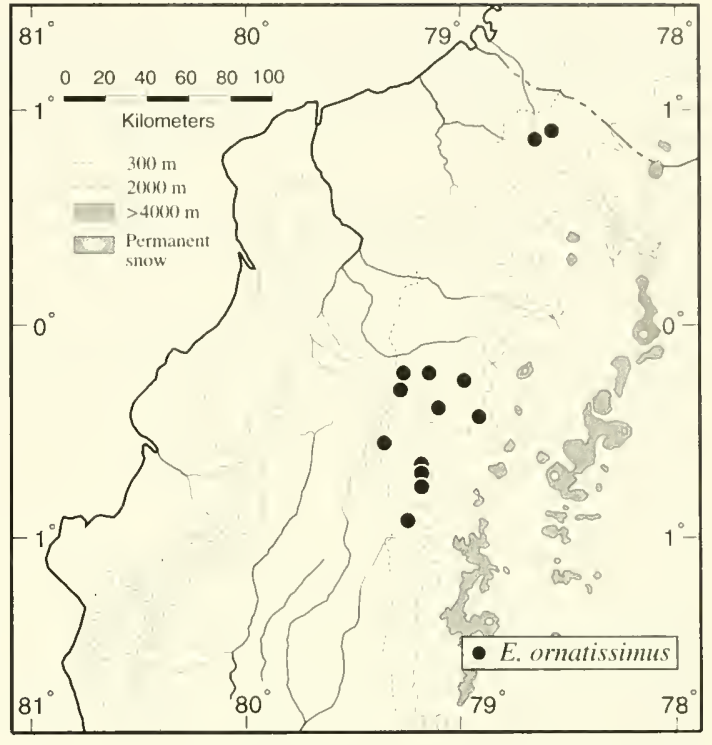

Fig. 42. Distribution of Eleutherodactylus ornatissimus.

length of eye; (3) snout rounded to subacuminate in dorsal view, rounded in profile; (4) upper eyelid lacking tubercles, usually narrower than IOD; cranial crests absent; (5) vomerine odontophores oval, not prominent; (6) males having vocal slits; nuptial pads absent; (7) first finger shorter than second: dises broad; (8) fingers lacking lateral fringes; (9) ulnar tubercles absent; (10) heel bearing small tubercles; outer edge of tarsus bearing minute tubercles; inner edge of tarsus lacking tubercles and folds; (11) inner metatarsal tubercle oval, $4 \times$ round outer metatarsal tubercle; supernumerary tubercles at bases of Toes II-IV; (12) toes bearing narrow lateral fringes; webbing absent; fifth toe much longer than third; (13) dorsum cream to gray with brown markings; venter cream finely stippled with brown; lower flank, anterior and posterior surfaces of thighs, and concealed surfaces of shanks unpigmented (lemon yellow in life); (14) SVL in males 15.5-19.4 mm, in females 18.4-25.9 mm.

Eleutherodactylus panillus is most similar to $E$. palmeri (Boulenger) and E. ridens (Cope) among named species. The concealed surfaces of the flanks and hind limbs are red in E. ridens and yellow in the other two species. Eleutherodactylus palmeri has nuptial pads in males (absent in the other two species) and small tubercles on the upper eyelid 
and heel, whereas $E$. ridens has a tubercle on the heel but none on the eyelid: minute tubercles are present on the eyelids and heels of E. parvillus, but these are not always evident in preserved specimens.

Description.-The original description by Lynch (1976a) is complete.

Coloration in life.-At least in the vicinity of Santo Domingo de los Colorados, Provincia Pichincha, young individuals have orange flash colors, whereas these are yellow in adults. The variation is documented in the following description.

\section{KU 111345-51 from Tandapi, Provincia} Pichincha: Dorsum brown, pale orange-tan, or greenish brown becoming rusty laterally, or in female, grayish tan, with brown spots, broad orangish-brown dorsolateral stripe, or broad brown vertebral mark and black interorbital bar; limbs orange-tan to rusty-brown with dark brown bars (brown with black bars in female); venter gray to nearly black; lower flank, groin, anterior and posterior surfaces of thighs, and concealed surfaces of shanks orange-yellow to lemon-yellow; cream spots below eyes in some individuals; iris grayish brown to reddish brown (JDL, 17-23 July 1967).

Natural history.-This small species seems to be about equally abundant in cloud forest and lowland tropical rainforest. By day, individuals have been found beneath leaf litter and in the axils of elephant ear plants, whereas at night the frog is active on low $(<3 \mathrm{~m})$ vegetation at the edge of, and within, forests. However, the observation by R. W. McDiarmid of an individual (USNM 285795) in a small bromeliad about $30 \mathrm{~m}$ up in a tree that was felled indicates that this species also invades the canopy of the rainforest.

Distribution.-Eleutherodactylus parvillus occurs at elevations of 220-2000 $\mathrm{m}$ in the lowlands and on the western slopes of the Andes in Ecuador (Fig. 43). The only localities for the species at elevations above $1000 \mathrm{~m}$ are in the drainage of the Río Blanco in Provincia Pichincha. Four sites are in the humid tropical regime, seven in the humid subtropical, and three in the humid temperate.

Remarks.-The report of this species from Colombia by Lynch and Ruíz (1983) applies to individuals now identified as Eleutherodactylus

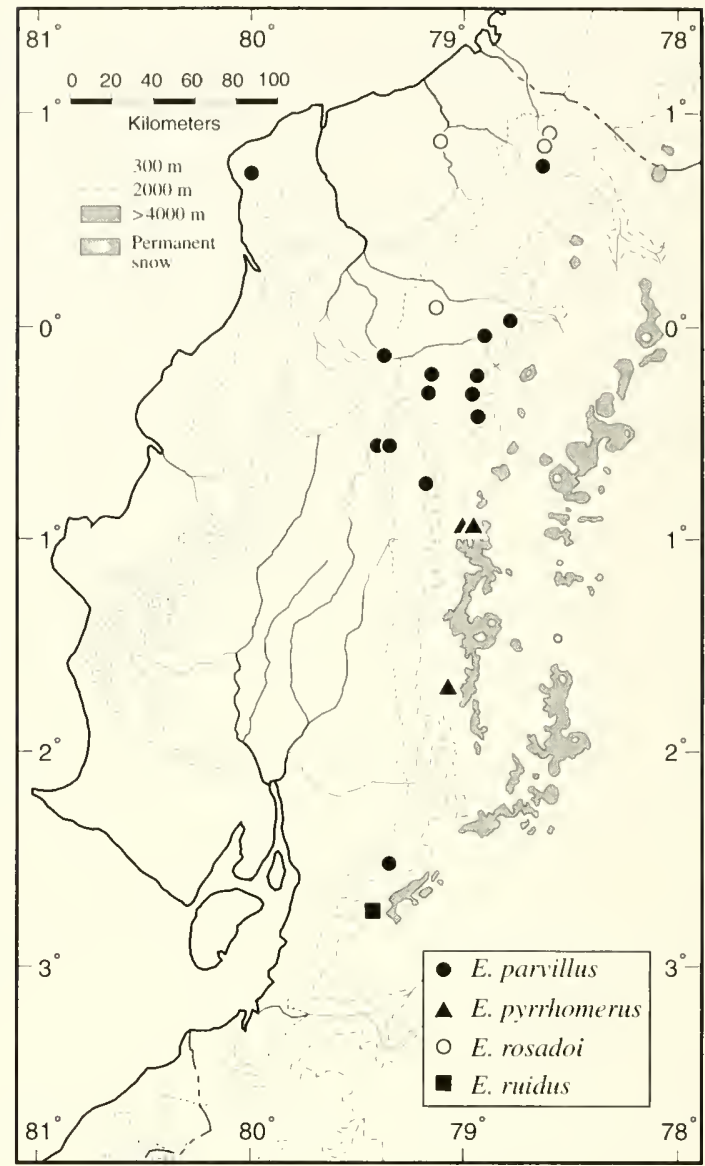

Fig. 43. Distribution of four species of Eleutherodactylus in western Ecuador.

palmeri (Boulenger). That Colombian species also has yellow flash markings in the groin and on the concealed surfaces of the hind limbs. It is not known to which species Savage (1981) referred when he reported that $E$. ridens ranged as far south as Ecuador; he may have meant E. parvillus.

\section{Eleutherodactylus phoxocephalus Lynch Plate 5}

Eleulherodactylus phoxocephalus Lynch. 1979a:29.Holotype: adult male, from Pilaló, 2340 m, Provincia Cotopaxi, Ecuador.

Diagnosis.-A member of the Eleutherodactylus (Elentherodactylus) imistrigatus group 
having ( 1 ) skin on dorsum shagreen, that on venter areolate; discoidal fold prominent; dorsolateral folds absent; (2) tympanic membrane and tympanic annulus evident, round, its length $1 / 3-1 / 2$ length of eye; (3) snout rounded in dorsal view, pointed in profile. bearing terminal keel: (4) upper eyelid lacking tubercles, narrower than 1OD: cranial crests absent; (5) vomerine odontophores oblique; (6) males having vocal slits and nuptial pads; (7) first finger shorter than second; dises broad; (8) fingers bearing lateral keels; (9) ulnar tubercles absent; (10) heel and tarsus lacking tubercles and folds; (11) inner metatarsal tubercle oval, 4-6x round outer metatarsal tubercle; supernumerary tubercles at bases of Toes II-IV: (12) toes bearing lateral fringes; webbing absent; fifth toe much longer than third; (13) dorsum gray to brown with few or no darker markings; venter cream; lower flank, groin, and concealed surfaces of limbs white with brown or black reticulations; (14) SVL in males 22.3-29.9 $\mathrm{mm}$, in females $29.6-38.4 \mathrm{~mm}$.

Eleutherodactylus phoxocephalus superficially resembles $E$. subsigillatus in having the flanks and concealed surfaces of the hind limbs reticulated with brown or black, but it is distinguished easily by the presence of a papilla or vertical keel on the snout; also, E. phoxocephalus lacks tubercles on the upper eyelid, heel, and tarsus.

Description.-The original description by Lynch (1979a) is complete.

Coloration in life.-The dorsal coloration is highly variable, as is evident from the following descriptions.

KU 131404-79 from Pilaló, Provincia Cotopaxi: Dorsum pale greenish brown, pale yellow, rustybrown, pale brown, or dark brown with brown (black middorsally) mottling or fine reticulations; axilla, groin, posterior surfaces of thigh, and concealed surface of shank yellow with brown reticulations (faint in juveniles, dark in adults); venter cream with green tint and fine brown reticulations in adults; throat dusky in females, pale yellow in males; iris pale bronze with fine black reticulation and median, horizontal, brown streak; some individuals with cream spots (with or without black borders) on dorsum (JDL, 3 July 1970).

KU 142075-101 from Pilaló, Provincia Cotopaxi: Dorsum brown to reddish brown; some individuals with olive-green longitudinal streaks, others with yellow spots outlined with dark brown: groin and posterior surfaces of thighs yellow with black mottling; belly white; throat yellow; iris copper (WED. 7 July 197I).

$K U$ 165556-58 from $5 \mathrm{~km}$ E of Chiriboga. Provincia Pichincha: Dorsum pale green with dark or reddish-brown markings, or yellowish tan with green middorsal stripe bordered by black; limbs orange-tan with pale green cross bars; groin and posterior surfaces of thighs yellow and dull brown; belly white to creamy yellow; other ventral surfaces pale pinkish gray to dull yellowish-tan; iris bronze to coppery brown with fine black reticulations (WED. 4 April, 11 May 1975).

Natural history.-Although E. phoxocephalus is widely distributed, most observations on the natural history of the species were made in the vicinity of the type locality, where the frogs are abundant in forest-edge situations, but scarce in the interior of the forest. By day, individuals were in the axils of elephant ear plants and in terrestrial and arboreal bromeliads up to $13 \mathrm{~m}$ above the ground. At night, individuals were perched on vegetation.

Distribution.-In western Ecuador (Provincia Pichincha southward). E. phoxocephalus occurs in upper humid montane forest at subparamo at elevations of 1800-3100 m (Fig. 44); two localities are in the humid subtropical regime, 12 in the humid temperate, and one in the humid subtemperate. In southern Ecuador, it occurs in subparamo at elevations of 2010-2960 m (Lynch. 1979a). The species also is known from humid montane forests at elevations of 1850-2770 $\mathrm{m}$ in the Cordillera de Huancabamba in northern Peru (Duellman and Wild, 1993).

Remarks.-In spite of lacking tubercles on the eyelid, heel, and tarsus, we think that $E$. phoxocephalus is most closely related to $E$. eugeniae, nyctophylax, and subsigillatus. The grouping of these four allopatric species admittedly is phenetic. Additionally, there is an assortment of phenetically similar species in Colombia, among which are $E$. boulengeri Lynch, a species widespread in subparamo habitats in the Cordillera Central, and E. tayrona Lynch and Ruíz. a species inhabiting cloud forests in the Sierra Nevada de Santa Marta. Until these species have been studied 


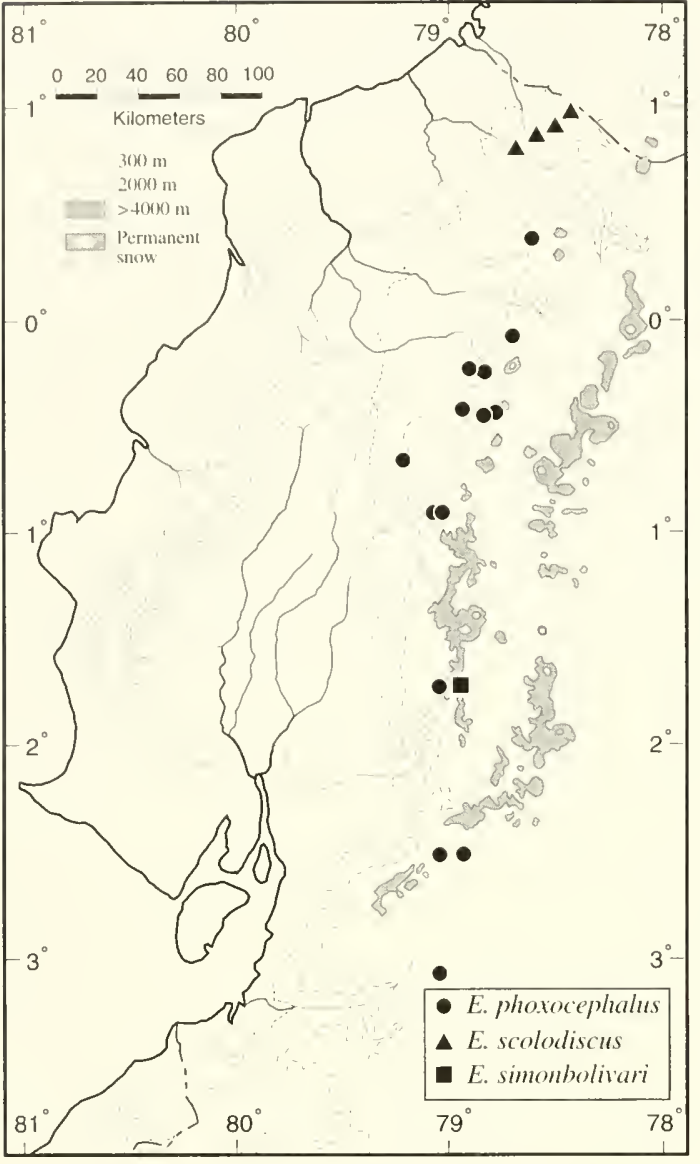

Fig. 44. Distribution of three species of Eleutherodactilus in western Ecuador.

more closely, most of the species loosely referred to as forming the "E. lacrimostus assembly" (Lynch, 1980d) should be considered as potentially closely allied to E. eugeniae, nyctophylax, phoxocephalus, and subsigillatus.

\section{Eleutherodactylus pteridophilus sp. nov.}

\section{Plate 6}

Holotype.-KU 179106, adult female, one of a series collected at La Delicia, $2710 \mathrm{~m}\left(\approx 00^{\circ} 22^{\prime} \mathrm{N}\right.$, $78^{\circ} 25^{\prime} \mathrm{W}$ ), Cordillera de Intac, Provincia lmbabura, Ecuador, on 3 June 1977 by David C. Cannatella and John D. Lynch.

Paratypes.-KU 179107-39, USNM 286043. 239848. (See Appendix I for localities.)
Diagnosis.-A member of the Eleutherodactylus (Eleutherodactylus) unistrigatus group having (1) skin on dorsum smooth in males, bearing scattered tubercles in females, that on venter areolate; discoidal fold present; dorsolateral folds absent; (2) tympanic membrane absent; tympanic annulus present, its length $1 / 4-2 / 5$ length of eye; (3) snout short. subacuminate in dorsal view, rounded in profile, bearing terminal keel; (4) upper eyelid bearing warts, narrower than IOD; cranial crests absent; (5) vomerine odontophores oval; (6) males lacking vocal slits and nuptial pads; (7) first finger shorter than second; Fingers II-IV bearing large, round discs; (8) fingers bearing fleshy lateral fringes; (9) ulnar tubercles small, conical: (10) heel and outer edge of tarsus bearing small tubercles; inner edge of tarsus lacking tubercle or fold; (II) inner metatarsal tubercle oval, 4-6× subconical outer metatarsal tubercle; supernumerary tubercles at bases of toes; (12) toes bearing lateral fringes; webbing absent; fifth toe much longer than third; (13) dorsum pale to medium brown with darker markings outlined with cream; venter cream with brown flecks forming loose reticulation; posterior surfaces of thighs brown with cream mottling; (14) SVL in males 17.6-25.1 $\mathrm{mm}(\bar{x}=22.4 \pm 0.3, n=32)$ $\mathrm{mm}$, in females 31.9-33.9 $\mathrm{mm}(\bar{x}=33.1, n=3)$.

Elentherodactylus pteridophilus is distinctive among the Eleutherodactylus in western Ecuador in lacking secondary sex characters and in having an extremely long fifth toe. In pattern and some aspects of tuberculation, it resembles the smaller $E$. verecundus. Eleutherodactylus siopelus also is similar to E. pteridophilus, but it lacks a tympanic annulus.

Description.- $(n=26 ; 23$ for proportions of males, 3 for females) Head slightly narrower than body, as wide as long; HW in males $34.6-39.0 \%(\bar{x}$ $=36.5 \pm 0.2)$ SVL. in females $37.3-40.0 \%(\bar{x}=$ $38.9) \%$ SVL; E-N in males $65.8-86.2 \%(\bar{x}=77.2$ $\pm 1.2)$ length of eye, in females $76.2-83.7 \%(\bar{x}=$ $81.2) \%$ length of eye: snout about as long as eye, deep (not flattened) (Fig. 45); nostrils weakly protuberant, directed dorsolaterally; canthus rostralis moderately angular, concave; loreal region flat, sloping abruptly to lips; lips weakly flared posteriorly; upper eyelid $77.8-108.7 \%(\bar{x}=90.3 \pm 1.5)$ IOD, in females $84.2-100.0 \%(\bar{x}=90.6)$ IOD; 

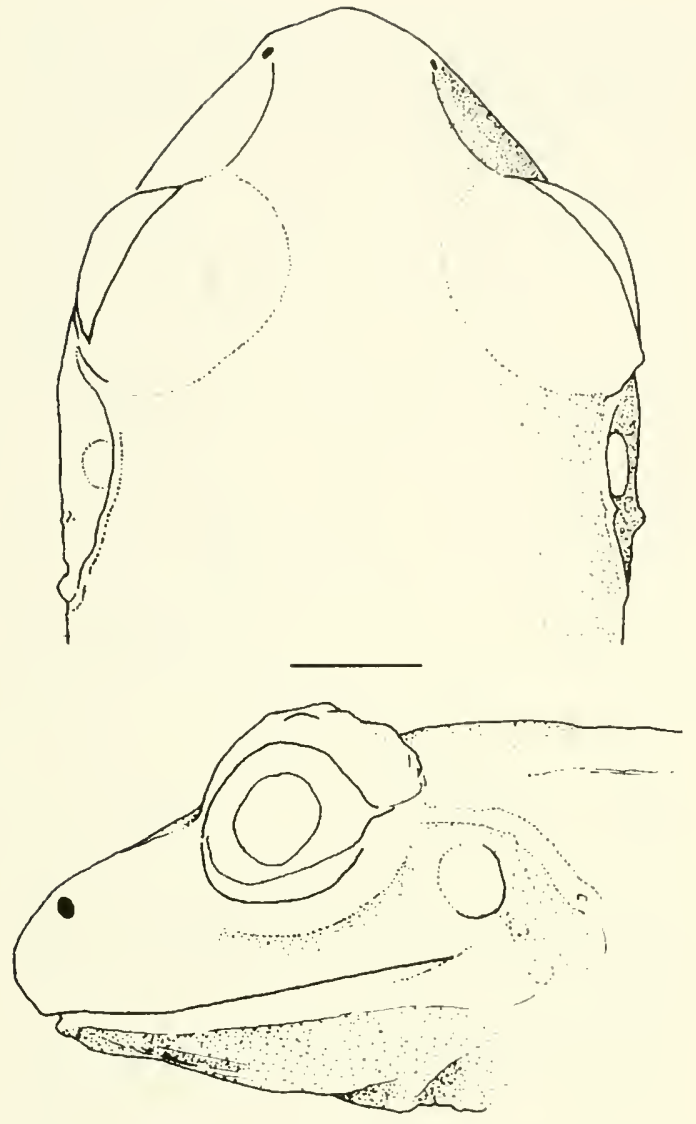

Fig. 45. Eleutherodactylus pteridophilus, o, KU 179113. Scale bar $=2 \mathrm{~mm}$.

interorbital space flat; upper eyelid bearing low tubercles; supratympanic fold indistinct; tympanic annulus round, indistinct externally, prominent only upon drying, its length $23.7-37.9 \%(\bar{x}=31.3)$ length of eye, separated from eye by distance slightly greater than diameter of tympanic annulus: postrictal tubercles indistinct; tongue longer than wide, its posterior border not or feebly notched. posterior $1 / 3-2 / 5$ not adherent to floor of mouth: choanae small, round, not concealed by palatal shelf of maxillary arch: vomerine odontophores posteromedian to choanae, separated medially by a distance equal to width of one odontophore in males to one half width of odontophore in females, each three times size of choana in females, each bearing two to four teeth in transverse row; males lack vocal slits.
In males, shin on dorsum of body smooth except for a few small warts on upper flanks, in females with small warts on occiput and posterior part of dorsum and larger warts on flanks; skin on venter areolate: discoidal fold well anteriad to groin; cloalcal sheath absent; pair of warts ventral to cloacal opening. Palmar tubercle bifid (inner lobe largest), much larger than oval thenar tubercle; supernumerary palmar tubercles numerous, all smaller and less pungent than round, subconical subarticular tubercles; fleshy fringe along outer edge of palm and Finger IV; disc on thumb scarcely expanded: those on Fingers II-IV 1 1 $1 / 2-2$ times width of digit proximal to disc; fingers long, slender. When hind limbs flexed perpendicular to body axis. heels touching or barely overlapping: shank $47.0-56.4 \%(\bar{x}=$ $50.8, n=24)$ SVL: inner margin of tarsus lacking tubercles or fold; inner metatarsal tubercle not compressed: subarticular tubercles round, not conical: supernumerary plantar tubercles at bases of toes; discs on toes as large as those of outer fingers: tip of Toe $\mathrm{V}$ extending to distal edge of distal subarticular tubercle of Toe IV; tip of Toe $11 \mathrm{I}$ extending to distal edge of penultimate subarticular tubercle of Toe IV.

In preservative, dorsum pale to medium brown with dark markings consisting of interorbital bar. W-shaped occipital mark, sacral chevron, suprainguinal spots, canthal-supratympanic stripe. and labial bars; dorsal markings continue as diagonal bars onto flanks; darks bars on limbs fecbly oblique, those on flanks narrower than interspaces. In most specimens dark markings on dorsum outlined with cream; several individuals with tan areas along midline between dorsal spots: most individuals with unpigmented tympanic region. Belly and throat cream with brown flecks forming loose reticulation; cloacal triangle dark brown: posterior surfaces of thighs brown with some cream mottling.

Measurements of holotype: SVL 33.9, shank 16.5, HW 13.4, head length 11.9. upper eyelid width 3.2. IOD 3.8, tympanic annulus length 1.2. eye length 4.3, E-N 3.6.

Coloration in life.-The dorsum is green. tan. yellowish brown, or reddish brown with reddishbrown to brown markings: the side of the head. flanks, and concealed surfaces of the hind limbs are 
washed with yellow. The throat is flesh colored, and the belly is yellowish white; the iris is reddish copper with black flecks.

Natural history. - At the type locality in June 1977, the holotype was found along a trail in cloud forest, whereas 10 males were on ferns at the edge of the road at night. In January 1978. JDL found all individuals on ferns along the edge of a road or along edges of pastures. Height of perch site for 23 individuals was $0.2-2.5 \mathrm{~m}(\bar{x}=0.96)$ above the ground. The use of ferns by this species stands out dramatically in comparison to the low frequencies with which most other Andean Eleutherodactylus perch on ferns.

No evidence of reproductive activity was noted in June 1977, when the only female that was found was gravid. The collection made in January 1978 contained 20 males having swollen testes, one adult female, and two juvenile females (SVL 15.9 and $16.1 \mathrm{~mm}$ ). The adult female is not gravid and did not appear to have laid eggs recently. On 16 January 1978, males were calling; the call is a single note, "whoop."

Distribution.-This species is known from only five localities at elevations of $1500-2710 \mathrm{~m}$ in the humid tropical regime (2 localities) and the humid temperate regime ( 3 localities) on the western flank of the Andes in provincias Imbabura and Pichincha, Ecuador (Fig. 46).

Etymology.-The specific epithet is an adjective derived from the Greek noun, pteris meaning a "kind of fern," and the Greek adjective, philos meaning "loving." Thus, the name means "fern loving" and is used in allusion to the microhabitat selection evident in this species.

Remarks.-There is some pattern polymorphism in Eleutherodactylus pteridophilus. Five specimens (KU 132629, 179129, 179136-38) differ from the above description in having a broad, pale, middorsal raphe edged in black. Also, pale, black-edged patches occur on the heels of these individuals. In another individual (KU 179116), a darker raphe begins in the scapular region and broadens at the level of the sacrum Another specimen (KU 179108) has a white stripe along the canthus and outer edge of the eyelid continuing as a dorsolateral stripe to the groin. The remaining 31 specimens have simple patterns of dark spots, but

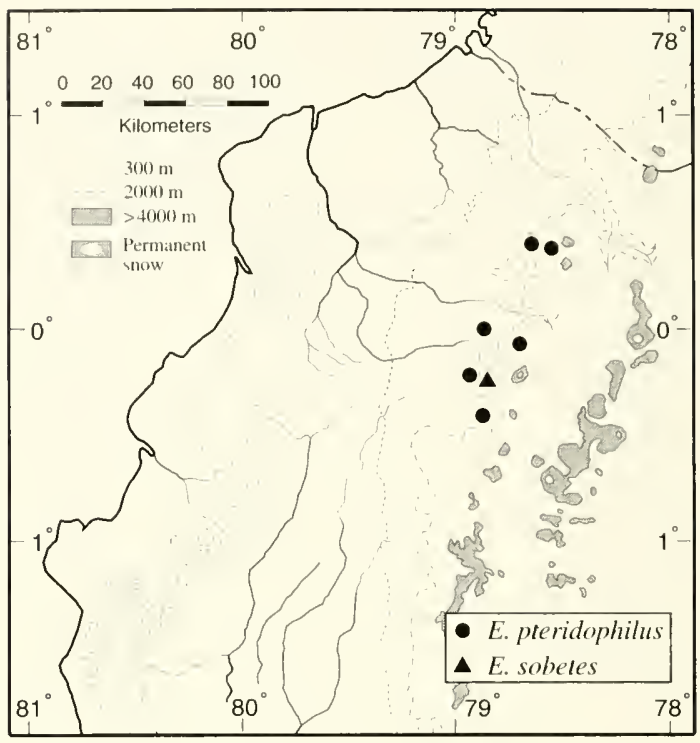

Fig. 46. Distribution of two species of Eleutherodactylus in western Ecuador.

the spots vary in intensity; in some individuals, they are present only as a concentration of dark flecks that provide only a hint of the more common distinct pattern of spots.

Although JDL cannot point to evidence, he thinks that $E$. pteridophilus is a northern replacement of the much larger E. thymalopsoides; no other species seems to group with this pair of species.

\section{Eleutherodactylus pyrrlomerus Lynch Plate 8}

Elentherodactylus pyrrhomerus Lynch, 1976c:310.Holotype: KU 131606, adult female, from east edge of Pilaló, $2580 \mathrm{~m}$. Provincia Cotopaxi, Ecuador.

Diagnosis. - A member of the Eleutherodactylus (Eleutherodacty/us) myersi group having (1) skin on dorsum minutely tuberculate with low ridges and $\mathrm{W}$-shaped occipital fold, that on venter areolate; discoidal fold absent; dorsolateral folds absent; (2) tympanic membrane and tympanic annulus prominent, round, its length $1 / 3-2 / 5$ length of eye; (3) snout rounded, acuminate in dorsal view, rounded in profile; (4) upper eyelid bearing one conical tubercles, narrower than IOD; cranial crests absent; (5) vomerine odontophores low, oval; (6) 
males having vocal slits; nuptial pads absent; (7) first finger shorter than second; discs narrow; (8) fingers lacking lateral fringes; (9) ulnar tubercles indistinct; (10) heel lacking small tubercle; outer edge of tarsus bearing small tubercles; inner edge of tarsus bearing elongate tubercle: ( 11 inner metatarsal tubercle elongate, $4 \times$ round outer metatarsal tubercle; supernumerary plantar tubercles numerous; (12) toes lacking lateral fringes; webbing absent; fifth toe slightly longer than third; (13) dorsum brown with darker brown spots; venter cream with brown reticulation; colorless areas (bright red in life) in axilla, groin, and on anterior and posterior surfaces of thighs: (14) SVL in males $16.2-18.9 \mathrm{~mm}$, in females $19.8-24.0 \mathrm{~mm}$.

Eleutherodactylus pyrhomerus is most similar to two other members of the E. myersi group-E. floridus and E. leoni in sharing (or expected to share in the case of E. floridus) red flash colors in the groin and on the concealed surfaces of the thighs. These three species also are alike in their small size, head shape, and absence of dorsolateral folds. Eleutherodactylus floridus differs by having larger digital discs (barely expanded in E. leoni and E. pyrrhomerus), and E. floridus and E. pyrrhomerns are larger and have white testes in contrast to the smaller E. leoni with black testes.

Description.-The original description by Lynch (1976c) is complete.

Coloration in life.-Field notes on living specimens from the vicinity of the type locality reveal that the dorsum is brown to grayish brown with darker brown markings; some individuals have a middorsal stripe that is cream with green cast and edged in black. The venter is gray with brown mottling or black flecks; a cream bar across the mental region was noted in some individuals. The axilla, groin, and concealed surfaces of the thighs and shank are red to salmon-red in adults; these flash colors are less evident in smaller individuals and absent in the smallest juveniles. The iris is creamy green with a median, horizontal, reddishbrown streak.

Natural history.--In the vicinity of Pilaló, Provincia Pichincha, this species was most commonly found under stones, logs, and wood chips along roadcuts and in pastures by day. Only two individuals, both adults, were found at night; they were perched on broad leaves 0.5 and $1.0 \mathrm{~m}$ above the ground in cloud forest.

Distribution.-Elentherodacty/us pyrhomerus seems to be restricted to the upper humid montane forest-humid temperate regime ( 7 localities) and humid subtemperate regime (1 locality) at elevations of 2075-3000 $\mathrm{m}$ on the western flank of the Andes in provincias Cotopaxi and Bolivar, Ecuador (Fig. 43).

Remarks. - Inexplicably, males of E. pyrrhomerus are rarely found; the same is true for $E$. floridus and E. leoni.

\section{Eleutherodactylus quinquagesimus Lynch and Trueb \\ Plate 4}

Eleutherodactylus quinquagesimus Lynch and Trueb. 1980:392.-Holotype: KU 167859, adult female, from Quebrada Zapadores, $2010 \mathrm{~m}, 5 \mathrm{~km}$ ESE Chiriboga, Provincia Pichincha, Ecuador.

Diagnosis.-A member of the Eleutherodactylus (Eleutherodactylus) devillei group having (1) skin on dorsum smooth anteriorly and shagreen posteriorly, that on venter areolate; discoidal fold prominent; dorsolateral folds on anterior half of body; interocular fold present; (2) tympanic membrane and tympanic annulus evident. small. its length $1 / 6-1 / 4$ length of eye; (3) snout subacuminate to rounded in dorsal view, rounded in profile. papilla at tip; (4) upper eyelid lacking tubercles, broader than IOD; cranial crests present; (5) vomerine odontophores round in outline; (6) males lacking vocal slits and nuptial pads; (7) first finger shorter than second; discs broad: (8) fingers bearing lateral fringes; (9) ulnar tubercles conical; (10) heel bearing prominent calcar; outer edge of tarsus bearing row of conical tubercles: inner edge of tarsus bearing nonconical tubercle; (11) inner metatarsal tubercle oval, 6-8 $\times$ subconical outer metatarsal tubercle; supernumerary tubercles only at bases of toes; (12) toes bearing lateral fringes; webbing absent; fifth toe longer than third: (13) dorsum brown with darker brown markings; venter tan with brown mottling; posterior surfaces of thighs chocolate-brown with white flecks; (14) SVL in Ecuadorian males $27.8-30.8 \mathrm{~mm}$, in females 33.6 $40.1 \mathrm{~mm}$. 
Eleutherodactylus quinquagesimus is easily recognized by the presence of an interocular fold. Even if that is not noticed, the species is distinguished by a prominent calcar on the heel. Some caution must be exercised in identifying this species by color pattern, because there is geographic variation in color pattern even across the relatively restricted geographic distribution of the species (Lynch and Trueb, 1980).

Description.-The original description by Lynch and Trueb (1980) is complete except for variation in coloration (described below) and in adult size. (See Remarks.)

Coloration in life.-The individual and geographic variation in this predominately brown frog are documented in the following descriptions, which are arranged from north to south.

KU 202625 from $5 \mathrm{~km}$ W of La Gruel, Provincia Carchi: Dorsum black with white marks on flanks and thighs; labial stripe yellow; venter black with white mottling; iris dark reddish-brown (WED, 26 February 1984).

KU 1.32656 and 132777-78 from La Delicia, Provincia Imbabura: Dorsum dark brown (two with large white blotches on head and back); venter black with or without white flecks; one with flanks and anterior surfaces of thighs with black and white bars (SRE, 11 August 1970).

KU 179365-68 from La Delicia, Provincia Imbabura: Dorsum brown with black markings and bronze canthal stripe and dorsolateral fold: flanks brown with white spots; throat and belly black with cream and white mottling on belly; posterior surfaces of thighs brown; iris copper with brown flecks (JDL. 3 June 1977).

KU 167881-86 from $9 \mathrm{~km}$ SE Tandayapa, Provincia Pichincha: At night, dorsum reddish tan to yellowish tan; throat and anterior part of belly dull yellowish-green with brown mottling; other ventral surfaces, groin, Fingers I and II, and Toes IIII dull orange: iris dark reddish-copper with black flecks (WED, 9 April 1975).

KU 167852-69 from Quebrada Zapadores. Provincia Pichincha: At night, dorsum tan to yellowish tan with faintly darker markings; by day. dorsum dark brown to dull olive with or without bronze-tan upper lip; venter dull olive-tan with or without dark brown mottling; iris dark reddish- brown; one individual (KU 167852) with dull olive flanks with creamy-yellow spots, dull orange groin. and Fingers I and II and toes I-III orange brown (WED, 3, 4 April 1975).

KU 179376-77 from Quebrada Zapadores, Provincia Pichincha: Dorsum brown with touch of green on eyelids and snout and white labial stripe in one: nearly black with pale whitish bronze areas on face in another; white flecks on flanks, upper arms, and face in one individual and white area in groin in another; throat brown, with dark brown mottling in one individual; belly brown or dirty-yellow with brown flecks and spots; undersides of legs pale orange with brown spots; iris deep chocolate-brown (JDL, 8, 9 July 1977).

KU 179378-81 from I km SW San Ignacio, Provincia Pichincha: Dorsum pale brown to dark brown with copper marks on face; white areas on upper arms, flanks, and concealed surfaces of limbs: posterior surfaces of thighs brown; belly brown with bluish white mottling; iris deep chocolatebrown (JDL, 10 July 1977).

Natural history.-All individuals have been found in cloud forest at night. Most were perched on leaves and branches at heights to $2.5 \mathrm{~m}$ above the ground, but one was sitting amidst dead bamboo leaves on the ground. No reproductive activity has been noted. However, males with swollen testes and females with mature eggs have been found in January, April, May, June, and July, thereby suggesting that reproduction may be aseasonal. In Ecuador, juvenile females (straight oviducts) are less than $27 \mathrm{~mm}$ SVL.

Distribution.-Eleutherodactylus quinquagesimus inhabits cloud forests at elevations of 1410-2710 $\mathrm{m}$ on the western slopes of the Andes in Ecuador and extreme southern Colombia (Fig. 47). Most (8) of the localities are in the humid temperate regime; only one is in the humid subtropical regime.

Remarks.- Specimens of this species from La Planada, Departamento Nariño, Colombia, are smaller than those from Ecuador; SVLs of adult males from La Planada are only 20.3-24.6 $(\bar{x}=$ $23.2 \pm 0.2, n=17$ ) and of adult females 30.5-34.0 $(\vec{x}=32.3 \pm 0.4, n=9)$.

Eleutherodactylus quinquagesimus is highly distinctive from other species in western Ecuador 


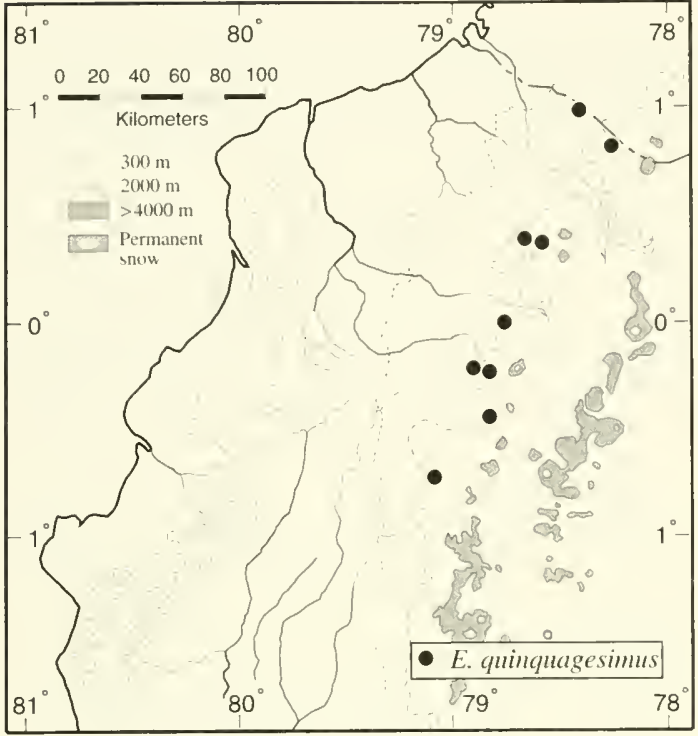

Fig. 47. Distribution of Elentherodactylus quinquagesimus in Ecuador.

but has the fifth toe longer than the third, as in frogs of several species groups. Here we associated $E$. quinquagesimus with the $E$. devillei group not because we have pressing evidence for doing so, but because it is not apparent where else the species might belong. We do not consider E. quinquagesimus to be closely related to the cis-Andean $E$. devillei or to E. appendiculatus, truebae, or vertebralis on the Pacific versant. Eleutherodactylus quinquagesimus is less easily placed in any of the other species groups in the E. conspicillatus series.

The trivial name, proposed on the fiftieth birthday of WED, is dated, but there is no provision in the Code of Zoological Nomenclature for keeping up with aging: besides, 65 in Latin is less euphonious.

\section{Eleutherodactylus rosadoi Flores Plate 7}

Eleutherodactylus roseus-Lynch, 1980b:180-82. Eleutherodactilus rosadoi Flores, 1988b:34.-Holotype: MCZ 92937, adult female, from the Río San Miguel. about $1 \mathrm{~km}$ above the Río Cayapas, Provincia Esmeraldas, Ecuador.

Diagnosis.-A member of the Eleutherodactylus (Eleutherodactylus) unistrigatus group having (1) skin on dorsum bearing many small warts, that on venter arcolate; discoidal fold prominent; dorsolateral folds absent; (2) tympanic membrane and tympanic annulus prominent, its length $2 / 5$ length of eye: (3) snout subacuminate in dorsal view, rounded in profile, with small papilla at tip; (4) upper eyelid bearing one or two conical tubercles, as wide as or broader than IOD; cranial crests absent; (5) vomerine odontophores oval in outline, not prominent: (6) males lacking vocal slits; nuptial pads present; testes black: (7) first finger shorter than second: discs broad, rounded: (8) fingers bearing weakly crenulated lateral fringes: (9) ulnar tubercles nonconical; ( 10 ) heel and outer edges of tarsus bearing small tubercles: inner surface of tarsus bearing tubercle; (11) inner metatarsal tubercle oval, $4 \times$ round outer metatarsal tubercle; supernumerary palmar tubercles low: (12) toes bearing narrow lateral fringes; webbing absent; fifth toe much longer than third; (13) dorsum brown with darker brown markings, including large postaxillary blotch; venter cream with brown flecks forming spots and/or reticulum; posterior surfaces of thighs cream with brown mottling; posterior part of flank, adjacent anterior surface of thigh, and concealed surfaces of shank and tarsus unpigmented: (14) SVL in two males 16.5 and $16.7 \mathrm{~mm}$. in three females $23.4-25.7 \mathrm{~mm}$.

The combination of conical tubercles on the eyelid and heel in such a small frog enables distinction from other species in Ecuador. A few species (e.g., E. latidiscus and E. muricatus) share this combination of characters, but these species are not sexually mature at the size of E. rosadoi. Additionally, the black mesorchium in E. rosadoi distinguishes males from most other Eleutherodacty/us. Eleutherodactylus roseus, an equally small frog in which males have black mesorchia, differs from $E$. rosadoi in having a single tubercle on the upper eyelid, a shagreen dorsum lacking folds. and in lacking a tympanic annulus and nuptial pads. Eleutherodactylus rosadoi also is similar to the equally small $E$. colomai. These two species are separated readily by snout shape (truncate in profile in E. colomai), heel anatomy (large, conical tubercle in E. colomai), and testis color (white in $E$. colomai). 
Description.-The original description by Flores (1988b) has been augmented by additional material. (See Remarks.)

Coloration in life.-Examination of color transparencies taken by Luis A. Coloma of two specimens (KU 219051 and QCAZ 7862) from the Río Canoi, $4 \mathrm{~km} \mathrm{~S}$ of Pedro Vicente Maldonado, Provincia Pichincha, reveals that in the former the dorsum of the body and limbs is tan with dark brown markings consisting of an irregular interorbital bar, irregular chevron in scapular region, spots in the sacral region, broad canthal stripe, large blotch in the postaxillary region, and transverse bars on the limbs; the lower flanks are yellowish tan. In the latter specimen, the dorsum is reddish tan with a narrow cream middorsal stripe bordered by broader, irregular dark brown marks; other markings are dark brown and consist of labial bars, broad canthal stripe, large postaxillary blotch, and transverse bars on the limbs; the heels are tan. In both individuals, the iris is pale bronze with small black flecks.

Natural history.-The holotype and paratype were in amplexus (Flores, 1988b), as was the pair collected on Isla Gorgona, Colombia. All individuals have been found at night on low vegetation in lowland tropical rainforest.

Distribution.- - This species is known from low elevations $(<600 \mathrm{~m})$ in northwestern Ecuador and on Isla Gorgona, Colombia (Fig. 43). One of the Ecuadorian localities is in the humid tropical regime, and three are in the humid subtropical regime.

Remarks.-Eleutherodactylus rosadoi remains inexplicably rare in collections. The measurements for QCAZ 7862 and KU 218051, an adult male and an adult female, respectively, are: SVL 16.7, 25.7; shank 8.4, 12.3; HW 7.0, 10.4; upper eyelid width 1.9, 3.1; IOD 1.9. 2.8; tympanic annulus 1.1, 1.5; eye length 2.7. 3.3; E-N 2.3. 3.2. Each individual has a minute heel tubercle. The male has no obvious eyelid tubercles, but the female has well-developed tubercles on the upper eyelids. The male has a pale middorsal stripe extending from the level of the anterior edges of the orbits nearly to the level of the sacrum.

Initially, this species was confused with $E$. roseus (Boulenger), known only from lowlands in north- ern Chocoan Colombia (Lynch, 1980b). Eleutherodacty/us rosadoi is likely to remain poorly known until collectors intensify their efforts on small eleutherodactylines in leaf litter by day and on low vegetation at night.

\section{Eleutherodactylus ruidus Lynch}

Eleutlerodactylus ruidus Lynch, 1979a:40.-Holotype: AMNH 17590, adult female, from Molleturo, 2317 m, Provincia Azuay, Ecuador.

Diagnosis.-A member of the Eleutherodactylus (Elentherodactylus) unistrigatus group having (1) skin on dorsum warty with W-shaped occipital folds, that on venter areolate; discoidal fold relatively prominent; dorsolateral folds absent; (2) tympanic membrane and tympanic annulus absent; (3) snout short, rounded in dorsal view and in profile; (4) upper eyelid bearing flattened warts, as wide as IOD; cranial crests low on posterior parts of frontoparietals; (5) vomerine odontophores triangular in outline; (6) males lacking vocal slits; nuptial pads present; (7) first finger shorter than second; discs broad; (8) fingers bearing lateral fringes; (9) ulnar tubercles absent; (10) heel bearing small tubercles; outer edge of tarsus lacking tubercles; inner edge of tarsus bearing fold; (11) inner metatarsal tubercle oval, $2 \times$ round outer metatarsal tubercle; supernumerary plantar tubercles at bases of toes; (12) toes having lateral fringes; webbing absent; fifth toe much longer than third; (13) dorsum brown with darker markings: venter cream with diffuse brown spots on throat; posterior surfaces of thighs brown; (14) SVL in males $25.8-31.1 \mathrm{~mm}$, in females $37.1-39.8 \mathrm{~mm}$.

Eleutherodactylus ruidus is the only species in western Ecuador having the combination of characters, tympanic annulus absent and fifth toe markedly longer than third. In other species lacking an ear (E. duellmani, gentryi, hamiotae, siopelus, sobetes, and surdus), the fifth toe is only slightly longer than the third.

Description.-The original description by Lynch (1979a) is complete and based on all known specimens.

Coloration in life.-Unknown.

Natural history.-Little is known about this frog. The species has been collected only once from 
beneath stones in pastureland and scrubby vegetation in an area having little forest in June 1922. At that time, G. H. Tate collected 16 specimensseven adult males having nuptial pads, seven gravid females, and two juvenile females, the largest of which (SVL $29.0 \mathrm{~mm}$ ) shows initial signs of developing oviductal convolutions.

Distribution.-Eleutherodactylus ruidus is known only from the type locality at $2317 \mathrm{~m}$ in the humid temperate regime on the Pacific slopes of the Cordillera Occidental in Ecuador (Fig. 43).

Remarks.-Lynch (1979a) suggested relationships of E. ruichls with E. balionotus and E. riveti, species that inhabit paramo and subparamo in southern Ecuador.

\section{Eleutherodactylus scolodiscus Lynch and}

\section{Burrowes}

\section{Plate 8}

Eleutherodactylus scolodiscus Lynch and Burrowes, 1990:20.-Holotype: IND-AN 1416, adult female. from Reserva La Planada, 1780 m, Municipio de Ricaurte, Departamento Nariño, Colombia.

Diagnosis.-A member of the Eleutherodactylus (Eleutherodactylus) diastema group having (1) skin on dorsum shagreen, that on venter areolate; discoidal fold present; dorsolateral folds absent; (2) tympanic membrane absent but tympanic annulus evident beneath skin, its length about $1 / 3$ length of eye; (3) snout subacuminate in dorsal view, rounded in profile, with papilla at tip; (4) upper eyelid bearing small tubercles, narrower than IOD; cranial crests absent; (5) vomerine odontophores absent or only barely evident: (6) males having vocal slits; nuptial pads absent; (7) first finger shorter than second; discs broad, with papilla at tip of disc on Finger III; (8) fingers bearing fleshy lateral keels; (9) ulnar tubercles absent; (10) heel bearing minute tubercle: tarsus lacking tubercles or folds; (11) inner metatarsal tubercle oval, $5 \times$ round outer metatarsal tubercle; supernumerary tubercles numerous; (12) toes bearing lateral fringes; webbing absent; dises broad, bearing distal papillae of Toes II-IV; fifth toe much longer than third: (13) dorsum cream with fine black flecks providing hint of markings: venter cream with fewer black llecks; axilla, groin, and concealed surfaces of thighs unpigmented (orange in life); (14) SVL in males 17.9-20.4 $\mathrm{mm}$, in females 18.4-22.3 $\mathrm{mm}$.

By having papillae on the tips of some digits, $E$. scolodiscus can be confused with E. chalceus and E. gularis. Living individuals of E. scolodiscus are recognizable immediately by the blue iris (black in E. chalceus and E. gularis). Eleutherodactylus chalceus is a larger frog (SVL in males 17.5-26.9 $\mathrm{mm}$, in females $27.7-31.2 \mathrm{~mm}$ ) and has areolate skin on all surfaces, whereas E. gularis is about the same size as E. scolodiscus but has smooth skin on the dorsum. The larger E. calcarulatus has a bluegray iris, but it differs in having a prominent tympanic annulus and heel tubercle, and lacking papillae on the tips of the digits.

Description.-The original description by Lynch and Burrowes (1990) is complete.

Coloration in life.-According to Lynch and Burrowes (1990), in living specimens from La Planada, Departamento Nariño, Colombia, the dorsum was pale tan with a pink or orange suffusion; some individuals also had brown flecks on the dorsum. The limbs were tan with brown flecks forming transverse bars in some individuals. The groin and posterior surfaces of the thighs were orange, and the venter was uniform white. The iris was pale bright-blue with fine black reticulations.

Description of two Ecuadorian specimens are, as follow.

KU 177651 from Maldonado, Provincia Carchi: Dorsum pinkish orange; venter somewhat yellow; iris blue (JDL, 17 May 1977).

USNM 286292 from Chical, Provincia Carchi: Groin and anterior surfaces of thighs yellow; dorsum of body and hind limbs with rosey-red (E. W. Schupp, 25 September 1979).

Natural history.-Little is known about this recently described species. At the type locality, individuals were found at night on leaves and mossy branches in dense cloud forest and along closed-canopy streams (Lynch and Burrowes, 1990). One Ecuadorian specimen was on vegetation below a waterfall at night. and another came from the canopy of a felled tree by day.

Distribution.-Eleutherodacty/us scolodiscus is known from few localities at elevations of 1200 
$1780 \mathrm{~m}$ in the humid subtropical regime on the Pacilic slopes ol the Andes in northern Ecuador and adjacent Colombia (Fig. 44).

Remarks.-Specimens from Ecuador ( 3 males 17.6-19.0 $\mathrm{mm}$ SVL; I lemale $20.1 \mathrm{~mm} \mathrm{SVL}$ ) are about the same size as those from the type locality. At present. E. scolodiscus seems to be the nearest relative of the larger E. chalceus, and this pair of species is related to other members of the $E$. diastema group ( $E$. diastema, gularis, hylacformis, and vocator). The digital papillae of E. chalceus and $E$. scolodiscus are larger than those of $E$. gularis, but are smaller than those in undescribed species in northwestern Colombia and eastern Panama.

\section{Elentherodactilus simonbolivari Wiens and Coloma \\ Plate 8}

Eleutherodactylus simonbolivari Wiens and Coloma. 1992: 197.-Holotype: QCAZ 1459, adult female, from Bosque Protector Cashca Totoras, $3200 \mathrm{~m}, 10$ $\mathrm{km}$ SE of Santiago on road to Santa Rosa de Totoras. Provincia Bolívar, Ecuador.

Diagnosis.-A member of the Eleutherodactylus (Eleutherodacty/us) orestes group having (1) skin on dorsum bearing low warts of irregular sizes (appears more or less smooth), that on venter areolate: discoidal fold evident; dorsolateral folds absent; (2) tympanic anmulus not well defined externally, round, its length $1 / 3-1 / 2$ length of eye: (3) snout rounded in dorsal view and in profile: (4) upper eyelid lacking tubercles, narrower than IOD; cranial crests absent; (5) vomerine odontophores low; (6) males having vocal slits: nuptial pads absent; testes white: (7) first finger shorter than second: discs narrow; (8) fingers lacking lateral fringes; (9) ulnar tubercles indistinct or absent; (10) heel bearing small tubercles; tarsus lacking tubercles and fold; (11) inner metatarsal tubercle oval, I.5x round outer metatarsal tubercle; supernumerary plantar tubercles indistinct or absent; (I2) toes lacking lateral fringes; dises narrow, as large as those on fingers; webbing absent; fifth toe longer than third; (13) dorsum brown with darker brown markings; venter orange (in life) in males, brown with pale spots in females; white spots in axilla and groin and on concealed surfaces of limbs; (14) SVL in males 16.0-19.2 $\mathrm{mm}$, in females $18.5-22.0 \mathrm{~mm}$.

Eleutherodactylus simonbolivari is most similar to E. orestes Lynch in the Andes of southern Ecuador. The skin on the dorsum in E. simombolivari is smooth or nearly so, but usually it is areolate (rarely smooth with scattered tubercles) in E. orestes. Living males of $E$. simonbolivari are reddish brown above and orange below, whereas those of E. orestes are brown above and gray below. In E. orestes, the groin and concealed surfaces of the limbs are black with large white spots, whereas $E$. simonbolivari has smaller white spots on a black background and appears to have a black venter covered with white flecks (pale areas corresponding to individual warts).

Description.- The original description by Wiens and Coloma (1992) is based on all known specimens.

Coloration in life.-As reported by Wiens and Coloma (1992), sexual dimorphism is evident in coloration. They described males as having a reddish-brown dorsum with darker spots; labial bars brown; venter and digits orange; ventral surfaces of thighs gray; white spots present in axilla and groin and on concealed surfaces of shanks and tarsi. In contrast, females were described as having a dark brown dorsum with or without reddish tint; labial bars brown with white borders; flanks nearly black with minute white spots; venter dark brown to nearly black with paler spots corresponding to centers of pustules; axilla. groin, and concealed surfaces of shank and tarsus black witl white spots. The iris is gray with a median, horizontal, gray streak.

Natural history.-At the type locality, all individuals were in the vicinity of a spring in upper humid montane forest. The frogs, all adults, were in leaf litter and under rotting logs and under moss on logs by day.

Distribution.-This species is known only from elevations of $3000-3300 \mathrm{~m}$ in the vicinity of the type locality in the humid subtemperate regime in the Cordillera Occidental in Provincia Bolívar, Ecuador (Fig. 44).

Remarks.-Wiens and Coloma (1992) used the results of analysis of molecular data to argue that $E$. simonbolivari was the sister species of $E$. 
orestes. They also postulated that these two species were allied to E. trepidotus and E. ocreatus, but those two species have much shorter fifth toes than do E. orestes, simonbolivari, and vidua. Eleutherodactylus ocreatus and E. trepidotus share the same toe length state as do the species placed in the $E$. myersi subgroup (E. gladiator; leoni, myersi. pyrrlomerus, and repens) by Lynch (1984a).

\section{Eleutherodactylus siopelus Lynch and Burrowes}

Elemherodactylus siopelus Lynch and Burrowes, 1990:22.-Holotype: IND-AN 1563, adult female, from Reserva Natural La Planada, 1780 m, Municipio de Ricaurte, Departamento Nariño, Colombia.

Diagnosis.-A member of the Eleutherodactylus (Eleutherodactylus) devillei group having (1) skin on dorsum shagreen, that on venter areolate; discoidal fold evident posteriorly; dorsolateral folds short, extending to level of sacrum; (2) tympanic membrane and tympanic annulus absent; (3) snout subacuminate in dorsal view, rounded in profile; (4) upper eyelid bearing small tubercle, narrower than IOD; cranial crests present, low; (5) vomerine odontophores triangular in outline: (6) males lacking vocal slits and nuptial pads; (7) first finger shorter than second; discs large; (8) fingers bearing lateral fringes: (9) ulnar tubercles conical: (10) heel bearing calcar; outer edge of tarsus bearing row of conical tubercles; inner edge of tarsus bearing low fold on distal quarter; (11) inner metatarsal tubercle oval, $3 \times$ flat outer metatarsal tubercle; supernumerary plantar tubercles numerous; (12) toes bearing fleshy lateral fringes; webbing absent; fifth toe longer than third; ( 13) dorsum brown with darker brown markings; venter white with brown flecks; lower flanks with cream flecks on darker background: posterior surfaces of thighs brown with cream flecks: (14) SVL in males 18.6$27.3 \mathrm{~mm}$, in females $34.3-40.0 \mathrm{~mm}$.

By virtue of having cranial crests and a calcar on the heel, E. siopelus is distinguished easily from most species of Eleutherodactylus. Those features and the absence of a tympanic annulus distinguish it from all Eleutherodactylus known to us. Eleutherodactylus quinquagesinus also has cranial crests and calcars, but it has an evident (albeit small) tympanic annulus, and an interocular fold.

Description.-The original description by Lynch and Burrowes (1990) is based on all known specimens.

Coloration in life.-According to Lynch and Burrowes (1990), the dorsum is uniformly chocolate-brown or tan with brown chevrons and limb bars; the flanks are brown with varying amounts of white mottling. The venter is white with brown blotches. The posterior surfaces of the thighs are brown in males and brown with small white flecks in females. The iris is golden-yellow.

Natural history.-All individuals were perched on vegetation overhanging streams by $0.5-2.0 \mathrm{~m}$ in cloud forest at night.

Distribution.-Eleutherodactylus siopelus is known only from the type locality in cloud forest on the western slopes of the Andes in extreme southern Colombia. In spite of the absence of records from Ecuador, we suspect that the species will be found in Ecuador, at least in northern Provincia Carchi.

Remarks.-A single juvenile female (SVL 31.I $\mathrm{mm}$ ) is known. The relationships of E. siopelus remain obscure. The initial impression of JDL is that $E$. siopelus is allied closely to E. acatallelus found at higher elevations $(2000-2600 \mathrm{~m})$ in the Cordillera Occidental in departamentos Cauca and Valle del Cauca, Colombia. Our association of $E$. siopelus (and E. acatallelus) in the E. devillei group is made on the basis of negative, rather than positive, evidence; in other words, this group is one of convenience.

\section{Eleutherodactylus sobetes Lynch Plate 4}

Eleutherodactylus sobetes Lynch, 1980c:334.-Holotype: KU 179389, adult female, from Quebrada Zapadores, $2010 \mathrm{~m}, 5 \mathrm{~km}$ ESE Chirihoga. Provincia Pichincha, Ecuador.

Diagnosis.-A member of the Eleutherodactylus (Eleutherodactylus) surdus group having (1) skin on dorsum smooth with many small pustules, that on venter areolate: discoidal fold well anteriad to groin; dorsolateral folds thin; (2) tympanic membrane and tympanic annulus absent: (3) snout short, subacuminate in dorsal view, rounded 
in profile: (4) upper eyelid lacking tubercles, as wide as IOD: cranial crests present: (5) vomerine odontophores massive oval: (6) males unknown; (7) first finger shorter than second; discs broad; (8) fingers bearing thick lateral fringes; (9) ulnar tubercles absent; $(10)$ heel bearing conical tubercle; outer edge of tarsus bearing thin fold with smalt tubercles: inner edge of tarsus bearing indistinct tubercle: (11) inner metatarsal tubercle oval, 5-6x subconical outer metatarsal tubercle; supernumerary tubercles low, at bases of toes: (12) toes bearing lateral fringes; webbing absent; fifth toe longer than third; (13) dorsum brown with bold brown markings: dorsolateral folds cream; venter cream with brown spots peripherally: posterior surfaces of thighs brown; (14) SVL in one adult female 41.3 $\mathrm{mm}$.

Eleutherodactylus sobetes is distinguished readily from other species in the E. surdus group because it has distinct pustules on the skin of the dorsum and a conical tubercle on the heel. Furthermore, the digits of $E$. sobetes are longer and more slender than those in other species of the group. (See Fig. 1 in Lynch, 1980c.) Living individuals are readily identified by having an orange iris. Eleutherodactylus degener also has an orange iris but is a much smaller frog having smooth skin on the dorsum and a much longer fifth toe.

Description.-The original description by Lynch (1980c) is based on all known specimens.

Coloration in life.-KU 179289-90 from Quebrada Zapadores, Provincia Pichincha: Dorsum dark brown and dull olive-yellow; groin and posterior surfaces of thighs pale violet; venter dirty-yellow with brown markings; iris bright orange (JDL, 9 July 1977).

Natural history.-The two known specimens were found in the same ravine (Quebrada Zapadores) in cloud forest at night in 1977; one was on a branch $1 \mathrm{~m}$ above the forest floor, and the other was on low vegetation beside a stream. Although the locality was searched extensively in 1977 and has been visited many times by other biologists, no additional specimens have been found. There was nothing peculiar about the habitat or behavior of the frogs in 1977 to suggest why the species should seem to be so rare. The second specimen is a juvenile female with a SVL of $34.4 \mathrm{~mm}$.
Distribution.-This species is known only from the type locality at an elevation of $2010 \mathrm{~m}$ in the humid temperate regime on the western flank of the Andes in Ecuador (Fig. 46).

Remarks.-Lynch (1980c) suggested that $E$. sobetes was allied to E. duellmami and E. surdus, a position with which we have no disagreement. However, Lynch's (1980c) hypothesis concerning several Andean species is weak and rejected here. That hypothesis placed too much emphasis on the absence of a tympanic annulus and ignored several species described subsequently from Colombia. Furthermore, if we are correct in interpreting the variation in the length of the toes as a systematic character, then E. baryecuus and E. ruidus have no relationship with the other frogs that Lynch included in the E. surdus group.

\section{Eleutherodactylus subsigillatus (Boulenger) Plate 6}

Hylodes subsigillatus Boulenger, 1902:52.-Holotype:

BM 1947.2.17.1, adult female, from Salidero, Provincia Esmeraldas, Ecuador.

Eleutherodactylus subsigillatus-Peters, 1955:339.

Diagnosis.-A member of the Eleutherodactylus (Eleutherodactylus) unistrigatus group having (1) skin on dorsum smooth to finely shagreen, that on venter areolate; discoidal fold prominent; dorsolateral folds absent; (2) tympanic membrane and tympanic annulus evident, round, its length $1 / 4-$ $2 / 5$ length of eye; (3) snout subacuminate in dorsal view, rounded in profile, bearing papilla at tip; (4) upper eyelid usually lacking tubercles, (occasionally 1 minute tubercle), slightly narrower than IOD: cranial crests absent; (5) vomerine odontophores oval to subtriangular in outline; (6) males having vocal slits and white nuptial pads; (7) first finger shorter than second; outer fingers bearing broad discs (larger than tympanic annulus): (8) fingers bearing narrow lateral fringes; (9) ulnar tubercles low, if visible; (10) heel bearing small conical tubercle; outer edge of tarsus bearing vague tubercles; inner edge of tarsus bearing tubercle; (11) inner metatarsal tubercle oval, 5-6x round outer metatarsal tubercle; supernumerary plantar tubercles numerous; ( 12) toes bearing lateral fringes; webbing absent; fifth toe much longer than third: 
(13) dorsum pale tan with brown markings, becoming darker on flanks; venter white to cream with scattered dark flecks or loose reticulum; lower flanks and anterior surfaces of thighs with dark brown or black bars or reticulum enclosing white spots; (14) SVL in males 19.3-28.5 mm, in females 30.0-33.4 mm.

Elentherodactylus subsigillatus is most similar to E. engeniae, nyctophylax, and phoxocephalus. It is most easily distinguished from those species by the pattern on the lower flanks and anterior surfaces of the thighs-barred in E. subsigillatus, cream or white with brown reticulations in E. eugeniae and E. phoxocephalus and brown with cream flecks in E. nyctoplylax. Of these four species, only $E$. eugeniae and E. subsigillatus have a terminal papillae on the snout; E. phoxocephalus has a vertical keel, and the snout in E. nyctophylax is unadorned. The tubercles on the upper eyelid and heels of $E$. subsigillatus are small and easily overlooked; of the four species discussed here, the only other having tubercles on the eyelids and heels is $E$. nyctoplylax.

Description.-The species was redescribed in detail by Lynch (1980b).

Coloration in life.- The general appearance of E. subsigillatus is tan, brown, or dull green; variation is documented in the following descriptions:

$K U$ 131566-70 from Balsapamba, Provincia Bolivar: Dorsum tan to dark brown with green and white flecks; throat dusky; rest of venter dirty cream with brown flecks or reticulations; posterior surfaces of thighs black with white flecks; anterior surfaces of thighs dirty gray and black with cream to pale yellow spots; iris chalk-white with black reticulations and soft bronze, median, horizontal streak; concealed edge of eye pale orange to yellow (JDL, 17 July 1970).

KU 177839-43 from Santo Donningo de los Colorados, Provincia Pichincha: Dorsum various shades of green and brown (one with decidedly orange cast on posterior part of body and hind limbs); throat pale green, yellow, or gray; rest of venter usually pale yellow (white in 1 individual), with or without brown flecks or spots; concealed surfaces of hind limbs greenish-yellow, yellow, or orange; iris yellowish bronze above and gray below red, median, horizontal red streak (JDL, 8-14 June, 1977).
Natural history.-This species usually is encountered at night on vegetation in forest: individuals have been found at heights of $0.6-10 \mathrm{~m}$ above the ground. Juveniles have been found in bromeliads and axils of elephant ear plants by day. Observations in the vicinity of Santo Domingo de los Colorados have led JDL to conclude that this species is difficult to find; although they are heard on rainy nights, relatively few individuals can be located. The late James A. Peters secured the largest available series from a chorus in the plaza at Santo Domingo de los Colorados on 8-9 May 1959; he described the call as a single, clear, belllike note. At the same locality. JDL heard individuals calling in December, February, June, and August and described the note as a single, sharp, explosive "tweet" (Lynch, 1980b).

Distribution.-Eleutherodactylus subsigillatus is widely distributed at elevations of $100-930 \mathrm{~m}$ in western Ecuador and southwestern Colombia (Fig. 48). Most records (9) are from the humid subtropical regime on the lower slopes of the Andes or the humid tropical regime (4) in the northwestern part of Ecuador, but records from Provincia Manabí reveal the presence of the species at localities in dry tropical (1) and dry subtropical (1) regimes in western Ecuador.

Remarks.-Males 18.2-19.5 mm SVL lack vocal slits are presumed to be immature. Females as large as $27.5 \mathrm{~mm} \mathrm{SVL} \mathrm{(KU} \mathrm{131567)} \mathrm{are} \mathrm{imma-}$ ture in that they have thin, straight oviducts.

\section{Eleutherodactylus sulculus Lynch and Burrowes}

Eleutherodactylus sulculus Lynch and Burrowes. 1990:24.-Holotype: IND-AN 1481, adult female. from Reserva La Planada. $1780 \mathrm{~m}$. Municipio de Ricaurte, Departamento Nariño. Colombia.

Diagnosis.-A member of the Eleutherodactylus (Eleutherodactylus) devillei group having (1) skin on dorsum finely shagreen, that on venter areolate; discoidal fold well anteriad to groin; traces of dorsolateral folds in sacral region: (2) tympanic membrane and tympanic annulus prominent, its length $1 / 3-1 / 2$ length of eye; (3) snout round in dorsal view and in profile; (4) upper eyelid bearing low warts, narrower than IOD; cranial crests present; 


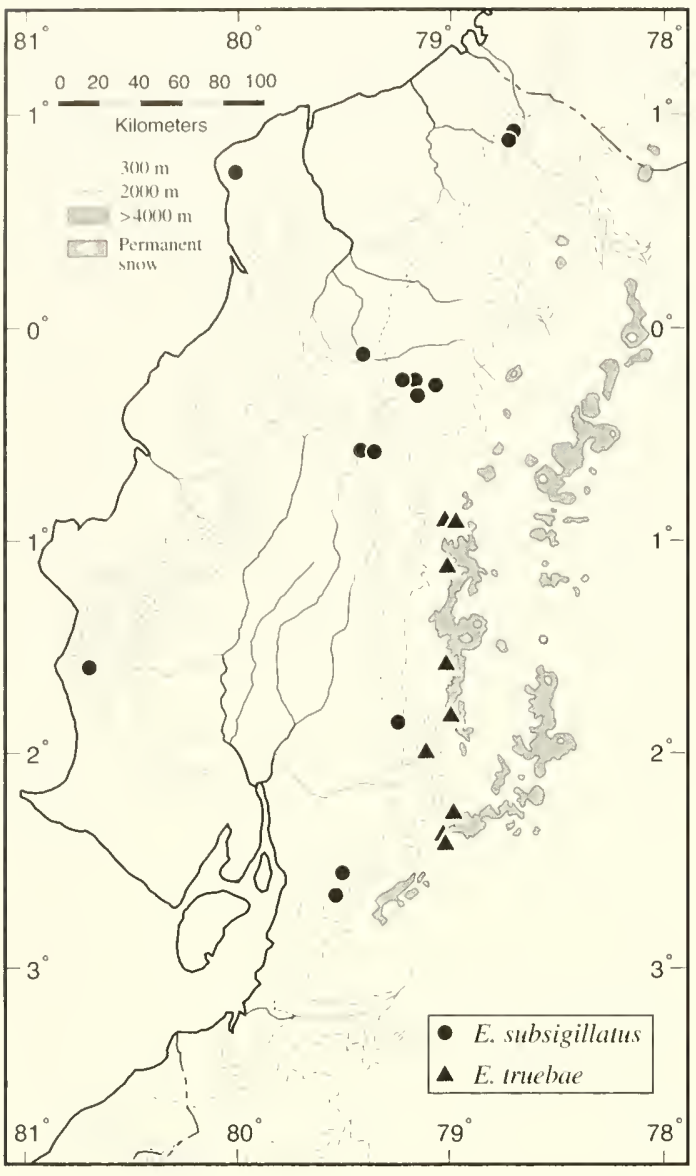

Fig. 48. Distribution of two species of Eleutherodactylus in western Ecuador.

(5) vomerine odontophores subtriangular in outline; (6) males lacking vocal slits; nuptial pads absent; (7) first finger shorter than second; dises broad; (8) fingers bearing lateral fringes; (9) ulnar tubercles absent; (10) heel and outer edge of tarsus lacking enlarged tubercles; inner edge of tarsus bearing low fold on distal end; (11) inner metatarsal tubercle oval, $6 \times$ subconical outer metatarsal tubercle; supernumerary plantar tubercles numerous; (12) toes bearing lateral fringes; webbing absent; fifth toe longer than third: (13) dorsum brown, becoming darker on flanks; venter cream with brown spots or reticulum; posterior surfaces of thighs brown; (14) SVL in one male $26.3 \mathrm{~mm}$, in one female $43.0 \mathrm{~mm}$.

Eleutherodactylus sulculus is distinctive in hav- ing an obvious interorbital furrow between elevated cranial crests formed by upturned lateral edges of the frontoparietals. Other species in westem Ecuador having cranial crests lack tympana.

Description.- The original description by Lynch and Burrowes (1990) is complete.

Coloration in life.-According to Lynch and Burrowes (1990), the dorsum is tan, brown, or reddish brown with darker brown markings, and the venter is creamy white with brown mottling. The posterior surfaces of the thighs are brown with white mottling, and the iris is bronze-brown with a golden outer rim.

Natural history.-Limited data from the type locality indicate that individuals were found on vegetation $1.0-2.5 \mathrm{~m}$ above the ground at night.

Distribution.-Eleutherodactylus sulculus is known only from the type locality at an elevation of $1780 \mathrm{~m}$ in cloud forest on the western slopes of the Andes in extreme southern Colombia; it is expected to occur in adjacent northern Provincia Carchi, Ecuador.

Remarks.-Lynch (1992b) identified $E$. sulculus as the sister species of E. cacao, a species known from the Munchique region of Departamento Cauca, Colombia. There seems to be no Ecuadorian vicariant of these species. Rather, the relatives of E. cacao and E. sulculus occur at comparable elevations in Departamento Valle del Cauca, Colombia.

\section{Eleutherodactylus surdus (Boulenger) Plate 4}

Hylodes surdus Boulenger, 1882:212.-Syntypes: BM 1947.2.17.25-26, adult females, from "West Ecuador" and "South America," respectively.

Eleutherodactylus surdus_Peters: 1955:350.

Eleutherodactyilus alberchi Flores, 1988a:110.-Holotype: MCZ 97483, adult female, from Quebrada Silante Grande. 2300 m. Alóag-Santo Domingo de los Colorados Road, Provincia Pichincha, Ecuador. New synonymy.

Diagnosis.-A member of the Eleutherodactylus (Eleutherodactylus) sutclus group having (1) skin on dorsum smooth, that on venter areolate; discoidal fold distinct; dorsolateral folds absent or only feebly developed; (2) tympanic membrane 
and tympanic annulus absent: (3) snout short, rounded in dorsal view and in profile; (4) upper eyelid lacking tubercles, narrower than IOD; cranial crests present; (5) vomerine odontophores oval; (6) males lacking vocal slits and nuptial pads; (7) first finger shorter than second; dises broad; (8) fingers bearing lateral keels; (9) ulnar tubercles absent; (10) heel and tarsus lacking tubercles; (11) inner metatarsal tubercle oval, $5 \times$ indistinct oval outer metatarsal tubercle; supernumerary tubercles at bases of Toes II-IV; (12) toes bearing thick lateral fringes; webbing absent; fifth toe longer than third; (13) dorsum gray with indefinite brown or black markings; venter cream with brown mottling; posterior surfaces of thighs brown with white spots; (14) SVL in males $24.5-36.9 \mathrm{~mm}$, in females 40.4-54.6 mm.

Eleutherodactylus surdus is most similar to $E$. duellnani but differs in having a smoother texture to the skin on the dorsum and white spots on the posterior surfaces of the thighs, and in lacking dorsolateral folds (if present, feebly developed) and basal webbing between the toes. Also, male $E$. surdus lack nuptial pads. Both species lack tympana and have cranial crests, which are best developed in females.

Description.-The redescription of E. surdus by Lynch (1980c) is augmented by the original description of E. alberchi by Flores (1988a).

Coloration in life.- - In general, the dorsum is pale to dark brown with darker brown markings; some individuals have a green or reddish-orange tint and/or yellow flecks. The variation is documented in the following descriptions.

KU 111385-94 from $21 \mathrm{~km}$ E Alóag, Provincia Pichincha: Dorsum brown with dark brown blotches and yellow-green areas; flanks and hind limbs yellowish tan with black or brown bars; groin and posterior surfaces of thighs black, latter with yellow spots; venter off-white with black or dark brown marbling; iris in females bright reddishbronze with brown blotches; iris in males more reddish, with brown to black reticulations (JDL, 14 July 1967).

KU 130888-90 from La Delicia, Provincia Imbabura: Dorsum and limbs brown with some dull-orange tint (green tint on flanks in one individual), darker brown markings, and yellow flecks; groin and concealed surfaces of thighs black with white flecks or spots; venter white with black reticulations; iris rich golden-copper with black flecks and reddish-brown, median, horizontal streak (JDL, 5 August 1970).

Natural history.-Most individuals of this species have been found under stones or clods of dirt in disturbed situations in cloud forest by day; however, at some localities many individuals were observed sitting on bare dirt banks or mossy banks at night, and a few were on broad leaves $0.2-0.6 \mathrm{~m}$ above the ground. On some of these banks along streams, E. surclus occurs in microsympatry with $E$. duellmani.

Early in our exploration of western Ecuador (1967), E. surclus was found most easily beneath stones beside the road from Alóag to Santo Domingo de los Colorados. Between 1967 and 1970. the portions of this road in upper humid montane forest were well watered; only a few minutes were required to find several specimens. By 1977, this road had been improved, and the ground near the road was better drained; at this time, searches for $E$. surdus were futile. The apparent disappearance of the species from this area must be viewed as human modification of a previously human-made habitat and not interpreted as a decline in the species (see Flores, 1988a); we continued to find E. surdus at other sites in the late 1970s, and Luis A. Coloma and his associates found the species in the 1980s.

Distribution.-Elentherodactylus surdus inhabits the upper slopes of the Cordillera Occidental at elevations of 1550-3190 m in provincias I mbabura and Pichincha, Ecuador (Fig. 49). Of 12 records of occurrence, nine are in the humid temperate regime, one in the humid subtropical, and two in the humid subtemperate.

Remarks.-Flores (1988a) based his description of $E$. alberchi on four specimens from a single locality. He diagnosed the species, in part, on the presence of a "concealed tympanic annulus." Upon searching through samples of Eleutherodactylus from the higher parts of the montane forests in western Ecuador. JDL found that the only frogs having large white spots on the concealed surfaces of the hind limbs were E. surdus, a species lacking tympana and tympanic annuli. Examination of the type series of E. alberch $i$ by JDL revealed that none 


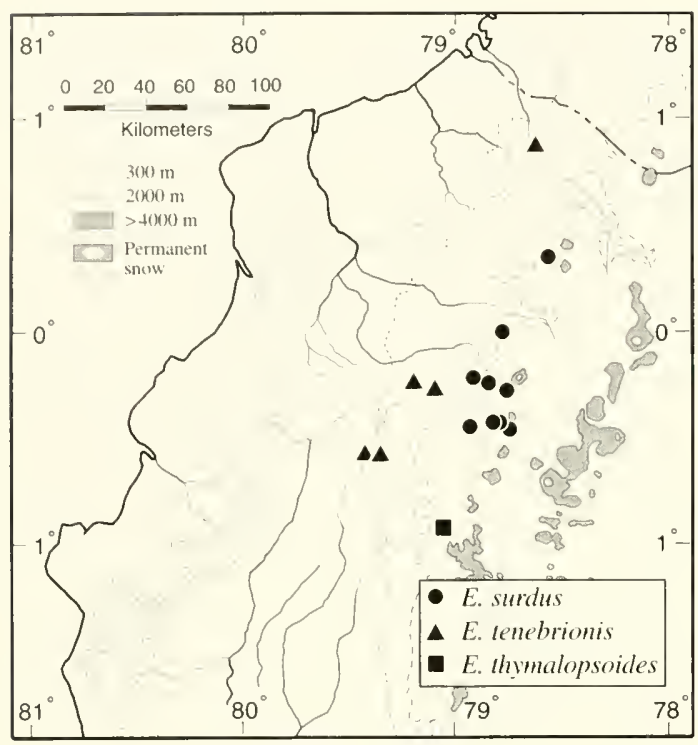

Fig. 49. Distribution of three species of Eleulherodactylus in western Ecuador.

had been dissected: subsequent dissection by JDL revealed the absence of tympana and tympanic annuli in the type series. The "interocular fold" cited by Flores (1988a) as a character of E. alberchi seems to us to be over-interpreted; there is an interocular dark bar, but we do not find an interocular fold.

Subsequently, Flores (1993) transferred $E$. alberchi to the E. surdus group and claimed that $E$. alberchi and E. surdus differ "in several important features." Except for the putative "interocular fold," all difference are of degree of prominence of tubercles and folds. As is evident in Flores' (1988a) illustration, the dorsolateral folds in the holotype of E. alberchi are not well developed. Such folds are absent or feebly developed in E. surdus. Careful examination of the postaxial surface of the forearm and of the heel reveal the presence of small tubercles that are highlighted by pale colors, but it is an error to attempt to distinguish $E$. alberchi and $E$. surdus on the presence or absence of these tubercles. Lynch's (1980c) descriptions emphasize the differences between E. duellmani and E. surdus; the tubercles in E. duellmani are visible without relying on flecks of color to locate the tubercles. There seem to be no characters to distinguish $E$. alberchi; thus, we place E. alberchi Flores, 1993. as a junior synonym of Hylodes surdus Boulenger, 1882.

As we indicated in the account of E. duellmani, we reject Lynch's (1980c) hypothesis of relationships of the E. surdus assembly. The characters that have been used to link several species are poorly understood, and their interpretation is purely phenetic. Nevertheless, we think that E. duellmani, hamiotae, sobetes, and surdus are closely related.

\section{Eleutherodactylus taeniatus (Boulenger)}

Hylodes taeniatus Boulenger. 1912:188.-Holotype: BM 1947.2.16.99 from "Noananoa" [= Noanama], Río

San Juan, Departamento Chocó, Colombia. Eleuherodactylus taeniatus-Gorham, 1966:103.

Remarks.-Lynch's (1980b) report of this species from western Ecuador was based on six specimens purportedly collected from the Río Caoni, sector de Lagartera. Provincia Esmeraldas, by Charles M. Fugler in August 1963. These specimens (UIMNH 53396, 53398, 53422-23, 63426, and 53431 ) were reexamined by JDL in 1984; they seem to be E. ockendeni (Boulenger), a relatively common species in the upper Amazon Basin. The UIMNH collection also contains specimens of Elentherodactylus malkini Lynch, Ischnocnema quixensis (Jiménez de la Espada), and Osteocephalus taurinus Steindachner having the same locality data and collector; all of these records are presumed to be errors in transcribing field data rather than spectacular geographic disjunctions. Eleutherodactylus taeniatus does not occur in Ecuador; the closest records are in the drainage of the Río San Juan in northwestern Colombia.

\section{Eleutherodactylus tenebrionis Lynch and Miyata Plate 3}

Eleutherodactylus tenebrionis Lynch and Miyata, 1980:7.-Holotype: MCZ 90326, adult male, from Tinalandia, $800 \mathrm{~m}, 16 \mathrm{~km}$ E Santo Domingo de los Colorados. Provincia Pichincha, Ecuador.

Diagnosis.-A member of the Eleutherodactylus (Eleutherodactylus) cerasinus group having (1) skin on dorsum smooth with scattered 
tubercles, that on venter areolate; discoidal fold present; dorsolateral folds absent; (2) tympanic membrane and tympanic annulus distinct, round, its length $1 / 4-2 / 5$ length of eye: (3) snout rounded in dorsal view, truncate in profile; (4) upper eyelid bearing one small tubercle, broader than IOD: cranial crests low in females, absent in males; (5) vomerine odontophores triangular in outline; (6) males having vocal slits: nuptial pads absent; (7) first finger shorter than second; discs broad; (8) fingers lacking lateral fringes; (9) ulnar tubercles absent; (10) heel bearing small tubercles; tarsus lacking tubercles; (11) inner metatarsal tubercle oval, $4 \times$ flat outer metatarsal tubercle; supernumerary tubercles only at bases of toes; (12) toes lacking lateral fringes; webbing absent; fifth toe longer than third; (13) dorsum brown; venter cream with extensive brown reticulation; posterior surfaces of thighs brown with small cream flecks; (14) SVL in males 20.8-26.8 mm, in females $30.6-36.9 \mathrm{~mm}$.

Eleutherodactylus tenebrionis is most similar to the larger E. labiosus, which has flared lips and finely tuberculate skin on the dorsum. Like other species in the E. cerasinus assembly, E. tenebrionis has a long fifth toe and large discs on digits lacking lateral fringes. (See Remarks.)

Description.-The original description by Lynch and Miyata (1980) is complete.

Coloration in life.-Lynch and Miyata (1980:10) described the coloration as: “...burnt umber with black and dull golden flecks above; the venter is gray with gray-brown mottling. The iris is blue gray. At night they tend to be much paler yellowish-tan dorsally with prominent black spots in the shoulder region." However, some field notes are somewhat contradictory to this description:

KU 165874-75 from Estación Biológica Rio Palenque, Los Ríos: Dorsum brown with dark brown markings; venter bluish gray with brown and black reticulation; iris bluish gray with black reticulations and dull brown triangles (WED, 29 March 1975).

KU 179224-26 from Santo Domingo de los Colorados, Provincia Pichincha: At night, dorsum tan with dark brown markings; by day, dorsum dark brown with darker markings; venter and lower surfaces of hind limbs dull brown with cream flecks: iris blue-gray with black flecks and gray, median, horizontal streak (JDL, I1 June 1977).

KU 179230 from $2 \mathrm{~km} \mathrm{E,} \mathrm{I} \mathrm{km} \mathrm{S} \mathrm{Santo} \mathrm{Domingo}$ de los Colorados, Provincia Pichincha: Dorsum dull gray-brown with pale gray flecks along flanks and on concealed surfaces of limbs; black spots on shoulders; venter dull brown with grayish-cream flecks; iris flecked with blue (JDL. 31 December 1977).

Natural history.-Eleutherodactylus tenebrionis remains rare in collections. The apparent scarcity probably is a consequence of it being an inhabitant of primary, perhaps undisturbed, forests. During field work in 1968, 1970, and 1977 in the immediate vicinity of Santo Domingo de los Colorados, Provincia Pichincha, JDL found $E$. tenebrionis only in what appeared to be primary forest. Despite spending considerable time in secondary forests and in banana groves, where many Elentherodactylus occurred, no E. tenebrionis were found in these habitats.

Distribution.- This species is restricted to primary forests at elevations of $220-830 \mathrm{~m}$ along the base of the Andes in Ecuador (Fig. 49). Only one record is from the humid tropical regime, whereas five are from the humid subtropical regime.

Remarks.-Lynchet al. ( 1994) did not mention E. tenebrionis in their treatment of the E. cerasinus group, but E. tenebrionis seems to belong to that group. Among the species in that group, $E$. tenebrionis resembles E. labiosus in color pattern but not in size or texture of the skin on the dorsum. The distribution of E. tenebrionis is encompassed within that of E. labiosus.

\section{Eleutherodactylus thymalopsoides Lynch Plate 6}

Eleutherodactylus thymalopsoides Lynch, 1976a:25.Holotype: KU 131533, adult female, from Pilaló. $2460 \mathrm{~m}$. Provincia Cotopaxi, Ecuador.

Diagnosis.-A member of the Eleutherodactylus (Elentherodactylus) unistrigatus group having (1) skin on dorsum finely granular, that on venter areolate; discoidal fold prominent: dorsolateral folds thin: (2) tympanic membrane and tympanic annulus distinct, higher than long, its length $2 / 5$ length of eye: (3) snout rounded in dorsal view and in profile: (4) upper eyelid bearing nonconical 
tubercles, narrower than lOD; cranial crests present; (5) vomerine odontophores oval to triangular in outline; (6) males lacking vocal slits; nuptial pads present: (7) first finger slightly shorter than second: discs broad: (8) fingers bearing lateral fringes; (9) ulnar tubercles nonconical: (10) heel and outer edge of tarsus bearing small tubercles; inner surface of tarsus bearing tubercle; (11) inner metatarsal tubercle elongate, $6-8 \times$ round outer metatarsal tubercle; supernumerary tubercles at bases of Toes II-IV; (12) toes bearing narrow lateral fringes; webbing absent; discs broad; fifth toe longer than third: (13) dorsum brown without pattern; venter gray; flanks and concealed surfaces of thighs brown with cream spots edged with black (yellow with or without orange centers in life); (14) SVL in males 28.0-34.4 mm. in females 46.9-55.4 mm.

Eleutherodacty/us thymalopsoides is a large. robust frog with cranial crests and thin dorsolateral folds; it is most easily recognized by the yellow or orange spots evident on the flanks and posterior surfaces of the thighs in living individuals. It is superficially similar to the smaller E. pteridophilus, but that species lacks a tympanic membrane and nuptial pads.

Description.-The original description by Lynch (1976a) is complete.

Coloration in life.- The coloration of this primarily brown frog with yellow spots has been described as follows.

KU 131533-37 from Pilaló, Provincia Cotopaxi: When found in bromeliads by day, dorsum black with faint green suffusion; labial stripe cream; later changed to dorsum fawn-brown with darker brown and green tint middorsally; upper flanks pale blue with pale and dark brown bars: venter and concealed surfaces of limbs blue to fleshy-gray; axilla, groin, and posterior surfaces of thighs black with yellow spots having orange centers; smaller individuals with green flanks, brown bellies, and yellow spots on venter; iris bright copper with diffuse reddish-brown, median, horizontal streak (JDL, 3 July 1970).

KU 177863-68from Pilaló, Provincia Cotopaxi: Dorsum dark green to brown; two individuals with reddish-brown spots with cream centers on dorsum; limbs and side of face dark brown; spots in axilla and groin and on flanks and concealed sur- faces of limbs yellow in smaller individuals, orange in larger ones; venter and undersides of limbs brown; iris brown with a touch of bronze (JDL, 29 June 1977).

Natural history.-At the time of its description, E. thymalopsoides was known only from adults that had been found in large terrestrial bromeliads. Subsequently, adults and juveniles were found in terrestrial and arboreal bromeliads by day and perched on vegetation and tree limbs ( $1-3 \mathrm{~m}$ above the ground) at night in, or at the edge of cloud forest.

Distribution.-This species is known only from upper humid montane forest in the humid temperate regime in the immediate environs of Pilaló (2460-2480 m), Provincia Pichincha, Ecuador (Fig. 49).

Remarks.-Most young individuals have uniform yellow spots in the axilla and groin and on the flanks and concealed surfaces of the hind limbs, whereas adults, especially females, have red or orange centers to the yellow spots. However, yellow spots are absent in some juveniles and males.

Flores (1988a) allied E. thymalopsoides with $E$. surdus (as E. alberchi) because they share (1) cranial crests, (2) dorsolateral folds, (3) tlecked testes, and (4) boldly patterned groin and concealed tarsi. Superficially, E. thymalopsoides does resemble E. surdlus, but the two species differ in the length of the fifth toe (long in E. thymalopsoides and short in E. surdus). Because of the extremely long fifth toe (Toe $\mathrm{V}$ extending to distal edge of distal subarticular tubercle of Toe IV), we place E. thymalopsoides in the E. unistrigatus group rather than the E. devillei group as done by Flores (1988a).

\section{Eleutherodactylus truebae sp. nov.}

\section{Plate 4}

Holotype.-KU 202620, adult female, one of a series collected $4 \mathrm{~km} \mathrm{~N}$ Zhud, $3040 \mathrm{~m}\left(02^{\circ} 28^{\prime} \mathrm{S}\right.$, $79^{\circ} 00^{\prime} \mathrm{W}$ ). Provincia Cañar, Ecuador, on 15 March 1984 by John E. Simmons.

Paratypes.-KU I30887, 202619, USNM 239649-50, 239653-55, 239661, 239664, QCAZ 2570, 2474-75, 2493. (See Appendix I for data.)

Diagnosis.-A member of the Eleutherodactylus (Eleutherodactylus) devillei group having 
(1) skin on dorsum shagreen, bearing low, flat warts, that on venter areolate; (liscoidal fold present: dorsolateral folds indistinct; (2) tympanic annulus absent, but tympanic annulus usually visible, higher than long, its length about $1 / 3$ length of eye; ( 3 ) snout subacuminate in dorsal view, rounded in profile; (4) upper eyelid smooth or bearing low tubercles, narrower than IOD; cranial crests low in females, absent in males; (5) vomerine odontophores oval in outline, elevated; (6) males lacking vocal slits; nuptial pads present; (7) first finger shorter than second; discs about twice as wide as digits; (8) fingers bearing lateral fringes; (9) ulnar tubercles indistinct; (10) heel bearing small tubercles; outer edge of tarsus lacking tubercles: inner surface of tarsus bearing diffuse foldlike tubercle; (11) inner metatarsal tubercle elongate, $4 \times$ oval, subconical outer metatarsal tubercle; supernumerary tubercles at bases of toes; (12) toes bearing prominent lateral keels; webbing absent; fifth toe longer than third; (13) dorsum brown with darker brown markings; throat brown; rest of venter dirty yellow with brown mottling; posterior surfaces of thighs brown with small cream spots; (14) SVL in males 25.5$39.0 \mathrm{~mm}$, in females $45.0-45.8 \mathrm{~mm}$.

Eleutherodactylus truebae is most similar to $E$. vertebralis, but the two are easily distinguished because a tympanic membrane is present in $E$. vertebralis (absent in E. truebae). Another character allowing for easy distinction is that the dorsal surfaces of the digital discs are black in $E$. vertebralis, whereas those surfaces are the same color as the dorsal surfaces of the digits in $E$. truebae. The dorsolateral folds of E. vertebralis are more prominent than those in E. truebae. In living individuals, the iris is brown in E. truebae, whereas it is red (or copper) in E. vertebralis.

Description.- $(n=19$; 11 males, 8 females $)$ Head as wide as, or narrower than, wider than long; HW $35.4-41.1 \%(\bar{x}=38.0 \pm 0.5)$ SVL in males, $36.2-39.6(\bar{x}=37.4 \pm 0.5)$ in females; snout subacuminate in dorsal view, rounded in profile; $E$ N 71.4-85.7.7\% $(\bar{x}=78.2 \pm 1.3)$ length of eye in males, $76.9-86.7 \%(\bar{x}=81.4 \pm 1.1)$ in females; nostrils weakly protuberant, directed dorsolaterally; canthus rostralis angular, weakly concave; loreal region slightly concave, sloping abruptly to lips: lips not flared; upper eyelid smooth or bearing small, low tubercles; upper eyelid width 76.2$90.9 \%$ IOD $(\bar{x}=85.3 \pm 1.3)$ in males, $66.7-85.7 \%$ $(\bar{x}=77.4 \pm 2.8)$ in females; cranial crests low, evident only in females; supratympanic fold swollen (not prominent), obscuring upper edge of tympanic annulus; tympanic annulus obscure, only anterior and ventral parts raised above level of skin, not visible externally in some specimens, higher than long, its length $28.6-37.2 \%(\bar{x}=33.6 \pm 0.9)$ length of eye in males, $27.8-40.0 \%(\bar{x}=34.2 \pm 1.5)$ in females, separated from eye by distance equal to $1-1 \frac{1}{2}$ lengths of tympanic annulus; postrictal (ubercles low, fused into ridge. Choanae small, round. not concealed by palatal shelf of maxillary arch. vomerine odontophores posteromedian to choanae. oval to triangular in outline, elevated, each slightly longer than size of a choana, separated medially by distance equal to width of odontophore, each bearing three to five teeth in transverse row; tongue longer than wide, its posterior border not notched, posterior $1 / 5$ not adherent to floor of mouth; males lacking vocal slits.

Dorsum finely shagreen with some slightly larger warts evident on dorsum postsacrally and indistinct dorsolateral folds composed of low warts; cloacal sheath and enlarged tubercles in cloacal region absent; skin on throat wrinkled; skin on venter areolate; discoidal fold well anteriad to groin. Upper surfaces of arms smooth; ulnar tubercles minute (easily overlooked); thenar tubercle oval, much smaller than bifid (or divided) palmar tubercle; supernumerary palmar tubercles low; subarticular tubercles round, elevated, nonconical; fingers bearing fringes; first finger shorter than second: thumb lacking expanded disc; discs on Fingers 11-IV about $1 \frac{1}{2}$ times width of digits, rounded apically; all fingers having ventral pads defined by circumferential grooves; diffuse nuptial pad on thumb in males. Heel and outer edge of tarsus appear smooth but bearing minute tubercles (easily overlooked); inner surface of tarsus lacking tubercles but having indistinct fold on distal third: inner metatarsal tubercles twice as long as wide, about four times size of subconical outer metatarsal tubercle: supernumerary plantar tubercles only at bases of toes; subarticular tubercles round to longer than wide. nonconical; toes bearing prominent lateral keels: webbing absent; all toes bearing dises slightly 
smaller than those on outer fingers; tip of Toe V extending to point between penultimate and distal subarticular tubercles on Toe IV: tip of Toe III extending to middle of penultimate tubercle on Toe IV: when hind limbs flexed perpendicular to axis of body, heels overlapping: shank $50.8-59.9 \%(\bar{x}=$ $56.0 \pm 0.9)$ SVL in males, $54.6-60.0 \%(\bar{x}=57.2 \pm$ $0.6)$ in females.

Dorsum brown with darker brown markings consisting of interorbital bar, W-shaped occipital fold, and sacral chevron, all outlined with cream; dorsolateral folds edged with cream, thereby breaking dorsal pattern into dorsal and lateral portions: flanks with oblique dark blotches; limbs colored like dorsum; width of transverse bars on shanks equal to, or slightly narrower than, width of interspaces; groin and concealed surfaces of thighs brown with small cream spots or flecks; throat brown with diffuse cream flecks; venter pale brown with brown mottling; canthal-supratympanic stripe and labial bars dark brown, prominent.

Measurements of holotype: SVL 45.0, shank 25.1, HW 17.8, head length 15.0, chord of head length 16.7, upper eyelid width 3.7 , IOD 4.5, tympanic annulus length 1.5 , eye length $5.2, \mathrm{E}-\mathrm{N} 4.0$.

Coloration in life. - The coloration evident on a color transparency of a paratopotype (KU 202619) includes the following. Dorsum brown with dark brown chevrons on body and transverse bars on limbs narrowly bordered by orange-tan; dorsolateral folds orange tan; flanks dull brown with irregular dark brown vertical marks and with many small tan flecks ventrally; canthal and supratympanic stripes brownish black; iris brown with dull bronze ring around pupil.

Natural history.-All specimens have been found under rocks by day in disturbed areas in upper humid montane forest.

Distribution.-This species is known from elevations of 2870-3190 $\mathrm{m}$ at the upper edge of humid montane forests on the western slopes of the Andes in provincias Bolívar. Cañar, and Cotopaxi. Ecuador (Fig. 48).

Etymology.-The specific name is a noun in the genitive case and is a patronym for our colleague and collaborator, Linda Trueb, who has collected many Eleutherodactylus in western Ecuador and who for more than a quarter of a century has tolerated WED as a husband and JDL as a frequent house guest with a penchant for consuming quantities of her favorite spirits. Not coincidentally, Trueb (derived from the German triib) means clouded or troubled. The first of these meanings pertains to the weather conditions characteristic of localities where the frog bearing her name lives, whereas the second describes her attitude when so effectively wielding her editorial red pens, as she has done for many years with our manuscripts.

Remarks.-Elentherodactylus truebae seems to be the sister species of E. vertebralis, which replaces $E$. truebae to the north. The differences between the two species are consistent with treating them as distinct species, and we would not be surprised to find them in sympatry in the area above Pilaló, Provincia Cotopaxi. The apparent nearest relative of this pair of species is the cis-Andean $E$. devillei (Lynch and Duellman, 1980).

\section{Eleutherodactylus unistrigatus (Günther) Plate I}

Hyyodes unistrigatus Günther, 1859:416.-Syntypes: BM 1947.2.17.7-9 from "western Ecuador."

Hylodes lehmanni Boettger, 1892.-Syntypes: SMF 1200. la from Páramo del Bordoncillo, $3500 \mathrm{~m}$ Iprobably along frontier of departamentos Nariño and Putumayo]. Colombia. Synonymy fide Lynch, 1981 a.

Phyllohates equatorialis Barbour, 1908:320.-Syntypes: MCZ 2261 from "Equator," Synonymy fide Barbour and Noble, 1920.

Eleutherodactyhs unistrigtaus-Barbour and Noble. 1920:401

Syrrhophus coeruleus Andersson, 1945:24.-Syntypes: NHRM 1913 (5 specimens). Synonymy fide Lynch. 1981 a.

Eleutherodactylus unistrigatuts [unistrigatus]—Cochran: 1948:1

Eleutherodactylus unistrigatus-Lynch, $1981 \mathrm{a}: 32$.

Remarks.-We provide neither a diagnosis or description here. For a complete account of this species, see Lynch ( I98 Ia), who briefly mentioned the existence of populations of E. unistrigatus in cloud forests at Pilaló and Mindo. Provincia Pichincha. Normally, this species is found in grasslands and cultivated areas in inter-Andean valleys from southern Colombia to central Ecuador(Lynch, 
198 Ia). In frogs from these valleys, reproduction is restricted to the rainy season in December-March. Populations in the cloud forests are in far less seasonal environments but nonetheless retain an annual reproductive pattern reflecting the seasonality of the inter-Andean valleys. Frogs of this species at Pilaló are not active reproductively during April-July when adults and juveniles can be found simultaneously, but reproduction (as indicated by calling males) occurs in January and February when only adults can be found.

The species occurs in the forested regions in the humid temperate and humid subtemperate regimes in provincias Cotopaxi, Imbabura, and Pichincha (Fig. 50). These populations may have become established as a result of human commerce, but we suspect that they represent remnants of a formerly larger distribution of the species during glacial maxima. Human commerce may have been responsible for some of these isolated populations, but the presence of isolates in areas of extremely poor or newly opened roads suggests a more general phenomenon to explain their existence.

\section{Eleutherodactylus verecundus Lynch and Burrowes Plate 7}

Eleutherodactylus verecundus Lynch and Burrowes, 1990:26.-Holotype: IND-AN 1834, adult female, from Reserva Natural La Planada, 1780 m, Municipio de Ricaurte, Departamento Nariño, Colombia.

Diagnosis.-A member of the Eleutherodactylus (Eleutluerodactylus) unistrigatus group having (1) skin on dorsum bearing low, flat warts, that on venter areolate; discoidal fold present; partial dorsolateral folds present; (2) tympanic annulus visible, round, its length, $1 / 5-1 / 3$ length of eye; (3) snout subacuminate in dorsal view, rounded to nearly spatulate in profile: (4) upper eyelid bearing tubercles, narrower than IOD; cranial crests absent; (5) vomerine odontophores subtriangular in outline, prominent; (6) males having vocal slits; nuptial pads absent; (7) first finger shorter than second; discs broad; (8) fingers bearing lateral keels; (9) ulnar tubercles large, two; (10) heel bearing conical tubercle; outer edge of tarsus bearing row of small tubercles; inner edge of tarsus

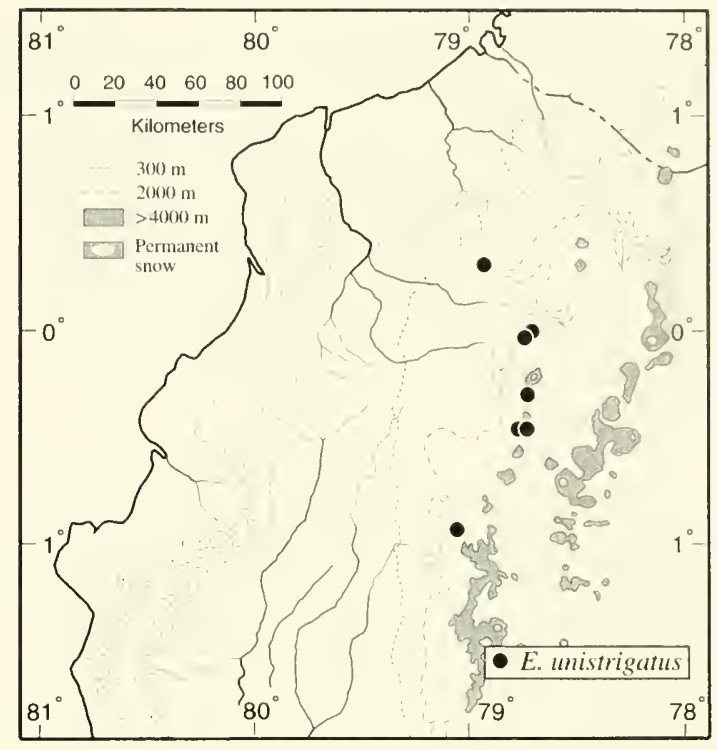

Fig. 50. Distribution of Eleutherodactylus unistrigatus on the forested Pacific slopes of Ecuador.

bearing short fold; (11) inner metatarsal tubercle oval, $2 \times$ round outer metatarsal tubercle; supernumerary palmar tubercles low: (12) toes bearing lateral fringes; webbing absent; fifth toe much longer than third; (13) dorsum brown with dark brown blotches outlined in cream and pale dorsolateral stripes; venter brown with darker brown spots; throat of females with brown chevrons: posterior surfaces of thighs brown with cream flecks; (I4) SVL in males $18.0-21.9 \mathrm{~mm}$, in females 20.7-22.5 $\mathrm{mm}$.

Recognition of this species depends on its small size, indistinct tympanic annulus, pale dorsolateral stripes, warty dorsum, and tubercles on the upper eyelid, heel, and tarsus. This combination of characters prevents confusion with any other species known from Ecuador.

Description.-The original description by Lynch and Burrowes (1990) is complete.

Coloration in life.-According to Lynch and Burrowes (1990), the dorsum is brown with darker brown markings (interorbital bar, scapular chevrons, sacral blotch, and suprainguinal spots on the body and transverse bars on the limbs). The dorsolateral stripes are cream or orange. and the postrictal tubercles are orange. The venter is tan or brown with brown or reddish-brown flecks, and the toes 
are orange with brown pads; the iris is copperyorange.

Natural history.-At the type locality, this small, nocturnal species was found sitting on leaves $0.3-1.5 \mathrm{~m}$ above the ground in the forest and along streams. One individual was on a steep dirt bank behind a small cascade. At the Reserva Florístia Ecológica Río Guajalito, Provincia Pichincha, one individual was in an arboreal bromeliad by day in October 1994.

Distribution.-This species is known from five localities at elevations of $900-1800$ in cloud forest in the humid subtropical regime (4 localities) and humid temperate regime (I locality) on the westem flank of the Andes in extreme southern Colombia and provincias Carchi and Pichincha, Ecuador (Fig. 51).

Remarks.-At the time of the original description, only one juvenile female (SVL $20.1 \mathrm{~mm}$ ) was known, and Lynch and Burrowes (1990) suggested that the species was unusual in that females were not markedly larger than males. Material from the region around Lita. Provincia Carchi, confirms the slight difference in size between the sexes-two adult males have SVLs of 18.4 and $18.7 \mathrm{~mm}$, and two adult females, 20.7 and $21.4 \mathrm{~mm}$. A single

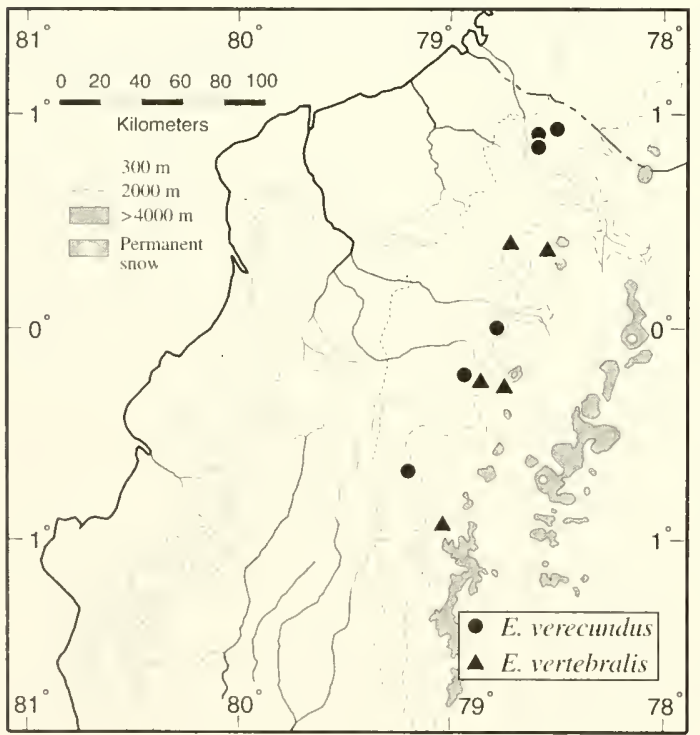

Fig. 51. Distribution of two species of Eleutherodacty/us in western Ecuador. juvenile male without vocal slits has a SVL of 12.2 $\mathrm{mm}$.

Lynch and Burrowes (1990) suggested an affinity between E. verecundus and E. cabrerai of northwestern Colombia. Moreover, JDL is aware of another similar frog from the Munchique region in Departamento Cauca, Colombia. Neither Colombian taxon, both of which are larger than $E$. verecundus, is sufficiently well studied to sustain a detailed comparison with $E$. verecundus.

\section{Eleutherodactylus vertebralis (Boulenger)} Plate 4

Hylodes vertehralis Boulenger, 1886:415.—Syntypes: BM 1947.2.17.5-6, adult females, from Intac (= Cordillera de Intac, Provincia Imbabura), Ecuador. Eletherodactylus (sic) vertebralis-Peters, 1955:346.

Diagnosis.-A member of the Elentherodactylus (Eleutherodactylus) devillei group having (1) skin on dorsum shagreen anteriorly and warty posteriorly, that on venter areolate; discoidal fold prominent; dorsolateral folds complete; (2) tympanic membrane and tympanic annulus prominent, its length about $1 / 4-1 / 2$ length of eye: (3) snout subacuminate in dorsal view, rounded in profile; (4) upper eyelid bearing low tubercles, narrower than IOD; cranial crests present; (5) vomerine odontophores triangular in outline; (6) males lacking vocal slits; nuptial pads present; (7) first finger shorter than second; discs large, rounded; (8) fingers bearing narrow lateral keels; (9) ulnar tubercles absent; (10) heel bearing small conical tubercle; outer edge of tarsus bearing row of small tubercles: inner surface of tarsus bearing indistinct tubercle; (11) inner metatarsal tubercle oval, 4-8× conical outer metatarsal tubercle; supernumerary tubercles numerous, in rows; ( 12 ) toes bearing lateral fringes; webbing absent; fifth toe slightly longer than third; (13) dorsum brown with darker markings: face dark, obscuring markings; cream edge to upper lip; tops of digits black; venter creamy yellow with brown spots; posterior surfaces of thighs brown with cream flecks; (14) SVL in males 21.1-33.8 $\mathrm{mm}$, in females 35.0-45.2 $\mathrm{mm}$.

Elentherodactylus vertebralis is most similar to E. truebae, from which it differs in having a promineni tympanic annulus and black pigment on the 
upper surfaces of the digital dises. In turn, these two species are most similar to the cis-Andean $E$. deville $i$; all have dorsolateral folds and the filth toe only slightly longer than the third.

Description.-The species was redescribed by Lynch (1980e).

Coloration in life.-As noted by Lynch (1980e:414), the coloration is highly variable, as is evident from the following descriptions.

KU 177976-82 from La Delicia, Provincia Imbabura: Dorsum bronze-brown to reddish brown; digital pads dark dorsally; venter creamy yellow, variously marbled with brown; concealed surfaces of thighs brown, with small creamy-brown flecks in some individuals: iris nearly red with black flecks and forming horizontal streak (JDL, 16 January 1968).

KU 179143-52 from Pilaló, Provincia Cotopaxi: Dorsum green, brick-red, brown, olive-brown or yellowish brown, with black flecks in most individuals; some individuals with pale yellowishcream bar across ear anterior to supratympanic stripe; belly creamy yellow (with orange tint in one individual) with black or dark brown marbling or reticulations; tops of digits black; concealed surfaces of thighs usually brown (axilla, groin, lower flanks, and concealed surfaces of hind limbs orange in two individuals); iris copper (JDL, 30 June 1977).

Natural history.-Eleutherodactylus vertebralis is best known from Pilaló, Provincia Cotopaxi, where it is one of three abundant species of the genus; the others are E. actites and E. phoxocephalus. During field work from 1968 through 1978, we found E. vertebralis to be abundant at Pilaló at the forest edge and deep in the forest. Few other Eleutherodactylus were encountered deep in the forest, but at night in the forest $E$. vertebralis occupied moss-encrusted leaves and branches $0.3-3.0 \mathrm{~m}$ above the ground.

Reproduction probably is aseasonal because juveniles were found in June, July, and January, and males were heard calling in those same months. On the night of 30 June 1977, an amplectant pair was perched on a vine $1.5 \mathrm{~m}$ above the ground. Swollen ova were visible through the female's abdominal wall; she had ovulated. For 2 days, the pair was isolated in a plastic bag with moss and small limbs.
Each night the male emitted soft peeps: this is one of the most common calls heard at Pilaló, but the calls had not been traced to a particular frog. After about $30 \mathrm{hr}$ in anplexus, the female deposited 67 loosely adherent eggs on the moss.

Distribution.- This species is known from elevations of 1800-2800 $\mathrm{m}$ in upper humid montane forests on the Pacific slopes of the Cordillera Occidental in the provinces of Cotopaxi, I mbabura, and Pichincha, Ecuador (Fig. 51). Six localities are in the humid temperate regime, and two are in the humid subtropical regime.

Remarks.-Sexual maturity in males is evidenced by nuptial pads and greatly swollen testes. Females with SVLs of 31.5-33.0 have slight convolutions of the oviducts; those with SVLs up to $31.0 \mathrm{~mm}$ have straight oviducts.

One of the syntypes has a relatively broad, pale raphe down the middle of the back (hence Boulenger's choice of a specitic name). Unfortunately, this pattern morph does not occur in most specimens, and it is not peculiar to E. vertebralis. Much of the confusion surrounding the identity of E. vertebralis can be traced to assumptions about the vertebral raphe. Cochran and Goin (1970) reported E. vertebralis widely from Andean Colombia, but their reports apply largely to three other species-E. anolirex Lynch in the Cordillera Oriental and to E. supernatis Lynch and E. permixtus Lynch, Ruíz and Ardila in the Cordillera Central (Lynch, 1980e, 1983; Lynch et al., 1994).

\section{Eleutherodactylus w-nigrum (Boettger) Plate 2}

Hylodes w-nigrmm Boettger, 1892:28.-Holotype: SMF 3804, juvenile female, from [Lago] Zurucuchu [approximately $15 \mathrm{~km}$ W Cuenca. Provincia Azuay]. Ecuador.

Hylodes buergeri Werner, 1899:466.-Syntypes: BM 1947.2.15.71 (only surviving specimen) from Alto de Sibaté near Bogotá or from Fusagasugá. Departamento Cundinamarca, Colombia. Synonymy fide Cochran and Goin, 1970.

Eleutherodactylus buergeri-Dunn, 1944:73.

Eleutherodactwlus w-nigrum-Peters, 1955: 337 : Cochran and Goin. 1970:395.

Diagnosis.-A member of the Eleutherodactylus (Eleutherodactylus) conspicillatus group 
having (1) skin on dorsum finely shagreen, that on venter smooth; discoidal fold evident; dorsolateral folds absent: (2) tympanic membrane and tympanic annulus prominent, higher than long, its length $1 / 4-1 / 3$ length of eye: (3) snout acuminate in dorsal view, rounded in profile: (4) upper eyelid lacking tubercles, wider than IOD: cranial crests absent: (5) vomerine odontophores triangular in outhe: (6) males with vocal slits, nuptial pads, and white testes: (7) first finger longer than second; discs about twice width of digits; (8) fingers bearing lateral keels; (9) ulnar tubercles absent: (10) heel bearing minute tubercle; outer tarsal tubercles absent: low foldlike tubercle on distal $1 / 4-1 / 3$ of tarsus; ( 11 ) inner metatarsal tubercle elongate. about $10 \times$ round outer metatarsal tubercle; supernumerary plantar tubercles few; (12) toes bearing lateral fringes; webbing absent; fifth toe slightly longer than third; (13) dorsum pale brown with darker brown or black markings: venter white to cream, in females with diffuse pale spots becoming more prominent posteriorly; black spots on lower flank and groin; posterior surfaces of thighs black with white spots, or cream with black spots or bars; (14) SVL in males $25.0-46.1 \mathrm{~mm}$, in females $43.2-71.5$ $\mathrm{mm}$, geographically variable.

The identification of adults seldom is a problem, because they usually have prominent black spots or bars on the flanks, groin, and concealed surfaces of the hind limbs. Eleutherodactylus w-nigrum appears to have a smaller tympanic annulus than other species in the E. conspicillatus group, but this impression is difficult to demonstrate with measurements for every species. The absence of dorsolateral and tarsal folds, prominent conical tubercles on the heel, and webbing in E. w-nigrum enable ready distinction from most other species in the $E$. conspicillatus group. Eleutherodactylus w-nigrum is distinguished from $E$. actites only by coloration (posterior surfaces of thighs with black flecks in $E$. actites), and it is separable from E. lymani by not having flared lips and dorsolateral folds. Juveniles are more difficult to identify, because the dark spots on the flanks characteristic of adults are rarely present and the posterior surfaces of the thighs are mostly cream (yellow in life). Juvenile E. achatinus have prominent dorsolateral folds and larger tym- pana; juvenile E. actites have dark pigment behind the knee, and juvenile E. illotus have conical tubercles on the heel.

Description.-Cochran and Goin's (1970) description is complete, but their account of variation is based on several species. Additional descriptive notes were provided by Lynch (1979b) and Lynch and Duellman (1980).

Coloration in life.-As might be expected, coloration is highly variable in this widely distributed species. This is evident from the descriptions of individuals from the eastern slopes of the Andes (Lynch and Duellman, 1980) and the following descriptions of individuals from the western slopes of the Andes.

\section{KU 110975-92 from Tandapi, Provincia} Pichincha: Dorsum pale brown, becoming rustybrown middorsally with brown spots edged with yellow-cream; some green tint on dorsum: venter white to yellow; chin and belly with pale browngray flecks; undersides of thighs yellow; groin and concealed surfaces of thighs black with yellow spots; iris pale bronze with reddish-bronze, horizontal streak (JDL, 15 July 1967).

KU 111045-55 from Tandapi, Provincia Pichincha: Dorsum brown with darker brown blotches edged in cream and pale green: lip orangebrown with black flecks; canthal stripe black; venter cream; groin and posterior surfaces of thighs black with yellow mottling; iris bright yellowbronze above, reddish bronze below, heavily reticulated with black (JDL, 21 July 1967).

KU 131263-71 from Gnaranda, Provincia Bolívar: Dorsum pale brown with medium brown to dark brown markings and with or without pale cream flecks; venter dull creamy yellow with or without dark reticulations; undersides of limbs and throat dirty creamy-gray: lip cream with bronze cast; canthal and supratympanic stripe black; posterior thigh yellow reticulated with brown; groin same but with less brown and a duller yellow; iris pale gray-bronze with reddish-brown, horizontal streak and some black reticulation (JDL, 12-15 July 1970).

KU 141833-35 from $14.8 \mathrm{~km}$ E Chiriboga, Provincia Pichincha: Dorsum reddish copper; dark brown canthal and supratympanic stripes; flanks 
and posterior surfaces of thighs green-yellow with dark brown mottling; transverse bars on forearms, dorsal thighs, and shanks inconspicuous; gular area white; belly white to yellow posteriorly in groin: iris metallic-yellow reticulated with black; diffuse horizontal bar of deep coppery-red (WED, I July 1971).

KU 141836-43 from $7.7 \mathrm{~km}$ E Chiriboga, Provincia Pichincha: Dorsum pale brown with darker brown markings: dark brown canthal and supratympanic stripes; tips of fingers yellow; flanks and thighs yellowish brown with darker brown markings: throat and belly creamy-white; peripheral suffusion of yellow posteriorly on belly; iris gold, reticulated with dark brown; deep brownishred horizontal streak (WED, I July 1971).

KU 165690-726 from $9 \mathrm{~km}$ SE Tandayapa, Provincia Pichincha: Dorsum yellowish tan, reddish tan, or grayish tan with darker markings of the same color; some with creamy-yellow or dullorange middorsal stripe. In juveniles, throat and belly white and ventral surfaces of hind limbs yellow; in larger individuals, throat and belly creamy yellow and ventral surfaces of hind limbs pale orange; in large females throat and belly dull yellow and ventral surfaces of hind limbs dull orange. Posterior thighs uniformly yellowish orange in juveniles, heavily mottled with black in larger individuals and mottling enclosing yellow, orange, or red spots. Some individuals with brown flecks on venter and some large females with bluishpurple spots in groin and on ventral surfaces of hind limbs. Iris golden-bronze with black reticulations and median, horizontal, dark red streak (WED, 9 April 1975).

KU 165740-82 from $5 \mathrm{~km}$ ESE Chiriboga, Provincia Pichincha: Dorsum tan with or without pinkish-bronze cast, reddish brown, or olive-gray with darker brown markings; throat and belly yellow; ventral surfaces of hind limbs dull yellow in smaller individuals and deep orange in largest; posterior thighs dark brown to black with yellow to orange-red spots; iris bronze with black reticulations and median, horizontal, red streak (WED, 3 April 1975).

Natural history.-Eleutherodactylus w'-nigrum is a common species in cloud forests. Our experi- ence suggests that juveniles are most active by day and less so at night. Juveniles have been observed hopping in leaf litter along trails and roads by day. In contrast, scarching modest-sized streams choked with fallen branches and vegetation at night yields few, if any, juveniles but large numbers of adults and subadults. Males most often are encountered sitting on low $(<1.5 \mathrm{~m})$ vegetation or substrate in the immediate vicinity of streams, whereas females normally are sitting on the ground a few to several meters away from the stream and at an elevation a few meters above the stream bed.

The call is reminiscent of that of many Gastrotheca and consists of a series of notes"braaack, bonk, bonk, bonk, bonk." Despite its abundance, we have not found eggs of E. W-rigrum. Although relatively few collections are available from September-December, juveniles seem to be present throughout the year; this suggests that reproduction is aseasonal (our estimate) or that $E$. w-nignm requires more than $1 \mathrm{yr}$ to reach sexual maturity.

Distribution.-Eleutherodactylus w-ligrum is widely distributed in cloud forest and subparamo on the eastern and western slopes of the Andes in Ecuador, the Cordillera Occidental and Central in Colombia, and the Cordillera Oriental in Colombia as far north as Departamento Santander (Lynch, 1979b; 1984). In western Ecuador, the species occurs at elevations of $800-3200 \mathrm{~m}$ (Fig. 52). Most records (49) of occurrence are in the humid temperate regime, and 29 localities are in the humid subtropical regime. In the southern part of its range. E. w-nigtum also occurs in the dry tropical regime (1 locality) and dry subtropical regime (3 localities).

Remarks. - On the northern Pacific slopes of the Andes in Ecuador (provincias Carchi, Imbabura, Pichincha, and northern Cotopaxi), there seems to be little or no interpopulational variation in sizes of adult males and females. Adults males have SVLs of $25.0-46.1 \mathrm{~mm}(\bar{x}=33.0 \pm 0.6)$ and adult females, $50.2-75.0 \mathrm{~mm}(\bar{x}=59.8 \pm 1.2)$. All females with a SVL less than $46 \mathrm{~mm}$ have straight, thin oviducts. Series of adults from the southern part of Ecuador are much smaller than the large series available from the north. However, three adult males and three adult females from Guaranda. 


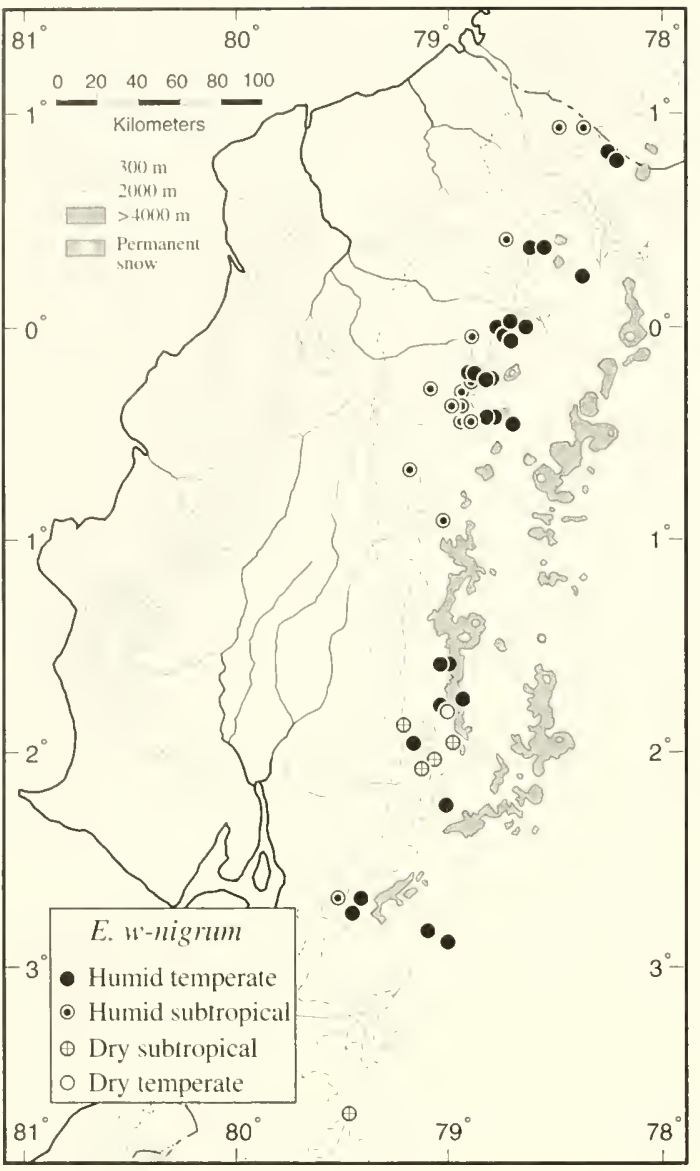

Fig. 52. Distribution of Eleutherodactylus w-nigrum in western Ecuador with respect to bioclimatic regimes.

Provincia Bolívar, are markedly smaller than those from the north: SVL in the males is $29.1-32.6 \mathrm{~mm}$ $(\bar{x}=31.0)$ and females, $43.2-46.1 \mathrm{~mm}(\bar{x}=44.9)$. The values for the males, but not the females, are within the range of variation in northern Ecuador. Small females also are known from provincias Azuay and Chimborazo, but these samples also include females of an "expected" size. Two adult females from Provincia El Oro have SVLs of 60.0 and $63.6 \mathrm{~mm}$.

\section{Eleutherodactylus walkeri Lynch Plate 7}

Eleutherodactylus walkeri Lynch. 1974:381.--Holotype: KU 131652, adult male, from La Palma, 920 m, Provincia Pichincha, Ecuador.
Diagnosis.-A member of the Eleutherodactylus (Eleutherodactylus) unistrigatus group having ( 1) skin on dorsum finely shagreen, that on venter areolate; discoidal fold prominent; dorsolateral folds absent; (2) tympanic membrane and tympanic annulus prominent, its length $1 / 3$ length of eye; (3) snout subacuminate in dorsal view, rounded in profile: (4) upper eyelid lacking tubercles, slightly narrower than IOD; cranial crests absent; (5) vomerine odontophores oval; (6) males having vocal slits; nuptial pads absent: (7) first finger shorter than second; discs large, not emarginate; (8) fingers bearing lateral keels; (9) ulnar tubercles obscure or absent; (10) heel lacking tubercles; outer edge of tarsus bearing faint tubercles: inner edge of tarsus bearing small tubercle; (11) inner metatarsal tubercle oval, 5-6x conical outer metatarsal tubercle: supernumerary tubercles few; (12) toes bearing weak lateral fringes; webbing absent; fifth toe much longer than third; (13) dorsal coloration polymorphic - with or without pale dorsolateral stripes; venter cream with brown flecks; posterior surfaces of thighs brown, with or without black areas enclosing cream spots; groin black with cream (yellow in life) spots; (14) SVL in males 13.8-18.5 $\mathrm{mm}$, in females $19.4-25.3 \mathrm{~mm}$.

By having yellow spots in the groin and (in some individuals) on the posterior surfaces of the thighs, E. walkeri is immediately recognizable among the species of Eleutherodactylus in the lowlands of western Ecuador. The only similar species is $E$. luteolateralis, which has a limited distribution in cloud forests in Provincia Pichincha, Ecuador. Eleutherodactylus luteolateralis always has a dorsal pattern of pale and dark stripes, whereas $E$. walkeri is polymorphic in dorsal pattern (including stripes).

Description.-The original description by Lynch (1974) is complete.

Coloration in life.- Lynch (1974) described four color patterns. Morph A.-Pattern of interorbital bar, scapular and sacral chevrons, and lumbar bar: flanks and side of head not darker than dorsum and top of head. Morph B.-Flanks and side of head much darker than dorsum and top of 
head; dark vertebral stripe from tip of snout to vent bordered by paravertebral dark stripe; chevrons and bars absent. Morph C.-As in A except for fine, cream vertebral stripe edged in dark brown passing through chevrons and bars. Morph D.-As in A except for broad, pale cream dorsolateral stripes; chevrons and bars present between dorsolateral stripes.

This variation is evident in the following descriptions written in the field.

KU I20215-20 from Santo Domingo de los Colorados, Provincia Pichincha: Dorsum and limbs gray, brown, rust, or black with black markings; some individuals with brown blotches; those that are rust posteriorly are brown posteriorly (black individual with white spots); venter dull black, gray, or cream (in rust individuals); vocal sac yellow; groin dark gray with lemon-yellow spots; posterior surfaces of thighs gray; cream line above vent; iris gray with black reticulations with tendency for brown, median, horizontal streak (JDL, 31 July 1968).

KU 131613-27 from Balzapamba, Provincia Bolívar: Dorsum dark gray to black with black markings or cream flecks; venter dark gray with paler gray flecks; groin and concealed surfaces of hind limbs black with lemon-yellow spots; some individuals with broad, tan dorsolateral stripes; iris rich brown with some black flecks and brown, median, horizontal streak (JDL, 14 July 1970).

Natural history.-Although it occurs in wet areas, E. walkeri can tolerate conditions in the relatively dry forests of southwestern Ecuador. This small species is abundant in banana and cacao groves and seemingly less abundant in primary forest. During the day, the frogs seek refuge in the litter on the forest floor and in bromeliads, and axils of leaves of bananas and elephant ear plants. At night, they perch on vegetation $0.2-2.0 \mathrm{~m}$ above the ground. Calling males and amplectant pairs are common, at least in April-August.

Distribution.-Elentherodactylus walkeri is widespread at elevations of 100-1270 $\mathrm{m}$ in the lowlands and lower slopes of the Andes in Ecuador (Fig. 53). Of 37 records of occurrence, 26 are in the humid subtropical regime, and only four are in the humid tropical regime. Its distribution into the provincias of El Oro, Guayas, and Manabí speaks for its tolerance to at least seasonally dry conditions; six localities are in the dry subtropical regime and one is in the dry tropical regime.

Remarks.-In the region around Santo Domingo de los Colorados, Provincia Pichincha. some individuals have orange, rather than yellow, spots in the groin and on the posterior surfaces of the thighs. These spots are orange in all individuals in a sample from $11.7 \mathrm{~km} \mathrm{~W}$ of Piñas, Provincia El Oro(USNM 286253-56, 286258-62,286269-76).

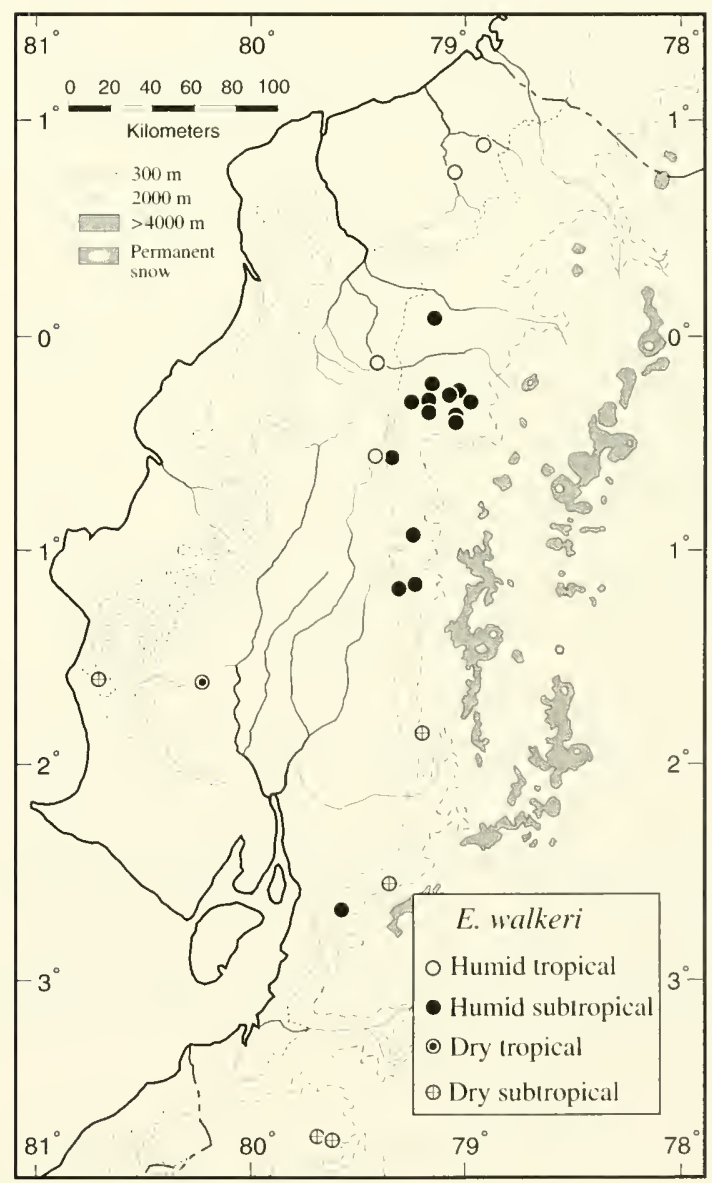

Fig. 53. Distribution of Eleutherodactylus walkeri with respect to bioclimatic regimes. 


\section{ECOLOGY}

Of the 147 species of frogs known from the Pacific lowlands and western slopes of the Andes in Ecuador (updated from Coloma, 1991), 61 (41.2\%) are Eleutherodacty/us. With one exception ( $E$. hectus), all of the Eleutherodacty/us are nocturnal. Some species are terrestrial, but most are arboreal. Ranging from sea level to elevations of more than $3000 \mathrm{~m}$. Eleutherodactylus are conspicuous members of all anuran assemblages except those in arid regions.

\section{The Eleutheromactylus Way of Life}

Because Eleutherodactylus deposit terrestrial eggs that undergo direct development into miniatures of the adults, the reproductive biology of these frogs is not associated with aquatic environments. Consequently, Eleutherodactylus can inhabit all terrestrial environments that have sufficient moisture for the survival of eggs, hatchlings, and adults.

Diurnal retreats for these nocturnal frogs include leaf litter on the forest floor (e.g., E. achatimus and $E$. longirostris), depressions under rocks on land (e.g., E. truebae and E. w-nigrum) or in seepages $(E$. duellmani), under bark on $\operatorname{logs}(E$. calcamlatus), and in axils of elephant ear plants (e.g., E. omatissimms and E. parvillus), terrestrial bromeliads (E. celator), arboreal bromeliads (e.g., E. cajamarcensis and E. phoxocephalus), and palm fronds (E. latidiscus). On the other hand, with the exception of a few large, toadlike, terrestrial species (e.g., E. anomahs and E. necerus), members of this genus characteristically perch on leaves and branches of herbs, ferns, bushes, and trees at night. At such times, collectors usually are under the impression that Eleutherodacty/us sit on leaves or branches and do nothing, although males of some species vocalize. This sedentary behavior is typical of sit-and-wait predators.

\section{Eleutherodactylus Communities}

Although we did not set out to undertake definitive studies of communities of Eleutherodactylus in western Ecuador, sufficient data were obtained at nine sites to ascertain basic community structure
(Table 6). The sites, their locations (Fig. 54), general descriptions, and numbers of species of Eleutherodactylus are, as follow.

1. Centro Cientifico Río Palenque, Provincia Los Ríos, 200-220 m, 34 $00^{\prime} \mathrm{S}, 79^{\circ} 20^{\prime} \mathrm{W}$ : Humid tropical regime; mean annual rainfall $2650 \mathrm{~mm}$; mean annual temperature $24.4^{\circ} \mathrm{C}$. Primary lowland tropical rainforest with adjacent clearing and banana grove; two small streams. Eleven species; the diurnal, terrestrial eleutherodactyline Barycholos pulcher also is present.

2. Santo Domingo de los Colorados, Provincia Pichincha, 550-600 m, $00^{\circ} \mathrm{I} 5^{\prime} \mathrm{S}, 79^{\circ} 10^{\prime} \mathrm{W}$ : Humid subtropical regime; mean annual rainfall $2906 \mathrm{~mm}$; mean annual temperature $22^{\circ} \mathrm{C}$. Primary and secondary humid tropical rainforest with banana and cacao groves and small streams. Thirteen species; the diurnal, terrestrial eleutherodactyline Barycholos pulcher also is present.

3. Río Faisanes (4 km NE Dos Ríos), Provincia Pichincha, $1380 \mathrm{~m}, 00^{\circ} 19^{\prime} \mathrm{S}, 78^{\circ} 49^{\prime} \mathrm{W}$ : Humid subtropical regime. Rainfall and temperature unknown. Rocky stream in disturbed cloud forest. Fourteen species.

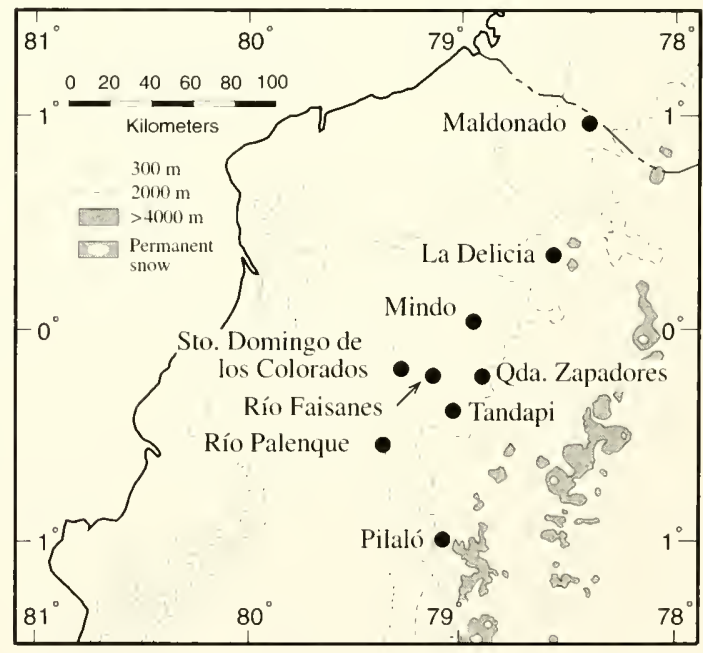

Fig. 54. Northwestern Ecuador showing locations of nine sites at which communities of Eleutherodactylus were studied. 


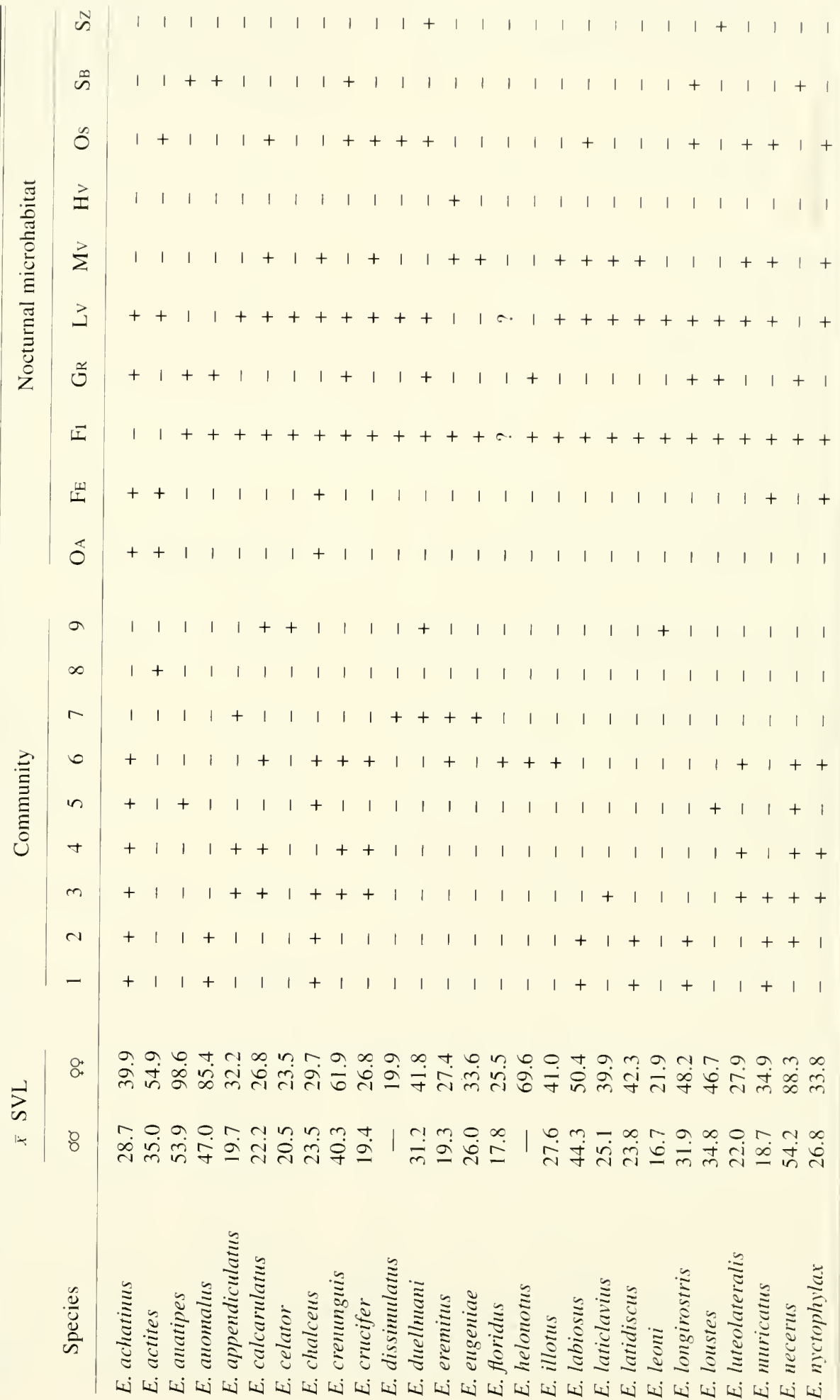




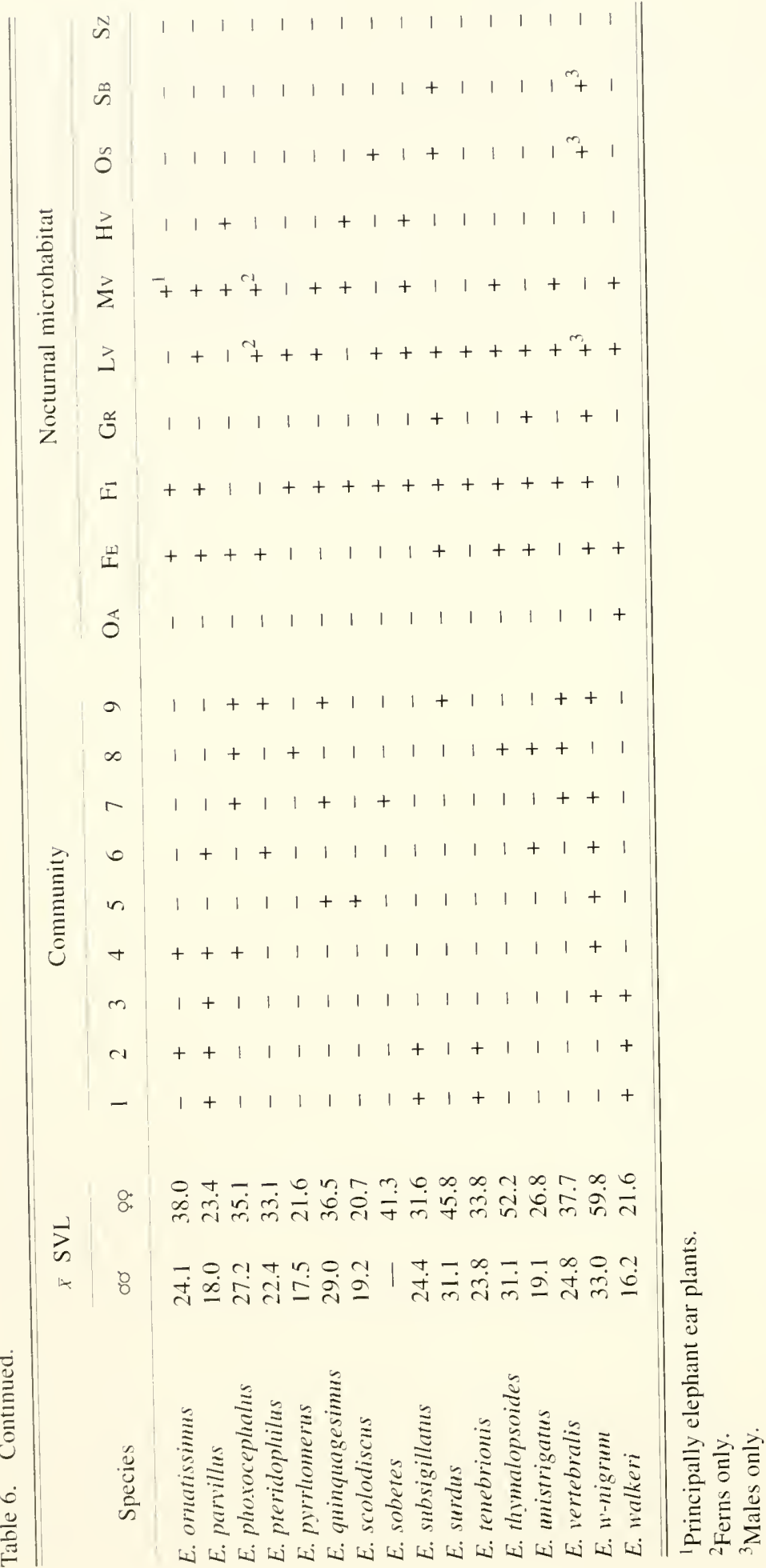


4. Tandapi, Provincia Pichincha, $1460 \mathrm{~m}, 00^{\circ} 24^{\prime} \mathrm{S}$, $78^{\circ} 47^{\prime} \mathrm{W}$ : Humid subtropical regime. Mean annual rainfall $1800 \mathrm{~mm}$; mean annual temperature $15^{\circ} \mathrm{C}$. Disturbed cloud forest and clearings with a fast flowing river and small streams. Twelve species.

5. Maldonado, Provincia Carchi, $1410 \mathrm{~m}, 00^{\circ} 54^{\prime} \mathrm{N}$, $78^{\circ} 06^{\prime} \mathrm{W}$ : Humid subtropical regime. Mean annual rainfall $1000 \mathrm{~mm}$; mean annual temperature $16^{\circ} \mathrm{C}$. Disturbed cloud forest with some pastures and three small streams. Eight species.

6. Mindo, Provincia Pichincha, $1410 \mathrm{~m}, 00^{\circ} 02^{\prime} \mathrm{S}$, $78^{\circ} 46^{\prime} \mathrm{W}$ : Mean annual rainfall $3466 \mathrm{~mm}$; mean annual temperature $16.4^{\circ} \mathrm{C}$. Humid subtropical regime. Steep slopes with cloud forest and small streams. Sixteen species.

7. Quebrada Zapadores, Provincia Pichincha, 2010 m, $00^{\circ} 15^{\prime} \mathrm{S}, 78^{\circ} 43^{\prime} \mathrm{W}$ : Humid temperate regime. Rainfall and temperature unknown, but at Chiriboga, $5 \mathrm{~km} \mathrm{~W}$ of Quebrada Zapadores at $1960 \mathrm{~m}$, mean annual rainfall $2003 \mathrm{~mm}$; mean annual temperature $16.2^{\circ} \mathrm{C}$. Deep ravine with cloud forest and high-gradient stream. Ten species.

8. Pilaló, Provincia Cotopaxi, $2400 \mathrm{~m}, 00^{\circ} 56^{\prime} \mathrm{S}$, $58^{\circ} 59^{\prime} \mathrm{W}$ : Humid temperate regime. Mean annual rainfall $1490 \mathrm{~m}$; mean annual temperature $12.6^{\circ} \mathrm{C}$. Disturbed cloud forest with many bromeliads; adjacent clearings and small streams. Six species.

9. La Delicia, Provincia Imbabura, $2710 \mathrm{~m}, 00^{\circ} 22^{\prime}$ $\mathrm{N}, 78^{\circ} 25^{\prime} \mathrm{W}$ : Humid temperate regime. Rainfall and temperature unknown. Steep slopes supporting cloud forest; many terrestrial bromeliads (along roadside) and one small stream. Ten species.

In the following paragraphs, we address abundance, body sizes, food, and microhabitat of the species found at these nine localities.

Species diversity.-The numbers of species at the nine sites range from six to fourteen. Comparison of species occurrence among sites was accomplished by calculating the coefficient of biogeographic resemblance (CBR; Duellman, 1990). The highest CBR (0.92) is between the two lowland sites. Río Palenque and Santo Domingo de los Colorados, which has all 11 species known from Río Palenque (Table 7). Only two to four species $(\mathrm{CBR}=0.17-0.32)$ are shared between the lowland sites and three of the sites in cloud forest in the humid subtropical regime. However, five lowland species (E. achatinus, chalceus, muricatus, parvillus, and walkeri) present at both Río Palenque and Santo Domingo de los Colorados and also $E$. necerus at Santo Domingo de los Colorados are among the 14 species at the lowest site in cloud forest, Río Faisanes (1380 m).

Three of the four sites in cloud forest in the humid subtropical regime also have high CBRs (0.64-0.77). The three sites (Río Faisanes, Mindo, and Tandapi) closely approximate one another geographically and altitudinally, whereas the fourth

Table 7. Occurrence of species of Eleutherodactylus in nine communities in western Ecuador. Abbreviations in headings to columns correspond to sites in first column. The number of species in each community is shown in boldface in the common cell; the numbers of species that are shared by two communities are shown in the upper right, and the coefficients of bigeographic resemblance are in italics in the lower left.

\begin{tabular}{lrrrrrrrrr}
\hline \multicolumn{1}{c}{ Site } & PAL & SDC & RFA & TAN & MAL & MIN & QZA & PIL & LDE \\
Río Palenque (PAL) & $\mathbf{1 1}$ & 11 & 5 & 2 & 2 & 3 & 0 & 0 & 0 \\
Santo Domingo (SDC) & 0.92 & $\mathbf{1 3}$ & 6 & 3 & 3 & 4 & 0 & 0 & 0 \\
Río Faisanes (RFA) & 0.40 & 0.44 & $\mathbf{1 4}$ & 10 & 4 & 10 & 2 & 0 & 2 \\
Tandapi (TAN) & 0.17 & 0.32 & 0.77 & $\mathbf{1 2}$ & 3 & 9 & 3 & 1 & 3 \\
Maldonado (MAL) & 0.21 & 0.30 & 0.36 & 0.30 & $\mathbf{8}$ & 4 & 2 & 0 & 2 \\
Mindo (MIN) & 0.22 & 0.28 & 0.67 & 0.64 & 0.33 & $\mathbf{1 6}$ & 2 & 1 & 3 \\
Qda. Zapadores (QZA) & 0.00 & 0.00 & 0.17 & 0.27 & 0.22 & 0.15 & $\mathbf{1 0}$ & 2 & 5 \\
Pilaló (PIL) & 0.00 & 0.00 & 0.00 & 0.11 & 0.00 & 0.09 & 0.25 & $\mathbf{6}$ & 2 \\
La Delicia (LDE) & 0.00 & 0.00 & 0.17 & 0.27 & 0.24 & 0.24 & 0.50 & 0.25 & $\mathbf{1 0}$ \\
\hline \hline
\end{tabular}


site, Maldonado, although at the same elevation as Mindo, is about $75 \mathrm{~km} \mathrm{NE}$ of Mindo and separated from the other sites by the Río Chota Valley; the CBRs between Maldonado and the other sites are 0.30-0.33.

The three sites in cloud forest in the humid temperate regime (Quebrada Zapadores, Pilaló, and La Delicia) share no species with the lowland sites and few species $(\mathrm{CBR} s=0.00-0.27)$ with the sites in cloud forest in the humid subtropical regime. Four species (E. duellmani, quinquagesimus, vertebralis, and w'-nigrum) are shared by Quebrada Zapadores and La Delicia, whereas two species ( $E$. phoxocephalus and E. vertebralis) are common to all three high cloud forest sites. The CBRs among these three high sites are $0.25-0.50$.

No attempt was made to determine actual abundance of species. However, during visits at five sites. all individuals observed were collected; these values range from 50 specimens of eight of the 11 species at Río Palenque to 372 specimens of eight of the 12 species at Tandapi. During these visits, selectivity in collecting was minimized; although biases of preferred microhabitat (of frogs and collectors) and of collecting schedules versus activity cycles of the frogs exist, they are relatively constant among sites. Other variables also exist-the time spent at each site and the times of the year that sites were visited. Thus, we have utilized these data only to provide crude estimates of relative abundance and rank order of abundance (Table 8).

Differences in sampling effort at the five sites resulted in vastly different numbers of individuals at some of the sites. This discrepancy in the data can be overcome by application of Krebs' (1989) rarefaction algorithm, which extrapolates the number of species that can be expected in a given sample size. Based on this algorithm, the numbers of species expected in a sample of 30 specimens at each site are: Río Palenque 7, Tandapi 6, Quebrada Zapadores 6, Mindo 5, and Pilaló 4.

Only one taxonomic comparison can be made with rank abundance data for Río Palenque with other sites; the forest-edge species E. achatinus is ranked third in abundance at the lowland site (Río Palenque) and second and fourth at two sites in cloud forest-Tandapi and Mindo, respectively. Among the sites in cloud forest, six of the nine

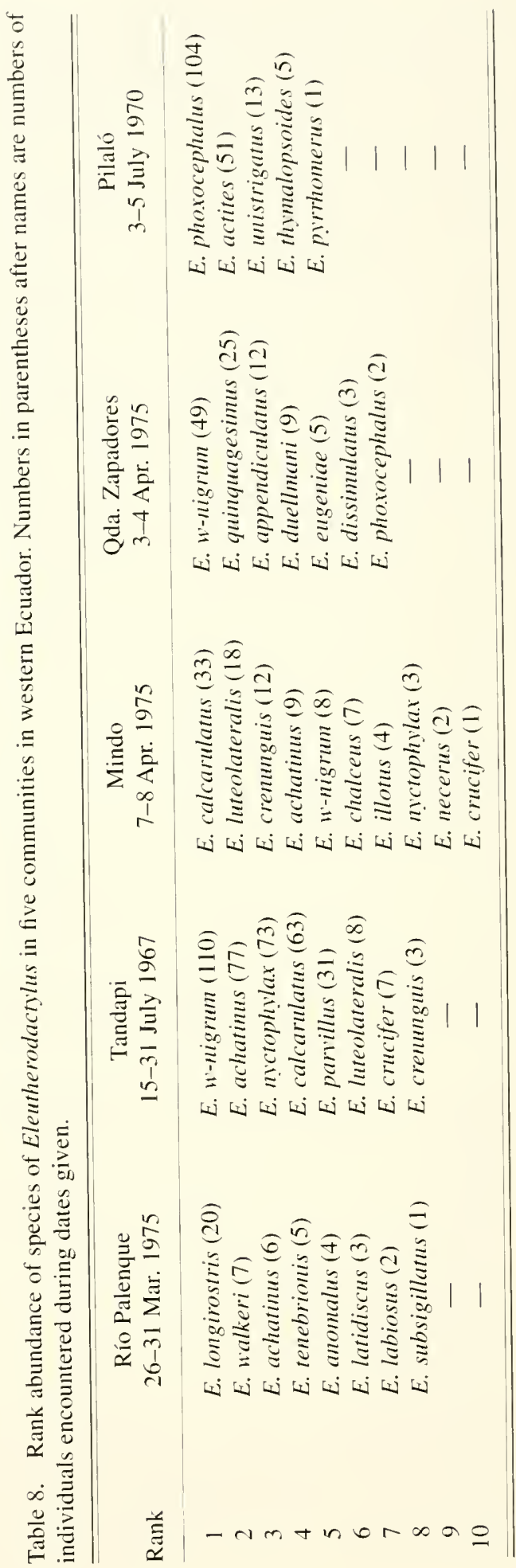


species at Tandapi are among the 10 species at Mindo, and one species at Tandapi is among the seven species at Quebrada Zapadores, which shares one species with Pilaló. Rankings among the six species shared by Tandapi and Mindo are entirely different. Eleutherodactylus w-nigrum is the most common species at Tandapi, but it is ranked fifth at Mindo, where E. calcarulatus is most abundant (fourth at Tandapi). Likewise, the second-ranked species at Mindo, E. luteolateralis, is sixth at Tandapi, and the third-ranked species at Mindo, $E$. crenunguis, is the least abundant of eight species at Tandapi.

Eleutherodactylus w-migrum is the only species shared by Tandapi and Quebrada Zapadores, and it is the most abundant species at both sites. Eleutherodactylus phoxocephalus is the most abundant species at Pilaló; this species is shared with Quebrada Zapadores, where it is the least abundant species. In most cases, there is no ready explanation for differences in relative abundance, at least among sites in cloud forest. However, the difference in abundance and ranking of E. phoxocephalus at Quebrada Zapadores and Pilaló might relate to the great abundance of arboreal bromeliads, the diurnal retreat of E. phoxocephalus, at Pilaló, as compared with the scarcity of these plants at QuebradaZapadores. Abundance may change with time. The greater abundance of E. luteolateralis at Mindo than at Tandapi (in 1967) may reflect recency of disturbance at Tandapi; the species was more common there in 1968 and 1970 as regrowth occurred (Lynch 1976a).

It is obvious from the data presented in Table 9 that great unevenness exists in the abundances of species in all five communities. The ratios of relative abundances of the most abundant : secondmost abundant species vary from $1: 0.35$ to $1: 0.70$ (Table 9); in no case do these represent the same pair of species. The ratios of the most abundant : least abundant species range from $1: 0.01$ to $1: 0.05$; again the same pairs of species are not involved.

Data on biomass are not available, but extrapolation of mass from body size reveals no clear relationships between size and relative abundance or rank of abundance, as illustrated for four of the communities (Fig. 55). At Tandapi and Quebrada
Table 9. Ratios of relative abundance of four most common species of Eleuherodactylus in five communities in western Ecuador.

\begin{tabular}{lc}
\hline \multicolumn{1}{c}{ Community } & Relative abundance \\
Río Palenque & $1: 0.35: 0.30: 0.25$ \\
Tandapi & $1: 0.70: 0.66: 0.57$ \\
Mindo & $1: 0.54: 0.36: 0.27$ \\
Quebrada Zapadores & $1: 0.51: 0.24: 0.18$ \\
Pilaló & $1: 0.49: 0.13: 0.05$ \\
\hline
\end{tabular}

Zapadores, the largest species, E. W-nigrum, is the most abundant, whereas at Mindo the second smallest, at Pilaló the second largest, and at Río Palenque the third largest species are the most abundant. The smallest species are the least abundant at Mindo and Pilaló.

Body size.-Hutchinson (1959) suggested a critical size ratio of 1.3 for coexistence of species in the same trophic level. Subsequently, two ideas regarding size and coexistence promulgated the literature (reviewed in Simberloff and Boecklen, 1981): (1) There is a minimum size ratio compatible with coexistence of ecologically similar species. (2) Three or more ecologically similar species tend to have constant size ratios between species adjacent in size-ranking, but the constant factor may vary among sites.

Ratios (larger SVL/smaller SVL) were computed for adjacent-sized species in the nine communities of Eleutlerodacty/us in western Ecuador; as examples, six of these are illustrated graphically in Figures 56 and 57. Clearly there is a linear relationship that falls between ratios of 1.00 and 1.50. The few exceptions are females of the larger species-E. anomalus at Río Palenque and $E$. crenunguis and E. necerus at Tandapi and Mindo. The size ratios between adjacent species is not constant; there tend to be minor differences among smaller species, whereas the differences are greater among larger species. When these data are treated on a $\log -\log$ scale, the differences are reduced.

Food.-No analysis of stomach contents was undertaken, but cursory examination of stomach contents revealed diverse kinds of insects ranging from ants to orthopterans, and also spiders. Among the species that we have examined. there is no ant specialist, such as E. acuminatus in the Amazon Basin (Duellman, 1978). 


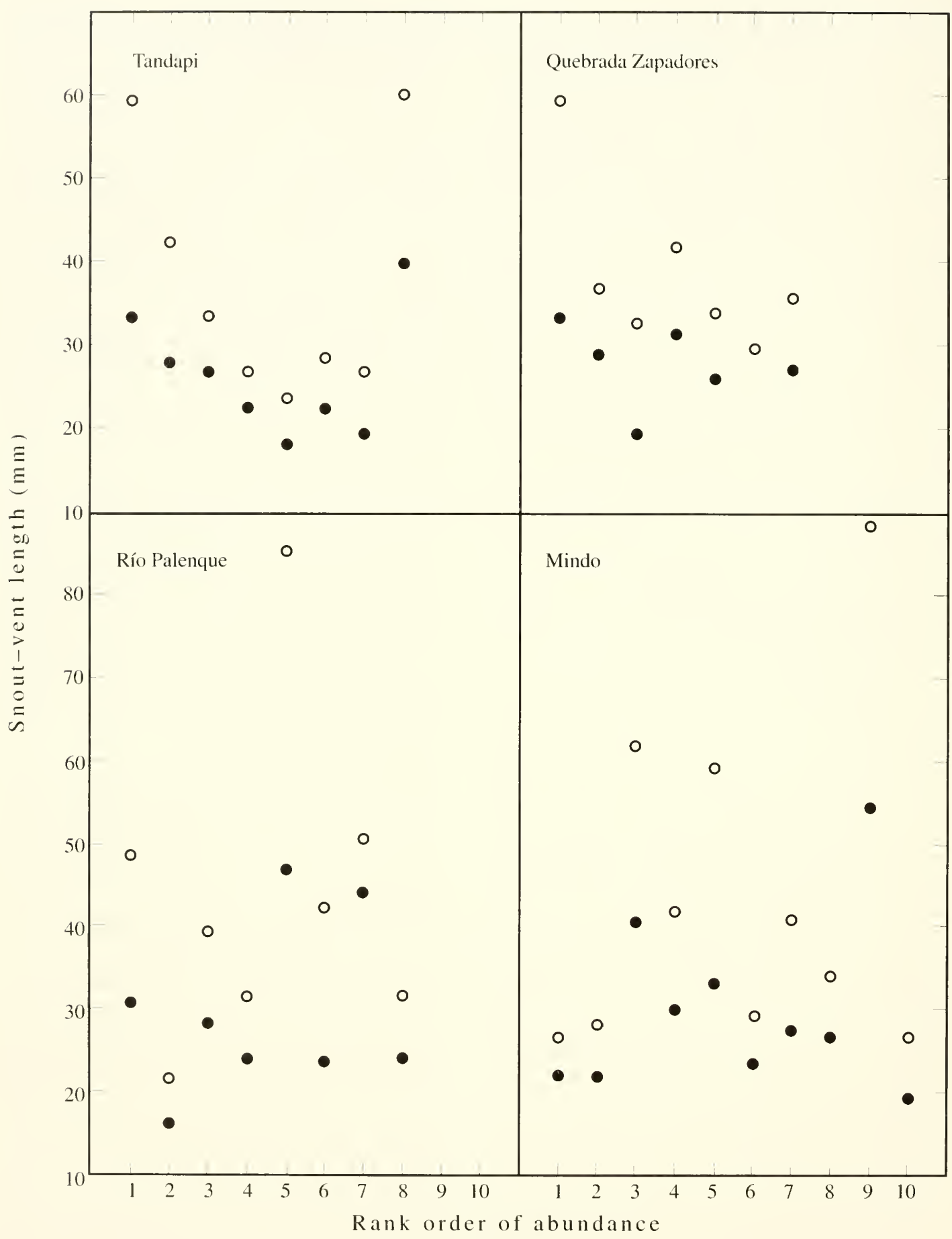

Fig. 55. Rank order of abundance and body size among Eleutherodactylus in four communities in western Ecuador. Solid dots are males; open circles are females. 


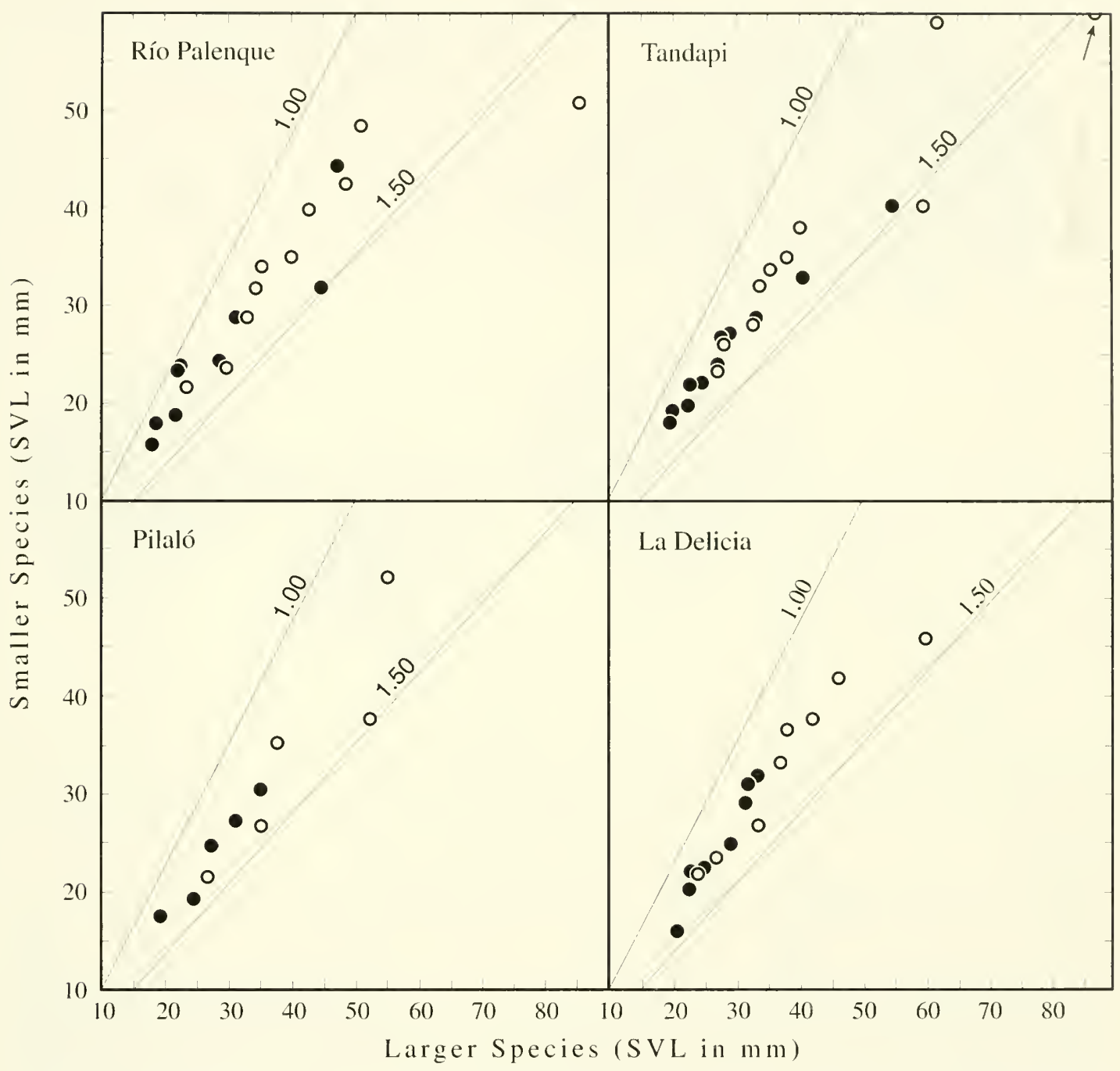

Fig. 56. Ratios of body sizes in succeeding larger species of Eleutherodactylus in four communities in western Ecuador. Solid dots are males; open circles are females.

Microhabitat.--Our best data are on the utilization of the structural habitat by the frogs, but even here the data have limitations. Because most Eleutherodactylus perch on leaves or branches and call infrequently (if at all), observations are most effective at heights of within $1.5 \mathrm{~m}$ of the ground. Observations at higher levels tend to be opportunistic - vegetation on a steep slope below the observer, attraction by vocalization, or bending smaller trees down or climbing larger ones because of observation of an eyeshine or vocalization by a frog (not necessarily an Eleutherodactylus). The following synthesis of microhabitat utilization is based on data on the species in the nine communities (Table 6) augmented by our knowledge of the species from throughout their ranges if we do not have personal experience with a particular species within a certain community (e.g., E. ornatissimus at Río Palenque). Our perceptions of microhabitat utilization in five communities are illustrated in Figures 58-62.

Of the 43 species in one or more of the nine 


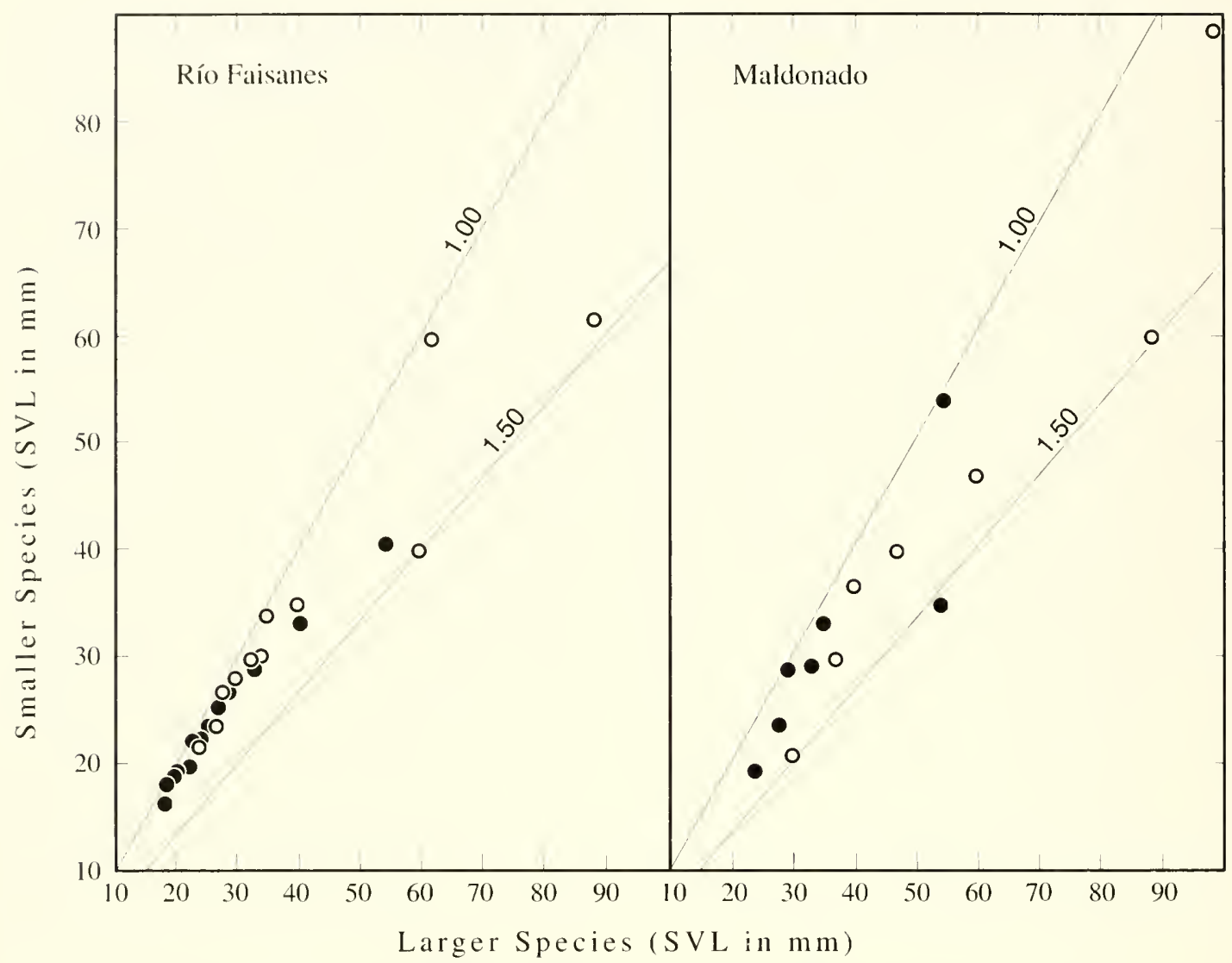

Fig. 57. Ratios of body sizes in succeeding larger species of Eleutherodactylus in two communities in western Ecuador. Solid dots are males; open circles are females.

communities, three (E. achatinus, actites, and walkeri) inhabit clearings and (with E. phoxocephalus and E. pteridophilus) forest-edge situations. Nine other species (E. chalceus, muricatus, nyctophylax, omatissimus, parvillus, surdus, thymalopsoides, unistrigatus, and w-rigrum) also are found at the edge of the forest but range into the interior of the forest. All other species are exclsuively forest inhabitants.

The most obvious microhabitat distinction for nocturnal activity is between the terrestrial and arboreal species. Four large ( $\bar{x}$ SVL oo 47.0-54.2 $\mathrm{mm}$, фо 69.0-98.6 mm) toadlike species ( $E$. anatipes, (momalus, helonotus, and necerus) are strictly terrestrial and usually found on the banks of streams. Adult females of $E$. w-nigrum ( $\bar{x}$ SVL 59.8 $\mathrm{mm})$ are terrestrial. Six other species most com- monly are on low vegetation, but some individuals have been observed on the ground; three of these (E. crenunguis, longirostris, and surdus) are always near streams; two others (E. duellmani and $E$. loustes) usually are in the spray zone of waterfalls, whereas the sixth, E. umistrigatus, is wide ranging. Only four species (E. eremitus, phoxocephalus, scolodiscus, and subsigillatus) are known to occur on vegetation at heights of $4 \mathrm{~m}$ or more; of these, only the latter has been found on low vegetation $(<1$ $\mathrm{m})$. Many arboreal species have been found only, or most commonly, on vegetation along and over streams; these include E. actites, calcarulatus, crenunguis, crucifer, dissimulatus, labiosus, longirostris, luteolateralis, muricatus, nyctophylax, sobetes, surdus, and males of w-nigrum. However, the apparent abundance of these species at, or their 


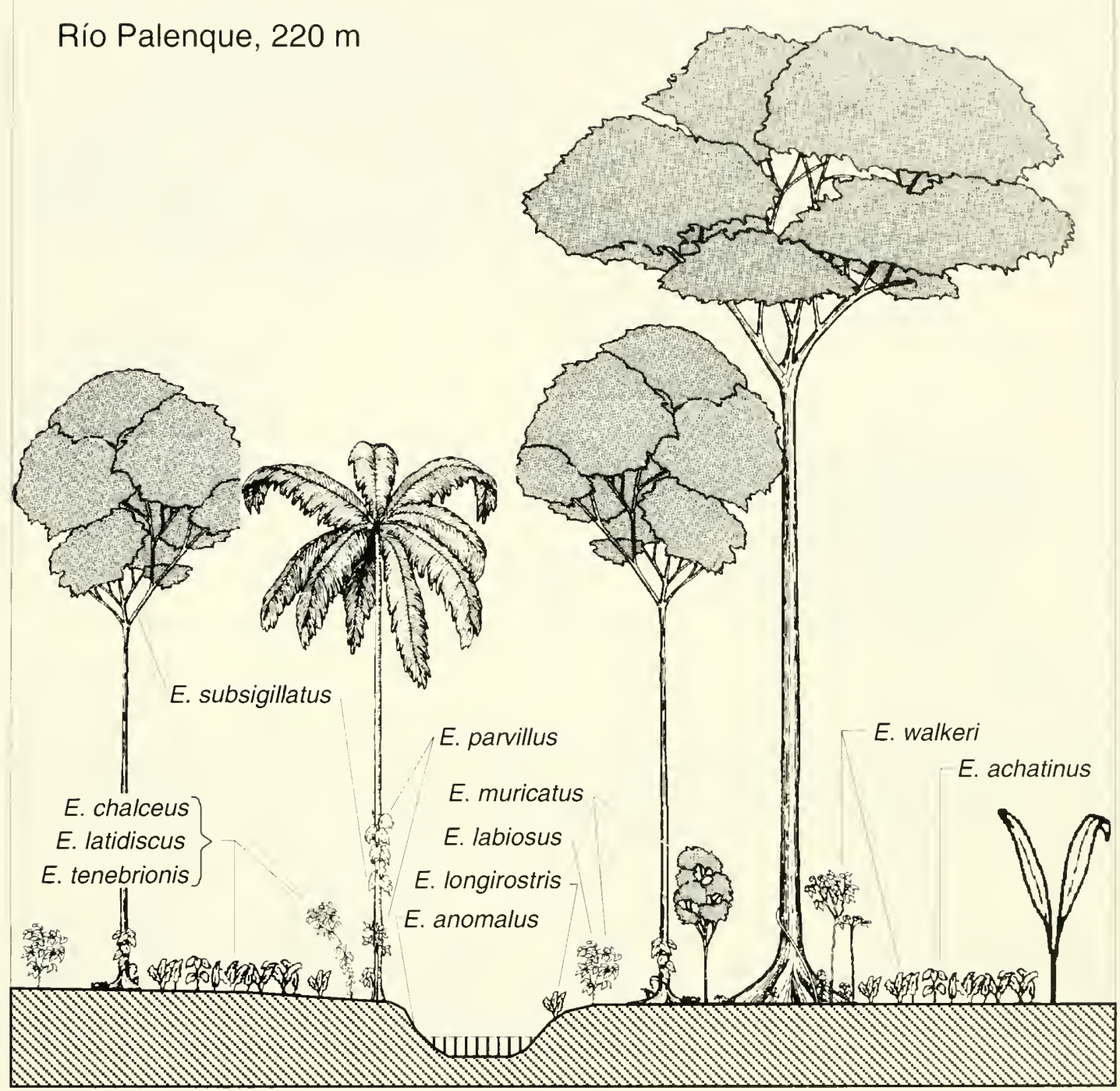

Fig. 58. Nocturnal microhabitats of 11 species of Eleutherodactylus at the Estación Biológica Río Palenque, Provincia Los Ríos, Ecuador.

restriction to, streams may be simply the use of such streams as "trails" by collectors.

Nocturnal observations notwithstanding, our experiences with several species suggest that bromeliads are a microhabitat utilized for diurnal retreats. Especially noteworthy are E. ciucifer in arboreal bromeliads at Tandapi, E. phoxocephalus in arboreal bromeliads at Pilaló, and E. celator in terrestrial bromeliads at La Delicia. Likewise, in dry subtropical areas, E. cajamarcensis is abundant by day in small arboreal bromeliads. The apparent rarity of E. eremitus and, in some places, $E$. subsigillatus may reflect inadequate sampling of bromeliads, especially where they are inaccessible without special equipment.

\section{Discussion}

Our data on the ecology of Eleutherodactylus in western Ecuador have severe limitations and are sufficient solely to generalize and point out areas 


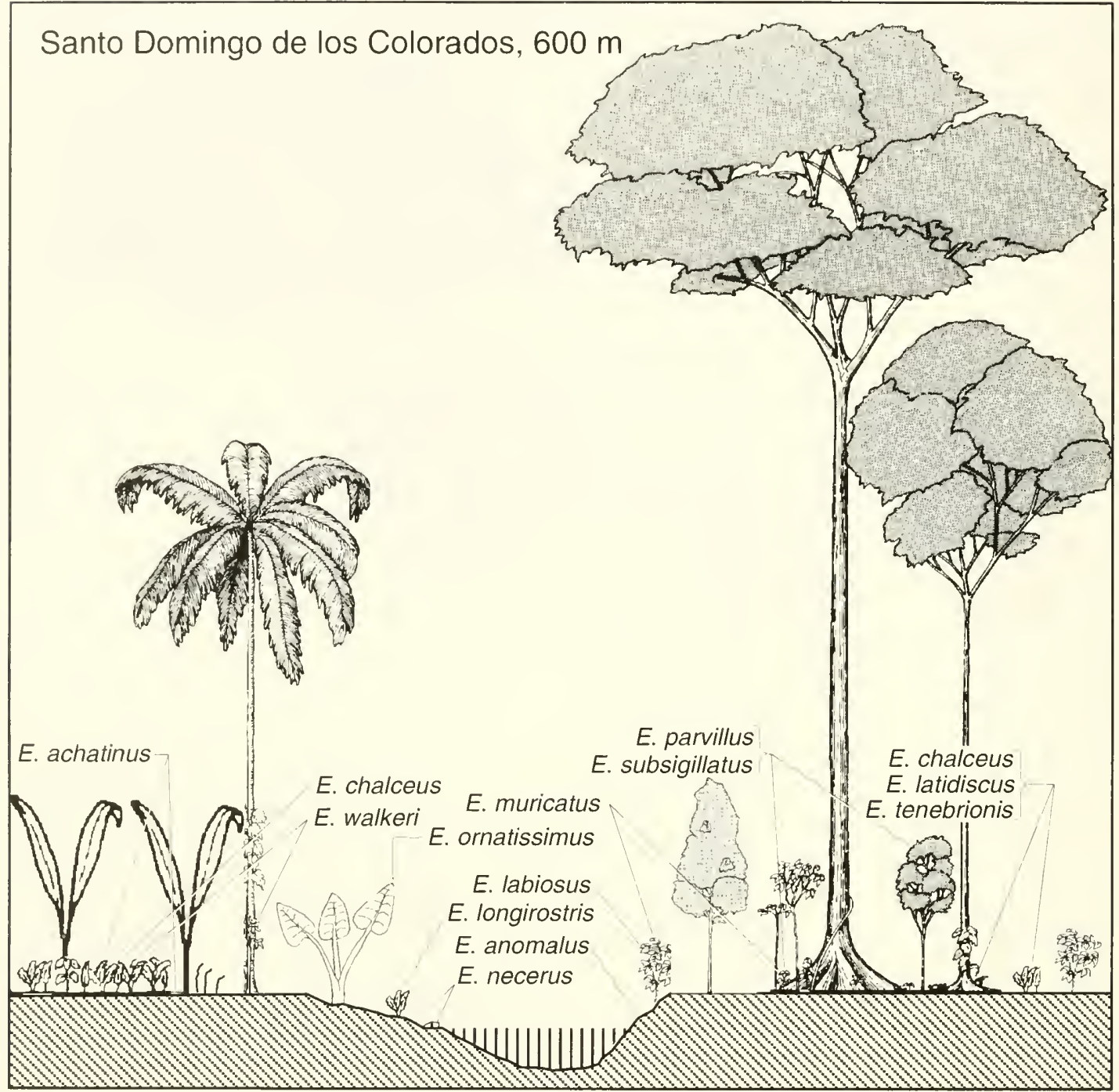

Fig. 59. Nocturnal microhabitats of 13 species of Eleutherodactylus at Santo Domingo de los Colorados. Provincia Pichincha. Ecuador.

for future research. Studies need to be carried out throughout the year (and for 2 or more years) at specific sites in various environments (e.g., lowland tropical rainforest and cloud forest), where different assemblages of species exist. The only such existing studies are those by Duellman (1978) at Santa Cecilia, Ecuador; Schlüter (1984) at Panguana, Peru; Burrowes (1987) at La Planada, Colombia; Heyer et al. (1990) at Boracéia in southeastern Brazil; and Rodríguez (1992) at Cocha Cashu, Peru. All of these studies included
Eleutherodacty/us in analyses of the ecology of anuran faunas; only that by Burrowes (1987) includes species that occur in western Ecuador, and only that by Rodríguez (1992) contains real data on abundance.

A crude estimate of abundance can be obtained by comparing the numbers of museum specimens that exist for each species (Fig. 63). Specimens of the six most abundant species (in descending order-E. achatinus, w'-nigrum, walkeri, longirostris, actites, and phoxocephalus) constitute more than 
Tandapi, $1460 \mathrm{~m}$

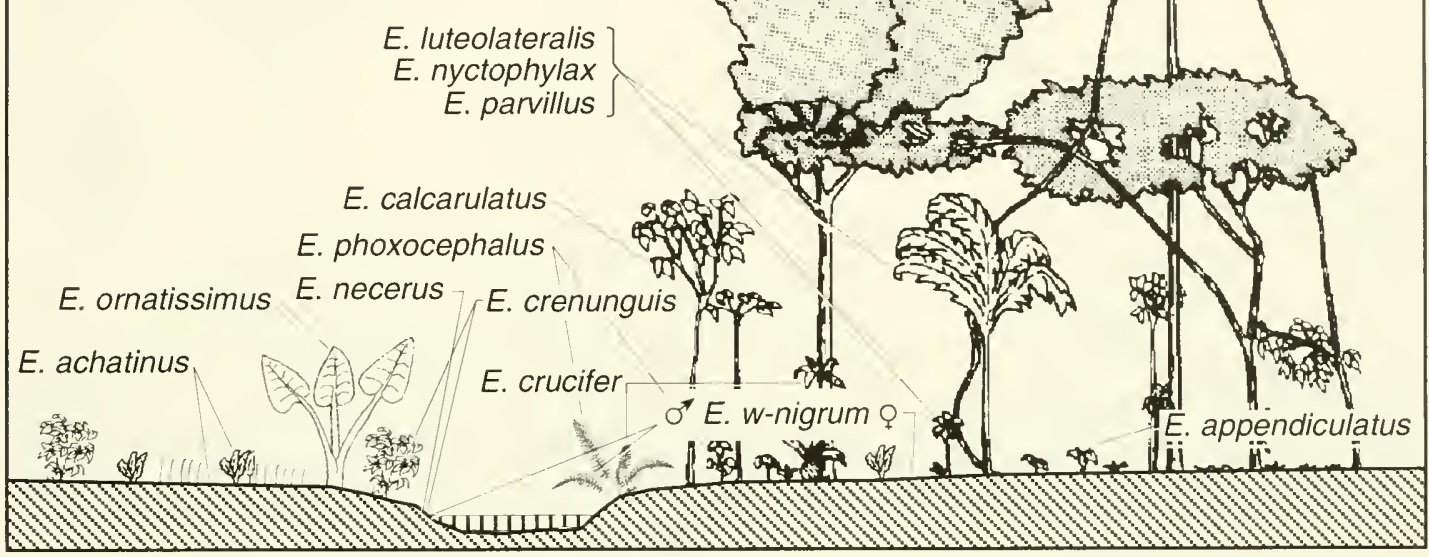

Fig. 60. Nocturnal microhabitats of 12 species of Eleutherodacty/us at Tandapi, Provincia Pichincha, Ecuador.

$50 \%$ of the total. At the low end of the spectrum. four species (E. babax, colomai, helonotus, and sobetes) are represented by only two specimens each and three (E. apiculatus, degener, and hectus) are represented by three specimens each. However. this representation incorporates several biases. First, some species simply are more conspicuous than others; this is especially true of larger species (e.g., E. actites and E. w-nigrum) that inhabit the edge of the forest, where they are more easily detected by eyeshine than smaller species in more secluded situations in the interior of the forest. The six species represented by more than 200 specimens inhabit, but are not restricted to, the forest edge. In the case of species determined to be abundant at a given locality, individuals frequently were not collected during subsequent visits to that locality; thus, the large numbers of these specimens may under-represent the actual abundance of these spe- cies. The apparent rarity of some species, even at localities that have been worked repeatedly, presumably indicates that the species actually does occur in low densities or that it utilizes a microhabitat not usually investigated by collectors. However. differences in densities of some species seem to defy explanation; for example, E. caprifer is abundant in the spray zone of a waterfall at the type locality, but rarely is found in similar microhabitats at other sites.

In the absence of any evidence for interspecific competition, the disparities in relative abundances and rank-abundances of given species in the five communities analyzed are inexplicable. The apparent decline in relative abundance of E. achatinus from the lowland site, Río Palenque (mean annual temperature $24.4^{\circ} \mathrm{C}$ ), to the upland sites, Mindo and Tandapi (mean annual temperatures $16.4^{\circ} \mathrm{C}$ and $15.0^{\circ} \mathrm{C}$, respectively), may reflect the species 


\section{Quebrada Zapadores, 2010 m}

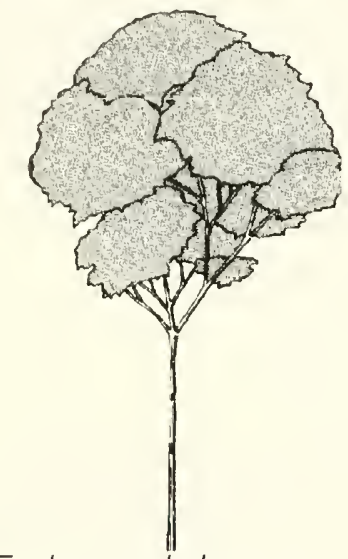

E. phoxocephalus E. duellmani 7

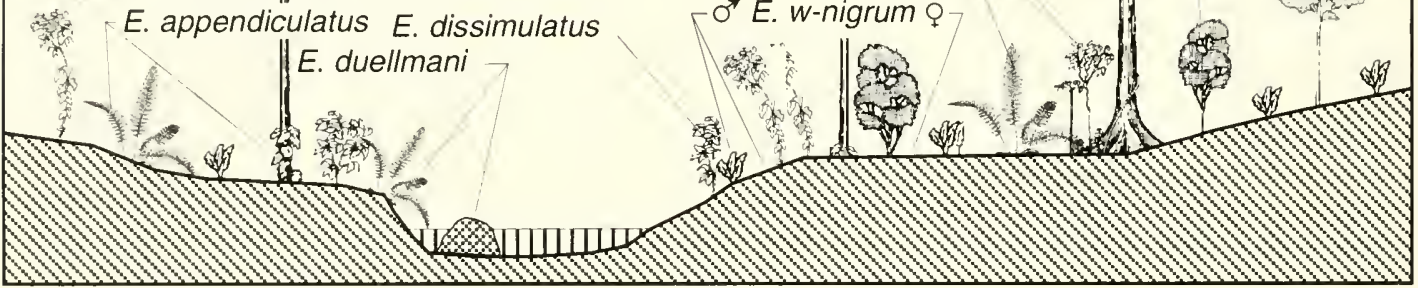

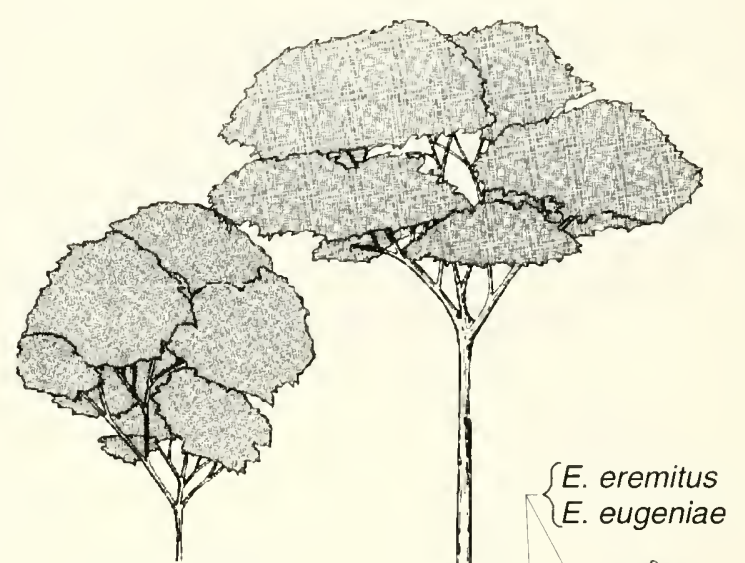

E. sobetes]

E. vertebralis

E. quinquagesimus

$\|$

E. w-nigrum 9

Fig. 61. Nocturnal microhabitats of I0 species of Eleutherodactylus at Quebrada Zapadores, Provincia Pichincha, Ecuador.

having reached the upper limits of its distribution at these upland sites where possibly, it has reached the lower limits of its temperature tolerance. As an effect of low temperatures, the species might require more time to develop mature eggs, thereby reducing the number of times individual females can breed during the year. Similarly, there probably is a negative correlation between temperature and rates of ovarian development (as noted for Eleutherodactylus coqui in Puerto Rico by Townsend and Stewart [1986]), and growth; thus a longer time would be required for individuals to reach sexual maturity. Because there is an inverse relationship between temperature and metabolic activity, suboptimal temperature regimes would affect growth in a species, as well as its ability to capture prey and escape predators (Miller and Zoghby, 1986; Putnam and Bennett, 1981). Any one of these factors, or a combination thereof, may be responsible for lower abundances of E. achatinus at higher elevations.

A completely different situation apparently exists with E. w-nigrum, which is the most abundant species at Tandapi and Quebrada Zapadores but fifth in rank-abundance at Mindo; all three sites are in cloud forest. At Quebrada Zapadores, E. wnigrum is the largest species of Eleutherodactylus, but at Tandapi and Mindo it is barely exceeded in size by E. crenunguis. Eleutherodactylus crenunguis the least abundant species at Tandapi and third in rank-abundance at Mindo, where E. necerus, ninth in rank-abundance, is a much larger species. Eleutherodactylus necertus and adult females of $E$. $w$-nigrum are terrestrial (but the former is exclusively streamside); also, individuals of E. crenunguis sometimes are active on the ground. Possibly in the terrestrial microhabitat, these three species use the same food resources and compete with one another. 


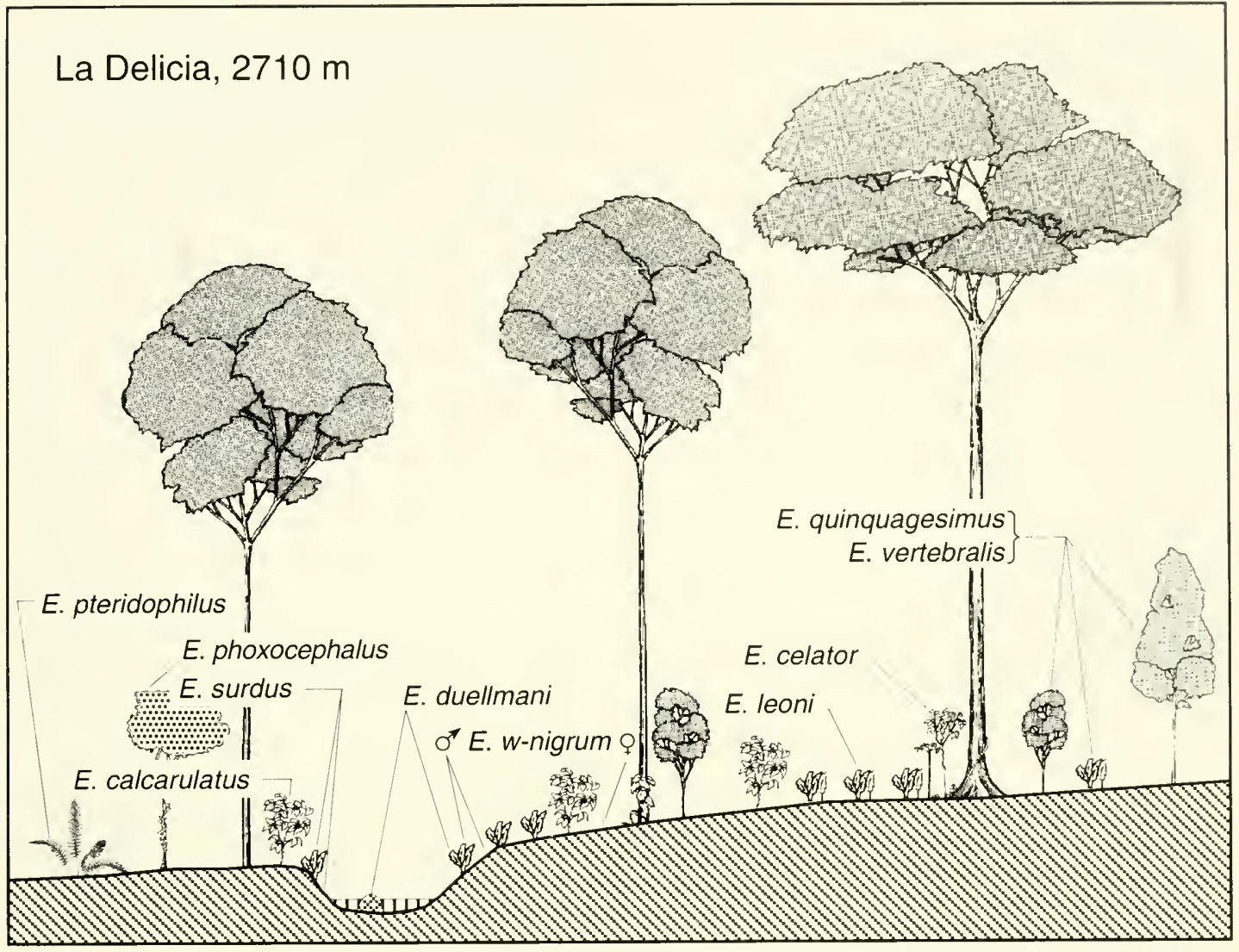

Fig. 62. Nocturnal microhabitats of 10 species of Eleutherodactylus at La Delicia. Provincia Imbabura. Ecuador.

The reversal in relative abundance of $E$. w-nigrum and E. crenunguis at Tandapi and Mindo might have resulted from other factors that differentially influence the abundances of these species at those sites.

Throughout the lowlands and lower cloud forests in western Ecuador, the most obvious correlation of body size of Eleutherodactylus is with terrestrial versus arboreal habits. All 10 nocturnal, terrestrial species (E. anatipes, anomalus, babax, cerastes, helonotus, longirostris, loustes, lymani, necerus, and $w$-nigrum) in these habitats are large ( $\bar{x}$ SVL $९$ 46.7-98.6 mm, $\bar{x}=65.1$ ). In contrast, most arboreal species have SVLs less than $35 \mathrm{~mm}$; only four arboreal species (E. actites, crenunguis, labiosus, and thymalopsoides) have SVLs greater than $50 \mathrm{~mm}$ ( $\bar{x}$ SVL $९$ 50.4-61.9 mm, $\bar{x}=56.1)$. However, the one diurnal species (E. hectus, $\bar{x} \mathrm{SVL}$
○९ $20.7 \mathrm{~mm}$ ) is terrestrial, as are E. leoni ( $\bar{x} \mathrm{SVL}$ Qฺ $21.9 \mathrm{~mm}$; E. myersi group) and E. simonbolivari $(\bar{x}$ SVL ọ $20.6 \mathrm{~mm}$ : E. orestes group) at high elevations in upper cloud forest and subparamo. Thus, within any given assemblage, most species are arboreal and have SVLs of $15-35 \mathrm{~mm}$ in males and $20-45 \mathrm{~mm}$ in females, and considerable overlap in body sizes exists among these arboreal species within assemblages (Fig. 55).

The ratios of body sizes of species making up different communities do not conform to Hutchinson's (1959) predictions. The results conform to those obtained for a community of primarily arboreal species of Eleutherodactylus at Santa Cecilia, Ecuador (Duellman, 1978) and for Eleutherodactylus in the southern Andes of Ecuador (Lynch, 1979a). The ratios of all three of these studies are less disparate than those for members of 


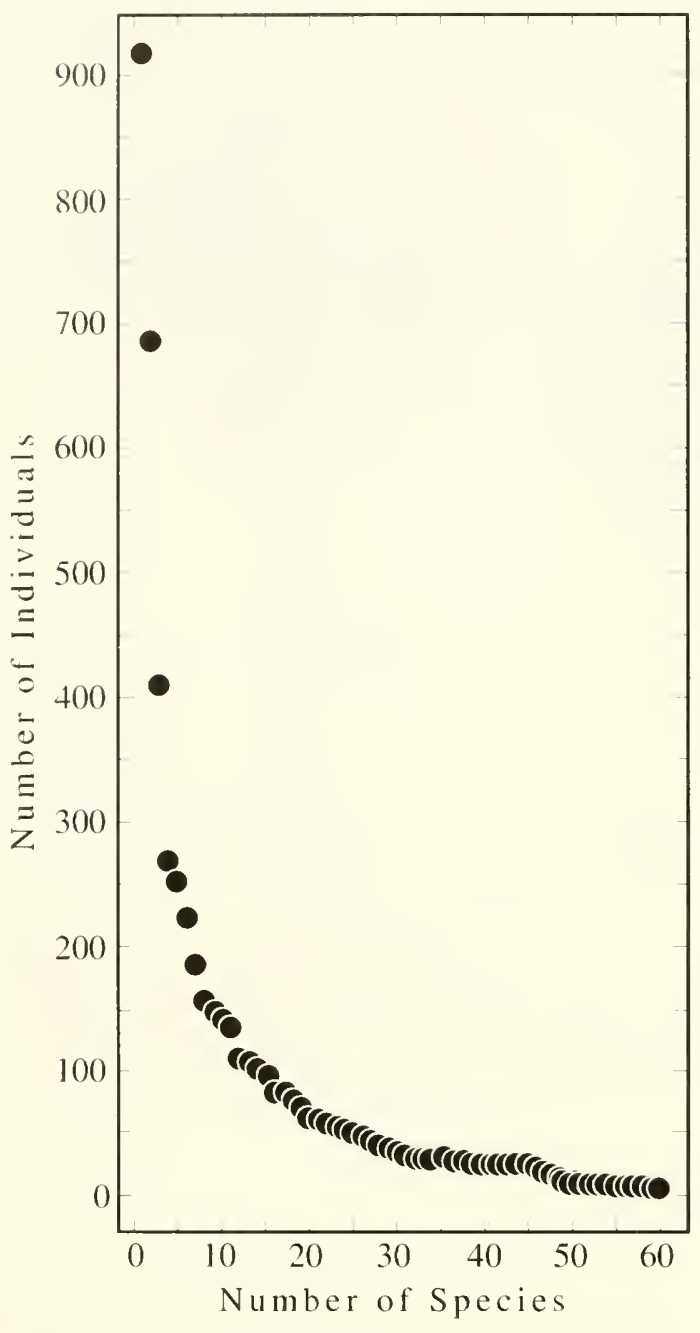

Fig. 63. Relative abundance of 61 species of Eleutherodactylus in western Ecuador based on numbers of specimens collected.

the Eleutherodactylus "fitzingeri group" in the Chocoan region (Lynch and Myers, 1983). This apparent discrepancy probably is because Lynch and Myers compared ratios among species throughout the region and, thereby, included many allopatric species; furthermore, they were using data only on a small segment of the entire Eleutherodactylus fauna in the region.

Diets of neotropical frogs are poorly known, and those studies in which analyses of stomach contents were undertaken (e.g., Duellman, 1978) have included identifications of prey only to the ordinal or familial level. Such crude distinctions probably do not reflect accurately prey discrimination by the lrogs. With few exceptions (none known in western Ecuador), Eleutherodactylus are insectivorous generalists that employ a sit-and-wait feeding strategy.

Generally, there is a positive correlation between body size and prey size (Toft, 1985), but this generalization has limited application to frogs such as Eleutherodactylus, most of which seem to be feeding generalists. True, the generalization applies to the maximum size of prey that can be captured and ingested, but frogs do not necessarily forage only on maximum-size prey. For example, the large, predaceous frog Ceratophrys cornuta is capable of consuming large orthopterans and small vertebrates; these make up $75 \%$ of the volume of prey eaten, but ants constitute $70 \%$ of the prey items consumed (Duellman and Lizana, 1994). Small arthropods compose the bulk of diets of many species of Eleutherodactylus, including all large, broad-headed taxa, dissected by JDL.

Moreover, juveniles of larger species of Eleutherodactylus grow through size ranges of adults of smaller species; these juveniles would be expected to forage on prey of the same size being eaten by adults of smaller species. The common occurrence of juveniles of some arboreal species (e.g., E. achatimus and E. walkeri) in the leaf litter on the forest floor may be indicative of a greater abundance of appropriate-sized prey (ants, termites, and small beetles) on the ground than on the bushes. Such habitat segregation by age and size would eliminate potential competition for food by juveniles and adults.

Within given microhabitats, broadly sympatric species usually occur together. Microhabitat specialists tend to be segregated geographically. For example, three species that inhabit seepages in the upper cloud forest (E. duellmani, hamiotae, and surdus) do not occur sympatrically.

Of course, Eleutherodactylus exist in communities containing other species of frogs, and consideration of resource utilization must include these species. If we view most of the species of Eleutherodactylus as small members of a nocturnal-arboreal-insectivore guild. most other members of that guild in the lowlands and Andean slopes 
in Ecuador are centrolenids. Duellman and Burrowes (1989) identified 20 species of centrolenids on the Pacific versant of Ecuador and southern Colombia. At lower elevations $(<1500$ m), small to moderate-sized species of Hyla (e.g., H. alytolylax and $H$. carnifex ) also are members of that guild. However, because of their breeding habits, the hylids and centrolenids are nearly always collected in the immediate vicinity of streams. a subarea of the forest frequented by many species of Eleutherodactylus.

Because of their similarities in size, structure. and microhabitat utilization, we suggest that several pairs of species are ecological replacements either altitudinally or latitudinally. The pairs $E$. labiosus-crenunguis, E. latidiscus-laticlavius, $E$. nyctophylax-engeniae, and E. walkeri-luteolateralis are examples of apparent low elevationhigh elevation replacement. The pairs E. ocellatus- crenunguis and E. vertebralis-truebae are examples of apparent north-south latitudinal replacement. Not all instances of ecogeographic replacement are self evident. For example, E. w-nigrum is a large, conspicuous, and usually abundant species throughout the upper cloud forest. However, within its latitudinal range, the species is absent at Pilaló, Provincia Cotopaxi, where apparently it is replaced by $E$. actites, which is known only from that area.

Until far more diverse and precise information is available, most explanations of ecological associations of Eleutherodactylus in western Ecuador must be considered as highly speculative. Now that the taxonomy of these frogs has been studied thoroughly and the species can be identified with more confidence than was possible in the past, we hope that detailed ecological studies will be undertaken to address the many fascinating aspects of the ecology of Eleutherodactylus in western Ecuador.

\section{BIOGEOGRAPHY}

Assuming that most of the species of Eleutherodactylus in western Ecuador are now known and that a reasonable perception of their geographic ranges and microhabitats exists, we attempt to synthesize the available data on biogeography of these frogs. Although we are concerned principally with western Ecuador, data from extralimital regions, especially Chocoan Colombia, have been included.

\section{Patterns of Distribution}

Data used for the biogeographic synthesis include (1) species groups, as defined in the section Subgenera and Species Groups, (2) body size, (3) microhabitat, (4) macrohabitat (bioclimatic regimes, as defined in the section on Western Ecuador), (5) altitudinal range. (5) latitudinal distribution, and (6) area of geographical distribution (Appendix IV), together with the 681 locality records for 61 species (Appendix I). For purposes of this synthesis, we use mean SVL of females for body size. Microhabitat is defined as the usual place of activity: all species except $E$. hectus are nocturnal.

Bioclimatic regimes.-The distribution of species in the six bioclimatic regimes inhabited by
Eleutherodactylus in western Ecuador is highly uneven (Table 10). Also, the distribution of collecting sites is uneven; the large number of sites in the humid subtropical and humid temperate regimes reflect the accessibility of these sites and collectors proclivities for spending more time at sites where frogs are common (perhaps also the higher comfort levels of doing field work in the subtropics. as opposed to the hotter lowlands and the colder highlands).

Only five species are known from the dry tropical regime; E. achatinus is represented by 11 records. E. longirostris by two, and the others by one each. No species is restricted to that regime: instead, their occurrence in the dry tropics is peripheral to their distributions in the humid tropics. Three of the species are in the E. unistrigatus group; one is in the E. conspicillatus group. and one in the E. fitzingeri group. The mean body size is $37.0 \mathrm{~mm}(21.6 \mathrm{~mm}$ in E. walkeri to $48.6 \mathrm{~mm}$ in E. (ongirostris). The latter is a terrestrial streamside species; the other four are arboreal and have a mean body size of $34.2 \mathrm{~mm}$ (21.6 $\mathrm{mm}$ in E. walkeri to $42.3 \mathrm{~mm}$ in E. latidiscus).

Three of the five species occurring in the dry tropical regime are among the seven species in the dry subtropical regime, which again seems to be a 
peripheral habitat for species that are more widespread in other environments. However, in western Ecuador, E. lymani occurs only in the dry subtropics, but elsewhere it also occurs in the dry temperate regime. Three of the species are in the $E$. conspicillatus group, three in the E. unistrigatus group, and one in the E. diastema group. Body size ranges from $21.6 \mathrm{~mm}$ in E. walkeri to $60.2 \mathrm{~mm}$ in E. lymani $(\bar{x}=38.2 \mathrm{~mm})$. Only E. lymani is terrestrial. Among the six arboreal species, body size ranges from $21.6 \mathrm{~mm}$ in E. walkeri to $59.8 \mathrm{~mm}$ in E. w-nigrum $(\bar{x}=34.6)$.

Rather surprisingly, only 15 species have been recorded from the humid tropical regime; none of these is restricted to the regime. These species belong to eight groups, of which the E. unistrigatus group is represented by eight species; the $E$. cerasinus and E. conspicillatus groups have two species each, whereas the E. anomalus, diastema, and fitzingeri groups have one species each. Size ranges from $21.6 \mathrm{~mm}$ in E. walkeri to $85.4 \mathrm{~mm}$ in E. anomalus $(\bar{x}=37.4)$. Only two species are terrestrial-E. anomalus (SVL $85.4 \mathrm{~mm}$ ) and $E$. longirostris (SVL $48.2 \mathrm{~mm}$ ); both are streamside inhabitants. The mean size for the 13 arboreal species is $32.9 \mathrm{~mm}$ (21.6 $\mathrm{mm}$ in E. walkeri to 50.4 $\mathrm{mm}$ in E. labiosus).

By far, the greatest number of species (46, $75.4 \%$ ) inhabits the humid subtropical regime; 12 species $(26.0 \%$ of the total) are restricted to this regime. All species groups, except the E. curtipes group, are represented in this assemblage of species. The range in size is from $20.7 \mathrm{~mm}$ in E. hectus and E. scolodiscus to $98.6 \mathrm{~mm}$ in $E$. anatipes $(\bar{x}=$
40.2). Nine species are terrestrial; the mean SVL in these is $61.3 \mathrm{~mm}(20.7 \mathrm{~mm}$ in the diurnal $E$. lectus to $98.6 \mathrm{~mm}$ in $E$. (inatipes). Five of the terrestrial species are streamside dwellers, and these generally are large frogs; the range in size is $46.7 \mathrm{~mm}$ in E. loustes to $98.6 \mathrm{~mm}$ in E. anatipes $(\bar{x}=73.4)$. Most species (34) are arboreal; these range in size from $20.7 \mathrm{~mm}$ in $E$. scolodiscus to $61.9 \mathrm{~mm}$ in $E$. crenunguis $(\bar{x}=35.0)$. Three arboreal species-E. caprifer $(42.7 \mathrm{~mm})$, E. duellmani $(41.8 \mathrm{~mm})$, and E. surdus $(45.8 \mathrm{~mm})$ - $\mathrm{seem}$ to be restricted to spray zones of waterfalls.

The second largest assemblage of species (33, $54.1 \%$ ) is in the humid temperate regime, but only seven species groups are represented-cerasimus (1 species), conspicillatus (3), curtipes (1), devillei (4), myersi (3), surdus (5) and unistrigatus (17). The total range in size is from $21.6 \mathrm{~mm}$ in $E$. pyrrhomerus to $59.8 \mathrm{~mm}$ in $E$. w-nigrum $(\bar{x}=34.5)$. Three species are terrestrial and have sizes of 21.9 (E. leoni) to $36.0 \mathrm{~mm}$ (E. hamiotae); the latter is a streamside species. The mean body size of 30 arboreal species is $35.5 \mathrm{~mm}(21.6 \mathrm{~mm}$ in $E$. pyrrhomerus to $59.8 \mathrm{~mm}$ in E. w-nigrum); two of these species-E. duellmani $(41.8 \mathrm{~mm})$ and $E$. surdus $(45.8 \mathrm{~mm})$-occur only in the spray zones of waterfalls.

Only eight species inhabit the cold humid subtemperate regime. Six species groups are represented-curtipes (1 species), devillei (1), myersi (2), orestes (1), surdus (1), and umistrigatus (2). Body size ranges from $20.6 \mathrm{~mm}$ in E simonbolivari to $45.8 \mathrm{~mm}$ in $E$. surdus $(\bar{x}=31.0)$. Three terrestrial species have sizes of $20.6 \mathrm{~mm}$ in E. simonbolivari

Table 10. Distribution of species of Eleuherodactylus in bioclimatic regimes in western Ecuador.

Bioclimatic Regime

\begin{tabular}{|c|c|c|c|c|c|c|c|}
\hline Parameter & $\begin{array}{l}\text { Dry } \\
\text { tropical }\end{array}$ & $\begin{array}{c}\text { Dry } \\
\text { subtropical }\end{array}$ & $\begin{array}{l}\text { Humid } \\
\text { tropical }\end{array}$ & $\begin{array}{c}\text { Humid } \\
\text { subtropical }\end{array}$ & $\begin{array}{l}\text { Humid } \\
\text { temperate }\end{array}$ & $\begin{array}{c}\text { Humid } \\
\text { subtemperate }\end{array}$ & Total \\
\hline cality records & 16 & 28 & 87 & 363 & 167 & 20 & 681 \\
\hline rcent of records & 2.3 & 4.1 & 12.8 & 53.3 & 24.5 & 3.0 & 100 \\
\hline mber of species & 5 & 7 & 15 & 46 & 33 & 8 & 61 \\
\hline rcent of species & 8.2 & 11.5 & 24.5 & 75.4 & 54.1 & 13.1 & 一 \\
\hline demic species & 0 & 1 & 0 & 12 & 7 & 1 & - \\
\hline rcent endemic & 0.0 & 14.3 & 0.0 & 26.0 & 21.2 & 12.5 & - \\
\hline
\end{tabular}


to $33.5 \mathrm{~mm}$ in E. gentryi $(\bar{x}=25.3)$. Body sizes are noticeably larger in the five arboreal species, in which the mean SVL is $34.4 \mathrm{~mm}(21.6 \mathrm{~mm}$ in $E$. pyrrhomerus to $45.8 \mathrm{~mm}$ in E. surdus).

Some patterns are evident with respect to species groups. Of the three species groups of the subgenus Craugastor; the E. anomalus and $E$. bufoniformis groups are restricted to the humid tropical and humid subtropical regimes, whereas the sole member of the E. fitzingeri group in the region (E. longirostris) also ventures into riparian situations in the dry tropical regime. Of the 12 species groups in the subgenus Eleutherodactylus, two (E. conspicillatus and E. unistrigatus) encompass all six regimes. The E. cerasinus and $E$. diastema groups are essentially restricted to the humid tropical and humid subtropical regimes; one record of a member of the $E$. diastema group ( $E$. gularis) is from the dry subtropical regime, and one record for the E. cerasinus group is from the humid temperate regime. All members of the E. dolops, loustes, and sulcatus groups are confined to the humid subtropical regime. Of the other five groups, the $E$. devillei, myersi, and surdus groups are primarily inhabitants of the humid temperate and humid subtemperate regimes, but some members of all three groups enter the humid tropical regime. The E. curtipes and E. orestes groups are distributed primarily in the humid subtemperate regime.

ln general, specific fidelity to bioclimatic regimes is rather low; the highest amount of endemism $(26.0 \%)$ is in the humid subtropical regime, followed by the humid temperate regime (21.2\%), dry subtropical regime $(14.3 \%)$, and the humid subtemperate regime ( $12.5 \%)$; the dry tropical and humid tropical regimes lack endemics. The greatest number of shared species (22) is between the humid subtropical and humid temperate regimes, and 14 species are shared by the humid tropical and humid subtropical regimes. Although fewer numbers of species are shared by other regimes, the highest coefficient of biogeographic resemblance is between the dry tropical and dry subtropical regimes (Table 11).

In five of the regimes, arboreal species account for more than $80 \%$ of the eleutherodactylines in the regime; the exception is the humid subtemperate regime, where only $62.5 \%$ of the species are arboreal, and most of these are most commonly found by day under stones. Only one species, E. longirostris, seems to be associated with streams in the dry regimes, and only one, E. surdus, does so in the humid subtemperate regime. Terrestrial species associated with streams and arboreal species associated with spray zones of waterfalls are most numerous in the humid tropical, subtropical, and temperate regimes, where they account for $20.0 \%$. $17.4 \%$, and $9.6 \%$ of the species, respectively.

Little variation in mean female body size is evident among arboreal species in the six regimes. Terrestrial species generally are larger than arboreal species in each regime, except in the humid temperate and subtemperate regimes, where terrestrial species are smaller. This is owing to the fact that terrestrial species in these regimes are members of the E. myersi group, all of which are small frogs. Variation in body size is discussed more fully in a following section on altitudinal distribution.

Table 11. Distribution of species of Eleutherodactylus in six bioclimatic regimes in western Ecuador. Abbreviations in headings to columns correspond to regimes in first column. The number of species in each regime is shown in boldface in the common cell; the numbers of species that are in common to two regimes are shown in the upper right, and the coefficient of biogeographic resemblance are in italics in the lower left.

\begin{tabular}{lrrrrrr}
\hline \multicolumn{1}{c}{ Regime } & DTR & DST & HTR & HST & HTE & HSE \\
\hline Dry tropical (DTR) & $\mathbf{5}$ & 4 & 5 & 6 & 1 & 0 \\
Dry subtropical (DST) & 0.67 & $\mathbf{7}$ & 5 & 5 & 1 & 0 \\
Humid tropical (HTR) & 0.50 & 0.45 & $\mathbf{1 5}$ & 14 & 2 & 0 \\
Humid subtropical (HST) & 0.24 & 0.19 & 0.46 & $\mathbf{4 6}$ & 22 & 2 \\
Humid temperate (HTE) & 0.05 & 0.05 & 0.08 & 0.56 & $\mathbf{3 3}$ & 6 \\
Humid subtemperate (HSE) & 0.00 & 0.00 & 0.00 & 0.07 & 0.31 & $\mathbf{8}$ \\
\hline \hline
\end{tabular}


Latitudinal distribution.- The eleutherodactyline fauna in western Ecuador represents the southern terminus of the rich fauna on the Pacific lowlands and the western slopes of the Cordillera Occidental in Colombia (hereinafter referred to as the Chocoan fauna). The latitudinal gradient from humid tropical forest to dry tropical forest in the lowlands of western Ecuador and the lower, drier mountains in the Huancabamba Depression in southern Ecuador are reflected in the diminution of species south of $1^{\circ} \mathrm{S}$ Lat. in the lowlands and in the highlands (Fig. 64).

Among the species of Eleutherodactylus inhabiting the Pacific versant of South America, none has a distribution that includes both Colombia and Peru. Three species in western Ecuador $(E$. cajamarcensis, lymani, and phoxocephahus) range into northern Peru. Thirty-two species are endemic to western Ecuador. Another 24 species of Eleutherodactylus reach the southern limits of their distributions in western Ecuador. Of these, two species primarily distributed at elevations less than $1000 \mathrm{~m}$ (E. achatinus and E. longirostris) range northward into Panama. Fourteen other species range for varying distances northward into Colombia: eight of these (E. anatipes, anomalus, caprifer: chalceus, gularis, labiosus, latidiscus, and subsigillatus) are strictly Chocoan and have their major distributions on the lowlands and lower $(<1000 \mathrm{~m})$ slopes of the Cordillera Occidental of Colombia. Three other species, E. babax, cerastes, and ocellatus, are primarily Chocoan at intermediate elevations (1200-1800 m), and E. duellmani is Chocoan at higher elevations (1500-2700 m). Ten species (E. apiculatus, appendiculatus, colomai, degener, eremitus, hectus, laticlavins, lonstes, quinquagesimus, and scolodiscus) known from intermediate elevations in Ecuador barely range into Colombia; they are known there only from La Planada $\left(1^{\circ} 10^{\prime} \mathrm{N}, 1780 \mathrm{~m}\right)$ and/or slightly lower elevations on the Pacific slopes of the Cordillera Occidental. Two other species, E. unistrigatus and E. w-nigrum, range northward at elevations of more than $2000 \mathrm{~m}$ into various ranges of the Andes of Colombia. One other high-Andean species, E. leoni, is not yet known from the western slopes of the Andes in Colombia, but this species also occurs in the Cordillera Oriental of Ecuador and Colombia (Lynch and Duellman. 1980).
Among the 32 species endemic to western Ecuador, 25 are restricted to the area within one degree of the equator; however, except for La Planada, the lrog fauna of Departamento Nariño in soutliwestern Colombia has been poorly sampled. One of these species, E. rosadoi, also occurs on Isla Gorgona off the coast of Colombia, but it is unknown from the mainland of Colombia. Of these 27 species, nine (e.g.. E. muricatus, ormatissimus, and tenebrionis) inhabit, but are not restricted to, lowlands below $1000 \mathrm{~m}$. Of the 18 species that are distributed solely above $1000 \mathrm{~m}$, nine are at elevations above $1500 \mathrm{~m}$, and three of those do not descend below $2000 \mathrm{~m}$. Of the other seven species endemic to western Ecuador, only E. walkeri is restricted to the lowlands. where it ranges to $3^{\circ} 43^{\prime}$ S Lat. Two other species, E. crucifer and E. parvillus, are distributed primarily at intermediate elevations; the former ranges to $1^{\circ} 16^{\prime} \mathrm{S}$ Lat. and the latter to $2^{\circ} 34^{\prime} \mathrm{S}$ Lat. The other four species $(E$. pyrrhomerus, ruidus, simonbolivari, and truebae) occur only at elevations above $2000 \mathrm{~m}$ south of the Equator.

Altitudinal distribution.- The great amount of physical relief in western Ecuador provides opportunities for considerable altitudinal distribution (Figs. 2, 3). Records for species of Eleutherodactylus in western Ecuador range in elevation from 20 to $3400 \mathrm{~m}$. Eleutherodactylus wnigrum has the greatest elevational range (800$3200=2400 \mathrm{~m}$ ), whereas five species are known from a single elevation (Fig. 65). Fifteen species that have their lowest limits below $500 \mathrm{~m}$ have elevational distributions of 520-1780 $\mathrm{m}(\bar{x}=1067)$, and nine species that have their highest limits above $3000 \mathrm{~m}$ have elevational distributions of $300-2400 \mathrm{~m}$ $(\bar{x}=1095)$; even by removing the widespread $E . w$ nigrum from the latter group, the distributions are $300-1640 \mathrm{~m}(\bar{x}=932)$. Twenty-three inhabitants of cloud forest having the limits of their distributions between $1000 \mathrm{~m}$ and $3000 \mathrm{~m}$ have elevational distributions of $20-1560 \mathrm{~m}(\bar{x}=816)$; four other species in this elevational range are known only from one locality. Thus, it seems that species that range into the lower elevations have greater altitudinal distributions than those at the highest elevations, which in turn have greater elevational distributions than those species restricted to intermediate elevations. 


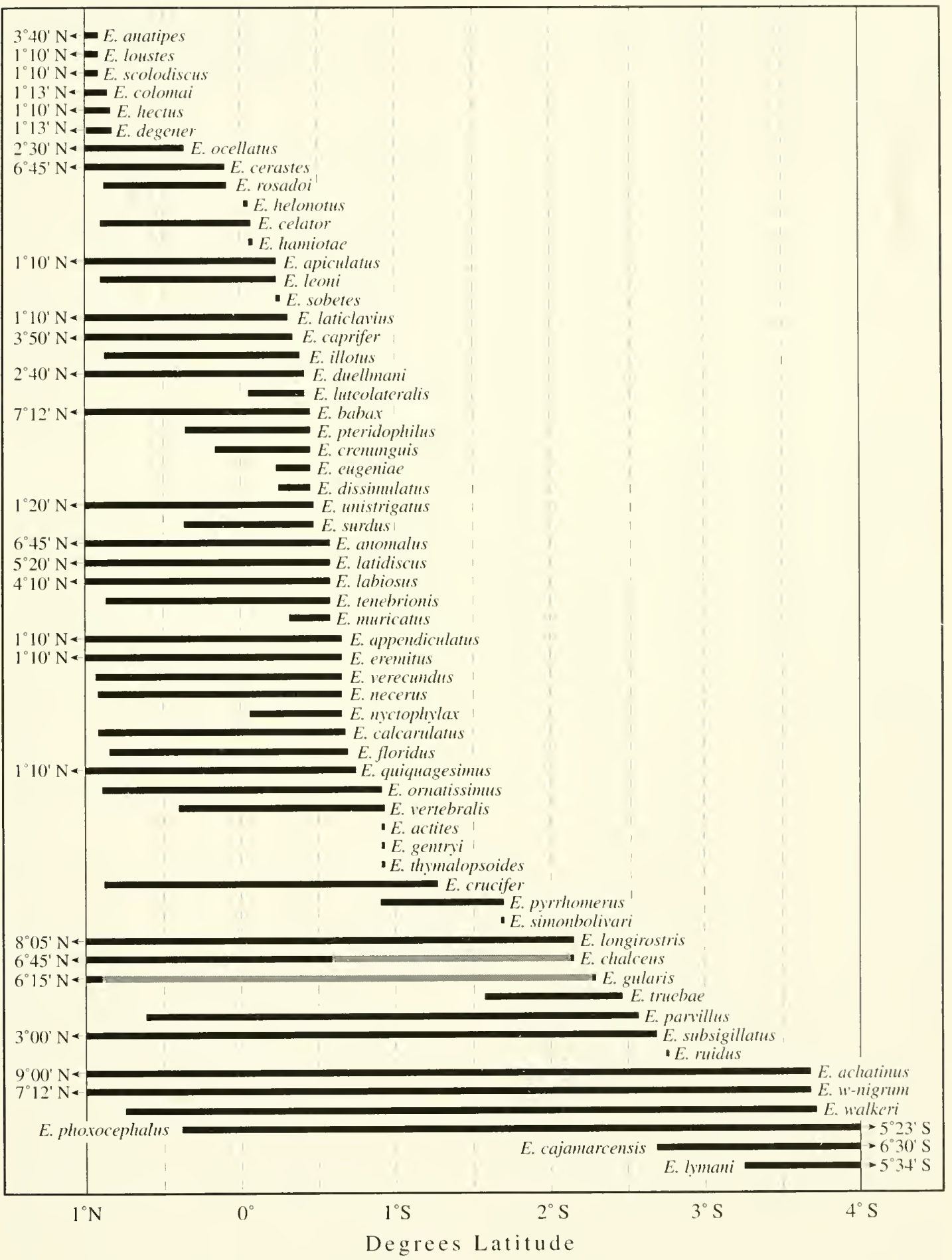

Fig. 64. Latitudinal distribution of species of Eleutherodactylus in western Ecuador. Shaded hars indicate major discontinuities in ranges. 
Upon examining altitudinal distributions by 100$m$ increments, the greatest concentration of species is between $1200 \mathrm{~m}$ and $2200 \mathrm{~m}$, and 28 species occur at elevations of $1800-1900 \mathrm{~m}$ (Fig. 66). Only 10 species occur below $200 \mathrm{~m}$, and an equal number occur at, or above, $3000 \mathrm{~m}$.

Mean body sizes are highest between $500 \mathrm{~m}$ and $1500 \mathrm{~m}$; this is diminished somewhat if the four species of the subgenus Crargastor are eliminated (Table 12). In that case, the range of mean body sizes of frogs of the subgenus Eleutherodactylus in 500 -m elevational increments varies only from $34.5-37.3 \mathrm{~mm}$. Thus, the somewhat larger mean body sizes at lower elevations are dictated by the presence of large species of the subgenus Craugastor:

Throughout the elevational range of the genus in western Ecuador, most species are arboreal (Table 13). However, only $50 \%$ of the species at elevations above $3000 \mathrm{~m}$ are arboreal; the highest percentage of terrestrial species $(37.5 \%)$ is in the high Andes. Only five species are terrestrial streamside inhabitants; three of these (E. anatipes, anomalus, and longirostris) are members of the subgenus Craugastor and occur only at elevations below $1500 \mathrm{~m}$. Other terrestrial streamside species include E. loustes (E. lonstes group) that is known from 1200-1410 $\mathrm{m}$ and E. hamiotae (E. surdus group) that is known only from $2140 \mathrm{~m}$. Of the three species that are arboreal in the spray zones of waterfalls, E. caprifer (E. conspicillatus group) is confined to elevations below $1000 \mathrm{~m}$, whereas the other two species (E. duellmani and E. surdus) are members of the E. surclus group and do not descend below $1500 \mathrm{~m}$.

Different patterns of altitudinal distribution are evident among species groups of Elentherodactylus in western Ecuador, although members of the $E$. umistrigatus group ( 27 species) and E. conspicillatus group ( 6 species) extend throughout the elevational range (Table 14). The four members of the subgenus Craugastor (E. anomalus, bufoniformis, and fitzingeri groups) are distributed primarily below $1500 \mathrm{~m}$, but E. necerus (E. bufoniformis group) ascends to $1540 \mathrm{~m}$. Likewise, members of the $E$. cerasimus and E. diastema groups primarily occur at elevations of less than $2000 \mathrm{~m}$. However, one member of the E. cerasinus group (E. crenunguis) is restricted to intermediate elevations of 800-1640 $\mathrm{m}$. whereas another member (E. ocellatus) occurs at elevations of $1255-2560 \mathrm{~m}$. The two species in the E. sulcatus group occur at lower intermediate elevations-E. cerastes at 500-1200 $\mathrm{m}$ and $E$. helonotus at $1410 \mathrm{~m}$. Each member of the E. dolops and E. loustes groups is restricted to intermediate elevations-E. habax at $1550-1780 \mathrm{~m}$ and E. loustes at $1200-1410 \mathrm{~m}$, respectively. Five species groups are restricted to higher elevations. Of these, $E$. gentryi (E. curtipes group) is distributed at 2850 $3380 \mathrm{~m}$. Of the four species in the E. devillei group, only two descend to elevations below $1500-E$. appendiculatus to $1460 \mathrm{~m}$ and E. quinquagesimus to $1410 \mathrm{~m}$. Two species in the E. myersi group are restricted to intermediate elevations, whereas the other two species occur primarily at elevations in excess of $2000 \mathrm{~m}$. The four members of the $E$. surdus group range from 1550 to $3190 \mathrm{~m}$, and the sole member of the E. orestes group (E. simonbolivari) occurs at elevations of $3000-3300 \mathrm{~m}$.

Trans-Andean distributions.-Three species that occur on the western slopes of the Andes in Ecuador also inhabit the Amazonian slopes in Ecuador and Colombia. Eleutherodactylus leoni occurs at elevations of 1960-3400 $\mathrm{m}$ on the western slopes and at elevations of $2540-2700 \mathrm{~m}$ on the Amazonian slopes (Lynch and Duellman, 1980). The ubiquitous $E$. w-nigrum occurs at elevations of $800-3200 \mathrm{~m}$ on the western slopes and at elevations of 1100-2540 m on the Amazonian slopes of Ecuador and also ranges far northward into Colombia. Eleutherodactylus unistrigatus primarily inhabits inter-Andean valleys, but apparently isolated populations exist at elevations as low as 2400 $\mathrm{m}$ on the western slopes of the Andes and at 2700 $\mathrm{m}$ on the Amazonian slopes, where also a contiguous inter-Andean population descends the Pastaza Trench to an elevation of $1800 \mathrm{~m}$.

Size of distributions. - Determination of areas of distribution was accomplished by measuring the area of the distribution of a species on a map by closely encircling peripheral localities. Although this method assumes a continuous distribution, it is a repeatable method. For species known from only one locality, the area was calculated as $10 \mathrm{~km}^{2}$; for those known from only two localities, the distance between the localities was measured, and a breadth 
1.111!1]OCHOH!! 93

onqया.11:3

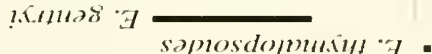

snp!nt.

shidullutid :I

ग1) $101111174=$

!llod :3

$\operatorname{saldog} \cdot 3$

suptydaroxoud 3

s?

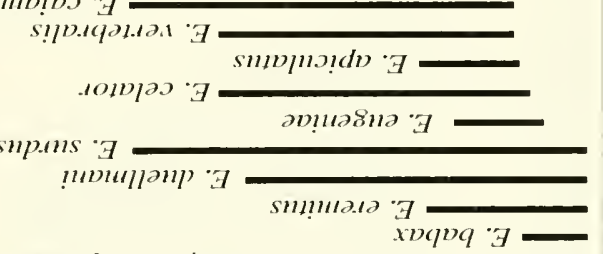

sm!!ydop!.1ว1d'] $x v q v 9 \cdot 3$

sninlno? puaddv :

s ग11130 :3

smuns $28 \mathrm{mb}$ bu!nb

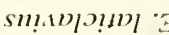
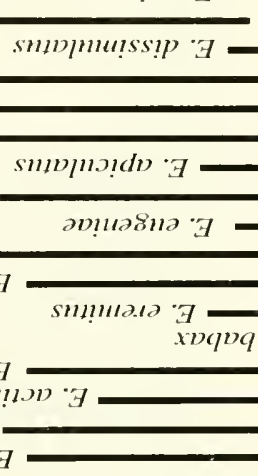

smmpmutssip

sninll

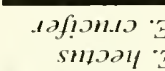

snos!poloos

SnIDIn.t)

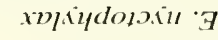

s! p.1วเр [оว!n! 3

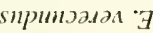

snl10

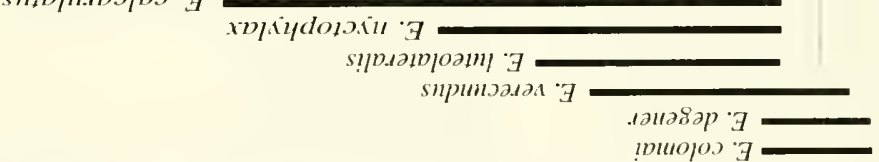

14n.181u-.4 3

ipituojos "3

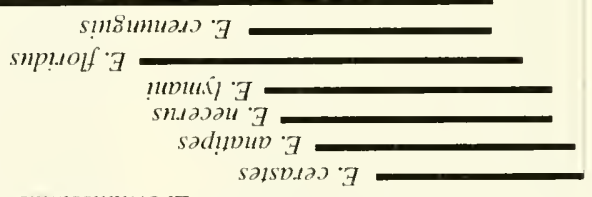

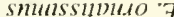

snlluivd : 7

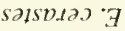

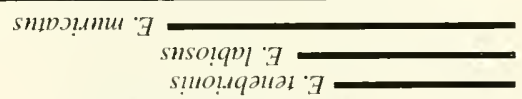

2.12.7p.11 3

smu|!! 1 !squs $\exists$

snipluouv :

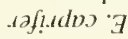

lopvso: 3

smunมนวD 3

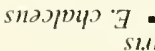

s1.101n 3

SHOS!p!1101 3

S!.1150.11810): 马

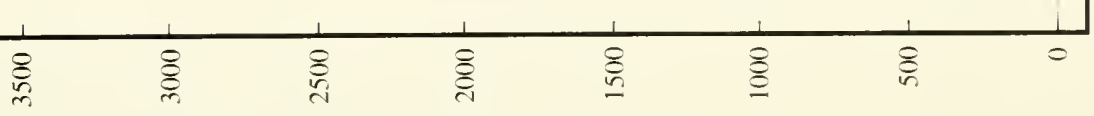

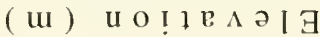




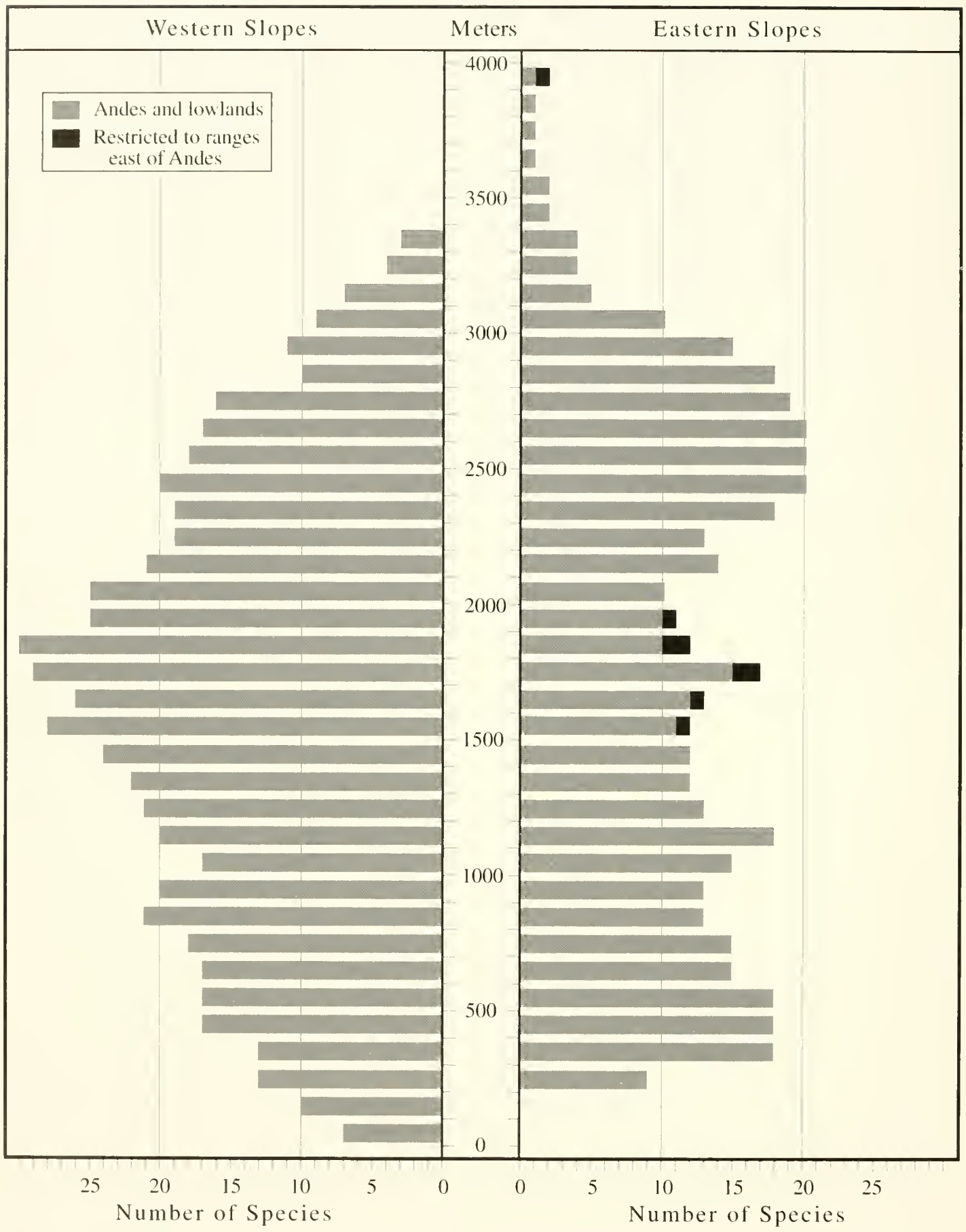

Fig. 66. Numbers of species of Eleutherodactylus at 100-m increments on the Pacific lowlands and western slopes of the Andes in Ecuador (including La Planada in extreme southwestern Colombia) compared with species at the same elevations in the Amazon Basin and on the eastern slopes of the Andes in Ecuador. Mountain ranges east of the Andes include the Cordillera del Cóndor, Cordillera de Cutucú, and Volcán Sumaco. 


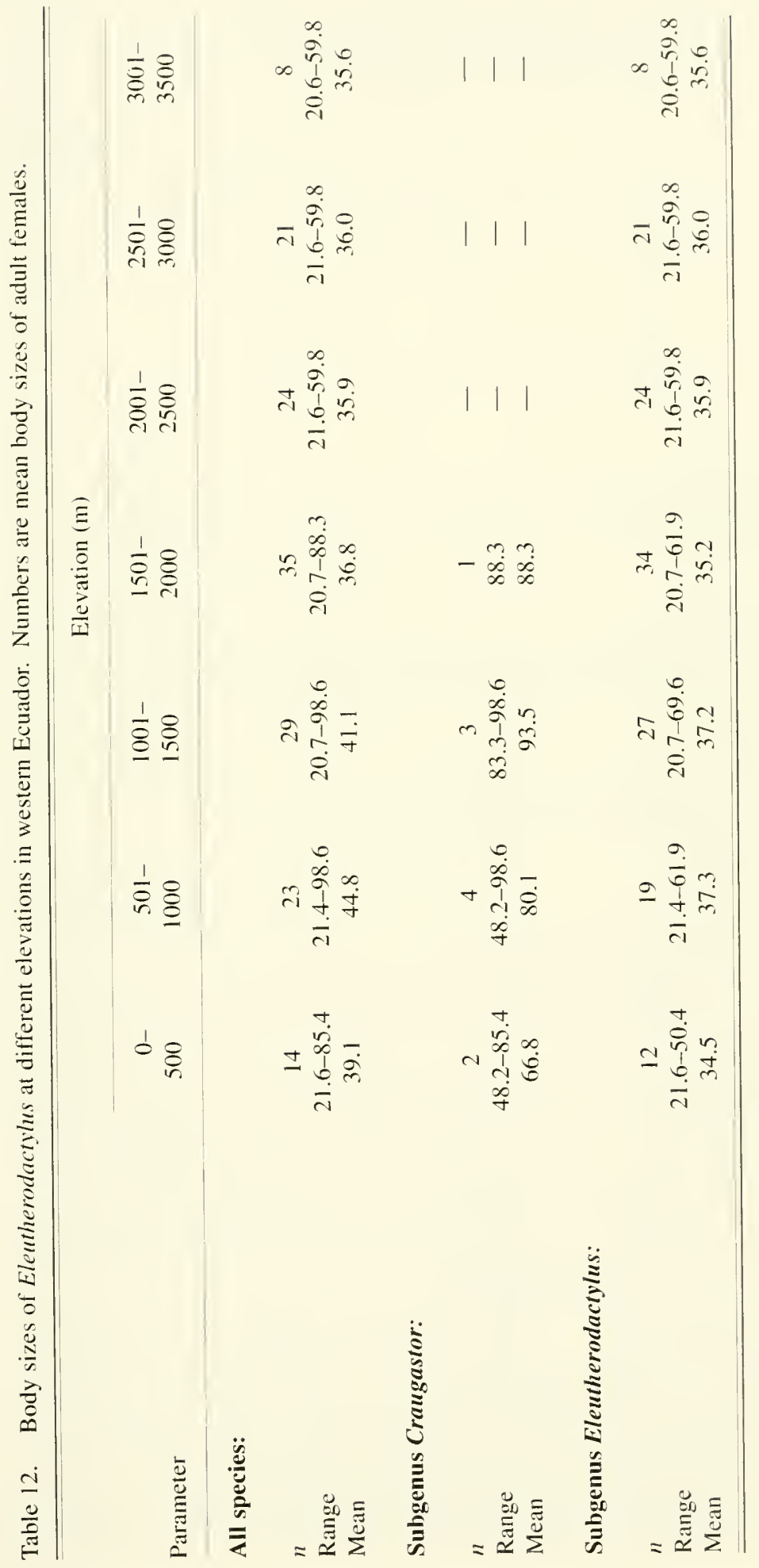


Table 13. Microhabitats utilized by Eleuherodactylus at different elevations in western Ecuador. Numbers are percents within given elevations.

Microhabitat

\begin{tabular}{rrcccc}
$\begin{array}{c}\text { Elevation } \\
\text { (meters) }\end{array}$ & $n$ & Arboreal & $\begin{array}{c}\text { Arboreal } \\
\text { (spray zone) }\end{array}$ & Terrestrial & $\begin{array}{r}\text { Terrestrial } \\
\text { (streamside) }\end{array}$ \\
$0-500$ & 15 & 80.0 & 6.7 & 0.0 & 13.3 \\
$501-1000$ & 23 & 69.6 & 4.3 & 8.7 & 17.4 \\
$1001-1500$ & 29 & 75.9 & 0.0 & 13.8 & 10.2 \\
$1501-2000$ & 35 & 80.8 & 5.7 & 11.4 & 2.9 \\
$2001-2500$ & 24 & 83.3 & 8.3 & 4.2 & 4.2 \\
$2501-3000$ & 21 & 81.0 & 9.5 & 9.5 & 0.0 \\
$3001-3500$ & 8 & 50.0 & 12.5 & 37.5 & 0.0 \\
\hline \hline
\end{tabular}

of $2 \mathrm{~km}$ was assigned. In two cases in which single outliers of a broad distribution exist (E. chalceus and $E$. gularis), the outlier was not included in the area.

With a few exceptions (E. cajanarcensis, lymani, unistrigatus, and w-nigrum), the most striking aspect of distributional area is the correspondence with altitudinal distribution. Eleven species ( $E$. achatinus, anomalus, caprifer; chalceus, gularis, labiosus, latidiscus, longirostris, rosadoi, subsigillatus, and walkeri) have the lower limits of their altitudinal distributions at, or below $150 \mathrm{~m}$; for these species, areas are $3277-39,687 \mathrm{~km}^{2}(\bar{x}=$ 16.963). In contrast, 20 species (E. apiculatus, appendiculatus, babax, calcarulatus, celator, crucifer; duellmani, eremitus, eugeniae, illotus, laticlavius, luteolateralis, nyctophylax, ocellatus, phoxocephalus, pteridophilus, quinquagesimus, scolodiscus, surdus, and vertebralis) known from three or more localities and having their lower limits of distribution at 1000-2000 $\mathrm{m}$ have areas of $354-8707 \mathrm{~km}^{2}(\bar{x}=2306)$. Likewise, species distributed at elevations greater than $2000 \mathrm{~m}$ have even smaller areas; five species (E. gentryi, leoni, pyrrhomerus, simonbolivari, and truebae) have areas of $50-2287 \mathrm{~km}^{2}(\bar{x}=1032)$.

Size of area of distribution is determined not only by longitudinal distribution, but also by altitudinal distribution. The lowland species ranging from Panama to southern Ecuador have the largest areas-E. achatinus $\left(39,687 \mathrm{~km}^{2}\right)$ and $E$. longirostris $\left(31,183 \mathrm{~km}^{2}\right)$ (Fig. 67). A few species having long latitudinal distributions have rather narrow altitudinal ranges on the Andean slopes and, consequently, have much smaller areas of distribution; examples are E. babax $\left(4262 \mathrm{~km}^{2}\right)$ and E. cerastes $\left(4194 \mathrm{~km}^{2}\right)$ (Fig. 68).

As expected, the 27 species endemic to the Andean slopes between $1^{\circ} \mathrm{N}$ Lat. and $1^{\circ} \mathrm{S}$ Lat. have rather small distributional areas. The sizes of their areas of distribution are $10-4783 \mathrm{~km}^{2}(\bar{x}=1438)$. Eight of these species are known from only one or two localities; the areas of distribution of the 19 species known from three or more localities are 50 $4783 \mathrm{~km}^{2}(\bar{x}=2030)$.

The exceptions to the general pattern of area of distribution and altitudinal distribution include two species that are distributed primarily in the Huancabamba Depression in northern Peru and southern Ecuador and that reach the northern limits of their distributions in western Ecuador. Both $E$. cajamarcensis and E. lymani inhabit locally humid areas within this region and have fragmented distributions within the region. Consequently, although the calculated areas of distribution $\left(20.532 \mathrm{~km}^{2}\right.$ for E. cajamarcensis and $23,559 \mathrm{~km}^{2}$ for E. lymani) encompass the outermost known ranges of the species, the actual areas of distribution are greatly exaggerated.

The ubiquitous $E$. w-rigrum in most areas of cloud forest at elevations of 800-3200 in the Andes north of the Huancabamba Depression has an estimated area of distribution of $27,266 \mathrm{~km}^{2}$. With a few exceptions (e.g., vicinity of Pilaló, Provincia Cotopaxi, Ecuador), this large species is distributed on all slopes of the Andes north of the depres- 


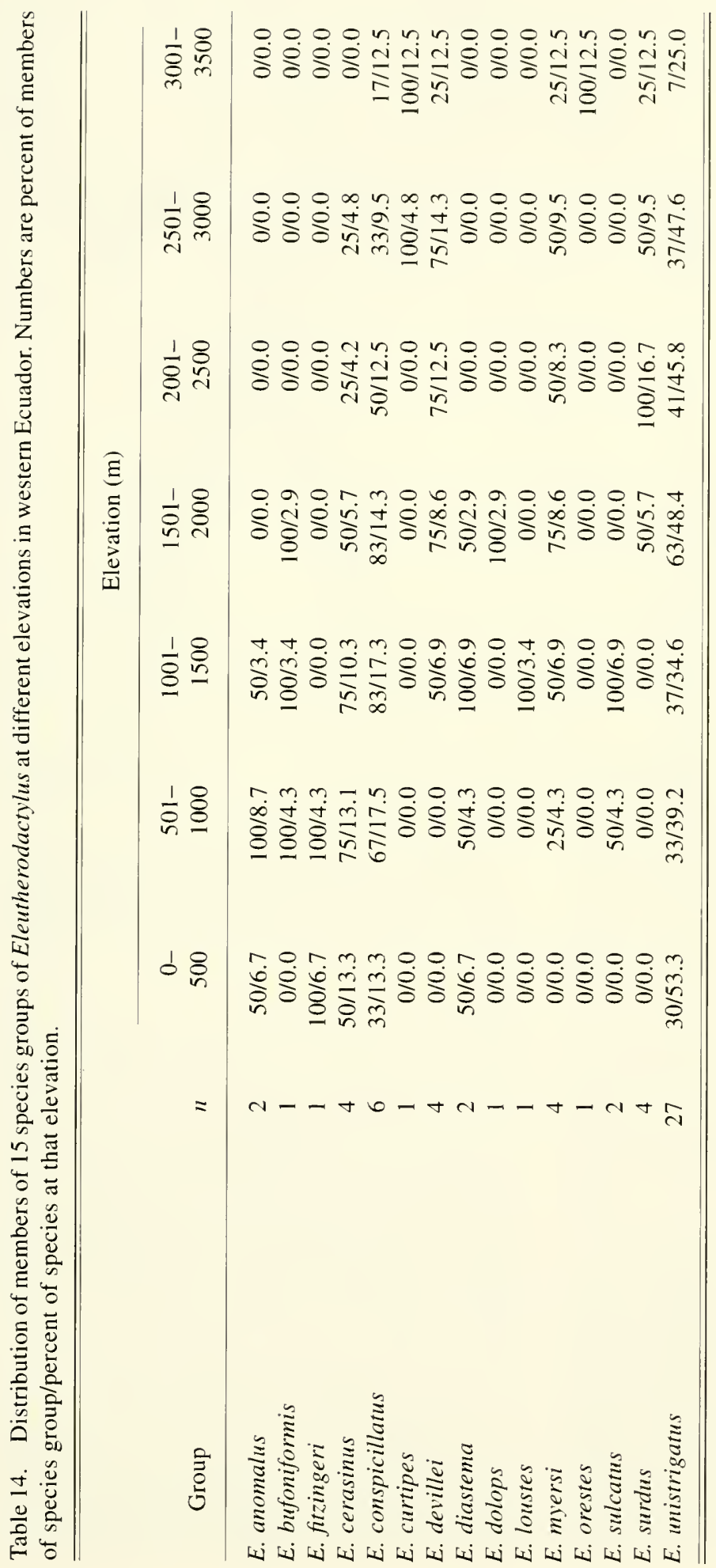




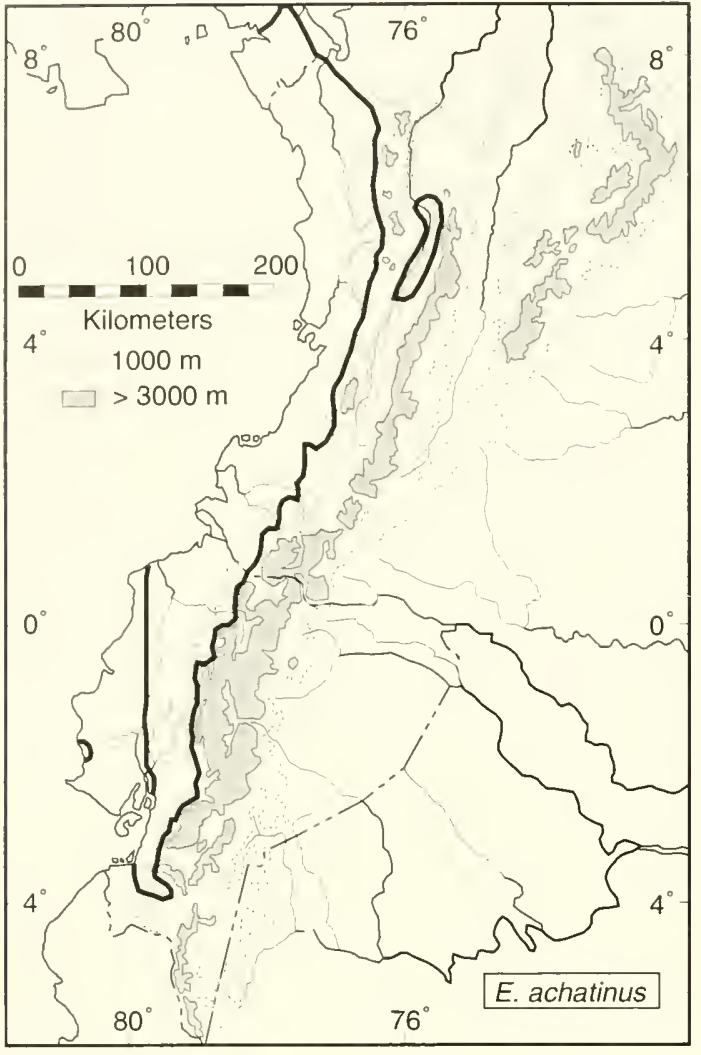

Fig. 67. Distribution of Elentherodactylus achatinus as an example of a broadly distributed species in the Chocoan lowlands. Note the disjunct populations in the lower Río Cauca Valley in northern Colombia and along the Pacific coast of western Ecuador.

sion (Fig. 69). Eleutherodactylus unistrigatus also is a widely distributed Andean species with an area of distribution of $16,524 \mathrm{~km}^{2}$ mostly encompassing inter-Andean valleys but also extending onto the western and eastern slopes of the Andes in Ecuador and southern Colombia (Fig. 70).

There is no clear correlation between body size and area of distribution. Excluding E. cajamarcensis and E. lymani for the reasons given above and using mean SVL of females as a measure of size, the 20thranked species in size (largest to smallest) is $E$. achatinus with a SVL of $41.2 \mathrm{~mm}$; it has the largest area of distribution $\left(39.687 \mathrm{~km}^{2}\right)$. The second largest area of distribution $\left(31,183 \mathrm{~km}^{2}\right)$ is that of $E$. longirostris, which is the 10th-ranked species in size (SVL $48.2 \mathrm{~mm}$ ). Nonetheless, the 10 largest

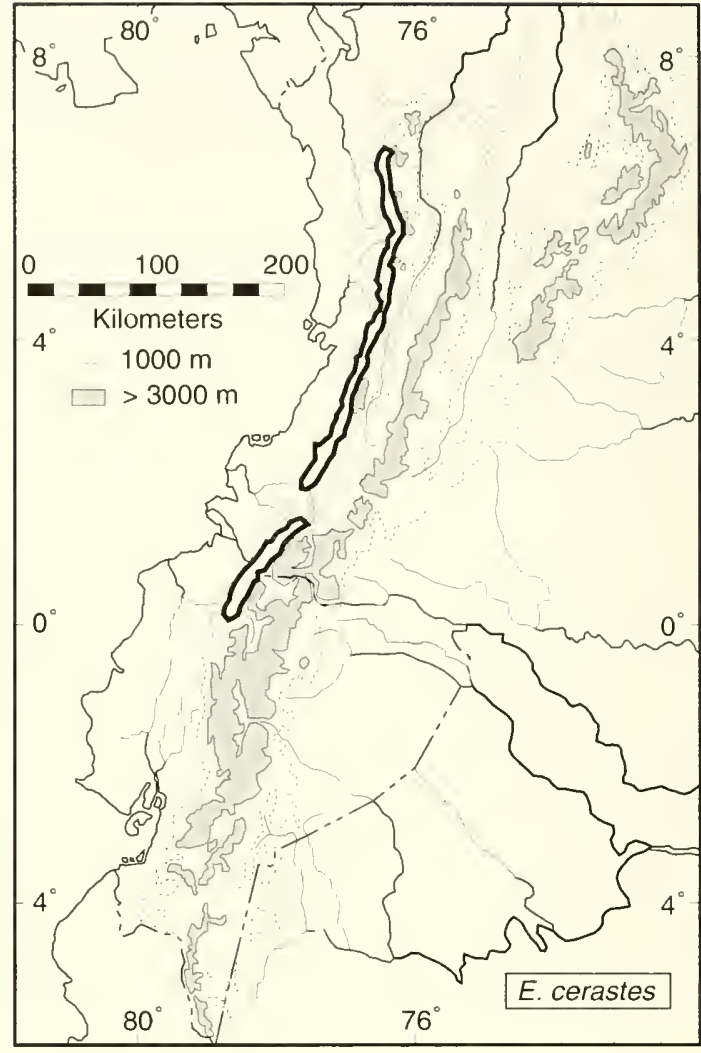

Fig. 68. Distribution of Eleutherodactylus cerastes as an example of a widely distributed species on the slopes of the Cordillera Occidental in Colombia and Ecuador. The hiatus in the range is at the Río Patia Valley.

species have areas of distribution of $10-31.183 \mathrm{~km}^{2}$ $(\bar{x}=8757)$ in contrast to $20-19,126 \mathrm{~km}^{2}(\bar{x}=4060)$ for the 10 smallest species.

Also, there is no significant difference between the areas of distribution of terrestrial and arboreal species. With the elimination of E. cajanarcensis and $E$. lymani, the areas of 12 terrestrial species are $10-31,183 \mathrm{~km}^{2}(\bar{x}=5845)$ compared to $10-39.687$ $\mathrm{km}^{2}(\bar{x}=5214)$ for 47 arboreal species.

\section{Patterns of Speciation}

Although the phylogenetic relationships are not known for all of the species of Eleutherodactylus in western Ecuador, certain groups and pairs of sister species have been identified; among these taxa 


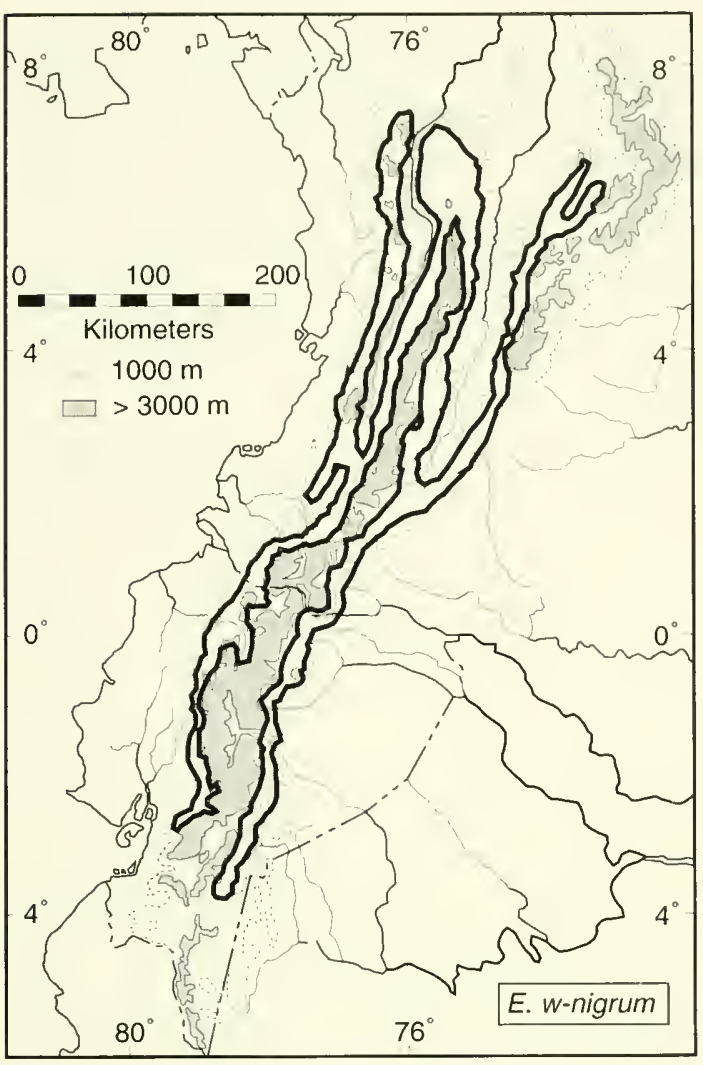

Fig. 69. Distribution of Eleutherodactylus wnigrum in cloud forests in the northern Andes. This is, by far, the most widespread distribution of a species of Eleutherodactylus inhabiting cloud forest.

there are repeated biogeographic patterns. However, precise knowledge of relationships (species level cladograms for three or more species) is not generaliy available. Phylogenetic hypotheses involving only pairs of species cannot be used to support some general hypothesis, because twospecies cladograms cannot be combined into a general cladogram (Nelson and Platnick, 1981). Of all of the species of Eleutherodactylus in western Ecuador, only one (E. loustes) is part of a published three-taxon statement (Lynch, 1992a). The absence of explicit phylogenetic hypotheses means that we cannot examine modes of speciation as discussed by Lynch (1989b) and are limited here to discussing possibilities.

Nevertheless, the general pattern is that nearest relatives (albeit in two-taxon statements) are allo-

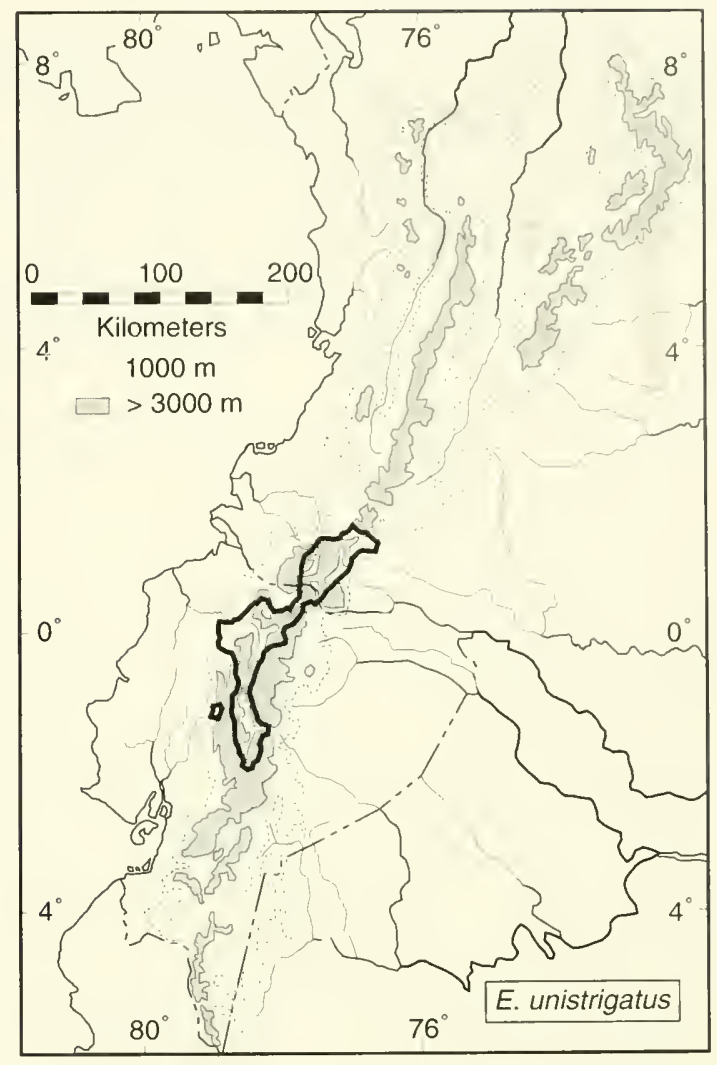

Fig. 70. Distribution of Eleuthe rodactylus unistrigatus as an example of a widespread distribution in the Andes of Ecuador.

patric and have relatively large geographic ranges (and estimated populations). This pattern supports Lynch's (1989b) contention that speciation by peripheral isolation is rare in the speciose genus Eleutherodactylus in western Ecuador. Elentherodactylus gentryi is the only potential example of speciation by peripheral isolation we see in this fauna.

Chocoan region.- The northern part of the Chocoan lowlands has an eleutherodactyline fauna that essentially is part of that in lower Central America. For example, the region is inhabited by $E$. bufoniformis, gaigei, and ridens, all of which range northward at least into Costa Rica: these species and some endemics (e.g., E. zygodactylus) do not range south of the Río San Juan. However, two species, E. achatimus and E. longirostris, range throughout the Chocoan lowlands from Panama to 
southern Ecuador. The Chocoan lowlands to the south of the Río San Juan are inhabited by many taxa (e.g., E. labiosus, latidiscus, and scolodiscus). The lowlands in Departamento Nariño in southwestern Colombia have not been collected intensively. It is likely that several species known now only from the Pacific lowlands of Ecuador will be found there; these include E. colomai, E. degener, and $E$. rosadoi.

Among the patterns that are evident is that displayed by the E. fitzingeri group of the subgenus Craugastor: Of the eight species in this group, which has five species endemic to Central America, two species (E. fitzingeri and E. raniformis) are distributed in lower Central America and the northern part of the Chocó, whereas E. longirostris ranges from Panama to southern Ecuador (Lynch and Myers, 1983). Among other groups in the subgenus Craugastor, patterns of speciation are evident among sister taxa. For example, sister species in the E. anomalus group exhibit a northsouth pattern of differentiation in the Chocoan lowlands in E. anatipes and E. zygodactylus - the former to the north of the Río San Juan and the latter to the south of the river (Fig. 71). Another pattern is exhibited by the lowland E. anomalus and its upland sister species, E. cheiroplethus (Lynch, 1990). In each case, the distributions of sister species are adjacent.

Members of the E. bufoniformis group of the subgenus Crangastor also have a north-south vicariance pattern, but in this case E. bufoniformis is restricted to lowlands north of Río San Juan northward into southeastern Costa Rica, whereas its sister species, E. necerus is restricted to elevations of $600-1540 \mathrm{~m}$ on the Andean slopes in Ecuador (Fig. 72). The distributions of this pair of species are dichopatric.

Other patterns involve partial sympatry of related species. For example, of the three recognized members of the Eleutherodactylus diastema group in the Chocoan region, E. gularis is coastal, E. chalceus partially overlaps $E$. gularis inland and completely overlaps E. scolodiscus on the lower Andean slopes (Fig. 73). Likewise, in the $E$. cerasinus group, E. labiosus is widespread in the Chocoan lowlands south of the Río San Juan; in the southeastern part of its range it is sympatric with its sister species, E. tenebrionis (Fig. 74), but other species in the group have allopatric distributions. Similarly, E. subsigillatus is widespread in the southern Chocoan lowlands, and it is sympatric with its putative sister species, E. degener in Provincia Esmeraldas, Ecuador; the apparent closest relatives of this pair of species are E. eremitus and E. phoxocephalus on the Andean slopes of Ecuador. The pattern of altitudinal replacement of related species is evident in other groups. For example, the E. loustes group consists of three species; E. loustes on the Andean slopes of Ecuador in adjacent Colombia is the sister species of $E$. jaime i on the Andean slopes of Departamento Cauca, Colombia, and E. hybotragus in the Chocoan lowlands (Lynch, 1992a). In western Ecuador, this pattern is repeated in the presumptive species pairs, $E$. walkeri in the lowlands and E. luteolateralis on the Andean slopes, and in E. latidiscus in the lowlands and E. laticlavius on the slopes (Figs. 75, 76). In each of these cases, the species in the lowlands have much greater areas of distribution than their putative highland sister species; for example the areas of distribution of the lowland $E$. walkeri and E. latidiscus are $19,126 \mathrm{~km}^{2}$ and 15,930 $\mathrm{km}^{2}$, respectively, in contrast to their respective putative upland sister species, E. luteolateralis $\left(606 \mathrm{~km}^{2}\right)$ and E. laticlavius $\left(1900 \mathrm{~km}^{2}\right)$.

On the Pacific slopes of the Cordillera Occidental of the Andes in Colombia and Ecuador, there seems to be a gradual latitudinal displacement of related species. However, the accumulating distributional data indicate the possibility of two major breaks. The first of these is in northern Departamento Valle, Colombia; this may be a reflection of greater antiquity of the northern part of the Cordillera Occidental (Galvis and Mojica, 1994), where there seems to be considerable endemism in Eleutherodactylus (e.g., E. bellona and half a dozen undescribed species). A second major break seems to exist between the area of La Munchique in Departamento Cauca, Colombia, and La Planada in southern Departamento Nariño, Colombia. This disruption probably reflects the effects of the low and dry Río Patía Valley, a barrier that is both climatological and a physiographic hiatus in the humid uplands of the Cordillera Occidental. This barrier creates disjunct distributions to the north 


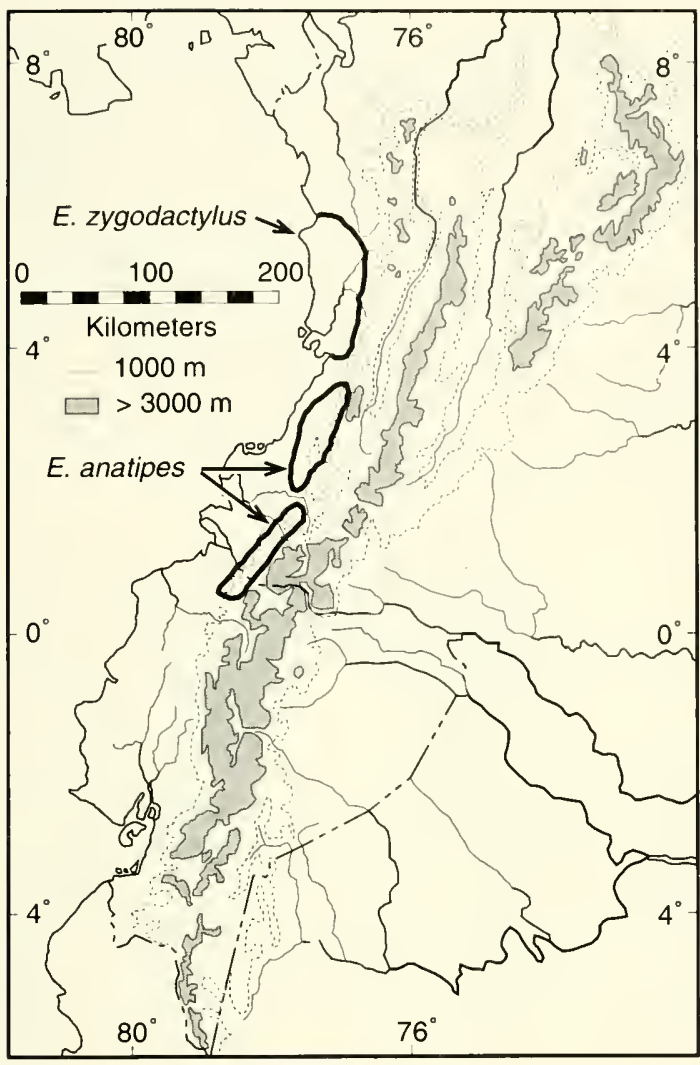

Fig. 71. Latitudinal replacement of sister species of Eleutherodactylus in the Chocoan lowlands. The disjunction in the range of $E$. anatipes is at the Río Patía Valley.

and south of the Río Patía in several species (e.g., E. babax, cerastes, and duellmani). To the south in Ecuador, the upper drainage of the Río Blanco seems to be a major region for speciation, which includes upland vicariants of lowland species, such as E. walkeri-E. luteolateralis and E. latidiscuslaticlavius.

Latitudinal replacement of sister species at middle elevations is evident on the slopes of the Cordillera Occidental. This vicariance pattern is exemplified by $E$. ocellatus to the north and $E$. crenunguis to the south (Fig. 77) and by $E$. illotus to the south and E. thectopternus to the north (Fig. 78).

Trans-Andean patterns.-Members of some lineages have representatives on both sides of the Andes. For example, the E. cerasinus group (Lynch

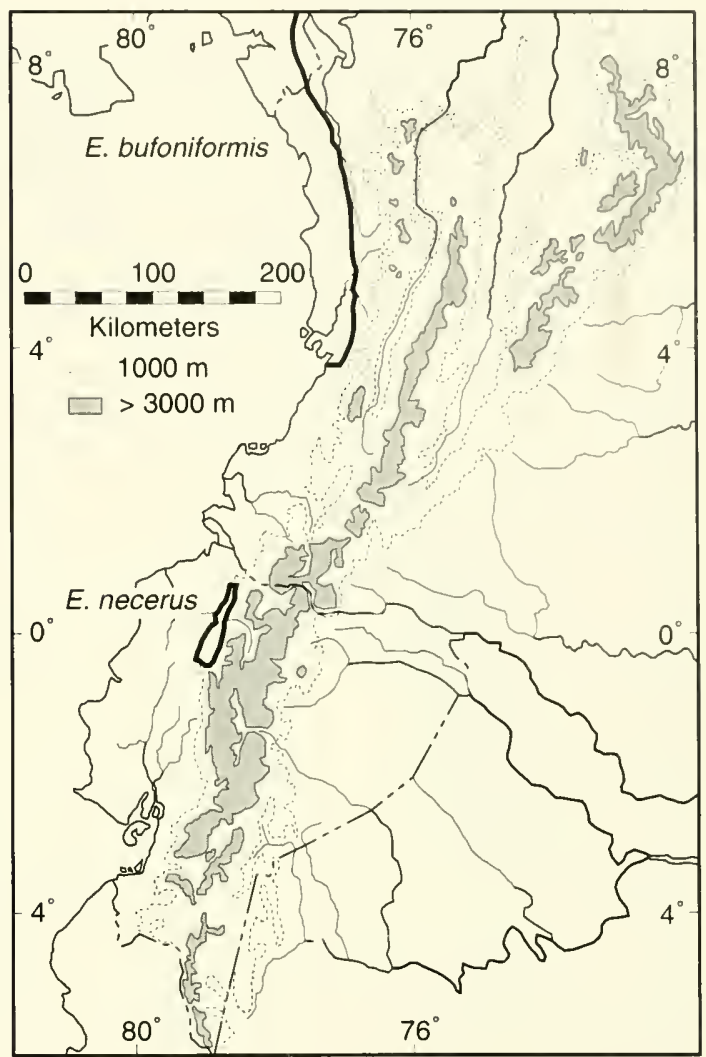

Fig. 72. Latitudinal and altitudinal replacement of sister species in the Chocoan region. Eleuthero-dactylus bufoniformis is restricted to the lowlands to the north and E. necerus to middle elevations to the south.

et al., 1994) consists of E. cerasinus in lower Central America, E. crenunguis, labiosus, ocellatus, orpacobates, and tenebrionis on the Pacific versant in Colombia and Ecuador (Figs. 74, 77) and E. rubicundus in cloud forests on the eastern slopes of the Andes in Ecuador. Similarly, the two species comprising the E. dolops group are distributed in cloud forests on opposite sides of the Andes: $E$. dolops occurs on the eastern slopes in northern Ecuador and southern Colombia, whereas E. babax has a lengthy distribution on the Pacific slopes in Colombia and Ecuador (Fig. 79), although the former example also demonstrates altitudinal shifts.

The Eleutherodactylus sulcatus group has a more complex distribution in the Amazon lowlands and on various slopes of the Andes (Lynch, 1986b). Eleutherodactylus sulcatus is widely distributed in 


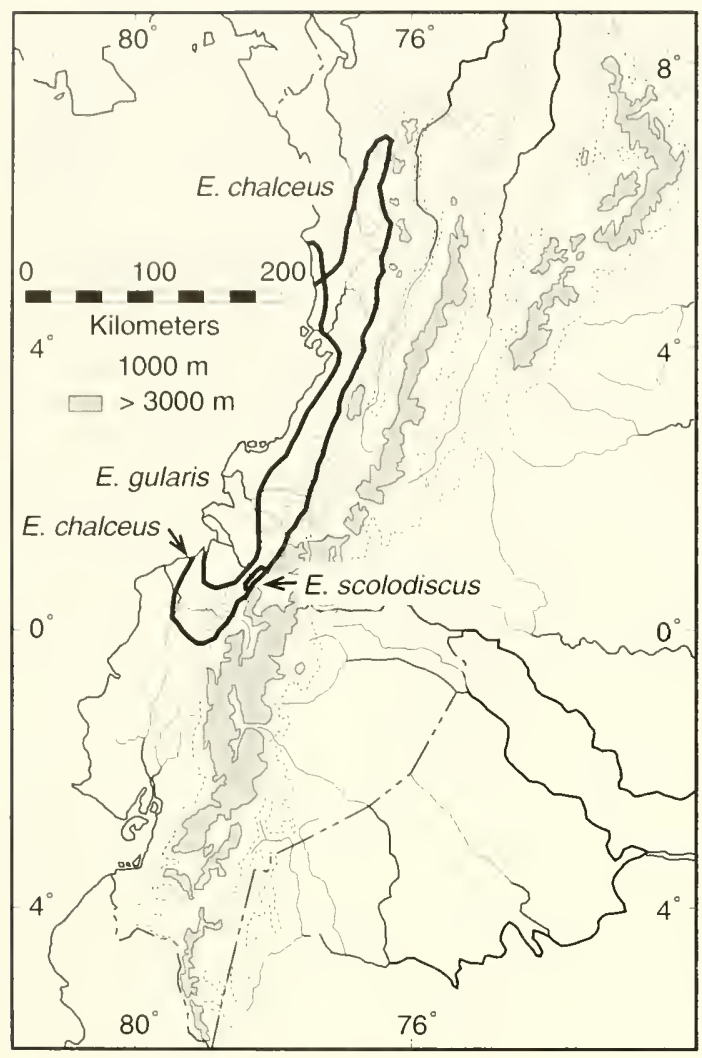

Fig. 73. Geographic replacement of members of the Elentherodactylus diastema group in the Chocoan region.

the Amazon Basin in Ecuador, northern Peru, and western Brazil: this species seems to be the sister taxon to the other members of the group, all of which are distributed in the Andes. Of these, E. comutus, with a moderately broad latitudinal distribution at elevations of $1150-1800 \mathrm{~m}$ on the Amazon slopes of the Andes in Ecuador and southern Colombia, seems to be the sister species of $E$. ingeri (eastern slopes of the Cordillera Oriental in Colombia) and E. cadenai (northern part of the Cordillera Occidental in Colombia. All of the other species now recognized occur on the Pacific slopes of the Cordillera Occidental; E. cercistes has a broad latitudinal range in Colombia and Ecuador, whereas E. helonotus, ruizi, and sernai have restricted distributions there.

High Andes.-At elevations above $1500 \mathrm{~m}$ on the slopes of the Andes, the pattern of latitudinal

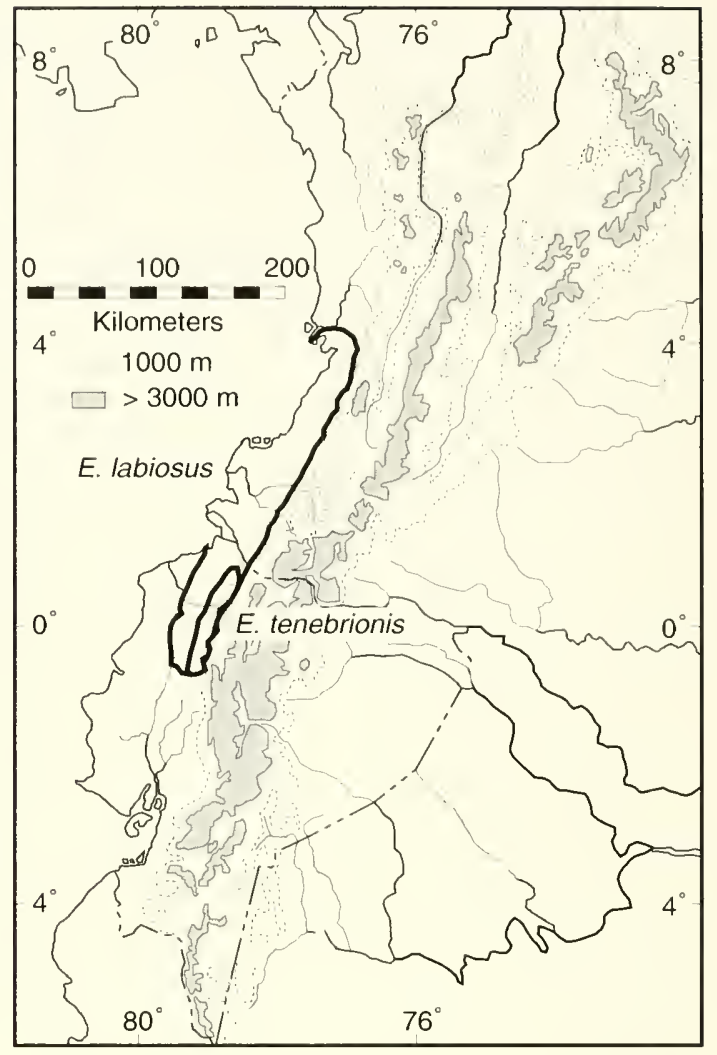

Fig. 74. Distributions of sister species in the Eleutherodactylus cerasinus group in the Chocoan region.

replacement of related species is confounded by the complex topography. For example, of the four species comprising the E. surdus group, E. duellmani has a comparatively extensive latitudinal range of about $150 \mathrm{~km}$ at elevations of $1550-2710 \mathrm{~m}$. lts range encompasses those of $E$. hamiotae and $E$. sobetes (each known from one, but different, localities in Ecuador). The fourth member of the group has a latitudinal distribution of about $75 \mathrm{~km}$ at elevations generally higher than those of the other species in the group (Fig. 80). Likewise, in the $E$. devillei group, $E$. truebae replaces $E$. vertebralis to the south, but in this case the closest relative, E. devillei, is on the eastern slopes of the Andes (Fig. 81).

In the cloud forests at higher elevations (>2000 $\mathrm{m})$, species tend to have small ranges and related species tend to replace one another geographically. 


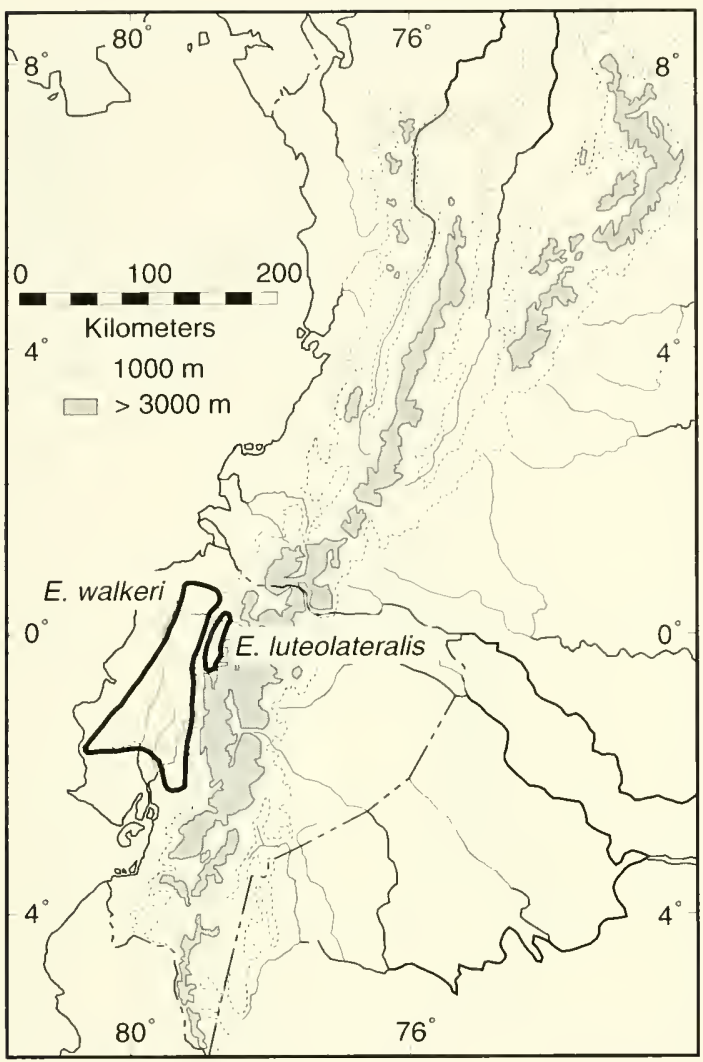

Fig. 75. Altitudinal replacement of sister species of Eleutlerodactylus in western Ecuador.

This is exemplified by the nine species in the $E$. myersi group (Fig. 82). Eleutherodactylus myersi has the most extensive distribution in the Cordillera Central in Colombia and the Nudo de Pasto in southern Colombia and adjacent Ecuador; three species (E. gladiator, repens, and trepidotus) are restricted to the Amazonian slopes of the Andes in Ecuador and southern Colombia, and four species (E. floridus, hectus, ocreatus, and pyrthomerus) are restricted to the Pacific slopes in Ecuador and extreme southern Colombia. Two of these species seem to be lower-elevation vicariants of this primarily highland group; E. floridus is known from elevations of $700-2000 \mathrm{~m}$, and E. hectus, from elevations of $1200-1750 \mathrm{~m}$. One species in this group, E. leoni occurs on both Pacific and Amazonian slopes of the Andes.

The species in the Eleutherodactylus orestes group are distributed at high elevations in the

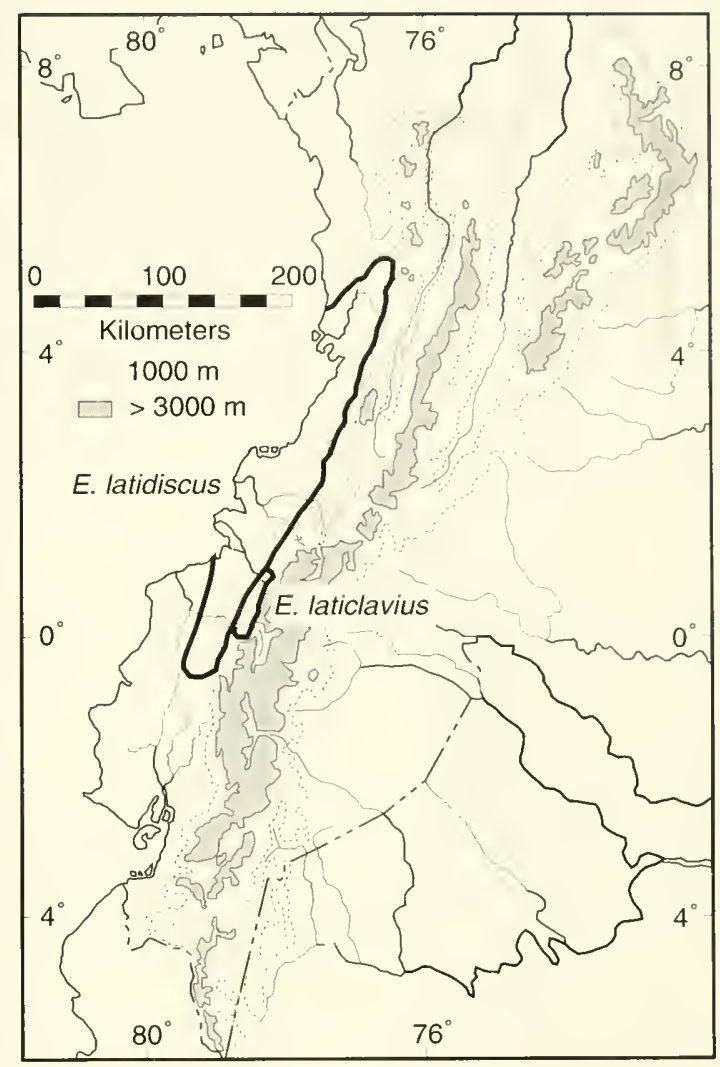

Fig. 76. Altitudinal replacement of sister species of Eleutherodactylus in the Chocoan region.

Andes of southern Ecuador (Fig. 83). The range of E. vidua is encompassed within the distribution of $E$. orestes in the Cordillera Oriental, whereas $E$. simonbolivari is restricted to the Cordillera Occidental.

Frogs of the E. curtipes group inhabit paramo and subparamo in the high Andes (2700-4400 m) of Ecuador and southem Colombia (Fig. 84). The ranges of E. buckleyi and $E$. curtipes overlap in southern Colombia and northern Ecuador; otherwise the two species seem to replace one another latitudinally. Eleutherodactylus cryophilius is disjunct to the south, and E. gentryi seems to be a peripheral isolate on the high Pacific slopes of the Cordillera Occidental in central Ecuador. The Colombian E. satagius and E. xestus have small. disjunct distributions on high peaks in the northern part of the Cordillera Occidental. 


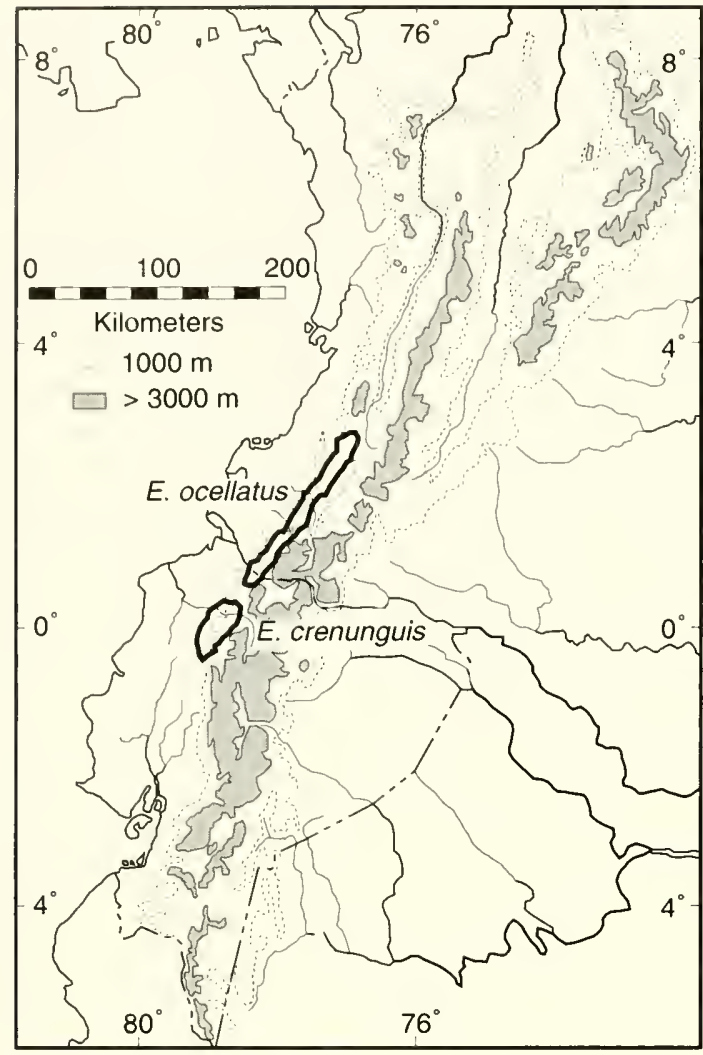

Fig. 77. Latitudinal replacement of sister species of Eleutherodactylus on the Pacific slopes of the Andes in Ecuador and Colombia.

\section{Historical Biogeography}

Although the Andes were uplifted moderately in the Cretaceous, some regions, such as the northern part of the Cordillera Occidental in Colombia and an island arc paralleling the Cordillera Occidental on the west, were uplifted in the early Tertiary, the major orogeny of the Andes north of the Huancabamba Depression commenced in the Pliocene (Galvis and Mojica, 1994; Sauer, 1971; Zeil, 1979). The resulting high mountain chain was affected by dramatic climatic changes during the Pleistocene (Simpson, 1975; van der Hammen, 1974), and climatic fluctuations (mostly oscillations in rainfall) had a marked effect on the adjacent lowlands (Haffer, 1974). (See foregoing section, Western Ecuador, for details.)

Speciation models of Andean anurans based on

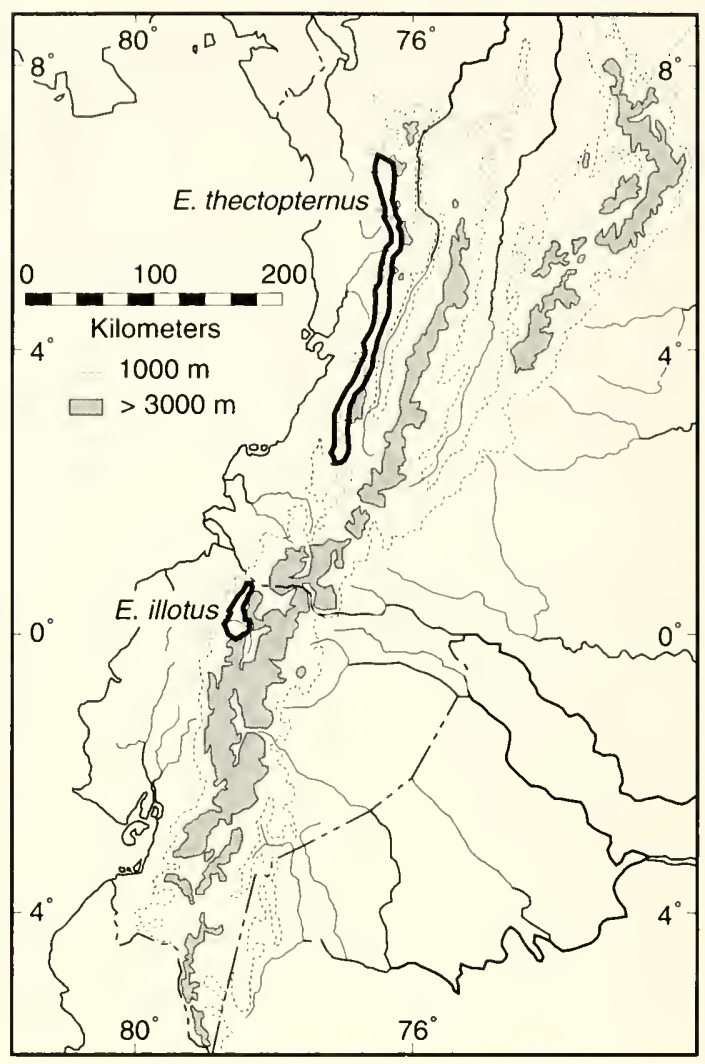

Fig. 78. Latitudinal replacement of sister species of Eleutherodactylus in the Andes of Colombia and Ecuador.

vicariance events resulting from alternating climatic depression and elevation were proposed by Duellman (1983a) and Lynch (1986c). Climatic conditions seem to be extremely important in limiting distributions of anurans. Usually in the case of frogs, such as Eleutherodactylus, that are primarily inhabitants of humid rainforest or cloud forest, environmental moisture is viewed as an important environmental variable in limiting distributions. This is evident in the southern termination of the distributions of many species of Eleutherodactylus on the Pacific lowlands of Ecuador, where in a distance of a few score kilometers rainfall diminishes from about $3000 \mathrm{~mm}$ to $600 \mathrm{~mm}$ or less annually. Moisture also seems to play an important role in the dry Río Patía Valley in southern Colombia resulting in disjunctions in the distributions of some species (e.g., E. babax and E. cerastes), as do 


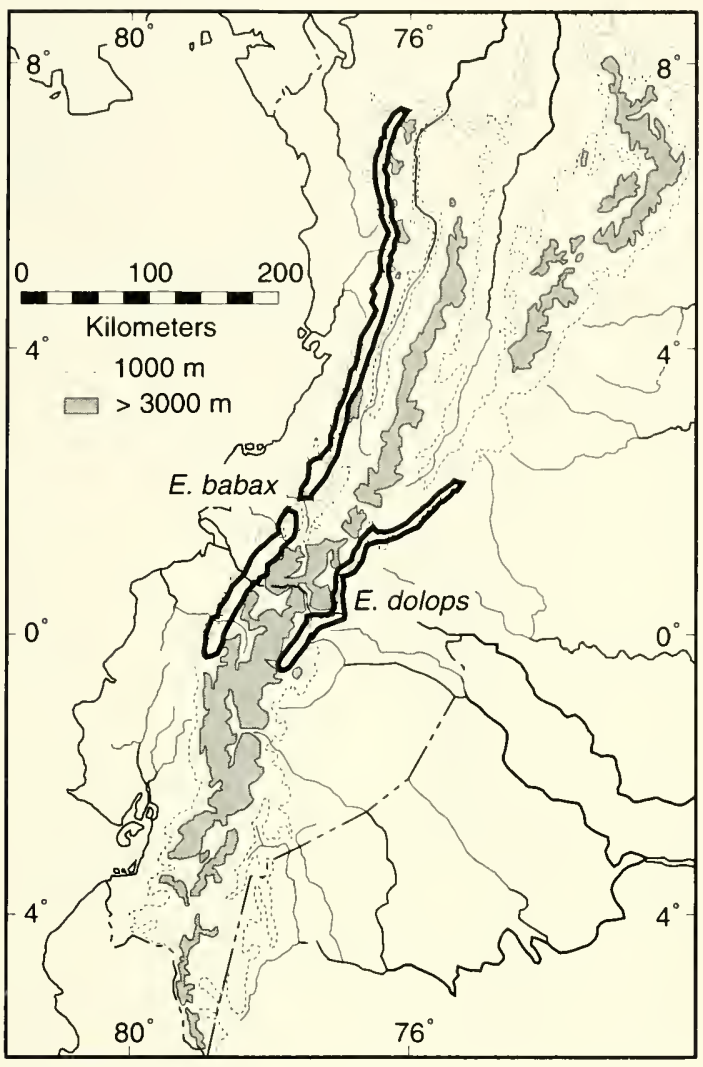

Fig. 79. Distributions of species in the Eleutherodactylus dolops group as an example of trans-Andean disjunction. The hiatus in the distribution of E. babax is at the Río Patía Valley.

the dry valleys in the Huancabamba Depression in distributions of E. cajamarcensis and E. lymani. However, temperature also may play an important role in distributions. As concluded by Rome et al. (1992), thermal adaptation of tolerance limits commonly is evident in interspecific analyses and is likely to play an important role in setting temporal and distributional limits on amphibians. One aspect of thermal tolerances that usually is not considered in amphibian biogeography is their reproductive biology, but the results of investigations by Moore (1939) and Zweifel (1968) show that development of eggs and embryos is tied closely with temperature. Thus, changes in temperature, as well as humidity, most likely have played an important role in the isolation and subsequent differentiation of populations of Eleutherodactylus as the Andes

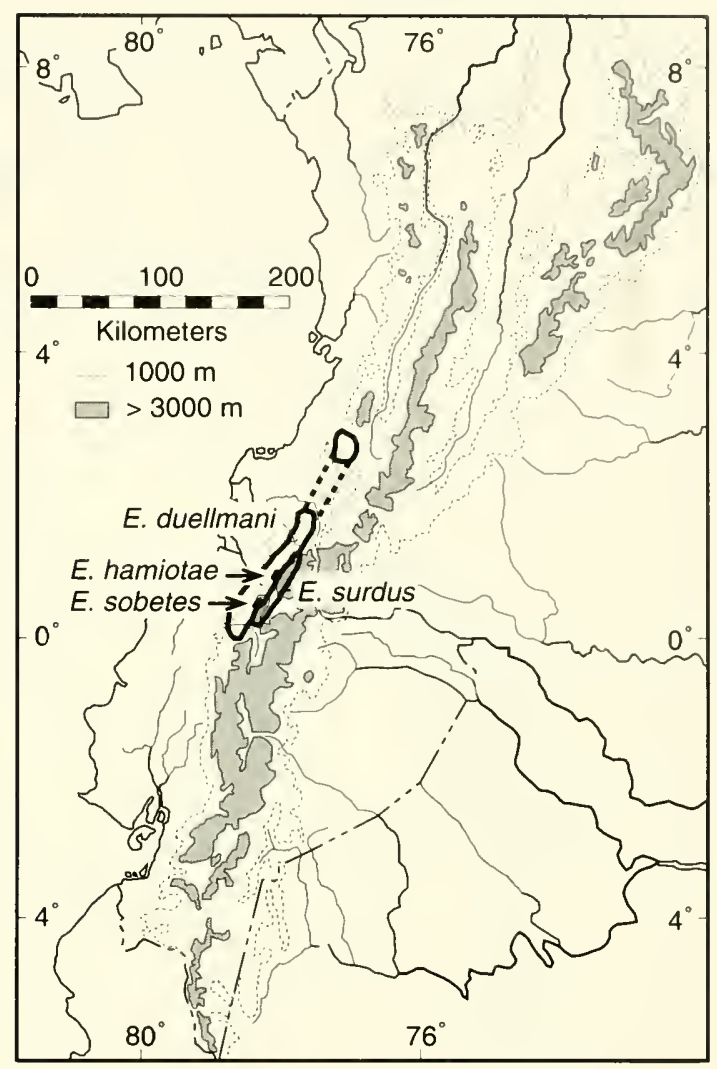

Fig. 80. Distributions of members of the Eleutherodactylus surdus group as an example of latitudinal and altitudinal replacement on the upper Andean slopes. The hiatus in the distribution of $E$. duellmani includes the Río Patía Valley.

were uplifted to higher (and cooler) elevations and the temperatures and rainfall fluctuated during the Pleistocene.

The complex topographic and climatic history since the Cretaceous and culminating in dramatic climatic changes during the Quaternary must have had a profound effect on speciation and distribution of organisms in western Ecuador and adjacent regions. By combining data on orogenic history of, and climatic vicissitudes in, western Ecuador, we propose a speciation model that incorporates the history of the region with possible vicariance events in the biota that are applicable to organisms that were inhabiting the region that is now western Ecuador prior to major uplift of the Andes.

Our graphic model and attendant cladograms 


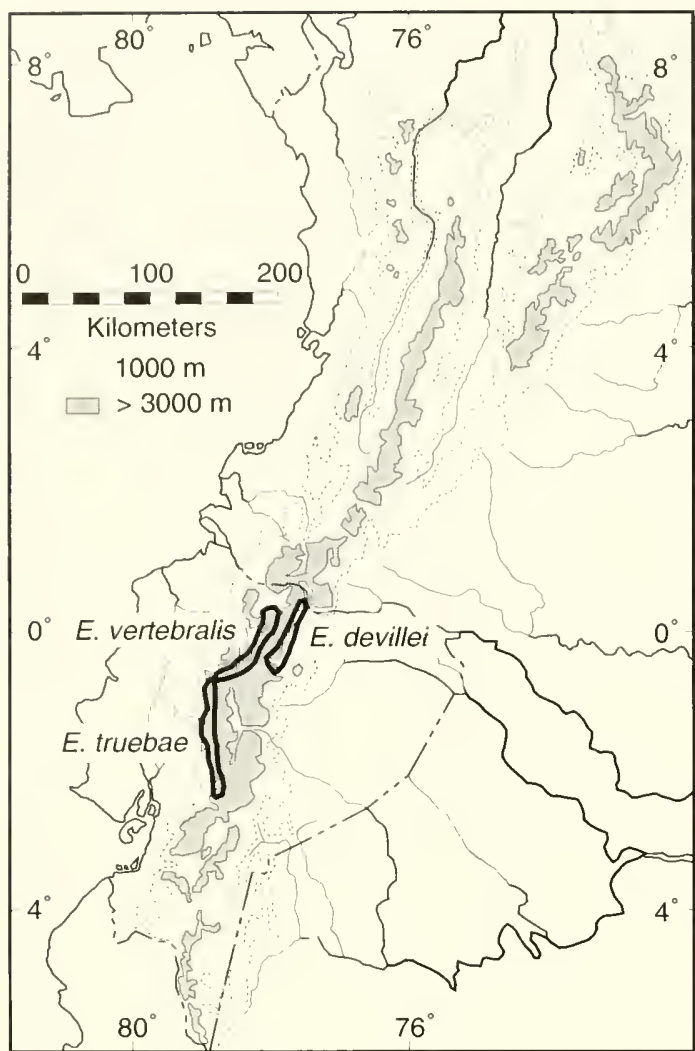

Fig. 81. Distributions of species in the Eleutherodactylus devillei group as an example of latitudinal replacement on the Pacific slopes with a disjunct species on the Amazonian slopes of the Andes.

(Figs. 85, 86) are not based on any known cladograms or examples, but instead represent our expectations of what will be found (combining and extending our previous suggestions [Duellman, 1983a; Lynch, 1986c]). We envision the primary cause of speciation as being adaptation to climates (elevated regions vs. lowland regions) coupled with fragmentation of the once contiguous lowlands. As uplift continued, the impact was greatest on upland species because they would be more subject to vicariance events, such as erosional fragmentation of elevational zones and/or deposition of discharge resulting in unsuitable habitat. The impacts of glacial stages would further fragment lower elevational zones, whereas interglacial stages would have the effect of generating additional vertical slicing of distributions on Andean

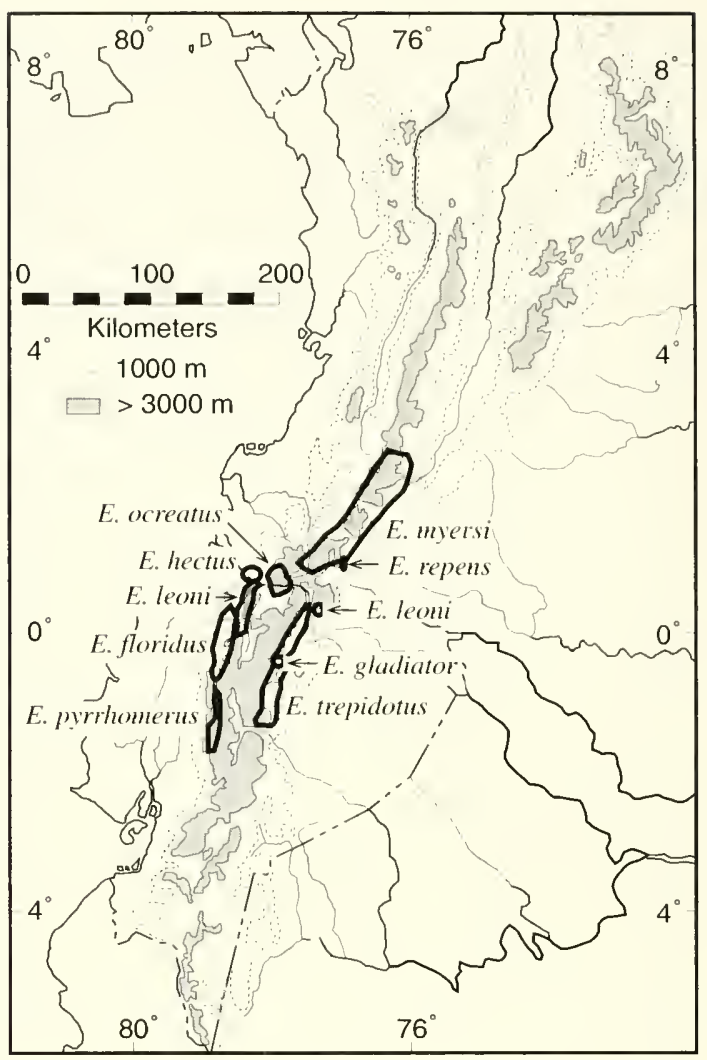

Fig. 82. Distributions of species in the Eleutherodactylus myersi group in the high Andes with species on eastern and western slopes of the Andes. Note that E. leoni occurs on both slopes.

slopes. This model emphasizes climatic compression during glacial times, which possibly could result in a mixture of species from the uplands and lowlands, as well as those from dry and humid environments. Possibly during interglacials, there was a resortment of taxa, but our ability to detect purported ecological compression will be limited by the resolution available in cladograms yet to be generated.

This graphic model attempts to incorporate what we think we know of the patterns of distribution among Andean Eleutherodactylus-i.e., distributions are most extensive in the topographically simple lowlands and near the upper limits of distributions (paramo and subparamo), whereas on the Andean slopes, distributions are narrow (limited altitudinal extent) and latitudinally elongated (but 


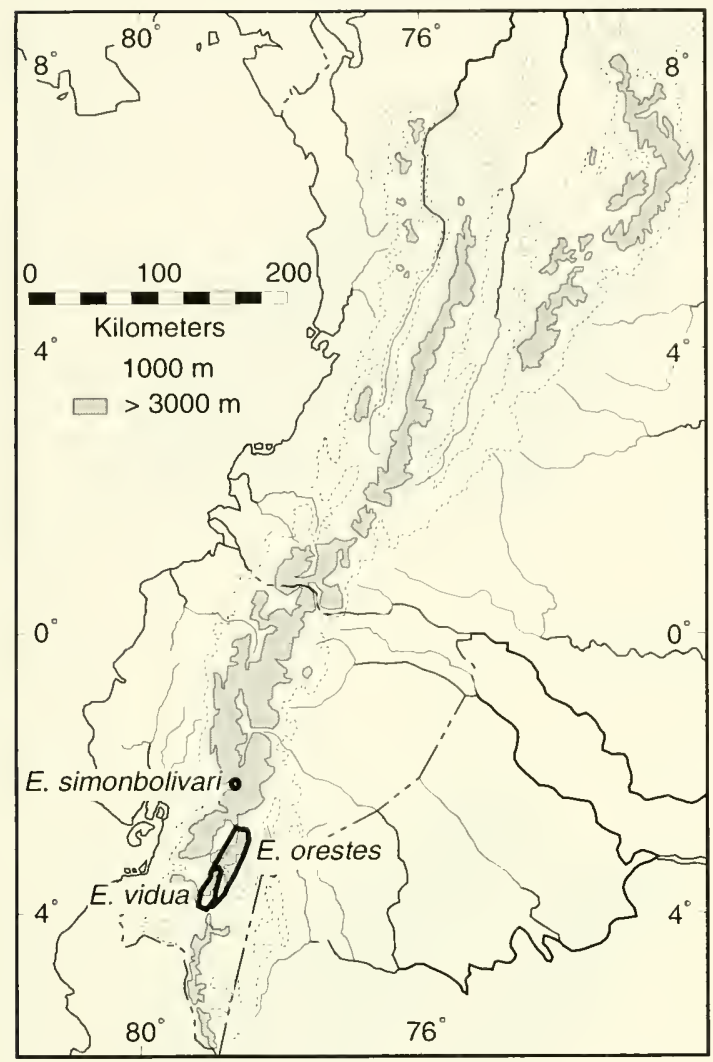

Fig. 83. Distributions of species in the Eleutherodactylus orestes group in the Andes.

not so elongated as in the lowlands). Our expectation is that as additional species-level cladograms become available for Eleutherodactylus in western Ecuador, this model will be seen as a general one, at least for those groups limited by moisture but enjoying substantial vertical distributions.

\section{Contparisons with Other Regions}

An obvious comparison to be made is that between the eleutherodactyline faunas on the opposite slopes of the Andes in Ecuador. Data were summarized from the comprehensive accounts of the Eleutherodactylus of the Amazonian slopes of the Andes (Lynch and Duellman, 1980), the southern Andes of Ecuador (Lynch, 1979a), and the Amazon Basin (Lynch, 1980a). Taxa that have been added subsequently to that region include $E$. ernesti (Flores, 1987), E. katoptroides (Flores,

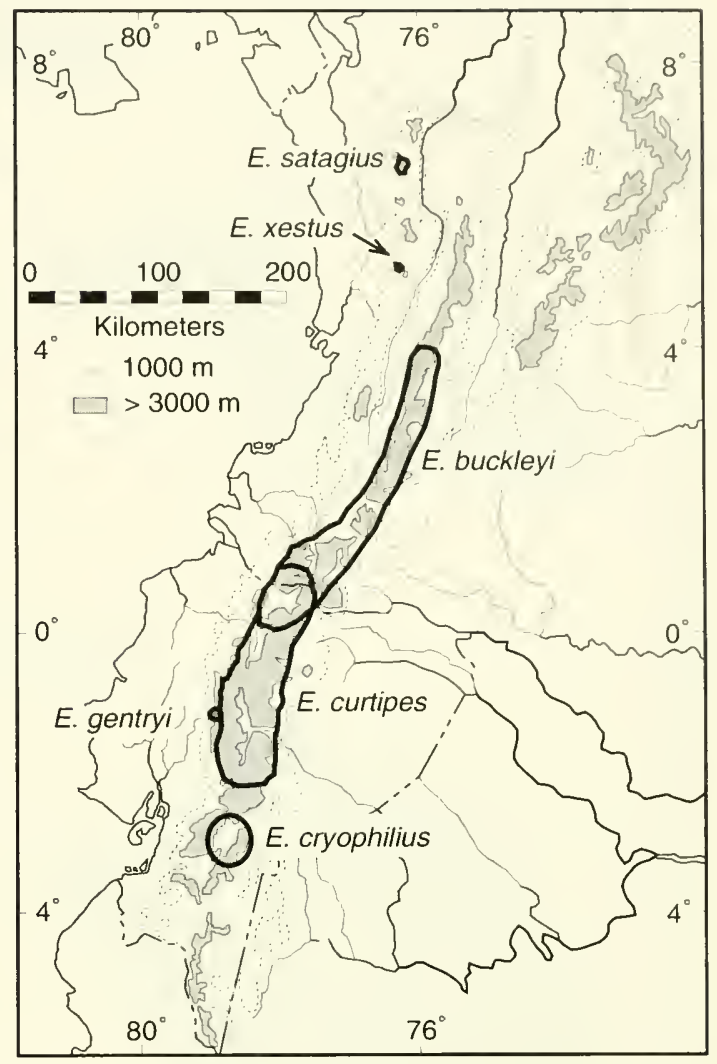

Fig. 84. Distributions of species in the Eleutherodactylus curtipes group in the Andes.

1988b), E. ganonotus and E. pecki (Duellman and Lynch, 1988), and E. librarius (Flores and Vigle, 1994). Herein, E. kirklandi (Flores, 1985) is considered to be a junior synonym of E. inusitatus Lynch and Duellman, 1980.

The eastern versant in Ecuador differs strikingly from the western versant. The eastern lowlands are entirely covered by humid tropical rainforest receiving up to $5000 \mathrm{~mm}$ of rainfall annually and displaying little or no seasonality. Furthermore, on the Andean slopes, cloud forest is nearly continuous throughout the length of the country. Unlike the western versant, the Cordillera Oriental is interrupted by the deep Pastaza Trench. Also, high elevations (>2000 $\mathrm{m}$ ) exist in isolated ranges (Cordillera del Cóndor, Cordillera de Cutucú, and Volcán Sumaco) to the east of the Cordillera Oriental. Thus, although there is greater latitudinal continuity of humid environments and a much greater 


\section{Moderate Uplift}
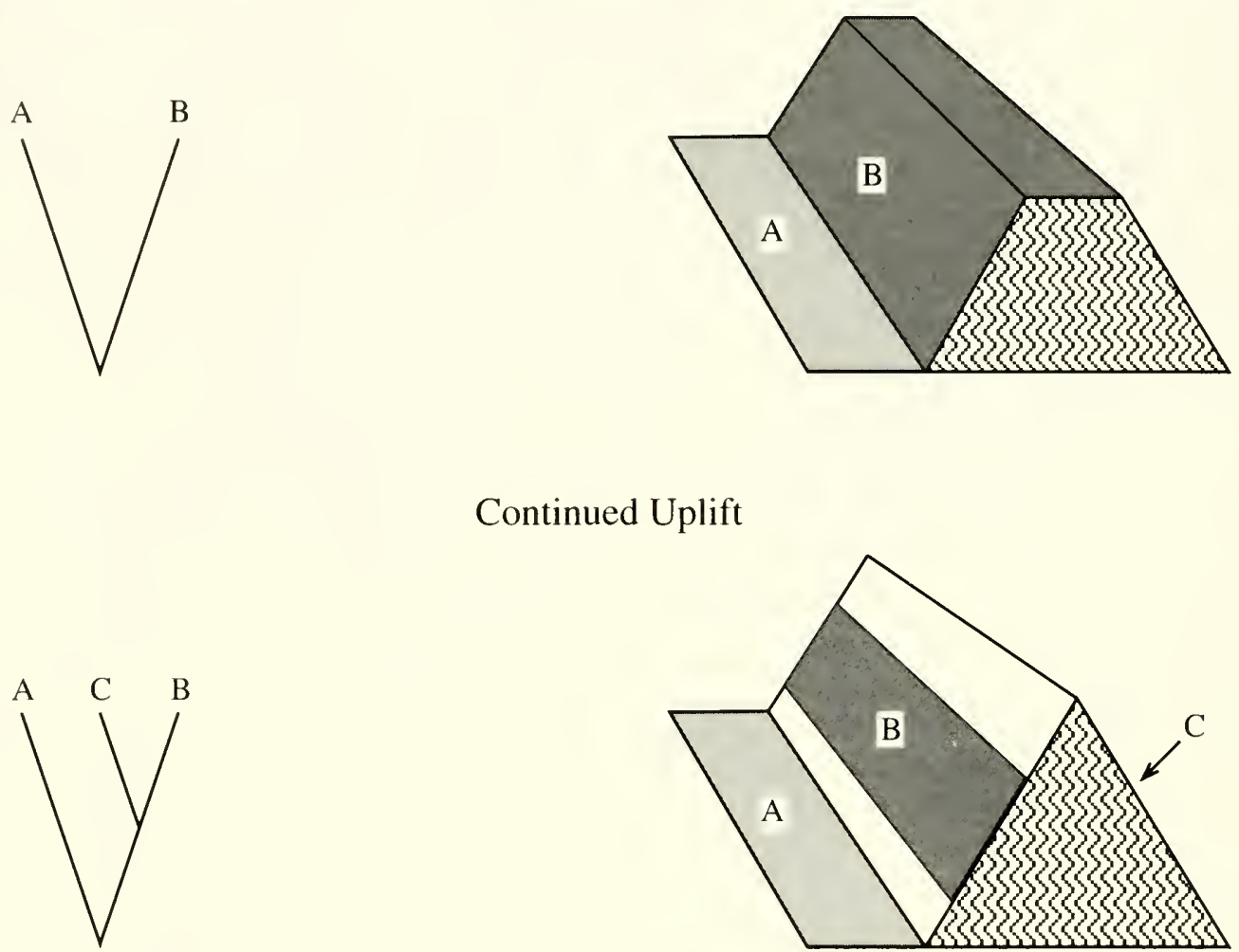

\section{Continued Uplift}

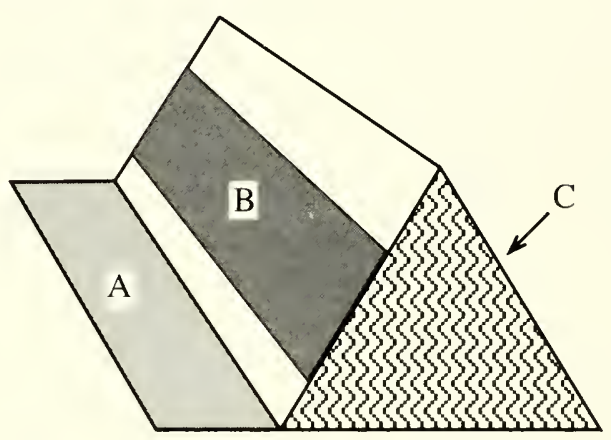

\section{Erosion/Volcanic Discharge}
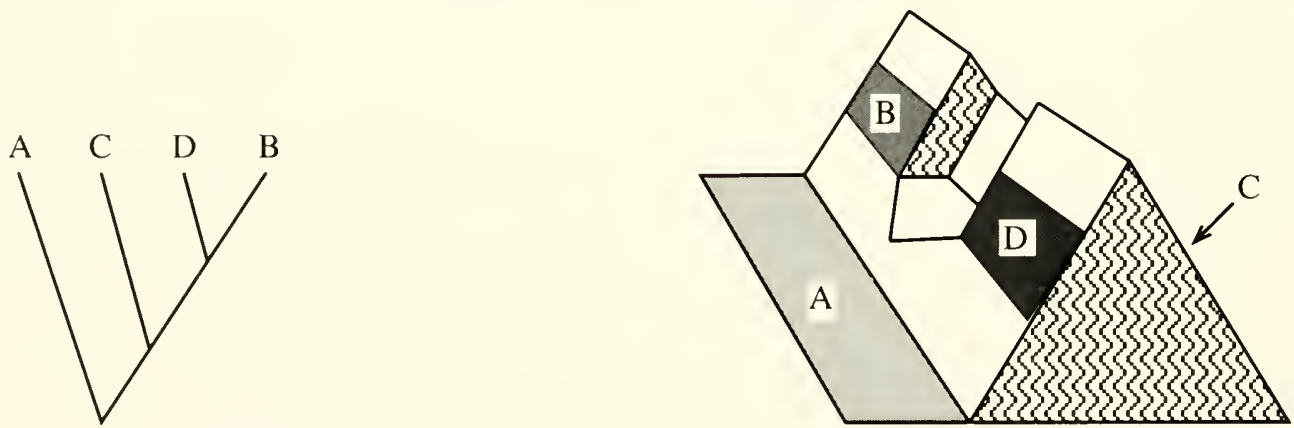

Fig. 85. Speciation model for taxa with respect to uplift and erosion of the Cordillera Occidental of the Andes. Changes in the Andes are shown in the diagrams to the right; phylogenetic history is shown in the cladograms to the left, and distributions of lineages are indicated by letters on the diagrams corresponding to letters in cladograms. Lineage $\mathrm{C}$ is a vicariant on the eastern slopes after continued uplift results in uninhabitable elevations that fragment the range of Lineage $\mathrm{B}$. 


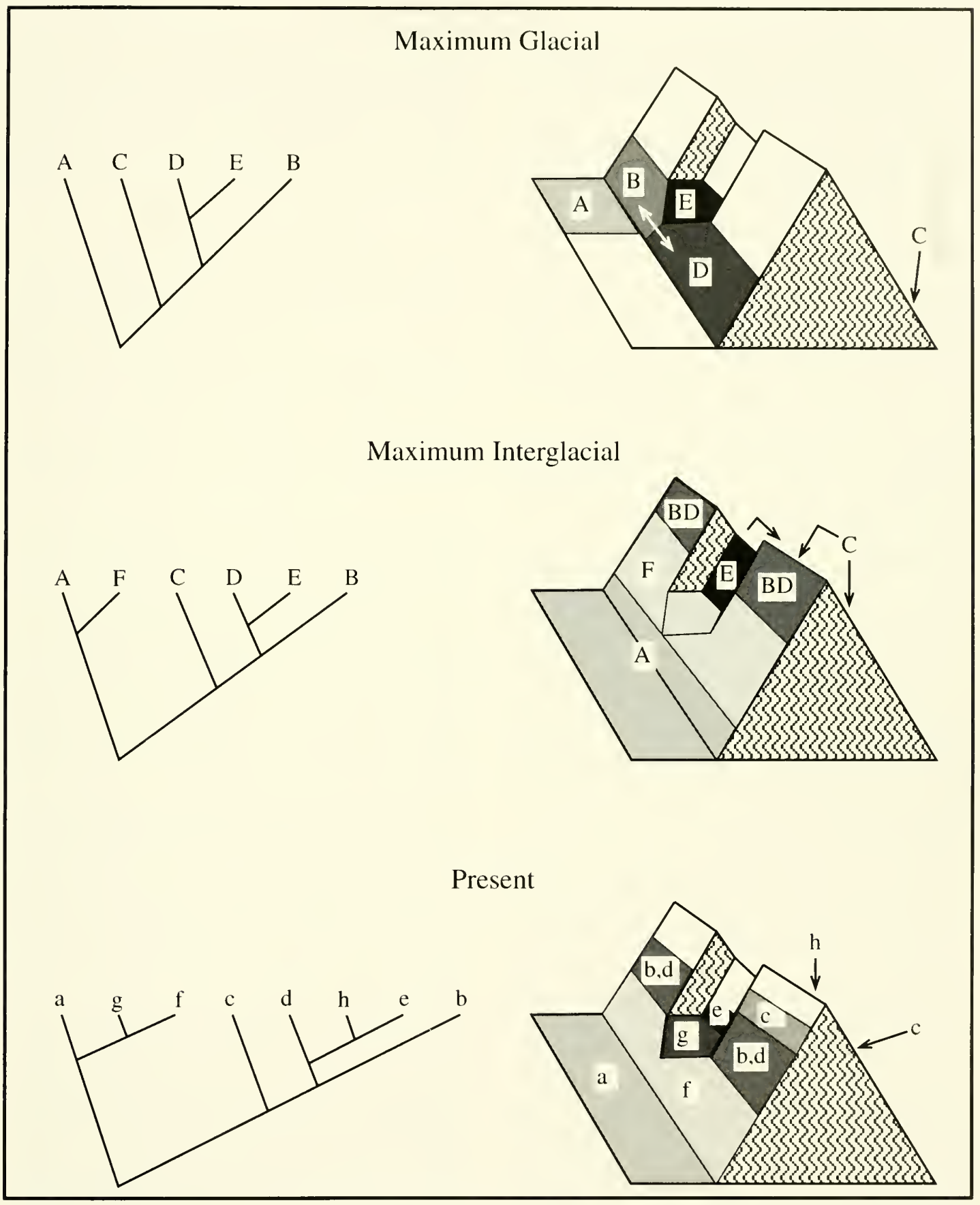

Fig. 86. Speciation model continued into the Quaternary. In Maximum Glacial, Lineage A is restricted to humid area in the lowlands; depression distributions of Lineages B and D results in their dispersal into the areas previously occupied by only one of the lineages. In the Maximum Interglacial. Lineages $\mathrm{C}$ and $\mathrm{E}$ disperse (indicated by angled arrows) across the crest of the mountains. In the Present, Species $\mathrm{H}$ has differentiated on the eastern slopes, whereas Species $\mathrm{C}$ is distributed on eastern and western slopes. Contemporaneous species (a$\mathrm{h}$, lower case identifiers) are products of lineages (identified by upper case letters in cladograms and diagrams representing earlier times). 
expanse of lowkand rainforest, the topography is more complex than in western Ecuador.

In contrast to 61 species of Eleutherodactylus in western Ecuador, 7 I species are known from the eastern slopes of the Andes and the Amazon Basin. The fowlands are inhabited by numerous species. As many as 16 species are known from Santa Cecilia at an elevation of $340 \mathrm{~m}$ (Duellman. 1978), and 15 species have been reported from Jatun Sacha at an elevation of $450 \mathrm{~m}$ at the base of the Andes (Flores and Vigle, 1994). Many of these species are widespread latitudinally in the upper Amazon Basin from southern Colombia and Ecuador southward to northern Peru (e.g., E. croceoinguinis, lanthanites, nigrovittatus), central Peru(e.g., E. martiae, sulcutus, and variabilis), and even southern Peru (e.g., E. altamazonicus, peruviamus, and ventrimarmoratus) (Lynch, 1980a, Duellman and Salas, 1991).

Of the species restricted to the Andean slopes, 20 occur to the north of the Pastaza Trench, and six of these enter the trench: 15 species occur south of the Pastaza Trench, and five of those enter the trench (Lynch and Duellman, 1980). In addition to these, E. emesti is restricted to high elevations on Volcán Sumaco (Flores, 1987), and E. condor and E. pecki are known only from the Cordillera de Cutucú and Cordillera del Cóndor (Duellman and Lynch, 1988).

The most striking contrast is in altitudinal distributions. Accumulated numbers of species at $100-\mathrm{m}$ increments throughout the latitudinal expanse of the country reveals that the greatest numbers of species occur at different elevations on the eastern and western slopes of the Andes (Fig. 66). On the western slopes, more species are found at elevations of 1400-2100 $\mathrm{m}$ than at other elevations, and as many as 28 species occur at elevations of 1800 $1900 \mathrm{~m}$. In contrast, on the eastern stopes, no more than 20 species are found within any $100-m$ increment, and these are at elevations of $2400-2700 \mathrm{~m}$. These altitudinal differences are apparent in the numbers of species in communities on the two slopes; on the eastern slopes, the largest community is 11 species at $1740 \mathrm{~m}$, and five other communities contain six or seven species (Lynch and Duellman, 1980). In contrast, seven communities on the western slopes of the Andes have six to thirteen species $(\bar{x}=10.7)$. On the other hand, communities in lowland rainforests contain more species in the eastem lowlands ( 16 at Santa Cecilia; 15 at Jatun Sacha) than those on the western lowlands ( 13 at Santo Domingo de los Colorados; 12 at Río Palenque).

\section{Comparisons with Other Taxa}

Only two other groups of frogs are represented by many species on the Pacific versant of Ecuador, but neither approaches the number of species of Eleutherodactylus. Seventeen species of centrolenids are known from the Pacific versant of Ecuador (Duellman and Burrowes, 1989). Four species (Centrolene prosoblepon, Cochranella spinosa, Hyalinobatrachimm fleischmanni, and $H$. valerioi) have extensive distributions in the lowlands and range at least from lower Central America through the humid tropical regime in western Ecuador; no centrolenids are known from the lowlands south of Quevedo, Provincia Los Ríos, Ecuador. Centrolene buckleyi occurs in the high Andes of Colombia to extreme northern Peru (Duellman and Wild, 1993), whereas the other species are restricted to the slopes of the Andes in southern Colombia and Ecuador; of these, Centrolene gemmatum, helodermatum, lynchi, peristictum, scirtetes, and Cochranella ocellifera are known only from elevations of 800-2000 $\mathrm{m}$ between $1^{\circ} \mathrm{N}$ Lat. and $1^{\circ} \mathrm{S}$ Lat. Thus, like Eleutherodactylus, centrolenids show a diminution of Chocoan species southward on the Pacific lowlands but a significant number of endemics in the cloud forests on the Pacific slopes of the Andes in Ecuador.

In contrast, dendrobatid frogs of the genus Colostethus exhibit a pattern of north-south geographic replacement, both in the lowlands and in the highlands. Fifteen species of Colostethus are known from the Pacific versant of Ecuador (Coloma. 1995). Colostethus talamancae is the only species that ranges from Central America to northwestern Ecuador. Colostethus chocoensis and C. Lehmanni extend from southern Chocoan Colombia into northwestern Ecuador, where these northern species broadly overlap $C$. awa and $C$. toachi in the lowlands and are replaced to the south by $C$. breviquartus and $C$. whymperi on the lowlands and lower slopes 
of the Andes. In contrast to patterns in Elentherodactylus, which seem to be restricted to more humid environments, C. machalilla oceurs in dry subtropical regime in the Cordillera de la Costa southward to about $3^{\circ} \mathrm{S}$. Lat., and $C$. infreguttatus inhabits dry subtropical habitats from about $1^{\circ} \mathrm{S}$ Lat. to at least $5^{\circ} \mathrm{S}$ Lat. in northern Peru. Four species (C. delatorreae, jacobuspetersi, maquipucuna, and vertebralis) inhabit western highlands, mostly above $2000 \mathrm{~m}$. There is no proliferation of species in the cloud forests in the Andes between $1{ }^{\circ} \mathrm{N}$ Lat. and $1{ }^{\circ} \mathrm{S}$ Lat.

With the exception of Gastrotheca, hylid frogs are represented by few species on the Pacific versant of Ecuador. Members of the Gastrotheca comnta group exhibit altitudinal replacement on the Pacific versant (Duellman, 1983b), whereas most members of the G. plumbea group show latitudinal replacement in the high Andes, but the sister species, G. plumbea and G. orophylax are on western and eastern slopes, respectively (Duellman and Hillis, 1987).

Bufonids are reasonably well represented on the Pacific versant of Ecuador. Again, the common pattern of diminution of Chocoan species (e.g., Bufo blombergi, coccifer, and haematiticus) exists. However, in Atelopus, four species (A. arthuri, coynei, longirostris, and mindoensis) are endemic to cloud forests on the Pacific versant in Ecuador. One species, A. elegans, in the Chocoan lowlands reaches the southern limits of its distribution in northwestern Ecuador; one species, A. balios, is known only from elevations of $350-650 \mathrm{~m}$ in the dry subtropical regime in southwestern Ecuador, and $A$. ignescens, prior to its great decline in the past decade, was widespread throughout the paramos of Ecuador and southern Colombia (Miyata, 1980b; Peters, 1973). As in Eleutherodacty/us, species of Atelopus on the western slopes of the Andes have relatives on the eastern slopes of the Andes. The three species of Andinopliryne exhibit latitudinal (A. atelopoides and $A$. olallai) and altitudinal ( $A$. colomai) replacement on the western slopes of the Andes in southern Colombia and Ecuador (Hoogmoed, 1985).

Among reptiles, only three genera of lizards are speciose in the region under consideration. At least 21 species of Anolis are known from the Pacific versant of Ecuador (Peters and Donoso-Barros, 1970); this region is the southern terminus of the genus in western South America. Five of these (A. auratus, biporcatus, chloris, latifrons, and tropidogaster) range from Central America to Ecuador; three others (A. culaemus, fraseri, and granuliceps) occur on the Pacific versant in $\mathrm{Co}$ lombia and Ecuador. Twelve species are endemic to the humid lowlands and cloud forests of the Pacific versant of Ecuador, and one species ( $A$. nigrolineatus) is the most southern species on the Pacific lowlands, where it occurs in the dry subtropical regime.

Gymnophthalmid lizards of the genus Proctoporus are speciose in the cloud forests of Ecuador. where nine species are endemic to the Pacific slopes (Kizirian. 1994): six of these are known only between $1^{\circ} \mathrm{N}$ Lat. and $1^{\circ} \mathrm{S}$ Lat. Gymnophthalmids of the genus Pholidobolus are represented by five species in Andean Ecuador; these lizards display a general pattern of latitudinal replacement in the high Andes throughout the length of the country (Montanucci, 1973; Hillis, 1985).

Thus, the same patterns exhibited by Elentherodactylus are evident in other groups of frogs and lizards. Although some species are widespread throughout the Chocoan lowlands (and northward into at least lower Central America) and reach the southern limits of their distributions in the humid lowland forests of western Ecuador, latitudinal replacement of species is common in the Chocoan lowlands and in the Andes, especially at higher elevations. Also, taxa inhabiting the upper western slopes of the Andes commonly have related species on the Amazonian slopes of the Andes. However. no other genera of amphibians or reptiles exhibit an amount of speciation on the Pacific slopes of the Andes between $1{ }^{\circ} \mathrm{N}$ Lat. and $1^{\circ} \mathrm{S}$ Lat. comparable to that in Eleutherodactylus, in which 27 species are endemic.

Woody plants (Gentry, 1982) and birds (Cracrult. 1985) show a gradual diminution of Chocoan species in the lowlands and on the Pacific slopes of the Andes. There is no great burst of endemic birds on the Pacific slopes of Ecuador, but there are many endemic species of plants both in the lowlands and on the slopes, which have not been thoroughly studied floristically. 


\section{FUTURE RESEARCH}

Assuming that we have encountered most of the species of eleutherodactyline frogs in western Ecuador, we consider the most urgent priority for future research is investigation of the putative decline in amphibian diversity and abundance during the past decade or so. Only a few biologists made the collections in the 1960s and 1970s that established western Ecuador as a region of species diversity; those collectors primarily were Kenneth Miyata and ourselves.

It is incontrovertible that habitat destruction has occurred at an accelerated rate in recent years (Dodson and Gentry, 1991; Parker and Carr, 1992; Mejía et al., 1995), and it seems plausible that habitat destruction would bring about coincident disappearance of apparently endemic species (especially the diversity "bubble" between $1^{\circ} \mathrm{N}$ and $1^{\circ} \mathrm{S}$ Lat.), but such disappearances are inferred based on tenuous evidence. Several investigators have worked in western Ecuador in the past decade (1985-1995), but those investigators may have far different field skills (search images and work habits) than did those who worked there earlier (19661980) when frog diversity seemed to be so great.

Before we agree that Eleutherodactylus surdus is on the verge of extinction, as claimed by Flores (1988a, 1993), we advocate a current estimate of its distribution and abundance by persons having field experience in its habitats; neither of us has collected at sites where E. surdus is known since 1978, when the species was abundant. Observing that no new records are available when no one has searched for the species in proper habitats at known sites of occurrence provides the illusion of a species (and biota) in peril.

Herein, we provide data on abundance of species of Eleutherodactylus at nine specific sites in western Ecuador; these data were accumulated in the period 1966-1978. By spending an equivalent number of collecting days (nights) at these sites, contemporary collectors should be able to gather sufficient data to determine the occurrence and abundance of the same (or other) taxa at these sites and thereby determine if changes in species composition and abundance have occurred at either local or regional scales. This is a unique opportu- nity and challenge to carry out nine ecological and biogeographic experiments and to provide potentially meaningful data pertaining to postulated declines in abundance of amphibian populations.

Although we have indicated that there is an area of endemicity over two degrees of latitude $\left(1^{\circ} \mathrm{N}-\right.$ $\left.1^{\circ} \mathrm{S}\right)$ on the western slopes of the Andes, we acknowledge that this assertion may be an illusion of past collecting efforts that focused on accessible and interesting sites rather than attempt to sample the fauna throughout the entire region. Aside from Patricia Burrowes's intensive fieldwork at La Planada, Departamento Nariño, Colombia (Lynch and Burrowes, 1990), little serious fieldwork has been carried out in western Nariño, Colombia. Thus, the postulated limit at $1^{\circ} \mathrm{N}$ Lat. is based more on failure to sample the herpetofauna immediately to the north than on the existence of latitudinal replacement of species.

Several species (e.g., E. crucifer, ornatissimus, and tenebrionis) were collected recently in northwestern Ecuador near the Colombian border; in each case the known distributions of these species were extended more than one degree of latitude to the north. It is unlikely that those distributions were (or are) disjunct; the gaps exist because little or no collecting has been done in the intervening area.

Now that descriptions, a key, and color illustrations are available for most of the eleutherodactyline frogs of western Ecuador, we anticipate an explosion of discoveries of distributional extensions that will render our stated distributions to be severe underestimates. However, we predict that our general conclusions concerning communities in altitudinal zones and relatively small distributional areas will be reinforced by additional sampling.

Some of the new species named herein $(E$. dissimulatus, gentryi, and truebae) have been known to us for nearly 30 years but are being described only now. Others (E. colomai and E. degener) have been discovered within the past 5 years; previously, we had noinkling of their existence. These species, as well as two undescribed taxa (seebelow) and an undescribed species of Phyllonastes (L. Coloma and JDL, in prep.), attest the fact that we are still in the discovery phase of documenting the eleuthero-dactyline fauna of westem Ecuador. 
We are aware of yet two more undescribed species of Eleutherodactylus in western Ecuador. One is a minute species from Provincia Esmeraldas; it is known from a single female found brooding an egg clutch in 1993 by Martha L. Crump. The other is represented by three specimens (an adult male and a juvenile female in an enclave of cloud forest west of Piñas, Provincia El Oro by WED in I975, and another immature female from Piñas collected by $\mathrm{H}$. Vargas in December 1994). Neither sample is judged to be adequate for a description, and we defer describing these species until additional material is available. ${ }^{1}$ The presence of these undescribed species is evidence of the incompleteness of the present endeavor and suggests that still other species may remain hidden in forest remnants in western Ecuador. We are concerned that small, isolated, enclaves of forest in southern Ecuador have not received sufficient attention. This is illustrated by the fact that three species obtained there by non-herpetologists either represent the only sample of a species (E. ruidus) or the most southern (and disjunct) records for the species (E. chalceus and E. gularis).

Although, in general, frogs of the genus Eleutherodacty/lus are sensitive to moisture, it should not be presumed that drier regions in southwestern Ecuador lack eleutherodactylines. Samples obtained on isolated hills along the coast by Ana Almendáriz, John Carr, and Alwin Gentry (Parker and Carr, 1992) surprised us, given our limited previous sampling in Provincia Manabí and our expectations that the region was too dry to support eleutherodactyline frogs.

Little did we image three decades ago that the 20th Century would be waning before our endeavors on the Eleutherodactylus in western Ecuador would come to fruition. In the intervening years we have learned much about these frogs and have become increasingly aware that there is so much yet to be known. We leave this challenge to our successors, to whom we bid: iQue les vaya bien!

\section{LITERATURE CITED}

Acosta-Solıs, M. 1984. Los Páramos Andinos del Ecuador. Quito, Ecuador: Publ. Cien. MAS.

Andersson, L. G. 1945. Batrachians from east Ecuador collected 1937, 1938 by Wm. Clarke-Macintyre and Rolf Blomberg. Ark. Zool. 37A(2): 1-88.

BARBour, T. 1908. Some new reptiles and amphibians. Bull. Mus. Comp. Zool. 51:315-325.

Barbour, T., and G. K. Noble. 1920. Some amphibians from northwestern Peru, with a revision of the genera Phyllobates and Telmatobius. Bull. Mus. Comp.Zool. 63:395-427.

Boettger, O. 1892. Katalog der Batrachier-Sammlung in Museum der Senckenbergischen Naturforschenden Gesellschaft in Frankfurt am Main. Frankfurt: Senckenbergische Naturf. Gesell.

Boulenger, G. A. 1882. Catalogue of the Batrachia Salientias. Ecaudata in the Collections of the British Museum. 2nd Ed. London: British Museum.

Boulenger, G. A. 1886. First report on additions to the

'In August 1995, we received from Luis A. Coloma a shipment of 74 Eleutherodactylus from western Ecuador. Included therein were 14 additional specimens of the small species collected earlier by M. L. Crump and specimens of three other species unknown to us. These will be treated in a subsequent paper. batrachian collection in the Natural History Museum. Proc. Zool. Soc. London 1886:411-416.

Boulenger, G. A. 1888. Note on the classification of the Ranidae. Proc. Zool. Soc. London I888:204-206.

Boulenger, G. A. 1898. An account of the reptiles and batrachians collected by Mr. W. F. H. Rosenberg in western Ecuador. Proc. Zool. Soc. London 1898: $107-$ 126, pls. 10-18.

Boulenger, G. A. 1899. Descriptions of new batrachians and reptiles collected by Mr. P. O. Simons in the Andes of Ecuador. Ann. Mag. Nat. Hist. (7)4:454 457.

Boulenger, G. A. 1902. Descriptions of new batrachians and reptiles from north-western Ecuador. Ann. Mag. Nat. Hist. (7)9:51-57.

Boulenger, G. A. 1912. Descriptions of new batrachians from the Andes of South America, preserved in the British Museum. Ann. Mag. Nat. Hist (8)10:185191.

Brown, K. S., Jr. 1982. Paleoecology and regional patterns of evolution in neotropical forest butterflies. Pp. 255-308 in Prance, G. T. (ed.), Biological Diversification in the Tropics. New York: Columbia Univ. Press.

Burrowes, P. A. 1987. An ecological study of a cloud forest herpetofauna in southern Colombia. Master's Thesis. Lawrence: Univ. Kansas. 
Cañadas C., L. 1983. El Mapa Bioclimático y Ecológico del Ecwador: Quito: Editores Asociados Cia., Ludi.

Cochran. D. M. 1948. A new subspecies of frog from ltatiaya, Brazil. Am. Mus. Novit. 1375:1-3.

Cochran, D. M., and C. J. Gorn. 1970. Frogs of Colombial. Bull. U.S. Natt. Mus. 288:1-655.

Colminalx, P. 1993. Pleistocene biogeography and diversity in tropical forests of South America. Pp.473499 in Goldblatt, P. (ed.). Biological Relationships Between Africa and Somth America. New Haven, Connecticut: Yale Univ. Press.

Coloma, L. A. 1991. Anfibios del Ecuador: Lista de Especies, Ubicaciom Altitudinal y Referencias Bibliográficas. Quito: Rept. Técn. EcoCiencia.

Coloma. L. A. 1995. Ecuadorian frogs of the genus Colostethus (Anura: Dendrobatidae). Misc. Publ. Nat. Hist. Mus. Univ. Kansas 87:1-72.

Cracraft, J. 1985. Historical biogeography and patterns of differentiation within the South American avifauna: areas of endemism. Ornithol. Monogr. 36:4984.

Despax. R. 1911. Reptiles et batraciens de l'Équateur recueillis par $\mathrm{M}$. le Dr. Rivet. Mission geodesique de l'Équateur 9B(2):17-44.

Dodson. C. H., and A. H. Gentry. 1985. Flora of Río Palenque. Selhyana $4: 1-628$.

Dodson. C. H., And A. H. Gentry. 1991. Biological extinction in western Ecuador. Ann. Missouri Bot. Gard. 78:273-295.

Dodson. C. H., A. H. Gentry, and F. de M. Valverde. 1985. Flora of Jameche, Los Ríos, Ecuador: Quito. Ecuador: Banco Central.

Duellman. W. E. 1978. The biology of an equatorial herpetofauna in Amazonian Ecuador. Misc. Publ. Mus. Nat. Hist. Univ. Kansas 65:1-352.

Duellman. W. E. 1979. The herpetofauna of the Andes: patterns of distribution, origin, differentiation, and present communities. Pp 371 -459 in Duellman. W. E. (ed.). The South American herpetofauna: its origin, evolution, and dispersal. Monogr. Mus. Nat. Hist. Univ. Kansas 7:1-485.

Duellman, W. E. 1983a. Compresión climática cuaternaria en los Andes: efectos sobre la especiación. Pp. 177-201, 269, 271, 278 in Salinas, P. J. (ed.), Zoologica Tropical, Actas VIII Congreso Latinoamericano de Zoología. Mérida, Venezuela: Univ. de Los Andes.

Duellman. W. E. 1983b. A new species of marsupial frog (Hylidae: Gastrotheca) from Colombia and Ecuador. Copeia 1983:868-874.

DuE LMAN, W.E. 1990. Herpetofaunasin neotropical rainforests: comparative composition, history, and resource use. Pp. 455-505 in Gentry, A. H. (ed.), Forr Neotropical Rainforests. New Haven, Connecticut: Yale Univ. Press.
Duetlman, W. E. 1992. A new species of the Eleutherodactylus conspicillatus group (Anura: Leptodactylidae) from northeastern Peru. Rev. Española Herpetol. 6:23-29.

Duellman, W. E. 1993. Amphibian species of the world: additions and corrections. Spec. Publ. Mus. Nat. Hist. Univ. Kansas 21:i-iii, 1-372.

Duellman, W. E., and P. A. Burrowes. 1989. New species of frogs. Centrolenella, from the Pacific verSint of Ecuador and southern Colombia. Occas. Pap. Mus. Nat. Hist. Univ. Kansas 132:1-14.

Duellman, W. E., and D. M. Hillis. 1987. Marsupial frogs (Anura: Hylidae: Gastrotheca) of the Ecuadorian Andes: resolution of taxonomic problems and phylogenetic relationships. Herpetologica 43:141173.

Duellman, W. E.. and M. Lizana. 1994. Biology of a sitand-wait predator, the leptodactylid frog Ceratoplurys cornutu. Herpetologica 50:51-64.

Duellman, W. E.. And J. D. Lynch. 1988. Anuran amphibians from the Cordillera de Cutucú, Ecuador. Proc. Acad. Nat. Sci. Philadelphia 140:125-142.

Duellman, W. E.. And A. W. Salas. 1991. An annotated checklist of the amphibians and reptiles of Cuzco Amazónico. Peru. Occas. Pap. Mus. Nat. Hist. Unjv. Kansas 143:1-13.

Duellman, W. E. and E. R. WiLd. 1993. Anuran amphibians from the Cordillera de Huancabamba, northern Peru: systematics, ecology, and biogeography. Occas. Pap. Mus. Nat. Hist. Univ. Kansas 157:1-53.

Dunn, E. R. 1926. Additional frogs from Cuba. Occas. Pap. Boston Soc. Nat. Hist. 5:209-215

Dunn, E. R. 1931. The amphibians of Barro Colorado Island. Occas. Pap. Boston Soc. Nat. Hist. 5:403421.

Dunn, E. R. 1933. Amphibians and reptiles from El Valle de Anton, Panama. Occas. Pap. Boston Soc. Nat. Hist. 8:65-79.

Dunn. E. R. 1934. Two new frogs from Darien. Am. Mus. Novit. 747:1-2.

Dunn, E. R. 1942. A new species of frog (Eleuthero(acty/us) from Costa Rica. Not. Nat. 104:1-2.

Dunn, E. R. 1944. Herpetology of the Bogotá area. Rev. Acad. Colombiana Cienc. Exacta Fis. Nat. 6:68-81.

Fairbridge, R. W. 1972. Climatology of a glacial cycle. Quat. Res. 2:283-302.

FLoRES. G. 1985. A new Eleutherodactylus from the Amazonian slopes of the Ecuadorian Andes. Herpetologica 41:447-450.

FLORES, G. 1987. A new Elentherodactylus from Volcán Sumaco, Ecuador. Herpetologica 43:90-95.

Flores, G. 1988a. A new species of Eleutherodactylus (Anura: Leptodactylidae) from the Pacific slopes of 
the Ecuadorian Andes, with comments on the E. devillei assembly. Copeia 1988:110-116.

Flores, G. 1988b. Two new species of Ecuadorian Elentherodactylus (Leptodactylidae) of the E. cruc $i$ fer assembly. J. Herpetol. 22:34-41.

Flores, G. 1993. A new species of earless Elentherodacty/us(Anura: Leptodactylidae) from the Pacific slopes of the Ecuadorian Andes, with comments on the Eleutherodactylus surdus assembly. Herpetologica 49: $427-434$.

Flores, G., and G. O. Vigle. 1994. A new species of Eleutherodactylus (Anura: Leptodactylidae) from the lowland rainforests of Amazonian Ecuador, with notes on the Eleutherodactylus fraterassembly. J. Herpetol. 28:416-424.

Foster, R. 1992a. Parque Nacional Machalilla (fog forest, dry forest, coastal scrub) site description and vegetation. Pp. 34-36 in Parker, IlI, T. A. and J. L. Carr (eds.), Status of forest remnants in the Cordillera de la Costa and adjacent areas of southwestern Ecuador. Conserv. Intern. RAP Working Pap. 2:1-172.

Foster, R. 1992b. Manta Real (cloud forest and wet forest) site description and vegetation. Pp 49-52 in Parker, III, T. A. and J. L. Carr (eds.), Status of forest remnants in the Cordillera de la Costa and adjacent areas of southwestern Ecuador. Conserv. Intern. RAP Working Pap. 2:1-172.

Fowler, H. W. 1913. Amphibians and reptiles from Ecuador, Venezuela, and Yucatan. Proc. Acad. Nat. Sci. Philadelphia 65:153-176, pls. 5-10.

Galvis V., J. 1982 ("1980”). Un arco de islas terciario en el occidente Colombiano. Geol. Colombiana 11:743.

Galvis V., J., and J. Mojlca. 1994. Geologia. Pp. 80-95 in Leyva, P. (ed.), Colombia Pacífico. Vol. 1. Bogotá. Colombia: Financeria Energética Nacional.

Gentry, A. H. 1982. Phytogeographic patterns as evidence for a Chocó refuge. Pp. 112-136 in Prance, G. T. (ed.), Biological Diversification in the Tropics. New York: Colombia Univ. Press.

Gentry, A. H. 1986. Species richness and floristic composition of Chocó region plant communities. Caldasia 15:71-91.

Gentry, A. H. 1988. Changes in plant community diversity and floristic composition on environmental and geographic gradients. Ann. Missouri Bot. Gard. 75:134.

Gentry, A. H. 1992. Additional botanical observations and transect data. Pp. 36-37 in Parker. II1, T. A. and J. L. Carr (eds.), Status of forest remnants in the Cordillera de la Costa and adjacent areas of southwestem Ecuador. Conserv. Intern. RAP Working Pap. 2:1-172.
Gorniam, S. W. 1966. Liste der rezenten Amphibien und Reptilien. Ascaphidae, Leiopelmatidae, Pipidae, Discoglossidae, Pelobatidae, Leptodactylidae. Rhinophrynidae. Das Tierreich 85:1-122.

Gunther, A. C. L. G. 1859. Second list of cold-blooded Vertebrata collected by Mr. Fraser in the Andes of westem Ecuador. Proc. Zool. Soc. London 1859:402422.

HafFer, J. 1969. Speciation in Amazonian forest hirds. Science 165:131-137.

HafFer, J. 1974. Avian speciation in tropical South America. Publ. Nuttall Ornith. Club 14:1-390.

HAFFER, J. 1979. Quaternary biogeography of tropical lowland South America. Pp. 107-140 in Duellman. W. E. (ed.), The South American herpetofauna: its origin, evolution, and dispersal. Monogr. Mus. Nat. Hist. Univ. Kansas 7:1-485.

Hedges, S. B. 1989. Evolution and biogeography of West Indian frogs of the genus Eleutherodactylus: slowevolving loci and the major groups. Pp. 305-370 in Woods, C. A. (ed.), Biogeograplyy of the West Indies/ Past, Present, and Future. Gainesville. Florida: Sandhill Crane Press.

Hedges, S. B., and R. Thomas. 1987. A new burrowing frog from Hispaniola with comments on the inoptatus group of the genus Eleutherodactylus (Anura: Leptodactylidae). Herpetologica 43:269-279.

Heyer. W. R. 1970. Studies on frogs of the genus Leptodactylus (Amphibia: Leptodactylidae). V1. Biosystematics of the melanonotus group. Contr. Sci. Los Angeles Co. Mus. 191:1-48.

Heyer, W. R., A. S. Rand, C. A. G. Cruz, O. L. Peixoto. And C. E. Nelson. 1990. Frogs of Boracéia. Arq. Zool. Mus. Zool. Univ. São Paulo 31:231-410.

HıLlis, D. M. 1985. Evolutionary genetics of the Andean lizard genus Plolidobolus (Sauria: Gymnophthalmidae): phylogeny, biogeography, and a comparison of tree construction techniques. Syst. Zool. 34:109-126.

Holdridge, L. R. 1947. Determination of world plant formations from simple climatic data. Science 105:367-368.

Holdridge, L. R. 1967. Life Zone Ecology: San José, Costa Rica: Tropical Science Center.

Hoogmoed, M. S. 1985. A new genus of toads (Amphibia: Anura: Bufonidae) from the Pacific slopes of the Andes in northern Ecuador and southern Colombia, with the description of two new species. Zool. Medel. 59:251-274.

Hutchinson, G. E. 1959. Homage to Santa Rosalia, or why are there so many kinds of animals? Am. Nat. 93:145-159.

Joglar. R. L. 1986. Phylogenetic relationships of the 
West Indian frogs of the genus Eleutherodactylus. Doctoral dissertation. Lawrence: Univ. Kansas.

Joglar, R. L. 1989. Phylogenetic relationships of the

West Indian frogs of the genus Eleutherodactylus: a morphological analysis. Pp. 37 1-408 in Woods, C. A. (ed.), Biogeography of the West Indies/Past, Present, and Future. Gainesville, Florida: Sandhill Crane Press.

KreBs, C. J. 1989. Ecological Methodology. New York: Harper Collins Publishers. Inc.

Kizirian, D. A. 1994. The alpha-level systematics of Ecuadorian Proctoporus and phylogenetic relationships among gymnophthalmid lizards. Doctoral dissertation. Lawrence: Univ. Kansas.

Leviton, A. E., R. H. Gibbs, Jr., E. Heal, and C. E. DAwson. 1985. Standards in herpetology and ichthyology: Part 1. Standard symbolic codes for institutional resource collections in herpetology and ichthyology. Copeia 1985:802-832.

LyNCH, J. D. 1968. Systematic status of some Andean leptodactylid frogs with a description of a new species of Eleutherodactylus. Herpetologica 24:289300.

LYNCH, J. D. 1969. Taxonomic notes on Ecuadorian frogs (Leptodactylidae: Eleutherodactylus). Herpetologica 25:262-274.

LyNCH, J. D. 1971 a (“1970”). Redescriptions of three little-known Eleutherodactylus from northwestern Ecuador (Amphibia: Leptodactylidae). Trans. Kansas Acad. Sci. 73:169-180.

LYNCH, J. D. 197 lb. Evolutionary relationships, osteology, and zoogeography of leptodactylid frogs. Misc. Publ. Mus. Nat. Hist. Univ. Kansas 53:1-238.

LYNCH, J. D. 1974. A new species of Eleutherodactylus (Amphibia: Leptodactylidae) from the Pacific lowlands of Ecuador. Proc. Biol. Soc. Washington 87:381387.

LYNCH, J. D. 1975a. A review of the broad-headed eleutherodactyline frogs of South America (Leptodactylidae). Occas. Pap. Mus. Nat. Hist. Univ. Kansas $38: 1-46$.

LYNCH, J. D. 1975b. The identity of the frog Eleutherodactylus conspicillatus (Günther), with descriptions of two related species from northwestern South America (Amphibia, Leptodactylidae). Contrib. Sci. Los Angeles Co. Nat. Hist. Mus. 272:119.

LyNCH, J. D. 1976a. New species of frogs (Leptodactylidae: Eleutherodactylus) from the Pacific versant of Ecuador. Occas. Pap. Mus. Nat. Hist. Univ. Kansas 55:1-33.

Lynch, J. D. 1976b. The species groups of the South American frogs of the genus Eleutherodactylus (Leptodactylidae). Occas. Pap. Mus. Nat. Hist. Univ. Kansas 61:1-24.
LynCH, J. D. 1976c. Three new leptodactylid frogs (genus Eleutherodactylus) from the Andean slopes of Colombia and Ecuador. Herpetologica 32:310-317.

LYNCH, J. D. 1977. A new frog (Leptodactylidae: Eleutherodactylus) from the Pacific lowlands of Ecuador. Copeia 1977:282-284.

LYNCH, J. D. 1979a. Leptodactylid frogs of the genus Eleutherodactylus from the Andes of southern Ecuador. Misc. Publ. Mus. Nat. Hist. Univ. Kansas 66:162.

LynCH, J. D. 1979b. A new frog species of the Eleutherodactylus fitzingeri group from the Pacific Andean versant in Ecuador. Herpetologica 35:228233.

LYNCH, J. D. 1979c. A new species of Eleutherodactylus from northern Ecuador (Amphibia: Leptodactylidae). Proc. Biol. Soc. Washington 92:498-504.

LYNCH, J. D. 1980a. A taxonomic and distributional synopsis of Amazonian frogs of the genus Eleutherodactylus. Am. Mus. Novit. 2696:1-24.

LYNCH, J. D. 1980b. Systematic status and distribution of some poorly known frogs of the genus Eleutherodactylus from the Chocoan lowlands of South America. Herpetologica 36:175-189.

LynCH, J. D. 1980c. Two new species of earless frogs allied to Eleutherodactylus surdus (Leptodactylidae) from the Pacific slopes of the Ecuadorian Andes. Proc. Biol. Soc. Washington 93:327-338.

LYNCH, J. D. 1980d. Eleutherodactylus eremitus, a new trans-Andean species of the lacrimosus assembly from Ecuador (Amphibia: Leptodactylidae). Breviora 462:1-7.

LYNCH, J. D. 1980e ("1979"). The identity of Eleutherodactylus vertebralis (Boulenger) with the description of a new species from Colombia and Ecuador (Amphibia: Leptodactylidae). J. Herpetol. 13:411-418.

LYNCH, J. D. 1981a. Leptodactylid frogs of the genus Eleutherodactylus in the Andes of northern Ecuador and adjacent Colombia. Misc. Publ. Mus. Nat. Hist. Univ. Kansas 72:1-46.

LYNCH, J. D. 1981b. The systematic status of Amblyphrynus ingeri (Amphibia: Leptodactylidae) with the description of an allied species in western Colombia. Caldasia 13:313-332.

Lynch, J. D. 1983. A new leptodactylid frog from the Cordillera Oriental of Colombia. Pp. 52-57 in Rhodin, A. G. J. and K. Miyata (eds.), Advances in Herpetology and Evolutionary Biology. Cambridge, Massachusetts: Mus. Comp. Zool., Harvard Univ.

LYNCH, J. D. 1984a. A new species of Eleutherodactylus (Amphibia: Anura: Leptodactylidae) from southern Andean Colombia. Herpetologica 40:234-237. 
LynCH, J. D. 1984b. New frogs (Leptodactylidae: Eleutherodacty/us) from cloud forest of the northern Cordillera Oriental, Colombia. Contr. Biol. Geol. Milwaukee Pub. Mus. 60:1-19.

LyNCH, J. D. 1986a. The definition of the Middle American clade of Eleutherodactylus based on jaw musculature (Amphibia: Leptodactylidae). Herpetologica 42:248-258.

LyNCH, J. D. 1986b. A new species of broad-headed Eleutherodactylus from the Cordillera Occidental of Colombia (Amphibia: Leptodactylidae). Caldasia 15:503-509.

LYNCH, J. D. 1986c. Origins of the high Andean herpetological fauna. Pp. 478-499 in Vuilleumier, F. and M. Monasterio (eds.), High Altitude Tropical Biology: New York: Oxford Univ. Press.

LYNCH, J. D. 1989a. Intrageneric relationships of mainland Eleutherodactylus (Leptodactylidae). I. A review of the frogs assigned to the Eleutherodactylus discoidalis species group. Contr. Biol. Geol. Milwaukee Publ. Mus. 79:1-25.

LyNCH, J. D. 1989b. The gauge of speciation: on the frequency of modes of speciation. Pp. 527-553 in Otte, D. and J. A. Endler (eds.), Speciation and Its Consequences. Sunderland, Massachusetts: Sinaur Associates, lnc.

LyNCH, J. D. 1990. A new large species of streamside Eleutherodactylus from western Colombia (Amphibia: Leptodactylidae). Herpetologica 46: 135-142.

LYNCH, J. D. 1992a. Two new species of Eleutherodactylus from southwestern Colombia and the proposal of a new species group (Amphibia: Leptodactylidae). J. Herpetol. 26:53-59.

LYNCH, J. D. 1992b. A new species of leptodactylid frog (Eleutherodactylus) from southwestern Colombia. Herpetologica 48:347-350.

LyNCH, J. D. 1993. The value of the $m$. depressor mandibulae in phylogenetic hypotheses for Eleutherodactylus and its allies (Amphibia: Leptodactyidae). Herpetologica 49:32-41.

LynCH, J. D. 1994. Two new species of the Eleutherodactylus conspicillatus group from the Cordillera Oriental of Colombia (Amphibia: Leptodactylidae). Rev. Acad. Colombiana Cien. Ex. Fis. Nat. 19:187193.

LYNCH, J. D. 1995. Three new species of Eleutherodactylus (Amphibia: Leptodactylidae) from páramos of the Cordillera Occidental of Colombia. J. Herpetol. 29:513-521.

LyNCH, J. D. 1996. The relationships of Hispaniolan frogs of the subgenus Pelorius (Eleutherodactylus: Leptodactylidae). Pp. 141-155 in Powell, R. and R. W. Henderson (eds.), West Indian Herpetology: A
Tribute to Albert Schwartz. Ithaca, New York: Soc. Study Amphib. Rept.

Lynch, J. D., And M. C. Ardila-Robayo. 1993. Eleutherodactylus anatipes. Cat. Am. Amph. Rept. 558:1-2.

LynCh, J. D., AND P. A. Burrowes. 1990. The frogs of the genus Eleutherodactylus (family Leptodactylidae) at the La Planada Reserve in southwestern Colombia with descriptions of eight new species. Occas. Pap. Mus. Nat. Hist. Univ. Kansas 136:1-31.

LynCh, J. D., and W. E. Duellman. 1980. The Eleutherodactylus of the Amazonian slopes of the Ecuadorian Andes (Anura: Leptodactylidae). Misc. Publ. Mus. Nat. Hist. Univ. Kansas 69: ]-86.

Lynch, J. D., And W. E. Duellman. 1995. A new fat little frog (Leptodactylidae: Eleutherodactylus) from lofty Andean grasslands of southern Ecuador. Occas. Pap. Nat. Hist. Mus. Univ. Kansas 173:1-7.

LynCH, J. D., AND K. Miyata. 1980. Two new species of Eleutherodactylus (Amphibia: Leptodactylidae) from the lowlands and lower cloud forests of western Ecuador. Breviora 457:1-12.

LynCH, J. D., AND C. W. Myers. 1983. Frogs of the fitzingeri group of Eleutherodactylus in eastern Panama and Chocoan South America (Leptodactylidae). Bull. Am. Mus. Nat. Hist. 175:48 1-572.

LynCh, J. D., ANd P. M. Ruíz-Carranza. 1983. New frogs of the genus Eleutherodactylus from the Andes of southern Colombia. Trans. Kansas Acad. Sci. 86:99112.

Lynch, J. D., P. M. Ruíz-Carranza, and M. C. ArdilaRoBayo. 1994. The identities of the Colombia frogs confused with Eleutherodactylus latidiscus (Boulenger) (Amphibia: Anura: Leptodactylidae). Occas. Pap. Nat. Hist. Mus. Univ. Kansas 170:1-42.

LynCh, J. D., And L. Trueb. 1980. A new species of Eleutherodactylus (Leptodactylidae) from the cloud forests of western Ecuador. Copeia 1980:392-396.

Mejía V., L. E., M. Castillo, and L. Zuñiga (eds.). 1995. Determinación de areas de bosques remanentes en la región occidental ecuatoriana. Fundación Natura. Quito, Serie Estudios 1:1-53.

Miller, K., ANd G. M. Zoghby. 1986. Thermal acclimation of locomotor performance in anuran amphibians. Can. J. Zool. 64:1956-1960.

Miyata, K. 1980a. Notes on the occurrence of Eleutherodactylus appendiculatus in Ecuador. J. Herpetol. 14:85-87.

Miyata, K. 1980b. A new species of Atelopus (Anura: Bufonidae) from the cloud forests of northwestern Ecuador. Breviora 458: 1-10.

Montanucci, R. R. 1973. Systematics and evolution of the Andean lizard genus Pholidobolus (Sauria: 
Teiidale). Misc. Publ. Mus. Nat. Hist. Univ. Kansas 59:1-52.

MoORe, J. A. 1939. Temperature tolerance and rates of development in the eggs of Amphibia. Ecology $20: 459-478$.

Myers, C. W., and W. E. Dutiman. 1982. A new species of Hyk from Cerro Colorado, and other tree lirog records and geographical notes from western Panama. Am. Mus. Novit. 2752:1-32.

Nelson, G.. and N. Platnick. 1981. Systematic's and Biogeography. Cladistics and Vicariance. New York: Columbia Univ. Press.

Nieden, F. 1923. Anural 1. Subordo Aglossa und Phaneroglossa, Sect. 1 Arcifera. Das Tierreich 46:ixxxii, 1-584.

Nobte, G. K. 1931. The Biology of the Amphibia. New York: McGraw-Hill Book Co.

PARKER, H. W. 1932. Some new or rare reptiles and amphibians from southern Ecuador. Ann. Mag. Nat. Hist. (10)14:264-273.

Parker. T. A.. III And J. L. Carr (eds.). 1992. Status of forest remnants in the Cordillera de la Costa and adjacent areas of southwestern Ecuador. Conserv. Intern. RAP Working Pap. 2:1-172.

PAYNTER, R. A., JR., And M. A. Traylor, JR. 1977. Onithological Gazetteer of Ecuador: Cambridge. Massachusetts: Mus. Comp. Zool., Harvard Univ.

Peters, J. A. 1955. Herpetological type localities in Ecuador. Rev. Ecuatoriana Entomol. Parasitol. 2:335352.

Peters, J. A. 1973. The frog genus Atelopus in Ecuador (Anura: Bufonidae). Smithsonian Contr.Zool. 145: 149.

Peters, J.A., and R. Donoso-Barros. 1970. Catalogue of the neotropical Squamata: Part 11. Lizards and amphisbaenians. Bull. U.S. Natl. Mus., 297:1-293.

Peters, W. 1874. Über eine neue Schildkrotenart. Cinosternon Effeldtii und einige andere neue oder weniger bekannte Amphibien. Monatsb. Deutsche Akad. Wissen. Berlin 1873:603-618.

Prance, G. T. 1982. A review of the phytogeographic evidences for Pleistocene climatic changes in the neotropics. Ann. Missouri Bot. Gard. 69:594-624.

Putnam, R. W., and A. F. Bennett. 1981. Thermal dependence on behavioural performance of anuran amphibians. Anim. Behav. 29:502-509.

Rodríguez, L. O. 1992. Structure et organization du peuplement d'anours de Cocha Cashu, Parc National Manu. Amazonie Péruvienne. Rev. Ecol. 47:151197.

Rome. L. C.. E. D. Stevens. And H. B. John-Alder. 1992. The influence of temperature and thermal acclimation on physiological function. Pp. 183-205 in Feder,
M. E. and W. W. Burggren (eds.), Environmental Physiology of the Amphibians. Chicago: Chicago Univ. Press.

Sauer. W. 1971. Geologievon Eculudor: Berlin: Gebrüder Borntraeger:

SavaGe, J. M. 1968. Distribution and synonymy of the neotropical frog. Eleutherodacty/us moro. Copeia 1968:878-879.

SAVAGE, J. M. 1975. Systematics and distribution of the Mexican and Central American stream frogs related to Eleutherodactylus rmgulosus. Copeia 2975:254306.

Savage, J. M. 1981. The systematic status of Central American frogs confused with Elentherodactylus cruentus. Proc. Biol. Soc. Washington 94:413-420.

Savage, J. M. 1987. Systematics and distribution of the Mexican and Central American rainfrogs of the Eleutherodactylus gollmeri group (Amphibia: Leptodactylidae). Fieldiana Zool. (NS) 33:1-57.

Savage, J. M., And W. R. Heyer. 1967. Variation and distribution in the treefrog genus Phyllomedusa in Costa Rica, Central America. Beitr. Neotrop. Fauna 5:111-131.

Savage, J. M., J. R. McCranie, and L. D. Wilson. 1988. New upland frogs of the Eleutherodactylus rugulosus group (Amphibia: Anura: Leptodactylidae) from Honduras. Bull. S. California Acad. Sci. 87:50-56.

Schluter, A. 1984. Ökologische Untersuchungen an einem Stillgewasser im tropischen Regenwald von Peru unter besonderer Berucksichtigung der Amphibien. Doctoral Dissertation. Hamburg: Univ. Hamburg.

Simberloff, D., and W. Boecklen. 1981. Santa Rosalia reconsidered: size ratios and competition. Evolution 35:1206-1228.

Simpson, B. 1975. Pleistocene changes in the flora of the high tropical Andes. Paleobiology 1:273-294.

Simpson, B. 1979. Quatemary biogeography of the high montane regions of South America. Pp. 157-188 in Duellman, W. E. (ed.), The South American herpetofauna: its origin, evolution, and dispersal. Monogr. Mus. Nat. Hist. Univ. Kansas 7: 1-485.

Stuart, L. C. 1955. A briel review of the Guatemalan lizards of the genus Anolis. Misc. Publ. Mus. Zool. Univ. Michigan 91:1-31.

ToFt, C. A. 1985. Resource partitioning in amphibians and reptiles. Copeia 1985: 1-21.

Townsend, D. S., and M. M. Stewart. 1986. The effect of temperature on direct development in a terrestrialbreeding neotropical frog. Copeia 1986:520-523.

Trewartha. G. T. 1943. An Introduction to Weather and Climate. New York: McGraw-Hill Book Co.

TRUEB, L. 1969. Variation in the tree frog Hyla lancasteri. Copeia 1968:285-299. 
Trueb, L. 1993. Patterns of cranial diversity among the Lissamphibia. Pp. 255-343 in Hanken, J. and B. K. Hall (eds.). The Skull. Vol. 2. Patterns of Structural and Systematic Diversity. Chicago: Univ. Chicago Press.

Valencia, R., And P. M. Jorgensen. 1992. Composition and structure of a humid montane forest on the Pasochoa Volcano, Ecuador. Nordic J. Bot. 12:239247.

VALVERde, F. DE M. 1991. Estado Actual de la Vegetación Natural de la Cordillera de Chongón-Colonche. Guayaquil, Ecuador: Univ. Guayaquil.

VAN DER HAMmEN, T. 1974. The Pleistocene changes of vegetation and climate in tropical South America. J. Biogeogr. 1:3-26.

van der Hammen, T., and A. M. Cleeff, 1986. Development of the high Andean páramo flora and vegetation. Pp. 153-201 in Vuilleumier, F. and M. Monasterio (eds.), High Altitnde Tropical Biogeography. New York, London: Oxford Univ. Press.

Vuilleumier, B. S. 1971. Pleistocene changes in the fauna and llora of South America. Science 173:771780 .

Wever. E. G. 1985. The Amphibian Ear: Princeton. New Jersey: Princeton Univ. Press.

Werner, F, 1894. Herpetologische nova. Zool. Anz. 17:410-415.

Werner, F. 1899. Ueher Reptilien und Batrachier aus Colombien und Trinidad. Verhand. Zool.-Bot. Gesell. Wien 49:47 I-484.

WhYMPER, E. 1892. Travels amongst the Great Andes of the Equator: 2nd Ed. London: John Murray.

Wiens, J. J., And L. A. Coloma. 1992. A new species of the Elentherodactitus myersi (Anura: Leptodactylidae) assembly from Ecuador. J. Herpetol. 26:196-207.

ZetL, W. 1979. The Andes: A Geological Review: Berlin: Gebriider Borntraeger.

ZWEIFEL, R. G. 1968. Reproductive biology of anurans of the arid southwest, with emphasis on adaptation of embryos to temperature. Bull. Am. Mus. Nat. Hist. 140:3-64.

\section{APPENDIX I}

\section{SPeCIMENS Examined}

The 5360 specimens identified to species from the Pacific versant of Ecuador are documented below, alphabetically by species. Localities are arranged alphabetically by provinces, which also are arranged alphabetically. Within a locality, specimens are arranged chronologically by catalogue number following museum abbreviations, which

\section{Eleutherodactylus achatinus (923 specimens)}

Ecuador: Prov: Azuay: $0.9 \mathrm{~km}$ W Luz María, 1770 m, QCAZ 7803; $7.7 \mathrm{~km}$ W Luz María, $1300 \mathrm{~m}$, QCAZ 7804-08; $11.2 \mathrm{~km}$ W Luz María. 930 m, QCAZ 780911: $12.9 \mathrm{~km}$ W Luz María, $740 \mathrm{~m}$, QCAZ 7812-13: $13.5 \mathrm{~km}$ W Luz María. $740 \mathrm{~m}$, QCAZ 7814-15. Prov. Bolivar: Balsapamba, $800 \mathrm{~m}, \mathrm{KU}$ 130387-453. Prov: Cañar: Chimbo, BM 98.3.1.31-32. Prov. Carchi: Maldonado, $1410 \mathrm{~m}, \mathrm{KU}$ 177597-611: Río Baboso. near Lita, MECN-LAC 30, 35, 37-40, 43-47, 49, 62. $65,78,80-81,107,120-22,126,144-46,150-51 ; 2$ km NE Río Blanco, $930 \mathrm{~m}$, USNM 204640-42. Prov: Chimborazo: Pagma Forest. ANSP 18244 (holotype of Hylodes pagmae); Río Pescado, 1600 lt. AMNH $17546-$ 47, 17550, 17634-35. Prov. Cotopaxi: Las Pampas, QCAZ 295, 543-48, 562; $3 \mathrm{~km}$ E Macuchi, $1500 \mathrm{~m}$. USNM 204636-37;18.6 km W Pilaló. $930 \mathrm{~m} . \mathrm{KU}$ 141751; 20.3 km W Pilaló, $830 \mathrm{~m}, 141769$. Prol: El are listed alphabetically. Localities that we believe to be incorrect are listed at the end of the records for a given species as erroneous locality. Only specimens from the Pacific versant of Ecuador are listed here; specimens from southern Ecuador listed by Lynch (1979) are not included. For detailed information on localities, see Appendix II.

Oro: $7 \mathrm{~km}$ NE Buena Vista, I00 ft, USNM 204643-49: Gualtaco. USNM 20465 I-57; 7 km ESE Machaliı, 10 m. USNM 204650; $3 \mathrm{~km}$ E Pasaje, $30 \mathrm{~m}$. AMNH 89738-42; $18 \mathrm{~km}$ W Piñas, $780 \mathrm{~m}, \mathrm{KU}$ 165088-92: 4.4 km NW Piñas, 1100 m, KU 141770-71. Pror: Esmeraldas: Bulum. UMMZ 58907; Cachabé. BM 1947.2.15.69 (holotype): $1 \mathrm{~km}$ SW Cachabé, $20 \mathrm{~m}$. USNM 204628-29; El Cristal, $1200 \mathrm{~m}$, ECO 72-76: Pambelar, BM 1901.6.27.13:2-4 km W Placer, 360$390 \mathrm{~m}$. USNM 204624-27: $10.5 \mathrm{~km}$ N Quininclé, I 30 m. KU 14 1747: region of Río Caoni, sector de Lagarterat. UIMNH 53425, 53428-30; Río San Miguel, ca. 1 km upstream from Río Cayapas, MCZ 92931-32, 92940, 92947-49; Río Cupa, EPN 1422-26; Salidero, 350 ft, BM 1901.8.3.13; San Javier. AMNH 10708, UIMNH 55720; San Miguel, EPN 1105, I120, MCZ 92942-46; $38 \mathrm{~km}$ NW Santo Domingo de los Colorados, $1000 \mathrm{ft}$, USNM 204609-15, 204617-21: 31 km NNW Santo Domingo de los Colorados, 1000 fi, USNM 204616. 
204622-23. Prol: Guayas: Bucay, 900 ft, AMNH 16250, 16987-88; $20 \mathrm{~km} \mathrm{~W} \mathrm{Guayas,} 300 \mathrm{ft}$, USNM 204660; Naranjal, AMNH 17631-32; near junction of Río Chimbo and Río del Oro, 2000 ft, CAS-SU 9434; Río Frío, UMMZ 123899. Prov: Imbabura: Lita, 520 m, KU 132605-09, MECN-LAC 226, 228, USNM 204658; Paramba, BM 98.3.1.30; Río Parambas, lbarraLita road, EPN 1112. Prov: Los Ríos: Echeandía, EPN 1462, 1468: Estación Biologica Río Palenque, $220 \mathrm{~m}$, AMNH 89730-32, KU 146049-55, 147557-60, 152572, 165082-87, 180638, MCZ 88427-30, 8990104. $89918,89920-26,89928-38,89940-47,92114$, 93456-62, 93464, 93468-72, 93474-75, 94800-06, 118035 (hatchlings); Quevedo, USNM 204630; $1 \mathrm{~km}$ N Quevedo, 300 ft, USNM 204631-35; 1 mi N Quevedo (Finca Playa Grande), UIMNH 93149-52; 4 km N Quevedo, 140 m, KU 130365-86, 135326-38; 3 km E Quevedo, MCZ 89913-15. Prov. Manabi: $2 \mathrm{~km} \mathrm{~W}$ Desvío, 250 m, USNM 204659; 38 km NW El Carmen, $330 \mathrm{~m}$, QCAZ 7816; $50 \mathrm{~km}$ WSW El Carmen, $400 \mathrm{~m}$, MCZ 92014-18; 23 km N Manglaralto, $120 \mathrm{~m}, \mathrm{MCZ}$ 92038-47; 25 km N Manglaralto, 60 km, MCZ 9201920: Río Ayampe, $25 \mathrm{~km} \mathrm{N,} 3.7 \mathrm{~km}$ E Montañita, $70 \mathrm{~m}$, QCAZ 7817-23; Río Cuaque, E of Pedernales, $190 \mathrm{~m}$, QCAZ 7824-25. Prov. Pichincha: $1 \mathrm{~km}$ N Buena Fé, MCZ 89905-12, 93320-419; 25.8 km W Chiriboga, 1720 m, KU 141748; Dos Ríos, 1270 m, KU 135491 93: 4 km E Dos Ríos, $1140 \mathrm{~m}$, KU 165093-111, 202285-86; 3 km W Dos Ríos, 1050 m, KU 14176567; Finca La Esperanza, NW of Santo Domingo de los Colorados, EPN 1380, 1384, 1417; Guatea, $2900 \mathrm{ft}$, BM 1920.2.9.8-9; La Concordia, Bosque Protector La Perla, 190 m, KU 217808, QCAZ 7826-32; 5.3 km W La Concordia, $190 \mathrm{~m}$, QCAZ 783-35; $5 \mathrm{~km} \mathrm{NW} \mathrm{La}$ Florida, 860 m, QCAZ 7836; La Palma, 920 m, KU 177618-21; 5 km E La Palma, 900 m, KU 165112-19; 12.6 km E La Palma, MCZ 92847; 14.4 km E La Palma, 1380 m, MCZ 91986; 16 km E La Palma, 1500 m, MCZ 89917; 22 km E La Palma, 1770 m, MCZ 89916; Llambo, USNM 204606-08; Miligali, USNM 204599600; Mindo, $4000 \mathrm{ft}$, UMMZ 55518; $18 \mathrm{~km} \mathrm{~N} \mathrm{Mindo,}$ USNM 204584; $3.5 \mathrm{~km} \mathrm{NE} \mathrm{Mindo,} 1540 \mathrm{~m}$, KU 165120-27, 165504; 1 km E Mindo, USNM 20457383; 4 km N Nanegal Chico, UMMZ 132918 (4); $1.5 \mathrm{~km}$ SW Nanegal Chico, USNM 204594-95; 5 km NW Nanegal Chico, USNM 204588-90; 10 km NW Nanegal Chico, USNM 204591-93; Nanegalito, USNM 204585-87; Pachijal, USNM 204601; Pacto, USNM 204603; below Pacto, USNM 204602; Playa Rica, QCAZ 865-67; Puerto de lla, USNM 204604; 8 km ESE Puerto Quito, $530 \mathrm{~m}$, KU 165128; 46 km N Quevedo (Hda. Cerro Chivo), MCZ 91987-92013; Río
Baba, $10 \mathrm{~km} \mathrm{~S}, 4 \mathrm{~km}$ ES Santo Domingo de los Colorados, 400 m, KU 141752-64, 146056-59; Río Baba, 24 km $\mathrm{S}$ Santo Domingo de los Colorados, UIMNH 93148; Río Canoi, $4 \mathrm{~km} \mathrm{~S}$ Vicente Maldonado, $570 \mathrm{~m}$, २CAZ m7837-38; Río Faisanes, 13.5 km E La Palma, 1380 m. KU 180639, MCZ 94470, 94917-18; Río Sapayo, 450 ft, BM 1902.7.29.25; Río Toachi, USNM 20459698; Río Toachi, 8 km E Alluriquín, 800 m, KU 141768; San Miguel de los Colorados, USNM 204605: Santo Domingo de los Colorados, 500-660 m, FMNH 173070-71, KU 117778-79, 119465-71, 119472 (C\&S), 141749-50, 109060, 177612-16, USNM 204549-53; $1 \mathrm{~km} \mathrm{N,} 2$ km E Santo Domingo de los Colorados, $620 \mathrm{~m}$, KU 177617; 2 km E Santo Domingo de los Colorados, 670 m, USNM 204566-68; 6 km E Santo Domingo de los Colorados, USNM 204569-73; $16 \mathrm{~km} \mathrm{E}$ Santo Domingo de los Colorados, MCZ 93318-19; 35 km E Santo Domingo de los Colorados (Hda. Lelia), CAS-SU 10607-09, 10614; 8 km SE Santo Domingo de los Colorados, UMMZ 132916 (4); $0.5 \mathrm{~km}$ S Santo Domingo de los Colorados, $670 \mathrm{~m}$, USNM 204554; $24 \mathrm{~km} \mathrm{~S}$ Santo Domingo de los Colorados ( 4 km E Río Baba bridge), UIMNH $93153-$ $54 ; 5 \mathrm{~km}$ W Santo Domingo de los Colorados, USNM 204555; $9 \mathrm{~km} \mathrm{~W}$ Santo Domingo de los Colorados (Hda. Espinosa), CAS 94853-54, CAS-SU 10481-92, 10495; 6 mi W Santo Domingo de los Colorados, CAS $85180 ; 18 \mathrm{~km}$ W Santo Domingo de los Colorados, USNM 204556-65; Tandapi, 1500 m, KU 111306-08 (C\&S), 111278-305, 111309-44, 120256-60, 13546368, 135470, 135483-84, 135487-88, MCZ 75172-74; $2.1 \mathrm{~km}$ E Tandapi, $1500 \mathrm{~m}, \mathrm{MCZ} 92839$; Tinalandia, 700 m, KU 202278-84, MCZ 88420, 88426, 89883900; 1 km E Vicente Maldonado, 670 m, KU 218226 , QCAZ 7839-42. Prov. Undetermined: $\mathrm{Km} 94$, Guayaquil-Cuenca road, CAS 94787. Erroneous LoCALITY: Prov. Cotopaxi: region of Sigchos, USNM 204638-39. Prov: Pichincha: $10 \mathrm{~km}$ E Chiriboga, 7000 ft, USNM 204548. No DATA: EPN 1442, MECN 175, UIMNH 90297-98.

\section{Eleutherodactylus actites (250 specimens)}

Ecuador: Prov. Cotopaxi: La Esperanza, $1500 \mathrm{~m}$, KU 131261-62; Pilaló, 2100-2800 m, KU 120111 (holotype), 120112-24, 131210-60, 141776-93, 141794-832, 177622-24, 202287-302, 202616, MCZ 103977; 2 km W Pilaló, 1820 m. UIMNH 90299-302, USNM 239616-25; 3 km W Pilaló, $1760 \mathrm{~m}$, USNM 239557-615. Erroneous Locality: Prov. Cotopaxi: Latacunga, $2770 \mathrm{~m}, \mathrm{MCZ} 104025$. 


\section{Eleutherodacty/us anatipes (4 specimens)}

Ecuador: Prov. Carchi: Maldonado, $1410 \mathrm{~m}, \mathrm{KU}$ 177625, 177626 (holotype). Prov. Esmeraldas: $2 \mathrm{~km} \mathrm{~S}$ junction of Río Lita and Río Mira. $520 \mathrm{~m}$, USNM 233092-93.

\section{Eleutherodactylus anomalus (56 specimens)}

Ecuador: Prov. Esmeraldas: Cachabé, BM 1947. 16.8-10 (syntypes); Lagarto, Reserva Mayronga, 100 m, QCAZ 4729-30, 4319, 4437-39; Río Cupa, CASSU 11455, USNM 204714; San Miguel-Telembí, EPN 1359; $38 \mathrm{~km}$ NW Santo Domingo de los Colorados, 1000 ft, USNM 204719-20. Prov. Esmeraldas: Estación Biologica Río Palenque, 220 m, KU 165129-32, MCZ 93420-22, UMMZ 127891 (4); USNM 285345-47. Prov. Pichincha: Río Toachi, USNM 204718; Santo Domingo de los Colorados, 580 m, FMNH 174027, KU 177627-29; 1 km N, 2 km E Santo Domingo de los Colorados, $620 \mathrm{~m}$, KU 177630-32; 6 km E Santo Domingo de los Colorados, USNM 204715-16; $35 \mathrm{~km}$ E Santo Domingo de los Colorados (Hda. Lelia), CASSU 10606; 8 km SE Santo Domingo de los Colorados, UMMZ 132815; $0.5 \mathrm{~km}$ S Santo Domingo de los Colorados, 670 m, USNM 204717; 9 km W Santo Domingo de los Colorados (Hda. La Espinosa), CASSU 10467-80; Tinalandia, 700 m, USNM 285960.

\section{Eleutherodactylus apiculatus (3 specimens)}

Ecuador: Prov. Pichincha: $4 \mathrm{~km}$ W Chiriboga, 2120 m, KU 142165-66; 6.2 km E Tandapi, Río Corazón, 1750 m, MCZ 98078.

\section{Eleutherodactylus appendiculatus (51 specimens)}

Ecuador: Prov. Cotopaxi: Las Pampas, QCAZ233, 587-89; Prov. Pichincha: $14 \mathrm{~km} \mathrm{~W}$ Chiriboga, $1960 \mathrm{~m}$, KU 165142; $25.7 \mathrm{~km}$ from La Palma on Hwy 28 (old road to Quito), $1820 \mathrm{~m}, \mathrm{MCZ}$ 91884-85, 94815-22; Las Máquinas, $3 \mathrm{~km}$ NW San Ignacio, AMNH 20143; Las Palmeras, QCAZ 853; Lloa, QCAZ 7968; Quebrada Zapadores, 5 km ESE Chiriboga, 2010 m, KU $165133-$ 41, 166230 (lot of young), 166264 (C\&S), 177634-37, MCZ 98030, USNM 285925; Río Blanco, USNM 204713; Río Faisanes, QCAZ 599; Tandapi, $1460 \mathrm{~m}$, QCAZ 129, 164, 600;6.2 km E Tandapi, $1750 \mathrm{~m}, \mathrm{MCZ}$ 91886; Tandayapa, 2300 m, CAS-SU 11460-61, USNM 204712. Prov. undetermined: "Ecuador," NHM 16507 (holotype). Erroneous Locality: Prov. Pastaza: Mera, Río Pastaza, AMNH 52841-42.

\section{Eleutherodactylus babax (2 specimens)}

Ecuador: Prov. Pichincha: $2 \mathrm{~km}$ E Tandapi, Quebrada La Plata, 1550 m, USNM 285970; 6.2 km E Tandapi, $1750 \mathrm{~m}$, MCZ 92031.

\section{Eleutherodactylus cajamarcensis (8 specimens)}

Ecuador: Prov. Azuay: Luz María, 1800 m, KU 217853-56, QCAZ 7889-92.

\section{Eleutherodactylus calcarulatus (221 specimens)}

Ecuador: Prov. Carchi: $14 \mathrm{~km}$ SE Maldonado, 2500 m., KU 179273. Prov. Cotopaxi: Reserva Otonga, $2100 \mathrm{~m}$, QCAZ 4545. Prov. Imbabura: $23 \mathrm{~km} \mathrm{~W}$ Apuela, 2190 m, KU 179385-86; above Cuellaje, 2560 m, ECO 251, QCAZ 8050-59, 8063-71; La Delicia, 2700 m, KU 132754, 132758-66, 132768-69, 13277176, 177652-57, 179384. Prov. Pichincha: $14 \mathrm{~km} \mathrm{~W}$ Chiriboga, $1960 \mathrm{~m}$, KU 165160-61, 165869-70; 4 km NE Dos Ríos, $1140 \mathrm{~m}$, KU 165159; 14.4 km E La Palma, $1380 \mathrm{~m}, \mathrm{MCZ}$ 91892; $25.7 \mathrm{~km}$ E La Palma, 1820 m, MCZ 94857-58, 94945; Mindo (Hda. San Vicente), 1465-1620 m, USNM 284352: $3.5 \mathrm{~km} \mathrm{NE}$ Mindo, 1540 m, KU 165162-89, 166266 (C\&S); Reserva Florística-Ecológica Río Guajalito, QCAZ 6434, 6558; Río Faisanes, 13.5 km E La Palma, 1280 m, MCZ 92086, 92106, 94814, 95498, 93423, USNM 285873; 1 km SW San Ignacio, 1920 m, KU 177662 , 179097-105; Tandapi, 1460 m, AMNH 114500-05, BM 1969.659-61, KU 111216-17, 111218 (holotype), 111219-40, 111242-75, 111276-79 (C\&S), 117774$75,120255,120270-76,135455-57,177659-61, \mathrm{MCZ}$ 75170-71, 75175-77; $2.1 \mathrm{~km}$ E Tandapi, $1500 \mathrm{~m}, \mathrm{MCZ}$ 94718, 94863, 95496-97, 95609-11, 98032, USNM 285972-73; 6.2 km E Tandapi, 1750 m, MCZ 9189394, 98076, USNM 285940. 2 km E Tandayapa, USNM 233094; 1 km SW Tandayapa, 1640 m. MCZ 90336. USNM 285949; 4.5 km W Tandayapa, QCAZ 4789.

\section{Eleutherodactylus caprifer (52 specimens)}

Ecuador: Prov. Carchi: Río Baboso, near Lita, MECN-LAC 50-51, 56, 87-88, 137. Prov. Esmeraldas: Cachabé, BM 98.3.1.29. Prov. Pichincha: $5 \mathrm{~km} \mathrm{NW} \mathrm{La}$ Florida, QCAZ 577-79, 581; La Palma, 920 m, KU 131589 (holotype), 131590-602, 177663-82; $1.1 \mathrm{~km}$ E La Palma, MCZ 95630-35. Erroneous locality: Prov. Cotopaxi: Las Pampas, QCAZ 500. 


\section{Eleutherodactylus relator (68 specimens)}

ECUAdOR: Prov: Carchi: $14 \mathrm{~km}$ SE Maldonado, 2500 m. AMNH 114527-31, KU 177684 (C\&S), 177689(C\&S), 177690-725. Prov: Imbabura: $22 \mathrm{~km} \mathrm{E}$ Apuela, 2860 m, QCAZ 2842-43; La Delicia, 2700 m, KU 131573 (holotype), 131574-88, 177726-29. Prov: Pichincha: Lloa, QCAZ 7972; $9.5 \mathrm{~km}$ NW Nono, 2530 $\mathrm{m}, \mathrm{KU} \mathrm{165200-()1.}$

\section{Eleutherodactylus cerastes (16 specimens)}

ECUADOR: Prol: Imbabura: Lita, USNM 19578688. 195795. Prov. Pichincha: Pachijal, USNM 19578993. MCZ 89462: road from Pacto to Guayllabamba, USNM 195797: Palma Real, USNM 195785 (holotype), 195794; Río Pitsará, USNM 195796 (3).

\section{Eleutherodactylus chalceus (140 specimens)}

Ecuador: Prol: Carchi: Maldonado, $1410 \mathrm{~m}, \mathrm{KU}$ 177638. Pros: Esmeraldas: Alto Tambo, 830 m. QCAZ 1259, 1291-93: Cachabé, BM 1947.2.15.38 (syntype of Syrrhophus areolatus); $10.5 \mathrm{~km} \mathrm{~N}$ Quinindé, KU 141774-75: Río San Miguel, ca $1 \mathrm{~km}$ upstream from Río Cayapas. MCZ 92972-76, 93016: San Miguel, MCZ 92977-80, QCAZ 166-67; 38 km NW Santo Domingo de los Colorados, $1000 \mathrm{ft}$, USNM 20473032. Prov. Imbabura: Lita, $570 \mathrm{~m}$, QCAZ 1309. Prov. Guayas: Chimbo, BM 1947.2.15.39 (syntype of Syrhopluts areolatus). Prov. Esmeraldas: Estación Biológica Río Palenque, 220 m, MCZ 88415-16, 89948-53. 91890. 92836. Prov. Pichincha: Centinela, $14.1 \mathrm{~km}$ ESE Patricia Pilar, 550-600 m, USNM 28556380; 4 km E Dos Ríos, 1120 m, KU 203322; 14.4 km E La Palma, 1380 m, MCZ 91887-89; $3.5 \mathrm{~km}$ NE Mindo, $1540 \mathrm{~m}$. KU 165143-49; 5 km NW Nanegal Chico, USNM 204721; Puerto Quito, MHNG 18879; Km 12 Quito-Puerto Quito road, 750 m. MECN (1); Río Baba, $10 \mathrm{~km} \mathrm{S,} 4 \mathrm{~km}$ E Santo Domingo de los Colorados, 400 m, KU 141773; Río Baba, 19 km S. 5 km E Santo Domingo de los Colorados, U1MNH 77409; Río Faisanes, $13.5 \mathrm{~km}$ E La Palma. $1380 \mathrm{~m}$, MCZ 94471$73,94813,95628$, USNM 285874-75: Santo Domingo de los Colorados, 600 m, KU 117487-91, 118129 (C\&S), 119474-500, 119501 (C\&S), 120252, 177639 48, MCZ 88413-14, WCAB 44396-400: $2 \mathrm{~km} \mathrm{E,} 1 \mathrm{~km}$ S Santo Domingo de los Colorados, 620 m. KU 177649 $50 ; 6 \mathrm{~km}$ E Santo Domingo de los Colorados. USNM 204724-28; 18 km E Santo Domingo de los Colorados. USNM 204729; $5 \mathrm{~km}$ W Santo Domingo de los Colorados, USNM 204722-23; Tinalandia, MCZ 88412,91891 .

\section{Eleutherodartylus colomai (3 specimens)}

Ecuador: Prov. Esmeraldas, Alto Tambo, $830 \mathrm{~m}$, QCAZ 1289 (holotype), 1296; El Cristal, $1200 \mathrm{~m}, \mathrm{ECO}$ 217.

\section{Eleutherodacty/us crenunguis (99 specimens)}

Ecuador: Prov. Los Ríos: Estación Biológica Río Palenque, QCAZ 172-73. Prov. Pichincha: $5 \mathrm{~km} \mathrm{NW}$ La Florida. $860 \mathrm{~m}$, QCAZ 7843-45; $1.1 \mathrm{~km} \mathrm{E} \mathrm{La}$ Palma, MCZ 95636-38, $12.6 \mathrm{~km}$ E La Palma, MCZ 90005, 94726; $16 \mathrm{~km}$ E La Palma, $1500 \mathrm{~m}, \mathrm{MCZ}$ 90007: Mindo (Hda. San Vicente), 1465-1620 m, USNM 284355; $3.5 \mathrm{~km}$ NE Mindo, $1540 \mathrm{~m}$, KU 165223-34: Nanegalito, USNM 239847; Pachijal, USNM 239851: Palma Real. USNM 239855-57; Quebrada La Plata, 3 km SE Tandapi, $1550 \mathrm{~m}, \mathrm{MCZ}$ 89973, 98133-34, USNM 285974; Río Faisanes, 13.5 km E La Palma. 1380 m. MCZ 93424-27. 94465. 94849-56, 94902-05, 95499-500, 97516-25, USNM 285877-83: Río Mulaule, trib. Río Blanco, USNM 239850; Río Pitsará, USNM 239853-54; 1 km SW Tandayapa, MCZ 97877, USNM 285950; Tandapi, $1460 \mathrm{~m}, \mathrm{KU} 111213-15,120125,120126$ (holotype), 120127-31, 131605, 177730-32. MCZ 105473; 2.1 km E Tandapi, $1550 \mathrm{~m}$. MCZ $9284095493-95,94823$; Tinalandia, MCZ 92083-84. 92107-08, 94713-16, USNM 217413.

\section{Elentherodactylus crucifer (48 specimens)}

Ecuador: Prov: Bolivar: Porvenir, $1760 \mathrm{~m}, \mathrm{BM}$ 1947.2.16.9l (holotype). Prov. Carchi: Río Baboso, near Lita, MECN-LAC 42. Prov: Cotopaxi: Las Pampas, QCAZ 591, 604-05. Prov: lmbabura: "above" Lita, $1200 \mathrm{~m}$, ECO 087, 123. Prov. Pichincha: $18 \mathrm{~km}$ E La Palma, 1600 m, MCZ 90013; 3.5 km NE Mindo, 1540 m, KU I65235; Reserva Florística-Ecológica Río Guajalito, near Las Palmeras, 1800 m, QCAZ 2627; Río Faisanes, $13.5 \mathrm{~km}$ E La Palma, $1380 \mathrm{~m}$. MCZ 94474-75; Río Toachi, USNM 211574; Tandapi, 1460 m, KU 111206-12, 120132-50, 131667-71, 177733 . QCAZ 603: $1.6 \mathrm{~km}$ W Tandapi. $1400 \mathrm{~m}$. KU 177734. Erroneous locality: Prov. Pastaza: $1 \mathrm{~km}$ W Puyo, MCZ 90012.

\section{Eleutherodactylus degener (3 specimens)}

Ecuador: Prov. Esmeraldas: Alto Tambo, $830 \mathrm{~m}$, QCAZ 1297. Prov. Esmeraldas: El Cristal, $1200 \mathrm{~m}$, ECO 77, 122. 


\section{Eleutherodactylus dissimulatus (13 specimens)}

ECUADOR: Prov: Pichinclal Quebrada Zapadores, 5 km ESE Chiriboga, 2020 m, KU 165923-25, 179087. 179088 (holotype), 179089-95; 1 km SW San lgnacio, 1920 m, KU 179096.

\section{Eleutherodactylus duellmani (139 specimens)}

Ecuador: Prov: Carchi: $5 \mathrm{~km}$ W La Gruel, $2340 \mathrm{~m}$. KU 202403-04; 26.9-27.3 km E Maldonado, $2420 \mathrm{~m}$, KU 217997-98, QCAZ 3084-89; 14 km SE Maldonado, 2500 m. KU 179251-67, 179268 (C\&S), 179269-72, 179274-95. Prov: Imbabura: La Delicia, 2700 m, KU 179296-315. Prov: Pichincha: $14.8 \mathrm{~km}$ ESE Chiriboga, $2410 \mathrm{~m}, \mathrm{KU} 179338-46 ; 14 \mathrm{~km}$ W Chiriboga, $1960 \mathrm{~m}$, KU 165910-12; Quebradil Zapadores, 5 km ESE Chiriboga, $2010 \mathrm{~m}$. KU 165913-21, 179316-24. 179325 (holotype), 179326-37; $2.1 \mathrm{~km}$ E Tandapi, $1550 \mathrm{~m}$. MCZ 94719-20, 95615-27, 97481: $9 \mathrm{~km} \mathrm{SE}$ Tandayapa, 2150 m, KU 165905-09, 202516.

\section{Eleutherodactylus eremitus (16 specimens)}

Ecuador: Pros: Cotopaxi: Las Pampas, KU 22168586; Palo Quemado, MHNG 18739. Pros: Pichincha: 2 km W Campamento Silante, $2100 \mathrm{~m}$, KU 140878; 8 km W Chiriboga, USNM 211209; $18 \mathrm{~km}$ NE La Palma, MCZ 90335, 25.7 km NE La Palma, $1820 \mathrm{~m}, \mathrm{MCZ}$ 92103 (holotype), $92104 ; 3.5 \mathrm{~km}$ NE Mindo, $1540 \mathrm{~m}$, KU 165884; Quebrada Zapadores, $5 \mathrm{~km}$ ESE Chiriboga, $2010 \mathrm{~m}, \mathrm{KU}$ 179085-86, USNM 285924; $6.2 \mathrm{~km} \mathrm{E}$ Tandapi, $1750 \mathrm{~m}, \mathrm{MCZ} 92105$, 94723; Tandayapa, USNM 211208; $8.6 \mathrm{~km}$ SE Tandayapa, $2000 \mathrm{~m}, \mathrm{MCZ}$ 98189.

\section{Eleutherodactylus eugeniae (15 specimens)}

Ecuador: Prov. Pichincha: Quebrada Zapadores, 5 km ESE Chiriboga, $2010 \mathrm{~m}$, KU 165899 (holotype), 165900-04, 179382-83, MCZ 98031; Reserva Florística-Ecológica Río Guajalito, near Las Palmeras, $1800 \mathrm{~m}$, QCAZ 2629; $6.3 \mathrm{~km}$ E Tandapi, 1700-1750 m, MCZ 94724, 98075, 98077, 98079-80.

\section{Eleutherodactylus floridus (27 specimens)}

Ecuador: Prov Cotopaxi: region of Sigchos, USNM 239672 (holotype) 239673. Prov. Imbahura: Lita, Río Mira, USNM 239674-75. Prov. Pichincha: Bosque Protector Mindo-Nambillo, 1700 m, QCAZ 7296: region of Gualea, USNM 239690; Milpe, $900 \mathrm{~m}$. USNM 239691-92: immediate environs of Mindo. USNM 239686-89; road to Mindo. USNM 239680; $12 \mathrm{~km}$
NW Nono, MCZ 90320-24; Río 13lanco, near mouth of Río Yambí, 700 m, USNM 239683; Río Lelia, tributary of Río Toachi, USNM 239676-79; Río Peripa headwaters, San Miguel de Congomá, USNM 239684; Río Toachi (Km 100-110), USNM 239685: Tandayapa, USNM 239681-82.

\section{Eleutherodactylus gentryi (69 specimens)}

ECuAdor: Prov: Cotopaxi: $5 \mathrm{~km}$ (by road) E Pilaló, $3200 \mathrm{~m}, \mathrm{KU} 131540$ (holotype), 131541-65; $8 \mathrm{~km}$ (airline) E Pilaló, $2850 \mathrm{~m}$. USNM 239741-62; $9 \mathrm{~km}$ (airline) E Pilaló, 3125-3200 m, USNM 239763-67, 239772-73; $10 \mathrm{~km}$ (airline) E Pilaló, $3200 \mathrm{~m}$. USNM 239739-40; 24.6 km E Pilaló, $3190 \mathrm{~m}$, QCAZ 784651; $27.6 \mathrm{~km}$ E Pilaló, 3380 m, KU 218109-11, QCAZ 7852-54.

\section{Eleutherodactylus gularis (11 specimens)}

Ecuador: Prov: Chimborazo: Huigra, 1235 m, ANSP 18113 (holotype of Hyloxalus huigrae). Pros: Esmeraldas: $1 \mathrm{~km}$ SW Cachabé, $20 \mathrm{~m}$. BM 1947.2.15.82 (holotype), USNM 211977; Durango, QCAZ 431617: Río San Miguel, MCZ 92909-10, 92919, $92926-$ 27; San Miguel de Cayapas, QCAZ 174.

\section{Eleutherodactylus hamiotae (5 specimens)}

Ecuador: Prov: Pichincha: $12 \mathrm{~km}$ W Nono, USNM 239843; $13.1 \mathrm{~km}$ NW Nono, $2140 \mathrm{~m}$. MCZ 97486. 98024-25. 98027 (holotype).

\section{Eleutherodactylus hectus (3 specimens)}

Ecuador: Prov. Esmeraldas: El Cristal, 1200 m, ECO 88, 119-20.

\section{Eleutherodactylus helonotus (2 specimens)}

Ecuador: Prov: Pichincha: Mindo, USNM 195784: Río Pitsará, BM 1970.178.

\section{Eleutherodactylus illotus (24 specimens)}

Ecuador: Prov: Carchi: $5.9 \mathrm{~km}$ E Maldonado, 1780 m. USNM 286283. Prov. Imbabura: above Cuellaje. $2560 \mathrm{~m}$, ECO 135-36, 149, 171, 175. Prov. Pichincha: $22 \mathrm{~km}$ NE Las Palmas, $1770 \mathrm{~m}$. MCZ 90339-40; Llambo (on Gualea road), USNM 239732-33; Miligali, USNM 239722: Mindo (road to), USNM 239727; Mindo (region), USNM 239730-31: $3.5 \mathrm{~km}$ NE Mindo, 1540 m. KU 165881 (holotype), 165882-83; Nanega- 
lito, USNM 239724; Pachijal, USNM 239723; below Pacto, USNM 239725-26; Río Faisanes, 15 kin NE La Palma, $1380 \mathrm{~m}$; San Tadeo, near Mindo, USNM 239729. Questionable Locality: Prov. Pichincha: Puerto de Ila, USNM 239728.

\section{Eleutherodactylus labiosus (109 specimens)}

Ecuador: Prov: Carchi: Río Baboso, near Lita, MECN-LAC 138. Prov. Esmeraldas: Alto Tambo, 830 m. QCAZ 1265: Hda. Equinox, $33 \mathrm{~km}$ NW Santo Domingo de los Colorados, USNM 212008 Río Cupa, USNM 239793. Prov. Imbabura: Lita, 570 m, QCAZ 1310. Prov. Los Ríos: Estación Biologica Río Palenque, KU 165895-96, MCZ 90053-54, 91954-56, 92113, 94461, 94866, USNM 285348-49. Prov. Pichincha: Centinela, 14.1 km ESE Patricia Pilar, MCZ 9757591, USNM 285591-613; 5 km NW La Florida, MECNLAC 210, QCAZ 569-70; La Palma, KU 131612 (holotype); $5 \mathrm{~km}$ E La Palma, KU 165894; $16 \mathrm{~km} \mathrm{NE}$ La Palma, MCZ 90006; Nanegal Grande, USNM 212005; Río Pitsará, USNM 239852; Santo Domingo de los Colorados, USNM 212006; $6 \mathrm{~km}$ E Santo Domingo de los Colorados, USNM 212007; $11 \mathrm{~km} \mathrm{E}$ Santo Domingo de los Colorados, USNM 285981; Tinalandia, 800 m. MCZ 88392-93, 88891-93, 8997492, 89993-90004; 90049-52; 91953.

\section{Eleutherodactylus laticlavius (26 specimens)}

Ecuador: Prov. Carchi: 22 km E Maldonado, 2560 m, QCAZ 3740, 4186. Prov. Esmeraldas: El Cristal, 1200 m, ECO 80-82, 84-86, 89-90, 92, 104-07, 124 25, 128-31, 224-225, 240, QCAZ 6339. Prov. Pichincha: Río Faisanes, 14.3 NE La Palma, $1380 \mathrm{~m}$, USNM 285876.

\section{Eleutherodactylus latidiscus (80 specimens)}

Ecuador: Prov. Carchi: Río Baboso, near Lita, MECN-LAC 33,74-75. Prov. Esmeraldas: Alto Tambo, 830 m, QCAZ 1254, 1258, 1260-61, 1263-64, 1266, 1295, 1298; Bilsa, EPN-AA 2510, 2513, 2517; Cachabé, BM 1947.2.15.66-67 (syntypes); Lagarto, Reserva Mayronga, 100 m, QCAZ 4728; San Miguel, MCZ 92920. Prov. Los Ríos: Estación Biológica, Río Palenque. 200 m, KU 165468-70, MCZ 88391, 9001416,92111-12,94455,94457-58. Prov. Manabi: $38 \mathrm{~km}$ NW El Carmen, $330 \mathrm{~m}$, QCAZ 7855. Prov. Pichincha: Centinela, $14.1 \mathrm{~km}$ SE Patricia Pilar, 550-600 m, MCZ 97555, 97557, 97574, USNM 285539-40, 285581-90; La Florida, MECN-LAC 205-06, 208; 5 km NW La
Florida, KU 218016-17, QCAZ 5856, 5857 (eggs), 5858; Santo Domingo de los Colorados, KU 109059 , 120222-26, 120232-33, 141957-61, 179397-98, 179400; Santo Domingo de los Colorados (Finca La Esperanza), USNM 239849; Tinalandia, MCZ 88422, 90017, 90330-33, 91221, 94717.

\section{Eleutherodactylus leoni (43 specimens)}

Ecuador: Prov. Carchi: $2 \mathrm{~km}$ E La Gruel, $2590 \mathrm{~m}$, KU 202410; 14 km SE Maldonado, $2500 \mathrm{~m}$, KU $177320-40 ; 26.9 \mathrm{~km} \mathrm{~W}$ Maldonado, $2420 \mathrm{~m}$, KU $218232-33 ; 51.3$ km W Tulcán, 3150 m, KU $218227-$ 31. Prov. Imbabura: above Cuellaje, 2560, QCAZ 8046-49; La Delicia, 2710 m, KU 132779; Nudo de Mojanda, N slope, 3400 m, KU 130870 (holotype), 130871-72. Prov. Pichincha: $14 \mathrm{~km}$ W Chiriboga, 1960 m, KU 165897-98; Lloa, 2800 m, QCAZ 796971. Erroneous Locality: Pichincha: Río Blanco, near mouth of Río Yambi, 700 m, USNM 212009.

\section{Eleutherodactylus longirostris (268 specimens)}

Ecuador: Prov. Esmeraldas: Bulum, $60 \mathrm{ft}$, AMNH 10698-700, MCZ 7600, UMMZ 83826 (5); Cachabé, BM 1947.2.15.56-60 (syntypes), USNM 233120;1 km SW Cachabé, $20 \mathrm{~m}$, USNM 23110-14; $1.5 \mathrm{~km} \mathrm{SW}$ Cachabé, USNM 233115-17; Hda Equinox, 38 km NW Santo Domingo de los Colorados, USNM 233108 09; La Boca, MHNG 18503; Pambelar, BM 1901. 6.27.14-15; Parroquia Carondelet, Río Bogotá, UIMNH 53558-59; Río Bogotá, USNM 233118-19; Río Durango, $350 \mathrm{ft}, \mathrm{AMNH}$ 10706-07, MCZ 3891-92, UMMZ 51272; Río San Miguel, ca. 1 km upstream from Río Cayapas, MCZ 92929, 92934, 92953-71; Salidero, AMNH 10702, 10704; UMMZ 51265; San Javier, AMNH 10709-10, MCZ 7599; San Miguel, EPN 1102,1104, 1108-09, 1115-16,1118, MCZ 85756, 85789, 92952-60; QCAZ 169-70; Urbina near San Lorenzo, EPN 1358. Prov. Guayas: Naranjito, Río Chimbo, USNM 233107. Prov. Prov. Los Ríos: Estación Biológica Río Palenque, AMNH 89728 -29, KU 147561-66, 152573, 165474-82, 165483-84 (C\&S), 165485-95, 166277-78 (C\&S), 180640, MCZ 8843133, 89919, 89927, 90055-107,91217-19, 93476-511, 94838-41, 94888, 118034 (hatchlings), QCAZ 168, USNM 285350-58. Manabí: $38 \mathrm{~km} \mathrm{NW}$ El Carmen, 330 m, KU 218018, QCAZ 7859. Prov. Pichincha: Finca La Esperanza, NW of Santo Domingo de los Colorados, EPN 1377, 1382; Hda. Cerro Chico, 45 km N Quevedo, 170 m, USNM 285727-29; La Concordia, Bosque Protector La Perla, 190 m, QCAZ 7860; Pacto 
(road to Guayllabamba). USNM 233124; Puerto de lla, USNM 233123; $8 \mathrm{~km}$ ESE Puerto Quito, $530 \mathrm{~m}$, KU 165496-503: Río Baba, 5-10 km SSW Santo Domingo de los Colorados, 500, AMNH 89727; Río Baba, 24 km S Santo Domingo de los Colorados, UIMNH 93158; Río Canoi, 4 km S Vicente Maldonado, $570 \mathrm{~m}$, QCAZ 7861; lower Río Toachi, USNM 233125; Santo Domingo de los Colorados, USNM 233121; 1 km N, 2 km E Santo Domingo de los Colorados, $6290 \mathrm{~m}$, KU 177804-06; 35 km E Santo Domingo de los Colorados, (Hda. Lelia), CAS-SU 10611; 2 km E. 1 km S Santo Domingo de los Colorados, $600 \mathrm{~m}, \mathrm{KU} 177803 ; 19 \mathrm{~km}$ S, $5 \mathrm{~km}$ E Santo Domingo de los Colorados, UIMNH 93610-11; 5 km SE Santo Domingo de los Colorados, USNM 285794; $18 \mathrm{~km}$ W Santo Domingo de los Colorados (Ramsey Farm, Km 19 on road to Chone), USNM 233122. Prov. undetermined: Northwestern Ecuador, CAS 66296. Erroneous locality: Prov. Pastaza: Sarayacu, BM 80.12.5.229, 80.12.5.249.

\section{Eleutherodactylus loustes (20 specimens)}

Ecuador: Prov. Carchi: Maldonado, $1410 \mathrm{~m}, \mathrm{KU}$ 179231-33, 179234 (holotype), 179235-50.

\section{Eleutherodactylus luteolateralis (81 specimens)}

Ecuador: Prov. Pichincha: $14 \mathrm{~km}$ W Chiriboga, 1960 m, KU 165160; 4 km NE Dos Ríos, $1140 \mathrm{~m}$, 165506 (\&S), 165507-21, 166279 (C\&S); $10.4 \mathrm{~km} \mathrm{E}$ La Palma, MCZ 93430-31, $10.6 \mathrm{~km}$ E La Palma, 1280 m. MCZ 91957-58; 12.6 km E La Palma, MCZ 92848; 13 km E La Palma, MCZ 90310; 14.4 km E La Palma, 1380 m, MCZ 91959-62, 92053; 16 km E La Palma, $1500 \mathrm{~m}, \mathrm{MCZ} 90309 ; 3.5 \mathrm{~km}$ NE Mindo, $1540 \mathrm{~m}, \mathrm{KU}$ 165522-38, 166280 (C\&S); Río Faisanes, 13.5 km E La Palma, 1380 m, MCZ 93428-29, 94476-78, 94843, USNM 285884; Tandapi, 1460 m, AMNH $114490-95$, KU 111378-84, 120151-54, 131672-73, 131674 (holotype), 121675-77, 135448-51.

\section{Eleutherodactylus lymani (14 specimens)}

Ecuador: Prov. Azuay: 4 km SW Cataviña, $1600 \mathrm{~m}$, USNM 212019; 55.4 km E Pasaje, 1000 m. KU I 52009, Río Minas, $20 \mathrm{~km}$ W Santa Isabel, $1250 \mathrm{~m}$, USNM 212020. Prov. El Oro: Cordillera de Chilla, Llanos de Guavos, AMNH 13738; El Chiral, AMNH 13961, 13964; Guainche, AMNH 16256; Piñas, AMNH 16257; Portovelo, 610 m, AMNH 16334, 16339, 16341-44. Prov. Loja: Loja, BM 1947.2.15.99 (holotype of Eleutherodactylus carrioni).

\section{Eleutherodactylus muricatus (16 specimens)}

Ecuador:Prov: Los Ríos: Estación Biologica Río Palenque, $220 \mathrm{~m}$, MCZ 92110, 94456, 94460. Prov. Pichincha: Río Faisanes, 14.4 km E La Palma, $1380 \mathrm{~m}$, MCZ 92091, 92095, 92100-01, 94469 (holotype), 94848, 97528-31, USNM 211 172-74; Santo Domingo de los Colorados, KU 179084.

\section{Eleutherodactylus necerus (58 specimens)}

EcuAdor: Prov. Carchi: Maldonado, $1410 \mathrm{~m}, \mathrm{KU}$ 179076-79; Prov. Cotopaxi: Las Pampas, $1500 \mathrm{~m}$. MCZ 104418, QCAZ 19,227,563-64. Prov. Pichincha: 13 km E Alluriquín, MCZ 88394; 4 km NE Dos Ríos, 1140 m, KU 165541 (C\&S). 165542-43, 166067; 14.4 km E La Palma, 1380 m, MCZ 91895-903; Mindo, USNM 195798 (holotype); $3.5 \mathrm{~km}$ NE Mindo, $1540 \mathrm{~m}$, KU 165544-45; road from Pacto to Río Guayllabamba, USNM 195851; Río Blanco near mouth of Río Yambi, USNM 195852; Río Faisanes, 13.5 km E La Palma. 1380 m, MCZ 92882, 94844-45. USNM 285885-91; Río Lelia, tributary of Río Toachi, USNM 195799; Santo Domingo de Jos Colorados, MCZ 113574-75; Tandapi, 1460 m, KU 179080-82, MCZ 105457-59. 105467-68; 2.1 km E Tandapi, $1500 \mathrm{~m}, \mathrm{MCZ} 95613$ 14, 98033; $2.1 \mathrm{~km}$ E Tandapi, Quebrada La Plata, 1550 m, USNM 285941, 285975-77; $1.6 \mathrm{~km}$ W Tandapi, KU 179083. Erroneous locality: Pastaza: Pastaza River. Canelos to Marañón, MCZ 19628.

\section{Eleutherodactylus nyctoplylax (153 specimens)}

Ecuador: Prov: Cotopaxi: Galápagos, $1720 \mathrm{~m}, \mathrm{KU}$ 221687; Palo Quemado, MHNG 18739; Reserva Otonga, 2100 m, QCAZ 4546; vicinity of San Francisco de las Pampas, $1800 \mathrm{~m}$, QCAZ 590, 592-94. 596-98, 2509. Prov. Pichincha: 4 km NE Dos Ríos, 1140 m, KU 165546 (C\&S), 165547; 10.4-10.6 km E La Palma, 1280-1300 m, MCZ 92087-89, 94725; 16 km E La Palma, MCZ 90108; 3.5 km NE Mindo, 1540 m, KU 165548-49: Tandapi, 1460 m, AMNH $114506-$ 1], BM 1969.654-58; KU 110896-908, 110909 (holotype), 110910-12, 110913 (C\&S), 110914-22, 110923 (C\&S), 1]0924-74, 111376-77, 117582-83, 130879$86,135428-46,135459,138789,177812-13, \mathrm{MCZ}$ 75158-63; 6.3 km E Tandapi. Río Corazón, $1700 \mathrm{~m}$. USNM 285938-39.

\section{Eleutherodactylus ocellatus (5 specimens)}

Ecuador: Prov. Carchi: $8 \mathrm{~km}$ W Maldonado, 1255 m, QCAZ 3741; 3 km up Río Blanco from Chical, 
1450-1500 m. USNM 286293. Prov: Imbabura: above Cuellaje, 2560 m. ECO 168-170.

\section{Eleutherodacty/us ornatissinus (26 specimens)}

Ecuador: Prol: Carchi: Río Baboso, near Lita, MECN-LAC 108. Prol: Cotopaxi: Galápagos, MHNG 18707: Palo Quemado. KU 221684: $20.3 \mathrm{~km}$ W Pilaló, 830 m. KU 141969 (C\&S) 141970-71. Prov. Esmeraldas: El Cristal, $1200 \mathrm{~m}$, ECO 083, 095. Prov: Pichincha: Centinela, 14.1 km SE Patricia Pilar, 550600 m, MCZ 97593; Río Babil, 4 km E, 10 km S Santo Domingo de los Colorados, $400 \mathrm{~m}$. KU 141967-68: Río Blanco, near mouth of Río Yambí, $700 \mathrm{~m}$, USNM 233205: Río Pitsará, USNM 233206: Santo Domingo de los Colorados, KU 119744-48, 119749 (C\&S), MCZ 106946; $6 \mathrm{~km}$ E Santo Domingo de los Colorados (Dyatt Farm), USNM 233201-02: 4 km W Santo Domingo de los Colorados (Finca La Esperanza), USNM 233203; $18 \mathrm{~km}$ W Santo Domingo de los Colorados, 650 m. USNM 233200: below Sigchos, USNM 233204: Tandapi. 1460 m. MCZ 105082.

\section{Eleutherodactylus parvillus (90 specimens)}

Ecuador: Prov: Azuay: Manta Real, Parroquia Molleturo, $650 \mathrm{~m}$, EPN-AA 2550. Prov: Cotopaxi: Reserva Otonga, $2000 \mathrm{~m}$, QCAZ 6565. Prov: Esmeraldas: Bilsa, $225 \mathrm{~m}$, EPN-AA 2488; El Cristal, $1200 \mathrm{~m}$, ECO 219; Hda. Equinox, $38 \mathrm{~km}$ NW Santo Domingo de los Colorados, $300 \mathrm{~m}$. USNM 239782. Prov: Los Ríos: Estación Biológica Río Palenque, MCZ 90115. Pros: Pichincha: Centinela, $14.1 \mathrm{~km}$ ESE Patricia Pilar, 550-600 m. USNM 285615-21, 285545; Mindo, 1500 m, QCAZ3415-17; Reserva Florística-Ecológica Río Guajalito, near Las Palmeras. $1800 \mathrm{~m}$. QCAZ 2628, 3263-64, 3448, 4254-55, 4821-22; Río Baba, 4 $\mathrm{km}$ E. $10 \mathrm{~km}$ S Santo Domingo de los Colorados, 400 m, KU 142146-50; Río Faisanes, $13.5 \mathrm{~km}$ E La Palma, 1380 m, MCZ 94479; Santo Domingo de los Colorados, $600 \mathrm{~m}$. KU 120251, 179394-96, 179399, 179401-03; $3 \mathrm{~km}$ E Santo Domingo de los Colorados. MCZ 98202; $2 \mathrm{~km} \mathrm{~N}, 1 \mathrm{~km}$ E Santo Domingo de los Colorados. 570 m, USNM 285795: Tandapi, 1460 m. AMNH $114495-$ 99, KU 111345 (holotype), 111346-73, 111375 (C\&S), 120242-45, 120246 (C\&S). 135445, 177218-25; 2 km W Tandayapa, $1840 \mathrm{~m}$, QCAZ 4788; Tinalandia, MCZ 94711.

\section{Eleutherodactylus phoxocephahus (221 specimens)}

Ecuador: Prov: Azuay: $10 \mathrm{~km}$ SW Victoria del Portete, 2700 m, KU 131281-82. Prov: Bolivar: San
Vicente, MECN 286, 288. Prov: Cañar: $18.4 \mathrm{~km} \mathrm{NW}$ El Tambo, 2960 m. KU 142118-31. Prov: Cañar: 15 km NW El Tambo, $2840 \mathrm{~m}$, KU 166059-65. Prov: Cotopaxi: Las Pampas, MHNG 18512, 18531 (2). QCAZ 595: Pilaló, 2460 m, KU 131404-78, 131479 (young), 131480-88, 131698-716. KU 142075 (holotуре), 142076-103, 177826-36, 180296, 202428-29, MHNG (7), MHNG 18737 (4), QCAZ 554-58, USNM 233240-52; 14.5 km E Pilaló, 3160 m. KU 142816. Prov: Imbabura: La Delicia, 2710 m, KU 179387. Pichincha: $7.7 \mathrm{~km}$ E Chiriboga (Finca Santa Lucía), $2120 \mathrm{~m}$. KU 142063-71; $4 \mathrm{~km}$ W Chiriboga, 2120 m, KU 142072-74; Los Alpes, 2500 m, KU 140876-77; $9.5 \mathrm{~km}$ NW Nono, $2530 \mathrm{~m}$. KU 165559-60; Quebrada Zapadores. 5 km ESE Chiriboga. 2010 m, KU $165556-$ 58, 180247: San lgnacio, 2030 m, KU 109137; Tandapi, $1460 \mathrm{~m}$. MHNG 18715.

\section{Eleutherodactylus pteridophilus (52 specimens)}

ECuAdor: Pros: Imbabura: above Cuellaje, $2560 \mathrm{~m}$, ECO 143-44, 150-52, 156-60. 172; La Delicia, 2710 m, KU 132629, 179106 (holotype), 179107-39. Prov. Pichincha: 14 km W Chiriboga, 1960 m, KU 165926; $13.1 \mathrm{~km}$ NW Nono, $2150 \mathrm{~m}$, USNM 286043: San Tadeo, near Mindo, USNM 239848; 6.2 km E Tandapi. $1750 \mathrm{~m}, \mathrm{MCZ} 92109,94721-22$.

\section{Eleutherodactyhs pyrhomerus (32 specimens)}

Ecuador: Prov: Bolivar: Bosque Protector Cashca Totoras, $3000 \mathrm{~m}$, KU 218030-33. Prol: Cotopaxi: Pilaló, 2400-2580 m. KU 131606 (holotype). $177837-$ 38; $1 \mathrm{~km}$ E Pilaló, $2075 \mathrm{~m}$. USNM 233253; $1.5 \mathrm{~km} \mathrm{E}$ Pilaló, $2200 \mathrm{~m}$, KU 187481 , USNM 233254-63: $3 \mathrm{~km}$ E Pilaló, $2900 \mathrm{~m}, \mathrm{KU}$ 131607-11; $4.6 \mathrm{~km}$ E Pilaló, $2600 \mathrm{~m}, \mathrm{KU}$ 152038; $5 \mathrm{~km}$ E. Pilaló, $2400 \mathrm{~m}$. USNM 233264-65; $6 \mathrm{~km}$ E Pilaló, $2670 \mathrm{~m}$. KU 142167-70. Prov: Imbabura: La Delicia, 2710 m. KU 179387. Erroneous locality: Prov: Pichincha: Tandapi, QCAZ 584.

\section{Eleutherodactylus quinquagesimus (70 specimens)}

Ecuador: Prol: Carchi: Maldonado, $1410 \mathrm{~m}, \mathrm{KU}$ 179391; $22 \mathrm{~km}$ E Maldonado, $2560 \mathrm{~m}$, QCAZ 4187.

Prov: Cotopaxi: Reserva Otonga. $2200 \mathrm{~m}$. QCAZ 4550. Prov: Imbabura: above Cuellaje, $2560 \mathrm{~m}$, ECO 162. 173-74, 176-78: La Delicia, 2710 m, AMNH 114517-21. KU 132755-56, 132770, 132777-78. 179365-68. Prov: Pichincha: $14 \mathrm{~km}$ W Chiriboga, 1960 m, KU 167875-80; Quebrada Zapadores, 5 km ESE Chiriboga, 2010 m, KU 166292-93(skeletons), 167852- 
58, I67859 (holotype), 167860-73, 179374-77; 1 km SW San lgnacio, 1920 m, KU 179378-81; Tandayapa, USNM 239846; $9 \mathrm{~km}$ SE Tandayapa, $2150 \mathrm{~m}$, KU 167881-86.

\section{Eleutherodactylus rosadoi (7 specimens)}

Ecuador: Prov. Carchi: Río Baboso, near Lita, MECN-LAC 70, 116. Prou. Esmeraldas: Río San Miguel, 1 km above Río Cayapas, MCZ 92937 (holotype), 92938. Prov: Imbabura: Lita, 520 m, KU 132780: Prov: Pichincha: Río Canoi, $4 \mathrm{~km}$ S San Vicente Maldonado, 570 m, KU 218051, QCAZ 7862.

\section{Elentherodactylus ruidus (16 specimens)}

Ecuador: Azuay: Molleturo, $2317 \mathrm{~m}$, AMNH 17588-89, 17590 (holotype), 17591-603.

\section{Eleutherodactylus scolodiscus (9 specimens)}

Ecuador: Prov: Carchi: Maldonado, $1410 \mathrm{~m}, \mathrm{KU}$ 177651; Río Baboso, near Lita, MECN-LAC 31; Río Blanco, $3 \mathrm{~km}$ up from Chical, 1450-1500 m, USNM 286292. Prov. Esmeraldas: El Cristal. 1200 m, ECO 78-79. 101-103, 110.

\section{Eleutherodactylus simonbolivari}

\section{(32 specimens)}

Ecuador: Prov. Bolńcar: Bosque Protector Cashca Totoras, $10 \mathrm{~km}$ SE Santiago, $3200 \mathrm{~m}$, KU 218252-56. QCAZ 936, 940-41, 943-44, 1458, 1459 (holotype). 1460-75, 1493-96 (C\&S).

\section{Eleutherodactylus sobetes (2 specimens)}

Ecuador: Prov. Pichincha: Quebrada Zapadores, 5 km ESE Chiriboga, 1920 m, KU 179389 (holotype), 179390.

\section{Eleutherodactylus subsigillatus (65 specimens)}

Ecuador: Prov: Azuay: $11.2 \mathrm{~km}$ W Luz María, 930 m. KU 218147: 12.9 km W Luz María, 740 m, KU 218248, QCAZ 7863-64. Prov. Bolivar: Balsapamba, 830 m, KU 131566-71. Prov. Cañar: Mantil Real, Parroquia Molleturo, $650 \mathrm{~m}$, EPN-AA 2538, 2551. Prov. Esmeraldas: Alto Tambo, 830 m, QCAZ 1297; Bilsa, 225 m. EPN-AA 2516; Hda. Equinox, 38 km NW Santo Domingo de los Colorados, $300 \mathrm{~m}$. USNM 233335; La Boca, MHNG 18816; Salidero, 350 ft., BM 1947.2.17.1 (holotype). Prov. Los Ríos: Estación
Biológica Río Palenque, 220 m, MCZ 90140-12.94459. Prov. Manabí: Parque Nacional Machalilla, Cerro San Sebastián (Bola de Oro), 750 m, EPN-AA 2437-39. 2458, 2460-61. Prov. Pichincha: Centinela, $14.1 \mathrm{~km}$ ESE Patricia Pilar, 550-600 m, USNM 285622-26. 285538, 28554 I-45; 5 km NW La Florida, MECNLAC 209; Río Baba, 10 km S, 4 km E Santo Domingo de los Colorados, $400 \mathrm{~m}$, KU 146172; Santo Domingo de los Colorados, $580 \mathrm{~m}$. KU 177839-41, USNM 233320-34; $2 \mathrm{~km}$ E, $1 \mathrm{~km}$ S Santo Domingo de los Colorados, 600 m, KU 177842-44, USNM 285796; 9 $\mathrm{km}$ W Santo Domingo de los Colorados (Hda. Espinosa), CAS-SU: 10508, 10513, 10516.

\section{Eleutherodactylus surdus (91 specimens)}

Ecuador: Prov: Imbabura: La Delicia, $2710 \mathrm{~m}, \mathrm{KU}$ 130888-90, 177845-59. Prov. Pichincha: $5 \mathrm{~km} \mathrm{~W}$ Alóag, west slope Cerro Corazón, 2945 m, KU 109073 ; 7 km W Alóag, west slope Cerro Corazón. 2810 m. KU 109074, 109077 (C\&S); Chiriboga, QCAZ 585, 774; Chontapamba, USNM 239844: Los Alpes, $21 \mathrm{~km} \mathrm{~W}$ Alóag, 2600 m, KU $111387-94,117584-617,130891-$ 96; Otongoro, MECN (2), QCAZ 566-68, 586; Quebrada Silante Grande, Alóag-Santo Domingo de los Colorados road, $2300 \mathrm{~m}$, MCZ 97482. 97483 (holotype), 97484-85: Salto Dos Novias, north slope Cerro Corazón, 2635, KU 109075-76; 4.7 km SW San Juan, $14 \mathrm{~km}$ W Chillogallo, $3190 \mathrm{~m}$. KU 141972-73; $2 \mathrm{~km} \mathrm{E}$ Tandapi, Quebrada La Plata, $1550 \mathrm{~m}, \mathrm{MCZ} 98034$. USNM 285971; 9.4 km SW Tandayapa, $2390 \mathrm{~m}$, KU 202516. Prov: undetermined: "West Ecuador," BM 1947.2.17.25 (syntype); "South America," BM 1947.2.17.26 (syntype).

\section{Eleutherodactylus tenebrionis (40 specimens)}

Ecuador: Prov: Esmeraldas: Alto Tambo, $830 \mathrm{~m}$, QCAZ 1294. 1303-04. Prov: Los Ríos: Estación Biológica Río Palenque, 220 m. KU 146171, 152574. 165874-78. MCZ94864-65, 94867, 98164-66. USNM 211175. 285359. Prov. Pichincha: Centinela, 570-600 m. MCZ 97596-97. USNM 211176, 285627-28: Santo Domingo de los Colorados, 580 m, KU 179224-27; 2 $\mathrm{km}$ E. I km S Santo Domingo de los Colorados, $600 \mathrm{~m}$. KU 179228-30; Tinalandia, 800 m, MCZ 88890, 90325. 90326 (holotype), 90327-29, 92079-81, 94712.

\section{Eleutherodactylus thymalopsoides (27 specimens)}

Ecuador: Prov: Cotopaxi: Pilaló, $2460 \mathrm{~m}, \mathrm{KU} 131533$ (holotype), 131534-37, 177861-80, 202517-18. 


\section{Eleutherodactylus truebae (47 specimens)}

Ecuador: Pron: Bolivar: Bosque Protector Cashca Totoras, Quebrada Ramoshuiacao, 3000 m, KU 218142-45, QCAZ 2470, 2474-75, 2493, QCAZ 786567; 14.1 km E Guaranda, $3030 \mathrm{~m}$, KU 218139. Pros: Cañar: $20 \mathrm{~km}$ N Gun, 2909 m, USNM 239649-65; 4 km N Zhud, 3040 m, KU 202619, 202620 (holotype). Prov: Chimborazo: $7.7 \mathrm{~km}$ SW Compud, $2570 \mathrm{~m}, \mathrm{KU}$ 141974:35 km SW Desvío Panamericana, 2860 m. KU 218140; 15 km N Pallatanga, $2860 \mathrm{~m}$, USNM 239648: $20 \mathrm{~km}$ N Pallatanga, $3000 \mathrm{~m}$, USNM 239647. Prov. Cotopaxi: $5 \mathrm{~km}$ E Pilaló, $3200 \mathrm{~m}$, KU 130887; $24.6 \mathrm{~km}$ E. Pilaló, 3190 m, KU 218103-08; road from Pilaló to Latacunga, 2870 m, KU 218113-15. QCAZ7868-69.

\section{Eleutherodactylus unistrigatus (104 specimens)}

Ecuador: Prov: Cotopaxi: Pilaló, $2400 \mathrm{~m}, \mathrm{KU}$ 177888-969, 143557, 202535-36. Prov. Imbabura: 35 km E Apuela, 3220, KU 218057-60. Prov. Pichincha: $5 \mathrm{~km}$ W Alóag. N slope Cerro Corazón, 2945 m, KU 109066-67, 7 km W Alóag, KU 109068-69, 16 km W Alóag, $2810 \mathrm{~m}$, KU $111132-35 ; 9.5 \mathrm{~km}$ NW Nono. 2530, KU 165591-92 $4.5 \mathrm{~km} \mathrm{~W}$ Nono, $2600 \mathrm{~m}$. KU 218088-89: San Juan, 3400 m, KU 177518-20.

\section{Eleutherodactylus verecundus (14 specimens)}

Ecuador: Prov: Cotopaxi: Las Pampas, QCAZ 58283. Prov: Carchi: Río Baboso, near Lita, MECN-LAC 32: Río Blanco, $3 \mathrm{~km}$ upstream from Chical, 1450 1500 m. USNM 286291. 286294. Prov. Esmeraldas: El Cristal, 1200 m. ECO 91, 93-94, 108-09, I21. Prov. Pichincha: Reserva Florística-Ecológica Río Guajalito, near Las Palmeras, 1800 m, QCAZ 4820; 6469, 6562.

\section{Eleutherodactylus vertebralis (150 specimens)}

Ecuador: Prov: Cotopaxi: Pilaló, $2400 \mathrm{~m}$. KU 120103-10, 131290-300, 131538-39, 142173, 165871-72, 179140-63, 179165-215, 202546-55; 1 km W Pilaló, 2340 m, KU 131301; 4.6 km E Pilaló, 2600 m. KU 152032-33. Prov. Imbabura: 1ntac, BM 1947.2.17.5-6 (syntypes); La Delicia, 2710 m. KU 132737-48, 132750-53, 132757, 177970-84. Prov. Pichincha: Lloa, $2800 \mathrm{~m}$, QCAZ 7966-67; Quebrada Zapadores, $5 \mathrm{~km}$ ESE Chiriboga, $2010 \mathrm{~m}$, KU 179216 : $3 \mathrm{~km}$ from Tandayapa, road to Quito, $1800 \mathrm{~m}, \mathrm{MCZ}$ 90145.

\section{Eleutherodactylus w-nigrum (686 specimens)}

Ecuador: Prov. Azuay: Cuenca, CAS 63956; 10-15 km E Luz María, 2500 m, KU 218125-32, QCAZ 7870-77; 0.9 km W Luz María, 1770 m, QCAZ 7878; $11.2 \mathrm{~km}$ W Luz María, $930 \mathrm{~m}, \mathrm{KU} 218147 ; 12.9 \mathrm{~km} \mathrm{~W}$ Luz María, KU 2 I 8148-49; Molleturo, 7600 ft, AMNH 17640-43; Zurucuchu, SMF 3804 (holotype) [only photograph examined]. Prov. Bolivar: Balsapamba, AMNH 33916-17; 10 km NE Bilován, 2540 m, KU 141851-59: Bosque Protector Cashca Totoras, 3000 $\mathrm{m}, \mathrm{KU}$ 218142-45; Guaranda, 2640 m, KU 13126371; $4.7 \mathrm{~km}$ E Guaranda, $2700 \mathrm{~m}, \mathrm{KU} 218121-22 ; 11.1$ $\mathrm{km}$ E Guaranda, $2600 \mathrm{~m}$, KU 202572; $29 \mathrm{~km} \mathrm{E}$ Guaranda, $2710 \mathrm{~m}$, KU 218136-38; $2.5 \mathrm{~km}$ S Guaranda, 2550 m, KU 141293; 4.6 km S Guaranda, KU 202569$70 ; 5.4 \mathrm{~km} \mathrm{~S}$ Guaranda, $2680 \mathrm{~m}$, KU 179217-18; Hacienda Lizo, Río Tatahuazo, 2510 m, KU 218120; San Vicente, MECN 284-85. Prov: Carchi: $5 \mathrm{~km}$ W La Gruel, 2340 m, KU 202561, 202571, 202573; Maldonado, $1410 \mathrm{~m}, \mathrm{KU}$ 177533-34; $14 \mathrm{~km}$ SE Maldonado, $2500 \mathrm{~m}$, KU 177535; $27.3 \mathrm{~km} \mathrm{E}$ Maldonado, 2420 m. KU 218133-35; Río Blanco, 3 $\mathrm{km}$ upstream from Chical, 1450-1500 m, USNM 286295. Prov: Chimborazo: Las Cochas, $\mathrm{N}$ of Huigra, 8100 ft. CAS-SU 9477; Paitanga, BM 80.12.5.273; 20 $\mathrm{km}$ NNE Pallatanga, $2550 \mathrm{~m}$, KU 165840-43; $35 \mathrm{~km}$ SW junction Panamerican Hwy on road to Pallatanga, $2860 \mathrm{~m}$, KU 218140. Prov. Cotopaxi: Las Pampas, QCAZ 607; 4.6 km E Pilaló, $2600 \mathrm{~m}$, KU 152034-37; $10.5 \mathrm{~km}$ W Pilaló, $1520 \mathrm{~m}$. QCAZ 7879. Prov. El Oro: El Chiral, AMNH 13960. Prov. Imbabura: $16.1 \mathrm{~km} \mathrm{E}$ Apuela, $2400 \mathrm{~m}$. MCZ 95539; $16.7 \mathrm{~km}$ EApuela, 2470 m, MCZ 95537-38; 17.4 km E Apuela. 2500 m. MCZ 95544; Intac, BM 78.1.25.23-24; La Delicia, 2700 m. KU 130454-57, 177536-41; Quebrada San Miguel. 1 $\mathrm{km}$ N Otavalo, $2560 \mathrm{~m}$, KU 117771. Prov. Pichincha: Alóag-Santo Domingo road. 2900 m, MHNG 18724 (11); 7 km W Alóag, 28 10, KU 109064; Bosque Protector Mindo-Nambillo, $1700 \mathrm{~m}$, QCAZ 7308; $9.3 \mathrm{~km} \mathrm{~W}$ Calacalí, $2380 \mathrm{~m} ; 14.7 \mathrm{~km}$ W Calacalí, $2130 \mathrm{~m}, \mathrm{KU}$ 218123-24, QCAZ 7880-81; 2 km W Campamento Silante, $2100 \mathrm{~m}$, KU 130463-64: Chiriboga, BM 1940.2.20.1, EPN 1379, MECN 355, QCAZ 3227; 7.7 $\mathrm{km}$ E Chiriboga (Finca Santa Lucía), $2120 \mathrm{~m}, \mathrm{KU}$ 141836-43; $14.8 \mathrm{~km}$ E Chiriboga. $2540 \mathrm{~m}$. KU 14183335 177564: $2.2 \mathrm{~km}$ W Chiriboga, $1980 \mathrm{~m}$. MCZ 98182 $83 ; 4 \mathrm{~km}$ W Chiriboga, $2120 \mathrm{~m}, \mathrm{KU} 141844-50 ; 14 \mathrm{~km}$ W Chiriboga, $1960 \mathrm{~m}$, KU 165838-839, 166232 (young), 209553-55 (C\&S); $14.4 \mathrm{~km}$ E La Palma, 1380 m. MCZ 92060-66; 16 km E La Palma, $1500 \mathrm{~m}$, MCZ 90308; 18 km E La Palma, 1600 m, MCZ 90294- 
307; 20.6 km E La Palma, 1600 m, MCZ 92056-58; 22 km E La Palma, 1770 m. MCZ 90287-93; 23 km E La Palma, 1900 m, MCZ 90276-86; 25.7 km E La Palma, 1820 m, MCZ 92059, 94488, 94490-92, 94859-61, 94919-44; Las Máquinas. AMNH 20144; Las Palmeras, MECN 354, QCAZ 884; Loma Las Peñas, 2 km due S Tandapi, $1600 \mathrm{~m}$, MCZ 90231; Los Alpes, $2600 \mathrm{~m}$, KU 117772-73, 130458-62; Milligali, MCZ 3008; $3.5 \mathrm{~km}$ NE Mindo, $1540 \mathrm{~m}$, KU 165733-39; above Mindo, 1500-1610 m. MCZ 113474, 113485; Mindo (Hda. San Vicente), 1465-1620 m, USNM 284356-57, 284360: road to Mindo, $7500 \mathrm{ft}$, UMMZ 55504; $10 \mathrm{~km}$ N Nono (road to Tandayapa), $2200 \mathrm{~m}, \mathrm{MCZ} 90232-34$; $15 \mathrm{~km} \mathrm{~N}$ Nono (road to Tandayapa), $2100 \mathrm{~m}, \mathrm{MCZ}$ 90235-38; 9.5 km NW Nono, 2530 m, KU 165728-32; $10 \mathrm{~km} \mathrm{NW}$ Nono (road to Nanegal), $2200 \mathrm{~m}, \mathrm{MCZ}$ 90240-43; 12 km NW Nono (road to Nanegal), MCZ 90244-75: Quebrada La Plata, 3 km SE Tandapi. 1560 m, MCZ 90227-30; Quebrada Zapadores, 5 km ESE Chiriboga, 2010 m, KU 165740-82, 166287-88 (skeletons), 177565-66; Río Faisanes, $13.5 \mathrm{~km}$ E La Palma, 1380 m, MCZ 92864-71, 92880-81,93447-48, 9448081,94906-16, 95629; San Ignacio, 2030 m, KU 109065 , 109070; 1 km W San Ignacio, 1900 m, KU 177542-63; Tandapi, $1460 \mathrm{~m}$, KU 110975-77 (C\&S), 110978$1084,135339-42,135447,135469,135471-82$, 135485-86, 135489-90, 138779-87, MCZ 75164-69, QCAZ 606; 2 km E Tandapi, Quebrada La Plata, 1550 m, USNM 285967-69; $2.1 \mathrm{~km}$ E Tandapi, $1500 \mathrm{~m}$, MCZ 92841-45, 94824-36, 95612,95483-92; 6.1 km E Tandapi, $1650 \mathrm{~m}$, KU 177567; 6.2 km E Tandapi, 1700-1750 m, MCZ 92067-78, 93432-51; Tandayapa, 2300 m, CAS-SU 10351-52, MCZ 88417-18, USNM 239845; 7 km SE Tandayapa, 1900 m, MCZ 90239; 9 km SE Tandayapa, 2150 m, KU 165689-727; 1.4 km SW Tandayapa, $1820 \mathrm{~m}$, KU 202591; $2.3 \mathrm{~km}$ SW Tandayapa, $1900 \mathrm{~m}$, KU 202587-90: 9.4 km SW Tandayapa, 2390 m, KU 202574-86; Tinalandia, 800 m, MCZ 88419, 88423-25. Prov. undetermined: West Ecuador, BM 60.6.16.95, 60.6.16.98, 60.6.16.100, 60.6.16.102-03, 60.6.16.107. ERroneOus locality: Prov. Pichincha: Santo Domingo de los Colorados, FMNH 172461.

\section{Eleutherodactylus walkeri (407 specimens)}

Ecuador: Prov. Azuay: $11.2 \mathrm{~km}$ W Luz María, 930 m, QCAZ 7882; 12.9 km W Luz María, 740 m, KU 218149, QCAZ 7883; 13.5 W Luz María, 740 m, KU 218119; Manta Real, Parroquia Molleturo, $650 \mathrm{~m}$, EPN-AA 2543-45, 2552-54, 2584. Prov. Bolivar: Balsapamba, $800 \mathrm{~m}$, KU 131613-51; 6 km ESE Balsapamba, 1270 m, KU 142039-40. Prov. Cotopaxi:
0.7 km N Las Juntas, $320 \mathrm{~m}$, USNM 286068; $11 \mathrm{~km} \mathrm{E}$ Moraspungo, $840 \mathrm{~m}$, USNM 286085; $18.6 \mathrm{~km}$ W Pilaló, 930 m, KU 142172, 20.3 km W Pilaló, KU 142034-38, 142171. Prov. El Oro: $11.7 \mathrm{~km}$ W Piñas, $708-800 \mathrm{~m}$, USNM 286253-56, 286258-62, 286269-76; $32.6 \mathrm{~km}$ SSE Portovelo, $990 \mathrm{~m}$, KU 142041. Prov. Esmeraldas: 3.9 km E Durango, QCAZ 8072; Hda. Equinox, 38 km NW Santo Domingo de los Colorados, $300 \mathrm{~m}$. USNM 233423-24; vicinity of San Miguel, MCZ 92908, 92911-18,92921-25,92933,92935-36,92941,9295051, QCAZ 171. Prov. Guayas: Río Frio, UMMZ 123900. Prov. Los Ríos: Estación Biológica Río Palenque, 220 m, KU 146173, 147567-68, 165653-58, MCZ 90218 , 92054, 94842, USNM 285360-62. Prov. Manabí: environs of Guale, Río Ayampe, 500 m, QCAZ 4227; Parque Nacional Machalilla, Cerro San Sebastián (Bola del Oro), 750 m, EPN-AA 2436. Prov. Pichincha: Centinela, 14.1 km ESE Patricia Pilar, 550-600, USNM 285629-68; 4 km E Dos Ríos, 1120 m. KU 202557-59: 5 km NW La Florida, QCAZ 601-02; $5 \mathrm{~km} \mathrm{~W} \mathrm{La}$ Florida, 860 m, KU 218116-17, QCAZ 4061, QCAZ 7884-85; La Palma, 920 m, CAS 134064-66, KU 131652 (holotype), 131653-63, 178013-14; 1-2 km E La Palma, MCZ 90206-08; 19.3 km E Patricia Pilar, 430 m, USNM 285687-90; Río Baba, 5-10 km SSW Santo Domingo de los Colorados, $500 \mathrm{~m}$, AMNH 89733-36; Río Baba, 10 km S, 4 km E Santo Domingo de los Colorados, KU 142013-30; Río Baba, 19 km S, $5 \mathrm{~km}$ E Santo Domingo de los Colorados, U1MNH 93560-61; Río Canoi, 4 km S Vicente Maldonado, 570 m, KU 218118, QCAZ 7886; Río Toachi, USNM 233439-40; San Miguel de los Colorados, USNM 233441; Santo Domingo de los Colorados, $600 \mathrm{~m}$, FMNH 174092, 172464, 174334, KU 120215-21, 120227-31, 177985-8009; 2 km E, 1 km S Santo Domingo de los Colorados, KU 178010-11, 178012 (C\&S); $6 \mathrm{~km}$ E Santo Domingo de los Colorados (Dyott Farm), USNM 233425-37; 8 km SE Santo Domingo de los Colorados (Hda. Delta), UMMZ 131675 (10); $9 \mathrm{~km}$ W Santo Domingo de los Colorados (Hda. Espinosa), CAS-SU 10514, 10517; $18 \mathrm{~km} \mathrm{~W}$ Santo Domingo de los Colorados (Ramsey Farm), 650 m, USNM 233438; Tinalandia, MCZ 88395-411, 88421, 90146-204, 90209-17, 90219-26, 90334,, 92055, 92851-63, 94710,95482 USNM 217415; Toachi, $860 \mathrm{~m}$, QCAZ 7887; 1 km E Vicente Maldonado. 570 m, QCAZ 7888. 


\section{APPENDIX II}

GAZETTEER

Following is a list of localities on the Pacific lowlands and western slopes of the Andes in Ecuador where specimens of Eleutherodactylus were collected. After each place name the province is given in parentheses, followed by geographic coordinates, elevation and bioclimatic regime (see section on Western Ecuador). Spellings and coordinates given to seconds were taken from the Indice Toponímico de la República del Ecuador (no date); others were determined from the 1974 and 1991 editions of Mapa de Ecuador, Instituto Geográfico Militar, Quito ( I:1,000,000) and Salvador et al. (1995). Elevations were determined from altimeter readings at the sites or from listings in the Indice Toponímico de la República del Ecuador (1972). When known, specific sites and habitats are given, followed by names of collectors and months and years that they collected at the sites. Names of some of the collectors are abbreviated: $\mathrm{JAP}=$ James A. Peters, JDL $=$ John D. Lynch, $\mathrm{KM}=$ Kenneth Miyata, LAC $=$ Luis A. Coloma, RWM $=$ Roy W. McDiarmid, SRE = Stephen R. Edwards, WED = William E. Duellman. The boldfaced number at the end of each entry refers to the number on the map (Fig. 87).

Alluriquin (Pichincha)-00 $23^{\prime}$ S. $78^{\circ} 58^{\prime} \mathrm{W}, 700 \mathrm{~m}$ : humid subtropical. Village on the lower slope of the Cordillera Occidental on the Alóag-Santo Domingo de los Colorados road. Collections made in disturbed humid lower montane forest at $12 \mathrm{~km} \mathrm{E,} 940 \mathrm{~m}$, by LAC in July 1989 , and at $13 \mathrm{~km}$ E by KM. 69

Alóag (Pichincha)—00 $28^{\prime}$ S, 78 $35^{\prime} \mathrm{W}, 2890 \mathrm{~m}$; humid temperate. Village on the highway from the junction of the Panamerican Highway to Santo Domingo de los Colorados, which borders the north slope of Cerro Corazón. Collections were made in remnants of humid upper montane forest at $5 \mathrm{~km}$ W Alóag $(2945 \mathrm{~m})$ and $7 \mathrm{~km}$ W of Alóag $(2810 \mathrm{~m})$ by WED in March 1967, and $16 \mathrm{~km}$ W Alóag $(2810 \mathrm{~m})$ and $21 \mathrm{~km} \mathrm{~W} \mathrm{Alóag}(2640 \mathrm{~m})$ by JDL in July 1967.79

Alto Tambo (Esmeraldas) - $00^{\circ} 51^{\prime} 42^{\prime \prime}$ N, 78 $30^{\prime} 54^{\prime \prime}$ W. $830 \mathrm{~m}$ : humid subtropical. A village on the Ibarra-San Lorenzo railroad and Río Mira. Collection in disturbed lower humid montane forest by Stella de la Torre and others in December 1990. 15

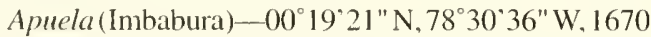
$\mathrm{m}$; humid subtropical. A village on the Pacific slope of the Cordillera Occidental. Collections were made in upper humid montane forest at various distances along the road from Apuela to Otavalo- $16.1 \mathrm{~km} \mathrm{E}(2400 \mathrm{~m})$, $16.7 \mathrm{~km} \mathrm{E}(2470 \mathrm{~m}), 17.4 \mathrm{~km} \mathrm{E}(2500 \mathrm{~m})$ by KM, $22 \mathrm{~km}$ $\mathrm{E}(2860 \mathrm{~m})$ by LAC in June 1989, and in páramo $35 \mathrm{~km}$ $\mathrm{E}(3220 \mathrm{~m})$ by LAC in June 1989. Collections also were made in the Cordillera de Intag, $2190 \mathrm{~m}, 23.2 \mathrm{~km}$ (by road) W of Apuela, by JDL in January 1978. 28

Ayampe (Guayas) - $01^{\circ} 40^{\circ} 3 \mathrm{l}^{\prime \prime} \mathrm{S}, 80^{\circ} 48^{\circ} 36^{\prime \prime} \mathrm{W}, 12$ $\mathrm{m}$; dry tropical. A village and river $25 \mathrm{~km}$ N of Montañita on the boundary of Provincial Manabí and Provincia Guayas. Collection from dry forest at edge of river 3.7 km E, $70 \mathrm{~m}$, by LAC. 103

Balsapamba (Bolívar)-01 $47^{\prime}$ S, 79 10' W, $800 \mathrm{~m}$; dry subtropical. Village on the lower slopes of the Cordillera Occidental. Collections made in cutover forest in the immediate vicinity of the village by JDL in July 1970 and $6 \mathrm{~km}$ ESE on the road to Chillanes, $1270 \mathrm{~m}$ by WED in July 1971. Collection from " $10 \mathrm{~km}$ E, $9500 \mathrm{ft}$ " by JAP in June 1954. 109

Biblián (Cañar)-02 $42^{\circ} 42^{\prime \prime}$ S, 78 $53^{\prime} 12^{\prime \prime}$ W, 2630 $\mathrm{m}$; humid temperate. Town in the northern part of the Hoya de Cuenca. Collections from disturbed subpáramo at $0.5 \mathrm{~km} \mathrm{~N}, 2620 \mathrm{~m}$ by R. R. Montanucci in May 1971. and $10 \mathrm{~km} \mathrm{NE}, 2540 \mathrm{~m}$ by WED in July 197I. 126

Bilován (Bolívar)-0 -0 $48^{\circ}$ S. $79^{\circ} 05^{\prime} \mathrm{W}$; humid temperate. Village on western slopes of Cordillera Occidental. Collection from $10 \mathrm{~km} \mathrm{NE}, 2540 \mathrm{~m}$, by WED in July 1971. 109B

Bilsa (Esmeraldas)-_See San José de Bilsa.

Bola del Oro (Manabí)-See Parque Nacional Machalilla.

Bosque Protector Cashca Totoras (Bolívar)-01 ${ }^{\circ} 42^{\prime}$ $\mathrm{S}, 78^{\circ} 53^{\prime} \mathrm{W}, 3000 \mathrm{~m}$; humid temperate. A reserve in the uppermost drainage of the Río Chimbo on the Pacific slope of the Cordillera Occidental. Collections from humid upper montane forest by LAC in December 1986, November-December 1987, February 1989, and January 1990. 104

Bosque Protector Mindo-Nambillo (Pichin-cha)See Mindo.

Bucay' (Guayas)—02 $10^{\prime} \mathrm{S}, 79^{\circ} 06^{\prime} \mathrm{W}, 275 \mathrm{~m}$; dry tropical. Village on the railroad and Guayaquil-Riobamba road at the mouth of the Río Chimbo Valley at the base of the Cordillera Occidental. Collection by G. H. Tate in December 1921 and March 1922. 116

Buena Fé (Los Ríos) - $00^{\circ} 53^{\circ} 40^{\prime \prime}$ S, 79²9⒈ 15" W, $200 \mathrm{~m}$; humid tropical. Small village on the highway between Santo Domingo de los Colorados and Quevedo and situated in area predominately cultivated in bananas. 
Collections made 1 kin N Buena Fé by KM in January 1979. 86

Buenavista (E1 Oro)-032 $21^{\prime} 21^{\prime \prime} \mathrm{S} .79^{\circ} 50^{\prime} 16^{\prime \prime} \mathrm{W} .27$ $\mathrm{m}$; dry tropical. Village on road $6 \mathrm{~km}$ SW Pasaje on Pacific lowlands; cutover semideciduous forest. Collections made at $7 \mathrm{~km} \mathrm{SE}, 30 \mathrm{~m}$, by JAP in August 1954. 134

Bulúm (Esmeraldas)-See San Francisco.

Cachabé (Esmeraldas)—See San Javier de Cachabé.

Calacalí (Pichincha) $-00^{\circ} 00^{\circ} 10^{\prime \prime} \mathrm{N}, 78^{\circ} 30^{\circ} 40^{\prime \prime} \mathrm{W}$, $2815 \mathrm{~m}$; humid temperate. A small village in the Cordillera Occidental. Collections were made on the western slope of the cordillera at a point $14.7 \mathrm{~km}$ (by road) SW of Calacalí on the road to Nono, $2130 \mathrm{~m}$ by LAC in March 1990. 43

Campamento Silante (Pichincha) $-00^{\circ} 26^{\prime} \mathrm{S}, 78^{\circ} 42^{\prime}$ W, $2100 \mathrm{~m}$; humid temperate. Road maintenance camp on highway between Alóag and Tandapi on the Pacific slope of Cordillera Occidental; disturbed humid upper montane forest. Collections in vicinity of camp and $2 \mathrm{~km}$ W, $2100 \mathrm{~m}$ by JDL in August 1970. 73

Cañar (Cañar)—02 $33^{\circ} 20^{\prime \prime}$ S. 78 56’ 15"W, 3140 m; humid temperate. Town in the Cordillera Occidental of the Andes. Collections made in disturbed low forest 5.6 $\mathrm{km}$ NNW, $2920 \mathrm{~m}$ by WED in March 1984 and $28.2 \mathrm{~km}$ N. 2915 m by R. R. Montanucci in May 1971. 122

Carondelet (Esmeraldas)_-See Parroquia Carondelet.

Cataviña (Azuay) - $03^{\circ} 15^{\prime} 12^{\prime \prime} \mathrm{S}, 79^{\circ} 15^{\prime} 42^{\prime \prime} \mathrm{W}, 1580$ $\mathrm{m}$; dry subtropical. A hacienda in the valley of the Río Jubones between Santa lsabel and Girón on the Pacific slope of the Cordillera Occidental. Collection from $4 \mathrm{~km}$ SW, $1600 \mathrm{~m}$ by JAP in February 1959. 130

Centinela, $14.1 \mathrm{~km}$ (by road) SE Patricia Pilar (Pichincha)-00³5' S, 79²1' W, 550-600 m; humid subtropical. A site on a north-south ridge, Montañas de Ila, on the Pacific coastal plain east of the Río Palenque; humid lower montane forest, now cutover; collections by KM and RWM in January and October 1979. 81

Centro Cientifico Río Palenque (Los Ríos) - $00^{\circ} 34^{\prime}$ $\mathrm{S}, 79^{\circ} 20^{\circ} \mathrm{W}, 200-220 \mathrm{~m}$; humid tropical. A biological station of 167 ha $56 \mathrm{~km} \mathrm{~N}$ Quevedo; humid tropical rainforest, oil palm plantation, and banana plantation. Collections made C. F. Walker and E. H. Taylor in August 1962, by WED in April 1972 and March 1975, by D. C. Dodson in January 1972, by J. E. Simmons in July 1972, by G. O. Vigle in December 1977, by RWM in December 1978, and by KM and RWM in January and October 1979.82

Cerro San Sebastián (Manabí)—See Parque Nacional Machalilla.

Chimbo (Chimborazo)-02 09' S, $79^{\circ} 05^{\prime}$ W. 345 m; dry subtropical. Railroad bridge over Río Chimbo above Bucay at base of Cordillera Occidental. 115
Chiriboga (Pichincha) - $00^{\circ} 13^{\circ} 42^{\prime \prime} \mathrm{S}, 78^{\circ} 46^{\circ} 00^{\prime \prime} \mathrm{W}$, $1910 \mathrm{~m}$; humid temperate. A small village on the "old road" between Quito and Santo Domingo de los Colorados. Collection from disturbed cloud forest in immediate vicinity by C. Fierro in May 1986 and Maty 1988. Collections from disturbed cloud forest at various distances along the road to the east and west of Chiriboga - $10 \mathrm{~km} \mathrm{E} \mathrm{by} \mathrm{JAP} \mathrm{in} \mathrm{March} \mathrm{1959;} 14.8 \mathrm{~km} \mathrm{E}$ (2410 $\mathrm{m}$ ) by WED in July 1971 and by JDL in January $1978 ; 0.6 \mathrm{~km}$ W (1880 m) by RWM in March 1979, 4 km W (2120 $\mathrm{m}$ ) by WED in July 1971; $8 \mathrm{~km}$ W by JAP in May 1959; 14 km W (1960 m) by WED in May 1975; and $25.8 \mathrm{~km}$ W ( $1720 \mathrm{~m}$; humid subtropical) by WED in July 1971.50

Clontapamba (Pichincha)-Not located. Collection by Manuel Olalla in April 1955.

Compud (Chimborazo) - $02^{\circ} 20^{\circ} 28^{\prime \prime} \mathrm{S}, 78^{\circ} 56^{\circ} 03^{\prime \prime} \mathrm{W}$. $2570 \mathrm{~m}$; humid temperate. A village on the Panamerican Highway in the Cordillera Occidental. Collection from disturbed humid upper montane forest $7.7 \mathrm{~km} \mathrm{SW,} 2570$ $\mathrm{m}$ by WED in July 1971. 119

Commina San Vicente de Asacoto (Chimborazo)Dry temperate. A settlement at $2100 \mathrm{~m}$ in the Cantón Pallatanga on the Pacific slope of the Cordillera Occidental. Collection from small areas of secondary forest by $\mathrm{A}$ Almendáriz in September 1986. Not located.

Cordillera de Chilla, Llanos de Guavos (El Oro)Mountain chain SW of Chilla $\left(03^{\circ} 29^{\prime} \mathrm{S}, 79^{\circ} 36^{\circ} \mathrm{W}\right)$. Collection by H. E. Anthony in August 1920. 134

Cruz de Lizo (Bolívar)- $01^{\circ} 43^{\circ} 30^{\prime \prime} \mathrm{S}, 78^{\circ} 59^{\circ} 54^{\prime \prime} \mathrm{W}$ $2720 \mathrm{~m}$; humid temperate. A village in the western Andean Chimbo Basin, $3.1 \mathrm{~km} \mathrm{~S}$ of Santiago. Collections from disturbed areas by LAC in September 1983. 108

Cuellaje (Imbabura) - $00^{\circ} 22^{\prime} \mathrm{N}, 78^{\circ} 32^{\prime} \mathrm{W}, \approx 1500 \mathrm{~m}$; humid subtropical. A settlement on the west slope of the Cordillera Occidental, below (west of Apuela). Collections from "above Cuellaje, $2560 \mathrm{~m}$ " by A. Quiguango and others in January and September 1994. 26A

Cuenca (Azuay)-02 $02^{\circ}$ S, $79^{\circ} 00^{\prime} \mathrm{W}, 2543 \mathrm{~m}$; humid temperate. City in an inter-Andean basin. 128A

Desío (Manabí)-0 $01^{\circ} 03^{\prime}$ S. 79 57' W dry tropical. A site on the Quevedo-Manta road. $16 \mathrm{~km} \mathrm{~W}$ of Pichincha in the Cordillera de Balzar. Collection from $2 \mathrm{~km} \mathrm{W.} 250$ $\mathrm{m}$. by JAP in October 1965.92

Desío Panamericana (Chimborazo)-01 $42^{\prime} \mathrm{S}$. $78^{\circ} 46^{\prime} \mathrm{W}, 3200 \mathrm{~m}$; humid subtemperate. Junction of Panamerican Highway and road to Guayaquil. Collection from disturbed upper montane forest $35 \mathrm{~km}$ SW on road to Pallatanga, $2860 \mathrm{~m}$ by LAC in April 1990. 105

Dos Ríos (Pichincha)-00 19' S. $78^{\circ} 5 \mathrm{I}^{\prime} \mathrm{W}, 1270 \mathrm{~m}$; humid subtropical. A small village $(=10 \mathrm{~km}$ NE Las Palmas) on the "old road" between Quito and Santo Domingo de los Colorados; disturbed lower montane 


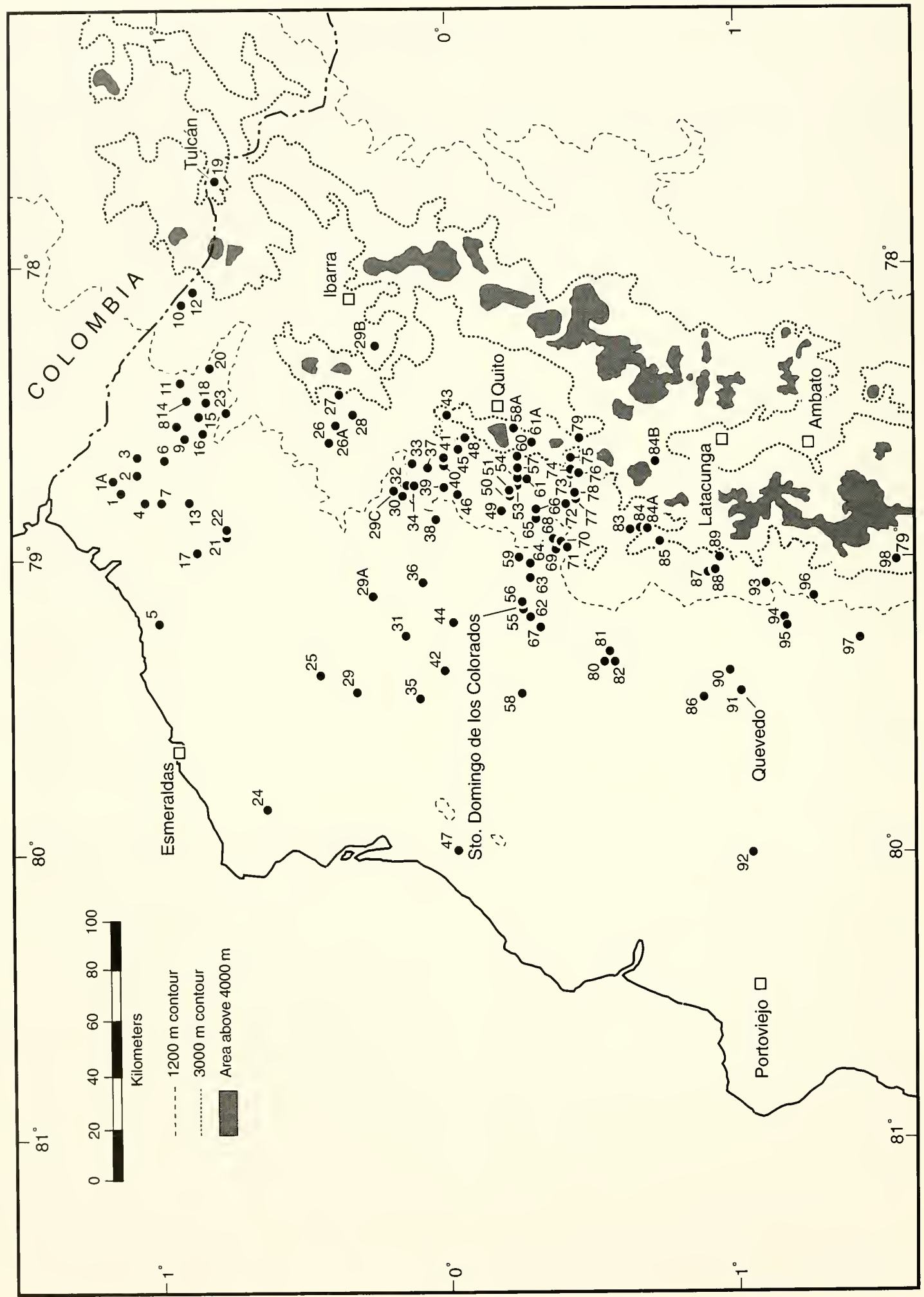




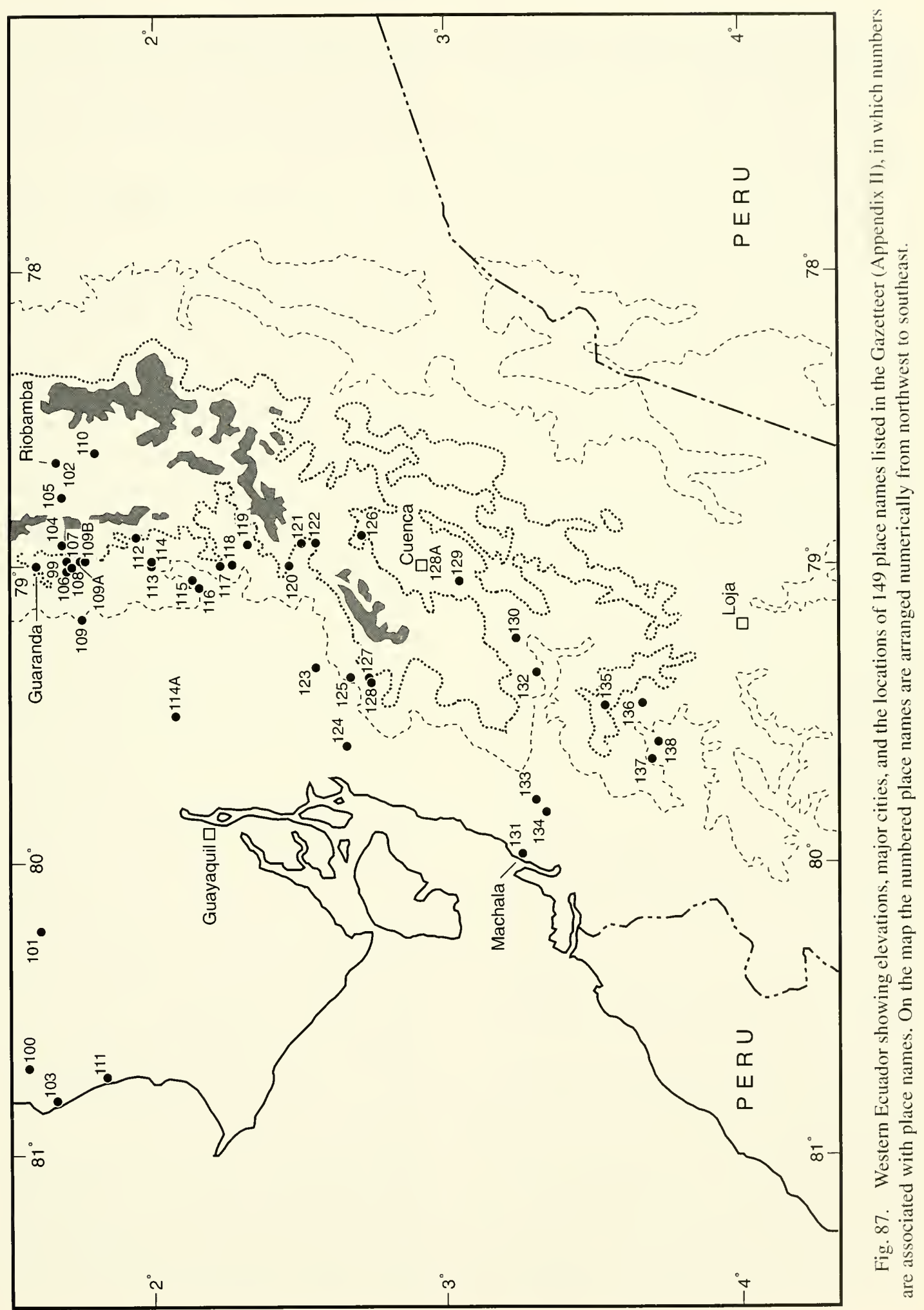


rainforest. Collections by T. H. Fritts in July 1970. Collections also made along the road $-3 \mathrm{~km} \mathrm{~W}(1050 \mathrm{~m})$ by WED in July 1971 and $4 \mathrm{~km} \mathrm{NE} \mathrm{(1140} \mathrm{m)} \mathrm{in} \mathrm{April}$ 1975 and March 1984. 65

Durmgo (Esmeraldas) - $00^{\circ} 53^{\prime} \mathrm{N}, 78^{\circ} 48^{\prime} \mathrm{W},<300$ $\mathrm{m}$ : humid tropical. A settlement on the Pacific coastal plain. Collection from lowland tropical rainforest by LAC and others in March 1994. 13

Echeandía (Bolívar) - $01^{\circ} 25^{\circ} 58^{\prime \prime} \mathrm{S}, 79^{\circ} 16^{\prime} 15^{\prime \prime} \mathrm{W}$ $280 \mathrm{~m}$; dry tropical. Small village on coastal plain east of Ventinas. Collection by R. Jiménez. 97

El Carmen (Manabí)-00 16'08" S, 79²8' 20" W, $250 \mathrm{~m}$; dry tropical. Town on Pacific lowlands. Collection from $50 \mathrm{~km}$ WSW on roald to Chone, $400 \mathrm{~m}$; and 38 $\mathrm{km}$ NW on road to Pedernales, $330 \mathrm{~m}$, by LAC, December 1989.58

El Chiral (El Oro)—0340’36" S, 79 28“48" W. 1630 $\mathrm{m}$; dry subtropical. A settlement north of Zaruma on the south face of the Cordillera de Chilla. Collection by H. E. Anthony in July 1920. 136

El Corcovado (Cotopaxi)-01 07’36" S, $79^{\circ} 07^{\prime} 12^{\prime \prime}$. $2000 \mathrm{~m}$; humid temperate. Settlement $3.5 \mathrm{~km} \mathrm{NW}$ of El Corazón on western slope of Cordillera Oriental. Collection by G. Onore in July 1991.93

El Cristal (Esmeraldas) $-00^{\circ} 45^{\prime}$ N. $78^{\circ} 30^{\prime} \mathrm{W}, 1200$ $\mathrm{m}$; humid subtropical. Settlement on the north slope of the Cordillera de Lachas, SSW of Lita. Collection by M. L. Crump and others in December 1993 and by A. Quiguango and others in August 1994. 23

El Placer (Esmeraldas)—00 $51^{\prime} 18^{\prime \prime}$ N, $78^{\circ} 33^{\circ} 42^{\prime \prime}$ W: dry tropical. Settlement on the Pacific coastal plain. Collection from 2-4 km W, 360-390 m by JAPin November 1958. 16

El Tambo (Cañar)—023 $\mathrm{I}^{\prime} \mathrm{S}, 78^{\circ} 56^{\prime} \mathrm{W}, 2960 \mathrm{~m}$; humid temperate. Village on Panamerican Highway in valley of upper Río Cañar (Pacific drainage). Collections from disturbed upper montane forest $15 \mathrm{~km} \mathrm{NW}, 2840 \mathrm{~m}$ by WED in July 1971 and from subpáramo $18.4 \mathrm{~km} \mathrm{NW}$. $2960 \mathrm{~m}$ by WED in July 1971. 121

El Torneado (Bolívar) $01^{\circ} 45^{\prime} 25^{\prime \prime} \mathrm{S}, 79^{\circ} 08^{\circ} 08 \mathrm{a} \mathrm{W}$. $2430 \mathrm{~m}$; dry temperate. A site $6.4 \mathrm{~km}$ NE of Balsapamba. Collection by A. Almendáriz in June 1987. 129A

Estación Biológica Río Palenque (Los Ríos)-See Centro Cientifico Río Palenque.

Estación Forestal La Favorita (Pichincha)Parroquia Chiriboga, $00^{\circ} 13^{\circ} 42^{\prime \prime}$ S, $78^{\circ} 45^{\prime} 54^{\prime \prime} \mathrm{W}, 1900$ $\mathrm{m}$ : humid temperate. A small field station located on the "old road" between Quito and Santo Domingo de los Colorados Pacific slopes of the Cordillera Occidental. The area of the station is mostly secondary forest amid remnants of upper humid montane forest: collections by A. Almendáriz in July 1987. 51

Finca La Esperanza (Pichincha)-00¹5' S, $79^{\circ} 09^{\prime}$
W, $500 \mathrm{~m}$; humid subtropical. A farm just NW of Santo Domingo de los Colorados. Collection by C. Durán. $\mathbf{5 5}$

Finca Santa Lucía (Pichincha)-00 15' S. $78^{\circ} 42^{\prime} \mathrm{W}$, $2120 \mathrm{~m}$; humid temperate. A small farm $7.7 \mathrm{~km} \mathrm{E}$ Chiriboga: disturbed humid upper montane forest. Collection by WED in July 1971. 54

Galápagos (Pichincha)-00 24'2 1" S, $78^{\circ} 58^{\circ} 00^{\prime \prime} \mathrm{W}$. $1720 \mathrm{~m}$; humid subtropical. A village in humid montane forest $2.5 \mathrm{~km}$ N of San Francisco de Las Pampas. Collections by $\mathrm{G}$. Onore. 71

Guaincle (El Oro)-Collection by G. H. Tate in August 1921. Not located. Possibly this is Guaynche, Provicia Loja, $04^{\circ} 02^{\prime} 17^{\prime \prime} \mathrm{S}, 79^{\circ} 59^{\prime} 13^{\prime \prime} \mathrm{W}, 1120 \mathrm{~m}$.

Guale (Manabí)_01 37’38" S, 80¹4’15" W, 60 m; dry tropical. Collection from Finca Canta La Piedra on the Río Ayampe in the vicinity of Guale by Ana Agreda and Luis Vinueza in September 1993. 101

Gualéa (Pichincha)-00 $07^{\circ} 00^{\prime \prime} \mathrm{N}, 78^{\circ} 44^{\circ} 48^{\prime \prime} \mathrm{W}$, $1300 \mathrm{~m}$; humid subtropical. Settlement $3.9 \mathrm{~km} \mathrm{NW}$ Nanegalito on Pacific slope of Cordillera Occidental. Specimens in BM. 33

Graltaco(ElOro)_-Not located: collection by Ramón Ollala in February 1951.

Guanujo (Bolívar)-01 33²0" S, 7900`24" W, 2900 $\mathrm{m}$; humid subtemperate. Village in the upper Río Chimbo valley north of Guaranda. Collection in disturbed upper montane forest by LAC in December 1984. 98

Guaranda (Bolívar)—01 $35^{\prime} 18^{\prime \prime}$ S, 78 59'58'W, 2670 $\mathrm{m}$ : humid temperate. Town in the upper Río Chimbo valley on the Pacific slope of the Cordillera Occidental. Collections from disturbed upper montane forest in immediate vicinity of town by JDL in July 1970 and $4.7 \mathrm{~km}$ $\mathrm{E}(2700 \mathrm{~m})$ by LAC in January 1990. Collections from subpáramo along road to Riobamba-11.1 km E (2600 m) by WED in March 1984, 14. I km E (3030 m) by LAC in April 1990, and $29 \mathrm{~km} \mathrm{E} \mathrm{(2710} \mathrm{m)} \mathrm{by} \mathrm{LAC} \mathrm{in} \mathrm{July}$ 1989. Collections from disturbed upper montane forest on road to San Miguel and Chillanes $-2.5 \mathrm{~km} \mathrm{~S}(2550 \mathrm{~m})$ by R. R. Montannuci in May 1971, 4.6 km S (2410 m) by WED in March 1984, and $5.4 \mathrm{~km} \mathrm{~S} \mathrm{(2680} \mathrm{m})$ by JDL in January 1978. 99

Guatea (Pichincha)-See Gualea.

Guavas (Guayas)—00 $58^{\prime} 36^{\prime \prime}$ S. $79^{\circ} 23^{\prime} 45^{\prime \prime} \mathrm{W}$; humid tropical. Village on Pacific coastal plain NW of Quevedo. Collection from $20 \mathrm{~km}$ W (90 m: dry tropical) USNM. 90

Gum (Cañar)—See Zhud.

Huigra (Chimborazo)—02 17"06" S, 78 58 48" W. $1230 \mathrm{~m}$; dry subtropical. Settlement on the railroad 6.9 $\mathrm{km}$ W of Chunchi in Río Chanchán Valley on the west slope of the Cordillera Occidental: subtropical, semiarid forest. Collection by S. N. Rhoades in 1911. 118

Intac (Imbabura) - See Intag. 
Intag (Imbabura)-00 $24^{\prime} \mathrm{N}, 78^{\circ} 36^{\prime} \mathrm{W}, 1200 \mathrm{~m}$; humid subtropical. Settlement on north slope of Cordillera de lntag; lower humid montane forest. Collection by Buckley for BM. 26

Km 94 (Guavaquil-Cuenca road)-Not located. Collection by G. P. Frymire and C. H. Dodson in January 1958.

La Boca (Esmeraldas) - $01^{\circ} 08^{\prime}$ N. 78 46' W, <100 m; humid tropical. Village at junction of Río Bogotá and Río Tululbí. 1A

La Concordia (Pichincha) $-00^{\circ} 00^{\circ} 15^{\prime \prime}$ N, 79 23'12" $\mathrm{W}, 180 \mathrm{~m}$; humid tropical. A village on the Pacific lowlands. Collections from a remnant of humid tropical rainforest. Bosque Protector La Perla, $190 \mathrm{~m}$ by LAC in April 1990, and from $5.3 \mathrm{~km} \mathrm{W,} 190 \mathrm{~m}$ by LAC in April 1990. 42

La Delicia (Imbabura)— $\approx 00^{\circ} 22^{\prime}$ N. $78^{\circ} 25^{\prime} \mathrm{W}, 2710$ $\mathrm{m}$; humid temperate. Settlement on road between Otavalo and Apuela near crest of Cordillera Occidental: disturbed upper humid montane forest. Collections by SRE in August 1970 and by JDL in June 1977 and January 1978. 27

La Esperanza (Cotopaxi)-0054' S, 7903' W, 1500 $\mathrm{m}$; humid subtropical. Settlement on road and Quevedo and Pujilí; cutover montane forest. Collection by JDL in July 1970.87

La Florida (Pichincha) - $00^{\circ} 16^{\circ} 48^{\prime \prime} \mathrm{S}, 79^{\circ} 01^{\circ} 00^{\prime \prime} \mathrm{W}$, $1000 \mathrm{~m}$; humid subtropical. A village on the lower slopes of the Cordillera Occidental, $15 \mathrm{~km}$ SE of Santo Domingo de los Colorados. Collections from $5 \mathrm{~km} \mathrm{NW,} 860 \mathrm{~m}$ by LAC in September 1984. December 1989, and May 1993 by LAC. $\mathbf{5 9}$

Lagarto, Reserva Marronga (Esmeraldas)-01 $00^{\prime}$ N, $79^{\circ} 13^{\circ} \mathrm{W}, 100 \mathrm{~m}$; humid tropical. A village on the Rio Lagarto on the Pacific coastal plain. Collection from forest reserve by $\mathrm{G}$. Onore in October and December 1993.5

La Gruel (Carchi)-00 $53^{\prime}$ N, $78^{\circ} 05^{\prime}$ W, 2500 m; humid temperate. A village on the road between Tulcán and Maldonado. Collections from subpáramo $2 \mathrm{~km} \mathrm{E}$, $2590 \mathrm{~m}$, and from disturbed upper humid montane forest $5 \mathrm{~km} \mathrm{W,} 2340 \mathrm{~m}$ by WED, February 1984. Name was provided by local inhabitants but does not appear on maps; possibly official name is Laurel, which does appear on recent maps. 12

La Palma (Pichincha) - $00^{\circ} 22^{\prime} 40^{\prime \prime} \mathrm{S}, 78^{\circ} 55^{\prime} 49^{\prime \prime} \mathrm{W}$, $920 \mathrm{~m}$ : humid subtropical. A small village at the junction of the "old" and "new" roads between Quito and Santo Domingo de los Colorados: disturbed lower montane rainforest. Collections by JDL in August 1970 and July 1977. Collections also from various distances and elevations along the "old road" (vía Chiriboga) - $3 \mathrm{~km} \mathrm{NE}$ $(1540 \mathrm{~m})$ in April 1975 and $5 \mathrm{~km} \mathrm{E}(900 \mathrm{~m})$ in March
1975 by WED; $1.1 \mathrm{~km} \mathrm{E,} 10.4 \mathrm{~km} \mathrm{E,} 10.6 \mathrm{~km} \mathrm{E,} 12.6 \mathrm{~km}$ E, $13 \mathrm{~km} \mathrm{E,} 14.4 \mathrm{~km} \mathrm{E,} 16 \mathrm{~km} \mathrm{E}(1500 \mathrm{~m}), 18 \mathrm{~km} \mathrm{E}, 20.6$ $\mathrm{kmE}(1600 \mathrm{~m}), 22 \mathrm{kmE}(1770 \mathrm{~m}), 23 \mathrm{~km} \mathrm{E}(1900 \mathrm{~m})$, and $25.7 \mathrm{~km} \mathrm{E}(1820 \mathrm{~m})$ by KM in January and October 1979. 68

Las Cochas (Chimborazo) - $02^{\circ} 14^{\prime} 48^{\prime \prime}$ S, 78 $59^{\prime} 36^{\prime \prime}$ W, $2520 \mathrm{~m}$; humid temperate. A site northwest of the village of Huigra in the upper Rio Chanchan valley. Collection by J. R. Wiggins in October 1944. 117

Las Juntas (Cotopaxi)—01 1 $11^{\prime} 06^{\prime \prime} \mathrm{S}, 79^{\circ} 13^{\prime} 48^{\prime \prime} \mathrm{W}$; humid subtropical. Village in foothills of the Andes. Collection from $0.7 \mathrm{~km} \mathrm{~N}(320 \mathrm{~m})$ by RWM in October 1979. 95

Las Máquinas (Pichincha)—00 $02^{\circ} 54^{\prime \prime} \mathrm{S}, 78^{\circ} 36^{\prime} 45^{\prime \prime}$ W, $2800 \mathrm{~m}$; humid temperate. A site $4.4 \mathrm{~km} \mathrm{NW}$ of Nono on the Pacific slope of the Cordillera Occidental; humid montane forest. $\mathbf{4 5}$

Las Palmas (Pichincha)-See La Palma.

Las Palmeras (Pichincha)- $00^{\circ} 12^{\prime} 00^{\prime \prime} \mathrm{S}, 78^{\circ} 49^{\prime} 36^{\prime \prime}$ W. $1800 \mathrm{~m}$; humid subtropical. A settlement $9 \mathrm{~km} \mathrm{~W}$ Chiriboga on the Pacific slope of the Cordillera Occidental; disturbed humid montane forest. Collection by LAC in October 1984. 49

Las Pampas (Cotopaxi)—See San Francisco de Las Pampas.

Laurel (Carchi)_See La Gruel.

Lita (Imbabura) - $00^{\circ} 50^{\circ} 24^{\prime \prime} \mathrm{N}, 78^{\circ} 27^{\circ} 18^{\prime \prime} \mathrm{W}, 570 \mathrm{~m}$; humid subtropical. A village on the Ibarra-San Lorenzo railroad. Collections by Manuel Ollala in April 1959 and from disturbed humid lower montane forest in the vicinity of the village by SRE in August 1970. LAC in September 1984, and Stella de la Torre and others in December 1990. 18

Lizo (Bolívar)—See Cruz de Lizo.

Llambo (Pichincha) $\left.-00^{\circ} 0\right]^{\prime}$ N. $78^{\circ} 40^{\prime} \mathrm{W}$ : humid temperate. A settlement on the road between Nono and Gualéa on the Pacific slope of the Cordillera Occidental: humid montane forest. Collection by $\mathrm{C}$. Ollala in April 1929. 40

Lloa (Pichincha)-00 09' S, 78 35' W. $2800 \mathrm{~m}$ : humid temperate. A village on the south slope of Volcán Pichincha. Collection by A. Quiguango and A. Ruíz in March 1994. 58A

Loma Las Peñas (Pichincha)-00²7' S, 78 46' W. $1600 \mathrm{~m}$; humid subtropical. A hill $2 \mathrm{~km}$ due S Tandapi; humid montane forest. Collection by KM in June 1975. 78

Los Alpes (Pichincha) $-00^{\circ} 26^{\prime} \mathrm{S}, 78^{\circ} 39^{\prime} \mathrm{W}, 2500$ $2600 \mathrm{~m}$; humid temperate. A settlement $20 \mathrm{~km}$ W Alóag on the road to Santo Domingo de los Colorados; disturbed upper humid montane forest.. Collections by JDL in July 1967 and August 1970. 75

Luz Maria (Azuay) $02^{\circ} 41^{\circ} 18^{\prime \prime} \mathrm{S}, 79^{\circ} 24^{\prime} 36^{\prime \prime} \mathrm{W}$, 
$1880 \mathrm{~m}$; hunid temperate. A village $7.5 \mathrm{~km} \mathrm{NW}$ of Molleturo on the Pacific slopes of the Cordillera Occidental. Collections were made in humid montane forest at $1-15 \mathrm{~km} \mathrm{E}(2500 \mathrm{~m})$ along the road from Luz María and in cloud forest (humid subtropical regime) $7.7 \mathrm{~km} \mathrm{~W}$ (1300 m), $11.2 \mathrm{~km} \mathrm{W(930} \mathrm{m),} 12.9 \mathrm{~km} \mathrm{~W}(740 \mathrm{~m}), 13.5$ $\mathrm{km} \mathrm{W(740} \mathrm{m)} \mathrm{by} \mathrm{L.AC} \mathrm{in} \mathrm{April} \mathrm{1990.} 125$

Machala (El Oro)-03 15’24" S, 79 57’20" W, $35 \mathrm{~m}$; dry tropical. A town on the Pacific coastal plain; tropical dry forest. Collection from $7 \mathrm{~km} \mathrm{SE}, 10 \mathrm{~m}$, by JAP in March 1959. 131

Machalilla (Manabí)-See Parque Nacional Machalilla.

Macuchi (Cotopaxi)-00 55’36" S, 7902`48" W, $1600 \mathrm{~m}$; humid subtropical. A settlement on the Río San Pablo $2 \mathrm{~km}$ SE of El Tingo on the road to Pilaló. Collection by JAP in January 1959. 88

Maldonado (Carchi) $-00^{\circ} 54^{\prime} 39^{\prime \prime} \mathrm{N}, 78^{\circ} 06^{\prime} 30^{\prime \prime} \mathrm{W}$, $1410 \mathrm{~m}$; humid subtropical. Village in the valley of the Río San Juan on the Pacific slopes of the Cordillera Occidental. Cut over cloud forest. Collection in vicinity of village and $14 \mathrm{~km}$ (airline) SE ( $2500 \mathrm{~m}$ ) by JDL in May 1977. Collections from $22 \mathrm{~km} \mathrm{E}$ along road to Tulcán ( $2560 \mathrm{~m}$; humid temperate) by LAC in March and July 1993, from 26.9-27.3 km E along road to Tulcán (2420 m; humid temperate) by LAC in June 1989 and from 14 $\mathrm{km} \mathrm{W}$ on road to Lita (1255 m) by LAC in March 1993. 10

Manglaralto (Guayas)_-0 ${ }^{\circ} 50^{\circ} 40^{\prime \prime} \mathrm{S}, 80^{\circ} 44^{\prime} 30^{\prime \prime} \mathrm{W}$, $5 \mathrm{~m}$; dry tropical. Village on Pacific coast; tropical dry forest. Collections from along road $\mathrm{N}$ to Puerto López$23 \mathrm{~km} \mathrm{~N}(60 \mathrm{~m})$ and $25 \mathrm{~km} \mathrm{~N}(120 \mathrm{~m})$ by KM in August 1975. 111

Manta Real (Cañar)-0234' S, 79 $21^{\circ}$ 'W, 250 m; dry tropical. A village at the base of the Andes. Collections were made above the village in cloud forest at an elevation of $650 \mathrm{~m}$ by Ana Almendáriz in July 1991. 123

Miligali (Pichincha) $-00^{\circ} 16^{\prime} \mathrm{S}, 78^{\circ} 46^{\prime} \mathrm{W}, 1625-$ $2000 \mathrm{~m}$; humid subtropical. Settlement on western slope of Cordillera Occidental; in subtropical forest according to Paynter and Traylor (1977). Collections by Manuel Ollala in January 1955. 60

Millegale (Pichincha)-See Miligali.

Milligalli (Pichincha)-See Miligali.

Milpe (Pichincha)-0002'42" N, 78 51'16", 900 m; humid subtropical. A settlement on the western slope of the Cordillera Occidental. Collection by Manuel Olalla in February 1958. 38

Mindo(Pichincha)-00 02'54" S, 7846’21 "W, 1410 $\mathrm{m}$; humid subtropical. A village on the Pacific slope of the Cordillera Occidental; disturbed humid upper montane forest. Collections by L. Ponce in April 1953, M. Olalla in May 1959, M. S. Foster at Hacienda San
Vicente in February 1985, LAC in September 1992, and from adjacent Bosque Protector Mindo-Nambillo by A. López in March 1994. Collections from disturbed forest along roads $-18 \mathrm{~km} \mathrm{~N}(1500 \mathrm{~m})$ by JAP in June 1966; $3.5 \mathrm{~km} \mathrm{NE}$ (1540 m) by WED in April 1975; $1 \mathrm{~km} \mathrm{E}$ $(1400 \mathrm{~m})$ by JAP in June 1966. 46

Molleturo (Azuay) - $02^{\circ} 45^{\prime} 15^{\prime \prime} \mathrm{S}, 79^{\circ} 23^{\prime} 48^{\prime \prime} \mathrm{W}, 2560$ $\mathrm{m}$; humid temperate. Village on the Pacific slope of the Cordillera Occidental. Collection by LAC and others in October 1993. 128

Moraspungo (Cotopaxi)-01 10'48" S, 79¹2’03" $\mathrm{W}$; humid tropical. A village near the base of the Andes. Collections from $9.1 \mathrm{~km} \mathrm{E}(800 \mathrm{~m})$ and $11 \mathrm{~km} \mathrm{E}(840 \mathrm{~m})$ road to El Corazón by Charles W. Myers in November 1979 and RWM in October 1979, respectively. 94

Nanegal Chico (Pichincha) - See Nanegalito.

Nanegal Grande (Pichincha)-00 $08^{\prime} 36^{\prime \prime} \mathrm{N}$, $78^{\circ} 40^{\prime} 36^{\prime \prime} \mathrm{W}, 1800 \mathrm{~m}$; humid temperate. A village on the Pacific slope of the Cordillera Occidental; disturbed humid upper montane forest. Collection by Manuel Ollala in August 1950. 33

Nanegalito (Pichincha) $-00^{\circ} 04^{\prime} 00^{\prime \prime}$ N, 78 $40^{\prime} 50^{\prime \prime}$ $\mathrm{W}, 1600 \mathrm{~m}$; humid subtropical. A village on the Pacific slope of the Cordillera Occidental; disturbed humid upper montane forest. Collection by Gonzalo Herrera in March 1957. Collections in disturbed forest along roads$4 \mathrm{~km} \mathrm{~N}$ by C. F. Walker in July 1962; $1.5 \mathrm{~km} \mathrm{SW,} 5 \mathrm{~km}$ NW, and $10 \mathrm{~km} \mathrm{NW}$ by JAP in November 1958. 37

Naranjal (Guayas)—02 40’30" S, 79³6’30" W, 24 $\mathrm{m}$; dry tropical. A town on the Pacific coastal plain; cacao groves. Collection by G. H. Tate in May 1922. 124

Naranjito (Guayas) - $02^{\circ} 09^{\prime} \mathrm{S}, 79^{\circ} 27^{\prime} \mathrm{W},<200 \mathrm{~m}$; dry tropical. A town on the Pacific coastal plain. Collection by Manuel Ollala in May 1964. 114A

Nono (Pichincha) - $00^{\circ} 03^{\prime} 50^{\prime \prime} \mathrm{S}, 78^{\circ} 34^{\prime} 54^{\prime \prime} \mathrm{W}, 2730$ $\mathrm{m}$; humid temperate. A village on the Pacific slope of the Cordillera Occidental; disturbed humid upper montane forest. Collections along road NE to Tandayapa- $4.5 \mathrm{~km}$ NW $(2600 \mathrm{~m})$ by LAC in December 1989; $9.5 \mathrm{~km} \mathrm{NW}$ $(2530 \mathrm{~m})$ by WED in April 1975; $13.1 \mathrm{~km} \mathrm{NW}(2100 \mathrm{~m})$ by $\mathrm{KM}$ in March 1979. Collections along road NW to Nanegal-10 km NW (2200 m) and $12 \mathrm{~km} \mathrm{NW}$ by JAP in October 1958 and KM in March 1979. 48

Otavalo (Imbabura)-0 $00^{\circ} 13^{\prime} \mathrm{N}, 78^{\circ} 15^{\prime} \mathrm{W}, 2554 \mathrm{~m}$, humid temperate. City in an inter-Andean basin. 29B

Otongoro (Pichincha) - $00^{\circ} 15^{\prime} 18^{\prime \prime} \mathrm{S}, 78^{\circ} 41^{\prime} 48^{\prime \prime} \mathrm{W}$; humid subtemperate. A site on a tributary of the RíoSaloya on the upper slope of the Cordillera Occidental SW of Lloa. Collection from humid montane forest on Quito-Chiriboga road, $3300 \mathrm{~m}$ by LAC in October, 1984. 57

Pachijal (Pichincha) $-00^{\circ} 09^{\circ} 05^{\prime \prime}$ N, 78 $57^{\prime} 36^{\prime \prime} \mathrm{W}, \approx$ $1200 \mathrm{~m}$; humid subtropical. Settlement on Pacific slope of Cordillera Occidental near Río Pachijal, a tributary of 
the Río Guayllabamba; lower humid montane forest. Collection by G. Olalla in September 1959. 30

Pacto (Pichincha) - $00^{\circ} 08^{\prime} 36^{\prime \prime}$ N, $78^{\circ} 45^{\prime} 36^{\prime \prime} \mathrm{W}, 1350$ $\mathrm{m}$; humid subtropical. A village on the Quito-Río Guayllabamba road on the Pacific slopes of the Cordillera Occidental. Collections in the vicinity by Pablo Mena in October 1954 and Manuel Olalla in December 1955. 32

Paitanga Chimborazo)-See Pallatanga.

Pallatanga (Chimborazo)-0 $1^{\circ} 59^{\prime} 48^{\prime \prime}$ S, 78 $57^{\prime} 48^{\prime \prime}$ W, 1520 m; dry subtropical. A village on the CajabambaGuayaquil road in the valley of the Río Coco on the Pacific slope of the Cordillera Occidental; collections from $3 \mathrm{~km} \mathrm{~N}(2280 \mathrm{~m}), 5 \mathrm{~km} \mathrm{~N}(2450 \mathrm{~m})$, and $15 \mathrm{~km} \mathrm{~N}$ $(2860 \mathrm{~m})$ by JAP in February 1959, and in cutover montane forest $20 \mathrm{~km} \mathrm{NNE}, 2550 \mathrm{~m}$ by WED in May 1975. 113

Palma Real (Pichincha)-00 05`54" N, 79 28'54" $\mathrm{W}, \approx 500-700 \mathrm{~m}$; humid subtropical. Settlement on Río Guayllabamba on lower Pacific slope of Cordillera Occidental (fide Paynter and Traylor, 1977). Collection by Manuel Olalla in June 1955. 35

Palo Quemado (Cotopaxi) - $00^{\circ} 38^{\prime} \mathrm{S}, 78^{\circ} 58^{\prime} \mathrm{W}, 1800$ m; humid temperate. Settlement, $8.2 \mathrm{~km} \mathrm{NE}$ of San Francisco de las Pampas on western slope of the Cordillera Occidental; disturbed humid upper montane forest. Collection by G. Onore in February 1988. 83

Pambelár (Esmeraldas)—See Pambilár.

Pambilár (Esmeraldas)—01 03'36" N, 7848'22" $\mathrm{W}$; humid tropical. Settlement on Pacific coastal plain 3 km NE of Concepción. Collection by W. F. H. Rosenberg for BM. 4

Paramba (Imbabura)-See Parambas.

Parambas (Imbabura)-0048'18" N, 78²1 '03" W, $780 \mathrm{~m}$; humid subtropical. A hacienda on the south bank of the Río Mira on the Pacific slope of the Cordillera Occidental; lower montane forest. Collection by Rosenberg for BM in October 1897. 20

Parque Nacional Machalilla (Manabí)_A park of about 55,000 ha on the Pacific coast (dry tropical) and extending inland to encompass parts of the Cordillera de la Costa (dry subtropical). Collections made at Bola del Oro on Cerro San Sebastián ( $01^{\circ} 36^{\prime}$ S, 80 42' W, 750 m) by Ana Almendáriz in January 1991. 100

Parroquia Carondelet (Esmeraldas)-01 $07^{\circ} 52^{\prime \prime} \mathrm{N}$, $78^{\circ} 45^{\prime} 34^{\prime \prime}$ W, $200 \mathrm{~m}$; humid tropical. Village on Río Bogotá in lowland humid tropical rainforest. Collection by Charles M. Fugler in August 1963. 1

Patricia Pilar (Pichincha) $-00^{\circ} 34^{\prime}$ S, $79^{\circ} 22^{\prime} \mathrm{W}, 180$ m. Town on Pacific lowlands in southern Pichincha. Collections from Centinela, $14.1 \mathrm{~km} \mathrm{SE}$ of town. See Centinela.

Pasaje (El Oro)- $03^{\circ} 19^{\prime} 12^{\prime \prime} \mathrm{S}, 79^{\circ} 48^{\prime} 12^{\prime \prime} \mathrm{W}, 28 \mathrm{~m}$; dry tropical. Town on the Pacific coastal plain; mostly cultivated tropical dry forest. Collections from $3 \mathrm{~km} \mathrm{E}$ $(30 \mathrm{~m})$ and $55.4 \mathrm{~km} \mathrm{E} \mathrm{(1000} \mathrm{m,} \mathrm{Prov.} \mathrm{Azuay)} \mathrm{in} \mathrm{tropical}$ dry forest in the valley of the Río Jubones by A. C. Echternacht in June 1971. 133

Pedro Vicente Maldonado (Pichincha)- $00^{\circ} 05^{\prime} 18^{\prime \prime}$ N, 79 $05^{\prime} 24^{\prime \prime} \mathrm{W}, 600 \mathrm{~m}$; humid subtropical. A village 3.5 km NW of Alvaro Pérez Intriago on the Pacific slopes of the Cordillera Occidental. Collections were made in disturbed areas $1 \mathrm{~km} \mathrm{E}(670 \mathrm{~m})$ and $4 \mathrm{~km} \mathrm{~S}$ (Río Caoni, $570 \mathrm{~m}$ ) by LAC in March 1990. 36

Pilaló (Cotopaxi) - $00^{\circ} 56^{\prime} 15^{\prime \prime}$ S, 7859’40" W, 2400 $\mathrm{m}$; humid temperate. Village on the Pacific slope of the Cordillera Occidental; disturbed humid upper montane forest with many arboreal bromeliads. Collections by JDL in June 1968, June 1977, and January 1978; by WED in July 1971 and March 1984; by LAC in August 1986 and May 1989. Also from $1 \mathrm{~km} \mathrm{~W}(2340 \mathrm{~m})$ by JDL in July 1970 and from $2 \mathrm{~km} \mathrm{~W}(2220 \mathrm{~m})$ and $3 \mathrm{~km} \mathrm{~W}$ $(2160 \mathrm{~m})$ by $\mathbf{J A P}$ in January 1959. Collections from eastward along road to Pujilí-1 km E (2475 m) by JAP in January 1959, $2 \mathrm{~km} \mathrm{E} \mathrm{(2480} \mathrm{m)} \mathrm{by} \mathrm{JAP} \mathrm{in} \mathrm{January}$ $1959,3 \mathrm{~km} \mathrm{E}(2900 \mathrm{~m})$ by JDL in July 1970, $4.6 \mathrm{~km} \mathrm{E}$ $(2600 \mathrm{~m})$ by A. C. Echternacht in May 1971, $5 \mathrm{~km} \mathrm{E}$ (2900 $\mathrm{m}$ ) by JAP in January $1959,6 \mathrm{~km} \mathrm{E} \mathrm{(2670} \mathrm{m}$ ) by WED in July $1971,8 \mathrm{~km}$ E $2850 \mathrm{~m}$ ) by JAP in January 1959. Collections in páramo from eastward along road to Pujilí-24.6 km E (3190 m) and $27.6 \mathrm{~km} \mathrm{E} \mathrm{(3380} \mathrm{m)} \mathrm{by}$ LAC in April 1989. Collections in disturbed lower montane forest along road to west to Quevedo- $18.6 \mathrm{~km} \mathrm{~W}$ $(930 \mathrm{~m})$ and $20.3 \mathrm{~km} \mathrm{~W}(830 \mathrm{~m})$ by WED in July 1971 , $29.6 \mathrm{~km} \mathrm{~W}(600 \mathrm{~m})$ by R. R. Montanucci in May 1971 . 89

Piñas (El Oro)—0340`43" S, 7940’48" W, 1010 m; dry subtropical. Town in the upper valley of the Rio Puyango at the southern base of the Cordillera de Chilla; disturbed tropical dry forest. Collections from town by G. H. Tate in September 1921, from Villa Elvita by H. Vargas in December 1994, and from riparian habitat 4.4 $\mathrm{km} \mathrm{NW}(1100 \mathrm{~m})$ and in disturbed humid montane forest at $18 \mathrm{~km} \mathrm{~W}(780 \mathrm{~m})$ by WED in July 1971 and March 1975, respectively. Also from 13-16.4 km W (585-800 m) by RWM in October 1979. 137

Placer (Esmeraldas) - See El Placer.

Playa Rica (Pichincha) $-00^{\circ} 10^{\prime}$ N, $78^{\circ} 40^{\prime} \mathrm{W}$, about $1200 \mathrm{~m}$. A site north of Nanegal Grande. Collection by D. Lombeida in October 1987. 29C

Portovelo (EI Oro) - $03^{\circ} 42^{`} 48^{\prime \prime} \mathrm{S}, 79^{\circ} 36^{\prime} 51^{\prime \prime} \mathrm{W}, 610$ $\mathrm{m}$; dry subtropical. Village $4 \mathrm{~km}$ south of Zaruma in upper valley of Río Puyango; tropical dry forest. Collection from village by G. H. Tate in September 1921 and from along stream $32.6 \mathrm{~km}$ SSE by WED in July 1971. 138 
Porvenir (Bolivar) - $01^{\circ} 16^{\circ} 24^{\prime \prime} \mathrm{S}, 79^{\circ} 07^{\prime} 48^{\prime \prime} \mathrm{W}, 1760$ $\mathrm{m}$; humid subtropical. A hacienda on the western slopes of the Cordillera Occidental, $11 \mathrm{~km} \mathrm{SW} \mathrm{Facundo} \mathrm{Vela.}$ Collection by P. O. Simons in March 1899.96

Pllerto de lla (Pichincha)-O $00^{\circ} 33^{\prime} \mathrm{S}, 79^{\circ} 22^{\prime} \mathrm{W}, 200$ m; humid tropical. Settlement on Río Baba on Pacific coastal plain about $40 \mathrm{~km}$ SSW of Santo Domingo de los Colorados; remnants of humid tropical rainforest. Collection by Pablo Mena in December 1954. 80

Plterto Quito (Pichincha)_00 08'42" N, 79 16'10" W. $280 \mathrm{~m}$; humid tropical. Town on Pacific coastal plain; cutover humid tropical rainforest. Collection from $8 \mathrm{~km}$ ESE (530 m) on road to Quito by WED in April 1975. 31

Puerto Velo. (El Oro)-See Portovelo.

Pulún (Esmeraldas)--See San Francisco.

Pungalá(Chimborazo)—0 - $1^{\circ} 48^{\circ} 48^{\prime \prime}$ S. $78^{\circ} 35^{\prime} 22^{\prime \prime} \mathrm{W}$, $2880 \mathrm{~m}$; dry temperate. A village $2 \mathrm{~km}$ SE of Licto ( $\mathrm{S}$ of Riobamba). Collections by LAC from $4 \mathrm{~km} \mathrm{W,} 2900 \mathrm{~m}$, in January 1990, and from $7 \mathrm{~km} \mathrm{NW}$ (road to Riobamba), $2880 \mathrm{~m}$, in August 1989. 110

Quebrala La Plata (Pichincha)- $00^{\circ} 27^{\prime} \mathrm{S}, 78^{\circ} 47^{\prime} \mathrm{W}$, $1560 \mathrm{~m}$; humid subtropical. A small tributary of the Río Pilatón, $3 \mathrm{~km}$ SE Tandapi. Collections by KM and RWM in February 1979. 77

Quebrada Silante Grande (Pichincha)-See Campamento Silante.

Quebrada Zapadores, $5 \mathrm{~km}$ ENE Chiriboga (Pichincha) $-00^{\circ} 15^{\prime} \mathrm{S}, 78^{\circ} 43^{\prime} \mathrm{W}, 2010 \mathrm{~m}$ humid temperate. Tributary of Río Saloya, $5 \mathrm{~km}$ ESE Chiriboga: disturbed upper humid montane forest. Collections by WED in April and May 1975, JDL in July 1977, and RWM in March 1979. 53

Quevedo(Los Ríos)—01 01 '30" S, 79²7’39" W, 53 $\mathrm{m}$; humid tropical. Town on Pacific coastal plain; small remnants of humid tropical rainforest, but mostly plantations of cacao and bananas. Collections from Quevedo by Gonzalo Herrera in December 1955; 1 km N, $300 \mathrm{ft}$, by JAP in August 1954; $1.6 \mathrm{~km} \mathrm{~N}$ (Finca Playa Grande) by George Key in March 1965 and June 1966: 4 km N. $140 \mathrm{~m}$; by JDL in July 1970; $46 \mathrm{~km} \mathrm{~N}$ (Hacienda Cerro Chivo) by $\mathrm{H}$. Weed in July 1992: $3 \mathrm{~km} \mathrm{E}$ (road to El Corazón) by KM in July 1975.91

Quinindé(Esmeraldas)—0 -0 18'50" N, 79²7’40" W. $40 \mathrm{~m}$ (= Rosa Zárate); humid tropical. Town on the Río Blanco on the Pacific lowlands. Formerly humid tropical rainforest; now mostly cultivated in bananas. Collection from disturbed forest $10.5 \mathrm{~km} \mathrm{~N}, 10 \mathrm{~m}$ by WED in July 1971. 29

Reserva Floristica-Ecológica Río Guajalito (Pichincha) $-00^{\circ} 14^{\prime} \mathrm{S}, 78^{\circ} 48^{\prime} \mathrm{W}, 1800-2200 \mathrm{~m}$; humid temperate. A natural reserve NE of Palmeras (ChiribogaSanto Domingo de los Colorados road). Collections by LAC and others in November 1991. December 1993, and
October and November 1994. 52

Reserva Otonga (Cotopaxi)- $00^{\circ} 44^{\prime} \mathrm{S}, 78^{\circ} 59^{\prime} \mathrm{W}$. 2000-2200 m; humid temperate. A natural reserve near San Francisco de las Pampas. Collections by LAC in August 1993, Molineros in March 1994, and 1. Tapia in November 1994. 85

Río Aycampe (Guayas)_-See Ayampe.

Río Baba (Pichincha)_Humid tropical. Southward flowing river on Pacific coastal plain; riparian rainforest along river. Collections made at $10 \mathrm{~km} \mathrm{S.} 4 \mathrm{~km}$ E Santo Domingo de los Colorados (08 $\left.18^{\prime} \mathrm{S}, 79^{\circ} 13^{\prime} \mathrm{W}, 400 \mathrm{~m}\right)$ by WED in July 1971 and April 1972, and at 19 and 24 $\mathrm{km}$ S Santo Domingo de los Colorados $\left(00^{\circ} 25^{\prime} \mathrm{S}, 79^{\circ} 17^{\prime}\right.$ W) by George Key in February-March 1965 and AprilJune 1966. 62

Río Baboso (Carchi)-0 -0 $53^{\prime} \mathrm{N}, 78^{\circ} 27^{\prime} \mathrm{W}$; humid subtropical. A tributary of the Río Mira $N$ of Lita. Collection from headwaters of Río Baboso in primary forest about 4-5 km N Lita, $900 \mathrm{~m}$ by LAC in September 1984. 14

Riobamba (Chimborazo)- $01^{\circ} 40^{\prime} \mathrm{S}, 78^{\circ} 38^{\prime} \mathrm{W}, 2750$ $\mathrm{m}$ dry temperate. City in the Andes. Collection from 70 $\mathrm{km} \mathrm{W}$ (road to Pallatanga), $2520 \mathrm{~m}$ (humid temperate) by LAC in August 1989. 102

Río Blanco (Carchi)—00 54’35" N, 78²2`24" W. $\approx 700 \mathrm{~m}$; humid subtropical. A village on the Río Blanco. a tributary of the Rio San Juan, on the lower slopes of the Cordillera Occidental. Collections from along the Río Blanco, $2 \mathrm{~km}$ NE, $930 \mathrm{~m}$, by JAP in November 1958, and from Chical, 1450-1500 m, $3 \mathrm{~km}$ up the Río Blanco by Alwyn. H. Gentry in September 1979. 11

Río Blanco (Pichincha) $-00^{\circ} 17^{\circ} 12^{\prime \prime} \mathrm{S}, 78^{\circ} 42^{\circ} 57^{\prime \prime}$; humid subtropical. A tributary of the Río Saloya on the western slope of the Cordillera Occidental. Collections from along the river by and near mouth of the Río Yambi by Manuel Olalla in May 1953 and February 1959. respectively. 61

Río Caoni (Esmeraldas)-Not located. Collection from "region of, sector de Largartera" by Charles $M$. Fugler in August 1963.

Rio Chimbo, near junction of Río del Oro (Guayas) Not located. Collection by 1. R. Wiggins in December 1944.

Río Coco (Chimborazo)-Canton Pallatanga, $01^{\circ} 59^{\circ} 48^{\prime \prime} \mathrm{S}, 78^{\circ} 57^{\prime} 48^{\prime \prime} \mathrm{W}, 1450 \mathrm{~m}$; humid subtropical. River on Pacific slope of Cordillera Occidental; cutover montane rainforest. Collection along river near Pallatanga by A. Almendáriz in September 1986. 114

Río Cuaque (Manabí) $-00^{\circ} 02^{\prime} \mathrm{S}, 79^{\circ} 57^{\prime} \mathrm{W}, 100 \mathrm{~m}$; dry tropical. Small river on western slope of Cerros de Cuaque E of Pedernales on road to El Carmen; tropical dry forest. Collection by LAC in December 1989. 47

Rio Cupa(Esmeraldas) $-00^{\circ} 26^{\prime} \mathrm{N}, 79^{\circ} 24^{\prime} \mathrm{W},<150 \mathrm{~m}$ 
(mouth); humid tropical. Small tributary of the Río Blanco on the Pacific lowlands. Humid tropical rainforest. Collection by A. Proaño in January 1952. 25

Rio Durango (Esmeraldas) $-01^{\circ} 05^{\prime} \mathrm{N}, 78^{\circ} 41^{\prime} \mathrm{W}$, $<150 \mathrm{~m}$; humid tropical. A tributary of the Río Bogotá. Lowland tropical rainforest. Collection by W. F. H. Rosenberg for BM. 3

Río Faisanes (Pichincha)-00¹9' S, 78²9' W, 1380 $\mathrm{m}$; humid subtropical. Stream in humid lower montane forest, $13.5 \mathrm{~km}$ from La Palma on "old" road to Quito. Collections by G. O. Vigle in January 1978 and KM and RWM in January and October 1979. 66

Rio Frio (Guayas)-Not located. Collection by T. H. Hubbell in April 1963.

Rio Guichichi (Chimborazo)—01 $57^{\prime} \mathrm{S}, 78^{\circ} 56^{\prime} \mathrm{W}$, 1700 m; dry subtropical. In Cantón Pallatanga. Collections along banks of river in cutover forest by $\mathrm{A}$. Almendáriz in September 1986. 112

Río Lelia (Pichincha) $00^{\circ} 18^{\prime} \mathrm{S}, 79^{\circ} 01^{\prime} \mathrm{W}, 1000 \mathrm{~m}$; humid subtropical. A tributary of the Río Toachi. Collection by Manuel Olalla in April 1959. 64

Río Lita (Esmeraldas)-Small river draining Pacific slope of Cordillera Occidental. $2 \mathrm{~km}$ S junction Río Lita and Río Mira, $00^{\circ} 56^{\circ} \mathrm{N}, 78^{\circ} 32^{\prime} \mathrm{W}, 520 \mathrm{~m}$ (humid subtropical). Collection by JAP in November 1958. 8

Rio Minas, $20 \mathrm{~km}$ W of Santa Isabel (Azuay)$03^{\circ} 18^{\prime} 18^{\prime \prime} \mathrm{S}, 79^{\circ} 22^{\prime} 24^{\prime \prime} \mathrm{W}, 1250 \mathrm{~m}$; dry subtropical. Collection by JAP in 1959. 132

Rio Parambas (Imbabura) - $00^{\circ} 01^{\prime} \mathrm{S}, 78^{\circ} 14^{\prime} \mathrm{W}$; humid subtropical. Collection from edges of river where it crosses the lbarra-Lita road by R. Barriga in August 1984. 44

Río Pescado (Chimborazo)-Collection by G. H. Tate in May 1922. Not located.

Rio Pitsará (Pichincha)-00¹4’36" N. 7906`48" W. Tributary of Río Guayllamba, SE of Golondrina. Collection by Manuel Olalla in July 1953. 29A

Río San Miguel (Esmeraldas) - River in Pacific lowlands. Collection from about $1 \mathrm{~km}$ above Río Cayapas, $00^{\circ} 51^{\prime} \mathrm{N}, 78^{\circ} 57^{\prime} \mathrm{W},<100 \mathrm{~m}$ (humid tropical). Collection by $\mathrm{KM}$ in June 1977. 17

Río Saloya (Pichincha)-Tributary of Río Blanco draining western slope of Volcán Pichincha. Elevation of $450^{\prime}$ of specimens in BM must refer to Río Blanco (humid tropical).

Río Sapayo (Pichincha)-See Río Saloya.

Río Tataluazo (Lizo) (Bolívar)-01 43' S, 7859' W. $2510 \mathrm{~m}$; dry temperate. A river in the Bosque Protector Cashca Totoras south of Santiago. Collection from near Cruz de Lizo by LAC in January 1990. 107

Río Toachi (Pichincha)-00²3' S, 78 56' W, $800 \mathrm{~m}$; humid subtropical. River on Pacific slope of Cordillera Occidental; remnants of humid lowland rainforest. Col- lection from gallery forest along river $8 \mathrm{~km}$ E Alluriquín by WED in July 1971. 70

Salidero (Esmeraldas) - $00^{\circ} 55^{\prime} \mathrm{N}, 78^{\circ} 34^{\prime} \mathrm{W}, 108 \mathrm{~m}$; humid tropical. Village in Andean foothills. Collection by W. F. H. Rosenberg in April-August 1919. 9

Salto dos Novias (Pichincha) $=00^{\circ} 26^{\prime} \mathrm{S}, 78^{\circ} 41^{\prime} \mathrm{W}$, $2635 \mathrm{~m}$; humid temperate. Waterfall on $\mathrm{N}$ slope of Cerro Corazón on road from Alóag to Santo Domingo de los Colorados; remnants of upper humid montane forest. Collection by WED in March 1967. 74

San Francisco (Esmeraldas) - $01^{\circ} 05^{\prime}$ N. $78^{\circ} 42^{\prime} \mathrm{W}$, $<150 \mathrm{~m}$; humid tropical. Settlement on Río Bogotá in disturbed humid tropical rainforest. Formerly known as Pulún. 2

San Francisco de Las Pampas (Cotopaxi) - $00^{\circ} 40^{\prime} \mathrm{S}$. $78^{\circ} 53^{\prime} \mathrm{W}, 1800 \mathrm{~m}$; humid subtropical. A village on the Pacific slopes of the Cordillera Occidental. Collections from humid montane forest in the vicinity of the village at elevations of $1600-2200 \mathrm{~m}$ by G. Onore and members of the Tapia family in November 1984, October 1985, March, May, and August 1986, December 1989, February 1990, October 1991, and November 1992, and by LAC in August 1986 and August 1993. 84

San Ignacio (Pichincha)— $\approx 00^{\circ} 27^{\prime} \mathrm{S}, 78^{\circ} 42^{\prime} \mathrm{W}, 2030$ $\mathrm{m}$; humid temperate. Settlement $10 \mathrm{~km}$ E of Tandapi on road to Alóag; upper humid montane forest. Collections from immediate vicinity by WED in March 1967 and from $1 \mathrm{~km}$ SW, 1920 m, by JDL in July 1977. 76

San Javier de Cachabé (Esmeraldas)-00 $58^{\prime} \mathrm{N}$, $78^{\circ} 48^{\prime}$ W, 20 m; humid tropical. Village on Río Cachabí and on Ibarra-San Lorenzo railroad; cut over humid tropical rainforest. Also spelled Cachabí and Cachaví. Collections by W. F. H. Rosenberg in April-August 1919. Charles M. Fugler in September 1963, and from 1 $\mathrm{km} \mathrm{SW}$ by L. Abuja and JAP in December 1958. 7

San José de Bilsa (Esmeraldas)—003' N, 795 ' 'W; humid tropical. A settlement on the western slope of the Montañas de Muise (northernmost part of the Cordillera de la Costa). Collections made in the vicinity of a camp in lowland tropical rainforest at an elevation of $225 \mathrm{~m}, 7$ $\mathrm{km}$ E of the village by Ana Almendáriz in January 1991 . 24

San Juan (Pichincha) - $00^{\circ} 17^{\prime}$ S. 78 35' W, 3400 m; humid temperate. Settlement near crest of QuitoChiriboga road south of Volcán Pichincha. Collection in disturbed high cloud forest by JDL in July 1977. 61A

San Miguel, $4 \mathrm{~km}$ del Campamento del MAG-See San Miguel de Cayapas.

San Miguel de Cayapas (Esmeraldas)-00 $45^{\prime} \mathrm{N}$, $78^{\circ} 54^{\prime}$ W. $<200 \mathrm{~m}$; humid tropical. Village at the junction of the Río San Miguel and Río Cayapas. Disturbed humid tropical rainforest. Collections by KM in June 1977 and A. Almendáriz in September 1984. 22 
San Miguel de Congomá (Pichincha)-See San Miguel de los Colorados

San Miguel de los Colorados (Pichincha)- $00^{\circ} 20^{\prime} \mathrm{S}$, $79^{\circ} 15 \mathrm{~W}, 500 \mathrm{~m}$; humid subtropical. Settlement, also known as San Miguel de Congomá, south of Santo Domingo de los Colorados on road to Quevedo. Now mostly cultivated in bananas. Collections by Antonio Proaño in November 1953 and by Manuel Olalla in December 1956. 67

San Mignel-Telembí(Esmeraldas)- $00^{\circ} 45^{\prime}$ N, $78^{\circ} 55^{\prime}$ W, <200 m (Telembí); humid tropical. Río Cayapas between San Miguel and Telembí; humid tropical rainforest. A. Almendáriz; September 1984. 21

San Tadeo (Pichincha) $-00^{\circ} 01^{\prime}$ N. $78^{\circ} 45^{\prime} \mathrm{W}, 1500 \mathrm{~m}$; humid subtropical. A site near Mindo. Collection by G. Olalla in August 1959. 39

Santo Domingo de los Colorados (Pichincha) - $00^{\circ} 15^{\prime}$ S. $79^{\circ} 10^{\prime}$ W. $600 \mathrm{~m}$; humid subtropical. Town near base of the Andes on the Pacific coastal plain; remnants of lowland tropical rainforest but mostly cutover and now in banana plantations. Collections by C. Olalla in May 1929, by E, H, Taylor in 1962, by WED in March 1967 and July 1971; by JDL in March, July, and August 1968 and June 1977. Collections also from $1 \mathrm{~km} \mathrm{~N}, 2 \mathrm{~km} \mathrm{E}$, $620 \mathrm{~m}$; JDL, December 1977; $2 \mathrm{~km}$ and $6 \mathrm{~km}$ E by P. D. Spoecker in June 1962; $3.5 \mathrm{~km}$ E (Hacienda Lelia) by F. H. Funkhouser in September 1950; $5 \mathrm{~km}$ E by George Key in February and August 1965; $8 \mathrm{~km}$ SE by C. F. Walker in August 1962; $0.5 \mathrm{~km} \mathrm{~S}$ by JAP in May 1959; $5 \mathrm{~km} \mathrm{~W}$ by César Duran in December 1965; $6 \mathrm{~km} \mathrm{~W}$ by E. S. Ross in February 1955; 9 km W (Hacienda Espinosa) by J. W. Funkhouser in September-November 1950; 18 $\mathrm{km} \mathrm{W}$ on road to Chone by JAP in May 1959. 56

San Vicente (Bolívar)—01 $43^{\prime} \mathrm{S}, 79^{\circ} 01^{\prime} \mathrm{W}$; humid temperate. Collection by LAC in December 1984. 106

Sigchos (Cotopaxi) - $00^{\circ} 42^{\prime} \mathrm{S}, 78^{\circ} 53^{\prime} \mathrm{W}, \approx 3000 \mathrm{~m}$; humid subtemperate. Village in the Cordillera Occidental; subpáramo. Collection from "region of Sigchos" by Manuel Olalla in June 1957, and from "below Sigchos" (Prov. Pichincha) by Antonio Proaño in October 1954. $84 a$

Sitio Torneado (Bolívar)—See El Torneado.

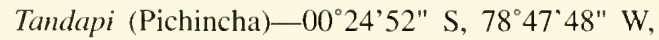
$1460 \mathrm{~m}$; humid subtropical. Small village (also named Manuel Cornejo Astorga) on south bank of Río Pilatón on road from Alóag to Santo Domingo de los Colorados; disturbed upper humid montane forest. Collections by WED in March 1967; JDL in July and August 1967, March and August 1968, August 1970, and June and
December 1977; and by Thomas H. Fritts in August 1970. Also collections along road to east and west-2.1 $\mathrm{km} \mathrm{E}(1500 \mathrm{~m})$ and $6.2 \mathrm{~km} \mathrm{E}(1750 \mathrm{~m})$ by KM and RWM in February 1979 , and $1.6 \mathrm{~km} \mathrm{~W}(1400 \mathrm{~m})$ by JDL in June 1977.72

Tandayapa (Pichincha)—00 $01^{\prime}$ N, 78 $39^{\prime} \mathrm{W}, 1830$ $\mathrm{m}$; humid temperate. A village on the road from Quito to Puerto Quito; upper humid montane forest with many bromeliads. Collections in vicinity of town by Leonides Ponce in March 1952, JAP in March 1953, and Mauro Proaño in April 1956. Also collections from $2 \mathrm{~km} \mathrm{E}$ by $\mathrm{JAP}$ in October and November 1958, and $9 \mathrm{~km} \mathrm{SE} \mathrm{(2150}$ $\mathrm{m})$ by WED in April 1975; also from various distances SW on road to Puerto Quito-1.4 km (1820 m) by WED in April 1984, $2 \mathrm{~km}$ (1840 m) by LAC in September 1993, $2.3 \mathrm{~km}(1900 \mathrm{~m})$ by WED in April 1984, 4-5 km by LAC in September 1993, $7 \mathrm{~km}(1900 \mathrm{~m})$ by KM and RWM in February 1979, and $9.4 \mathrm{~km}(2390 \mathrm{~m})$ by WED in April 1975 and April 1984. 41

Tinalandia (Pichincha) - $00^{\circ} 18^{\prime} \mathrm{S}, 79^{\circ} 04^{\prime} \mathrm{W}, 700 \mathrm{~m}$; humid subtropical. A hotel and park $15.5 \mathrm{~km}$ SE Santo Domingo de los Colorados; disturbed lowland tropical rainforest. Collections by KM in July-August 1972, July-August, 1975, and February 1979, E. E. Williams in August 1974, and by WED in March 1984. 63

Toacaso (Cotopaxi) $-00^{\circ} 45^{\prime} \mathrm{S}, 78^{\circ} 4 \mathrm{I}^{\prime} \mathrm{W}, 2990 \mathrm{~m}$; humid temperate. Small village SW of San Juan de Pastocalle. Collection by L. López in October 1989. 84B

Tulcán (Carchi) - $00^{\circ} 49^{\prime} \mathrm{N}, 77^{\circ} 44^{\prime} \mathrm{W}, 2960 \mathrm{~m}$; humid subtemperate. City in the Andes in the upper valley of the Río Carchi (a tributary of the Río San Juan). Collection from páramo $51.3 \mathrm{~km} \mathrm{~W}$ on road to Maldonado, $3150 \mathrm{~m}$, by LAC in June 1989. 19

Urbina (Esmeraldas) $-00^{\circ} 58^{\prime}$ N. $78^{\circ} 41^{\prime}$ W, 300 m; humid tropical. Village on Río Cachabí near base of Andes. 6

Vicente Maldonado (Pichincha)-See Pedro Vicente Maldonado.

Victoria del Portete (Azuay) - $03^{\circ} 03^{\prime} \mathrm{S}, 79^{\circ} 03^{\prime} \mathrm{W}$; humid temperate. Collection from $10 \mathrm{~km} \mathrm{SW}, 2700 \mathrm{~m}$ by JDL in July 1970. 129

Yerbabuena (Azuay)—02 $45^{\prime} \mathrm{S}, 79^{\circ} 23^{\prime} \mathrm{W}, 2730 \mathrm{~m}$; humid temperate. Collection by LAC and others in November 1992. 127

Zhud (Cañar) $-02^{\circ} 28^{\prime} \mathrm{S}, 7^{\circ} 00^{\prime} \mathrm{W}, 2980 \mathrm{~m}$; humid temperate. Smal] village on Panamerican Highway in upper valley of Río Cañar; disturbed subpáramo. Collection from $4 \mathrm{~km} \mathrm{~N}(3040 \mathrm{~m})$ by WED in March 1984. 120 


\section{APPENDIX III}

\section{SPeCies of ELEUTHERODACTYLUS}

Names applied in the genus Eleutherodactylus with subgeneric assignments, species-group assignments, the state of the lengths of Toes III and V (description of conditions in text), and nomenclatural or taxonomic status (Comments). Series are employed (listed in parentheses) only for the subgenus Eleutherodactylus. (See text.) Species-group assignments are incomplete because not all taxa are regularly assigned to groups (e.g., Hedges, 1989). In the case of West Indian taxa, we introduce a novel species group (E. abbotti group) to accomodate some taxa we believe wrongly assigned to Eulyyas by Hedges (1989); those taxa are here assigned to the subgenus Eleutherodactylus. Additionally, we elect to recognize only a martinicensis group (of the auriculatus series) in the West Indies, combining much of what Hedges treated as the martinicensis and montanus groups, because Hedges did not assign many of the species of his auriculatus series to species groups. The subgeneric assignments used here include many novel ones and do not necessarily agree with the assignments made on the basis of the literature (e.g., Duellman, 1993). This is especially true for the subgenus Eulyas. Abbreviations for subgenera are: $\mathrm{CR}=$ Craugastor, $\mathrm{EL}=$ Eleutherodactylus, $\mathrm{EU}=$ Euyhas, $\mathrm{PE}=$ Pelorius, $\mathrm{SY}=$ Syrrhopus. Within the subgenus Eleutherodactylus, we employ several series abbreviated as follows: (a) abbotti, (b) binotatus, (c) conspicillatus, (m) martinicensis, (s) sulcatus, and $(\mathrm{t})$ myersi. Toe conditions are: $\mathrm{A}=$ fifth toe shorter than third, $\mathrm{B}=$ fifth toe longer than third but not extending to distal subarticular tubercle of fourth toe, $\mathrm{C}=$ fifth toe much longer than third.

\begin{tabular}{|c|c|c|c|c|}
\hline $\begin{array}{c}\text { Species } \\
\text { Trivial name, author, date }\end{array}$ & Subgenus & group & $\begin{array}{c}\text { Toe } \\
\text { condition }\end{array}$ & Comments \\
\hline aaptus Lynch \& Lescure 1980 & $\mathrm{EL}(\mathrm{m})$ & unistrigatus & $\mathrm{C}$ & \\
\hline abbotti Cochran 1932 & EL(a) & abbotti & B & \\
\hline acatallelus Lynch \& Ruíz 1983 & $\mathrm{EL}(\mathrm{c})$ & devillei & $\mathrm{B}$ & \\
\hline acerus Lynch \& Duellman 1980 & $\mathrm{EL}(\mathrm{m})$ & unistrigatus & $\mathrm{C}$ & \\
\hline achatinus Boulenger 1898 & $\mathrm{EL}(\mathrm{c})$ & conspicillatus & $\mathrm{B}$ & \\
\hline acmonis Schwartz 1960 & $\mathrm{EU}$ & ricordii & A & \\
\hline actites Lynch 1979 & $\mathrm{EL}(\mathrm{c})$ & conspicillatus & $\mathrm{B}$ & \\
\hline acuminatus Shreve 1935 & $\mathrm{EL}(\mathrm{m})$ & unistrigatus & $\mathrm{C}$ & \\
\hline acutirostris Lynch 1984 & $\mathrm{EL}(\mathrm{c})$ & - & B & \\
\hline adamastus Campbell 1994 & $\mathrm{CR}$ & milesi & A & \\
\hline affinis Werner 1899 & $\mathrm{EL}(\mathrm{m})$ & unistrigatus & $\mathrm{C}$ & \\
\hline alalocophus Roa \& Ruíz 1991 & $\mathrm{EL}(\mathrm{m})$ & unistrigatus & $\mathrm{C}$ & \\
\hline alberchi Flores 1988 & - & - & - & $=$ surdus \\
\hline albipes Barbour \& Shreve 1937 & EU & ricordii & A & \\
\hline albolabris Taylor 1940 & - & - & - & $=$ pygmaeus \\
\hline albolabris Taylor 1943 & - & - & - & $=$ dixoni \\
\hline alcoae Schwartz 1971 & $\mathrm{EU}$ & - & A & \\
\hline alfredi Boulenger 1898 & $\mathrm{CR}$ & alfredi & $\mathrm{B}$ & \\
\hline altae Dunn 1942 & $\mathrm{EL}(\mathrm{m})$ & unistrigatus & $\mathrm{C}$ & \\
\hline altamazonicus Barbour \& Dunn 1921 & $\operatorname{EL}(m)$ & unistrigatus & $\mathrm{C}$ & \\
\hline alticola Lynn 1937 & $\mathrm{EU}$ & nubicola & A & \\
\hline amadeus Hedges 1987 & EL(a) & $a b b o t t i$ & $\mathrm{~B}$ & \\
\hline amelasma Schwartz 1958 & $\mathrm{EU}$ & ricordii & A & \\
\hline amianthus Schwartz \& Fowler 1973 & $\mathrm{EU}$ & gossei & A & \\
\hline amplinympha Kaiser, Green \& Schmidt 1994 & $\mathrm{EL}(\mathrm{m})$ & martinicensis & $\mathrm{C}$ & \\
\hline amulae Günther 1900 & - & - & - & $=$ nitidus \\
\hline anae Rivero 1986 & - & - & - & $=$ curtipes \\
\hline anatipes Lynch \& Myers 1983 & $\mathrm{CR}$ & anomalus & A & \\
\hline
\end{tabular}


Appendix III. Continued.

Species

Trivial name, author, date
Toe

Subgenus group condition Comments anciano Savage et al 1988

anderssoni Lynch 1968

andi Savage 1974

andicola Boettger 1892

andrew'si Lynn 1937

angelicuss Savage 1975

angustidigitormm Taylor 1940

anolirex Lynch 1973

amonalus Boulenger 1898

anomymus A. Lutz 1927

anotis Walkeri \& Test 1955

antillensis Reinhardt \& Luitken 1863

anzuetoi Stuart 1941

apanthecatus Schwartz 1965

aphantus Campbell 1994

apiculatus Lynch \& Burrowes 1990

aporostegus Schwartz 1965

apostates Schwartz 1973

appendiculatus Werner 1894

areolatus Boulenger 1898

armstrongi Noble \& Hassler 1933

atkinsi Dunn 1925

atratus Lynch 1979

audanti Cochran 1934

augusti Dugès 1879

auriculatoides Noble 1923

arriculatus Cope 1862

aurilegus Savage et al 1988

avocalis Taylor \& Smith 1945

azueroensis Savage 1975

babax Lynch 1989

bacchus Lynch 1984

bakeri Cochran 1935

balionotus Lynch 1979

barbouri Nieden 1923

barbudensis Auffenberg 1958

barlagnei Lynch 1965

bartonsmithi Schwartz 1960

baryecuus Lynch 1979

batraclylus Taylor 1940

bearsei Duellman 1992

beatae Boulenger 1903

beebei Cochran 1956

bellona Lynch 1992

berkenbuschii Peters 1870

bernali Lynch 1986

bicolor Rueda \& Lynch 1983

bicumulus Peters 1863

\begin{tabular}{|c|c|c|c|}
\hline CR & rugulosus & A & \\
\hline- & - & - & $=$ ockendeni \\
\hline CR & fitzingeri & A & \\
\hline- & - & - & $=$ uncertain relationships \\
\hline EU & nubicola & A & \\
\hline CR & rugulosus & A & \\
\hline SY & nitidus & A & \\
\hline $\mathrm{EL}(\mathrm{m})$ & unistrigatus & $\mathrm{C}$ & \\
\hline CR & anomalus & A & \\
\hline EL & - & - & $=$ nomen nudum, incertus \\
\hline $\mathrm{EL}(\mathrm{m})$ & unistrigatus & $\mathrm{C}$ & \\
\hline $\mathrm{EL}(\mathrm{m})$ & martinicensis & $\mathrm{C}$ & \\
\hline- & - & - & $=$ lineatus \\
\hline $\mathrm{EU}$ & ricordii & A & \\
\hline CR & biporcatus & A & \\
\hline $\mathrm{EL}(\mathrm{m})$ & unistrigatus & $\mathrm{C}$ & \\
\hline PE & ruthae & B & \\
\hline $\mathrm{EU}$ & ricordii & A & \\
\hline $\mathrm{EL}(\mathrm{c})$ & devillei & $\mathrm{B}$ & \\
\hline- & - & - & $=$ chalceus \\
\hline EU & ricordii & A & \\
\hline EU & ricordii & A & \\
\hline $\mathrm{EL}(\mathrm{m})$ & umistrigatus & $\mathrm{C}$ & \\
\hline EL(a) & abbotti & B & \\
\hline CR & augusti & A & \\
\hline $\mathrm{EL}(\mathrm{m})$ & martinicensis & $\mathrm{C}$ & \\
\hline $\mathrm{EL}(\mathrm{m})$ & martinicensis & $\mathrm{C}$ & \\
\hline CR & rugulosus & A & \\
\hline- & - & - & $=$ mugulosus \\
\hline CR & rugulosus & A & \\
\hline EL(c) & dolops & B & \\
\hline $\mathrm{EL}(\mathrm{m})$ & unistrigatus & $\mathrm{C}$ & \\
\hline $\mathrm{EL}(\mathrm{m})$ & & $\mathrm{C}$ & \\
\hline $\mathrm{EL}(\mathrm{m})$ & unistrigatus & $\mathrm{C}$ & \\
\hline- & - & - & $=$ gundlachi \\
\hline- & - & - & $=$ jolmstonei \\
\hline $\operatorname{EL}(m)$ & martinicensis & $\mathrm{C}$ & \\
\hline $\operatorname{EL}(m)$ & martinicensis & $\mathrm{C}$ & \\
\hline $\mathrm{EL}(\mathrm{m})$ & unistrigatus & $\mathrm{C}$ & \\
\hline EL(m) & - & $\mathrm{C}$ & \\
\hline $\mathrm{EL}(\mathrm{m})$ & unistrigatus & $\mathrm{C}$ & \\
\hline- & - & - & $=$ rhodopis \\
\hline- & - & - & $=$ inoptatus \\
\hline $\mathrm{EL}(\mathrm{m})$ & umistrigatus & $\mathrm{C}$ & \\
\hline CR & rugulosus & A & \\
\hline $\mathrm{EL}(\mathrm{m})$ & mistrigatus & $\mathrm{C}$ & \\
\hline EL(m) & unistrigatus & $\mathrm{C}$ & \\
\hline $\mathrm{EL}(\mathrm{m})$ & - & $\mathrm{C}$ & \\
\hline
\end{tabular}


Appendix III. Continued.

\section{Species}

Trivial name, author, date

bilineatus Bokermann 1974

binghami Stejneger 1913

marsupiata

binotatus Spix 1824

biporcatus Peters 1863

bisignatus Werner 1899

blairi Barbour 1928

bockermanni Donoso-Barros 1970

boconoensis Rivero \& Mayorga 1973

bocourti Brocchi 1877

bogotensis Peters 1863

bolbodactylus Lutz 1925

bolivari Taylor 1942

bothroboans Schwartz 1965

boulengeri Lynch 1981

brachypodius Rivero 1961

bransfordii Cope 1886

brederi Dunn 1934

bresslerae Schwartz 1960

brevicrus Andersson 1945

brevifrons Lynch 1981

brevipalmatus Schmidt 1920

brevirostris Shreve 1936

briceni Boulenger 1903

brittoni Schmidt 1920

brocchi Boulenger 1882

bromeliaceus Lynch 1979

buccinator Rodríguez 1994

buckleyi Boulenger 1882

buergeri Werner 1899

bufoniformis Boulenger 1896

bufonius Andersson 1945

bufonoides Lynch 1965

cabrerai Cochran \& Goin 1970

cacao Lynch 1992

cactorum Taylor 1939

cadenai Lynch 1986

cajamarcensis Barbour \& Noble 1920

calcaratus Boulenger 1908

calcaratus Andersson 1945

calcarulatus Lynch 1976

calcitrans Günther 1901

caliginosus Lynch 1996

campi Stejneger 1915

cantitans Myers \& Donnelly 1996

caprifer Lynch 1977

caribe Hedges \& Thomas 1992

carmelitae Ruthven 1922

Toe

Subgenus group condition Comments

EL

$\begin{array}{lc}\text { EL(b) } & \text { binotatus } \\ \mathrm{CR} & \text { biporcatus } \\ - & - \\ - & - \\ \mathrm{EL}(\mathrm{m}) & \text { unistrigatus } \\ \mathrm{EL}(\mathrm{c}) & - \\ \mathrm{CR} & \text { alfredi } \\ \mathrm{EL}(\mathrm{m}) & \text { unistrigatus } \\ \mathrm{EL}(\mathrm{b}) & \text { lacteus }\end{array}$

- $\quad$ -

PE ruthae B

EL(m) unistrigatus C

$\begin{array}{lll}- & -\end{array}$

CR rhodopis A

- $\quad$ -

EU ricordii A

- - -

EL(m) unistrigatus C

- $\quad-\quad-$

EU ricordii A

EL(c) - B B

$\mathrm{EL}(\mathrm{m})$ martinicensis $\mathrm{C}$

CR rugulosus A

$\mathrm{EL}(\mathrm{m})$ unistrigatus C

EL(c) conspicillatus B

EL(c) curtipes B

CR bufoniformis A

- $\quad-\quad-$

-
-

$\mathrm{EL}(\mathrm{m})$ unistrigatus $\mathrm{C}$

$\mathrm{EL}(\mathrm{m})$ unistrigatus $\mathrm{C}$

- $\quad$ - $\quad-$

EL(s) sulcatus A

$\mathrm{EL}(\mathrm{m})$ unistrigatus C

$\mathrm{EL}(\mathrm{m})$ unistrigatus $\mathrm{C}$

$\overline{\mathrm{EL}}(\mathrm{m}) \quad$ unistrigatus

- $\quad$ -

EL(c) conspicillatus B

SY leprus A

$\mathrm{EL}(\mathrm{m})$ unistrigatus $\mathrm{C}$

EL(c) conspicillatus B

EU -

EL(c) conspicillatus B
= Gastrotheca

= fenestratus

= podiciferus

= augusti

$=$ vilarsi

$=$ achatinus

= altamazonicus

= sierramaestrae

$=w$-nigrum

$=$ diadematus

= spatulatus

= augusti

$=$ anderssoni

= oniltemanus 
Appendix 111. Continued.

\begin{tabular}{|c|c|c|c|c|}
\hline $\begin{array}{l}\text { Species } \\
\text { Trivial name, author, date }\end{array}$ & Subgenus & group & $\begin{array}{l}\text { Toe } \\
\text { ondition }\end{array}$ & Comments \\
\hline carranguerorum Lynch 1994 & $\mathrm{EL}(\mathrm{c})$ & conspicillatus & $\mathrm{B}$ & \\
\hline carrioni Parker 1932 & - & - & - & $=$ lymani \\
\hline carvalhoi Lutz 1952 & $\mathrm{EL}(\mathrm{m})$ & unistrigatus & $\mathrm{C}$ & \\
\hline caryophyllaceus Barbour 1928 & $\mathrm{EL}(\mathrm{m})$ & unistrigatus & $\mathrm{C}$ & \\
\hline casparii Dunn 1926 & EU & ricordii & A & \\
\hline cavernicola Lynn 1954 & EU & cundalli & A & \\
\hline celator Lynch 1976 & $\mathrm{EL}(\mathrm{m})$ & unistrigatus & $\mathrm{C}$ & \\
\hline ceraemerus Schwartz 1968 & $\mathrm{EL}(\mathrm{m})$ & martinicensis & $\mathrm{C}$ & \\
\hline cerasinus Cope 1876 & $\mathrm{EL}(\mathrm{c})$ & cerasinus & $\mathrm{B}$ & \\
\hline cerasoventris Rivero 1984 & - & - & - & $=$ vanadise \\
\hline cerastes Lynch 1975 & $\mathrm{EL}(\mathrm{s})$ & sulcatus & A & \\
\hline ceuthospilus Duellman \& Wild 1993 & $\mathrm{EL}(\mathrm{m})$ & unistrigatus & $\mathrm{C}$ & \\
\hline chac Savage 1987 & $\mathrm{CR}$ & gollmeri & A & \\
\hline chalcens Peters 1873 & $\mathrm{EL}(\mathrm{m})$ & diastema & $\mathrm{C}$ & \\
\hline cheiroplethus Lynch 1990 & $\mathrm{CR}$ & anomalus & A & \\
\hline chersonesodes Schwartz 1965 & $\mathrm{EU}$ & ricordii & A & \\
\hline chiastonotus Lynch \& Hoomoed 1977 & $\mathrm{EL}(\mathrm{c})$ & conspicillatus & $\mathrm{B}$ & \\
\hline chica Noble 1918 & - & - & - & $=$ diastema \\
\hline chimboe Fowler 1913 & - & - & - & $=$ curtipes \\
\hline chiquito Lynch 1965 & - & - & - & $=$ greggi \\
\hline chloronotus Lynch 1970 & $\mathrm{EL}(\mathrm{m})$ & unistrigatus & $\mathrm{C}$ & \\
\hline chlorophenax Schwartz 1976 & $\mathrm{PE}$ & inoptatus & B & \\
\hline chlorosoma Rivero 1984 & $\mathrm{EL}(\mathrm{m})$ & tubernasus & $\mathrm{C}$ & \\
\hline cholorum Neill 1965 & SY & leprus & A & \\
\hline chrysozetetes McCranie et al 1989 & $\mathrm{CR}$ & milesi & A & \\
\hline cinereus Cope 1885 & - & - & - & $=$ fenestratus \\
\hline citriogaster Duellman 1992 & $\mathrm{EL}(\mathrm{c})$ & conspicillatus & $\mathrm{B}$ & \\
\hline cochranae Grant 1932 & $\mathrm{EL}(\mathrm{m})$ & martinicensis & $\mathrm{C}$ & \\
\hline coeruleus Andersson 1945 & - & - & - & $=$ unistrigatus \\
\hline colodactylus Lynch 1979 & $\mathrm{EL}(\mathrm{m})$ & unistrigatus & $\mathrm{C}$ & \\
\hline colomai Lynch \& Duellman 1996 & $\mathrm{EL}(\mathrm{m})$ & unistrigatus & $\mathrm{C}$ & \\
\hline colostichos LaMarca \& Smith 1982 & $\mathrm{EL}(\mathrm{m})$ & unistrigatus & $\mathrm{C}$ & \\
\hline condor Lynch \& Duellman 1980 & $\mathrm{EL}(\mathrm{c})$ & conspicillatus & $\mathrm{B}$ & \\
\hline conspicillatus Günther 1859 & $\mathrm{EL}(\mathrm{c})$ & conspicillatus & $\mathrm{B}$ & \\
\hline conspiculus Taylor \& Smith 1945 & $\mathrm{CR}$ & alfredi & $\mathrm{B}$ & \\
\hline cooki Grant 1932 & $\mathrm{EL}(\mathrm{m})$ & martinicensis & $\mathrm{C}$ & \\
\hline coqui Thomas 1965 & $\mathrm{EL}(\mathrm{m})$ & martinicensis & $\mathrm{C}$ & \\
\hline cornutus Jiménez de la Espada 1870 & $\mathrm{EL}(\mathrm{s})$ & sulcatus & A & \\
\hline corona Hedges \& Thomas 1992 & EL(a) & abbotti & $\mathrm{B}$ & \\
\hline cosnipatae Duellman 1978 & $\mathrm{EL}(\mathrm{c})$ & - & $\mathrm{B}$ & \\
\hline costaricensis Taylor 1952 & - & - & - & $=$ bransfordii \\
\hline counouspeus Schwartz 1964 & $\mathrm{EU}$ & ricordii & A & \\
\hline cramptoni Schmidt 1920 & - & - & - & $=$ locustus \\
\hline crassidigitus Taylor 1952 & $\mathrm{CR}$ & fitzingeri & A & \\
\hline cremnobates Lynch \& Duellman 1980 & $\mathrm{EL}(\mathrm{m})$ & unistrigatus & $\mathrm{C}$ & \\
\hline crenunguis Lynch 1976 & $\mathrm{EL}(\mathrm{c})$ & cerasinus & $\mathrm{B}$ & \\
\hline crepitans Bokermann 1965 & - & - & - & $=$ fenestratus \\
\hline cristinae Lynch \& Ruiz 1985 & $\operatorname{EL}(c)$ & - & $\mathrm{B}$ & \\
\hline
\end{tabular}


Appendix III. Continued.

\begin{tabular}{|c|c|c|c|c|}
\hline $\begin{array}{c}\text { Species } \\
\text { Trivial name, author, date }\end{array}$ & Subgenus & group & $\begin{array}{c}\text { Toe } \\
\text { condition }\end{array}$ & Comments \\
\hline croceoinguinis Lynch 1968 & $\mathrm{EL}(\mathrm{m})$ & unistrigatus & $\mathrm{C}$ & \\
\hline crucifer Boulenger 1899 & $\mathrm{EL}(\mathrm{m})$ & unistrigatus & $\mathrm{C}$ & \\
\hline cruentus Peters 1863 & $\mathrm{EL}(\mathrm{m})$ & unistrigatus & $\mathrm{C}$ & \\
\hline cruralis Boulenger 1902 & $\mathrm{EL}(\mathrm{c})$ & discoidalis & A & \\
\hline cruizi McCranie et al 1989 & $\mathrm{CR}$ & milesi & A & \\
\hline cryophilius Lynch 1979 & $\mathrm{EL}(\mathrm{c})$ & curtipes & $\mathrm{B}$ & \\
\hline cryptomelas Lynch 1979 & $\mathrm{EL}(\mathrm{m})$ & unistrigatus & $\mathrm{C}$ & \\
\hline cuaquero Savage 1980 & $\mathrm{CR}$ & fitzingeri & A & \\
\hline cubanus Barbour 1942 & $\mathrm{EU}$ & - & A & \\
\hline cunctator Dunn 1928 & - & - & - & $=$ orcutti \\
\hline cundalli Dunn 1926 & $\mathrm{EU}$ & cundalli & A & \\
\hline cuneatus Cope 1862 & EU & ricordii & A & \\
\hline curtipes Boulenger 1882 & $\mathrm{EL}(\mathrm{c})$ & curtipes & $\mathrm{B}$ & \\
\hline cystignathoides Cope 1877 & SY & leprus & $\mathrm{A}$ & \\
\hline danae Duellman 1978 & $\mathrm{EL}(\mathrm{c})$ & - & $\mathrm{B}$ & \\
\hline darlingtoni Cochran 1935 & $\mathrm{EU}$ & ricordii & A & \\
\hline darlingtoni Cochran 1935 & - & - & - & $=$ jugans \\
\hline daryi Ford \& Savage 1984 & $\mathrm{CR}$ & gollmeri & A & \\
\hline decoratus Taylor 1942 & $\mathrm{CR}$ & alfredi & $\mathrm{B}$ & \\
\hline degener Lynch \& Duellman 1996 & $\mathrm{EL}(\mathrm{m})$ & unistrigatus & $\mathrm{C}$ & \\
\hline delacruzi Estrada et al 1986 & - & - & - & $=$ symingtoni \\
\hline delicatus Ruthven 1917 & $\operatorname{EL}(c)$ & galdi & A & \\
\hline delius Duellman \& Mendelson 1995 & $\mathrm{EL}(\mathrm{m})$ & unistrigatus & $\mathrm{C}$ & \\
\hline dennisi Lynch 1970 & SY & longipes & A & \\
\hline devillei Boulenger 1880 & $\mathrm{EL}(\mathrm{c})$ & devillei & $\mathrm{B}$ & \\
\hline diadematus Jiménez de la Espada 875 & $\mathrm{EL}(\mathrm{m})$ & unistrigatus & $\mathrm{C}$ & \\
\hline diaphonus Lynch 1986 & $\mathrm{EL}(\mathrm{m})$ & unistrigatus & $\mathrm{C}$ & \\
\hline diastema Cope 1876 & $\mathrm{EL}(\mathrm{m})$ & diastema & $\mathrm{C}$ & \\
\hline dilatus Davis \& Dixon 1955 & SY & nitidus & A & \\
\hline dimidiatus Cope 1862 & EU & ricordii & A & \\
\hline diplasius Schwartz 1973 & $\mathrm{EL}(\mathrm{m})$ & martinicensis & $\mathrm{C}$ & \\
\hline discoidalis Peracca 1895 & $\mathrm{EL}(\mathrm{c})$ & discoidalis & A & \\
\hline dissimulatus Lynch \& Duellman 1996 & $\mathrm{EL}(\mathrm{m})$ & unistrigatus & $\mathrm{C}$ & \\
\hline divisa Wandolleck 1907 & - & - & - & $=$ guentherii \\
\hline dixoni Lynch 1991 & SY & nitidus & A & \\
\hline dolomedes Hedges \& Thomas 1992 & EU & - & A & \\
\hline dolops Lynch \& Duellman 1980 & $\mathrm{EL}(\mathrm{c})$ & dolops & A & \\
\hline dorsoconcolor Taylor 1941 & - & - & - & $=$ rhodopis \\
\hline dorsopictus Rivero \& Serna 1987 & $\mathrm{EL}(\mathrm{m})$ & unistrigatus & $\mathrm{C}$ & \\
\hline douglasi Lynch 1996 & $\mathrm{EL}(\mathrm{c})$ & galdi & $\mathrm{B}$ & \\
\hline dubitus Taylor 1952 & - & - & - & $=$ cruentus \\
\hline duellmani Lynch 1980 & $\mathrm{EL}(\mathrm{c})$ & surdus & $\mathrm{B}$ & \\
\hline dunnii Barbour 1922 & - & - & - & $=$ rhodopis \\
\hline eileenae Dunn 1926 & $\mathrm{EL}(\mathrm{m})$ & martinicensis & $\mathrm{C}$ & \\
\hline elassodiscus Lynch 1973 & $\mathrm{EL}(\mathrm{c})$ & nigrovittatus & A & \\
\hline elegans Peters 1863 & $\mathrm{EL}(\mathrm{m})$ & unistrigatus & $\mathrm{C}$ & \\
\hline emcelae Lynch 1985 & $\mathrm{CR}$ & fitzingeri & A & \\
\hline emiliae Dunn 1926 & $\mathrm{EU}$ & ricordii & $\mathrm{A}$ & \\
\hline
\end{tabular}


Appendix 111. Continued.

\begin{tabular}{|c|c|c|c|c|}
\hline $\begin{array}{l}\text { Species } \\
\text { Trivial name, author, date }\end{array}$ & Subgenus & group & $\begin{array}{l}\text { Toe } \\
\text { ondition }\end{array}$ & Comments \\
\hline emmetti Gorham 1966 & - & - & - & $=$ emleni \\
\hline emleni Dunn 1932 & - & - & - & $=$ rugulosus \\
\hline eneidae Rivero 1959 & $\mathrm{EL}(\mathrm{m})$ & martinicensis & $\mathrm{C}$ & \\
\hline engytympanum Günther 1900 & - & - & - & $=$ fleischmanni \\
\hline epipedus Heyer 1984 & $\mathrm{EL}(\mathrm{b})$ & binotatus & A & \\
\hline equatorialis Barbour 1908 & - & - & - & $=$ unistrigatus \\
\hline eremitus Lynch 1980 & $\mathrm{EL}(\mathrm{m})$ & unistrigatus & $\mathrm{C}$ & \\
\hline eremus Schwartz 1965 & $\mathrm{EU}$ & ricordii & A & \\
\hline eriphus Lynch \& Duellman 1980 & $\mathrm{EL}(\mathrm{m})$ & unistrigatus & $\mathrm{C}$ & \\
\hline ernesti Flores 1987 & EL(c) & devillei & $\mathrm{B}$ & \\
\hline erythromerus Heyer 1984 & EL(b) & binotatus & A & \\
\hline erythropleura Boulenger 1896 & $\mathrm{EL}(\mathrm{c})$ & devillei & $\mathrm{B}$ & \\
\hline ervthroproctus Schwartz 1960 & $\mathrm{EU}$ & ricordii & A & \\
\hline escoces Savage 1975 & $\mathrm{CR}$ & rugulosus & A & \\
\hline estradai Lynch 1991 & $\mathrm{EU}$ & ricordii & A & \\
\hline etheridgei Schwartz 1958 & $\mathrm{EU}$ & ricordii & A & \\
\hline eugeniae Lynch \& Duellman 1996 & $\mathrm{EL}(\mathrm{m})$ & unistrigatus & $\mathrm{C}$ & \\
\hline eunaster Schwartz 1973 & EL(a) & $a b b o t t i$ & $\mathrm{~B}$ & \\
\hline euphronides Schwartz 1969 & $\mathrm{EL}(\mathrm{m})$ & martinicensis & $\mathrm{C}$ & \\
\hline eurydactylus Hedges \& Schlüter 1992 & $\mathrm{EL}(\mathrm{m})$ & unistrigatus & $\mathrm{C}$ & \\
\hline euryglossus Cope 1894 & - & - & - & $=$ fleischmanni \\
\hline fassilianus Werner 1916 & - & - & - & $=$ bogotensis \\
\hline femurlaevis Cochran 1935 & - & - & - & $=$ oxyrhyncus \\
\hline fenestratus Steindachner 1864 & $\mathrm{EL}(\mathrm{c})$ & conspicillatus & B & \\
\hline festae Peracca 1904 & - & - & - & $=$ galdi \\
\hline festae Peracca 1904 & - & - & - & $=$ trepidotus \\
\hline fitzingeri O. Schmidt 1857 & CR & fitzingeri & A & \\
\hline flavescens Noble 1923 & $\mathrm{EL}(\mathrm{m})$ & martinicensis & $\mathrm{C}$ & \\
\hline flavomaculatus Parker 1938 & - & - & - & $=$ Phrynopus \\
\hline flavomaculatus & & & & \\
\hline fleischmanni Boettger 1892 & CR & rugulosus & A & \\
\hline floridus Lynch \& Duellman 1996 & $\mathrm{EL}(\mathrm{t})$ & myersi & B & \\
\hline florulentus Cope 1893 & - & - & - & = biporcatus \\
\hline footei Stejneger 1913 & - & - & - & $=$ Gastrotheca marsupiata \\
\hline fowleri Schwartz 1973 & $\mathrm{EL}(\mathrm{m})$ & martinicensis & $\mathrm{C}$ & \\
\hline frater Werner 1899 & $\mathrm{EL}(\mathrm{m})$ & unistrigatus & $\mathrm{C}$ & \\
\hline fraudator Lynch \& McDiarmid 1987 & EL & - & A & \\
\hline fuhrmanni Peracca 1914 & - & - & - & $=$ elegans \\
\hline furcyensis Shreve \& Williams 1963 & $\mathrm{EU}$ & ricordii & A & \\
\hline fuscatus Davis \& Dixon 1957 & - & - & - & $=$ mexicanus \\
\hline fuscofemora Zweifel 1956 & CR & alıusti & A & \\
\hline fuscus Lynn \& Dent 1943 & $\mathrm{EU}$ & gossei & A & \\
\hline fuscus Davis \& Dixon 1955 & - & - & - & $=$ maurus \\
\hline gaigeae Schmidt \& Smith 1944 & - & - & - & $=$ petrophilus \\
\hline gaigei Dunn 1931 & $\mathrm{EL}(\mathrm{c})$ & conspicillatus & $\mathrm{B}$ & \\
\hline galdi Jiménez de la Espada 1870 & $\mathrm{EL}(\mathrm{c})$ & galdi & B & \\
\hline ganonotus Duellman \& Lynch 1988 & $\mathrm{EL}(\mathrm{c})$ & - & $\mathrm{B}$ & \\
\hline gehrmanni Schwartz 1958 & - & - & - & $=$ eileenae \\
\hline
\end{tabular}


Appendix III. Continued.

\begin{tabular}{|c|c|c|c|c|}
\hline $\begin{array}{c}\text { Species } \\
\text { Trivial name, author, date }\end{array}$ & Subgenus & group & $\begin{array}{c}\text { Toe } \\
\text { condition }\end{array}$ & Comments \\
\hline gehrti Miranda-Ribeiro 1926 & - & - & - & $=$ bolbodactylus \\
\hline gentryi Lynch \& Duellman 1996 & $\operatorname{EL}(\mathrm{c})$ & curtipes & $\mathrm{B}$ & \\
\hline ginesi Rivero 1964 & EL & - & A & \\
\hline gladiator Lynch 1977 & EL(t) & myersi & B & \\
\hline glandulifer Cochran 1935 & $\mathrm{EU}$ & ricordii & A & \\
\hline glanduliferoides Shreve 1936 & EL(a) & abbotti & $\mathrm{B}$ & \\
\hline glandulosus Boulenger 1880 & $\mathrm{EL}(\mathrm{m})$ & unistrigatus & $\mathrm{C}$ & \\
\hline glaphycompus Schwartz 1973 & $\mathrm{EU}$ & ricordii & A & \\
\hline glaucoreins Schwartz \& Fowler 1973 & EU & cumdalli & A & \\
\hline glaucus Lynch 1967 & $\mathrm{CR}$ & alfredi & $\mathrm{B}$ & \\
\hline goini Schwartz 1960 & $\mathrm{EU}$ & ricordii & A & \\
\hline goldmani Noble 1924 & - & - & - & $=$ gollmeri \\
\hline gollmeri Peters 1863 & $\mathrm{CR}$ & gollmeri & A & \\
\hline gossei Dunn 1926 & EU & gossei & A & \\
\hline grabhami Dunn 1926 & EU & luteolus & A & \\
\hline gracilis Lynch 1986 & $\mathrm{EL}(\mathrm{m})$ & unistrigatus & $\mathrm{C}$ & \\
\hline grahami Schwartz 1979 & EU & ricordii & $\mathrm{A}$ & \\
\hline grandiceps Lynch 1984 & $\mathrm{EL}(\mathrm{m})$ & unistrigatus & $\mathrm{C}$ & \\
\hline grandis Dixon 1957 & SY & nitidus & A & \\
\hline grandoculis Van Lidth de Jeude 1904 & $\mathrm{EL}(\mathrm{m})$ & unistrigatus & $\mathrm{C}$ & \\
\hline granulosus Boulenger 1903 & - & - & - & $=$ cruralis \\
\hline gravenhorstii Fitzinger 1867 & - & - & - & $=$ nomen nudum \\
\hline greggi Bumzahem 1955 & $\mathrm{CR}$ & gollmeri & A & \\
\hline greyi Dunn 1926 & EU & ricordii & $\mathrm{A}$ & \\
\hline griphus Crombie 1986 & EU & nubicola & A & \\
\hline grisea Hallowell 1861 & - & - & - & $=$ fit-ingeri \\
\hline gryllus Schmidt 1920 & $\mathrm{EL}(\mathrm{m})$ & martinicensis & $\mathrm{C}$ & \\
\hline gualteri Lutz 1974 & $\operatorname{EL}(b)$ & binotatus & $\mathrm{B}$ & \\
\hline guanahacabibes Estrada \& Rodríguez 1985 & $\mathrm{EU}$ & ricordii & $\mathrm{A}$ & \\
\hline guantanamera Hedges et al $1992^{\circ}$ & $\mathrm{EL}(\mathrm{m})$ & martinicensis & $\mathrm{C}$ & \\
\hline guayanensis Rivero 1968 & - & - & - & $=$ nomen nudum \\
\hline guentherii Steindachner 1867 & $\mathrm{EL}(\mathrm{b})$ & binotatus & A & \\
\hline guentherii Keferstein 1868 & - & - & - & $=$ fit-ingeri \\
\hline guerreroensis Lynch 1967 & $\mathrm{CR}$ & alfredi & B & \\
\hline gularis Boulenger 1898 & $\mathrm{EL}(\mathrm{m})$ & diastema & $\mathrm{C}$ & \\
\hline gundlachi Schmidt 1920 & $\mathrm{EU}$ & ricordii & A & \\
\hline guttilatus Cope 1879 & SY & mannockii & A & \\
\hline gutturalis Hoogmoed et al 1977 & $\mathrm{EL}(\mathrm{c})$ & conspicillatus & $\mathrm{B}$ & \\
\hline habenatus Cope 1876 & - & - & - & $=$ podiciferus \\
\hline haitianus Barbour 1942 & EL(a) & abbotti & $\mathrm{B}$ & \\
\hline hamiotae Flores 1994 & $\mathrm{EL}(\mathrm{c})$ & surdus & B & \\
\hline hectus Lynch \& Burrowes 1990 & $\mathrm{EL}(\mathrm{t})$ & myersi & $\mathrm{B}$ & \\
\hline hedricki Rivero 1963 & $\mathrm{EL}(\mathrm{m})$ & martinicensis & $\mathrm{C}$ & \\
\hline helonotus Lynch 1975 & $\mathrm{EL}(\mathrm{s})$ & sulcatus & A & \\
\hline heminota Shreve \& Williams 1963 & $\mathrm{EU}$ & - & A & \\
\hline henselii Peters 1870 & - & - & - & $=$ guentherii \\
\hline hernandezi Lynch \& Ruíz 1983 & $\mathrm{EL}(\mathrm{m})$ & unistrigatus & $\mathrm{C}$ & \\
\hline heterodactylus Miranda-Ribeiro 1937 & EL(b) & binotatus & A & \\
\hline
\end{tabular}


Appendix 111. Continued.

\begin{tabular}{|c|c|c|c|c|}
\hline $\begin{array}{c}\text { Species } \\
\text { Trivial name, author, date }\end{array}$ & Subgenus & group & $\begin{array}{c}\text { Toe } \\
\text { condition }\end{array}$ & Comments \\
\hline hidalgoensis Taylor 1942 & - & - & - & $=$ decoratus \\
\hline hobartsmithi Taylor 1937 & $\mathrm{CR}$ & rhodopis & A & \\
\hline hoehnei Lutz 1958 & EL(b) & binotatus & $\mathrm{B}$ & \\
\hline holti Cochran 1948 & $\mathrm{EL}(\mathrm{b})$ & lacteus & $\mathrm{B}$ & \\
\hline huigrae Fowler 1913 & - & - & - & $=$ gularis \\
\hline humeralis Fowler 1916 & - & - & - & $=$ gollmeri \\
\hline hybotragus Lynch 1992 & $\mathrm{EL}(\mathrm{c})$ & loustes & $\mathrm{B}$ & \\
\hline hylaeformis Cope 1875 & $\mathrm{EL}(\mathrm{m})$ & diastema & $\mathrm{C}$ & \\
\hline hylaeformis Melin 1941 & - & - & - & $=$ melini \\
\hline hypostenor Schwartz 1965 & PE & ruthae & B & \\
\hline ignicolor Lynch \& Duellman & $\mathrm{EL}(\mathrm{m})$ & unistrigatus & $\mathrm{C}$ & \\
\hline ileamazonicus Rivero 1961 & - & - & - & $=$ vilarsi \\
\hline illotus Lynch \& Duellman 1996 & $\mathrm{EL}(\mathrm{c})$ & conspicillatus & $\mathrm{B}$ & \\
\hline imitatrix Duellman 1978 & $\mathrm{EL}(\mathrm{m})$ & unistrigatus & $\mathrm{C}$ & \\
\hline incanus Lynch \& Duellman 1980 & $\mathrm{EL}(\mathrm{m})$ & unistrigatus & $\mathrm{C}$ & \\
\hline incomptus Lynch \& Duellman 1980 & $\mathrm{EL}(\mathrm{m})$ & unistrigatus & $\mathrm{C}$ & \\
\hline ineptus Barbour 1928 & - & - & - & $=$ diasterna \\
\hline ingeri Cochran \& Goin 1961 & $\mathrm{EL}(\mathrm{s})$ & sulcatus & A & \\
\hline inguinalis Parker 1940 & $\mathrm{EL}(\mathrm{m})$ & unistrigatus & $\mathrm{C}$ & \\
\hline inoptatus Barbour 1914 & $\mathrm{PE}$ & inoptatus & $\mathrm{B}$ & \\
\hline insertus Lutz 1927 & EL & - & - & $=$ nomen dudium \\
\hline insignitus Ruthven 1917 & $\operatorname{EL}(\mathrm{c})$ & conspicillatus & B & \\
\hline intermedius Barbour \& Shreve 1937 & $\mathrm{EU}$ & ricordii & A & \\
\hline intermedius Cochran 1941 & - & - & - & $=$ haitianus \\
\hline interorbitalis Langebartel \& Shannon 1956 & SY & modestus & A & \\
\hline intusitatus Lynch \& Duellman 1980 & $\mathrm{EL}(\mathrm{m})$ & unistrigatus & $\mathrm{C}$ & \\
\hline ionthus Schwartz 1960 & $\mathrm{EL}(\mathrm{m})$ & martinicensis & $\mathrm{C}$ & \\
\hline izecksohni Caramaschi \& Kisteumacher 1988 & EL(b) & binotatus & A & \\
\hline jaimei Lynch 1992 & $\operatorname{EL}(c)$ & loustes & $\mathrm{B}$ & \\
\hline jamaicensis Barbour 1910 & $\mathrm{EU}$ & jamaicensis & A & \\
\hline jasperi Drewy \& Jones 1976 & $\mathrm{EL}(\mathrm{m})$ & martinicensis & $\mathrm{C}$ & \\
\hline johannesdei Rivero \& Serna 1987 & $\mathrm{EL}(\mathrm{c})$ & conspicillatus & $\mathrm{B}$ & \\
\hline johnstonei Barbour 1914 & $\mathrm{EL}(\mathrm{m})$ & martinicensis & $\mathrm{C}$ & \\
\hline johnwrighti Lynch 1996 & $\mathrm{EL}(\mathrm{m})$ & unistrigatus & $\mathrm{C}$ & \\
\hline jorgevelosai Lynch 1994 & $\mathrm{EL}(\mathrm{m})$ & unistrigatus & $\mathrm{C}$ & \\
\hline jota Lynch 1980 & $\mathrm{CR}$ & rhodopis & A & \\
\hline jugans Cochran 1937 & EU & ricordii & A & \\
\hline juipoca Sazaima \& Cardoso 1978 & $\mathrm{EL}(\mathrm{b})$ & binotatus & A & \\
\hline junori Dunn 1926 & $\mathrm{EU}$ & gossei & A & \\
\hline karlschmidti Grant 1931 & EU & - & A & \\
\hline katoptroides Flores 1988 & $\mathrm{EL}(\mathrm{m})$ & unistrigatus & $\mathrm{C}$ & \\
\hline kirklandi Flores 1985 & $\mathrm{EL}(\mathrm{m})$ & unistrigatus & $\mathrm{C}$ & $=$ incomptus \\
\hline klinikowskii Schwartz 1959 & $\mathrm{EU}$ & ricordii & A & \\
\hline koki Melin 1941 & - & - & - & $=$ sulcatus \\
\hline labiosus Lynch et al. 1994 & $\mathrm{EL}(\mathrm{c})$ & cerasinus & $\mathrm{B}$ & \\
\hline lacrimosus Jiménez de la Espada 1875 & $\mathrm{EL}(\mathrm{m})$ & unistrigatus & $\mathrm{C}$ & \\
\hline lactea Miranda-Ribeiro 1923 & $\mathrm{EL}(\mathrm{b})$ & lacteus & B & \\
\hline laevissimus Werner 1896 & - & - & - & $=$ rugulosus \\
\hline
\end{tabular}


Appendix III. Continued.

\begin{tabular}{|c|c|c|c|c|}
\hline $\begin{array}{c}\text { Species } \\
\text { Trivial name, author, date }\end{array}$ & Subgenus & group & $\begin{array}{c}\text { Toe } \\
\text { condition }\end{array}$ & Comments \\
\hline lamprotes Schwartz 1973 & $\mathrm{EL}(\mathrm{m})$ & martinicensis & $\mathrm{C}$ & \\
\hline lanciformis Cope 1877 & - & - & - & $=$ gollmeri \\
\hline lancinii Donoso-Barros 1965 & $\mathrm{EL}(\mathrm{c})$ & - & $\mathrm{B}$ & \\
\hline lanthanites Lynch 1975 & $\mathrm{EL}(\mathrm{c})$ & conspicillatus & $\mathrm{B}$ & \\
\hline lasalleorum Lynch 1995 & $\mathrm{EL}(\mathrm{m})$ & leptolophus & $\mathrm{C}$ & \\
\hline latens Lynch 1989 & $\mathrm{EL}(\mathrm{c})$ & nigrovittatus & A & \\
\hline laticeps Duméril 1853 & $\mathrm{CR}$ & gollmeri & A & \\
\hline laticlavius Lynch \& Burrowes 1990 & $\mathrm{EL}(\mathrm{m})$ & unistrigatus & $\mathrm{C}$ & \\
\hline latidiscus Boulenger 1898 & $\mathrm{EL}(\mathrm{m})$ & unistrigatus & $\mathrm{C}$ & \\
\hline latodactylus Taylor 1940 & - & - & - & $=$ longipes \\
\hline latrans Cope 1880 & $\mathrm{CR}$ & augusti & A & \\
\hline lauraster Savage et al. & $\mathrm{CR}$ & rhodopis & A & \\
\hline leberi Schwartz 1965 & $\operatorname{EL}(\mathrm{m})$ & martinicensis & $\mathrm{C}$ & \\
\hline lehmani Boettger 1892 & - & - & - & $=$ unistrigatus \\
\hline lehmanvalenciae Thorton 1965 & - & - & - & $=$ moro \\
\hline lentiginosus Rivero 1984 & $\mathrm{EL}(\mathrm{c})$ & - & $\mathrm{B}$ & \\
\hline lentus Cope 1862 & $\mathrm{EU}$ & ricordii & $\mathrm{A}$ & \\
\hline leoncei Shreve \& Williams 1963 & EU & ricordii & $\mathrm{A}$ & \\
\hline leoni Lynch 1977 & $\mathrm{EL}(\mathrm{t})$ & myersi & $\mathrm{B}$ & \\
\hline leprus Cope 1879 & SY & leprus & $\mathrm{A}$ & \\
\hline leptodactyloides Andersson 1945 & - & - & - & $=$ Leptodactylus \\
\hline leptolophus Lynch 1980 & $\mathrm{EL}(\mathrm{m})$ & leptolophus & $\mathrm{C}$ & \\
\hline leucopus Lynch 1976 & $\mathrm{EL}(\mathrm{m})$ & unistrigatus & $\mathrm{C}$ & \\
\hline lewisi Lynn \& Dent 1942 & - & - & - & $=$ luteolus \\
\hline librarius Flores \& Vigle 1994 & $\mathrm{EL}(\mathrm{m})$ & unistrigatus & $\mathrm{C}$ & \\
\hline limbatus Cope 1862 & $\mathrm{EU}$ & - & A & \\
\hline limbensis Lynn 1958 & EU & ricordii & $\mathrm{A}$ & \\
\hline lineatissimus Taylor 1941 & - & - & - & $=$ mexicanus \\
\hline lindae Duellman 1978 & $\mathrm{EL}(\mathrm{m})$ & unistrigatus & $\mathrm{C}$ & \\
\hline lineatus Brocchi 1879 & $\mathrm{CR}$ & gollmeri & A & \\
\hline lirellus Dwyer 1995 & $\mathrm{EL}(\mathrm{m})$ & unistrigatus & $\mathrm{C}$ & \\
\hline lividus Lynch \& Duellman 1980 & $\mathrm{EL}(\mathrm{m})$ & unistrigatus & $\mathrm{C}$ & \\
\hline locustus Schmidt 1920 & $\mathrm{EL}(\mathrm{m})$ & martinicensis & $\mathrm{C}$ & \\
\hline loki Shannon \& Werler 1955 & - & - & - & $=$ rhodopis \\
\hline longipes Baird 1859 & SY & longipes & A & \\
\hline longirostris Boulenger 1898 & $\mathrm{CR}$ & fitzingeri & $\mathrm{A}$ & \\
\hline loustes Lynch 1979 & $\mathrm{EL}(\mathrm{c})$ & loustes & $\mathrm{B}$ & \\
\hline lucioi Schwartz 1980 & EU & ricordii & $\mathrm{A}$ & \\
\hline luscombei Duellman \& Mendelson 1995 & $\mathrm{EL}(\mathrm{m})$ & unistrigatus & $\mathrm{C}$ & \\
\hline luteolateralis Lynch 1976 & $\mathrm{EL}(\mathrm{m})$ & unistrigatus & $\mathrm{C}$ & \\
\hline luteolus Gosse 1851 & $\mathrm{EU}$ & luteolus & A & \\
\hline lutitus Lynch 1984 & $\mathrm{EL}(\mathrm{m})$ & unistrigatus & $\mathrm{C}$ & \\
\hline lutosus Barbour \& Dunn 1921 & - & - & - & $=$ cruentus \\
\hline lymani Barbour \& Noble 1920 & $\mathrm{EL}(\mathrm{c})$ & conspicillatus & B & \\
\hline lynchi Duellman \& Simmons 1977 & $\mathrm{EL}(\mathrm{m})$ & unistrigatus & $\mathrm{C}$ & \\
\hline lynni Goin \& Cooper 1950 & - & - & - & $=$ cundalli \\
\hline lythrodes Lynch \& Lescure 1980 & $\mathrm{EL}(\mathrm{m})$ & unistrigatus & $\mathrm{C}$ & \\
\hline macdougalli Taylor 1942 & - & - & - & $=$ lineatus \\
\hline
\end{tabular}


Appendix 1II. Continued.

\begin{tabular}{|c|c|c|c|c|}
\hline $\begin{array}{c}\text { Species } \\
\text { Trivial name, author, ditte }\end{array}$ & Subgenus & group & $\begin{array}{c}\text { Toe } \\
\text { condition }\end{array}$ & Comments \\
\hline macrocephalus Peracca 1904 & - & - & - & $=$ sulcatus \\
\hline macrotympanum Taylor 1940 & - & - & - & $=$ vermucipes \\
\hline maculata Daudin 1801 & - & - & - & $=$ not applied \\
\hline maculosus Lynch 1991 & $\mathrm{EL}(\mathrm{m})$ & leptolophus & $\mathrm{C}$ & \\
\hline malkini Lynch 1980 & EL(c) & conspicillatus & $\mathrm{B}$ & \\
\hline mantipus Boulenger 1908 & EL(c) & nigrovittatus & A & \\
\hline margaritifer Boulenger 1912 & - & - & - & $=$ galdi \\
\hline mariposa Hedges et al 1992 & EL(a) & abbotti & $\mathrm{B}$ & \\
\hline marmoratus Boulenger 1900 & $\mathrm{EL}(\mathrm{m})$ & unistrigatus & $\mathrm{C}$ & \\
\hline marnockii Cope 1878 & SY & manockii & $\mathrm{A}$ & \\
\hline marshae Lynch 1964 & - & - & - & $=$ crientus \\
\hline martiae Lynch 1974 & $\operatorname{EL}(\mathrm{m})$ & untistrigatus & $\mathrm{C}$ & \\
\hline martinicensis Tschudi 1838 & $\mathrm{EL}(\mathrm{m})$ & martinicensis & $\mathrm{C}$ & \\
\hline matudai Taylor 1941 & $\mathrm{CR}$ & milesi & A & \\
\hline maurus Hedges 1989 & SY & nitidus & $\mathrm{A}$ & \\
\hline maussi Boettger 1893 & $\mathrm{CR}$ & biporcatus & $\mathrm{A}$ & \\
\hline medemi Lynch 1994 & $\mathrm{EL}(\mathrm{c})$ & conspicillatus & $\mathrm{B}$ & \\
\hline megacephalus Cope 1875 & - & - & - & $=$ biporcatus \\
\hline megalops Ruthven 1917 & $\mathrm{EL}(\mathrm{c})$ & - & A & \\
\hline megalotympanum Shannon \& Werler 1955 & $\mathrm{CR}$ & alfredi & $\mathrm{B}$ & \\
\hline melanoproctus Rivero 1984 & $\mathrm{EL}(\mathrm{c})$ & - & $\mathrm{B}$ & \\
\hline melanostictus Cope 1875 & $\mathrm{CR}$ & fitzingeri & A & \\
\hline melanotrigonum Schwartz 1966 & EL(a) & abbotti & $\mathrm{B}$ & \\
\hline melini Bokermann 1958 & - & - & - & $=$ ockendeni \\
\hline mendax Duellman 1978 & $\mathrm{EL}(\mathrm{m})$ & unistrigatus & $\mathrm{C}$ & \\
\hline mercedesae Lynch \& McDiarmid 1978 & $\mathrm{EL}(\mathrm{c})$ & - & B & \\
\hline merendonensis Schmidt 1933 & $\mathrm{CR}$ & rugulosis & $\mathrm{A}$ & \\
\hline merostictus Lynch 1984 & $\mathrm{EL}(\mathrm{m})$ & mnistrigatus & $\mathrm{C}$ & \\
\hline mexicanus Brocchi 1877 & $\mathrm{CR}$ & rlodopis & $\mathrm{A}$ & \\
\hline mexicanus Boulenger 1898 & - & - & - & $=$ occidentalis \\
\hline milesi Schmidt 1933 & CR & milesi & A & \\
\hline mimus Taylor 1955 & $\mathrm{CR}$ & gollmeri & $\mathrm{A}$ & \\
\hline minimus Taylor 1940 & - & - & - & $=$ pygmaeus \\
\hline minutus Noble 1923 & $\mathrm{EU}$ & - & A & \\
\hline miyatai Lynch 1984 & $\mathrm{EL}(\mathrm{m})$ & unistrigatus & $\mathrm{C}$ & \\
\hline modestus Taylor 1942 & SY & modestus & $\mathrm{A}$ & \\
\hline modipeplus Lynch 1981 & $\mathrm{EL}(\mathrm{m})$ & unistrigatus & $\mathrm{C}$ & \\
\hline molinoi Barbour 1928 & - & - & - & $=$ ridens \\
\hline molybrignus Lynch 1986 & $\mathrm{EL}(\mathrm{m})$ & unistrigatus & $\mathrm{C}$ & \\
\hline mondolfii Rivero 1984 & $\mathrm{EL}(\mathrm{m})$ & unistrigatus & $\mathrm{C}$ & \\
\hline monensis Meerwarth 1901 & $\mathrm{EU}$ & ricordii & A & \\
\hline monnichortum Dunn 1940 & $\mathrm{CR}$ & fitzingeri & A & \\
\hline montanus Schmidt 1919 & $\mathrm{EL}(\mathrm{m})$ & martinicensis & $\mathrm{C}$ & \\
\hline montanus Taylor 1942 & - & - & - & $=$ sartori \\
\hline moro Savage 1965 & $\operatorname{EL}(\mathrm{m})$ & unistrigatus & $\mathrm{C}$ & \\
\hline muricatus Lynch \& Miyata 1980 & $\mathrm{EL}(\mathrm{m})$ & unistrigatus & $\mathrm{C}$ & \\
\hline museous Ibáñez et al. 1994 & $\mathrm{EL}(\mathrm{m})$ & unistrigatus & - & \\
\hline myersi Goin \& Cochran 1962 & EL(t) & myersi & $\mathrm{A}$ & \\
\hline
\end{tabular}


Appendix III. Continued.

Species

Trivial name, author, date
Toe

Subgenus group condition Comments mystaceus Barbour 1922

natuls Ahl 1933

napeus Jiménez de la Espada 1875

nasutus Lutz 1925

natator Taylor 1939

nebulosus Taylor 1943

nebulosus Henle 1992

necerus Lynch 1975

neodreptus Schwartz 1965

nervicus Lynch 1994

nicefori Cochran \& Goin 1970

nigriventris Lutz 1925

nigrogrisea Andersson 1945

nigrovittatus Andersson 1945

nitidus Peters 1869

nivocolimae Dixon \& Webb 1966

noblei Barbour \& Dunn 1926

nortoni Schwartz 1976

notidodes Schwartz 1966

nubicola Dunn 1926

mubicola Dunn \& Emlen 1932

nubilis Günther 1900

nyctophylax Lynch 1976

oaxacae Taylor 1940

obesus Barbour 1928

obmutescens Lynch 1980

occidentalis Taylor 1941

ocellatus Lynch \& Burrowes 1990

ockendeni Boulenger 1912

ocreatus Lynch 1981

octavioi Bokermann 1965

oeus Heyer 1984

olibrus Schwartz 1960

oligaulax Schwartz \& Fowler 1973

omiltemanus Günther 1900

orarius Dixon 1957

orcesi Lynch 1972

orcutti Dunn 1928

orestes Lynch 1979

orientalis Barbour \& Shreve 1937

orientalis Barbour \& Shreve 1937

ornatissimus Despax 1911

orocostalis Rivero 1961

orpacobates Lynch et al 1994

orphnolaimus Lynch 1970

oxyrhyncus Duméril \& Bibron 1841

pagmae Fowler

pallidus Duellman 1958

\begin{tabular}{|c|c|c|c|}
\hline- & - & - & $=$ rhodopis \\
\hline- & - & - & $=$ parvus \\
\hline- & - & - & $=$ cornutus \\
\hline EL(c) & binotatus & B & \\
\hline- & - & - & $=$ berkenbuschii \\
\hline SY & pipilans & A & \\
\hline- & - & - & $=$ caliginosus \\
\hline CR & bufoniformis & A & \\
\hline EL(a) & abbotti & B & \\
\hline $\mathrm{EL}(\mathrm{m})$ & unistrigatus & $\mathrm{C}$ & \\
\hline $\mathrm{EL}(\mathrm{m})$ & unistrigatus & $\mathrm{C}$ & \\
\hline EL(b) & lacteus & B & \\
\hline $\operatorname{EL}(m)$ & unistrigatus & $\mathrm{C}$ & \\
\hline $\mathrm{EL}(\mathrm{c})$ & nigrovittatus & A & \\
\hline SY & nitidus & A & \\
\hline SY & modestus & A & \\
\hline CR & gollmeri & A & \\
\hline PE & inoptatus & $\mathrm{B}$ & \\
\hline EL(a) & abbotti & $\mathrm{B}$ & \\
\hline $\mathrm{EU}$ & nubicola & A & \\
\hline- & - & - & $=e m l e n i$ \\
\hline- & - & - & $=$ fitzingeri \\
\hline EL(m) & unistrigatus & $\mathrm{C}$ & \\
\hline- & - & - & $=$ mexicanlts \\
\hline- & - & - & $=$ punctariolus \\
\hline $\mathrm{EL}(\mathrm{m})$ & orcesi & $\mathrm{C}$ & \\
\hline CR & rhodopis & A & \\
\hline EL(c) & cerasinus & B & \\
\hline $\mathrm{EL}(\mathrm{m})$ & unistrigatus & $\mathrm{C}$ & \\
\hline $\mathrm{EL}(\mathrm{t})$ & myersi & A & \\
\hline EL(b) & binotatus & A & \\
\hline EL(b) & binotatus & A & \\
\hline $\mathrm{EL}(\mathrm{m})$ & martinicensis & $\mathrm{C}$ & \\
\hline EU & gossei & A & \\
\hline CR & rhodopis & A & \\
\hline SY & nitidus & A & \\
\hline $\mathrm{EL}(\mathrm{m})$ & orcesi & $\mathrm{C}$ & \\
\hline $\mathrm{EU}$ & nubicola & A & \\
\hline $\mathrm{EL}(\mathrm{c})$ & orestes & B & \\
\hline EU & - & A & \\
\hline- & - & - & $=$ estradai \\
\hline $\mathrm{EL}(\mathrm{m})$ & unistrigatus & $\mathrm{C}$ & \\
\hline- & - & - & $=$ bicumulus \\
\hline EL(c) & cerasinus & B & \\
\hline $\mathrm{EL}(\mathrm{m})$ & unistrigatus & $\mathrm{C}$ & \\
\hline $\mathrm{EU}$ & ricordii & A & \\
\hline- & - & - & $=$ achatinus \\
\hline SY & modestus & A & \\
\hline
\end{tabular}


Appendix I11. Continued.

\begin{tabular}{|c|c|c|c|c|}
\hline $\begin{array}{c}\text { Species } \\
\text { Trivial name, author, date }\end{array}$ & Subgenus & group & $\begin{array}{l}\text { Toe } \\
\text { condition }\end{array}$ & Comments \\
\hline palmatus Boulenger 1882 & - & - & - & $=$ rugulosus \\
\hline palmeri Boulenger 1912 & $\mathrm{EL}(\mathrm{m})$ & unistrigatus & $\mathrm{C}$ & \\
\hline pantoni Dunn 1926 & EU & gossei & A & \\
\hline parabates Schwartz 1964 & EU & - & A & \\
\hline paralius Schwartz 1976 & EU & ricordii & A & \\
\hline paramerus Rivero 1984 & $\mathrm{EL}(\mathrm{c})$ & - & $\mathrm{B}$ & \\
\hline parapelates Hedges \& Thomas 1987 & $\mathrm{PE}$ & ruthae & $\mathrm{B}$ & \\
\hline pardalis Barbour 1928 & $\mathrm{EL}(\mathrm{m})$ & unistrigatus & $\mathrm{C}$ & \\
\hline parvillus Lynch 1976 & $\mathrm{EL}(\mathrm{m})$ & unistrigatus & $\mathrm{C}$ & \\
\hline parvus Girard 1853 & $\mathrm{EL}(\mathrm{b})$ & parius & A & \\
\hline parnus Barbour \& Shreve 1937 & - & - & - & $=$ cubanus \\
\hline pastazensis Andersson 1945 & $\mathrm{EL}(\mathrm{m})$ & unistrigatus & $\mathrm{C}$ & \\
\hline patriciae Schwartz 1965 & $\mathrm{EL}(\mathrm{m})$ & martinicensis & $\mathrm{C}$ & \\
\hline paulodutrai Bokermann 1974 & EL(b) & ramagii & $\mathrm{B}$ & \\
\hline paulsoni Schwartz 1964 & $\mathrm{EU}$ & ricordii & A & \\
\hline paululus Lynch 1974 & $\mathrm{EL}(\mathrm{m})$ & unistrigatus & $\mathrm{C}$ & \\
\hline pecki Duellman \& Lynch 1988 & $\mathrm{EL}(\mathrm{m})$ & unistrigatus & $\mathrm{C}$ & \\
\hline pelviculus Cope 1878 & - & - & - & $=$ biporcatus \\
\hline pentasyringos Schwartz \& Fowler 1973 & EU & gossei & A & \\
\hline peraltae Barbour 1928 & - & - & - & $=$ cerasinus \\
\hline peraticus Lynch 1980 & $\mathrm{EL}(\mathrm{m})$ & leptolophus & $\mathrm{C}$ & \\
\hline percultus Lynch 1979 & $\mathrm{EL}(\mathrm{m})$ & unistrigatus & $\mathrm{C}$ & \\
\hline permixtus Lynch et al 1994 & $\mathrm{EL}(\mathrm{m})$ & unistrigatus & $\mathrm{C}$ & \\
\hline persimilis Barbour 1926 & - & - & - & $=$ bransfordii \\
\hline perwvianus Melin 1941 & $\mathrm{EL}(\mathrm{c})$ & conspicillatus & $\mathrm{B}$ & \\
\hline petersi Duellman 1954 & SY & nitidus & A & \\
\hline petersi Lynch \& Duellman 1980 & - & - & - & $=$ johnwrighti \\
\hline petersorum Lynch 1991 & - & - & - & $=$ johnwrighti \\
\hline petrobardus Duellman 1991 & $\mathrm{EL}(\mathrm{m})$ & unistrigatus & $\mathrm{C}$ & \\
\hline petrophilus Firschein 1954 & SY & marnockii & A & \\
\hline pezopetrus Schwartz 1960 & EU & ricordii & A & \\
\hline pharangobates Duellman 1978 & - & - & - & $=$ rhabdolaemus \\
\hline philipi Lynch \& Duellman 1995 & $\mathrm{EL}(\mathrm{m})$ & unistrigatus & $\mathrm{C}$ & \\
\hline phoxocephalus Lynch 1979 & $\mathrm{EL}(\mathrm{m})$ & unistrigatus & $\mathrm{C}$ & \\
\hline phragmipleuron Rivero \& Serna 1987 & $\mathrm{EL}(\mathrm{m})$ & unistrigatus & $\mathrm{C}$ & \\
\hline phyzelus Schwartz 1958 & - & - & - & $=$ varley $i$ \\
\hline pictissimus Cochran 1935 & EU & ricordii & A & \\
\hline pinarensis Dunn 1926 & $\mathrm{EU}$ & ricordii & A & \\
\hline pinchoni Schwartz 1967 & $\mathrm{EL}(\mathrm{m})$ & martinicensis & $\mathrm{C}$ & \\
\hline pipilans Taylor 1940 & SY & pipilans & A & \\
\hline pittieri Günther 1900 & - & - & - & $=$ rugulosus \\
\hline pituinus Schwartz 1965 & $\mathrm{EL}(\mathrm{m})$ & martinicensis & $\mathrm{C}$ & \\
\hline planirostris Cope 1862 & $\mathrm{EU}$ & ricordii & A & \\
\hline platydactylus Boulenger 1903 & $\mathrm{EL}(\mathrm{m})$ & unistrigatus & $\mathrm{C}$ & \\
\hline platyrhynchus Günther 1900 & - & - & - & $=$ melanostictus \\
\hline pleurostriatus Rivero 1984 & $\operatorname{EL}(\mathrm{c})$ & - & $\mathrm{B}$ & \\
\hline plicatus Günther 1900 & - & - & - & $=$ rhodopis \\
\hline plicatus Barbour 1914 & - & - & - & $=$ gundlachi \\
\hline
\end{tabular}


Appendix IIl. Continued.

Species

Trivial name, author, date
Toe

Subgenus group condition Comments plicifer Boulenger 1888

podiciferus Cope 1875

polymniae Campbell et al 1989

polyptychus Cope 1886

poolei Cochran 1938

portoricensis Schmidt 1927

probolaeus Schwartz 1965

prolatus Lynch \& Duellman 1980

prolixodiscus Lynch 1978

proserpens Lynch 1979

pruinatus Myers \& Donnelly 1996

psephosypharus Campbell et al 1994

pseudoacuminatus Shreve 1935

pteridophilus Lynch \& Duellman 1996

pugnax Lynch 1973

pulchrigulus Cope 1862

pulidoi Rivero 1984

pulvinatus Rivero 1968

pumilio Boulenger 1920

punctariola Peters 1863

purpurus Lynch 1967

pusillus Bokermann 1967

pycnodermis Lynch 1979

pygmaeus Taylor 1937

pyrrhomerus Lynch 1976

quaquaversus Lynch 1974

quinquagesimus Lynch \& Trueb 1980

racemus Lynch 1980

racenisi Rivero 1961

ramagii Boulenger 1888

ramosi Rivero 1959

randorum Heyer 1985

raniformis Boulenger 1896

ranoides Cope 1886

rayo Savage \& DeWeese 1979

rearki Taylor 1952

repens Lynch 1984

reticulatus Walker \& Test 1955

rhabdolaemus Duellman 1978

rhodesi Schwartz 1980

rhodopis Cope 1866

rhodoplichus Duellman \& Wild 1993

richmondi Stejneger 1904

ricordii Duméril \& Bibron 1841

ridens Cope 1866

riisei Reinhardt \& Lütken 1863

riveroi Lynch \& LaMarca 1993

riveti Despax 1911

\begin{tabular}{|c|c|c|c|}
\hline EL(b) & binotatus & A & \\
\hline CR & rhodopis & A & \\
\hline $\mathrm{CR}$ & alfredi & $B$ & \\
\hline- & - & - & $=$ bransfordii \\
\hline $\mathrm{EL}(\mathrm{m})$ & martinicensis & $\mathrm{C}$ & \\
\hline $\mathrm{EL}(\mathrm{m})$ & martinicensis & $\mathrm{C}$ & \\
\hline $\mathrm{EU}$ & ricordii & A & \\
\hline $\mathrm{EL}(\mathrm{m})$ & unistrigatus & $\mathrm{C}$ & \\
\hline $\mathrm{EL}(\mathrm{m})$ & unistrigatus & $\mathrm{C}$ & \\
\hline $\mathrm{EL}(\mathrm{m})$ & unistrigatus & $\mathrm{C}$ & \\
\hline EL & - & B & \\
\hline $\mathrm{CR}$ & rugulosus & A & \\
\hline $\mathrm{EL}(\mathrm{m})$ & unistrigatus & $\mathrm{C}$ & \\
\hline $\mathrm{EL}(\mathrm{m})$ & unistrigatus & $\mathrm{C}$ & \\
\hline $\mathrm{EL}(\mathrm{m})$ & unistrigatus & $\mathrm{C}$ & \\
\hline- & - & - & $=$ fitzingeri \\
\hline $\mathrm{EL}(\mathrm{m})$ & tubernasus & $\mathrm{C}$ & \\
\hline $\mathrm{EL}(\mathrm{c})$ & - & B & \\
\hline- & - & - & $=$ parvus \\
\hline CR & rugulosus & A & \\
\hline CR & alfredi & B & \\
\hline EL(b) & parvus & B & \\
\hline $\mathrm{EL}(\mathrm{m})$ & unistrigatus & $\mathrm{C}$ & \\
\hline $\mathrm{CR}$ & rhodopis & A & \\
\hline EL(t) & myersi & B & \\
\hline $\mathrm{EL}(\mathrm{m})$ & unistrigatus & $\mathrm{C}$ & \\
\hline EL(c) & devillei & B & \\
\hline $\mathrm{EL}(\mathrm{m})$ & orcesi & $\mathrm{C}$ & \\
\hline- & - & - & = bicumulus \\
\hline $\mathrm{EL}(\mathrm{b})$ & ramagii & B & \\
\hline- & - & - & $=$ cochranae \\
\hline $\mathrm{EL}(\mathrm{b})$ & - & B & \\
\hline $\mathrm{CR}$ & fitzingeri & A & \\
\hline- & - & - & $=$ rugulosus \\
\hline $\mathrm{CR}$ & fitzingeri & A & \\
\hline- & - & - & $=$ bransfordii \\
\hline $\mathrm{EL}(\mathrm{t})$ & myersi & A & \\
\hline $\mathrm{EL}(\mathrm{m})$ & - & $\mathrm{C}$ & \\
\hline EL(c) & - & B & \\
\hline EU & ricordii & A & \\
\hline $\mathrm{CR}$ & rhodopis & A & \\
\hline $\mathrm{EL}(\mathrm{m})$ & unistrigatus & $\mathrm{C}$ & \\
\hline EU & ricordii & A & \\
\hline $\mathrm{EU}$ & ricordii & A & \\
\hline $\mathrm{EL}(\mathrm{m})$ & unistrigatus & $\mathrm{C}$ & \\
\hline- & - & - & $=$ lentus \\
\hline $\mathrm{EL}(\mathrm{m})$ & unistrigatus & $\mathrm{C}$ & \\
\hline $\mathrm{EL}(\mathrm{m})$ & unistrigatus & C & \\
\hline
\end{tabular}


Appendix III. Continued.

Species

Trivial name, author, date

rogersi Goin 1955

ronaldi Schwartz 1960

rosadoi Flores 1988

rosemelimus Gorham 1966

roseus Boulenger 1918

roseus Melin 1941

rostralis Werner 1896

rozei Rivero 1961

rubicundus Jiménez de la Espada 1875

rubrimaculata Taylor \& Smith 1945

rucillensis Cochran 1939

rufescens Duellman \& Dixon 1959

rufifemoralis Noble \& Hassler 1933

rugosus Peters 1873

rugulosa Cope 1870

rugulosus Peters 1870

ruidus Lynch 1979

ruizi Lynch 1981

ruthae Noble 1923

rutheni Lynch \& Ruíz 1985

salaputium Duellman 1978

sallaei Günther 1868

saltator Taylor 1941

samaipatae Köhler \& Jungfer 1995

sanctaemartae Ruthven 1917

sandersoni Schmidt 1941

sammartinensis Shannon \& Werler 1955

sartori Lynch 1965

satagius Lynch 1995

savagei Pyburn \& Lynch 1981

saxatilis Webb 1962

schmidti Noble 1923

schultei Duellman 1990

schwartzi Thomas 1966

sciagraphus Schwartz 1973

scitulus Duellman 1978

scolobelpharus Lynch 1991

scolodiscus Lynch \& Burrowes 1990

semipalmatus Shreve 1936

sernai Rivero 1985

shrevei Schwartz 1969

sierramaestrae Schmidt 1920

silvicola Lynch 1967

simonbolivari Wiens \& Coloma 1992

simoterus Lynch 1980

siopelus Lynch \& Burrowes 1990

sisyphodemus Crombie 1977

smithi Taylor 1940

sobetes Lynch 1980
Toe

Subgenus group condition Comments

\begin{tabular}{|c|c|c|c|}
\hline EU & ricordii & A & \\
\hline $\mathrm{EL}(\mathrm{m})$ & martinicensis & $\mathrm{C}$ & \\
\hline $\mathrm{EL}(\mathrm{m})$ & unistrigatus & $\mathrm{C}$ & \\
\hline- & - & - & $=$ vilarsi \\
\hline $\mathrm{EL}(\mathrm{m})$ & unistrigatus & $\mathrm{C}$ & \\
\hline- & - & - & $=$ rosemelinus \\
\hline CR & gollmeri & A & \\
\hline $\mathrm{EL}(\mathrm{m})$ & unistrigatus & $\mathrm{C}$ & \\
\hline EL(c) & cerasinus & B & \\
\hline SY & leprus & A & \\
\hline EU & ricordii & A & \\
\hline SY & nitidus & A & \\
\hline $\mathrm{EU}$ & - & $\mathrm{A}$ & \\
\hline- & - & - & $=$ biporcatus \\
\hline CR & rugulosus & A & \\
\hline- & - & - & $=$ binotatus \\
\hline $\mathrm{EL}(\mathrm{m})$ & unistrigatus & $\mathrm{C}$ & \\
\hline EL(s) & sulcatus & A & \\
\hline $\mathrm{PE}$ & ruthae & B & \\
\hline EL(c) & - & B & \\
\hline $\mathrm{EL}(\mathrm{m})$ & unistrigatus & $\mathrm{C}$ & \\
\hline- & - & - & $=$ rhodopis \\
\hline CR & rhodopis & A & \\
\hline $\mathrm{EL}(\mathrm{c})$ & conspicillatus & $\mathrm{B}$ & \\
\hline $\mathrm{EL}(\mathrm{c})$ & - & $\mathrm{B}$ & \\
\hline- & - & - & $=$ rugulosus \\
\hline- & - & - & $=$ rhodopis \\
\hline CR & rhodopis & A & \\
\hline $\mathrm{EL}(\mathrm{c})$ & curtipes & $\mathrm{B}$ & \\
\hline EL(c) & conspicillatus & B & \\
\hline SY & nitidus & A & \\
\hline EU & ricordii & A & \\
\hline $\operatorname{EL}(m)$ & unistrigatus & $\mathrm{C}$ & \\
\hline $\mathrm{EL}(\mathrm{m})$ & martinicensis & $\mathrm{C}$ & \\
\hline $\mathrm{EU}$ & ricordii & A & \\
\hline EL(c) & - & B & \\
\hline $\mathrm{EL}(\mathrm{m})$ & leptolophus & $\mathrm{C}$ & \\
\hline $\mathrm{EL}(\mathrm{m})$ & diastema & $\mathrm{C}$ & \\
\hline $\mathrm{EU}$ & - & A & \\
\hline $\mathrm{EL}(\mathrm{s})$ & sulcatus & A & \\
\hline $\mathrm{EL}(\mathrm{m})$ & martinicensis & $\mathrm{C}$ & \\
\hline $\mathrm{EU}$ & ricordii & A & \\
\hline CR & alfredi & B & \\
\hline EL(c) & orestes & B & \\
\hline $\mathrm{EL}(\mathrm{m})$ & orcesi & $\mathrm{C}$ & \\
\hline EL(c) & devillei & $\mathrm{B}$ & \\
\hline EU & luteolus & A & \\
\hline- & - & - & $=$ guttilatus \\
\hline $\mathrm{EL}(\mathrm{c})$ & surdus & B & \\
\hline
\end{tabular}


Appendix III. Continued.

\begin{tabular}{|c|c|c|c|c|}
\hline $\begin{array}{l}\text { Species } \\
\text { Trivial name, author, date }\end{array}$ & Subgenus & group & $\begin{array}{l}\text { Toe } \\
\text { condition }\end{array}$ & Comments \\
\hline sommeri Schwartz 1977 & $\mathrm{EL}(\mathrm{m})$ & martimicensis & $\mathrm{C}$ & \\
\hline sonans Dunn 1925 & - & - & - & $=$ auriculatus \\
\hline spanios Heyer 1985 & $\mathrm{EL}(\mathrm{b})$ & - & B & \\
\hline spatulatus Smith 1939 & $\mathrm{CR}$ & alfredi & $\mathrm{B}$ & \\
\hline spilogaster Lynch 1984 & $\mathrm{EL}(\mathrm{m})$ & unistrigatus & $\mathrm{C}$ & \\
\hline spinosus Lynch 1979 & $\mathrm{EL}(\mathrm{m})$ & unistrigatus & $\mathrm{C}$ & \\
\hline stadelmani Schmidt 1936 & $\mathrm{CR}$ & milesi & A & \\
\hline stantoni Schmidt 1941 & - & - & - & $=$ laticeps \\
\hline staurometopon Schwartz 1960 & $\mathrm{EL}(\mathrm{m})$ & martinicensis & $\mathrm{C}$ & \\
\hline stejnegerianus Cope 1893 & $\mathrm{CR}$ & rhodopis & A & \\
\hline stenodiscus Walker \& Test 1955 & EL(c) & - & $\mathrm{B}$ & \\
\hline sternothylax Duellman \& Wild 1993 & $\mathrm{EL}(\mathrm{m})$ & unistrigatus & $\mathrm{C}$ & \\
\hline stuarti Lynch 1967 & $\mathrm{CR}$ & alfredi & $\mathrm{B}$ & \\
\hline subsigillatus Boulenger 1902 & $\mathrm{EL}(\mathrm{m})$ & unistrigatus & $\mathrm{C}$ & \\
\hline sulcatus Cope 1874 & $\mathrm{EL}(\mathrm{s})$ & sulcatus & A & \\
\hline sulculus Lynch \& Burrowes & EL(c) & devillei & $\mathrm{B}$ & \\
\hline supernatis Lynch 1980 & $\mathrm{EL}(\mathrm{m})$ & unistrigatus & $\mathrm{C}$ & \\
\hline surdus Boulenger 1882 & $\mathrm{EL}(\mathrm{c})$ & surdus & $\mathrm{B}$ & \\
\hline symingtoni Schwartz 1957 & $\mathrm{EU}$ & symingtoni & A & \\
\hline syristes Hoyt 1965 & SY & nitidus & A & \\
\hline taeniatus Boulenger 1912 & $\mathrm{EL}(\mathrm{m})$ & unistrigatus & $\mathrm{C}$ & \\
\hline talamancae Dunn 1931 & $\mathrm{CR}$ & fitzingeri & A & \\
\hline tamsitti Cochran \& Goin 1970 & $\mathrm{EL}(\mathrm{m})$ & unistrigatus & $\mathrm{C}$ & \\
\hline tarahumarensis Taylor 40 & $\mathrm{CR}$ & augusti & A & \\
\hline taurus Taylor 1958 & $\mathrm{CR}$ & rugulosus & A & \\
\hline taylori Lynch 1966 & $\mathrm{CR}$ & alfredi & $\mathrm{B}$ & \\
\hline tayrona Lynch \& Ruíz 1985 & $\mathrm{EL}(\mathrm{m})$ & unistrigatus & $\mathrm{C}$ & \\
\hline tenebrionis Lynch \& Miyata 1980 & EL(c) & cerasinus & $\mathrm{B}$ & \\
\hline teretistes Duellman 1958 & SY & modestus & A & \\
\hline terraebolivaris Rivero 1961 & $\mathrm{EL}(\mathrm{c})$ & conspicillatus & $\mathrm{B}$ & \\
\hline thectopternus Lynch 1975 & $\mathrm{EL}(\mathrm{c})$ & conspicillatus & $\mathrm{B}$ & \\
\hline thomasi Schwartz 1959 & $\mathrm{EU}$ & ricordii & A & \\
\hline thorectes Hedges 1988 & EL(a) & abbotti & $\mathrm{B}$ & \\
\hline thymalopsoides Lynch 1976 & $\mathrm{EL}(\mathrm{m})$ & unistrigatus & $\mathrm{C}$ & \\
\hline thymelensis Lynch 1972 & $\mathrm{EL}(\mathrm{m})$ & orcesi & $\mathrm{C}$ & \\
\hline tiptoni Lynch 1964 & - & - & - & $=$ cerasinus \\
\hline toa Estrada \& Hedges 1991 & $\mathrm{EU}$ & ricordii & A & \\
\hline toftae Duellman 1978 & $\mathrm{EL}(\mathrm{c})$ & - & $\mathrm{B}$ & \\
\hline trachyblepharis Boulenger 1918 & $\mathrm{EL}(\mathrm{m})$ & unistrigatus & $\mathrm{C}$ & \\
\hline trachydermus Campbell 1994 & $\mathrm{CR}$ & milesi & A & \\
\hline trepidotus Lynch 1968 & EL(t) & myersi & A & \\
\hline trinidadensis Schwartz 1959 & $\mathrm{EU}$ & ricordii & A & \\
\hline truebae Lynch \& Duellman 1996 & EL(c) & devillei & $\mathrm{B}$ & \\
\hline tubernasus Rivero 1984 & $\mathrm{EL}(\mathrm{m})$ & tubernasus & $\mathrm{C}$ & \\
\hline turquinensis Barbour \& Shreve 1937 & EU & ricordii & A & \\
\hline turumiquirensis Rivero 1961 & $\mathrm{EL}(\mathrm{m})$ & unistrigatus & $\mathrm{C}$ & \\
\hline tychathrous Schwartz 1965 & $\mathrm{PE}$ & ruthae & $\mathrm{B}$ & \\
\hline underwoodi Boulenger 1896 & - & - & - & $=$ bransfordii \\
\hline unicolor Tschudi 1838 & - & - & - & $=$ Suppressed \\
\hline
\end{tabular}


Appendix 111. Continued.

\begin{tabular}{|c|c|c|c|c|}
\hline $\begin{array}{c}\text { Species } \\
\text { Trivial name, author, date }\end{array}$ & Subgenus & group & $\begin{array}{l}\text { Toe } \\
\text { ondition }\end{array}$ & Comments \\
\hline unicolor Stejneger 1904 & EU & - & A & \\
\hline unistrigatus Günther 1859 & $\mathrm{EL}(\mathrm{m})$ & unistrigatus & $\mathrm{C}$ & \\
\hline uno Savage 1985 & $\mathrm{CR}$ & - & A & \\
\hline uranobates Lynch 1991 & $\mathrm{EL}(\mathrm{m})$ & leptolophus & $\mathrm{C}$ & \\
\hline urichi Boettger 1894 & $\mathrm{EL}(\mathrm{m})$ & martinicensis & $\mathrm{C}$ & \\
\hline vanadise LaMarca 1984 & $\mathrm{EL}(\mathrm{c})$ & - & $\mathrm{B}$ & \\
\hline variabilis Lynch 1968 & $\mathrm{EL}(\mathrm{m})$ & unistrigatus & $\mathrm{C}$ & \\
\hline varians Gundlach \& Peters 1864 & $\mathrm{EL}(\mathrm{m})$ & martinicensis & $\mathrm{C}$ & \\
\hline v'arleyi Dunn 1925 & $\mathrm{EU}$ & - & A & \\
\hline venancioi Lutz 1958 & EL(b) & - & $\mathrm{A}$ & \\
\hline ventrilineatus Shreve 1936 & $\mathrm{EU}$ & - & $\mathrm{A}$ & \\
\hline ventrimarmoratus Boulenger 1912 & $\mathrm{EL}(\mathrm{m})$ & unistrigatus & $\mathrm{C}$ & \\
\hline ventrivittatus Andersson 1945 & - & - & - & $=$ ventrimarmoratus \\
\hline venustus Günther 1900 & - & - & - & $=$ rhodopis \\
\hline verecundus Lynch \& Burrowes 1990 & $\mathrm{EL}(\mathrm{m})$ & unistrigatus & $\mathrm{C}$ & \\
\hline verrucipes Cope 1885 & SY & marnockii & A & \\
\hline verruculatus Peters 1870 & SY & - & - & $=$ nomen dubium \\
\hline versicolor Lynch 1979 & $\mathrm{EL}(\mathrm{m})$ & unistrigatus & $\mathrm{C}$ & \\
\hline vertebralis Boulenger 1886 & $\mathrm{EL}(\mathrm{c})$ & devillei & $\mathrm{B}$ & \\
\hline vicarius Lynch \& Ruiz 1983 & $\mathrm{EL}(\mathrm{m})$ & unistrigatus & $\mathrm{C}$ & \\
\hline vidua Lynch 1979 & $\operatorname{EL}(\mathrm{c})$ & orestes & $\mathrm{B}$ & \\
\hline vilarsi Melin 1941 & $\mathrm{EL}(\mathrm{c})$ & conspicillatus & $\mathrm{B}$ & \\
\hline vinhai Bokermann 1974 & $\mathrm{EL}(\mathrm{b})$ & - & $\mathrm{B}$ & \\
\hline viridicans Lynch 1977 & $\mathrm{EL}(\mathrm{c})$ & conspicillatus & $\mathrm{B}$ & \\
\hline vocalis Taylor 1940 & $\mathrm{CR}$ & rugulosus & A & \\
\hline vocator Taylor 1955 & $\mathrm{EL}(\mathrm{m})$ & diastema & $\mathrm{C}$ & \\
\hline vulcani Shannon \& Werler 1955 & - & - & - & $=$ berkenbuschii \\
\hline w-nigrum Boettger 1892 & $\mathrm{EL}(\mathrm{c})$ & conspicillatus & B & \\
\hline walkeri Lynch 1974 & $\mathrm{EL}(\mathrm{m})$ & unistrigatus & $\mathrm{C}$ & \\
\hline warreni Schwartz 1976 & EU & ricordii & A & \\
\hline weinlandi Barbour 1914 & $\mathrm{EU}$ & ricordii & A & \\
\hline werleri Lynch \& Fritts 1965 & - & - & - & $=$ laticeps \\
\hline wetmorei Cochran 1932 & $\mathrm{EL}(\mathrm{m})$ & martinicensis & $\mathrm{C}$ & \\
\hline whymperi Boulenger 1882 & - & - & - & $=$ curtipes \\
\hline wiensi Duellman \& Wild 1993 & $\mathrm{EL}(\mathrm{m})$ & unistrigatus & $\mathrm{C}$ & \\
\hline wightmanae Schmidt 1920 & EL(a) & - & $\mathrm{B}$ & \\
\hline williamsi Rivero 1961 & - & - & - & = bicumulus \\
\hline williamsi Schwartz 1968 & - & - & - & $=$ diplasius \\
\hline xestus Lynch 1995 & $\operatorname{EL}(\mathrm{c})$ & curtipes & $\mathrm{B}$ & \\
\hline xucanebi Stuart 1941 & $\mathrm{CR}$ & alfredi & B & \\
\hline yaviensis Myers \& Donnelly 1996 & $\mathrm{EL}(\mathrm{m})$ & unistrigatus & $\mathrm{C}$ & \\
\hline yucatanensis Lynch 1965 & $\mathrm{CR}$ & alfredi & $\mathrm{B}$ & \\
\hline zayasi Schwartz 1960 & EU & ricordii & $\mathrm{A}$ & \\
\hline zeuctotylus Lynch \& Hoogmoed 1977 & $\operatorname{EL}(\mathrm{c})$ & conspicillatus & $\mathrm{B}$ & \\
\hline zeus Schwartz 1958 & $\mathrm{EU}$ & - & $\mathrm{B}$ & \\
\hline zimmermanae Heyer \& Hardy 1991 & $\mathrm{EL}(\mathrm{m})$ & unistrigatus & $\mathrm{C}$ & \\
\hline zugi Schwartz 1958 & EU & ricordii & A & \\
\hline zygodactylus Lynch \& Myers 1983 & $\mathrm{CR}$ & anomalus & A & \\
\hline
\end{tabular}




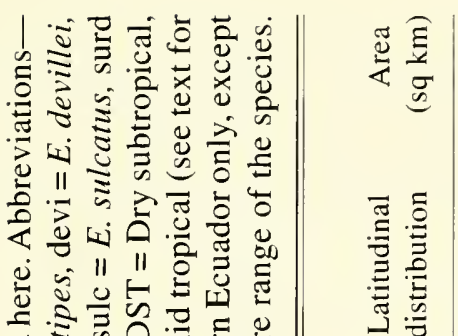

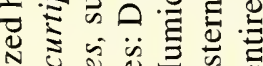

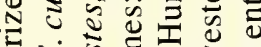
娄 है

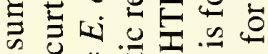
ऽ 홍ㅎㅇ

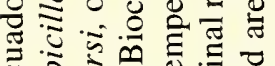

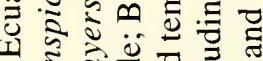
ป

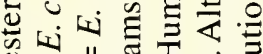

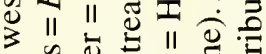
E 空 它向"

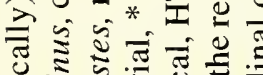

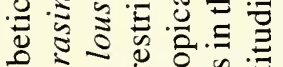

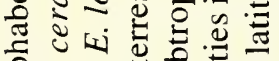

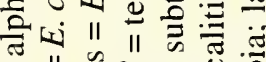
可

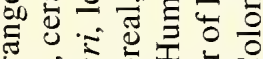

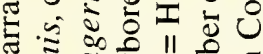

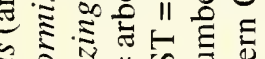

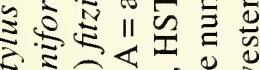

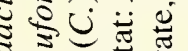

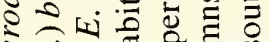
¿

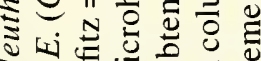

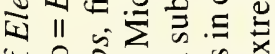
प융

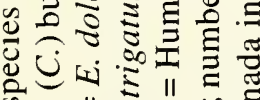

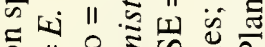

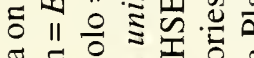

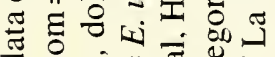

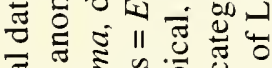
สำ

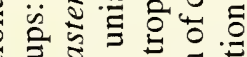

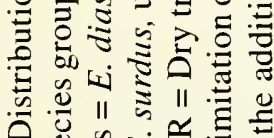

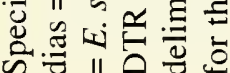
总品

넨

岂

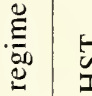

苛

举

욤 衿恼

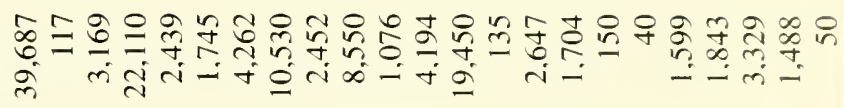

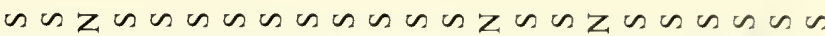

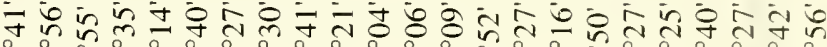

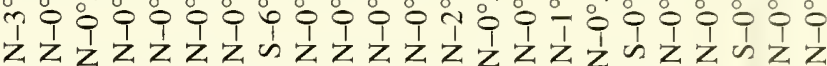

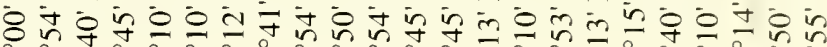
g.

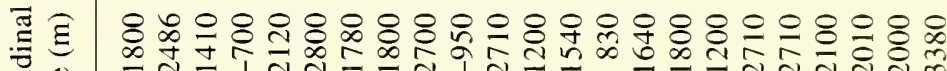

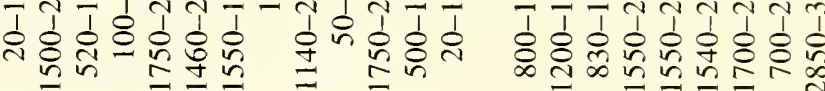

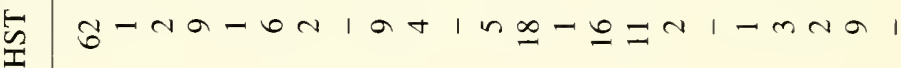

ते

$\infty$

$\begin{array}{lllllllllllllllllllll}1 & 1 & 1 & 1 & 1 & 1 & 1 & 1 & 1 & 1 & 1 & 1 & 1 & 1 & 1 & 1 & 1 & 1 & 1 & 1 & 1\end{array}$

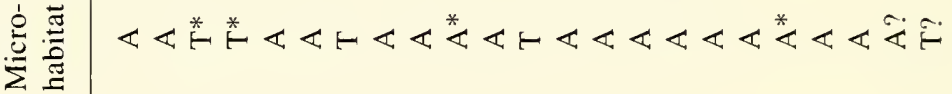

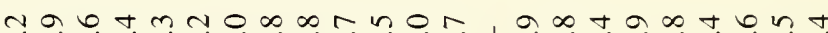

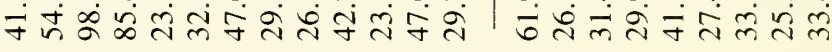

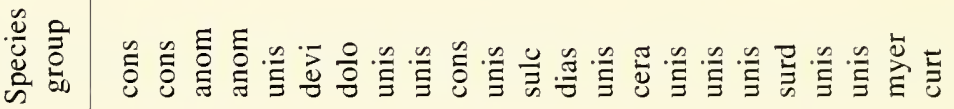

范

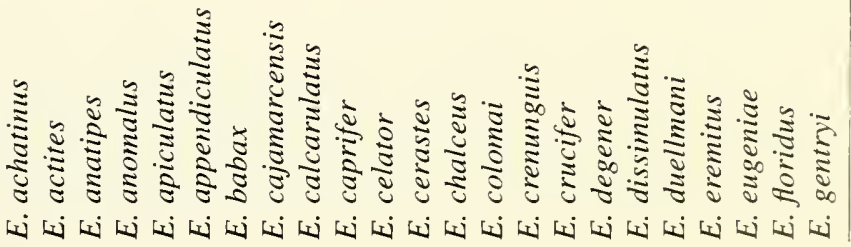




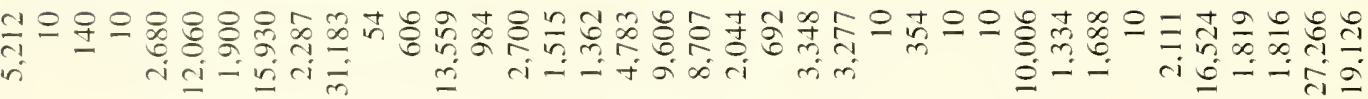

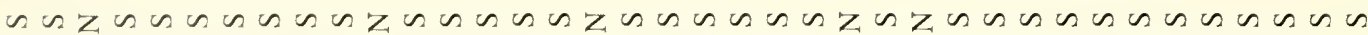

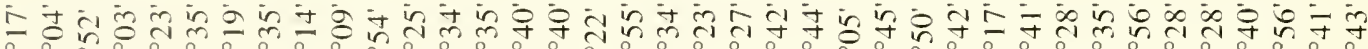

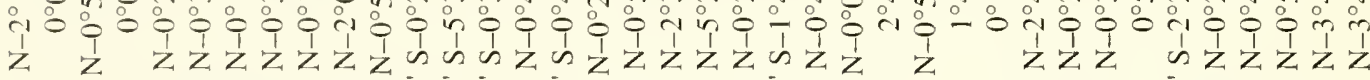

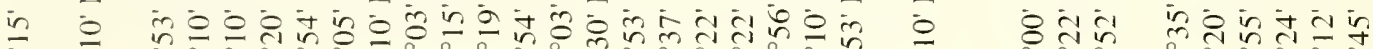
o 0 o o

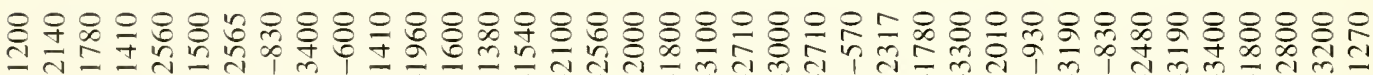

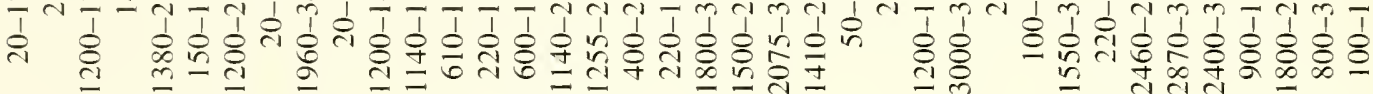

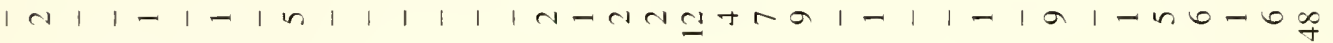

1 1- - I $-\infty$ I $81-1-$

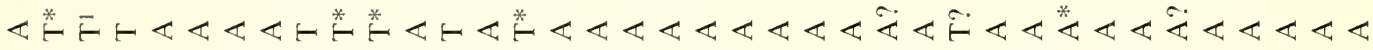

n

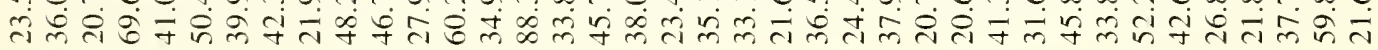

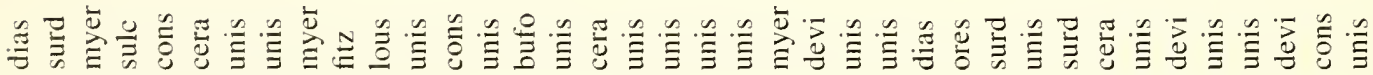

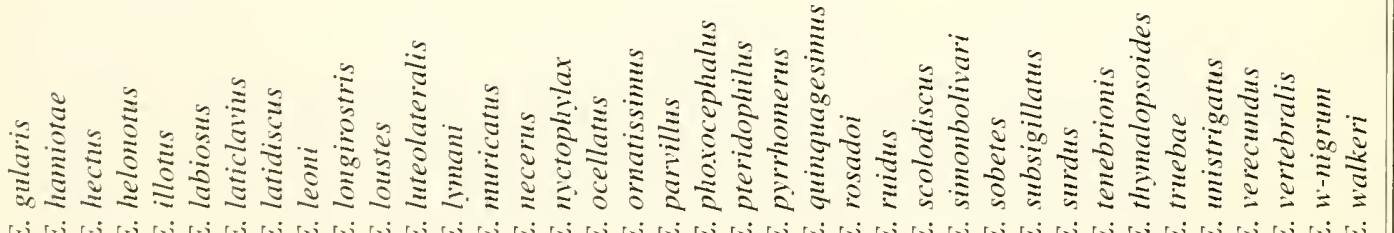




\section{SPECIAL PUBLICATIONS OF \\ THE UNIVERSITY OF KANSAS NATURAL HISTORY MUSEUM \\ (Numbers currently available)}

3. Maintenance of Rattlesnakes in Captivity. By James B. Murphy and Barry L. Armstrong. Pp. 1-40. 29 December 1978. ISBN 0-89338-006-7.

5. The Natural History of Mexican Rattlesnakes. By Barry L. Armstrong and James B. Murphy. Pp. 1-88. 14 December 1979. ISBN 0-89338-010-5.

7. A Diapsid Reptile from the Pennsylvanian of Kansas. By Robert R. Reisz. Pp. 174. 18 February 1981. ISBN 0-89338-011-3.

9. The Ecological Impact of Man on the South Florida Herpetofauna. By Larry David Wilson and Louis Porras. Pp. 1-89. 8 August 1983. ISBN 0-89338-018-0.

10. Vertebrate Ecology and Systematics: A Tribute to Henry S. Fitch. Edited by Richard A. Seigel, Lawrence E. Hunt, James L. Knight, Luis Malaret, and Nancy Zuschlag. Pp. I-277. 21 June 1984. ISBN 0-89338-019-0.

13. Geographic Variation Among Brown and Grizzly Bears (Ursus arctos) in North America. By E. Raymond Hall. Pp. 1-16. 10 August 1984.

15. Spring Geese and Other Poems. By Denise Low. Pp. 1-84. September 1984. ISBN 0-89338-024-5.

18. A Checklist of the Vertebrate Animals of Kansas. By George D. Potts and Joseph T. Collins. Pp. 1-42. September 1991. ISBN 0-89338-038-5.

19. The Compleat Cladist. A Primer of Phylogenetic Procedures. By E. O. Wiley, D. Siegel-Causey, D. R. Brooks, and V. A. Funk. Pp. 1-158. October 1991. ISBN 089338-035-0.

21. Amphibian Species of the World: Additions and Corrections. By William E. Duellman. Pp. 1-372. July 1993. ISBN 0-89338-045-8.

22. Guide to the Frogs of the Iquitos Region, Amazonian Peru. By Lily O. Rodríguez and William E. Duellman. Pp. 1-80+12 color plates. December 1994. ISBN 089338-047-4. 
LEPTODACTYLID FROGS of the genus Eleutherodactylus are the most diverse and abundant terrestrial vertebrates in the American tropics. They form a conspicuous element of the frog fauna on the Pacific lowlands and slopes of the Andes in western Ecuador. John D. Lynch and William E. Duellman have studied these frogs in western Ecuador for the past 30 years. In this book, they recognize 61 species (with 9 species described as new) and provide diagnoses of each species and accumulated information on their ecology, life history, and distribution. Keys in English and Spanish facilitate identification. Distribution maps are provided for each species, and 57 species are illustrated in 64 color photographs. Nine communities of Eleutherodactylus are analyzed ecologically, and the entire eleutherodactyline fauna is treated biogeographically. This volume also contains definitions and illustrations of taxonomic characters of Eleutherodactylus, definitions and subgenera and series, and a list of all species (including synonyms) in the genus with allocations to subgenera and species groups. Thus, this is the definitive work on the largest genus of vertebrates and a thorough account of the genus in western Ecuador. 